\title{
FIRST STREET
}

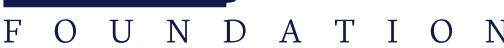

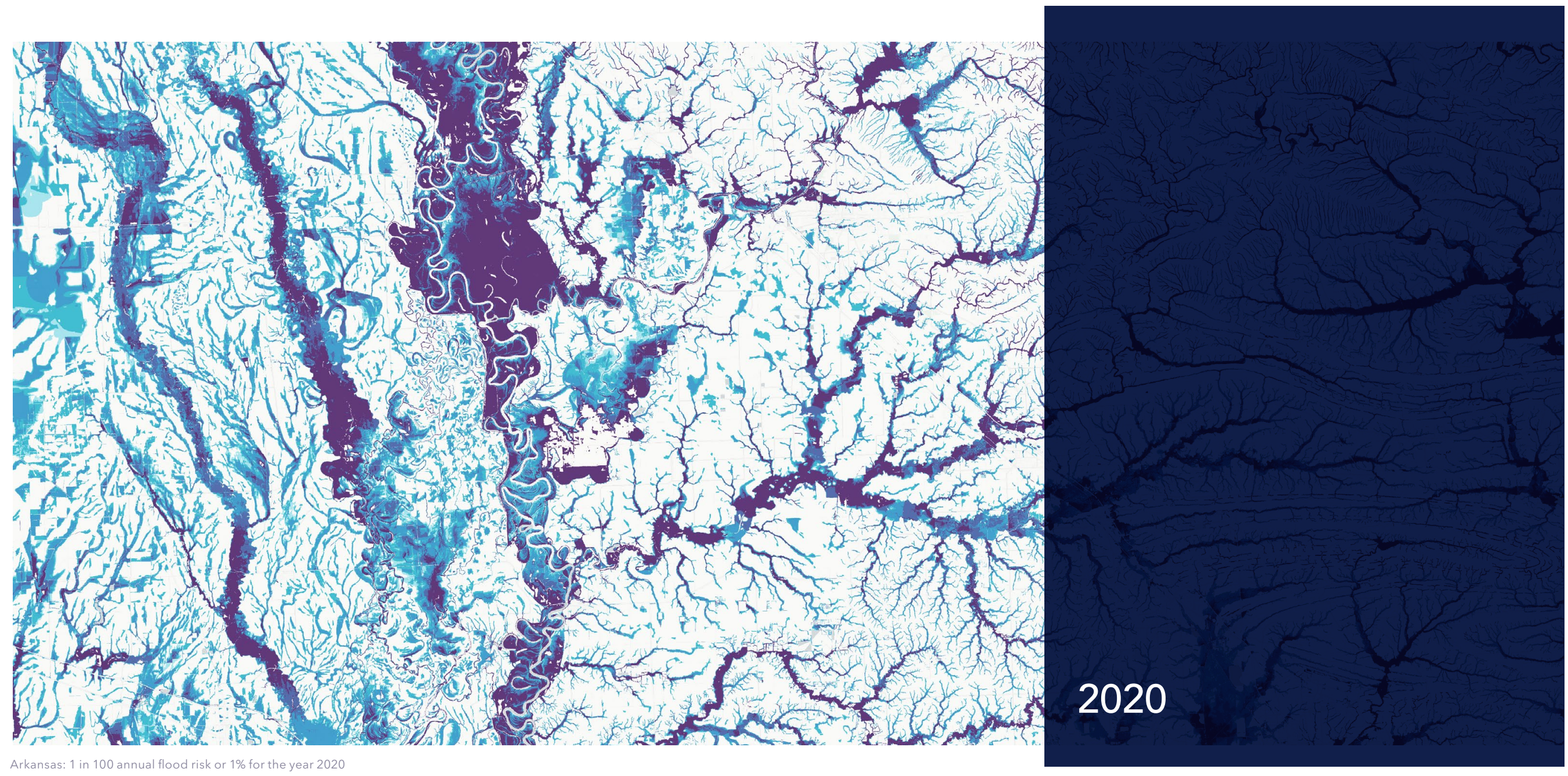

The First National Flood Risk Assessment Defining America's Growing Risk 


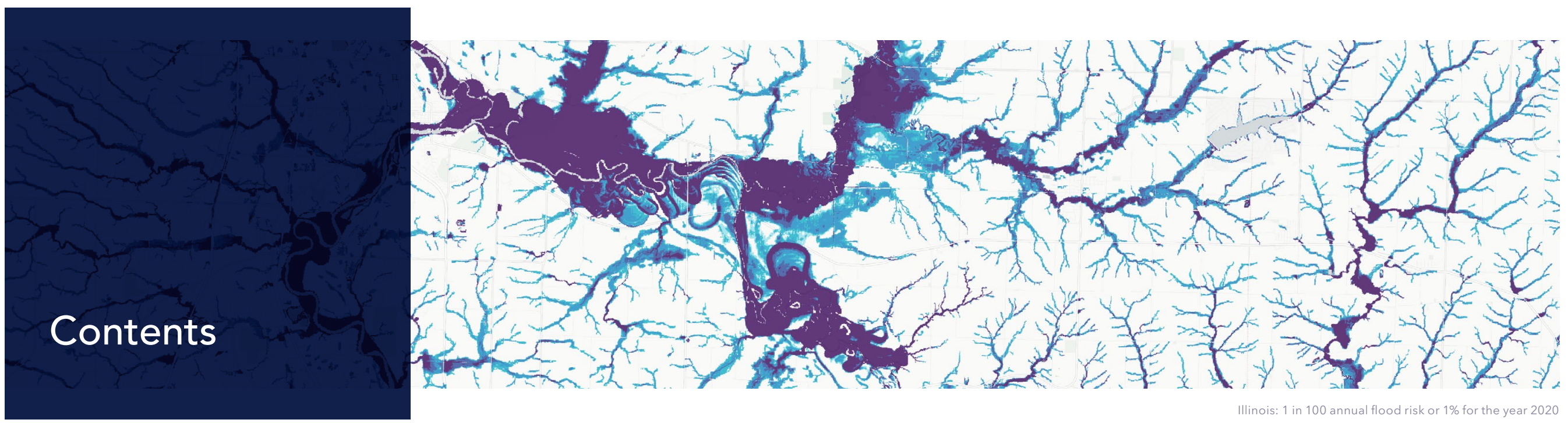

\section{Overview}

Abstract...................... 3

Introduction.................

Methodology..............6

National Overview.....8

Policy Implications...17

\section{Contiguous United States}

Alabama........18

Arizona..........21

Arkansas........24

California.......27

Colorado........30

Connecticut...33

Delaware.......36

Florida............39

Georgia.........42

Idaho..............45
Illinois...............48

Indiana...............51

lowa....................54

Kansas...............57

Kentucky............60

Louisiana...........63

Maine..................66

Maryland...........69

Massachusetts...72

Michigan.............75
Minnesota...........78

Mississippi...........81

Missouri................84

Montana...............87

Nebraska..............90

Nevada.................93

New Hampshire...96

New Jersey...........99

New Mexico.......102

New York.............105
North Carolina...108

North Dakota.....111

Ohio......................114

Oklahoma....... 117

Oregon..................120

Pennsylvania........123

Rhode Island........126

South Carolina......129

South Dakota........132

Tennessee.......
Texas....................138

Utah........................141

Vermont...................144

Virginia...................147

Washington..............150

Washington D.C......153

West Virginia.............154

Wisconsin.....

Wyoming. 


\section{Abstract}

The First Street Foundation Flood Model represents the culmination of decades of research and development made possible by building upon existing knowledge and frameworks regularly referenced in the identification of flood risk.

The outcome of this work is the development of a high precision, climate adjusted flood model that can be understood by individual property owners today and into the future. The high-level results indicate significantly more flood risk across the U.S. when compared to standard flood risk tools, nationally across the contiguous United States. These results are being made publicly available through a new tool, Flood Factor ${ }^{\mathrm{TM}}$, and represent the first free source of high-quality probabilistic flood risk information available to the public. This report provides a high-level national summary and a series of state reports with a focus on summarizing and providing insight into new findings around flood risk, adaptation, and changing environmental factors as they relate to flood risk.

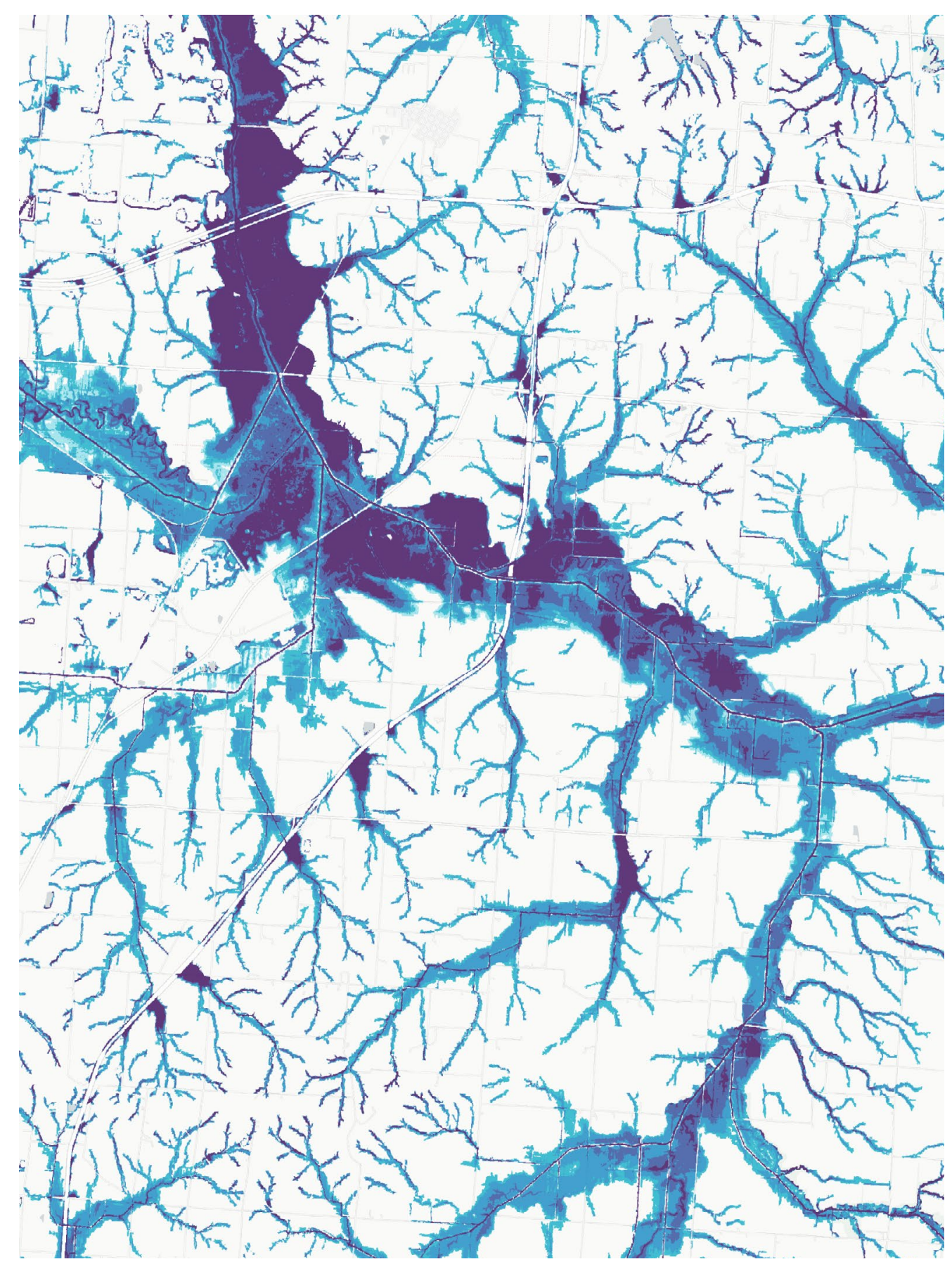




\section{Introduction}

The goal of the First Street Flood Model is to make flood risk transparent, easy to understand, informative, and available to everyone.

The model was produced in partnership with researchers and hydrologists from First Street Foundation; Columbia University; Fathom: George Mason University; Massachusetts Institute of Technology; Rhodium Group; Rutgers University; The University of California, Berkeley; and University of Bristol. This collaboration makes use of open government data and builds upon decades of research modeling, and expertise, brought together to develop a high-resolution, property-specific flood risk information at a national scale.

First Street Foundation is a non-profit research and technology group committed to defining America's flood risk. The Foundation provides this information for every property in the contiguous U.S., in a format that is publicly and freely accessible via Flood Factor ${ }^{\mathrm{TM}}$ an online database and visualization tool (www.floodfactor.com). The tool presents past, present and future flood risk with particular attention paid to recent and projected

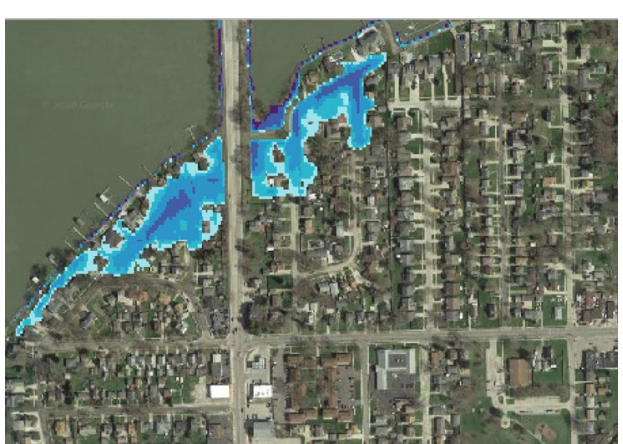

Past Flood

Toledo, Ohio, flooding event 2015

environmental changes contributing to flood risk. The public availability of this data is a benefit for property owners, and the wider public, as it represents the first freely available data of its kind across the nation. The democratization of this data is also of benefit to government officials looking to develop adaptation/mitigation efforts, and researchers

looking for high-resolution data on which to layer their research agenda.

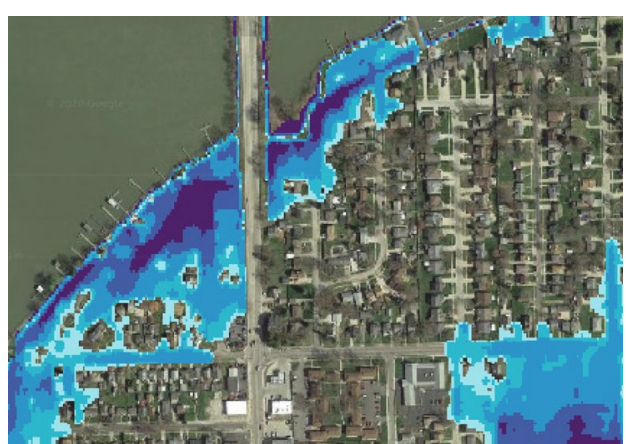

Current Risk:

Toledo, Ohio, 1 in 500 hazard annual flood risk, 2020

The First Street Flood Model allows for the understanding of risk from any type of flooding event by taking into account inundation from fluvial (riverine), pluvial (rainfall), storm surge and tidal sources. Each of these sources has

been, and continues to be, impacted by changing environmental factors in different ways and the modeling process has integrated those considerations directly into the final risk statistics. These environmental factors are built into the model with guidance from

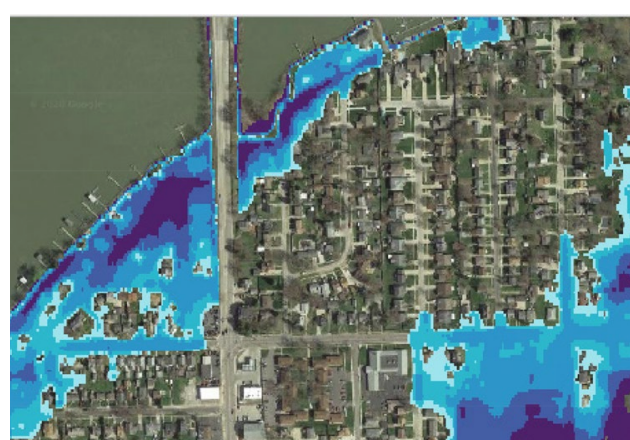

Future Risk:

Toledo, Ohio, 1 in 500 annual flood risk, 2050

the Intergovernmental Panel on Climate

Change's (IPCC) Representative Concentration Pathway (RCP) curves and the Coupled Model Intercomparison Project 5 (CMIP5) global climate model ensemble. The inclusion of these global climate models, forward-facing climate considerations (based upon the RCP 4.5 curve), and high-resolution flood risk layers ultimately contribute to the uniqueness of the First Street Flood Model in terms of coverage, precision, and climate adaptability. 


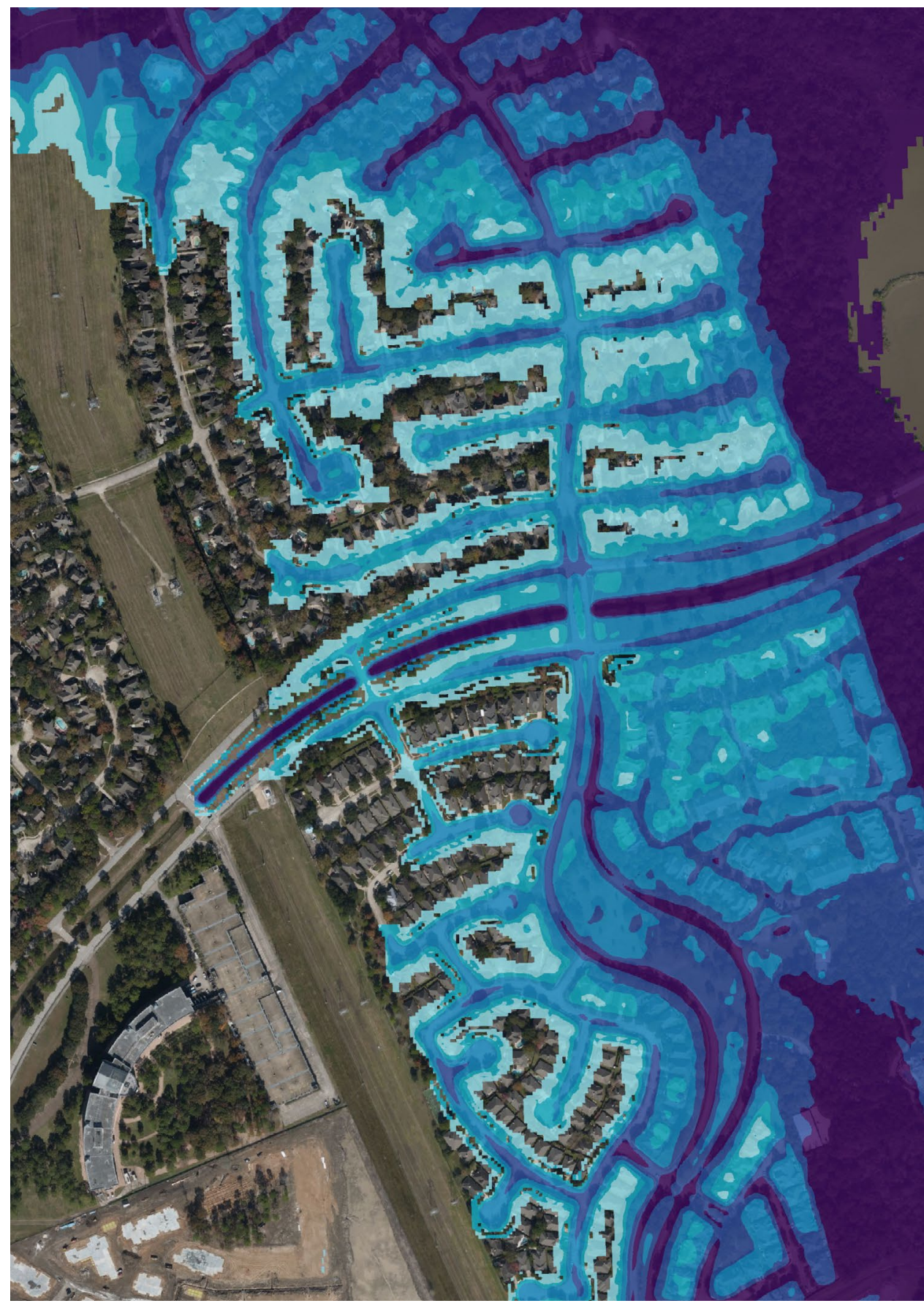

While the First Street Foundation's Flood Model makes flood risk easily accessible, it is important to note that the model itself is state-of-the-art and builds upon decades of peer-reviewed research and modeling experience (see First Street Flood Flood Model (FSF-FM) Technical Documentation, v3).First Street and its partners have developed a methodology that relies on a return-period based probabilistic approach. The included scenarios represent flooding events ranging from frequent (1-in-2-year events) to less frequent (1-in-500-year events) and from today (2020) into the climate adjusted future (2050) in five-year intervals. The resulting inundation depths associated with each event are tracked at a three-meter spatial resolution across the contiguous United States.

Each return-period/year combination was modeled in order to estimate the flooding depth from fluvial, pluvial, or coastal sources and then combined in order to create an estimated flood depth from any source at any likelihood at a high resolution across the country. Modeling the data using this approach allows for the estimation of flood probabilities and likelihoods for any depth of water for any location in the country. For the initial launch of the data, First Street Foundation has focused on the probability of flooding specifically to the buildings located on a property, or property centroid where buildings do not exist, however, the raw model data allows for a more exhaustive understanding of risk associated with the probability of flooding on roads, parking lots, and other places of interest.

Ultimately, the First Street Foundation Flood Model is a one-of-a-kind model allowing for the accurate, probabilistic understanding of flood risk, and takes into account both future and current environmental considerations. The model allows for a new perspective and understanding around risk at the property, neighborhood, city, state, and other geographic levels in a way that is different from any existing government or private models. The methodology employed allows for continual improvement of our understanding of the country's current flood risk and that changing risk moving forward. Importantly, the model methodology is also transparent and available for review by the public. First Street Foundation is committed to openness in its methodology, including the public release of its technical methodology document, and several forthcoming peer-reviewed scientific papers on the methodologies and results in academic journals. The methodology has also been independently reviewed by an expert panel. 


\section{Methodology}

The methodology used to create the First Street Flood Model brings together a multitude of resources and techniques in an innovative way and builds on previously peer-reviewed scientific research.

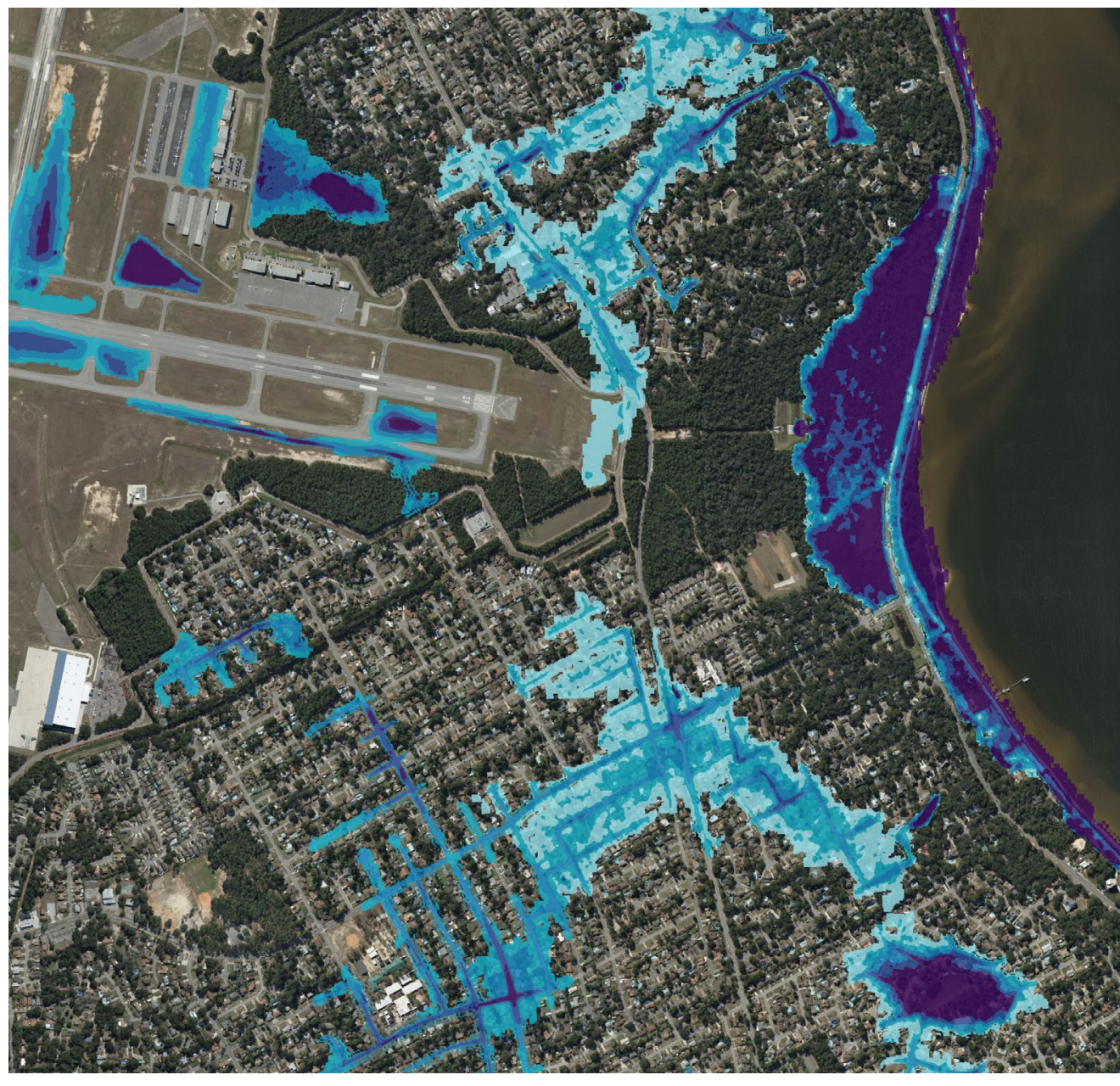

Pensacola, Florida: 1 in 100 annual flood risk or $1 \%$ for the year 2020
In doing so, the model represents flooding from multiple risks (fluvial, pluvial, and coastal sources) while also integrating current and future environmental considerations, all at a property level. This combination of high-resolution scale and national scope bring to the public a more exhaustive and comprehensive flood risk

tool than currently available. Additionally, while the complex probabilities and flood depths make this model valuable to researchers, government officials, and industry, the clear communication of risk is distilled and accessible in a way that anyone can understand.

The most valuable component of the model used in the development of this national report is the comprehensive nature of having past, present, and future flood risk coupled with methods that have been refined to the property-level. The ability to produce these results at the scale in this report required the creative application of previously peerreviewed hydrological modeling techniques

(Emanuel, 2018; Wing et. al, 2017; Khalid and Ferreira, 2020). Notably, the model provides the ability to capture flooding in areas of the country that do not have a gauge, are under-gauged, or are outside of typical flood risk models' purview. The method used to create that flood risk relies on a novel Regionalized Flood Frequency Analysis (RFFA) approach that makes use of traditional statistical propensity matching techniques to model the characteristics of ungauged streams, river reaches, and country with known gauged characteristics to produce likely flow parameters with high confidence. Additionally, a core component of the model is the ability to also include pluvial (rainfall) events as probabilistic flood risks with depths and associated return periods. Both the RFFA and pluvial flooding integrations have allowed for a model that captures risk that is generally not captured in most traditional flood risk mapping. As a result, the statistics contained in this national report generally identify significantly more flood risk to properties in the U.S. than can be accounted for by existing data and models of a similar scale.

The Federal Emergency Management Agency (FEMA) Special Flood Hazard Area (SFHA) designation is the U.S. legal standard in flood-risk identification and is widely used throughout government research, and private companies as the foundation to identify flood risk, price 
insurance premiums, as well as prepare for potential hazards. To highlight the additional coverage of the First Street Flood Model, its 1-in-100-year hazard layer (representing a 1\% annual risk of occurrence) was compared to the same probability zones outlined by the FEMA SFHA models. The National results, beginning on page 5 , indicate that the First Street Model generally captures around 1.7 times as many properties at risk as the FEMA SFHA designation. When digging into these differences, it is clear that the inclusion of pluvial flood risk, sea level rise, and ungauged streams are responsible for most of this additional risk.

In addition to the higher risk identified by the First Street Foundation Flood Model in comparison to standard SFHA flood risk definitions, the model also includes environmental factors to understand how flood risk has changed to date, and will change over the next 30 years. On average, the inclusion of these environmental factors show a nearly $11 \%$ increase in flood risk over the next 30 years (to 2050). These environmental factors are built into the model with guidance from the IPCC RCP curves and the CMIP5 global climate model ensemble. The combination of a more comprehensive, probabilistic approach coupled with the inclusion of environmental changes, highlights the significant risk that Americans are facing from flood risk today, and how that will increase into the future.

Importantly, the FEMA SFHAs and the First Street Foundation Flood Model align well along gauged river channels, and this agreement with FEMA SFHAs provides a source of validation for the fluvial risk identified in the model. However, the differences indicate the practical need for the more comprehensive approach that was used to produce the statistics in this report.
The comparison of the First Street results with SFHAs highlights the utility of the First Street Foundation Flood Model as a resource that pushes forward the country's understanding of national flood risk, and it does so by consistently building on trusted models, reports, and open data resources. To that point, this model relies heavily on data from the National Oceanic and Atmospheric Administration (NOAA), FEMA, the United States Geological Survey (USGS), the World Climate Research Programme (WCRP), and thousands of local government resources. As such, the results of this report should be

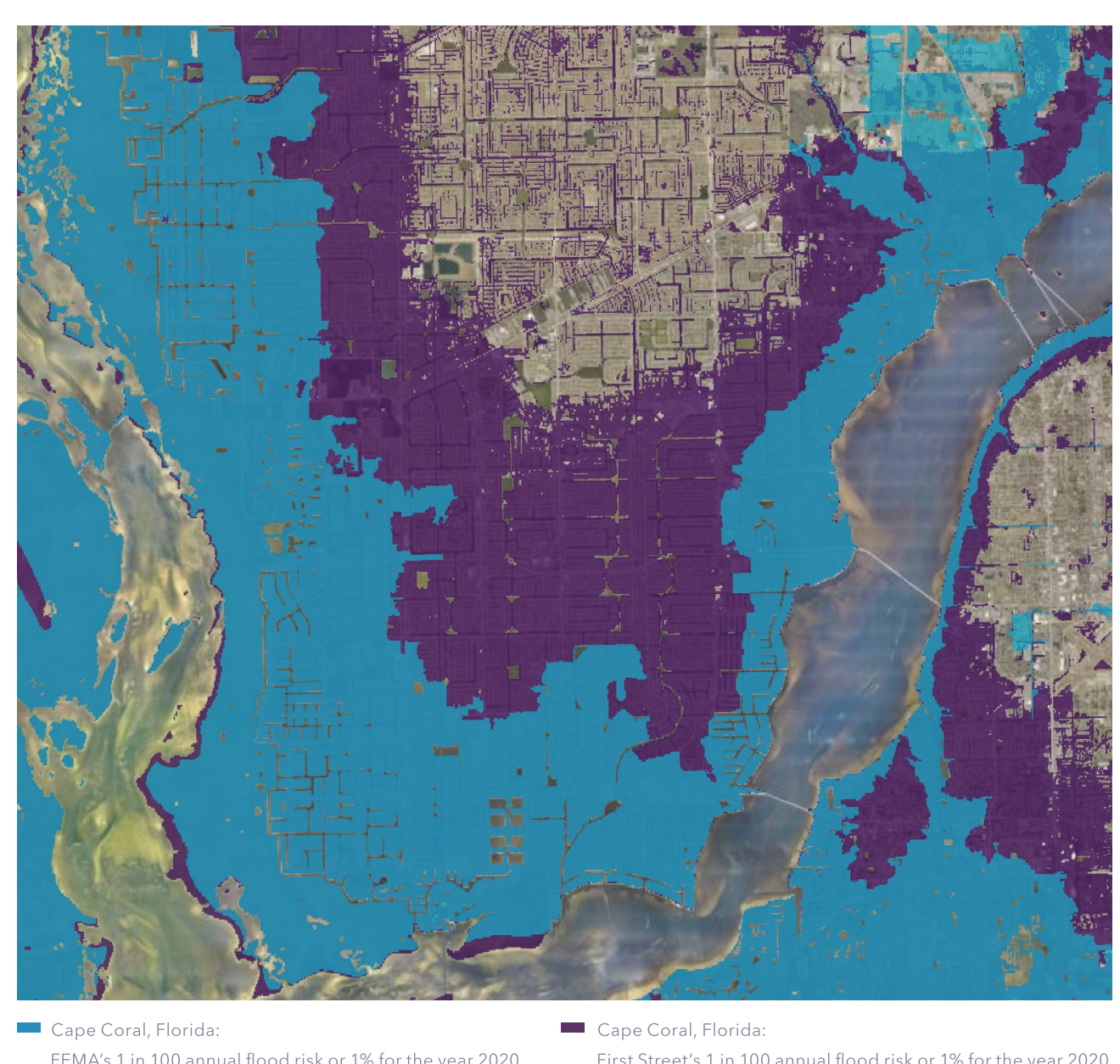

Cape Coral, Florida

- Cape Coral, Florida: FEMA's 1 in 100 annual flood risk or $1 \%$ for the year 2020

seen as an extension of those resources that take new and creative methods of modeling flood risk to the next level by comprehensively including geographic areas that may have been left out of alternative-risk models.

In addition to the open government data resources, the First Street Foundation Flood Model is built in partnership with researchers that are world-renowned for their expertise in the areas of flood risk and environmental modeling. These partner researchers provide access to a vast amount of commercial and academic resources including Fathom's fluvial/ pluvial models, Rhodium Group's coastal surge models, George Mason University's ADCIRC computational facilities, and Lightbox's. parcel and property records. The coupling of open government data resources with expert modelers and third-party data sources has produced a model that pushes the understanding of flood risk forward, today and into the future. Environmental change considerations are a particularly important part of the First Street Foundation Flood Model due to the fact that they are included in a highresolution and practical way, unlike many other previously existing models. Ultimately, making decisions about flood risk cannot be limited to our understanding of current climate, but must take into account future changes to our climate. As such, this report produces a comprehensive and consistent look at flood risk today and into the future across the country.

While the First Street Foundation Flood Model is both high-resolution and comprehensive in spatial and temporal coverage, it is only the first release of the model. The high-accuracy flood layers will be periodically refined in a way that will allow the model to remain authoritative on property-level flood risk into the future. As part of that process the model will be updated annually with the most recent - and accurate - data resources, climate model output, and any significant quality and technical updates identified following discussions with users of the model results. As a non-profit, First Street Foundation is committed to defining America's flood risk. The data user feedback loop is a vital part of achieving this through a transparent and scientifically rigorous method. The following results represent First Street Foundation's initial report of the state of flood risk in the United States, based on the First Street Flood Model 


\section{Defining Flood Risk National Overview}

First Street definitions of risk that are used in this report.

Substantial risk is analogous to the FEMA SFHA designation.

\begin{tabular}{|c|c|c|c|c|c|}
\hline $\begin{array}{l}\text { First Street Risk } \\
\text { Description }\end{array}$ & Return Period & $\begin{array}{l}\text { Annual Probability } \\
\text { flooding at least } 1 \mathrm{~cm}\end{array}$ & $\begin{array}{r}\text { Cumulative } \\
\text { Probability } \\
\text { flooding at least } \\
\text { once over } 30 \text { years }\end{array}$ & $\begin{array}{r}\text { Properties at risk } \\
\text { in } 2020 \\
48 \text { U.S. States + D.C. }\end{array}$ & $\begin{array}{r}\text { Percent of all } \\
\text { properties }\end{array}$ \\
\hline Almost Certain Risk & 5 Year (1 in 5) & $20.0 \%$ & $>99 \%$ & 3.6 million & $2.6 \%$ \\
\hline Substantial Risk & 100 Year ( 1 in 100) & $1.0 \%$ & $>26 \%$ & 14.6 million & $10.3 \%$ \\
\hline Any Risk & 500 Year ( 1 in 500$)$ & $0.2 \%$ & $>0 \%$ & 21.8 million & $15.4 \%$ \\
\hline
\end{tabular}




\section{Difference from FEMA National Overview}

At the national level, the First Street Foundation Flood Model identifies around 1.7 times the number of properties as having substantial risk* compared to the FEMA 1-in-100 SFHA designation. This equates to a total of 14.6 million properties across the country at substantial risk, of which 5.9 million properties and property owners are currently unaware of or underestimating the risk they face because they are not identified as being within the SFHA zone.

Washington D.C. (438\%), Utah (419\%), Wyoming (325\%), Montana (311\%), and Idaho (290\%) show the greatest difference between the First Street Foundation Flood Model estimates and FEMA SFHA designation, due mainly to First Street's nationwide coverage while FEMA's mapping in some of these locations is not yet complete. There are locations where First Street estimates risk is less than that designated by the FEMA SFHA, and while there are differences in this deviation county-by-county and city-by-city, at a state-wide leve Arizona, New Jersey, and Louisiana are the only states that show a lower count of properties currently with substantial risk in the First Street model in comparison to the FEMA SFHA. However, when adjusting for future environmental changes, in Arizona, additional properties fall into that risk categorization. In Louisiana, after adjusting for sea level rise that approaches or exceeds protective levee heights, the deviation shifts as the First Street methods uncover an additional 332,700 properties with substantial risk by the year 2050, in turn showing 248,800 more properties with substantial risk than FEMA defines currently. Similarly in New Jersey adjusting for environmental changes shifts the First Street estimate from 8,100 fewer properties currently at substantial risk than FEMA to identify73,600 more properties at substantial risk in 2050 than current FEMA estimates.
Difference in number of properties at

substantial flood risk* (FSF) compared to FEMA**

More properties at risk
in FSF model

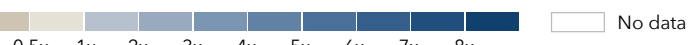

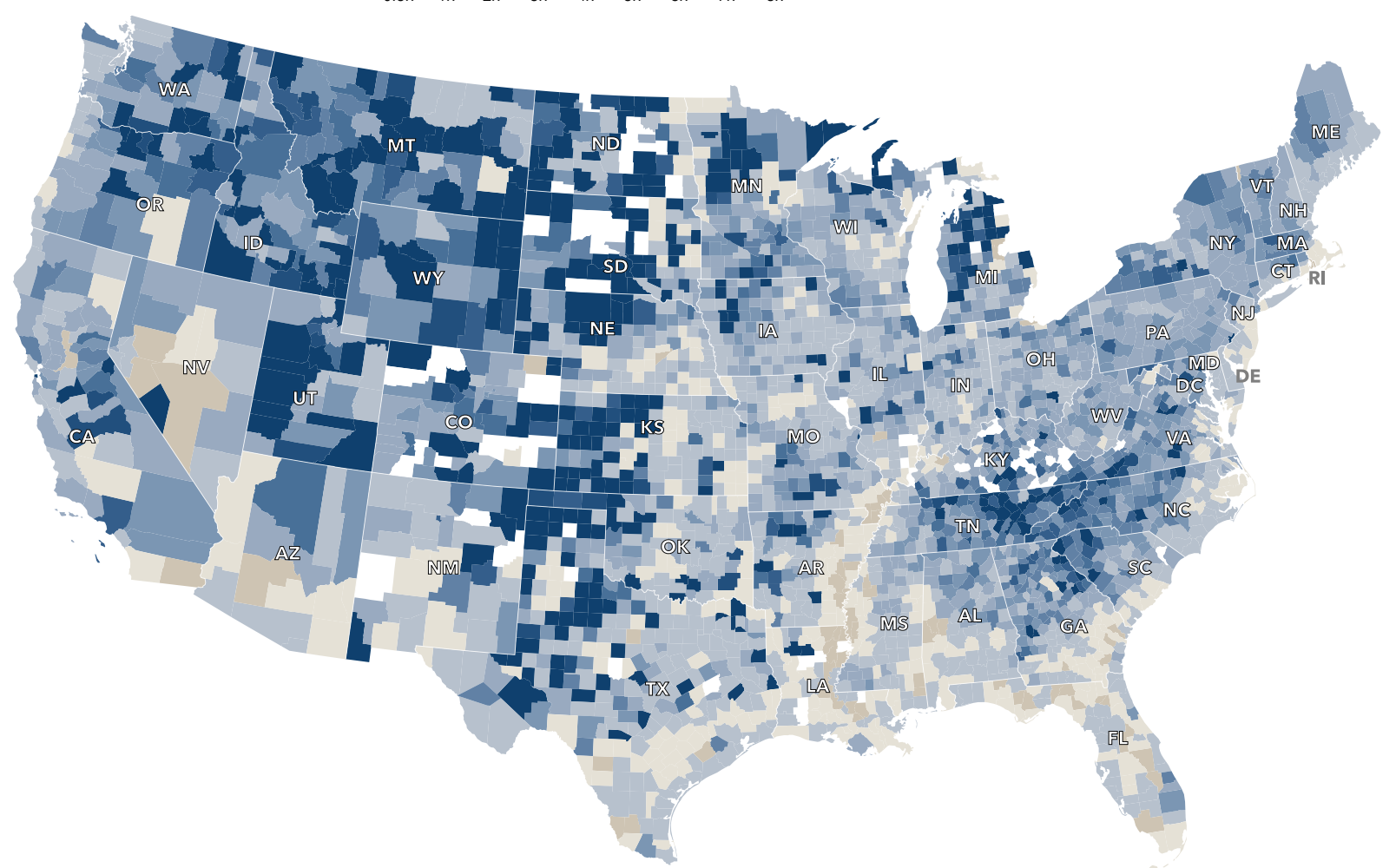

More properties at ris
in FSF model

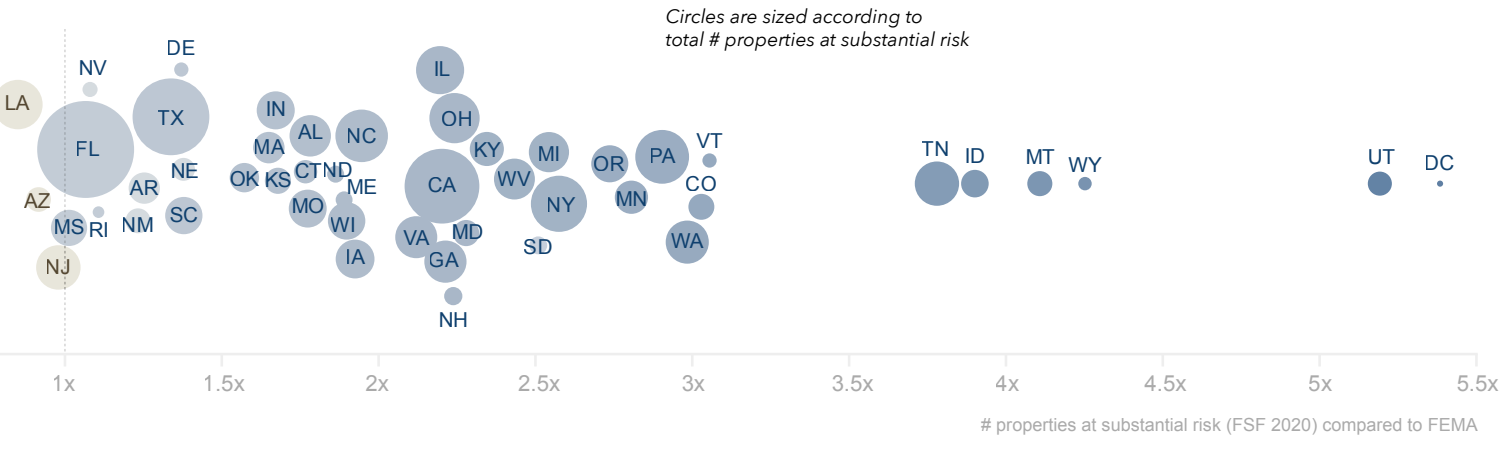


Properties with substantial flood risk

\section{National Overview}

Number of properties at substantial

flood risk ${ }^{\star}$ by county in 2020

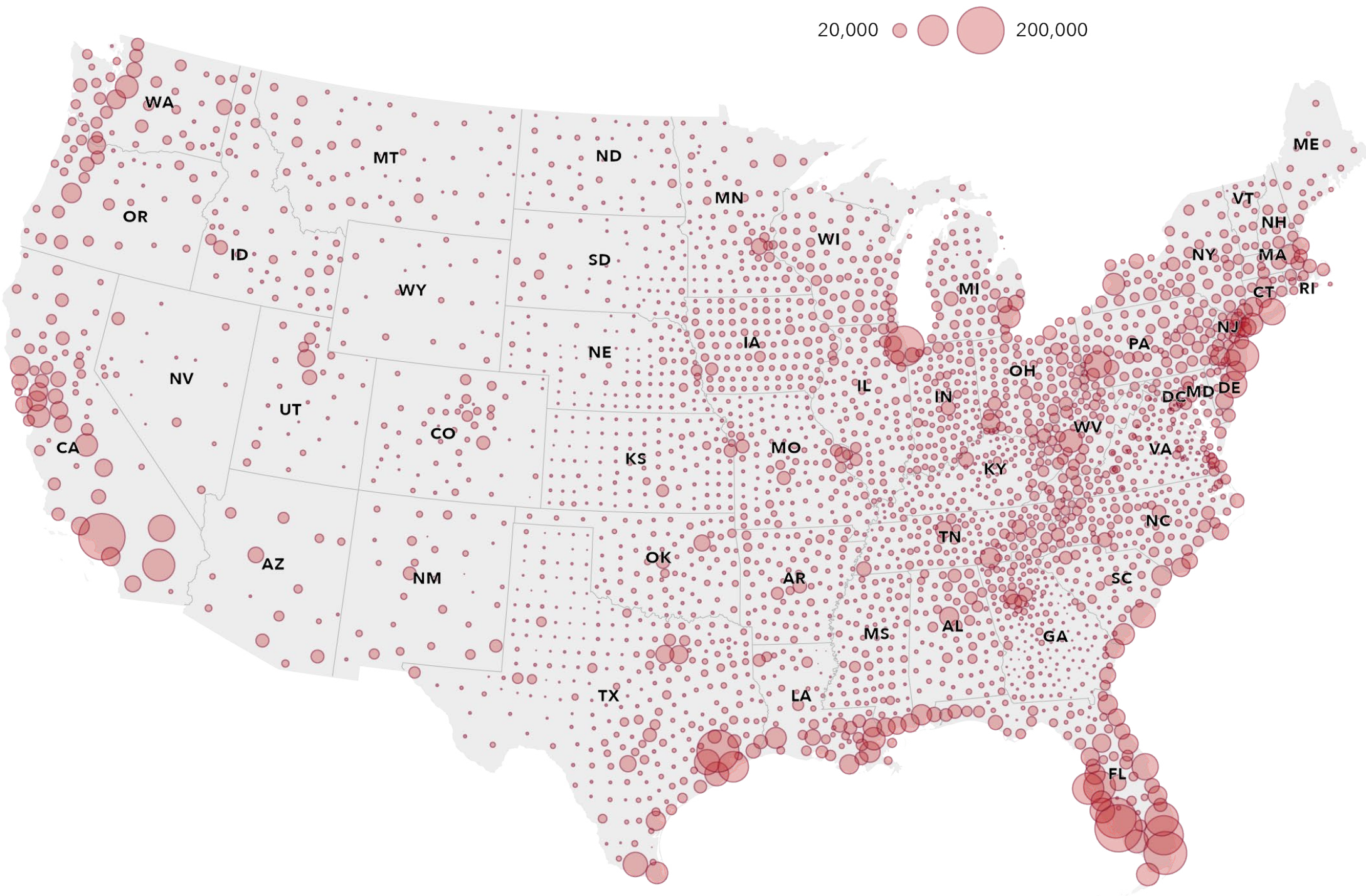


Flood risk change over time National Overview

Percent Change in Properties at

Substantial Risk, 2020-2050*

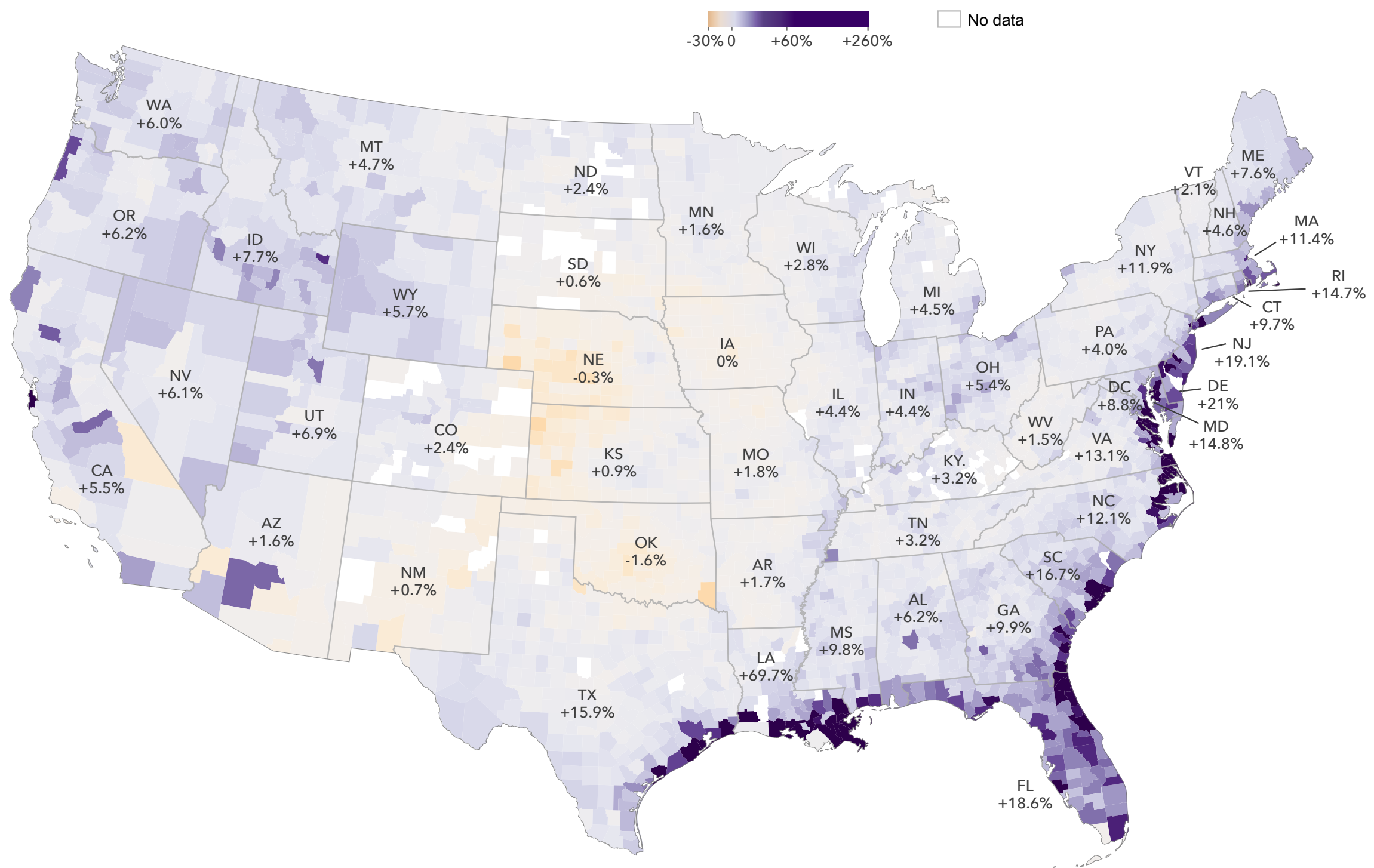




\section{Properties with substantial flood risk National Overview}

The top five states showing the greatest proportion of properties currently with substantial flood risk* include West Virginia (24.4\%), Louisiana (21.1\%), Florida (20.5\%), Idaho (14.8\%) and Montana (14.2\%), while Arizona (3.7\%), Nevada (3.7\%), Washington D.C. (5.3\%), Colorado (5.7\%), and Maryland (6.2\%) have the lowest proportion of properties currently with substantial risk.

When adjusting for future environmental changes, by 2050 the number of properties with substantial risk across the country will increase by $10.9 \%$ to 16.2 million. Louisiana (69.7\%), Delaware (21\%), New Jersey (19.1\%), Florida (18.6\%), and South Carolina (16.7\%) rank highest for the greatest proportional increase of properties with significant risk over the next 30 years.

While flood risk is changing for coastal and inland states due to the shift in precipitation patterns, the coastal states also face increased risk from sea level rise and surge due to changing hurricane patterns.
Proportion of properties at substantial flood risk and change over time

Coastal states Circles are sized according to total number of
properties at substantial risk (2020)

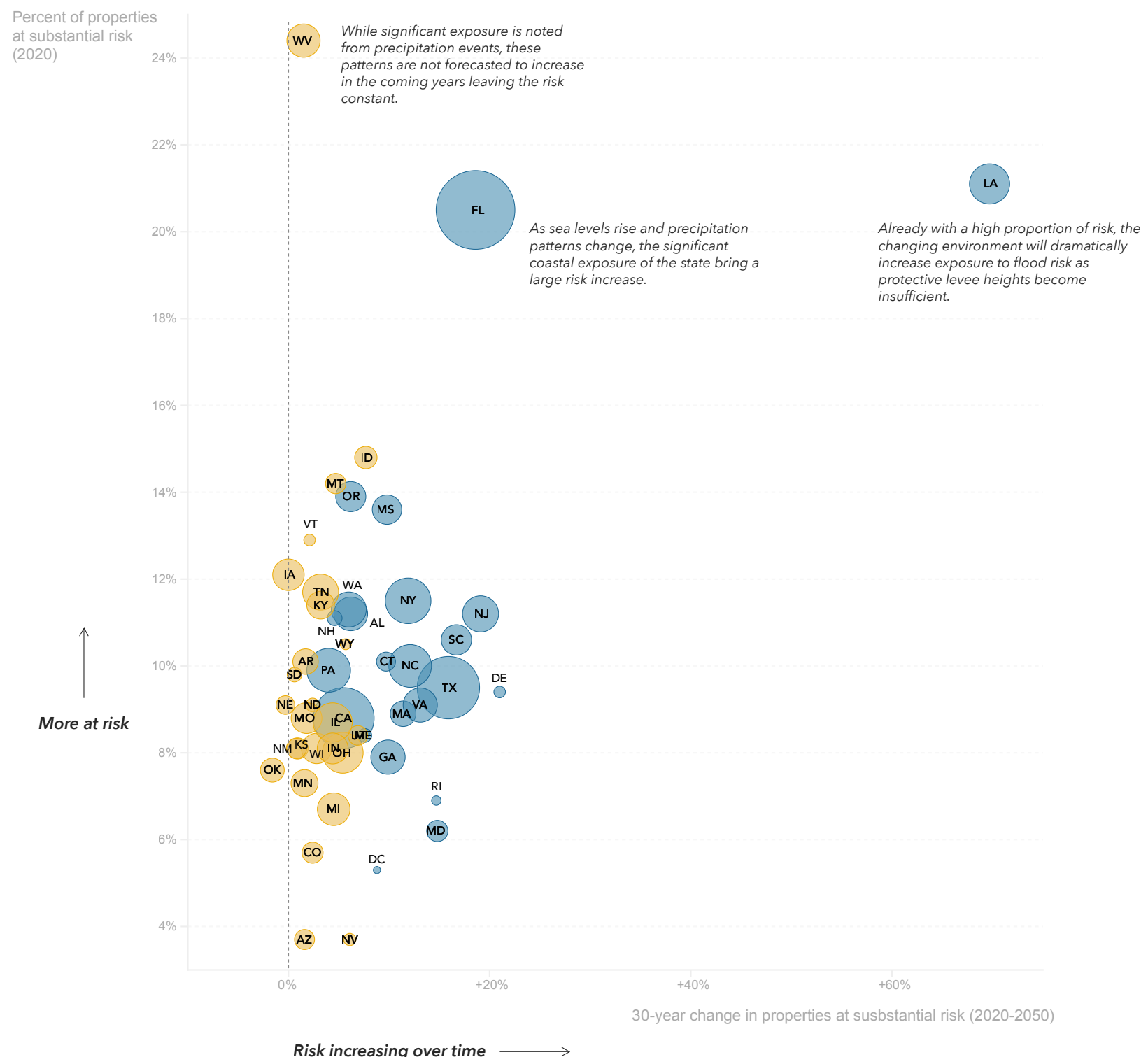




\section{Top cities with substantial risk National Overview}

\section{Greatest number of properties at substantial risk*}

\begin{tabular}{l|c|ccccc}
\hline City & \multicolumn{2}{c}{2020} & \multicolumn{2}{c}{2050} & \multicolumn{2}{c}{ Change } \\
\hline Cape Coral, FL & 90,239 & $69 \%$ & 108,710 & $84 \%$ & $+18,471$ & $+20.5 \%$ \\
\hline Los Angeles, CA & 80,323 & $12 \%$ & 82,738 & $12 \%$ & $+2,415$ & $+3.0 \%$ \\
\hline Chicago, IL & 77,212 & $13 \%$ & 84,019 & $14 \%$ & $+6,807$ & $+8.8 \%$ \\
\hline Houston, TX & 75,122 & $13 \%$ & 87,951 & $15 \%$ & $+12,829$ & $+17.1 \%$ \\
\hline New York, NY & 73,490 & $9 \%$ & 88,338 & $10 \%$ & $+14,848$ & $+20.2 \%$ \\
\hline New Orleans, LA & 48,064 & $32 \%$ & 147,862 & $98 \%$ & $+99,798+207.6 \%$ \\
\hline Tampa, FL & 43,111 & $32 \%$ & 52,756 & $39 \%$ & $+9,645$ & $+22.4 \%$ \\
\hline Philadelphia, PA & 32,859 & $6 \%$ & 37,453 & $7 \%$ & $+4,594$ & $+14.0 \%$ \\
\hline Jacksonville, FL & 28,956 & $8 \%$ & 47,948 & $14 \%$ & $+18,992$ & $+65.6 \%$ \\
\hline Portland, OR & 27,696 & $12 \%$ & 30,478 & $13 \%$ & $+2,782$ & $+10.0 \%$ \\
\hline Fresno, CA & 26,964 & $19 \%$ & 30,486 & $22 \%$ & $+3,522$ & $+13.1 \%$ \\
\hline Lehigh Acres, FL & 26,306 & $21 \%$ & 28,395 & $23 \%$ & $+2,089$ & $+7.9 \%$ \\
\hline Nashville-Davidson, TN & 24,809 & $10 \%$ & 25,687 & $10 \%$ & +878 & $+3.5 \%$ \\
\hline San Jose, CA & 22,932 & $10 \%$ & 23,851 & $10 \%$ & +919 & $+4.0 \%$ \\
\hline Corpus Christi, TX & 22,857 & $21 \%$ & 25,442 & $23 \%$ & $+2,585$ & $+11.3 \%$ \\
\hline Detroit, MI & 21,615 & $6 \%$ & 23,262 & $6 \%$ & $+1,647$ & $+7.6 \%$ \\
\hline Pittsburgh, PA & 17,323 & $12 \%$ & 18,211 & $13 \%$ & +888 & $+5.1 \%$ \\
\hline Indianapolis, IN & 17,246 & $6 \%$ & 17,882 & $6 \%$ & +636 & $+3.7 \%$ \\
\hline San Antonio, TX & 16,439 & $4 \%$ & 17,327 & $4 \%$ & +888 & $+5.4 \%$ \\
\hline Cincinnati, OH & 16,112 & $10 \%$ & 17,427 & $11 \%$ & $+1,315$ & $+8.2 \%$ \\
\hline & & & & & \\
\hline
\end{tabular}

Greatest proportion of properties at substantial risk*

\begin{tabular}{ll|l|l|}
\hline City & \multicolumn{2}{|c}{2020} \\
\hline Cape Coral, FL & 90,239 & $69 \%$ \\
\hline Tampa, FL & 43,111 & $32 \%$ \\
\hline New Orleans, LA & 48,064 & $32 \%$ \\
\hline Lehigh Acres, FL & 26,306 & $21 \%$ \\
\hline Corpus Christi, TX & 22,857 & $21 \%$ \\
\hline Fresno, CA & 26,964 & $19 \%$ \\
\hline Chicago, IL & 77,212 & $13 \%$ \\
\hline Houston, TX & 75,122 & $13 \%$ \\
\hline Pittsburgh, PA & 17,323 & $12 \%$ \\
\hline Los Angeles, CA & 80,323 & $12 \%$ \\
\hline Portland, OR & 27,696 & $12 \%$ \\
\hline San Jose, CA & 22,932 & $10 \%$ \\
\hline Nashville-Davidson, TN & 24,809 & $10 \%$ \\
\hline Cincinnati, OH & 16,112 & $10 \%$ \\
\hline Virginia Beach, VA & 13,785 & $10 \%$ \\
\hline Tulsa, OK & 14,859 & $10 \%$ \\
\hline New York, NY & 73,490 & $9 \%$ \\
\hline Atlanta, GA & 11,204 & $9 \%$ \\
\hline Jacksonville, FL & 28,956 & $8 \%$ \\
\hline Louisville, KY & 10,016 & $8 \%$ \\
\hline
\end{tabular}

Greatest relative growing substantial risk*

\begin{tabular}{l|rrrrrr}
\hline City & \multicolumn{2}{c}{2020} & \multicolumn{2}{c}{2050} & \multicolumn{2}{c}{ Change } \\
\hline New Orleans, LA & 48,064 & $32 \%$ & 147,862 & $98 \%$ & $+99,798$ & $+207.6 \%$ \\
\hline Jacksonville, FL & 28,956 & $8 \%$ & 47,948 & $14 \%$ & $+18,992$ & $+65.6 \%$ \\
\hline Virginia Beach, VA & 13,785 & $10 \%$ & 22,457 & $16 \%$ & $+8,672$ & $+62.9 \%$ \\
\hline San Diego, CA & 5,172 & $2 \%$ & 6,450 & $2 \%$ & $+1,278$ & $+24.7 \%$ \\
\hline Tampa, FL & 43,111 & $32 \%$ & 52,756 & $39 \%$ & $+9,645$ & $+22.4 \%$ \\
\hline Cape Coral, FL & 90,239 & $69 \%$ & 108,710 & $84 \%$ & $+18,471$ & $+20.5 \%$ \\
\hline New York, NY & 73,490 & $9 \%$ & 88,338 & $10 \%$ & $+14,848$ & $+20.2 \%$ \\
\hline Cleveland, OH & 6,516 & $4 \%$ & 7,752 & $5 \%$ & $+1,236$ & $+19.0 \%$ \\
\hline Henderson, NV & 1,657 & $1 \%$ & 1,961 & $2 \%$ & +304 & $+18.3 \%$ \\
\hline Memphis, TN & 15,508 & $6 \%$ & 18,248 & $8 \%$ & $+2,740$ & $+17.7 \%$ \\
\hline Houston, TX & 75,122 & $13 \%$ & 87,951 & $15 \%$ & $+12,829$ & $+17.1 \%$ \\
\hline Columbus, OH & 10,053 & $4 \%$ & 11,580 & $4 \%$ & $+1,527$ & $+15.2 \%$ \\
\hline Bakersfield, CA & 1,561 & $1 \%$ & 1,798 & $2 \%$ & +237 & $+15.2 \%$ \\
\hline Philadelphia, PA & 32,859 & $6 \%$ & 37,453 & $7 \%$ & $+4,594$ & $+14.0 \%$ \\
\hline Fresno, CA & 26,964 & $19 \%$ & 30,486 & $22 \%$ & $+3,522$ & $+13.1 \%$ \\
\hline Seattle, WA & 8,529 & $5 \%$ & 9,621 & $5 \%$ & $+1,092$ & $+12.8 \%$ \\
\hline Toledo, OH & 5,872 & $5 \%$ & 6,623 & $5 \%$ & +751 & $+12.8 \%$ \\
\hline Corpus Christi, TX & 22,857 & $21 \%$ & 25,442 & $23 \%$ & $+2,585$ & $+11.3 \%$ \\
\hline Portland, OR & 27,696 & $12 \%$ & 30,478 & $13 \%$ & $+2,782$ & $+10.0 \%$ \\
\hline Raleigh, NC & 6,515 & $5 \%$ & 7,139 & $6 \%$ & +624 & $+9.6 \%$ \\
\hline
\end{tabular}




\section{Properties with any flood risk National Overview}

The First Street Foundation Flood Model calculates the number of properties facing any risk ${ }^{*}$ of flooding. When looking at this broader level of risk, which is beyond the FEMA SFHA definition, the data identifies 23.5 million properties in the U.S. as at-risk over the next 30 years. Of these properties, 3.6 million were categorized as facing almost certain risk, with a $99 \%$ chance of flooding at least once over the next 30 years.

In current climate conditions, $21.8 \mathrm{M}$ properties are classified as at risk. The top five states showing the greatest proportion of properties currently with any risk are Louisiana (39.5\%), Florida (29.5\%), West Virginia (28.1\%), Idaho (23\%), and Oregon (20.7\%), while Maryland (7.9\%), Colorado (8.5\%), Washington D.C. (8.5\%), Oklahoma (10.0\%) and Georgia (10.3\%) have the lowest proportion of properties currently with any risk.

When adjusting for future environmental changes, by 2050 this will raise the number of properties with any risk across the country by $7.7 \%$ percent to 23.5 million. Virginia (28.4\%), Delaware (22.7\%), New Jersey (20.0\%), Rhode Island (18.7\%) and Maryland (18.6\%) rank highest for the greatest percent increase of properties with any risk over the next 30 years.
Proportion of properties at any flood risk and change over time

Coastal states Inland states Circles are sized according to total number of
properties at any risk (2020)
Percent of properties at any risk (2020)
(LA)

$35 \%$

$30 \%$

wv

$25 \%$

ID

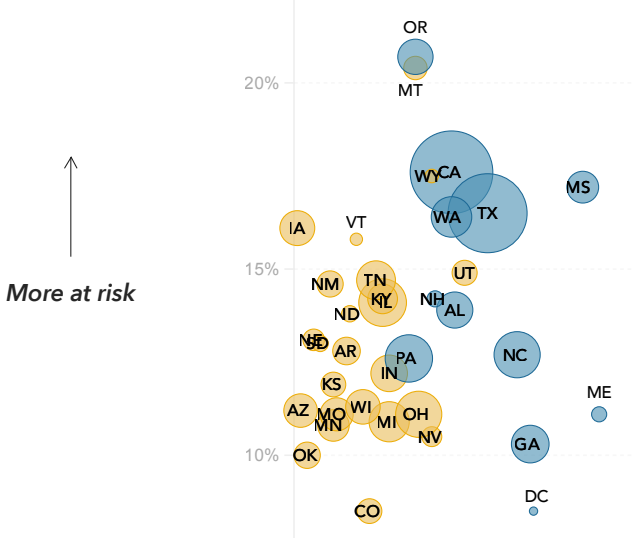

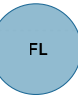

NY

(1)

(MA) DE

RI
O $\mathrm{MD}$ 


\section{Top cities with any risk National Overview}

\section{Greatest number of properties at risk*}

\begin{tabular}{|c|c|c|c|c|c|c|}
\hline City & 2020 & & & & Chan & \\
\hline Houston, TX & 186,481 & $32 \%$ & 202,317 & $34 \%$ & $+15,836$ & $+8.5 \%$ \\
\hline Chicago, IL & 154,824 & $26 \%$ & 160,068 & $27 \%$ & $+5,244$ & $+3.4 \%$ \\
\hline New Orleans, LA & 148,197 & $98 \%$ & 148,232 & $98 \%$ & +35 & $+0.0 \%$ \\
\hline Los Angeles, CA & 132,046 & $20 \%$ & 135,515 & $20 \%$ & $+3,469$ & $+2.6 \%$ \\
\hline New York, NY & 121,202 & $14 \%$ & 166,875 & $19 \%$ & $+45,673$ & $+37.7 \%$ \\
\hline Cape Coral, FL & $\mid 111,237$ & $86 \%$ & 126,436 & $97 \%$ & $+15,199$ & $+13.7 \%$ \\
\hline Sacramento, CA & \begin{tabular}{|l|}
101,792 \\
\end{tabular} & $68 \%$ & 109,416 & $74 \%$ & $+7,624$ & $+7.5 \%$ \\
\hline Phoenix, AZ & 62,351 & $13 \%$ & 61,466 & $13 \%$ & -885 & $-1.4 \%$ \\
\hline Tampa, FL & 58,414 & $43 \%$ & 72,178 & $54 \%$ & $+13,764$ & $+23.6 \%$ \\
\hline San Jose, CA & 56,243 & $25 \%$ & 59,298 & $26 \%$ & $+3,055$ & $+5.4 \%$ \\
\hline Fresno, CA & 54,255 & $39 \%$ & 55,332 & $39 \%$ & $+1,077$ & $+2.0 \%$ \\
\hline Philadelphia, PA & 53,378 & $10 \%$ & 60,561 & $11 \%$ & $+7,183$ & $+13.5 \%$ \\
\hline Jacksonville, FL & 48,408 & $14 \%$ & 64,113 & $18 \%$ & $+15,705$ & $+32.4 \%$ \\
\hline Portland, OR & 45,951 & $20 \%$ & 47,554 & $21 \%$ & $+1,603$ & $+3.5 \%$ \\
\hline Detroit, MI & 39,744 & $10 \%$ & 41,672 & $11 \%$ & $+1,928$ & $+4.9 \%$ \\
\hline Lehigh Acres, FL & 37,289 & $30 \%$ & 39,844 & $32 \%$ & $+2,555$ & $+6.9 \%$ \\
\hline Corpus Christi, TX & 36,952 & $34 \%$ & 47,248 & $43 \%$ & $+10,296$ & $+27.9 \%$ \\
\hline Indianapolis, IN & 34,124 & $11 \%$ & 34,808 & $11 \%$ & +684 & $+2.0 \%$ \\
\hline Nashville-Davidson, TN & 33,153 & $13 \%$ & 33,813 & $14 \%$ & +660 & $+2.0 \%$ \\
\hline Memphis, TN & 32,455 & $14 \%$ & 35,837 & $15 \%$ & $+3,382$ & $+10.4 \%$ \\
\hline
\end{tabular}

Greatest proportion of properties at risk*

\begin{tabular}{|l|r|r|}
\hline City & \multicolumn{2}{c}{2020} \\
\hline New Orleans, LA & 148,197 & $98 \%$ \\
\hline Cape Coral, FL & 111,237 & $86 \%$ \\
\hline Sacramento, CA & 101,792 & $68 \%$ \\
\hline Tampa, FL & 58,414 & $43 \%$ \\
\hline Fresno, CA & 54,255 & $39 \%$ \\
\hline Corpus Christi, TX & 36,952 & $34 \%$ \\
\hline Houston, TX & 186,481 & $32 \%$ \\
\hline Lehigh Acres, FL & 37,289 & $30 \%$ \\
\hline Chicago, IL & 154,824 & $26 \%$ \\
\hline San Jose, CA & 56,243 & $25 \%$ \\
\hline Virginia Beach, VA & 28,943 & $20 \%$ \\
\hline Portland, OR & 45,951 & $20 \%$ \\
\hline Los Angeles, CA & 132,046 & $20 \%$ \\
\hline Bakersfield, CA & 20,430 & $18 \%$ \\
\hline Pittsburgh, PA & 21,803 & $15 \%$ \\
\hline Scottsdale, AZ & 17,781 & $15 \%$ \\
\hline New York, NY & 121,202 & $14 \%$ \\
\hline Tulsa, OK & 21,727 & $14 \%$ \\
\hline Jacksonville, FL & 48,408 & $14 \%$ \\
\hline Memphis, TN & 32,455 & $14 \%$ \\
\hline
\end{tabular}

Greatest relative growing risk*

\begin{tabular}{lrrrrrr|r|}
\hline City & \multicolumn{2}{c}{2020} & \multicolumn{2}{c}{2050} & \multicolumn{2}{c}{ Change } \\
\hline Virginia Beach, VA & 28,943 & $20 \%$ & 52,125 & $37 \%$ & $+23,182$ & $+80.1 \%$ \\
\hline New York, NY & 121,202 & $14 \%$ & 166,875 & $19 \%$ & $+45,673$ & $+37.7 \%$ \\
\hline Jacksonville, FL & 48,408 & $14 \%$ & 64,113 & $18 \%$ & $+15,705$ & $+32.4 \%$ \\
\hline Corpus Christi, TX & 36,952 & $34 \%$ & 47,248 & $43 \%$ & $+10,296$ & $+27.9 \%$ \\
\hline Tampa, FL & 58,414 & $43 \%$ & 72,178 & $54 \%$ & $+13,764$ & $+23.6 \%$ \\
\hline San Francisco, CA & 7,839 & $5 \%$ & 9,321 & $6 \%$ & $+1,482$ & $+18.9 \%$ \\
\hline Cape Coral, FL & 111,237 & $86 \%$ & 126,436 & $97 \%$ & $+15,199$ & $+13.7 \%$ \\
\hline Philadelphia, PA & 53,378 & $10 \%$ & 60,561 & $11 \%$ & $+7,183$ & $+13.5 \%$ \\
\hline Baltimore, MD & 13,705 & $6 \%$ & 15,378 & $7 \%$ & $+1,673$ & $+12.2 \%$ \\
\hline Seattle, WA & 13,977 & $8 \%$ & 15,647 & $9 \%$ & $+1,670$ & $+11.9 \%$ \\
\hline Memphis, TN & 32,455 & $14 \%$ & 35,837 & $15 \%$ & $+3,382$ & $+10.4 \%$ \\
\hline San Diego, CA & 10,434 & $4 \%$ & 11,503 & $4 \%$ & $+1,069$ & $+10.2 \%$ \\
\hline Cleveland, OH & 12,261 & $7 \%$ & 13,354 & $8 \%$ & $+1,093$ & $+8.9 \%$ \\
\hline Houston, TX & 186,481 & $32 \%$ & 202,317 & $34 \%$ & $+15,836$ & $+8.5 \%$ \\
\hline Mesa, AZ & 5,447 & $3 \%$ & 5,899 & $4 \%$ & +452 & $+8.3 \%$ \\
\hline Columbus, OH & 17,728 & $6 \%$ & 19,117 & $7 \%$ & $+1,389$ & $+7.8 \%$ \\
\hline Henderson, NV & 11,706 & $9 \%$ & 12,588 & $10 \%$ & +882 & $+7.5 \%$ \\
\hline Sacramento, CA & 101,792 & $68 \%$ & 109,416 & $74 \%$ & $+7,624$ & $+7.5 \%$ \\
\hline Washington, DC & 11,692 & $9 \%$ & 12,541 & $9 \%$ & +849 & $+7.3 \%$ \\
\hline Lehigh Acres, FL & 37,289 & $30 \%$ & 39,844 & $32 \%$ & $+2,555$ & $+6.9 \%$ \\
\hline
\end{tabular}




\section{Flood Factors National Overview}

At a more granular level, the results shed light on the unevenness in which changing environmental factors will impact regions of the country. They also demonstrate the need to incorporate more localized data at a property level in order to fully understand flood risk. Viewing risk at a summarized city, county or state level looks very different than the property-level Flood Factor outputs. A property's Flood Factor is an indicator of its practical flood risk, ranging from 1-10. Properties with higher Flood Factors are either more likely to flood, more likely to experience high floods, or both. A property's Flood Factor is determined by its likelihood of flooding and the potential depth of that flood. Because flood risks accumulate over time, it specifically looks at the likelihood of water reaching the building, or center of an empty lot, at least once within the next 30 years.

Flood Factor scores increase as the 30-year cumulative flood likelihood increases, or as the projected depth of flooding increases. Properties with a less than $0.2 \%$ chance of experiencing any depth of flooding in any year within the next 30 years are considered to have minimal risk or a Flood Factor of 1. In totality, more than $16.5 \%$ of individual homes and properties in the U.S. are at any risk of flooding over the next 30 years. Out of those at risk, $64.1 \%$ are at major to extreme risk (Flood Factor 5 or above).

As with the national summaries, each region of the country also has a significant amount of unevenness associated with the current and future impact or risk. Detailed information for each state can be found at the end of the report.

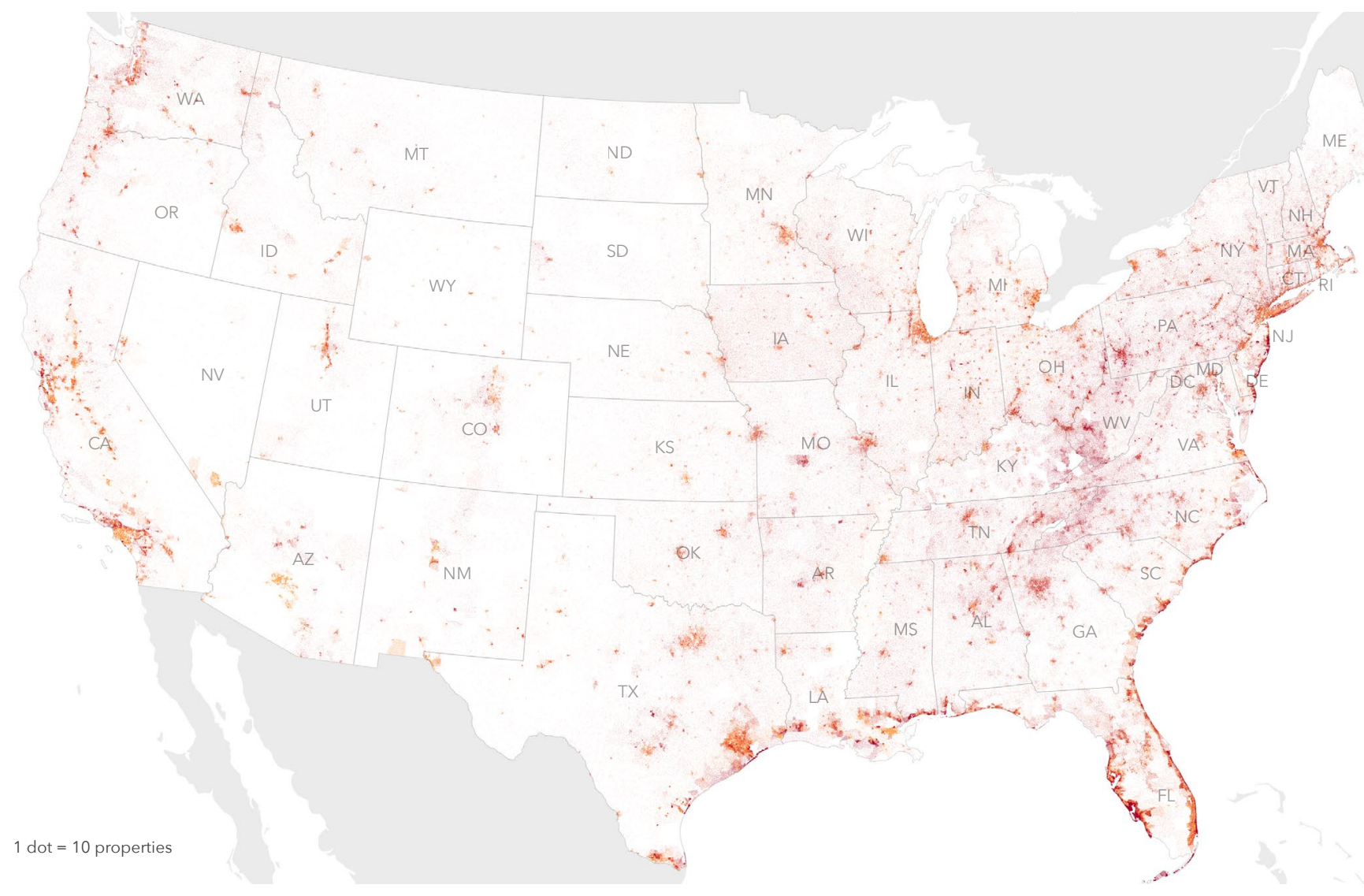

Total properties at risk* $23.5 \mathrm{M}$
Foctor distribution of properties at risk*

Minor

Moderate

Major

Severe

Extreme
$1.3 \mathrm{M}$

$7.2 \mathrm{M}$

$7.4 \mathrm{M}$

$2.8 \mathrm{M}$

$4.8 \mathrm{M}$ 


\section{Policy Implications}

Now and into the Future

The availability of the First Street property-level data on a national leve informs a wide range of possible adaptation, mitigation, and policy efforts. Individuals, industry and governments have been seeking the kinds of widely-available and consistent tools necessary for informed decision-making, especially ones that incorporate risk and climate change information at a high resolution and are of a sufficiently high quality (Berman, 2019). Such information has a number of uses, including making it possible for:

- Individual property owners in the U.S. (freely through floodfactor. com) to understand the risk associated with their property and mitigate their risk by buying insurance from federal or private providers, by seeking alternative properties with lower risk, or by adapting through modifications to their properties and/or the buildings on them.

- The real estate, mortgage, insurance, and investment communities have a consistent property-level dataset across the U.S. with which they can judge the severity and concomitant value of the risk associated with the properties under their control or consideration, and thus enable informed decision-making within and across those commercial communities. Actuarial estimates for specific buildings and structures could be built upon such property-level risk estimates.

- Governments at all levels, from the U.S. Federal Government to small towns, to have access to First Street's property-level flood risks that they need to drive informed policymaking and guide public investment in adaptations that will reduce the risk across wide swaths of properties. These adaptations include buyouts and public works that can reduce communities' risk for extended periods, as well as modifications of the operations of existing adaptation infrastructure.
Access to the First Street information is a necessary but insufficient condition for these sectors to make rapid progress on reducing flood risk. First Street intends to work with the entire community to further refine, update, and expand its Flood Model, to make the data more accurate and useful over time.

To begin to understand the flood risk exposure and its implications for our communities in the U.S., First Street has created the "First Street Foundation Flood Lab" through agreements with a collection of experienced academic and industry researchers who have secure access to the full suite of data used and produced by First Street. Flood Lab members will be able to drill into those data to derive the information products necessary to further understanding of flood risk, its consequences, and propose potential solutions. These experts represent a wide swath of disciplines, including finance, economics, public policy, risk management, hydrology and engineering, who will examine the implications of flood risk data on the mortgage industry, coastal communities, government policy, the National Flood Insurance Program, housing market low-income and disadvantaged communities, and other related topics. Enabled by data sharing agreements among the data providers and participants, the insights generated by the Flood Lab researchers will enable the data to be applied more rapidly and to greatest effect.

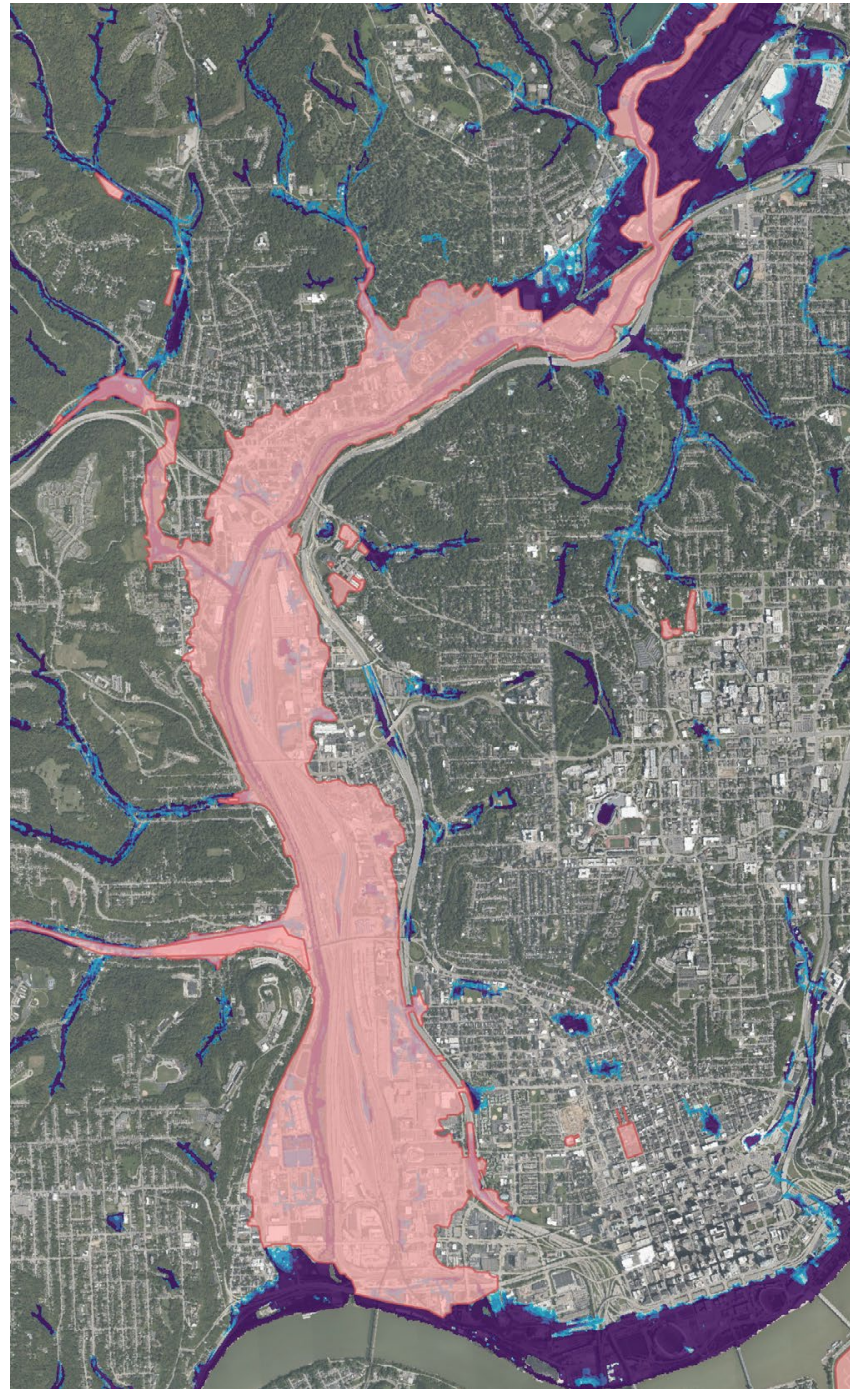

Ohio. Cincinnati Leveed Area 


\section{State Overview Alabama}

Flood risk is increasing in the state of Alabama. 334,900 properties currently have a substantial risk* of flooding. Over the next 30 years, the number of properties with this risk will increase by another $6.2 \%$, bringing the total number of properties with substantial risk to 355,700 .

To understand personal flood risk, Americans leverage the Federal Emergency Management Agency (FEMA) Flood Insurance Rate Maps (FIRM). These maps identify 187,900 properties as having substantial risk in the state of Alabama. In comparison, the First Street Foundation

Flood Model identifies 1.8 times the number of properties as facing this same level of risk. This discrepancy exists because the Foundation uses the current climate data, maps precipitation as a stand-alone risk, and includes areas that FEMA has not mapped. These new methods uncover an additional 147,000 properties currently not identified by FEMA as having substantial risk.

When adjusting for future environmental changes, the FEMA gap further widens to 167,800 by the year 2050

\section{Total properties at substantial risk}

\section{$\ln 2050$}

334,900

$$
\begin{aligned}
& \text { 30-year change } \\
& \Delta+20,800
\end{aligned}
$$

Mobile Bay faces tidal, riverine, and rainfall flooding Construction along the shoreline slows water absorption leading to inland flooding. Montgomery is subject to floods when the Alabama River rises due to heavy rainfall. Significant portions of the business district and downtown face risk, along with low-lying suburban and agricultural areas nearby. Upgrades to storm sewers may not fully alleviate flooding.

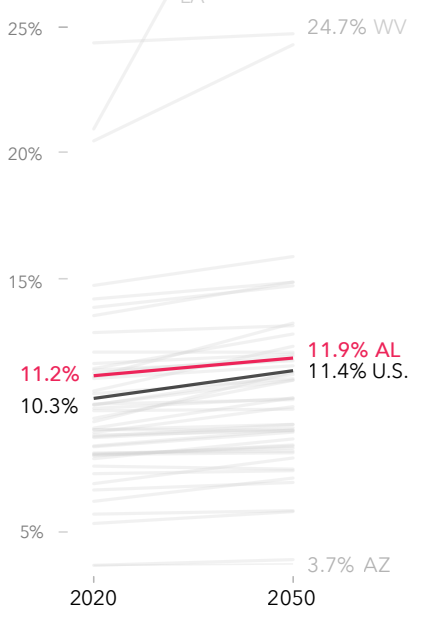

Percent of properties at substantial risk compared to other states Flood Model finds $10.3 \%$ of all properties across the contiguous United States at substantial risk of flooding today, and $11.4 \%$ at substantial risk in 30 years. Alabama has a greater proportion of properties at substantial risk, with $11.2 \%$ at substantial risk today and $11.9 \%$ at substantial risk in 2050.
Difference in number of properties currently at substantial risk compared to FEMA**

\section{$\Delta+147,000$}

More properties at risk in FSF model $\longrightarrow$
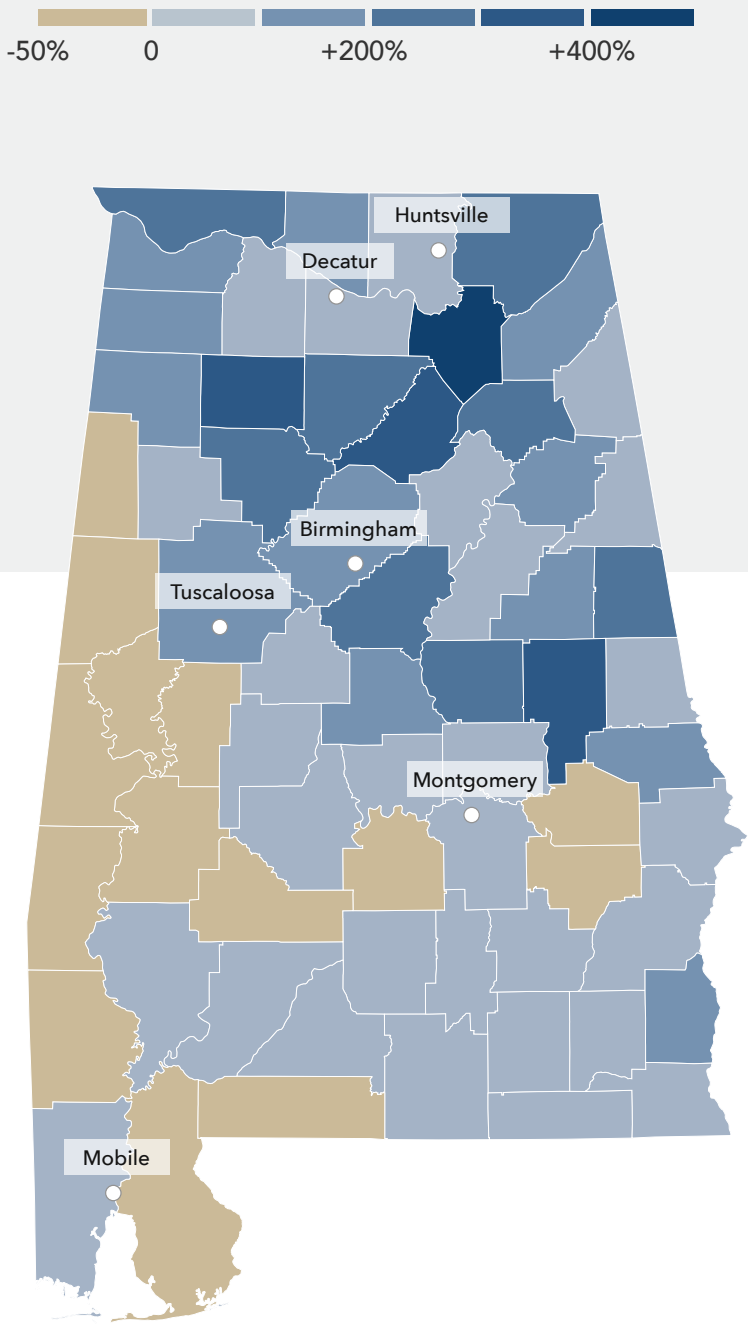


\section{Local details}

Alabama

The First Street Foundation Flood Model calculates the number of properties facing any risk* of flooding. When looking at this broader level of risk, the data identifies 439,300 properties in Alabama as at risk over the next 30 years. Of these properties, 94,000 were categorized as facing almost certain risk, with a $99 \%$ chance of flooding at least once over the next 30 years.

The city of Mobile has the greatest number of properties at risk of flooding in the state with 24,100 currently at risk, or $29 \%$ of its total number of properties. However, smaller cities or municipalities in the state, with fewer properties, may have a greater proportion of their total properties at risk. For example, $88 \%$ of properties in Dauphin Island are at risk of flooding. Other municipalities will see the greatest increase in risk over the next 30 years. Satsuma, for example, will see a $130 \%$ increase in the number of properties at risk.

Click here for a full breakdown of counties, cities, zip codes, and congressional districts in Alabama at risk.

\section{Greatest proportion of properties at risk*}

\begin{tabular}{lll} 
Municipality & \multicolumn{2}{c}{2020} \\
\hline Dauphin Island & 3,071 & $88 \%$ \\
\hline Selma & 7,366 & $73 \%$ \\
\hline Cedar Bluff & 1,269 & $53 \%$ \\
\hline Elba & 1,342 & $47 \%$ \\
\hline Orange Beach & 3,020 & $44 \%$ \\
\hline Gulf Shores & 4,135 & $43 \%$ \\
\hline Rainbow City & 2,544 & $43 \%$ \\
\hline Scottsboro & 3,735 & $42 \%$ \\
\hline Childersburg & 1,134 & $40 \%$ \\
\hline Decatur & 8,242 & $34 \%$ \\
\hline
\end{tabular}

\section{Greatest number of properties at risk*}

\begin{tabular}{|c|c|c|c|c|c|c|}
\hline Municipality & 20 & & 20 & 50 & & nange \\
\hline Mobile & 24,070 & $29 \%$ & 26,101 & $32 \%$ & $+2,031$ & $+8.4 \%$ \\
\hline Birmingham & 16,932 & $17 \%$ & 17,936 & $18 \%$ & $+1,004$ & $+5.9 \%$ \\
\hline Huntsville & 13,213 & $16 \%$ & 13,564 & $16 \%$ & +351 & $+2.7 \%$ \\
\hline Decatur & 8,242 & $34 \%$ & 8,361 & $35 \%$ & +119 & $+1.4 \%$ \\
\hline Montgomery & 7,936 & $10 \%$ & 8,596 & $10 \%$ & +660 & $+8.3 \%$ \\
\hline Selma & 7,366 & $73 \%$ & 7,860 & $78 \%$ & +494 & $+6.7 \%$ \\
\hline Gadsden & 6,405 & $26 \%$ & 6,303 & $26 \%$ & -102 & $-1.6 \%$ \\
\hline Gulf Shores & 4,135 & $43 \%$ & 5,266 & $55 \%$ & $+1,131$ & $+27.4 \%$ \\
\hline Tuscaloosa & 3,780 & $11 \%$ & 3,990 & $12 \%$ & +210 & $+5.6 \%$ \\
\hline Scottsboro & 3,735 & $42 \%$ & 3,785 & $42 \%$ & +50 & $+1.3 \%$ \\
\hline
\end{tabular}

\section{Greatest relative growing risk*}

\begin{tabular}{lrrrrrr} 
Municipality & \multicolumn{2}{c}{2020} & \multicolumn{2}{c}{2050} & \multicolumn{2}{c}{ Change } \\
Satsuma & 772 & $25 \%$ & 1,778 & $57 \%$ & +1006 & $+130 \%$ \\
\hline Saraland & 1,623 & $22 \%$ & 2,232 & $31 \%$ & +609 & $+38 \%$ \\
\hline Robertsdale & 71 & $3 \%$ & 91 & $4 \%$ & +20 & $+28 \%$ \\
\hline Gulf Shores & 4,135 & $43 \%$ & 5,266 & $55 \%$ & $+1,131$ & $+27 \%$ \\
\hline Pell City & 885 & $12 \%$ & 1,055 & $14 \%$ & +170 & $+19 \%$ \\
\hline Daleville & 147 & $6 \%$ & 172 & $6 \%$ & +25 & $+17 \%$ \\
\hline Chickasaw & 719 & $24 \%$ & 839 & $28 \%$ & +120 & $+17 \%$ \\
\hline Theodore & 153 & $6 \%$ & 177 & $7 \%$ & +24 & $+16 \%$ \\
\hline Fairhope & 826 & $8 \%$ & 952 & $9 \%$ & +126 & $+15 \%$ \\
\hline Midfield & 416 & $15 \%$ & 474 & $17 \%$ & +58 & $+14 \%$ \\
\hline
\end{tabular}

\section{Flood Factor distribution of properties at risk ${ }^{\star}(1000 s)$}

\section{Risk level}

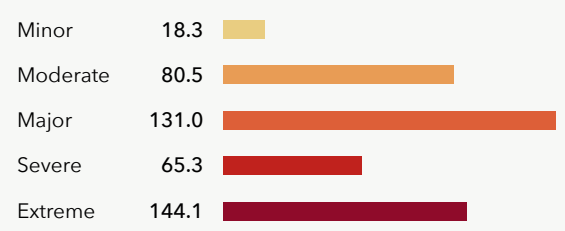

Extreme

144.1

More than $14.6 \%$ of individual properties and properties in Alabama are at any risk of flooding over the next 30 years. Out of those at risk $78 \%$ are at major to extreme risk.

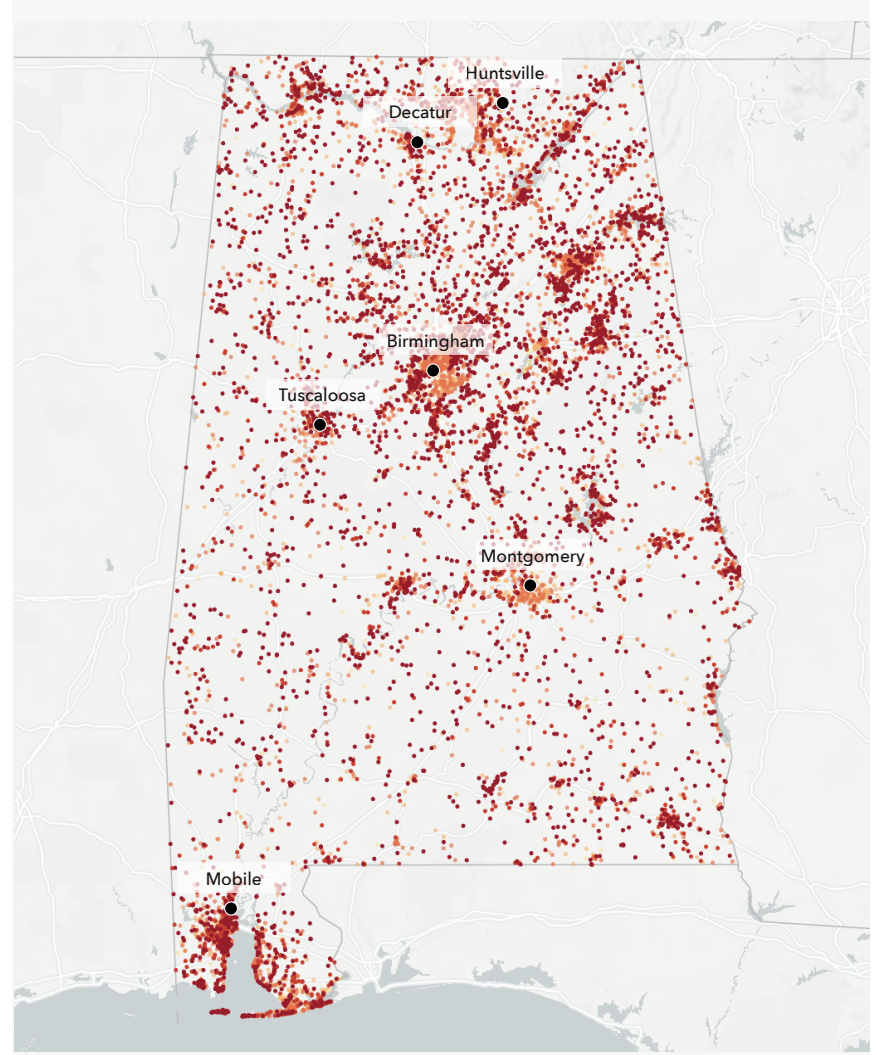




\section{Flood History \& Protection}

\section{Alabama}

\section{Claims History}

548,600 home and property owners in Alabama have made flood damage claims through FEMA since the year 2000.* These claims for reimbursement were made through either the National Flood Insurance Program (NFIP) or Individual Assistance Program (IAP). The greatest number of claims since the year 2000 have been concentrated in Mobile, Baldwin, Jefferson, Conecuh, and Madison counties.

\section{Storm Simulation}

The First Street Foundation Flood Model has recreated 3 flooding events that have occurred since the year 2000 in the state of Alabama. These events flooded around 21,010 properties across the state. $^{\star \star}$

\begin{tabular}{llr} 
Flood event & Date & $\begin{array}{r}\text { \# Properties } \\
\text { affected }\end{array}$ \\
Hurricane Isidore & Sep 2002 & 6,244 \\
\hline Hurricane Katrina & Aug 2005 & 12,564 \\
\hline Hurricane Gustav & Aug 2008 & 2,201
\end{tabular}
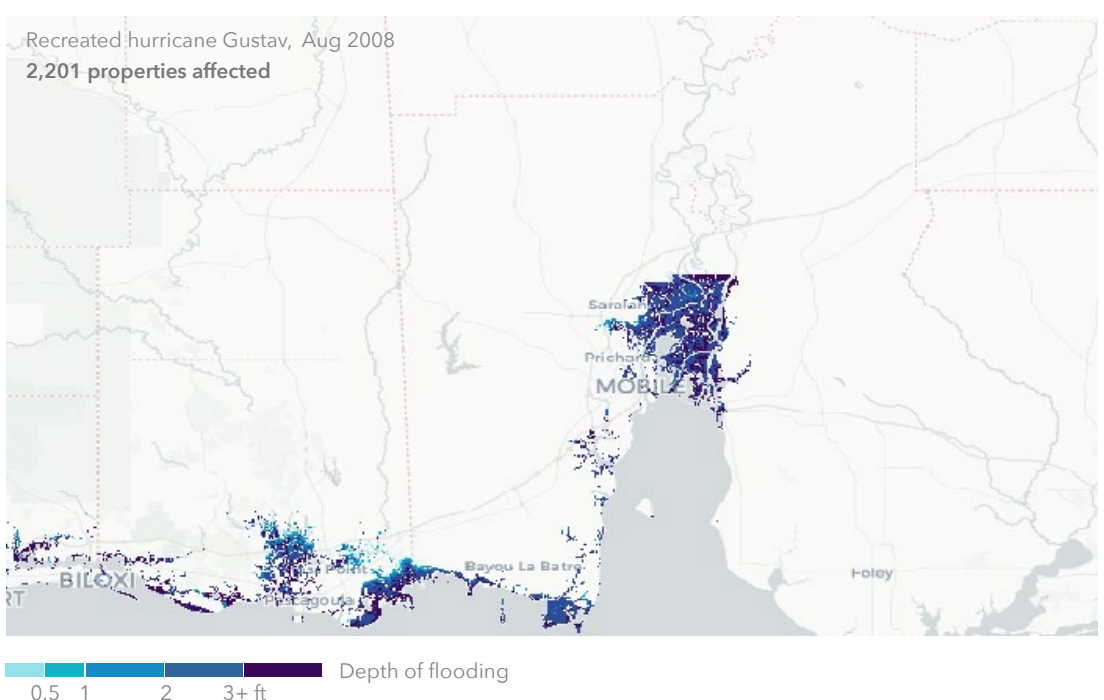

\section{5,000}

Properties served by

protection measures

The First Street Foundation Flood

Model incorporates 59 flood control

measures throughout the state which

protect 385,000 properties.

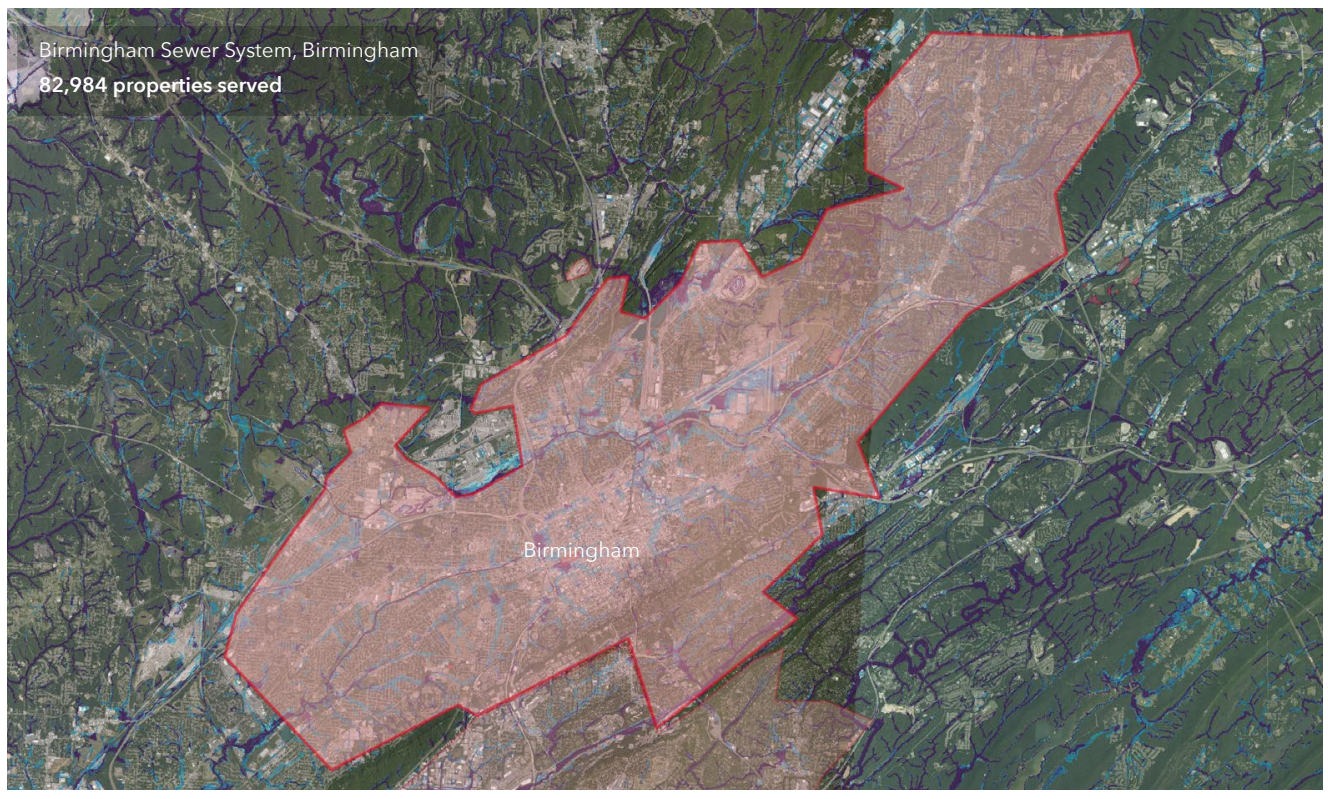

$\square$ Area of protectio
Top protection measures in state by quantity

Type
Example

Sewer upgrade

\# Properties served by type

System, Birminghan

281,568

Culvert

86,565

Huntsville Sewer System A. Huntsville

12,753

Eslava Creek Litter Trap, Mobile

Levee

Beach nourishment 


\section{State Overview Arizona}

Flood risk is increasing in the state of Arizona. 118,700 properties currently have a substantial risk* of flooding. Over the next 30 years, the number of properties with this risk will increase by another $1.6 \%$, bringing the total number of properties with substantial risk to 120,600 .

To understand personal flood risk, Americans leverage the Federal Emergency Management Agency (FEMA) Flood Insurance Rate Maps (FIRM). These maps identify 129,500 properties as having substantial risk in the state of Arizona. In comparison, the First Street Foundation Flood Model identifies 10,800 fewer properties as facing this same level of risk. This discrepancy exists because of differences in the methods used to estimate risk. The Foundation's Flood Model uses the current climate data, maps precipitation as a stand-alone risk, and may include adaptation improvements not taken into account by FEMA. When adjusting for future environmental changes, the FEMA gap narrows to 8,900 by the year 2050 .
Total properties at substantial risk $^{*}$

In 2020

\section{8,700}

30-year change

$$
\Delta+1,900(+1.6 \%)
$$

$\ln 2050$

120,600

Phoenix sees floods from heavy rains in the mountain surrounding the Valley of the Sun. Runoff from winter and spring storms move rapidly downhill into developed areas, overflowing the city's rivers where the floodplains are heavily developed, flat, and wide. Known protections include dams and levees, a complex drainage and cana network, as well as river channel modifications.

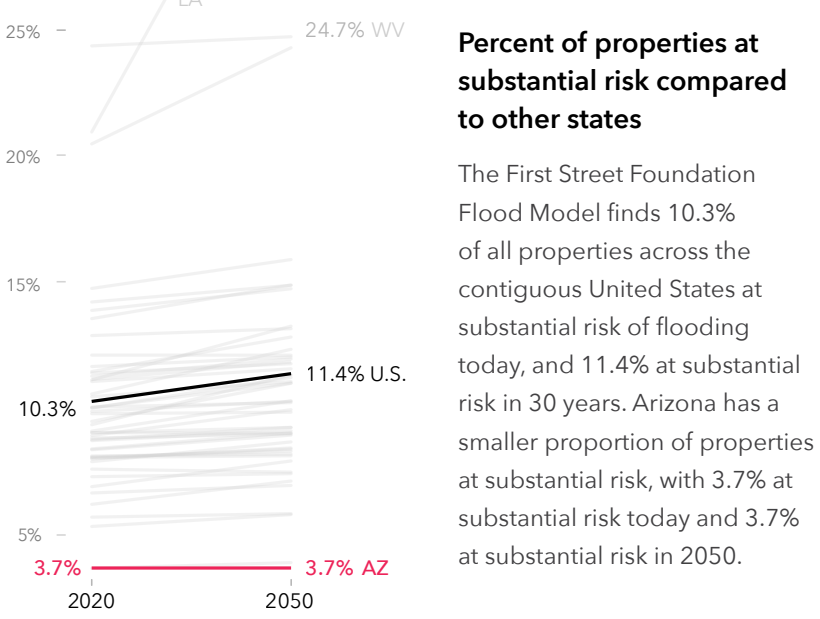

Difference in number of properties currently at substantial risk compared to FEMA**

$\nabla-10,800$

More properties at risk in FSF model $\longrightarrow$

$-50 \% \quad 0 \quad+50 \% \quad+150 \% \quad+250 \%$

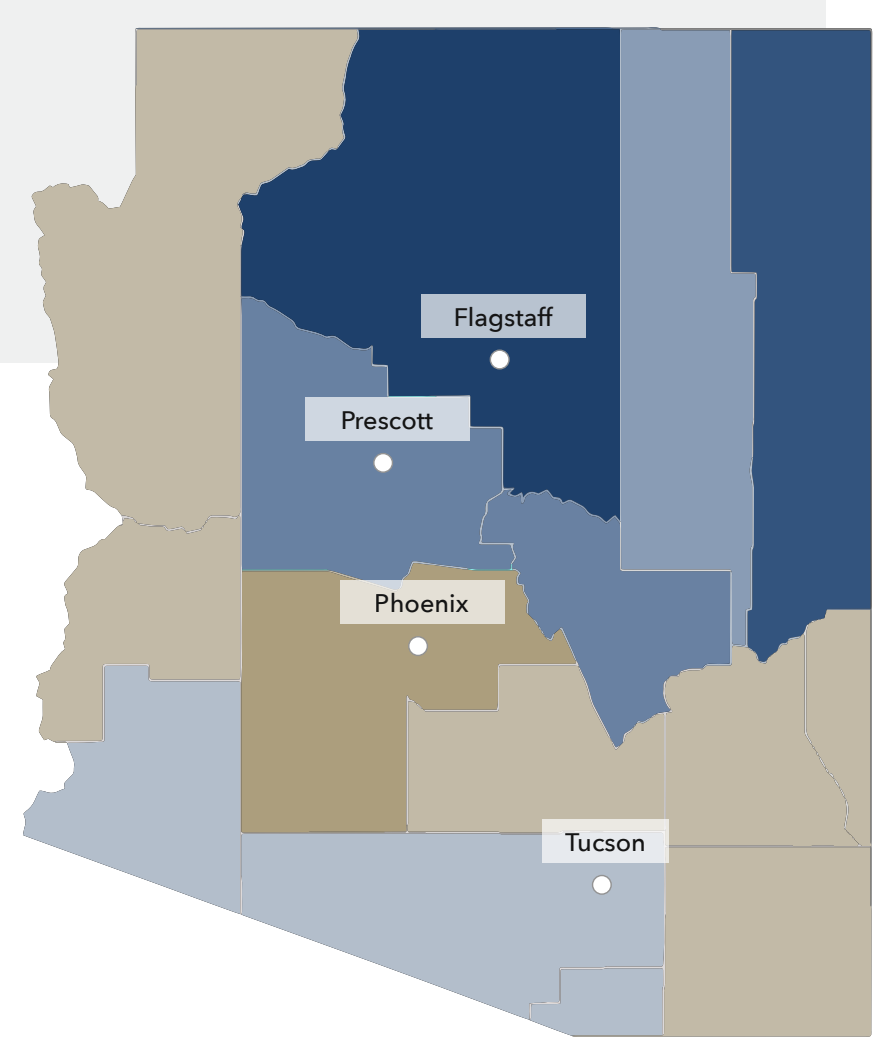




\section{Local details \\ Arizona}

The First Street Foundation Flood Model calculates the number of properties facing any risk* of flooding. When looking at this broader level of risk, the data identifies 367,600 properties in Arizona as at risk over the next 30 years. Of these properties, 24,700 were categorized as facing almost certain risk, with a $99 \%$ chance of flooding at least once over the next 30 years.

The city of Phoenix has the greatest number of properties at risk of flooding in the state with 62,400 currently at risk, or $13 \%$ of its total number of properties. However, smaller cities or municipalities in the state, with fewer properties, may have a greater proportion of their total properties at risk. For example, $65 \%$ of properties in Willcox are at risk of flooding. Other municipalities will see the greatest increase in risk over the next 30 years. Somerton, for example, will see a 15\% increase in the number of properties at risk.

Click here for a full breakdown of counties, cities, zip codes, and congressional districts in Arizona at risk.

\section{Greatest proportion of properties at risk*}

\begin{tabular}{lrr|} 
Municipality & \multicolumn{2}{c}{2020} \\
Willcox & 2,728 & $65 \%$ \\
\hline Cienega Springs & 988 & $43 \%$ \\
\hline Tolleson & 848 & $41 \%$ \\
\hline Doney Park & 842 & $41 \%$ \\
\hline Glendale & 25,429 & $37 \%$ \\
\hline Williams & 931 & $34 \%$ \\
\hline Camp Verde & 2,065 & $29 \%$ \\
\hline Holbrook & 714 & $27 \%$ \\
\hline Gold Canyon & 2,019 & $27 \%$ \\
\hline Bisbee & 1,119 & $26 \%$ \\
\hline
\end{tabular}

\section{Greatest number of properties at risk*}

\begin{tabular}{l|c|ccccc} 
Municipality & \multicolumn{2}{c}{2020} & \multicolumn{2}{c}{2050} & \multicolumn{2}{c}{ Change } \\
Phoenix & 62,351 & $13 \%$ & 61,466 & $13 \%$ & -885 & $-1.4 \%$ \\
\hline Glendale & 25,429 & $37 \%$ & 24,517 & $36 \%$ & -912 & $-3.6 \%$ \\
\hline Scottsdale & 17,781 & $15 \%$ & 18,769 & $16 \%$ & +988 & $+5.6 \%$ \\
\hline Peoria & 7,850 & $11 \%$ & 7,661 & $11 \%$ & -189 & $-2.4 \%$ \\
\hline Maricopa & 7,479 & $26 \%$ & 7,099 & $25 \%$ & -380 & $-5.1 \%$ \\
\hline Mesa & 5,447 & $3 \%$ & 5,899 & $4 \%$ & +452 & $+8.3 \%$ \\
\hline Tucson & 5,404 & $3 \%$ & 5,348 & $3 \%$ & -56 & $-1.0 \%$ \\
\hline Surprise & 5,236 & $8 \%$ & 5,099 & $8 \%$ & -137 & $-2.6 \%$ \\
\hline Lake Havasu City & 4,762 & $12 \%$ & 4,807 & $12 \%$ & +45 & $+0.9 \%$ \\
\hline Flagstaff & 4,466 & $20 \%$ & 4,608 & $20 \%$ & +142 & $+3.2 \%$
\end{tabular}

\section{Greatest relative growing risk*}

\begin{tabular}{lrlrlrl} 
Municipality & \multicolumn{2}{c}{2020} & \multicolumn{2}{c}{2050} & \multicolumn{2}{c}{ Change } \\
Somerton & 375 & $9 \%$ & 431 & $11 \%$ & +56 & $+15 \%$ \\
\hline Dolan Springs & 855 & $6 \%$ & 975 & $7 \%$ & +120 & $+14 \%$ \\
\hline White Hills & 130 & $3 \%$ & 148 & $4 \%$ & +18 & $+14 \%$ \\
\hline Sun Lakes & 158 & $2 \%$ & 179 & $2 \%$ & +21 & $+13 \%$ \\
\hline Chandler & 1,965 & $2 \%$ & 2,178 & $2 \%$ & +213 & $+11 \%$ \\
\hline Golden Valley & 671 & $6 \%$ & 741 & $7 \%$ & +70 & $+10 \%$ \\
\hline Winslow & 673 & $19 \%$ & 741 & $21 \%$ & +68 & $+10 \%$ \\
\hline Yuma & 4,103 & $13 \%$ & 4,504 & $14 \%$ & +401 & $+10 \%$ \\
\hline New River & 248 & $3 \%$ & 272 & $3 \%$ & +24 & $+10 \%$ \\
\hline Fort Mohave & 856 & $8 \%$ & 936 & $9 \%$ & +80 & $+9 \%$
\end{tabular}

\section{Flood Factor distribution of properties at risk ${ }^{\star}(1000 s)$}

\section{Risk leve}

Minor $\quad 28.5$

Moderate $\quad 223.2$

Major $\quad 55.5$

Severe 29.1

Extreme $\quad 31.2$

More than $11.2 \%$ of individual properties and properties in Arizona are at any risk of flooding over the next 30 years. Out of those at risk $32 \%$ are at major to extreme risk.

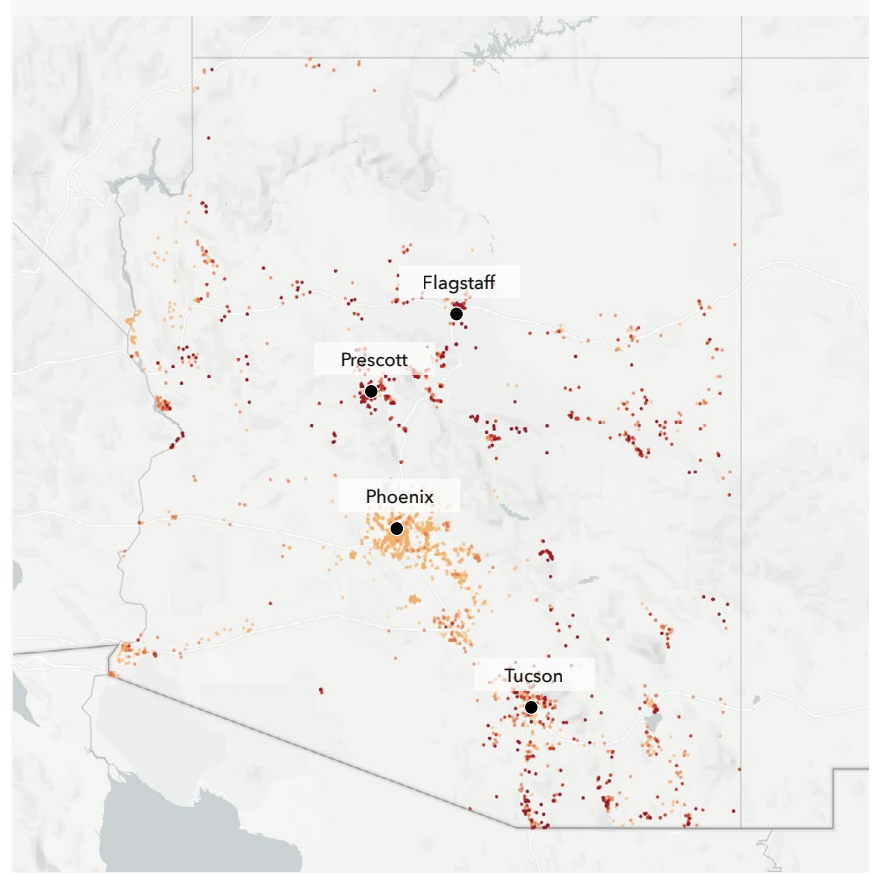




\section{Flood History \& Protection}

\section{Arizona}

1,900 home and property owners in Arizona have made flood damage claims through FEMA since the year 2000.* These claims for reimbursement were made through either the National Flood Insurance Program (NFIP) or Individual Assistance Program (IAP). The greatest number of claims since the year 2000 have been concentrated in Maricopa, Yavapai, Pima, Coconino, and Pinal counties.

\section{Storm Simulation}

The First Street Foundation Flood Model has recreated 1 flooding event that occurred since the year 2000 in the state of Arizona. This event flooded around 40 properties across the state.**

Recreated river flood Northwest AZ Jan 2005

43 properties affected in Arizon
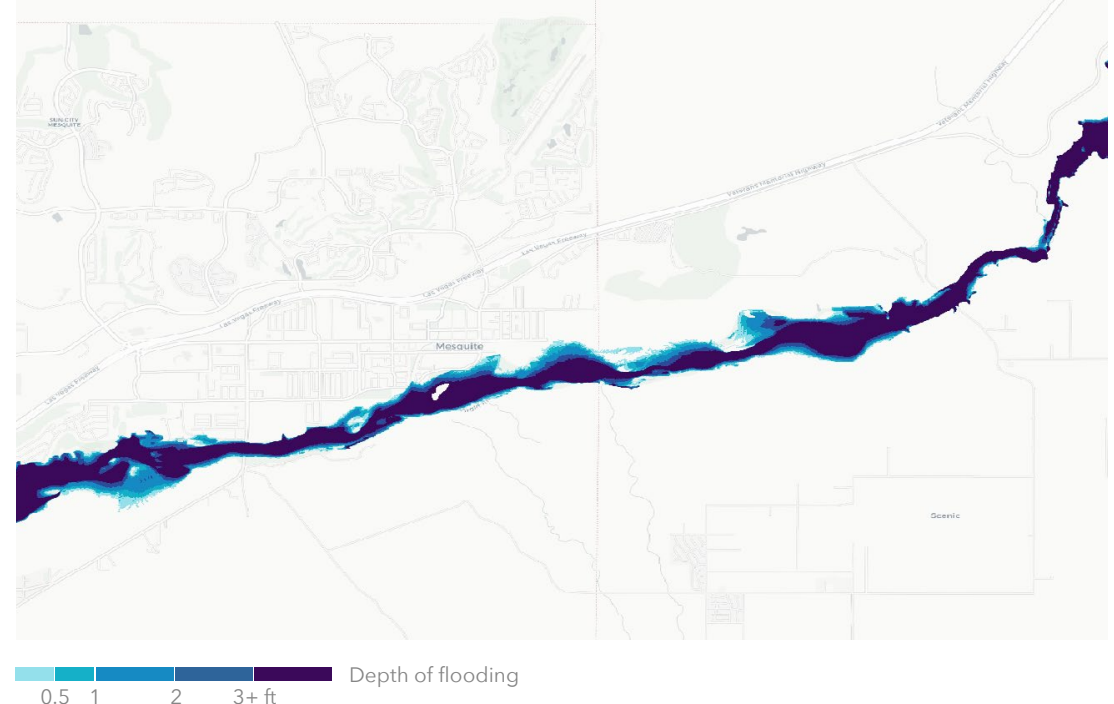

\section{1,900}

Properties served by

protection measures

The First Street Foundation Flood

Model incorporates 190 flood control

measures throughout the state which

protect 761,900 properties
Top protection measures in state by quantity

Type

\# Properties served by type

Spillway

437,705

- Arizona Canal Diversion Channel, Phoenix

147,695

Levee

197,679

Maricopa County Levee 30, Mesa

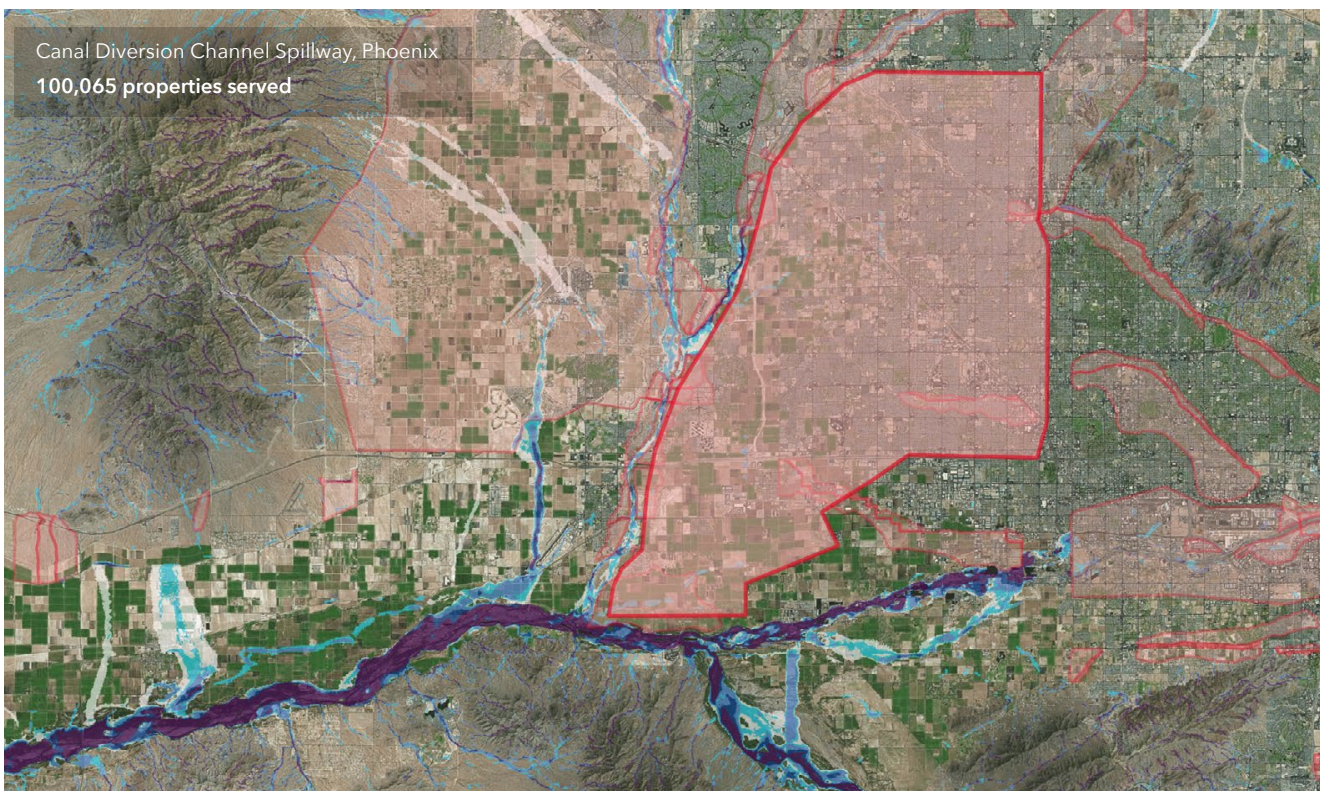

$\square$ Area of protection 


\section{State Overview Arkansas}

Flood risk is increasing in the state of Arkansas. 191,600 properties currently have a substantial risk* of flooding. Over the next 30 years, the number of properties with this risk will increase by another $1.7 \%$, bringing the total number of properties with substantial risk to 195,000 .

To understand personal flood risk, Americans leverage the Federal Emergency Management Agency (FEMA) Flood Insurance Rate Maps

(FIRM). These maps identify 152,900 properties as having substantial risk in the state of Arkansas. In comparison, the First Street Foundation Flood Model identifies 1.3 times the number of properties as facing this same level of risk. This discrepancy exists because the Foundation uses the current climate data, maps precipitation as a stand-alone risk, and includes areas that FEMA has not mapped. These new methods uncover an additional 38,700 properties currently not identified by FEMA as having substantial risk. When adjusting for future environmental changes, the FEMA gap further widens to 42,100 by the year 2050 .

\section{Total properties at substantial risk}

$\ln 2020$

\section{1,600}

30-year change

$\Delta+3,400(+2 \%)$

Arkansas experiences regular flooding when the

Arkansas and Mississippi rivers overtop. Other parts of the state may experience heavy rainfall flooding derived from steep slopes and developed land.

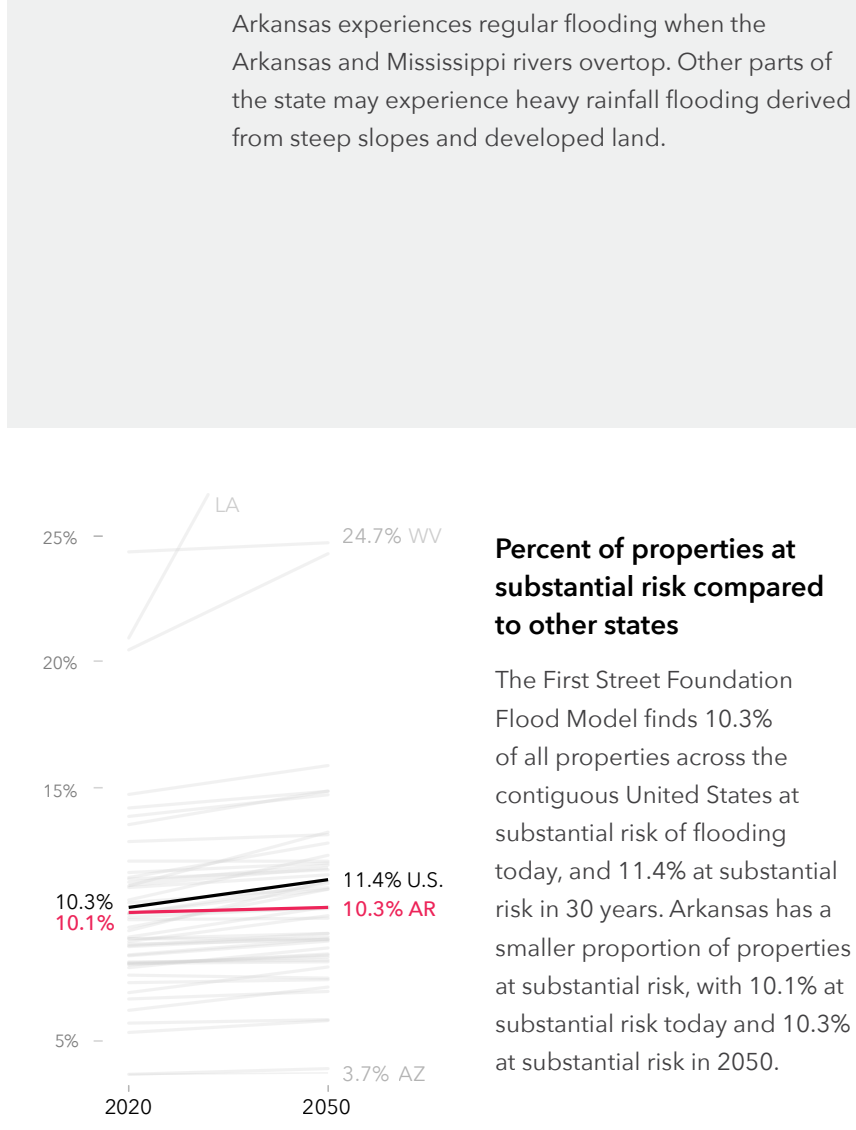

Difference in number of properties currently at substantial risk compared to FEMA**

$$
\Delta+38,700
$$

More properties at risk in FSF model $\longrightarrow$
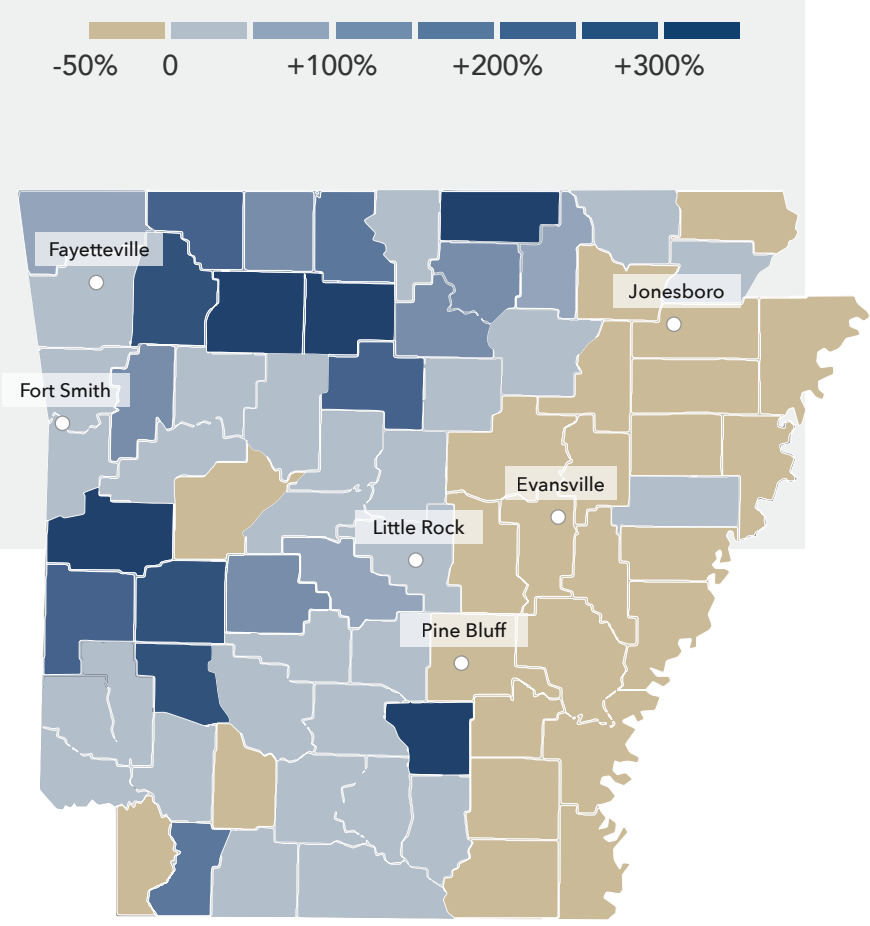


\section{Local details \\ Arkansas}

The First Street Foundation Flood Model calculates the number of properties facing any risk* of flooding. When looking at this broader level of risk, the data identifies 247,600 properties in Arkansas as at risk over the next 30 years. Of these properties, 79,400 were categorized as facing almost certain risk, with a $99 \%$ chance of flooding at least once over the next 30 years.

The city of North Little Rock has the greatest number of properties at risk of flooding in the state with 9,100 currently at risk, or $33 \%$ of its total number of properties. However, smaller cities or municipalities in the state, with fewer properties, may have a greater proportion of their total properties at risk. For example, $46 \%$ of properties in Rockwell are at risk of flooding. Other municipalities will see the greatest increase in risk over the next 30 years. Dermott, for example, will see a 15\%

increase in the number of properties at risk.

Click here for a full breakdown of counties, cities, zip codes, and congressional districts in Arkansas at risk.

\section{Greatest proportion of properties at risk*}

\begin{tabular}{lrr|} 
Municipality & \multicolumn{2}{c}{2020} \\
\hline Rockwell & 1,004 & $46 \%$ \\
\hline Piney & 1,042 & $38 \%$ \\
\hline North Little Rock & 9,140 & $33 \%$ \\
\hline Paragould & 1,788 & $23 \%$ \\
\hline Piggott & 517 & $23 \%$ \\
\hline Helena-West Helena & 1,490 & $22 \%$ \\
\hline Hardy & 717 & $19 \%$ \\
\hline Hot Springs & 3,230 & $17 \%$ \\
\hline Maumelle & 1,090 & $14 \%$ \\
\hline Newport & 488 & $14 \%$ \\
\hline
\end{tabular}

\section{Greatest number of properties at risk*}

\begin{tabular}{lcccccc} 
Municipality & \multicolumn{2}{c}{2020} & \multicolumn{2}{c}{2050} & \multicolumn{2}{c}{ Change } \\
\cline { 2 - 7 } North Little Rock & 9,140 & $33 \%$ & 9,352 & $34 \%$ & +212 & $+2.3 \%$ \\
\hline Little Rock & 7,553 & $10 \%$ & 7,754 & $10 \%$ & +201 & $+2.7 \%$ \\
\hline Jonesboro & 3,581 & $12 \%$ & 3,800 & $13 \%$ & +219 & $+6.1 \%$ \\
\hline Hot Springs & 3,230 & $17 \%$ & 3,246 & $17 \%$ & +16 & $+0.5 \%$ \\
\hline Hot Springs Village & 2,955 & $8 \%$ & 3,003 & $8 \%$ & +48 & $+1.6 \%$ \\
\hline Pine Bluff & 2,599 & $9 \%$ & 2,705 & $9 \%$ & +106 & $+4.1 \%$ \\
\hline Fort Smith & 2,435 & $7 \%$ & 2,495 & $7 \%$ & +60 & $+2.5 \%$ \\
\hline Fayetteville & 1,860 & $6 \%$ & 1,894 & $6 \%$ & +34 & $+1.8 \%$ \\
\hline Paragould & 1,788 & $23 \%$ & 1,807 & $24 \%$ & +19 & $+1.1 \%$ \\
\hline Helena-West Helena & 1,490 & $22 \%$ & 1,533 & $23 \%$ & +43 & $+2.9 \%$
\end{tabular}

\section{Greatest relative growing risk*}

\begin{tabular}{lcccccc} 
Municipality & \multicolumn{2}{c}{2020} & \multicolumn{2}{c}{2050} & \multicolumn{2}{c}{ Change } \\
Dermott & 123 & $5 \%$ & 141 & $6 \%$ & +18 & $+15 \%$ \\
\hline Trumann & 372 & $10 \%$ & 418 & $11 \%$ & +46 & $+12 \%$ \\
\hline Warren & 156 & $4 \%$ & 174 & $5 \%$ & +18 & $+12 \%$ \\
\hline Marion & 603 & $12 \%$ & 658 & $13 \%$ & +55 & $+9 \%$ \\
\hline Blytheville & 722 & $8 \%$ & 785 & $9 \%$ & +63 & $+9 \%$ \\
\hline West Memphis & 731 & $9 \%$ & 780 & $10 \%$ & +49 & $+7 \%$ \\
\hline Forrest City & 211 & $7 \%$ & 224 & $8 \%$ & +13 & $+6 \%$ \\
\hline Jonesboro & 3,581 & $12 \%$ & 3,800 & $13 \%$ & +219 & $+6 \%$ \\
\hline Russellville & 1,164 & $11 \%$ & 1,234 & $12 \%$ & +70 & $+6 \%$ \\
\hline Brinkley & 268 & $12 \%$ & 283 & $13 \%$ & +15 & $+6 \%$ \\
\hline
\end{tabular}

\section{Flood Factor distribution of properties at risk ${ }^{\star}(1000 s)$}

\section{Risk level}

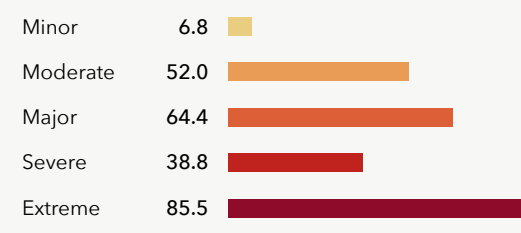

85.5

More than $13 \%$ of individual properties and properties in Arkansas are at any risk of flooding over the next 30 years. Out of those at risk $76 \%$ are at major to extreme risk.

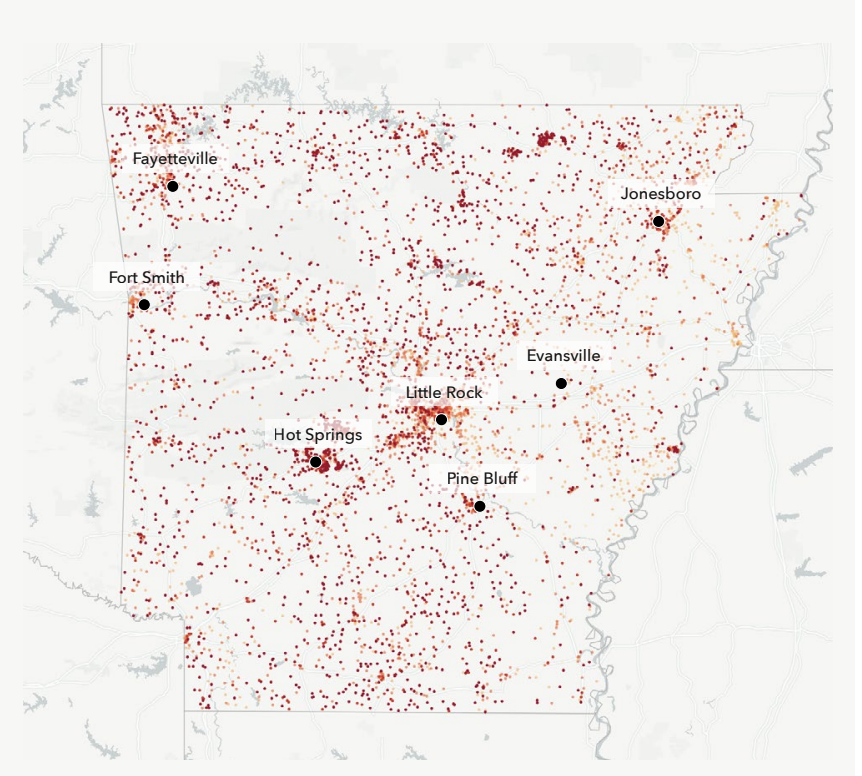




\section{Flood History \& Protection}

\section{Arkansas}

\section{Claims history}

64,100 home and property owners in Arkansas have made flood damage claims through FEMA since the year 2000.* These claims for reimbursement were made through either the National Flood Insurance Program (NFIP) or Individual Assistance Program (IAP). The greatest number of claims since the year 2000 have been concentrated in Sebastian, Pulaski, Crawford, Faulkner, and Phillips counties.

\section{Storm Simulation}

The First Street Foundation Flood Model has recreated 1 flooding events that have occurred since the year 2000 in the state of Arkansas. This event flooded around 1,90 properties across the state. ${ }^{\star \star}$
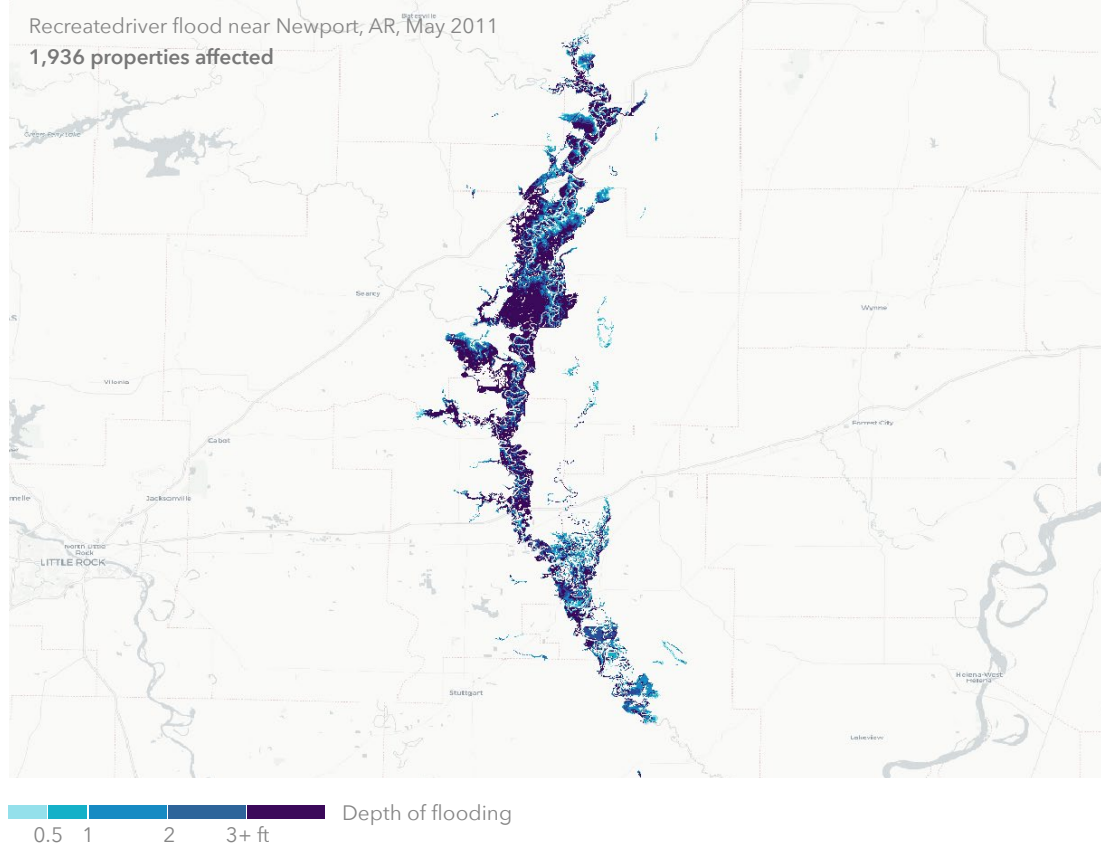

\section{9,500}

Properties served by

protection measures

The First Street Foundation Flood

Model incorporates 112 flood control

measures throughout the state which

protect 129,500 properties
Top protection measures in state by quantity

Type
Example

\# Properties served by type

Levee

129,468

Pervious pavement

Bioswale

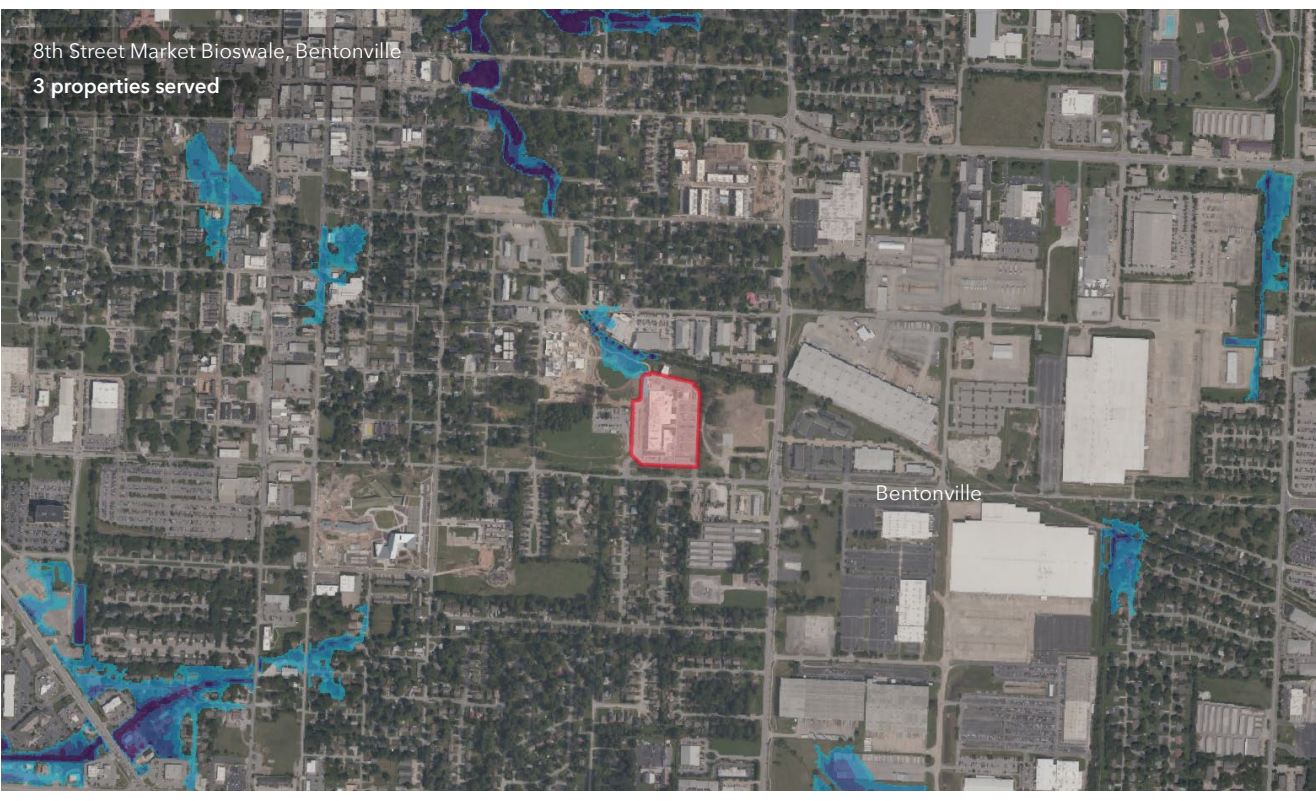

Area of protectio 


\section{State Overview \\ California}

Flood risk is increasing in the state of California. $1,090,900$ properties currently have a substantial risk* of flooding. Over the next 30 years, the number of properties with this risk will increase by another $5.5 \%$, bringing the total number of properties with substantial risk to $1,150,800$.

To understand personal flood risk, Americans leverage the Federal Emergency Management Agency (FEMA) Flood Insurance Rate Maps (FIRM). These maps identify 495,400 properties as having substantial risk in the state of California. In comparison, the First Street Foundation

Flood Model identifies 2.2 times the number of properties as facing this same level of risk. This discrepancy exists because the Foundation uses the current climate data, maps precipitation as a stand-alone risk, and includes areas that FEMA has not mapped. These new methods uncover an additional 595,500 properties currently not identified by FEMA as having substantial risk.

When adjusting for future environmental changes, the FEMA gap further widens to 655,400 by the year 2050
Total properties at substantial risk

$\ln 2020$

$1.09 \mathrm{M}$

30-year change

$\Delta+59,900$ $\ln 2050$

$1.15 \mathrm{M}$

$+595,500$

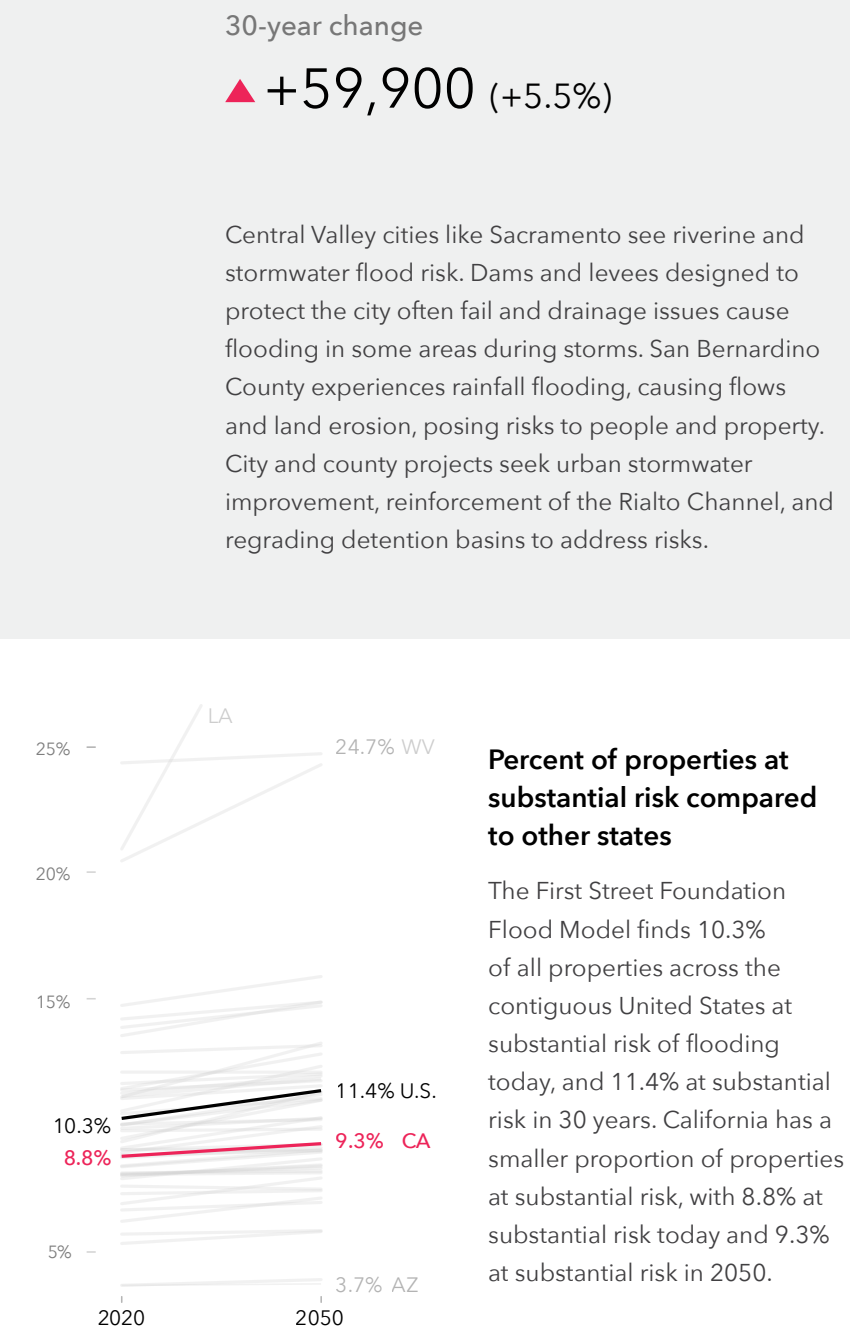

Central Valley cities like Sacramento see riverine and stormwater flood risk. Dams and levees designed to city often fail and drainage issues cause the
Difference in number of properties currently at substantial risk compared to FEMA**

More properties at risk in FSF model

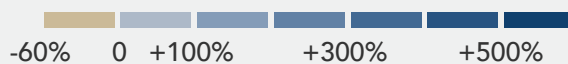

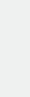




\section{Local details}

\section{California}

The First Street Foundation Flood Model calculates the number of properties facing any risk* of flooding. When looking at this broader level of risk, the data identifies 2,287,200 properties in California as at risk over the next 30 years. Of these properties, 108,500 were categorized as facing almost certain risk, with a $99 \%$ chance of

flooding at least once over the next 30 years.

The city of Los Angeles has the greatest number of properties at risk of flooding in the state with 132,000 currently at risk, or $20 \%$ of its total number of properties. However, smaller cities or municipalities in the state, with fewer properties, may have a greater proportion of their total properties at risk. For example, $100 \%$ of properties in Yuba City are at risk of flooding. Other municipalities will see the greatest increase in risk over the next 30 years. Wasco, for example, will see a \% increase in the number of properties at risk.

Click here for a full breakdown of counties, cities, zip codes, and congressional districts in California at risk.

\section{Greatest proportion of properties at risk*}

\begin{tabular}{lrl} 
Municipality & \multicolumn{2}{c}{2020} \\
Yuba City & 19,174 & $100 \%$ \\
\hline Orland & 2,994 & $100 \%$ \\
\hline Country Club & 3,624 & $100 \%$ \\
\hline Foster City & 7,234 & $99 \%$ \\
\hline August & 2,089 & $98 \%$ \\
\hline Lemon Hill & 3,074 & $96 \%$ \\
\hline Colusa & 1,934 & $96 \%$ \\
\hline Farmersville & 2,595 & $96 \%$ \\
\hline Linda & 5,628 & $94 \%$ \\
\hline Stockton & 76,446 & $92 \%$ \\
\hline
\end{tabular}

\section{Greatest number of properties at risk*}

\begin{tabular}{lcccccc} 
Municipality & \multicolumn{2}{c}{2020} & \multicolumn{2}{c}{2050} & \multicolumn{2}{c}{ Change } \\
Los Angeles & 132,046 & $20 \%$ & 135,515 & $20 \%$ & $+3,469$ & $+2.6 \%$ \\
\hline Sacramento & 101,792 & $68 \%$ & 109,416 & $74 \%$ & $+7,624$ & $+7.5 \%$ \\
\hline Stockton & 76,446 & $92 \%$ & 77,918 & $94 \%$ & $+1,472$ & $+1.9 \%$ \\
\hline San Jose & 56,243 & $25 \%$ & 59,298 & $26 \%$ & $+3,055$ & $+5.4 \%$ \\
\hline Fresno & 54,255 & $39 \%$ & 55,332 & $39 \%$ & $+1,077$ & $+2.0 \%$ \\
\hline Long Beach & 31,565 & $36 \%$ & 34,811 & $40 \%$ & $+3,246$ & $+10.3 \%$ \\
\hline Bakersfield & 20,430 & $18 \%$ & 21,051 & $19 \%$ & +621 & $+3.0 \%$ \\
\hline Santa Rosa & 19,914 & $37 \%$ & 20,917 & $39 \%$ & $+1,003$ & $+5.0 \%$ \\
\hline Yuba City & 19,174 & $100 \%$ & 19,193 & $100 \%$ & +19 & $+0.1 \%$ \\
\hline Visalia & 18,946 & $43 \%$ & 20,077 & $46 \%$ & $+1,131$ & $+6.0 \%$
\end{tabular}

\section{Greatest relative growing risk*}

\begin{tabular}{lrrrrrr} 
Municipality & \multicolumn{2}{c}{2020} & \multicolumn{2}{c}{2050} & \multicolumn{2}{c}{ Change } \\
Wasco & 0 & $0 \%$ & 314 & $6 \%$ & +314 & + Inf \\
\hline Coronado & 103 & $2 \%$ & 1,142 & $24 \%$ & +1039 & $+1009 \%$ \\
\hline Newman & 51 & $1 \%$ & 150 & $4 \%$ & +99 & $+194 \%$ \\
\hline Ripon & 93 & $2 \%$ & 267 & $5 \%$ & +174 & $+187 \%$ \\
\hline Olivehurst & 1,369 & $29 \%$ & 2,767 & $59 \%$ & $+1,398$ & $+102 \%$ \\
\hline Exeter & 43 & $1 \%$ & 82 & $3 \%$ & +39 & $+91 \%$ \\
\hline Huntington Beach & 11,343 & $22 \%$ & 21,431 & $42 \%$ & $+10,088$ & $+89 \%$ \\
\hline Vallejo & 2,002 & $5 \%$ & 3,671 & $10 \%$ & $+1,669$ & $+83 \%$ \\
\hline Imperial Beach & 149 & $3 \%$ & 270 & $6 \%$ & +121 & $+81 \%$ \\
\hline Alameda & 824 & $4 \%$ & 1,478 & $8 \%$ & +654 & $+79 \%$ \\
\hline
\end{tabular}

\section{Flood Factor distribution of properties at risk ${ }^{\star}(1000 s)$}

\section{Risk level}

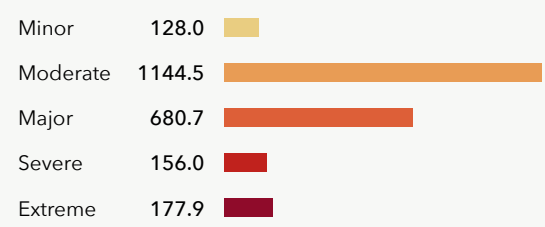

More than $18.5 \%$ of individual properties and properties in California are at any risk of flooding over the next 30 years. Out of those at risk $44 \%$ are at major to extreme risk.

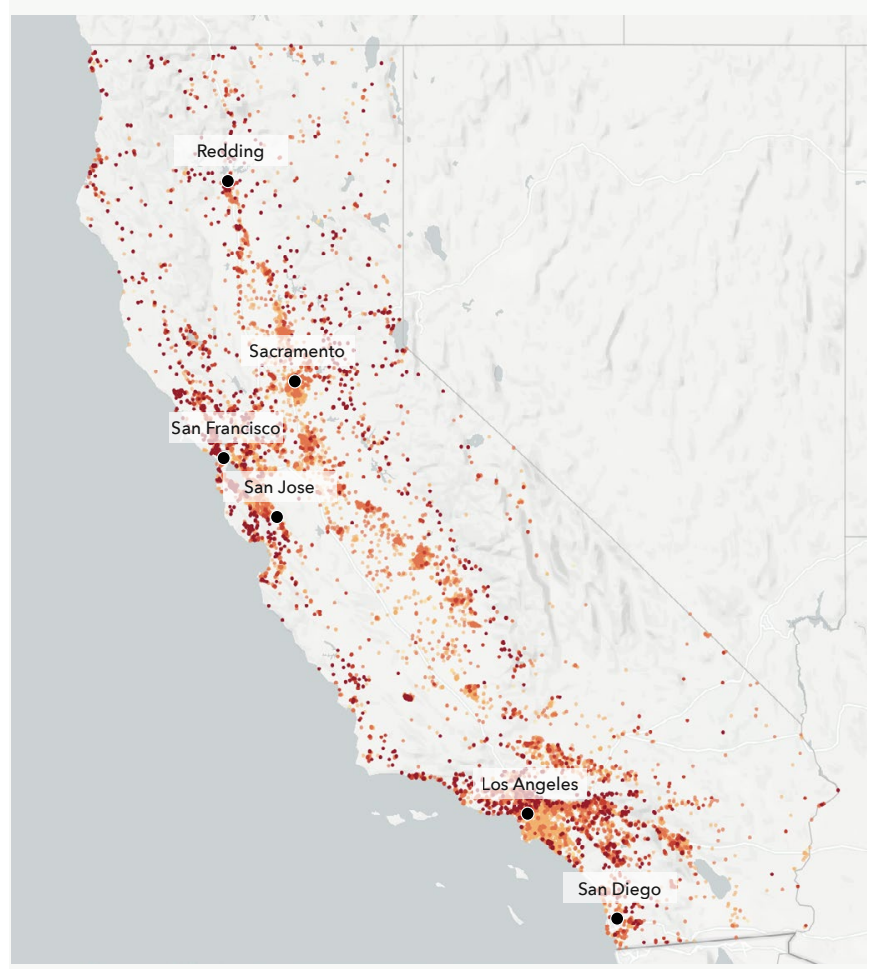


Flood History \& Protection

\section{California}

\section{Claims History}

155,600 home and property owners in California have made flood damage claims through FEMA since the year 2000. ${ }^{\star}$ These claims for reimbursement were made through either the National Flood Insurance Program (NFIP) or Individual Assistance Program (IAP). The greatest number of

claims since the year 2000 have been concentrated in Los Angeles, Sonoma, Butte, San Diego, and Napa counties.

\section{$4.85 \mathrm{M}$}

Properties served by

protection measures

The First Street Foundation Flood

Model incorporates 3,815 flood control

measures throughout the state which

protect $4,854,200$ properties.
Top protection measures in state by quantity

\begin{tabular}{lc}
$\begin{array}{l}\text { Type } \\
\text { Example }\end{array}$ & \# Properties served by type \\
Channel & $3,205,787$ \\
- Woodside Channel/Infrastructure Project & \\
\hline $\begin{array}{l}\text { Levee } \\
\text { Sacramento and Elk Grove }\end{array}$ & $1,689,870$ \\
\hline $\begin{array}{l}\text { Dam } \\
\text { Don Pedro MD 0, Modesto }\end{array}$ & $1,199,667$ \\
\hline $\begin{array}{l}\text { Sewer upgrade } \\
\text { Conveyance Channels, San Bernardino }\end{array}$ & 77,450 \\
\hline $\begin{array}{l}\text { Marsh/wetland restoration } \\
\text { Huntington Beach Wetland Restoration }\end{array}$ & 20,989
\end{tabular}

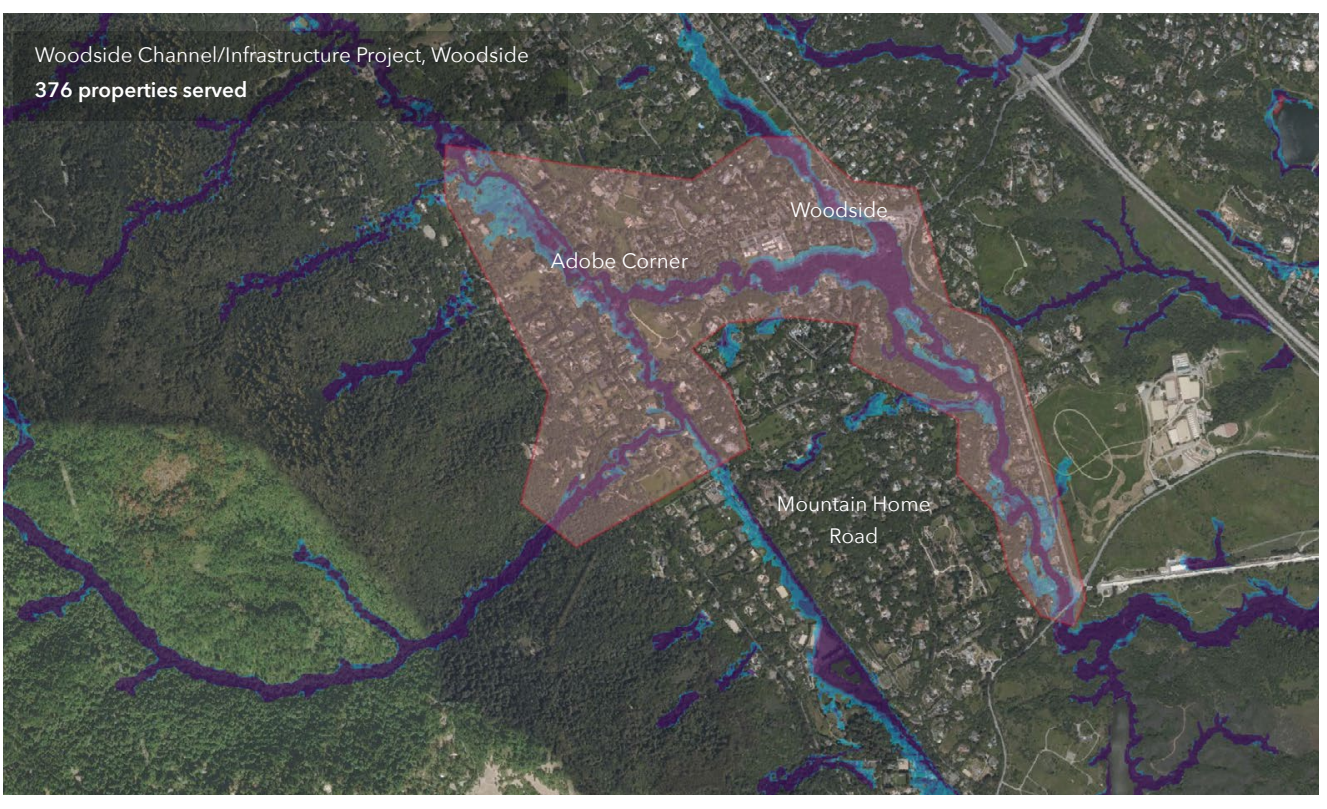

Area of protection 


\section{State Overview \\ Colorado}

\section{Total properties at substantial risk}

$\ln 2020$

\section{1,200}

30-year change

$$
\Delta+3,200(+2.4 \%)
$$

As the 2013 floods show, the Front Range from Fort Collins to South Denver are the most vulnerable to flooding due to its proximity to rivers and snowmelt. The western side of the state will also experience flooding primarily from the Colorado and Gunnison rivers.

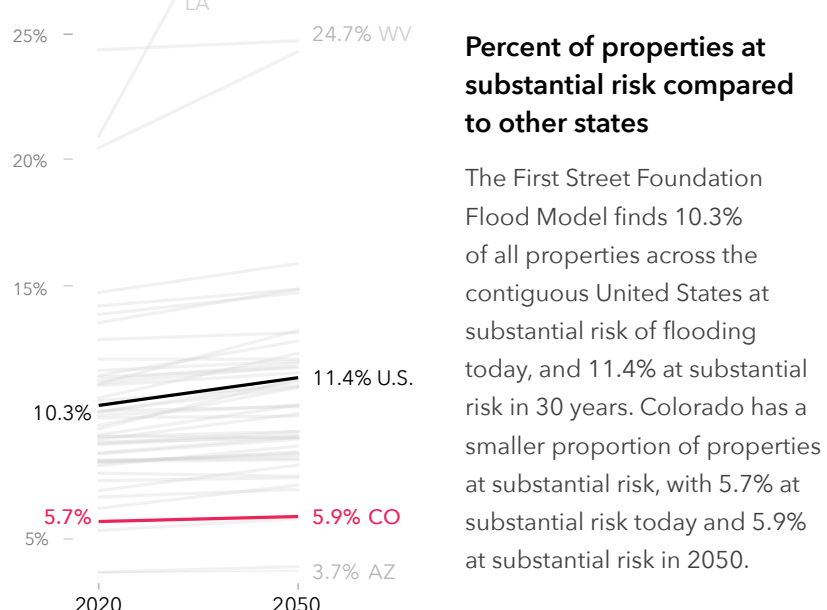

In 2050

134,400
Difference in number of properties currently at substantial risk compared to FEMA**

\section{$+87,900$} in FSF model at risk in FSF model $\longrightarrow$

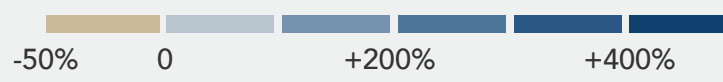

Flood risk is increasing in the state of Colorado. 131,200 properties currently have a substantial risk* of flooding. Over the next 30 years, the number of properties with this risk will increase by another $2.4 \%$, bringing the total number of properties with substantial risk to 134,400

To understand personal flood risk, Americans leverage the Federal Emergency Management Agency (FEMA) Flood Insurance Rate Maps (FIRM). These maps identify 43,300 properties as having substantial risk in the state of Colorado. In comparison, the First Street Foundation Flood Model identifies 3 times the number of properties as facing this same level of risk. This discrepancy exists because the Foundation uses the current climate data, maps precipitation as a stand-alone risk, and includes areas that FEMA has not mapped. These new methods uncover an additional 87,900 properties currently not identified by FEMA as having substantial risk. When adjusting for future environmental changes, the FEMA gap further widens to 91,100 by the year 2050 


\section{Local details}

\section{Colorado}

The First Street Foundation Flood Model calculates the number of properties facing any risk* of flooding. When looking at this broader level of risk, the data identifies 200,400 properties in Colorado as at risk over the next 30 years. Of these properties, 16,900 were categorized as facing almost certain risk, with a $99 \%$ chance of flooding at least once over the next 30 years.

The city of Colorado Springs has the greatest number of properties at risk of flooding in the state with 15,400 currently at risk, or $10 \%$ of its total number of properties. However, smaller cities or municipalities in the state, with fewer properties, may have a greater proportion of their total properties at risk. For example, $46 \%$ of properties in Lamar are at risk of flooding. Other municipalities will see the greatest increase in risk over the next 30 years. Edgewater, for example, will see a $23 \%$ increase in the number of properties at risk.

Click here for a full breakdown of counties, cities, zip codes, and congressional districts in Colorado at risk.

\section{Greatest proportion of properties at risk*}

\begin{tabular}{lrr} 
Municipality & \multicolumn{2}{c}{2020} \\
\hline Lamar & 1,621 & $46 \%$ \\
\hline Craig & 1,434 & $38 \%$ \\
\hline Vail & 933 & $33 \%$ \\
\hline Florence & 818 & $30 \%$ \\
\hline Wellington & 1,337 & $27 \%$ \\
\hline Manitou Springs & 723 & $26 \%$ \\
\hline Breckenridge & 950 & $25 \%$ \\
\hline Fort Morgan & 907 & $24 \%$ \\
\hline Fort Lupton & 661 & $22 \%$ \\
\hline Estes Park & 900 & $19 \%$ \\
\hline
\end{tabular}

\section{Greatest number of properties at risk*}

\begin{tabular}{lcccccc} 
Municipality & \multicolumn{2}{c}{2020} & \multicolumn{2}{c}{2050} & \multicolumn{2}{c}{ Change } \\
Colorado Springs & 15,440 & $10 \%$ & 15,443 & $10 \%$ & +3 & $0.0 \%$ \\
\hline Denver & 10,136 & $5 \%$ & 10,677 & $6 \%$ & +541 & $+5.3 \%$ \\
\hline Fort Collins & 4,559 & $8 \%$ & 4,755 & $8 \%$ & +196 & $+4.3 \%$ \\
\hline Aurora & 4,058 & $3 \%$ & 4,171 & $3 \%$ & +113 & $+2.8 \%$ \\
\hline Longmont & 4,023 & $13 \%$ & 4,151 & $13 \%$ & +128 & $+3.2 \%$ \\
\hline Boulder & 3,237 & $13 \%$ & 3,319 & $13 \%$ & +82 & $+2.5 \%$ \\
\hline Arvada & 2,730 & $6 \%$ & 2,856 & $6 \%$ & +126 & $+4.6 \%$ \\
\hline Loveland & 2,169 & $7 \%$ & 2,221 & $7 \%$ & +52 & $+2.4 \%$ \\
\hline Lakewood & 1,949 & $4 \%$ & 2,069 & $4 \%$ & +120 & $+6.2 \%$ \\
\hline Greeley & 1,838 & $6 \%$ & 1,885 & $6 \%$ & +47 & $+2.6 \%$
\end{tabular}

\section{Greatest relative growing risk*}

\begin{tabular}{lcccccc} 
Municipality & \multicolumn{2}{c}{2020} & \multicolumn{2}{c}{2050} & \multicolumn{2}{c}{ Change } \\
Edgewater & 1,626 & $15 \%$ & 398 & $18 \%$ & +74 & $+23 \%$ \\
\hline Fruitvale & 1,442 & $0 \%$ & 14 & $0 \%$ & +2 & $+17 \%$ \\
\hline Carbondale & 975 & $1 \%$ & 23 & $1 \%$ & +3 & $+15 \%$ \\
\hline Montrose & 833 & $10 \%$ & 1,156 & $11 \%$ & +110 & $+11 \%$ \\
\hline New Castle & 1,396 & $14 \%$ & 346 & $16 \%$ & +30 & $+10 \%$ \\
\hline Grand Junction & 723 & $4 \%$ & 1,247 & $4 \%$ & +100 & $+9 \%$ \\
\hline Mead & 977 & $3 \%$ & 94 & $3 \%$ & +7 & $+8 \%$ \\
\hline Clifton & 908 & $3 \%$ & 229 & $3 \%$ & +16 & $+8 \%$ \\
\hline Columbine & 672 & $2 \%$ & 240 & $2 \%$ & +15 & $+7 \%$ \\
\hline Orchard Mesa & 920 & $2 \%$ & 64 & $2 \%$ & +4 & $+7 \%$ \\
\hline
\end{tabular}

\section{Flood Factor distribution of properties at risk ${ }^{\star}(1000 s)$}

\section{Risk level}

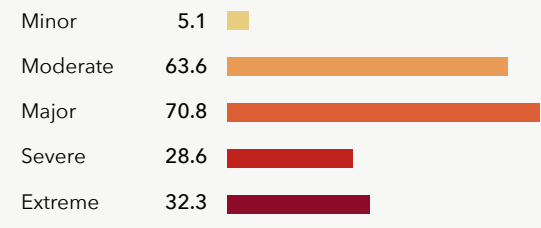

More than $8.7 \%$ of individual properties and properties in Colorado are at any risk of flooding over the next 30 years. Out of those at risk $66 \%$ are at major to extreme risk.

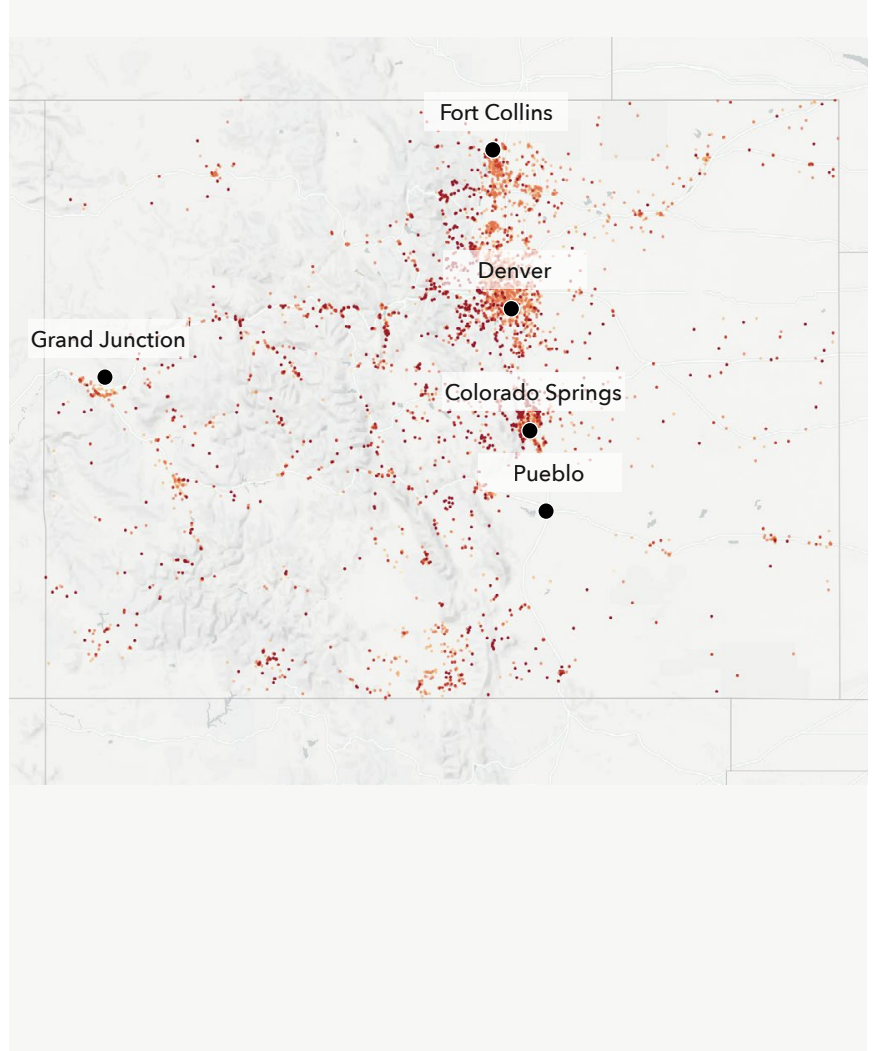




\section{Flood History \& Protection}

\section{Colorado}

\section{Claims History}

49,700 home and property owners in Colorado have made flood damage claims through FEMA since the year 2000. ${ }^{*}$ These claims for reimbursement were made through either the National Flood Insurance Program (NFIP) or Individual Assistance Program (IAP). The greatest number of claims since the year 2000 have been concentrated in Boulder, Larimer, Jefferson, Weld, and Arapahoe counties.

\section{Storm Simulation}

The First Street Foundation Flood Model has recreated 2 flooding events that have occurred since the year 2000 in the state of Colorado. These events flooded around 960 properties across the state. ${ }^{\star \star}$

\section{Flood event}

- River flood near Boulder, CO

Date

\# Properties
affected

River flood near Fort Morgan, $\mathrm{CO}$

Sep 2013

415

Sep 2013

541

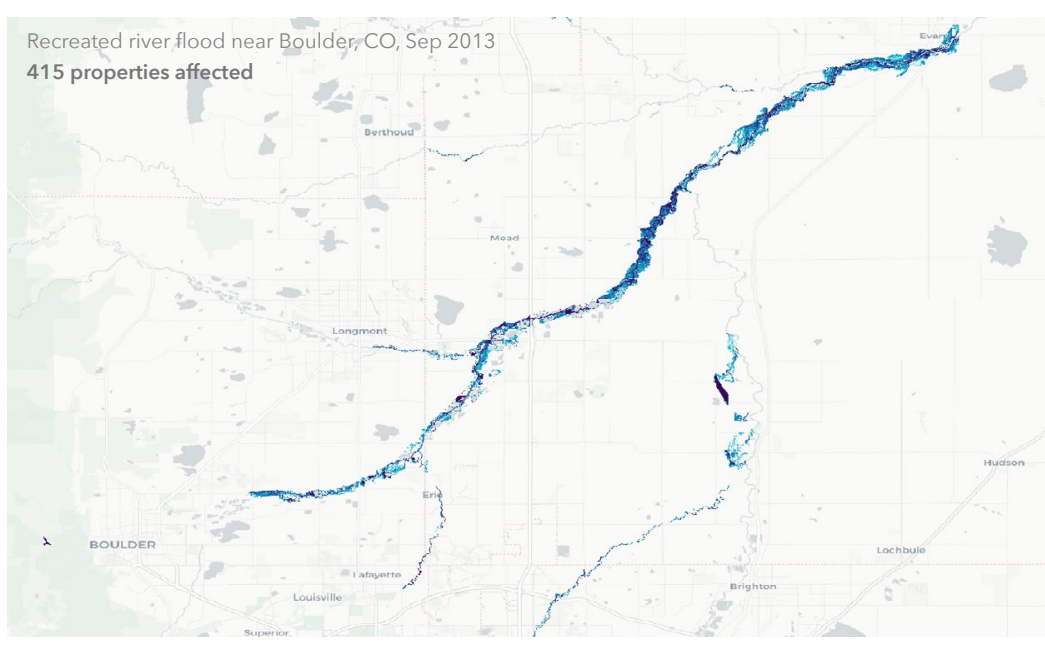

$\begin{array}{llll}0.5 & 1 & 2 & 3+\mathrm{ft}\end{array}$

\section{5,900}

Properties served by

protection measures

The First Street Foundation Flood

Model incorporates 46 flood control

measures throughout the state which

protect 15,900 properties.

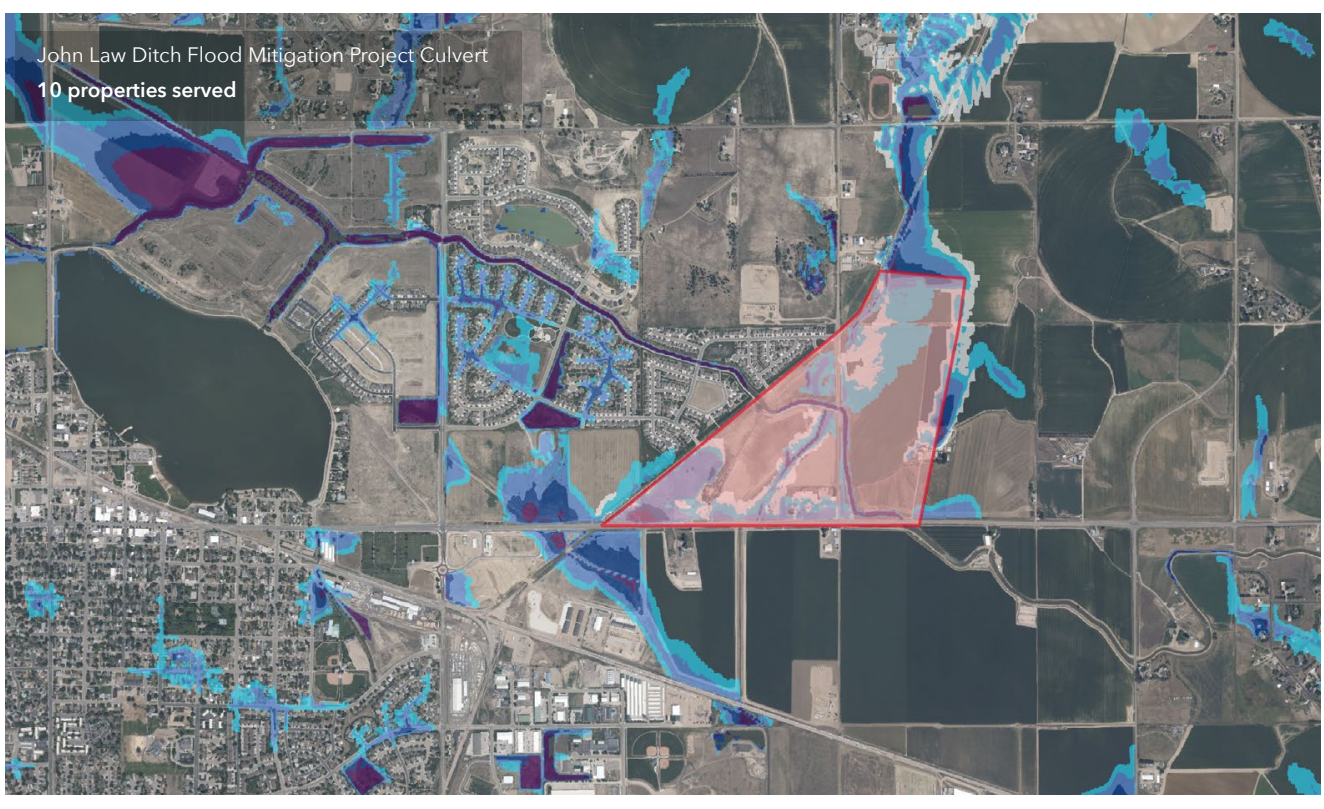

Top protection measures in state by quantity

Type
Example

Levee

\# Properties served by type

Alamosa Levees, Pio Grande, Right Levee, Ala mosa

Sewer upgrade

5,207

33rd st outfal, Denver

Detention basin

Culvert

John Law Ditch Flood Mitigation Project 


\section{State Overview \\ Connecticut}

Total properties at substantial risk *

In 2020

\section{6,700}

30-year change

$$
\Delta+10,300(+10 \%)
$$

$\ln 2050$

117,000

$$
\Delta+46,300
$$
in FSF model $\longrightarrow$
Difference in number of properties currently at substantial risk compared to FEMA**

More properties at risk

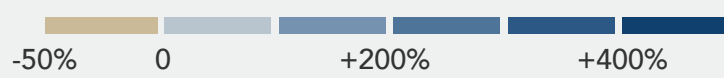

Coastal areas are vulnerable to wave action and storm surge. Low lying areas are susceptible to flooding from hurricanes and nor'easters. Hartford is subject to floods from intense rain and snowmelt. Authorities have built dikes, floodwalls, and conduits along the Connecticut River and improved the channel along the South Branch Park River.

number of properties with this risk will increase by another $9.7 \%$, bringing the total number of properties with substantial risk to 117,000 .

To understand personal flood risk, Americans leverage the Federal Emergency Management Agency (FEMA) Flood Insurance Rate Maps (FIRM). These maps identify 60,400 properties as having substantial risk in the state of Connecticut. In comparison, the First Street Foundation

Flood Model identifies 1.8 times the number of properties as facing this same level of risk. This discrepancy exists because the Foundation uses the current climate data, maps precipitation as a stand-alone risk, and includes areas that FEMA has not mapped. These new methods uncover an additional 46,300 properties currently not identified by FEMA as having substantial risk. When adjusting for future environmental changes, the FEMA gap further widens to 56,600 by the year 2050 .
Percent of properties at substantial risk compared to other states
$20 \%$

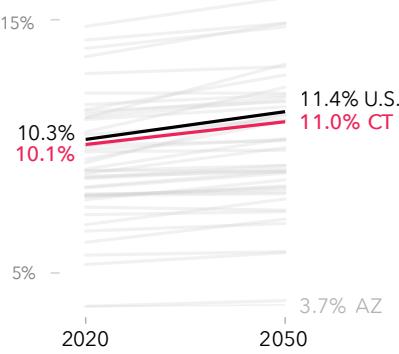

The First Street Foundation Flood Model finds $10.3 \%$ of all properties across the contiguous United States at substantial risk of flooding today, and $11.4 \%$ at substantial risk in 30 years. Connecticut has a similar proportion of properties at substantial risk, with $10.1 \%$ at substantial risk oday and $11 \%$ at substantial risk in 2050.

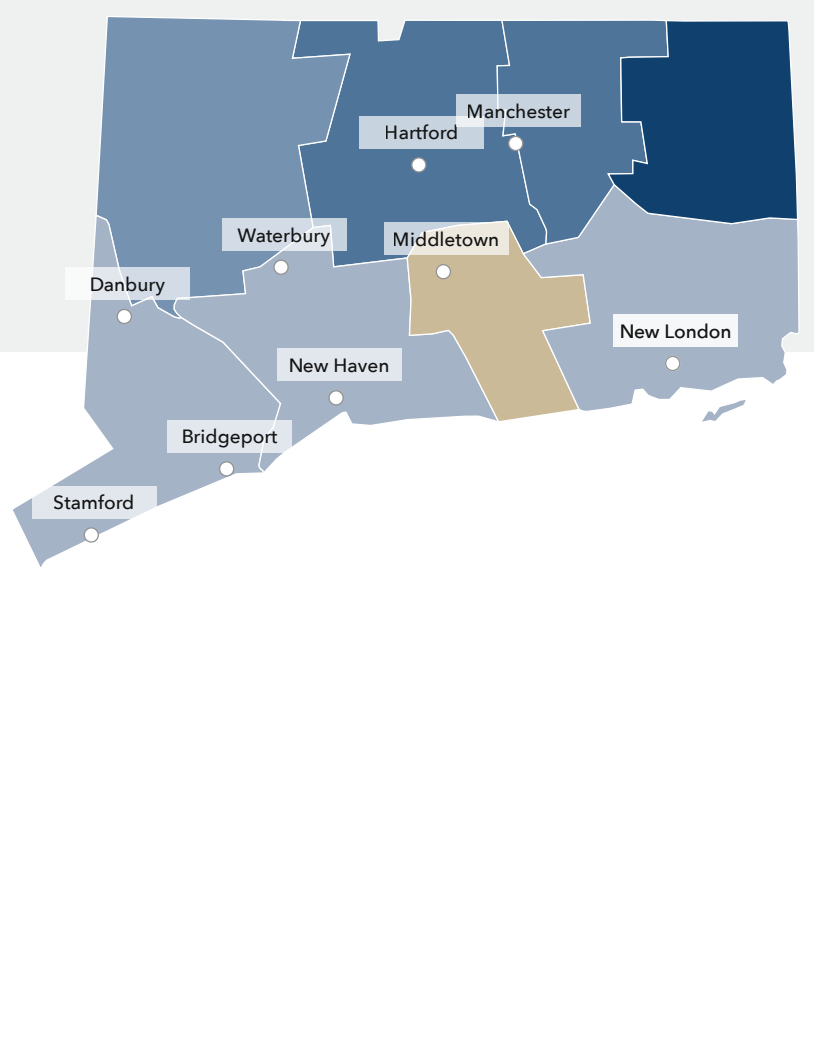




\section{Local details}

\section{Connecticut}

The First Street Foundation Flood Model calculates the number of properties facing any risk* of flooding. When looking at this broader level of risk, the data identifies 163,800 properties in Connecticut as at risk over the next 30 years. Of these properties, 29,600 were categorized as facing almost certain risk, with a $99 \%$ chance of flooding at least once over the next 30 years.

The city of Bridgeport has the greatest number of properties at risk of flooding in the state with 5,800 currently at risk, or $20 \%$ of its total number of properties. However, smaller cities or municipalities in the state, with fewer properties, may have a greater proportion of their total properties at risk. For example, $31 \%$ of properties in Old Greenwich are at risk of flooding. Other municipalities will see the greatest increase in risk over the next 30 years. West Haven, for

example, will see a $63 \%$ increase in the number of properties at risk.

Click here for a full breakdown of counties, cities, zip codes, and congressional districts in Connecticut at risk.

\section{Greatest proportion of properties at risk*}

\begin{tabular}{lrr} 
Municipality & \multicolumn{2}{c}{2020} \\
Old Greenwich & 725 & $31 \%$ \\
\hline Cos Cob & 632 & $29 \%$ \\
\hline Branford Center & 607 & $28 \%$ \\
\hline East Haven & 2,764 & $26 \%$ \\
\hline Westport & 2,533 & $26 \%$ \\
\hline Darien & 1,544 & $21 \%$ \\
\hline Norwalk & 4,661 & $21 \%$ \\
\hline Bridgeport & 5,836 & $21 \%$ \\
\hline Greenwich & 683 & $20 \%$ \\
\hline Hartford & 3,689 & $19 \%$ \\
\hline
\end{tabular}

\section{Greatest number of properties at risk*}

\begin{tabular}{lllllll} 
Municipality & \multicolumn{2}{c}{2020} & \multicolumn{2}{c}{2050} & \multicolumn{2}{c}{ Change } \\
Bridgeport & 5,836 & $21 \%$ & 7,206 & $25 \%$ & $+1,370$ & $+23.5 \%$ \\
\hline Stamford & 4,803 & $19 \%$ & 5,929 & $23 \%$ & $+1,126$ & $+23.4 \%$ \\
\hline Norwalk & 4,661 & $21 \%$ & 5,238 & $24 \%$ & +577 & $+12.4 \%$ \\
\hline Hartford & 3,689 & $19 \%$ & 3,975 & $21 \%$ & +286 & $+7.8 \%$ \\
\hline Milford city & 3,438 & $19 \%$ & 4,344 & $23 \%$ & +906 & $+26.4 \%$ \\
\hline Stratford & 2,981 & $17 \%$ & 4,015 & $23 \%$ & $+1,034$ & $+34.7 \%$ \\
\hline New Haven & 2,944 & $12 \%$ & 3,593 & $15 \%$ & +649 & $+22.0 \%$ \\
\hline East Haven & 2,764 & $26 \%$ & 3,411 & $32 \%$ & +647 & $+23.4 \%$ \\
\hline Westport & 2,533 & $26 \%$ & 2,777 & $28 \%$ & +244 & $+9.6 \%$ \\
\hline West Hartford & 2,370 & $12 \%$ & 2,443 & $12 \%$ & +73 & $+3.1 \%$
\end{tabular}

Greatest relative growing risk $^{*}$

\begin{tabular}{|c|c|c|c|c|c|c|}
\hline Municipality & 20 & 20 & & 050 & & ange \\
\hline West Haven & 1,824 & $13 \%$ & 2,971 & $21 \%$ & +1147 & $+63 \%$ \\
\hline Groton & 184 & $8 \%$ & 272 & $12 \%$ & +88 & $+48 \%$ \\
\hline New London & 521 & $8 \%$ & 747 & $12 \%$ & +226 & $+43 \%$ \\
\hline Stratford & 2,981 & $17 \%$ & 4,015 & $23 \%$ & $+1,034$ & $+35 \%$ \\
\hline Branford Center & 607 & $28 \%$ & 812 & $38 \%$ & +205 & $+34 \%$ \\
\hline Old Greenwich & 725 & $31 \%$ & 953 & $40 \%$ & +228 & $+31 \%$ \\
\hline Milford city & 3,438 & $19 \%$ & 4,344 & $23 \%$ & +906 & $+26 \%$ \\
\hline Bridgeport & 5,836 & $21 \%$ & 7,206 & $25 \%$ & $+1,370$ & $+24 \%$ \\
\hline East Haven & 2,764 & $26 \%$ & 3,411 & $32 \%$ & +647 & $+23 \%$ \\
\hline Stamford & 4,803 & $19 \%$ & 5,929 & $23 \%$ & $+1,126$ & $+23 \%$ \\
\hline
\end{tabular}

\section{Flood Factor distribution of properties at risk ${ }^{\star}(1000 s)$}

\section{Risk level}

Mino

Moderate

Major

Severe

Extreme

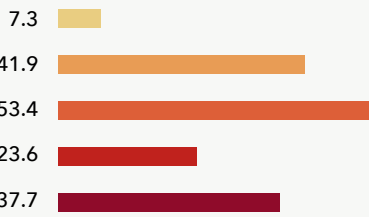

More than $15.4 \%$ of individual properties and properties in Connecticut are at any risk of flooding over the next 30 years. Out of those at risk $70 \%$ are at major to extreme risk. 


\section{Flood History \& Protection}

\section{Connecticut}

\section{Claims History}

45,200 home and property owners in Connecticut have made flood damage claims through FEMA since the year 2000. ${ }^{\star}$ These claims for reimbursement were made through either the National Flood Insurance Program (NFIP) or Individual Assistance Program (IAP). The greatest number of claims since the year 2000 have been concentrated in Fairfield, New Haven, New London, Hartford, and Middlesex counties.

\section{Storm Simulation}

The First Street Foundation Flood Model has recreated 6 flooding events that have occurred since the year 2000 in the state of Connecticut. These events flooded around 26,320 properties across the state $* \star$

\begin{tabular}{llr} 
Flood event & Date & $\begin{array}{r}\text { \# Properties } \\
\text { affected }\end{array}$ \\
Nor'easter & Feb 2003 & 112 \\
\hline Nor'easter & Nov 2009 & 2,111 \\
\hline Nor'easter & Mar 2010 & 274 \\
\hline Hurricane Irene & Aug 2011 & 8,165 \\
\hline River flood across central CT & Aug 2011 & 376 \\
\hline Hurricane Sandy & Oct 2012 & 15,278
\end{tabular}

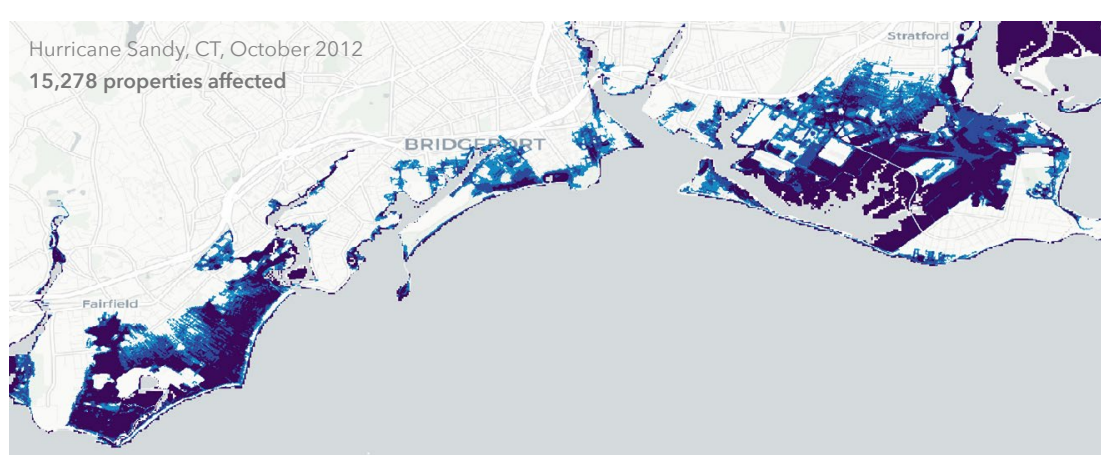
$\begin{array}{lll}0.5 & 1 & \text { Depth of flooding }\end{array}$

\section{3,500}

Properties served by

protection measures

The First Street Foundation Flood Model incorporates 2,258 flood control measures throughout the state which protect 13,500 properties.

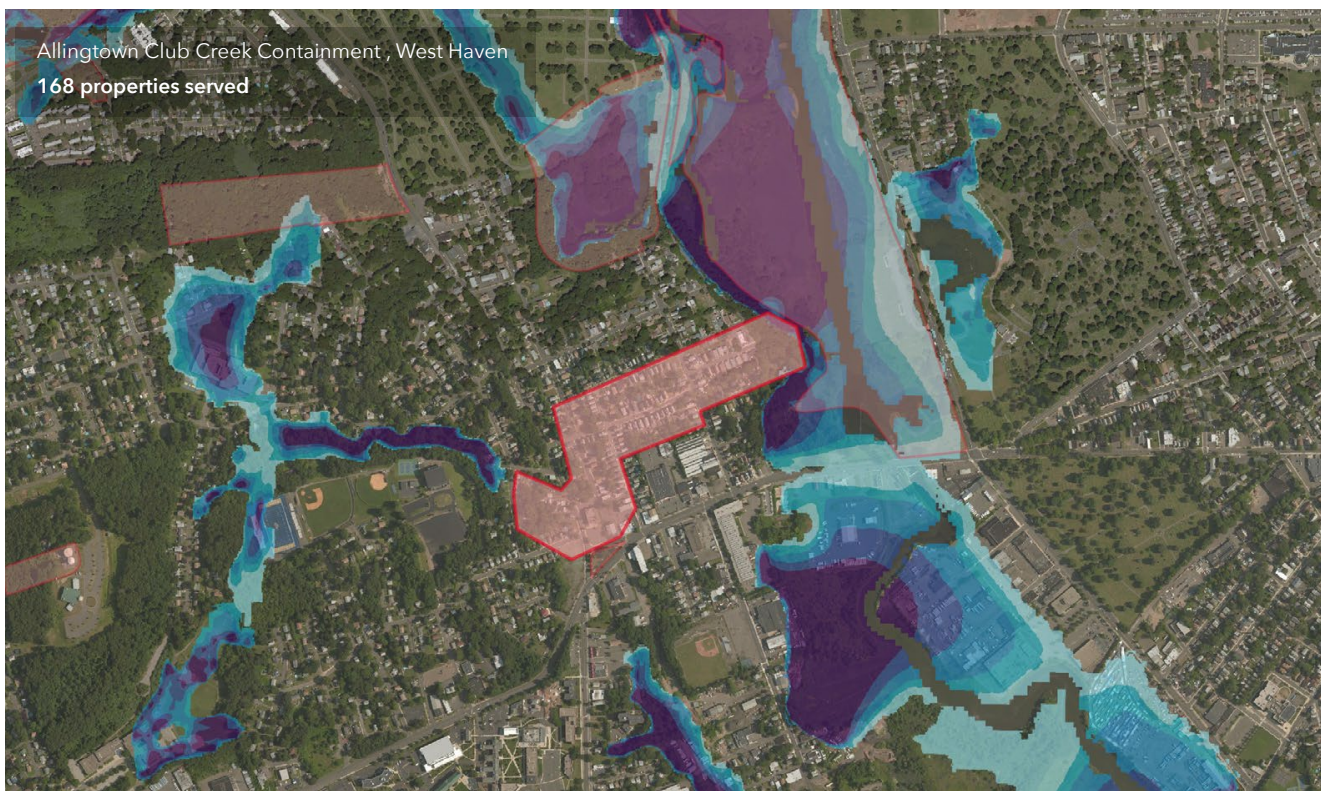

$\square$ Area of protection
Top protection measures in state by quantity

$$
\begin{aligned}
& \text { Type } \\
& \text { Example }
\end{aligned}
$$

Open space preserve

9,263

Levee

Stamford HSPP, Stamfor

Channel 


\section{State Overview Delaware} of properties with this risk will increase by another $21 \%$, bringing the total number of properties with substantial risk to 48,000 .

\section{To understand personal flood risk, Americans} leverage the Federal Emergency Management Agency (FEMA) Flood Insurance Rate Maps (FIRM). These maps identify 28,900 properties as having substantial risk in the state of Delaware. In comparison, the First Street Foundation Flood Model identifies 1.4 times the number of properties as facing this same level of risk. This discrepancy exists because the Foundation uses the current climate data, maps precipitation as a stand-alone risk, and includes areas that FEMA has not mapped. These new methods uncover an additional 10,700 properties currently not identified by FEMA as having substantial risk. When adjusting for future environmental changes, the FEMA gap further widens to 19,100 by the year 2050
Total properties at substantial risk *

\section{9,700}

30-year change

$$
\Delta+8,300(+21 \%)
$$

\section{Delaware is threatened by tidal flooding from regular} king tides and storm surges. Costly beach replenishment projects can reduce these effects in the short term, but long term flood protection may require a different approach. Stormwater is managed by a series of

drainage ditches and stormwater channels to help diver and capture floodwaters.

Difference in number of properties currently at substantial risk compared to FEMA**

$$
\Delta+10,700
$$

\section{More properties at risk} in FSF model $\longrightarrow$
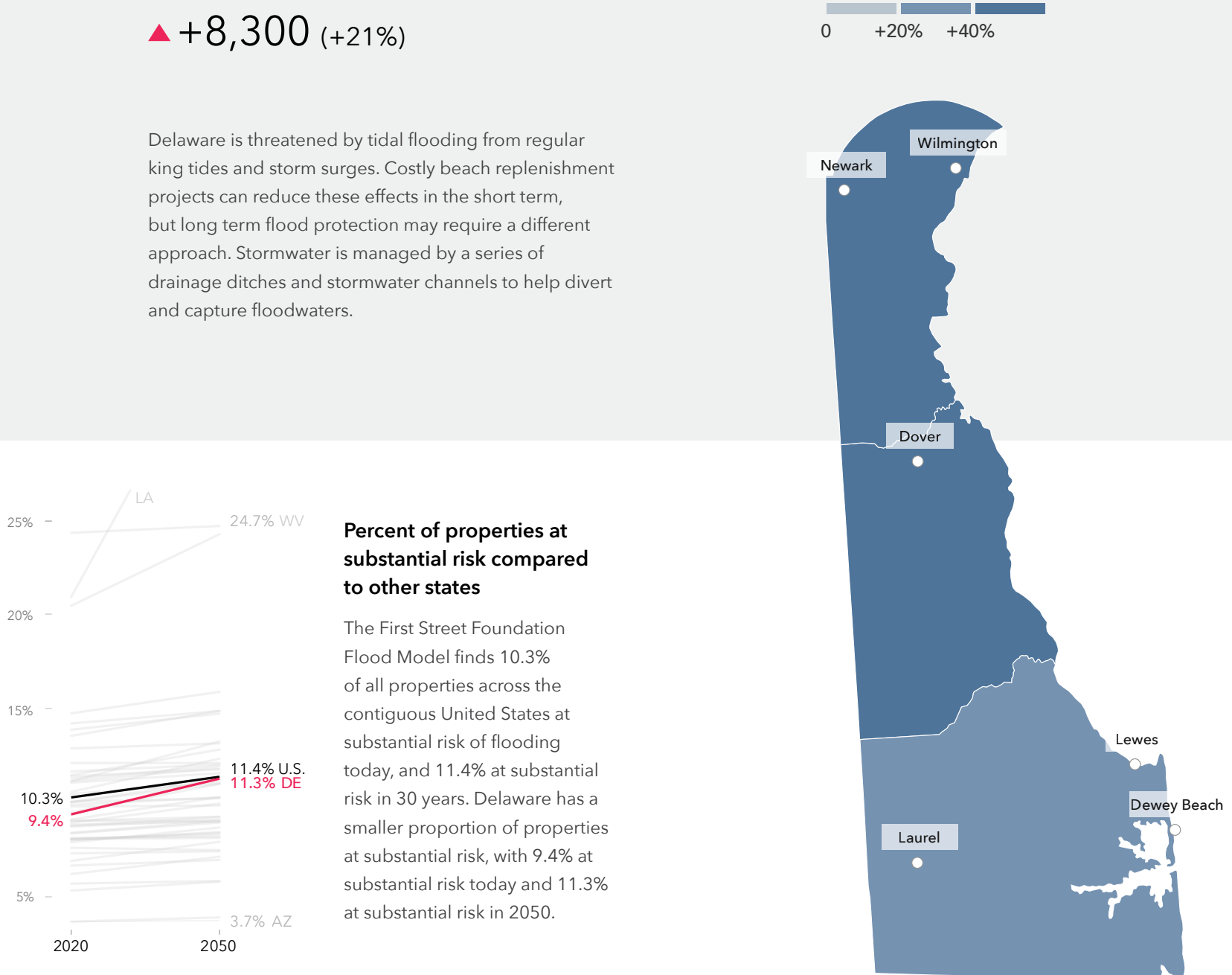


\section{Local details \\ Delaware}

The First Street Foundation Flood Model calculates the number of properties facing any risk* of flooding. When looking at this broader level of risk, the data identifies 66,900 properties in Delaware as at risk over the next 30 years. Of these properties, 14,200 were categorized as facing almost certain risk, with a $99 \%$ chance of flooding at least once over the next 30 years.

The city of Bethany Beach has the greatest number of properties at risk of flooding in the state with 2,100 currently at risk, or $97 \%$ of its total number of properties. However, smaller cities or municipalities in the state, with fewer properties, may have a greater proportion of their total properties at risk. For example, $97 \%$ of properties in Bethany Beach are at risk of flooding. Other municipalities will see the greatest increase in risk over the next 30 years. Rehoboth Beach, for example,

will see a $648 \%$ increase in the number of properties at risk.

Click here for a full breakdown of counties, cities, zip codes, and congressional districts in Delaware at risk.

\section{Greatest proportion of properties at risk*}

\begin{tabular}{lrr} 
Municipality & \multicolumn{2}{c}{2020} \\
Bethany Beach & 2,135 & $97 \%$ \\
\hline Lewes & 1,328 & $47 \%$ \\
\hline Ocean View & 1,036 & $38 \%$ \\
\hline Millsboro & 564 & $23 \%$ \\
\hline Seaford & 639 & $20 \%$ \\
\hline New Castle & 522 & $20 \%$ \\
\hline Georgetown & 321 & $12 \%$ \\
\hline Dover & 1,046 & $9 \%$ \\
\hline Milford & 505 & $8 \%$ \\
\hline Newark & 488 & $7 \%$ \\
\hline
\end{tabular}

\section{Greatest number of properties at risk*}

\begin{tabular}{l|cccccc} 
Municipality & \multicolumn{2}{c}{2020} & \multicolumn{2}{c}{2050} & \multicolumn{2}{c}{ Change } \\
\cline { 2 - 5 } Bethany Beach & 2,135 & $97 \%$ & 2,186 & $99 \%$ & +51 & $+2.4 \%$ \\
\hline Wilmington & 1,590 & $6 \%$ & 2,099 & $8 \%$ & +509 & $+32.0 \%$ \\
\hline Lewes & 1,328 & $47 \%$ & 2,252 & $80 \%$ & +924 & $+69.6 \%$ \\
\hline Dover & 1,046 & $9 \%$ & 1,116 & $9 \%$ & +70 & $+6.7 \%$ \\
\hline Ocean View & 1,036 & $38 \%$ & 1,698 & $63 \%$ & +662 & $+63.9 \%$ \\
\hline Seaford & 639 & $20 \%$ & 660 & $21 \%$ & +21 & $+3.3 \%$ \\
\hline Millsboro & 564 & $23 \%$ & 622 & $25 \%$ & +58 & $+10.3 \%$ \\
\hline New Castle & 522 & $20 \%$ & 587 & $22 \%$ & +65 & $+12.5 \%$ \\
\hline Milford & 505 & $8 \%$ & 721 & $12 \%$ & +216 & $+42.8 \%$ \\
\hline Newark & 488 & $7 \%$ & 521 & $7 \%$ & +33 & $+6.8 \%$
\end{tabular}

\section{Greatest relative growing risk*}

\begin{tabular}{lrrrrrr} 
Municipality & \multicolumn{2}{c}{2020} & \multicolumn{2}{c}{2050} & \multicolumn{2}{c}{ Change } \\
Rehoboth Beach & 33 & $2 \%$ & 247 & $11 \%$ & +214 & $+649 \%$ \\
\hline Lewes & 1,328 & $47 \%$ & 2,252 & $80 \%$ & +924 & $+70 \%$ \\
\hline Ocean View & 1,036 & $38 \%$ & 1,698 & $63 \%$ & +662 & $+64 \%$ \\
\hline Milford & 505 & $8 \%$ & 721 & $12 \%$ & +216 & $+43 \%$ \\
\hline Wilmington & 1,590 & $6 \%$ & 2,099 & $8 \%$ & +509 & $+32 \%$ \\
\hline Pike Creek Valley & 50 & $2 \%$ & 59 & $2 \%$ & +9 & $+18 \%$ \\
\hline Pike Creek & 30 & $1 \%$ & 34 & $1 \%$ & +4 & $+13 \%$ \\
\hline New Castle & 522 & $20 \%$ & 587 & $22 \%$ & +65 & $+13 \%$ \\
\hline Brookside & 193 & $4 \%$ & 214 & $5 \%$ & +21 & $+11 \%$ \\
\hline Millsboro & 564 & $23 \%$ & 622 & $25 \%$ & +58 & $+10 \%$
\end{tabular}

\section{Flood Factor distribution of properties at risk ${ }^{\star}(1000 s)$}

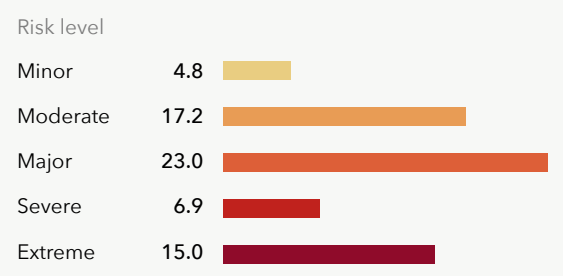

More than $15.8 \%$ of individual properties and properties in Delaware are at any risk of flooding over the next 30 years. Out of those at risk $67 \%$ are at major to extreme risk.

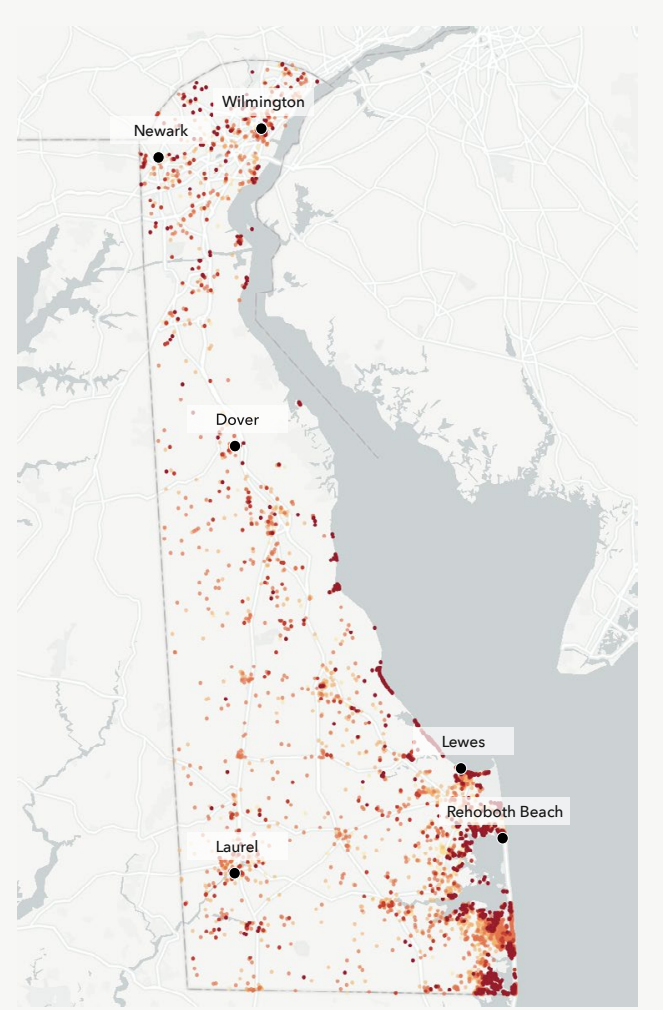


Flood History \& Protection

\section{Delaware}

\section{Claims History}

3,300 home and property owners in Delaware have made flood damage claims through FEMA since the year 2000.* These claims for reimbursement were made through either the National Flood Insurance Program (NFIP) or Individual Assistance Program (IAP). The greatest number of claims since the year 2000 have been concentrated in Sussex, New Castle, Kent, NA, and NA counties.

\section{Storm Simulation}

The First Street Foundation Flood Model has recreated 3 flooding events that have occurred since the year 2000 in the state of Delaware. These events flooded around 29,000 properties across the state. ${ }^{\star \star}$

\begin{tabular}{llr} 
Flood event & Date & $\begin{array}{r}\text { \# Properties } \\
\text { affected }\end{array}$ \\
Hurricane Isabel & Sep 2003 & 11,494 \\
\hline Hurricane Irene & Aug 2009 & 9,384 \\
\hline Nor'easter & Nov 2009 & 8,125
\end{tabular}

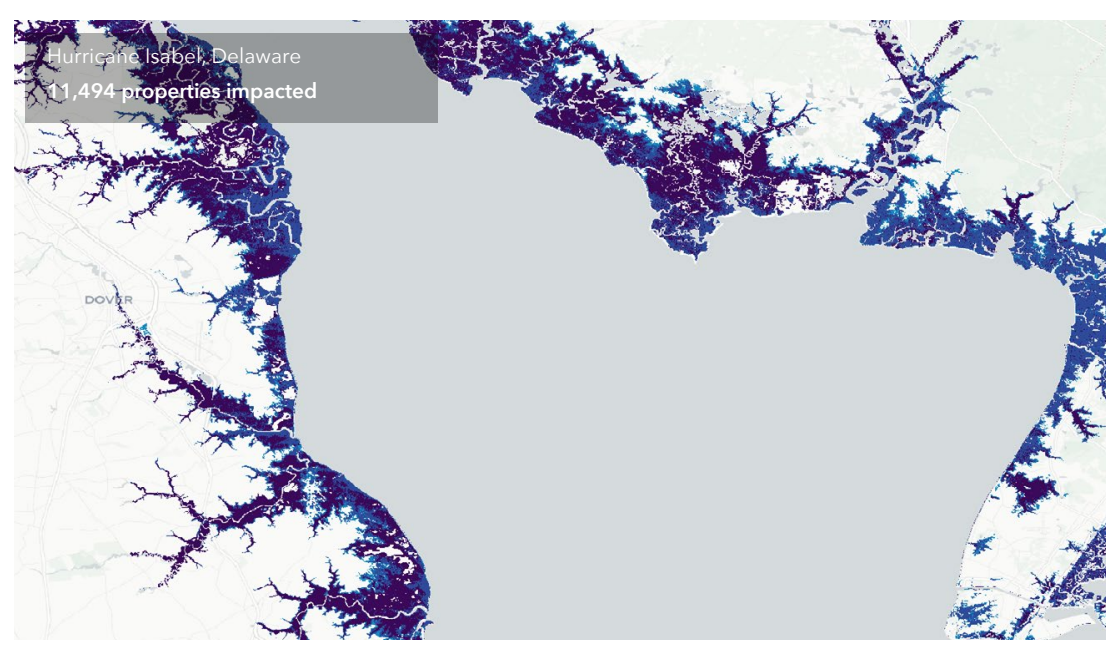

* Source: Fema.gov

** Based on model simulation of historic events. Historic recreations do not include precipitation. See methodology for full model details.

\section{2,500}

Properties served by

protection measures

The First Street Foundation Flood

Model incorporates 14 flood control

measures throughout the state which

protect 52,500 properties.

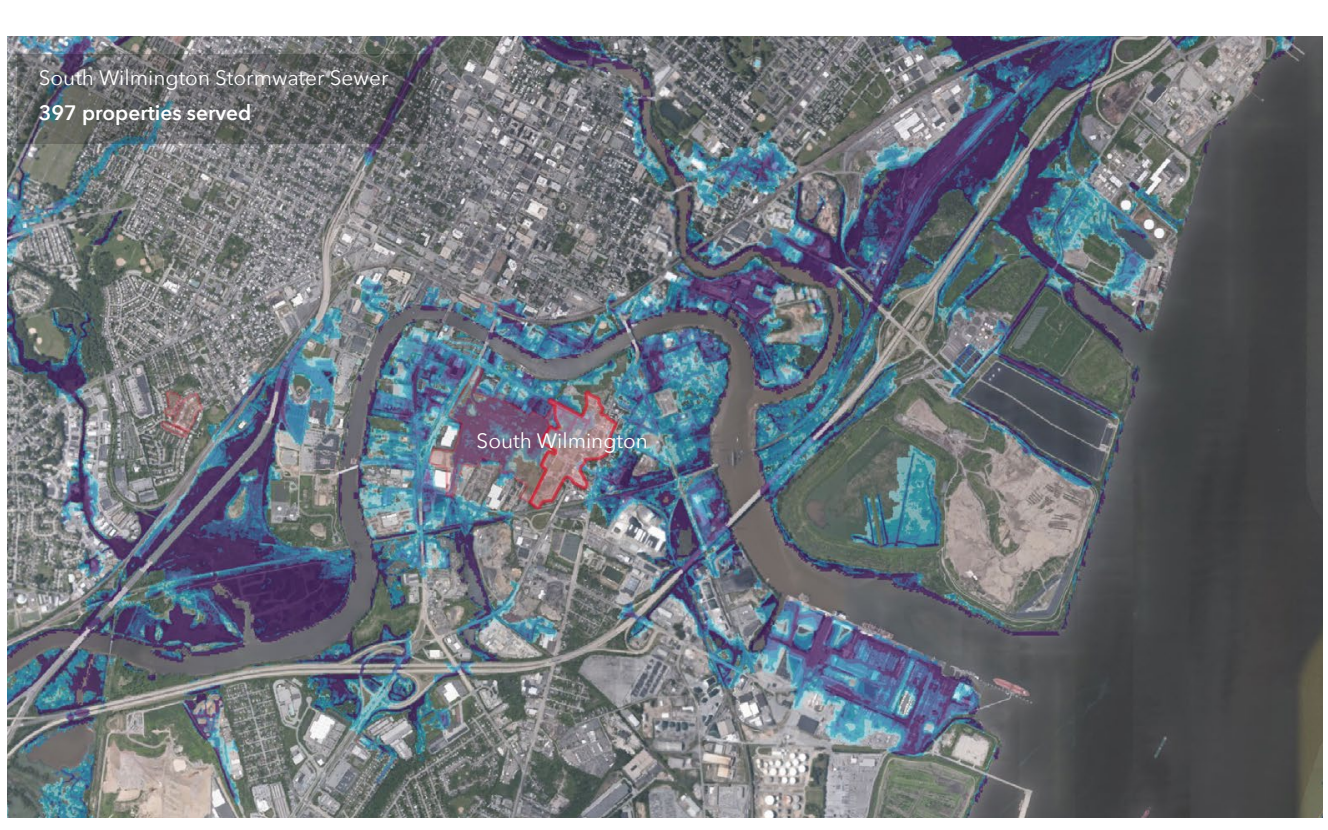

Top protection measures in state by quantity

Type
Example

Ditch

51,427

rmwater vault

Levee

Marsh/wetland restoration

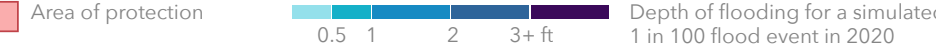




\section{State Overview Florida}

Flood risk is increasing in the state of Florida. $1,833,300$ properties currently have a substantial risk* $^{\star}$ of flooding. Over the next 30 years, the number of properties with this risk will increase by another $18.6 \%$, bringing the total number of properties with substantial risk to $2,174,400$

To understand personal flood risk, Americans leverage the Federal Emergency Management Agency (FEMA) Flood Insurance Rate Maps (FIRM). These maps identify $1,719,400$ properties as having substantial risk in the state of Florida. In comparison, the First Street Foundation Flood Model identifies 1.1 times the number of properties as facing this same level of risk. This discrepancy exists because the Foundation uses the current climate data, maps precipitation as a stand-alone risk, and includes areas that FEMA has not mapped. These new methods uncover an additional 114,000 properties currently not identified by FEMA as having substantial risk.

When adjusting for future environmental changes, the FEMA gap further widens to 455,000 by the year 2050 .

\section{Total properties at substantial risk}

$\ln 2020$

\section{$1.8 \mathrm{M}$}

30-year change

$\Delta+341,000$ $\ln 2050$

$2.2 \mathrm{M}$
Difference in number of properties currently at substantial risk compared to FEMA**

\section{$\Delta+114,000$}

Florida's extensive coastline, low elevation, and reliance on extensive drainage systems make it vulnerable to flooding. Both king tide and storm surge events, stability of the state, especially in places like Miami and the Keys. During the rainy season, from May to October, inland parts of the state, like Orlando, experience heavy rain and rising lakes resulting in economic and social losses.

of properties at substantial risk compared to other states

The First Street Foundation Flood Model finds $10.3 \%$ of all properties across the contiguous United States at

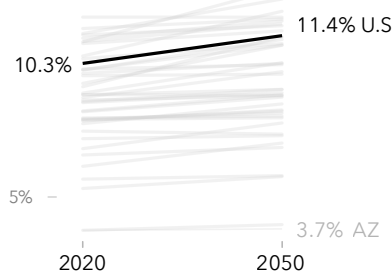
today, and $11.4 \%$ at substantia risk in 30 years. Florida has a greater proportion of properties at substantial risk, with $20.5 \%$ at substantial risk today and $24.3 \%$ at substantial risk in 2050 . exacerbated by sea level rise, threaten the long term

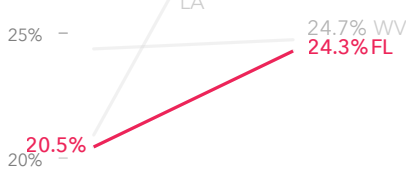

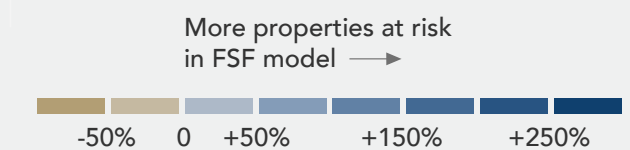

$-50 \%$

$+150 \%$

$250 \%$

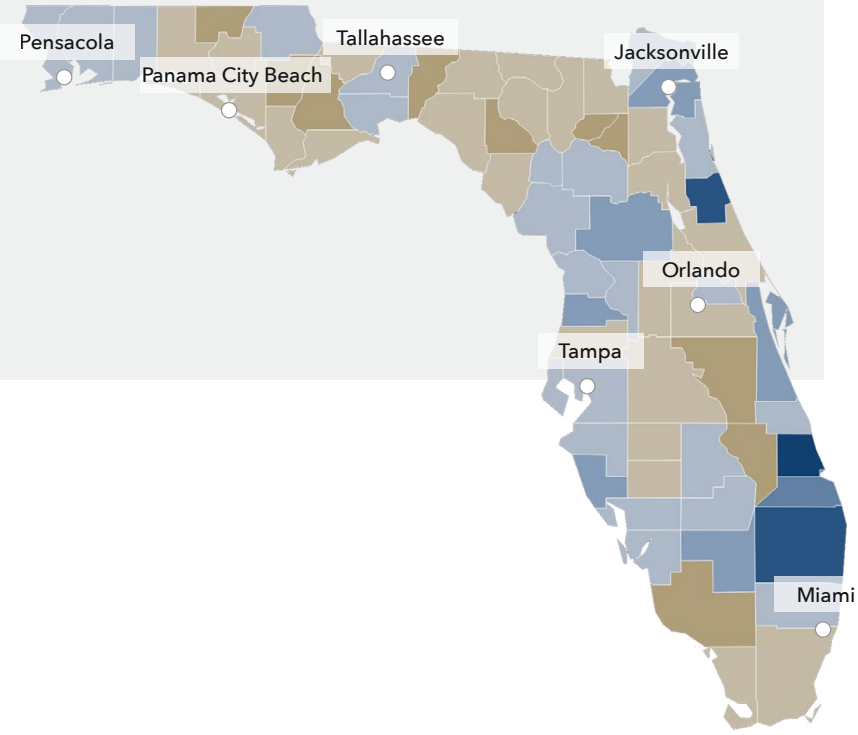




\section{Local details}

\section{Florida}

The First Street Foundation Flood Model calculates the number of properties facing any risk* of flooding. When looking at this broader level of risk, the data identifies 3,112,400 properties in Florida as at risk over the next 30 years. Of these properties, 313,200 were categorized as facing almost certain risk, with a $99 \%$ chance of flooding at least once over the next 30 years.

The city of Cape Coral has the greatest number of properties at risk of flooding in the state with 111,200 currently at risk, or $86 \%$ of its total number of properties. However, smaller cities or municipalities in the state, with fewer properties, may have a greater proportion of their total properties at risk. For example, 100\% of properties in Lighthouse Point are at risk of flooding. Other municipalities will see the greatest increase in risk over the next 30 years. Golden Gate, for example, will see a $2514 \%$ increase in the number of properties at risk.

Click here for a full breakdown of counties, cities, zip codes, and congressional districts in Florida at risk.

\section{Greatest proportion of properties at risk*}

\begin{tabular}{lll|} 
Municipality & \multicolumn{2}{c}{2020} \\
\hline Lighthouse Point & 4,113 & $100 \%$ \\
\hline Warm Mineral Springs & 5,097 & $100 \%$ \\
\hline Whiskey Creek & 2,063 & $100 \%$ \\
\hline South Patrick Shores & 2,536 & $100 \%$ \\
\hline Naples Park & 3,188 & $99 \%$ \\
\hline Siesta Key & 2,517 & $99 \%$ \\
\hline McGregor & 2,877 & $99 \%$ \\
\hline Wilton Manors & 3,950 & $99 \%$ \\
\hline Charlotte Park & 1,992 & $99 \%$ \\
\hline Cortez & 2,504 & $99 \%$ \\
\hline
\end{tabular}

\section{Greatest number of properties at risk*}

\begin{tabular}{|c|c|c|c|c|c|c|}
\hline \multirow{2}{*}{$\begin{array}{l}\text { Municipality } \\
\text { Cape Coral }\end{array}$} & \multicolumn{2}{|c|}{2020} & \multicolumn{2}{|c|}{2050} & \multicolumn{2}{|c|}{ Change } \\
\hline & 111,237 & $86 \%$ & 126,436 & $97 \%$ & $+15,199$ & $+13.7 \%$ \\
\hline Tampa & 58,414 & $43 \%$ & 72,178 & $54 \%$ & $+13,764$ & $+23.6 \%$ \\
\hline Jacksonville & 48,408 & $14 \%$ & 64,113 & $18 \%$ & $+15,705$ & $+32.4 \%$ \\
\hline Fort Lauderdale & 43,762 & $80 \%$ & 51,267 & $93 \%$ & $+7,505$ & $+17.1 \%$ \\
\hline St. Petersburg & 40,252 & $47 \%$ & 44,867 & $52 \%$ & $+4,615$ & $+11.5 \%$ \\
\hline Port Charlotte & 38,938 & $87 \%$ & 41,598 & $93 \%$ & $+2,660$ & $+6.8 \%$ \\
\hline Lehigh Acres & 37,289 & $30 \%$ & 39,844 & $32 \%$ & $+2,555$ & $+6.9 \%$ \\
\hline Miami & 34,932 & $52 \%$ & 39,628 & $59 \%$ & $+4,696$ & $+13.4 \%$ \\
\hline Port St. Lucie & 26,897 & $27 \%$ & 32,320 & $33 \%$ & $+5,423$ & $+20.2 \%$ \\
\hline North Port & 24,083 & $32 \%$ & 32,759 & $44 \%$ & $+8,676$ & $+36.0 \%$ \\
\hline
\end{tabular}

\section{Greatest relative growing risk*}

\begin{tabular}{|c|c|c|c|c|c|c|}
\hline \multirow{2}{*}{$\begin{array}{l}\text { Municipality } \\
\text { Golden Gate }\end{array}$} & \multicolumn{2}{|c|}{2020} & \multicolumn{2}{|c|}{2050} & \multicolumn{2}{|c|}{ Change } \\
\hline & 153 & $3 \%$ & 4,000 & $76 \%$ & +3847 & $+2514 \%$ \\
\hline Lauderdale Lakes & 682 & $11 \%$ & 4,555 & $76 \%$ & +3873 & $+568 \%$ \\
\hline Ormond-by-the-Sea & 1,504 & $34 \%$ & 4,311 & $98 \%$ & $+2,807$ & $+187 \%$ \\
\hline Holly Hill & 1,676 & $33 \%$ & 4,774 & $93 \%$ & $+3,098$ & $+185 \%$ \\
\hline Edgewater & 3,077 & $28 \%$ & 8,360 & $75 \%$ & $+5,283$ & $+172 \%$ \\
\hline West Perrine & 676 & $25 \%$ & 1,798 & $66 \%$ & $+1,122$ & $+166 \%$ \\
\hline Lake Park & 590 & $29 \%$ & 1,536 & $76 \%$ & +946 & $+160 \%$ \\
\hline Ocean City & 653 & $26 \%$ & 1,654 & $65 \%$ & $+1,001$ & $+153 \%$ \\
\hline Fleming Island & 1,310 & $11 \%$ & 3,071 & $26 \%$ & $+1,761$ & $+134 \%$ \\
\hline Crawfordville & 771 & $35 \%$ & 1,756 & $80 \%$ & +985 & $+128 \%$ \\
\hline
\end{tabular}

\section{Flood Factor distribution of properties at risk ${ }^{\star}(1000 s)$}

\section{Risk level}

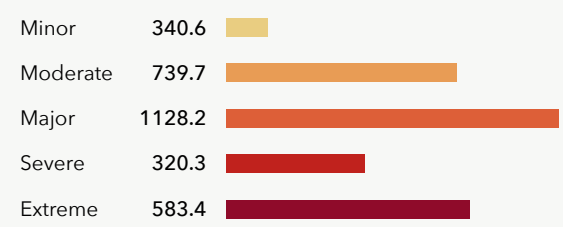

Extreme

583.4

More than $34.8 \%$ of individual properties and properties in Florida are at any risk of flooding over the next 30 years. Out of those at risk $65 \%$ are at major to extreme risk. 


\section{Flood History \& Protection}

\section{Florida}

Claims History

$4,850,500$ home and property owners in Florida have made flood damage claims through FEMA since the year 2000. ${ }^{*}$ These claims for reimbursement were made through either the National

Flood Insurance Program (NFIP) or Individual Assistance Program (IAP). The greatest number of

claims since the year 2000 have been concentrated in Miami-Dade, Broward, Palm Beach, Orange,

and Polk counties.

\section{Storm Simulation}

The First Street Foundation Flood Model has recreated 8 flooding events that have occurred since the year 2000 in the state of Florida. These events flooded around 364,420 properties across the state.**

\begin{tabular}{llr} 
Flood event & Date & $\begin{array}{r}\text { \# Properties } \\
\text { affected }\end{array}$ \\
- Hurricane Charley & Aug 2004 & 129,925 \\
\hline Hurricane Jeanne & Sep 2004 & 34,521 \\
\hline Hurricane Katrina & Aug 2005 & 235 \\
\hline Hurricane Wilma & Oct 2005 & 66,959 \\
\hline Hurricane Matthew & Sep 2016 & 43,324 \\
\hline Hurricane Hermine & Aug 2016 & 42,946 \\
\hline Hurricane Irma & Sep 2017 & 16,156 \\
\hline Hurricane Michael & Oct 2018 & 30,352
\end{tabular}

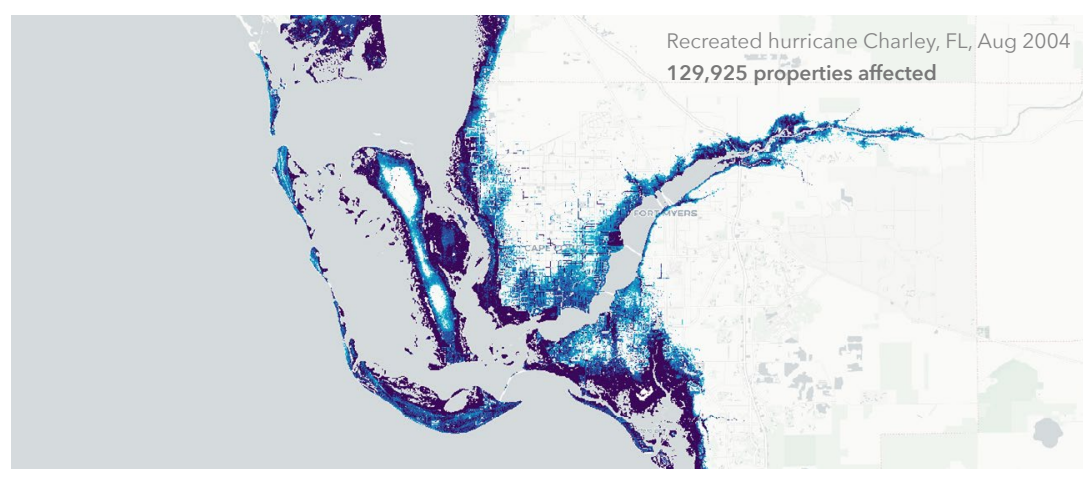

\section{0,000}

Properties served by

protection measures

The First Street Foundation Flood

Model incorporates 348 flood control

measures throughout the state which

protect 400,000 properties.
Top protection measures in state by quantity

Type
Example

Levee

East Coast Protective Levees, Wellingto

367,753

Pump station

- Pump station, Hollywoo

Beach nourishment

Panama City Beach Renourishment

Sewer upgrade

Hallandale Beach NE Quadrant Drainage Improvements

Retention pond

Shore Acres, St. Petersburg

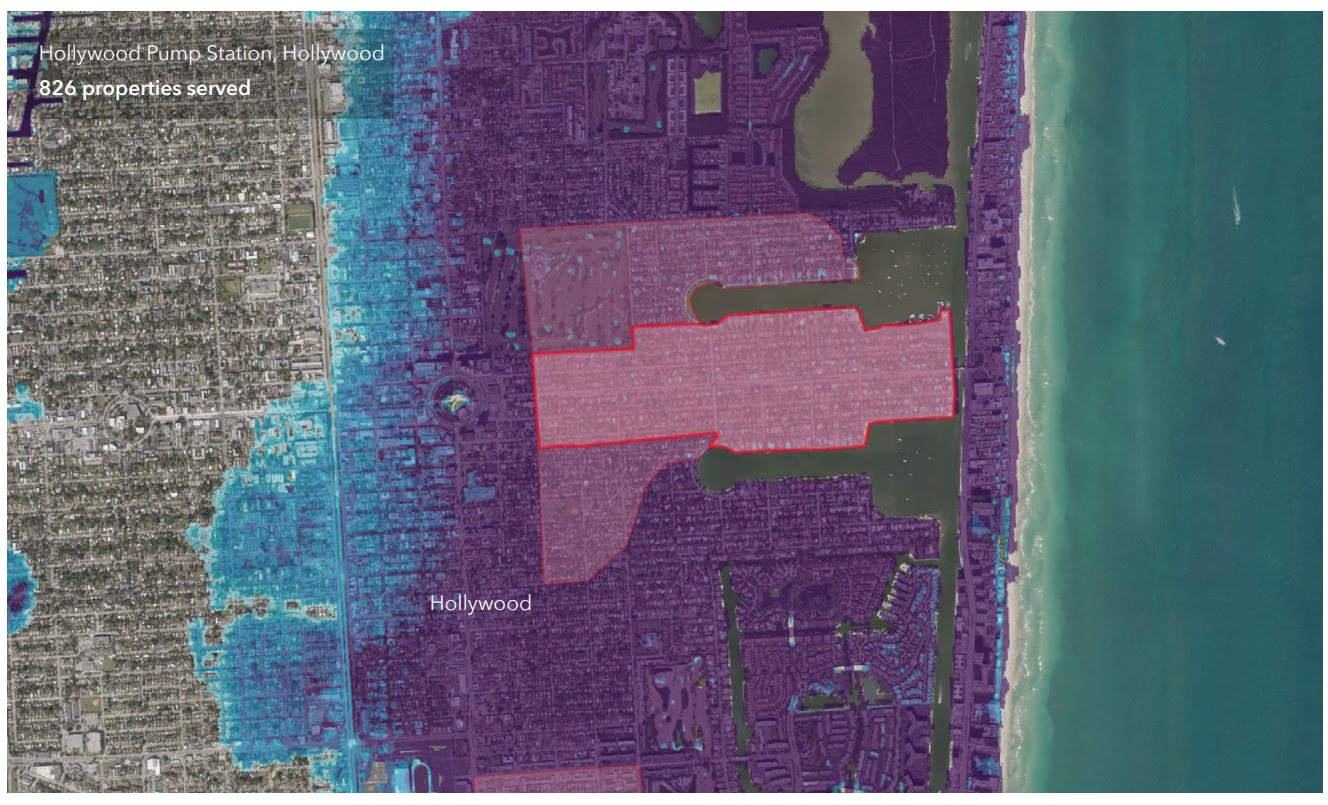

Area of protection 


\section{State Overview Georgia}

Flood risk is increasing in the state of Georgia. 347,700 properties currently have a substantial risk* of flooding. Over the next 30 years, the number of properties with this risk will increase by another $9.9 \%$, bringing the total number of properties with substantial risk to 382,100

To understand personal flood risk, Americans leverage the Federal Emergency Management Agency (FEMA) Flood Insurance Rate Maps (FIRM). These maps identify 157,100 properties as having substantial risk in the state of Georgia. In comparison, the First Street Foundation

Flood Model identifies 2.2 times the number of properties as facing this same level of risk. This discrepancy exists because the Foundation uses the current climate data, maps precipitation as a stand-alone risk, and includes areas that FEMA has not mapped. These new methods uncover an additional 190,600 properties currently not identified by FEMA as having substantial risk.

When adjusting for future environmental changes, the FEMA gap further widens to 225,000 by the year 2050.

\section{Total properties at substantial risk}

In 2020

347,700

30-year change

$\Delta+34,400(+10 \%)$

Coastal communities see hurricanes, tropical storms, and heavy rains. Flooding around Atlanta occurs in winter and spring when storms blanket the area with rain. Floods also occur during the summer when thunderstorms bring intense rains. In 2009 moisture pulled from the Gulf of Mexico and the Atlantic Ocean caused rains that fel faster than local watersheds could handle, dropping an estimated 10-20 inches of rain in under 24 hours.

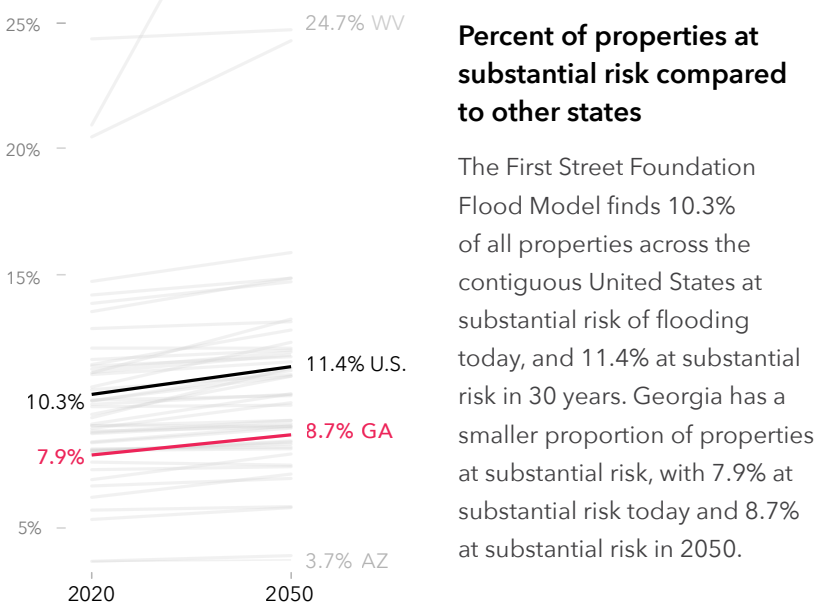

Difference in number of properties currently at substantial risk compared to FEMA**

$\Delta+190,600$
More properties at risk in FSF model $\longrightarrow$
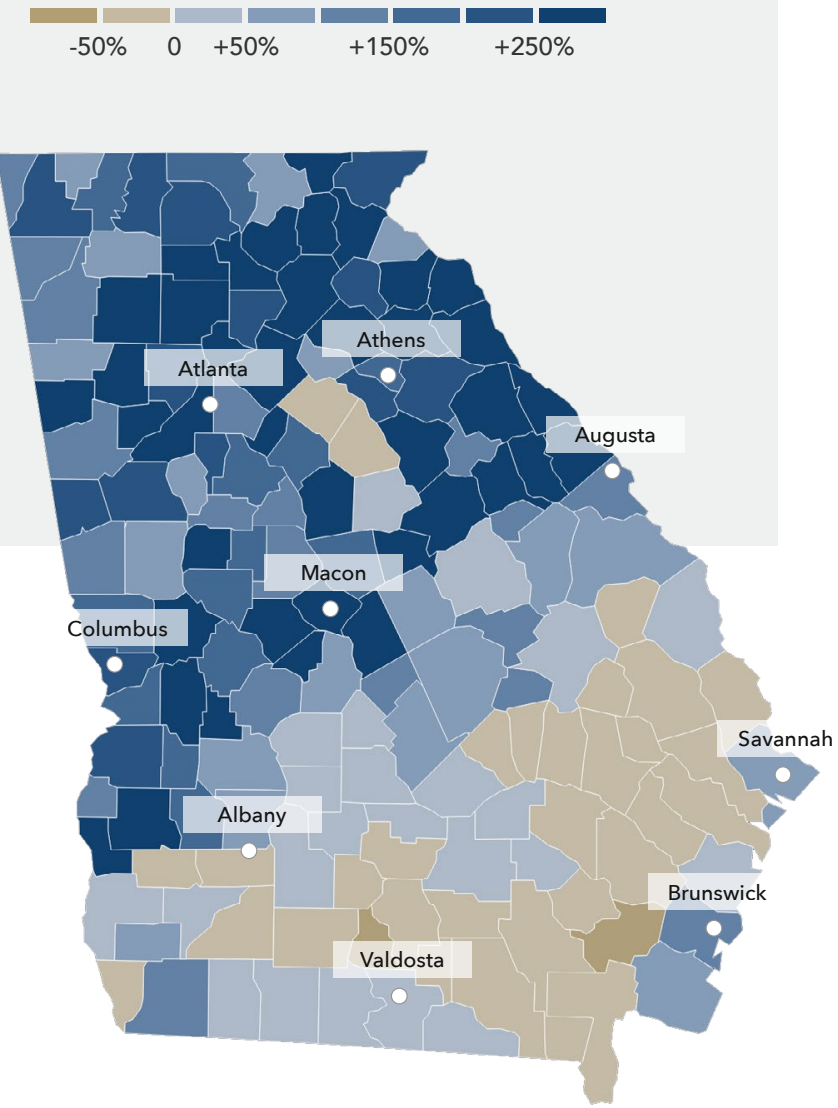


\section{Local details \\ Georgia}

The First Street Foundation Flood Model calculates the number of properties facing any risk* of flooding. When looking at this broader level of risk, the data identifies 487,400 properties in Georgia as at risk over the next 30 years. Of these properties, 70,500 were categorized as facing almost certain risk, with a $99 \%$ chance of flooding at least once over the next 30 years.

The city of Atlanta has the greatest number of properties at risk of flooding in the state with 14,200 currently at risk, or $11 \%$ of its total number of properties. However, smaller cities or municipalities in the state, with fewer properties, may have a greater proportion of their total properties at risk. For example, 100\% of properties in Brunswick are at risk of flooding. Other municipalities will see the greatest increase in risk over the next 30 years. Adel, for example, will see a $83 \%$ increase in the number of properties at risk.

Click here for a full breakdown of counties, cities, zip codes, and congressional districts in Georgia at risk.

\section{Greatest proportion of properties at risk*}

\begin{tabular}{lll|} 
Municipality & \multicolumn{2}{c}{2020} \\
Brunswick & 6,815 & $100 \%$ \\
\hline Skidaway Island & 4,698 & $99 \%$ \\
\hline Wilmington Island & 6,269 & $98 \%$ \\
\hline Whitemarsh Island & 3,026 & $98 \%$ \\
\hline St. Simons & 8,442 & $96 \%$ \\
\hline Tybee Island & 3,661 & $95 \%$ \\
\hline Country Club Estates & 2,414 & $90 \%$ \\
\hline Dock Junction & 2,748 & $73 \%$ \\
\hline St. Marys & 6,797 & $73 \%$ \\
\hline Georgetown & 1,759 & $44 \%$ \\
\hline
\end{tabular}

\section{Greatest number of properties at risk*}

\begin{tabular}{l|c|ccccc} 
Municipality & \multicolumn{2}{c}{2020} & \multicolumn{2}{c}{2050} & \multicolumn{2}{c}{ Change } \\
\cline { 2 - 5 } Atlanta & 14,227 & $11 \%$ & 14,887 & $11 \%$ & +660 & $+4.6 \%$ \\
\hline Savannah & 13,488 & $24 \%$ & 17,055 & $31 \%$ & $+3,567$ & $+26.4 \%$ \\
\hline Augusta-Richmond & 9,494 & $12 \%$ & 9,967 & $13 \%$ & +473 & $+5.0 \%$ \\
\hline Columbus & 8,851 & $13 \%$ & 9,558 & $14 \%$ & +707 & $+8.0 \%$ \\
\hline St. Simons & 8,442 & $96 \%$ & 8,623 & $98 \%$ & +181 & $+2.1 \%$ \\
\hline Brunswick & 6,815 & $100 \%$ & 6,815 & $100 \%$ & 0 & $0.0 \%$ \\
\hline St. Marys & 6,797 & $73 \%$ & 7,242 & $78 \%$ & +445 & $+6.5 \%$ \\
\hline Wilmington Island & 6,269 & $98 \%$ & 6,274 & $98 \%$ & +5 & $+0.1 \%$ \\
\hline Albany & 5,961 & $21 \%$ & 6,835 & $24 \%$ & +874 & $+14.7 \%$ \\
\hline Macon-Bibb & 5,932 & $9 \%$ & 6,168 & $9 \%$ & +236 & $+4.0 \%$
\end{tabular}

\section{Greatest relative growing risk*}

\begin{tabular}{|c|c|c|c|c|c|c|}
\hline Municipality & 20 & & & 050 & & ange \\
\hline Adel & 80 & $3 \%$ & 146 & $5 \%$ & +666 & $+83 \%$ \\
\hline Lovejoy & 28 & $1 \%$ & 48 & $2 \%$ & +200 & $+71 \%$ \\
\hline Richmond Hill & 791 & $14 \%$ & 1,179 & $21 \%$ & +8888 & $+49 \%$ \\
\hline Georgetown & 1,759 & $44 \%$ & 2,304 & $58 \%$ & +5985 & $+31 \%$ \\
\hline Rincon & 103 & $3 \%$ & 132 & $3 \%$ & +289 & $+28 \%$ \\
\hline Dock Junction & 2,748 & $73 \%$ & 3,482 & $93 \%$ & $+7 B A 4$ & $+27 \%$ \\
\hline Savannah & 13,488 & $24 \%$ & 17,055 & $31 \%$ & $+B 35887$ & $+26 \%$ \\
\hline Hinesville & 1,133 & $10 \%$ & 1,411 & $12 \%$ & +2288 & $+25 \%$ \\
\hline Garden City & 572 & $16 \%$ & 698 & $20 \%$ & $+42 B 6$ & $+22 \%$ \\
\hline Elberton & 78 & $3 \%$ & 95 & $4 \%$ & AP77 & $+22 \%$ \\
\hline
\end{tabular}

\section{Flood Factor distribution of properties at risk ${ }^{\star}(1000 s)$}

\section{Risk leve}

Minor $\quad 32.1$

Moderate $\quad 83.5$

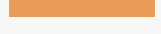

Severe $\quad 90.6$

Extreme

5.0

More than $11.1 \%$ of individual properties and properties in Georgia are at any risk of flooding over the next 30 years. Out of those at risk $76 \%$ are at major to extreme risk.

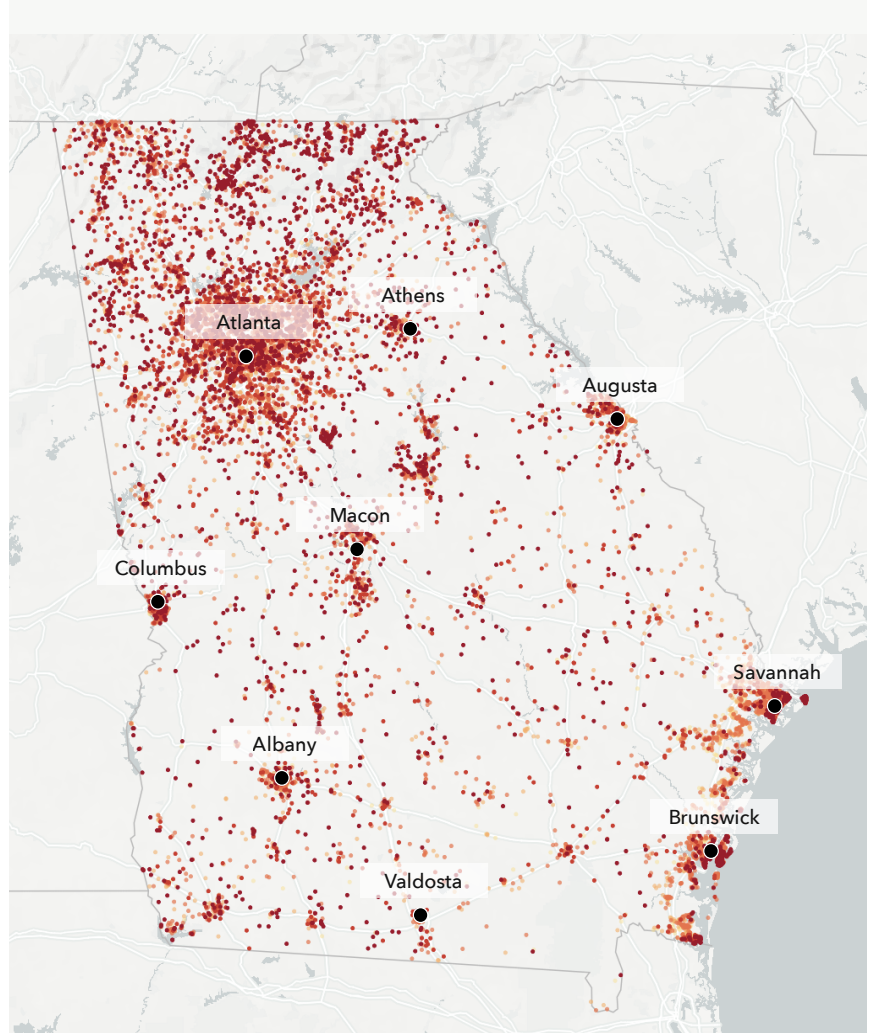


Flood History \& Protection

\section{Georgia}

\section{Claims History}

277,700 home and property owners in Georgia have made flood damage claims through FEMA since the year 2000. ${ }^{\star}$ These claims for reimbursement were made through either the National Flood Insurance Program (NFIP) or Individual Assistance Program (IAP). The greatest number of

claims since the year 2000 have been concentrated in Chatham, Dougherty, Glynn, Cobb, and Lee counties.

\section{7,500}

Properties served by

protection measures

The First Street Foundation Flood

Model incorporates 4,079 flood control

measures throughout the state which

protect 47,500 properties
Top protection measures in state by quantity

Type
Exampl

\# Properties served by type 38,303

- High Falls SP managed land, Jackso

7,735

Levee

Beach nourishment

Tybee Island Beach Renourishment

Marsh/wetland restoration

Sewer upgrade

Tybee Island stormwater retrofits and backflow preventor

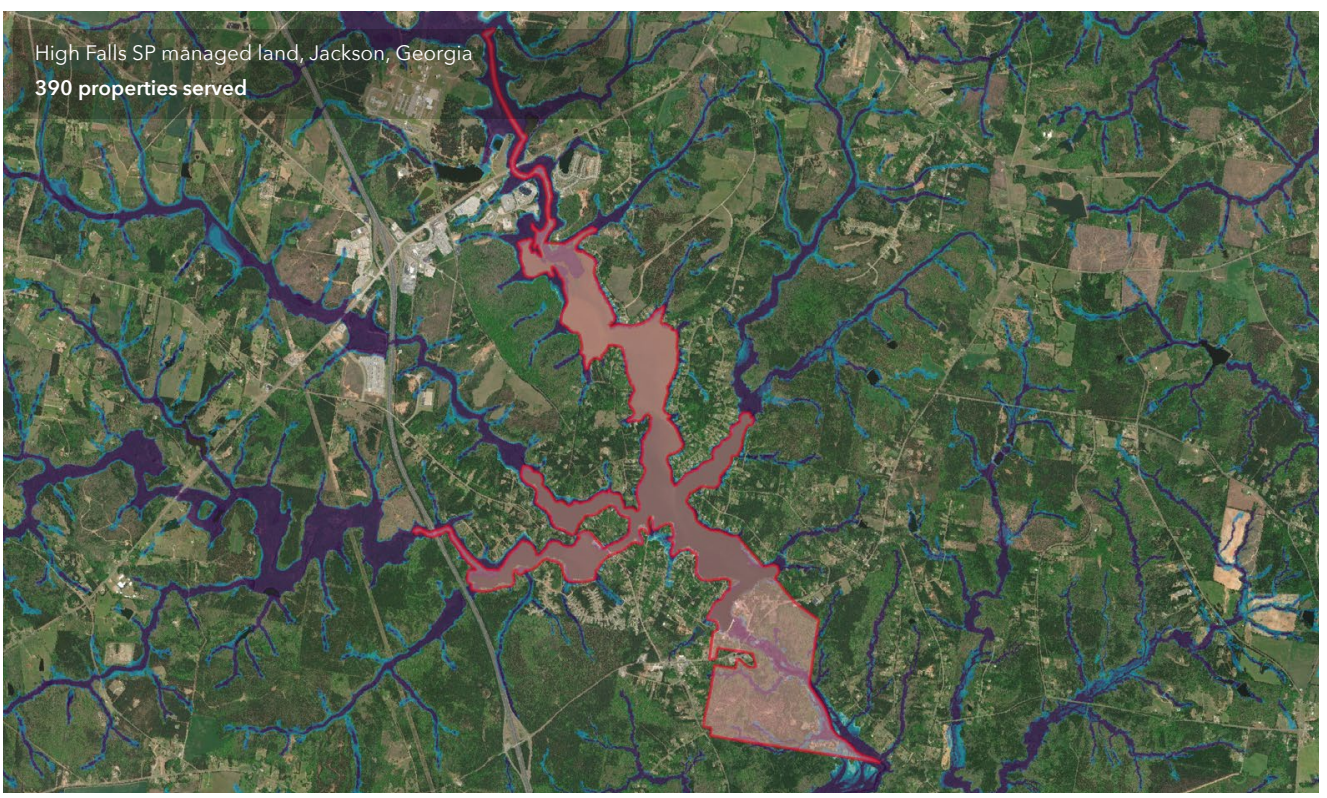




\section{State Overview Idaho}

Flood risk is increasing in the state of Idaho. 148,400 properties currently have a substantial risk* of flooding. Over the next 30 years, the number of properties with this risk will increase by another $7.7 \%$, bringing the total number of properties with substantial risk to 159,900

To understand personal flood risk, Americans leverage the Federal Emergency Management Agency (FEMA) Flood Insurance Rate Maps (FIRM). These maps identify 38,000 properties as having substantial risk in the state of Idaho. In comparison, the First Street Foundation Flood Model identifies 3.9 times the number of properties as facing this same level of risk. This discrepancy exists because the Foundation uses the current climate data, maps precipitation as a stand-alone risk, and includes areas that FEMA has not mapped. These new methods uncover an additional 110,400 properties currently not identified by FEMA as having substantial risk.

When adjusting for future environmental changes, the FEMA gap further widens to 121,900 by the year 2050 .

\section{Total properties at substantial risk}

In 2020

\section{8,400}

30-year change

$$
\Delta+11,500
$$

Difference in number of properties currently at substantial risk compared to FEMA**

$$
\Delta+110,400
$$

More properties at risk in FSF model $\longrightarrow$

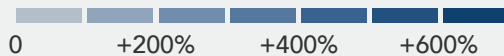

Snowmelt, heavy rainfall, and summer flash floods pose seasonal risks to Idaho communities. Rapidly melting snowpack and heavy rains caused disastrous flooding on the Snake River in 1997, prompting Presidential and FEMA Disaster Declarations for the counties of Bingham Bonneville, Buttle, Custer, Fremont, Jefferson, and Madison. These communities rely on levees, flood control dams and reservoirs to defend against severe flooding.
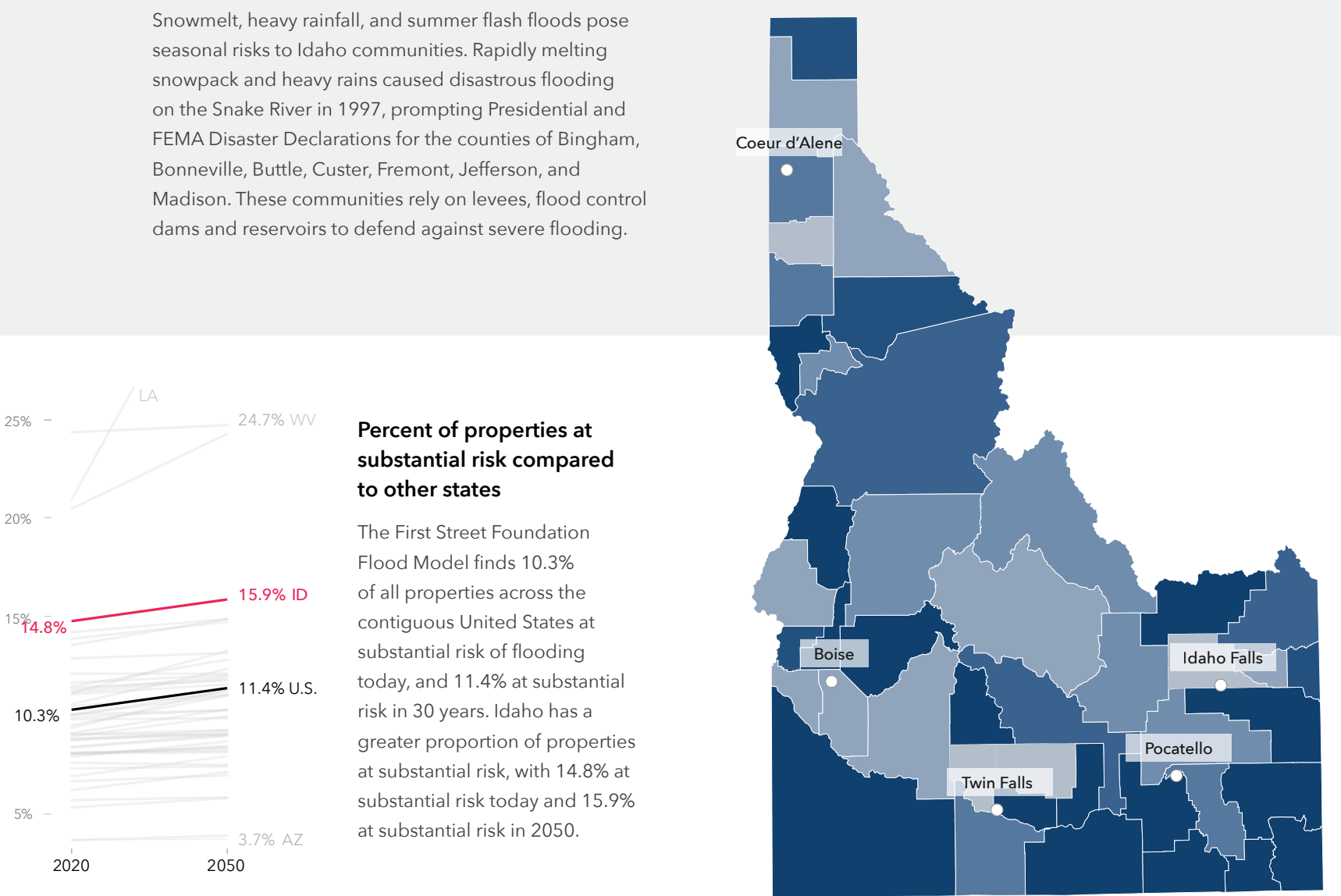


\section{Local details \\ Idaho}

The First Street Foundation Flood Model calculates the number of properties facing any risk* of flooding. When looking at this broader level of risk, the data identifies 243,800 properties in Idaho as at risk over the next 30 years. Of these properties, 34,000 were categorized as facing almost certain risk, with a $99 \%$ chance of flooding at least once over the next 30 years.

The city of Boise City has the greatest number of properties at risk of flooding in the state with 15,500 currently at risk, or 19\% of its total number of properties. However, smaller cities or municipalities in the state, with fewer properties, may have a greater proportion of their total properties at risk. For example, $81 \%$ of properties in Blackfoot are at risk of flooding. Other municipalities will see the greatest increase in risk over the next 30 years. Fruitland, for example, will see a $34 \%$

increase in the number of properties at risk.

Click here for a full breakdown of counties, cities, zip codes, and congressional districts in Idaho at risk.

\section{Greatest proportion of properties at risk*}

\begin{tabular}{lll} 
Municipality & \multicolumn{2}{c}{2020} \\
\hline Blackfoot & 3,881 & $81 \%$ \\
\hline Emmett & 2,176 & $76 \%$ \\
\hline Garden City & 3,202 & $60 \%$ \\
\hline Payette & 1,845 & $58 \%$ \\
\hline Ammon & 3,105 & $54 \%$ \\
\hline Star & 2,546 & $50 \%$ \\
\hline Middleton & 1,512 & $44 \%$ \\
\hline Hailey & 1,808 & $42 \%$ \\
\hline Eagle & 5,054 & $38 \%$ \\
\hline Salmon & 767 & $37 \%$ \\
\hline
\end{tabular}

\section{Greatest number of properties at risk*}

\begin{tabular}{l|c|ccccc} 
Municipality & \multicolumn{2}{c}{2020} & \multicolumn{2}{c}{2050} & \multicolumn{2}{c}{ Change } \\
Boise City & 15,529 & $19 \%$ & 17,179 & $21 \%$ & $+1,650$ & $+10.6 \%$ \\
\hline Meridian & 7,314 & $17 \%$ & 7,965 & $18 \%$ & +651 & $+8.9 \%$ \\
\hline Pocatello & 5,647 & $26 \%$ & 6,000 & $28 \%$ & +353 & $+6.3 \%$ \\
\hline Idaho Falls & 5,568 & $23 \%$ & 6,110 & $25 \%$ & +542 & $+9.7 \%$ \\
\hline Caldwell & 5,172 & $28 \%$ & 5,336 & $28 \%$ & +164 & $+3.2 \%$ \\
\hline Nampa & 5,056 & $16 \%$ & 5,359 & $17 \%$ & +303 & $+6.0 \%$ \\
\hline Eagle & 5,054 & $38 \%$ & 5,372 & $40 \%$ & +318 & $+6.3 \%$ \\
\hline Blackfoot & 3,881 & $81 \%$ & 3,965 & $83 \%$ & +84 & $+2.2 \%$ \\
\hline Garden City & 3,202 & $60 \%$ & 3,331 & $62 \%$ & +129 & $+4.0 \%$ \\
\hline Ammon & 3,105 & $54 \%$ & 3,300 & $57 \%$ & +195 & $+6.3 \%$
\end{tabular}

\section{Greatest relative growing risk*}

\begin{tabular}{lrrrrrr} 
Municipality & \multicolumn{2}{c}{2020} & \multicolumn{2}{c}{2050} & \multicolumn{2}{c}{ Change } \\
Fruitland & 77 & $4 \%$ & 103 & $5 \%$ & +26 & $+34 \%$ \\
\hline Mountain Home & 1,338 & $23 \%$ & 1,624 & $27 \%$ & +286 & $+21 \%$ \\
\hline Star & 2,546 & $50 \%$ & 2,934 & $58 \%$ & +388 & $+15 \%$ \\
\hline Sandpoint & 403 & $11 \%$ & 464 & $12 \%$ & +61 & $+15 \%$ \\
\hline Rupert & 422 & $17 \%$ & 470 & $19 \%$ & +48 & $+11 \%$ \\
\hline Boise City & 15,529 & $19 \%$ & 17,179 & $21 \%$ & $+1,650$ & $+11 \%$ \\
\hline Chubbuck & 860 & $16 \%$ & 950 & $17 \%$ & +90 & $+11 \%$ \\
\hline Twin Falls & 1,325 & $6 \%$ & 1,461 & $7 \%$ & +136 & $+10 \%$ \\
\hline Idaho Falls & 5,568 & $23 \%$ & 6,110 & $25 \%$ & +542 & $+10 \%$ \\
\hline Hailey & 1,808 & $42 \%$ & 1,972 & $46 \%$ & +164 & $+9 \%$
\end{tabular}

\section{Flood Factor distribution of properties at risk ${ }^{\star}(1000 s)$}

\section{Risk level}

Minor $\quad 15.5$

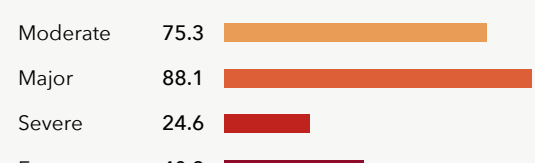

Extreme

40.2

More than $24.3 \%$ of individual properties and properties in Idaho are at any risk of flooding over the next 30 years. Out of those at risk $63 \%$ are at major to extreme risk.

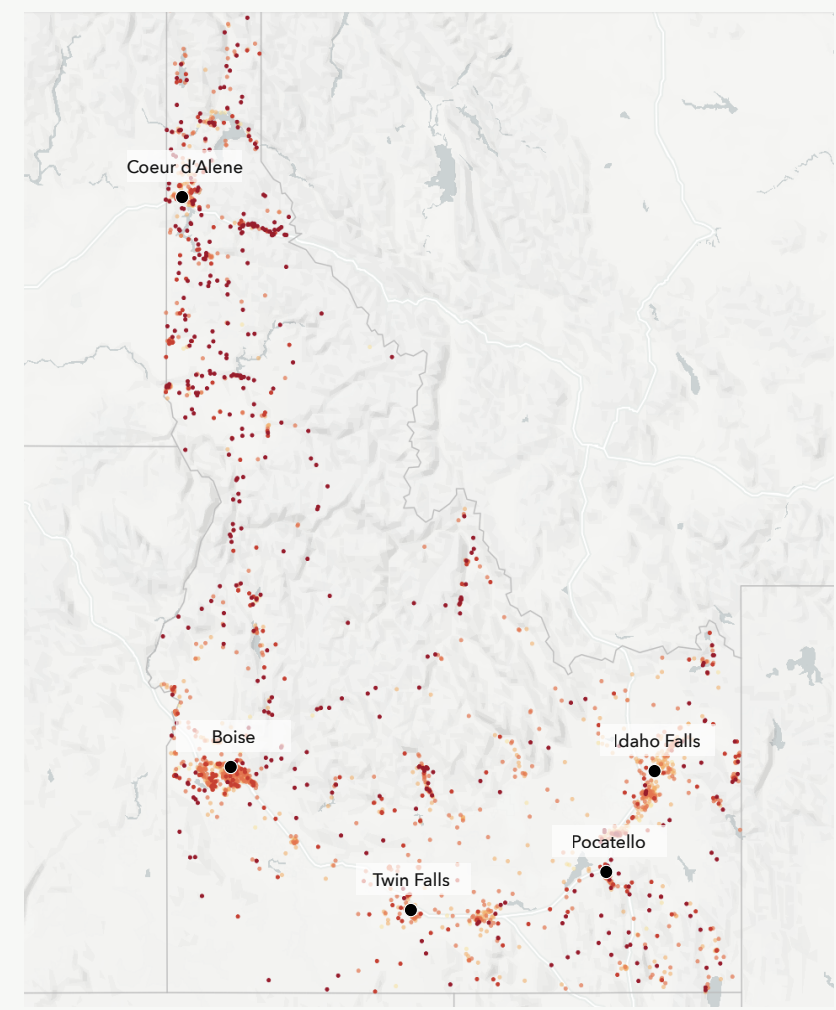




\section{Flood History \& Protection}

\section{Idaho}

\section{Claims History}

700 home and property owners in Idaho have made flood damage claims through FEMA since the year 2000.* These claims for reimbursement were made through either the National Flood Insurance Program (NFIP) or Individual Assistance Program (IAP). The greatest number of claims since the year 2000 have been concentrated in Blaine, Ada, Kootenai, Shoshone, and Gem counties.

\section{8,600}

Properties served by

protection measures

The First Street Foundation Flood

Model incorporates 149 flood control

measures throughout the state which

protect 18,600 properties.

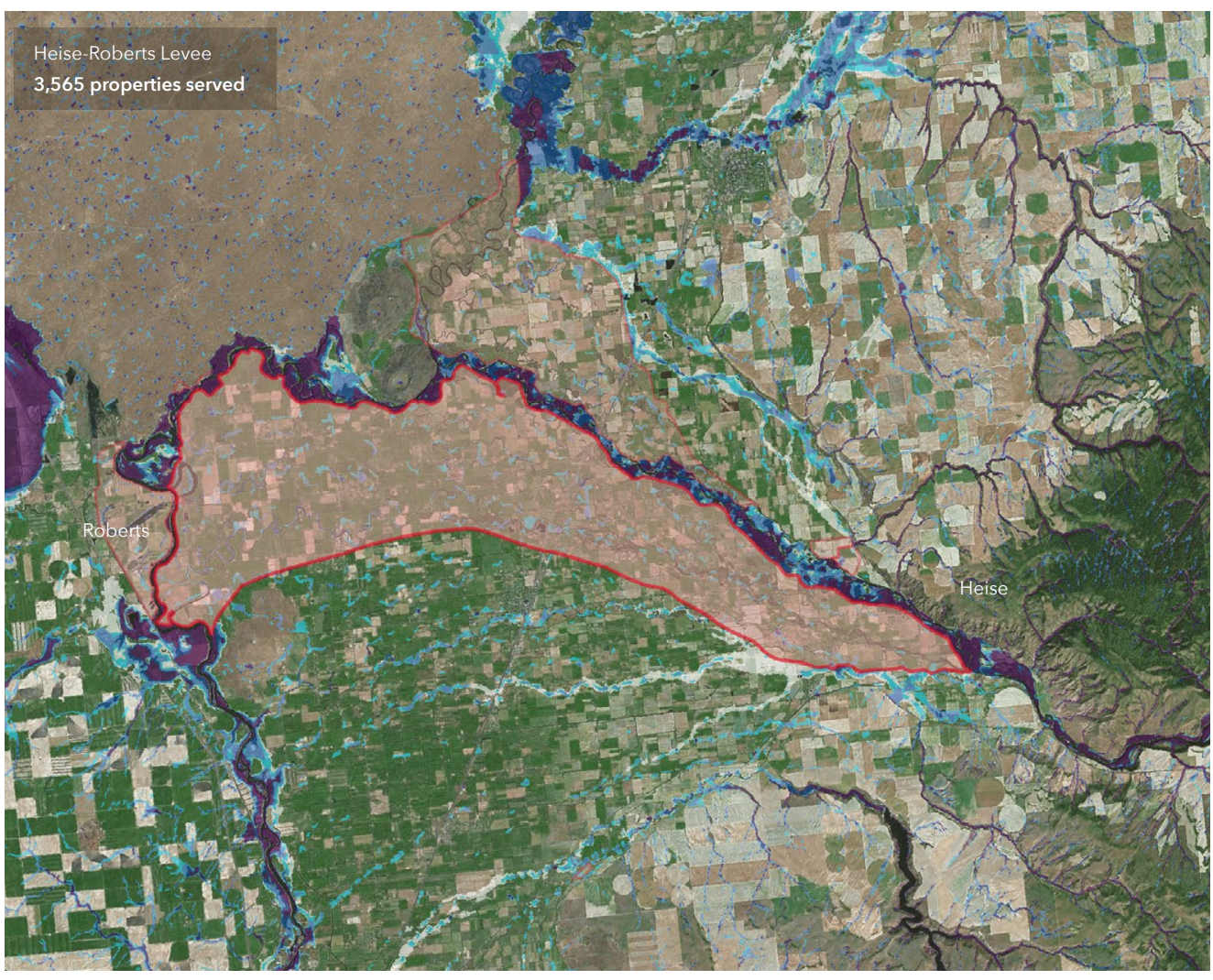

Area of protection

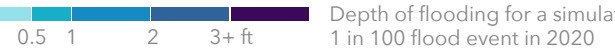

Top protection measures in state by quantity

Type
Example

Levee

\# Properties served by type

18,646 


\section{State Overview Illinois}

Flood risk is increasing in the state of Illinois. 451,700 properties currently have a substantial risk* of flooding. Over the next 30 years, the number of properties with this risk will increase by another $4.4 \%$, bringing the total number of properties with substantial risk to 471,800 .

To understand personal flood risk, Americans leverage the Federal Emergency Management Agency (FEMA) Flood Insurance Rate Maps (FIRM). These maps identify 205,700 properties as having substantial risk in the state of Illinois. In comparison, the First Street Foundation Flood Model identifies 2.2 times the number of properties as facing this same level of risk. This discrepancy exists because the Foundation uses the current climate data, maps precipitation as a stand-alone risk, and includes areas that FEMA has not mapped. These new methods uncover an additional 246,000 properties currently not identified by FEMA as having substantial risk. When adjusting for future environmental changes, the FEMA gap further widens to 266,100 by the year 2050 .
Total properties at substantial risk*

$\ln 2020$

451,700

30-year change

$\Delta+20,100$ $\ln 2050$

471,800

Difference in number of properties currently at substantial risk compared to FEMA**

$\Delta+246,000$

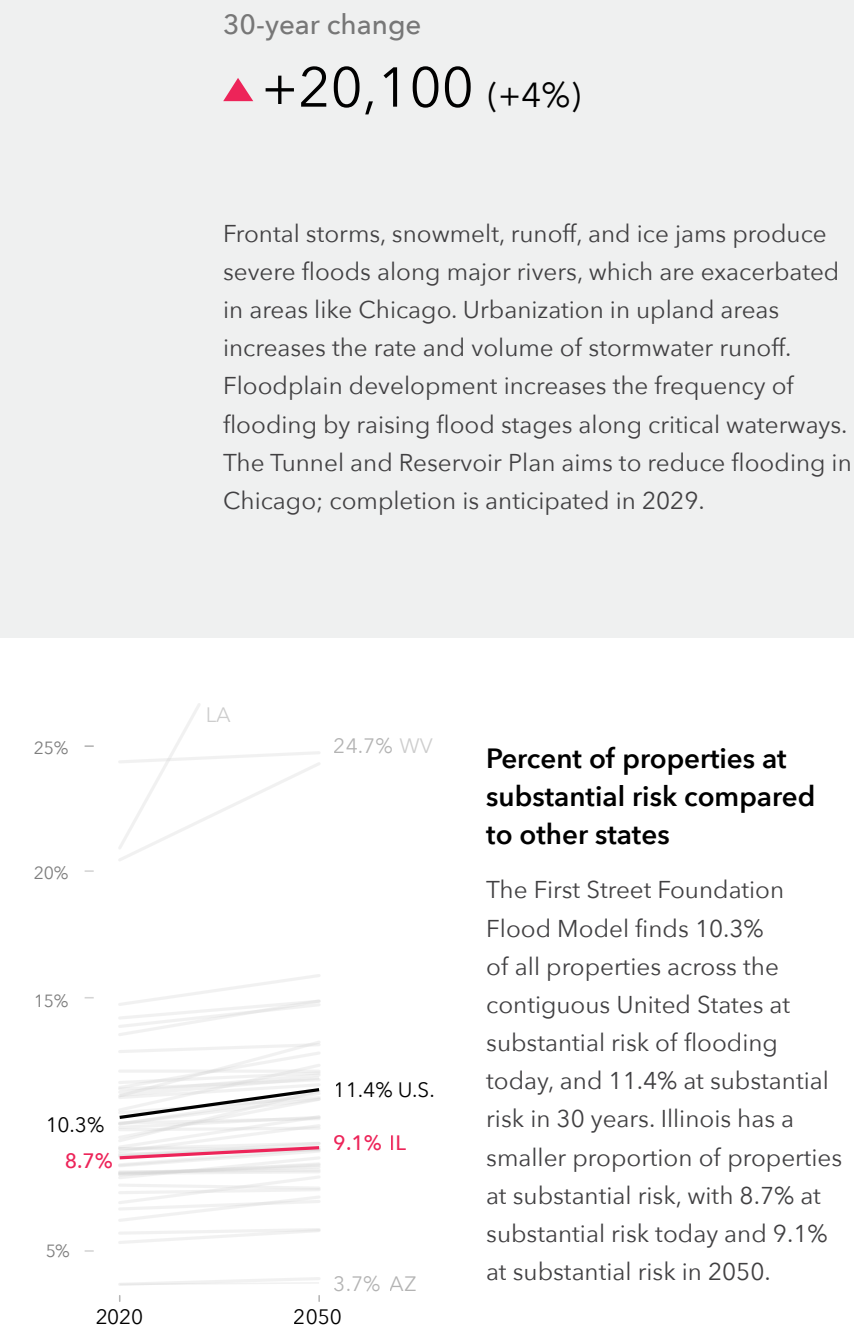

More properties at risk in FSF model $\longrightarrow$
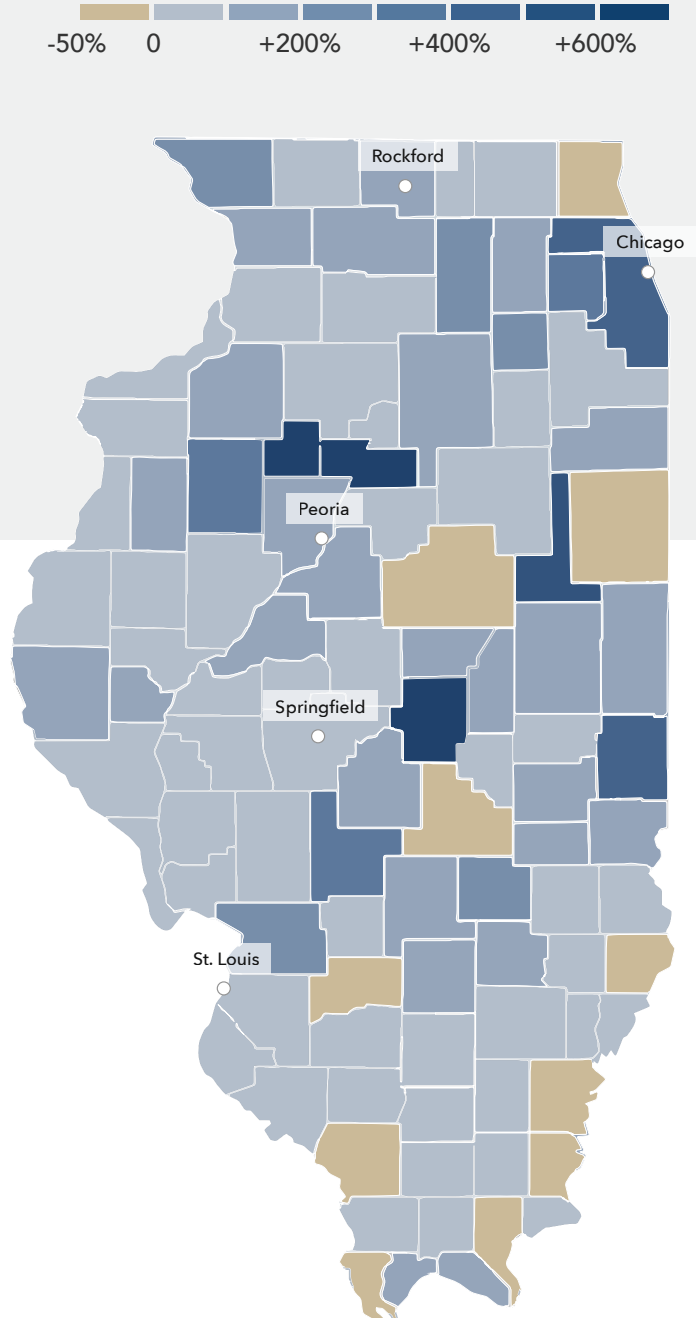


\section{Local details}

Illinois

The First Street Foundation Flood Model calculates the number of properties facing any risk* of flooding. When looking at this broader level of risk, the data identifies 748,100 properties in Illinois as at risk over the next 30 years. Of these properties, 89,700 were categorized as facing almost certain risk, with a $99 \%$ chance of flooding at least once over the next 30 years.

The city of Chicago has the greatest number of properties at risk of flooding in the state with 154,800 currently at risk, or $26 \%$ of its total number of properties. However, smaller cities or municipalities in the state, with fewer properties, may have a greater proportion of their total properties at risk. For example, $90 \%$ of properties in Stickney are at risk of flooding. Other municipalities will see the greatest increase in risk over the next 30 years. Morton Grove, for example, will see a 29\% increase in the number of properties at risk..

Click here for a full breakdown of counties, cities, zip codes, and congressional districts in Illinois at risk.

\section{Greatest proportion of properties at risk*}

\begin{tabular}{lrl} 
Municipality & \multicolumn{2}{c}{2020} \\
\hline Stickney & 2,069 & $91 \%$ \\
\hline Burnham & 1,320 & $66 \%$ \\
\hline Beardstown & 1,627 & $60 \%$ \\
\hline Palos Hills & 2,522 & $54 \%$ \\
\hline Midlothian & 2,789 & $51 \%$ \\
\hline Tuscola & 1,111 & $51 \%$ \\
\hline Milan & 1,107 & $45 \%$ \\
\hline Calumet City & 6,562 & $45 \%$ \\
\hline Harvey & 6,357 & $44 \%$ \\
\hline Rock Falls & 1,809 & $44 \%$ \\
\hline
\end{tabular}

\section{Greatest number of properties at risk*}

\begin{tabular}{|c|c|c|c|c|c|c|}
\hline Municipality & 20 & & & 50 & & ange \\
\hline Chicago & 154,824 & $26 \%$ & 160,068 & $27 \%$ & $+5,244$ & $+3.4 \%$ \\
\hline Joliet & 7,438 & $15 \%$ & 7,499 & $15 \%$ & +61 & $+0.8 \%$ \\
\hline Calumet City & 6,562 & $45 \%$ & 6,647 & $46 \%$ & +85 & $+1.3 \%$ \\
\hline Harvey & 6,357 & $44 \%$ & 6,401 & $44 \%$ & +44 & $+0.7 \%$ \\
\hline Rockford & 5,742 & $10 \%$ & 5,953 & $11 \%$ & +211 & $+3.7 \%$ \\
\hline East St. Louis & 5,668 & $25 \%$ & 5,979 & $26 \%$ & +311 & $+5.5 \%$ \\
\hline Aurora & 4,775 & $10 \%$ & 4,897 & $10 \%$ & +122 & $+2.6 \%$ \\
\hline Cicero & 4,654 & $27 \%$ & 5,554 & $33 \%$ & +900 & $+19.3 \%$ \\
\hline Evanston & 4,507 & $28 \%$ & 4,593 & $28 \%$ & +86 & $+1.9 \%$ \\
\hline Naperville & 3,994 & $9 \%$ & 4,148 & $10 \%$ & +154 & $+3.9 \%$ \\
\hline
\end{tabular}

\section{Greatest relative growing risk*}

\begin{tabular}{lrrrrrr} 
Municipality & \multicolumn{2}{c}{2020} & \multicolumn{2}{c}{2050} & \multicolumn{2}{c}{ Change } \\
Morton Grove & 264 & $3 \%$ & 340 & $4 \%$ & +76 & $+29 \%$ \\
\hline Paxton & 26 & $1 \%$ & 33 & $2 \%$ & +7 & $+27 \%$ \\
\hline Franklin Park & 617 & $8 \%$ & 741 & $10 \%$ & +124 & $+20 \%$ \\
\hline Forest Park & 171 & $5 \%$ & 205 & $6 \%$ & +34 & $+20 \%$ \\
\hline Cicero & 4,654 & $27 \%$ & 5,554 & $33 \%$ & +900 & $+19 \%$ \\
\hline Dixmoor & 265 & $13 \%$ & 316 & $15 \%$ & +51 & $+19 \%$ \\
\hline Crestwood & 627 & $20 \%$ & 741 & $24 \%$ & +114 & $+18 \%$ \\
\hline Pana & 83 & $3 \%$ & 96 & $4 \%$ & +13 & $+16 \%$ \\
\hline Bridgeview & 199 & $4 \%$ & 228 & $5 \%$ & +29 & $+15 \%$ \\
\hline Maywood & 393 & $5 \%$ & 450 & $6 \%$ & +57 & $+15 \%$
\end{tabular}

\section{Flood Factor distribution of properties at risk ${ }^{\star}(1000 s)$}

\section{Risk leve}

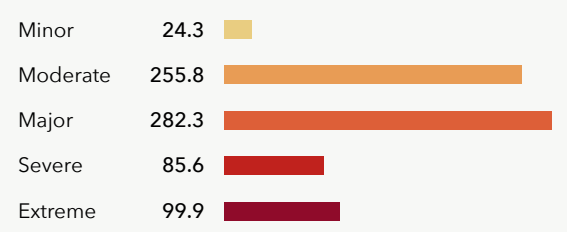

More than $14.5 \%$ of individual properties and properties in Illinois are at any risk of flooding over the next 30 years. Out of those at risk $63 \%$ are at major to extreme risk.

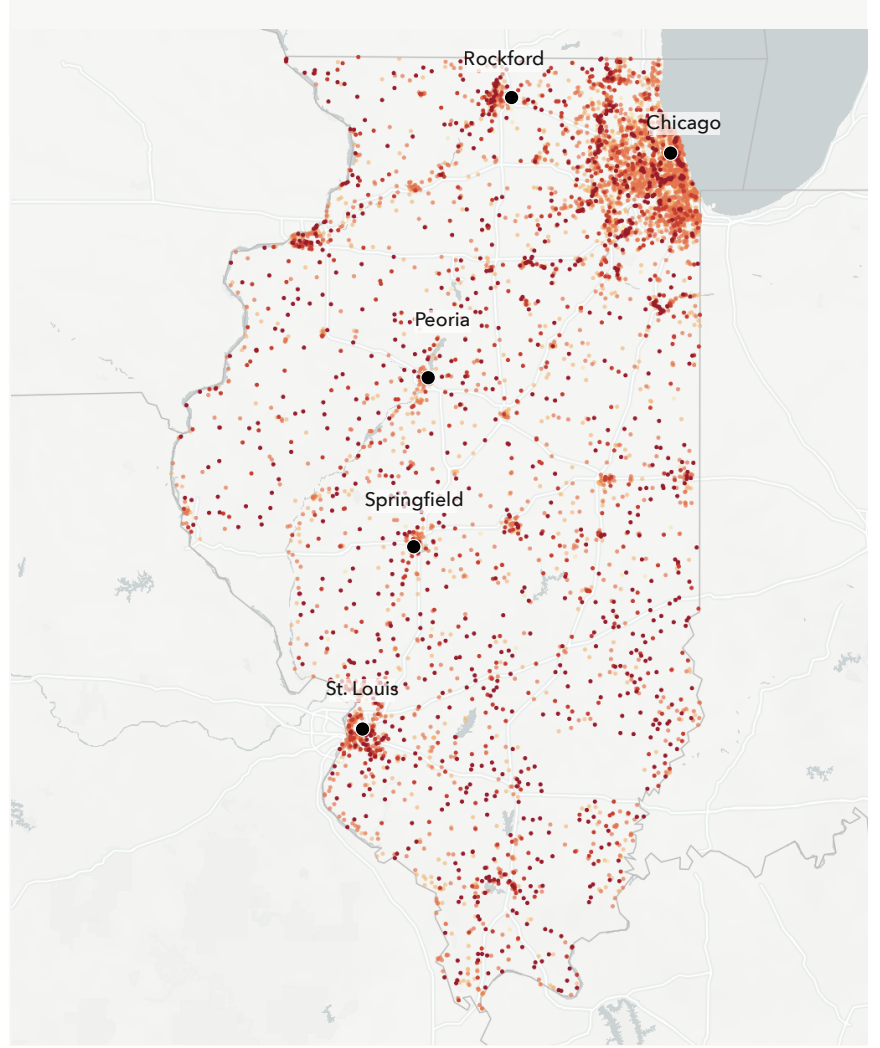




\section{Flood History \& Protection}

\section{Illinois}

\section{Claims History}

378,800 home and property owners in Illinois have made flood damage claims through FEMA since the year 2000.* These claims for reimbursement were made through either the National Flood Insurance Program (NFIP) or Individual Assistance Program (IAP). The greatest number of claims since the year 2000 have been concentrated in Cook, Will, DuPage, Lake, and Peoria counties.

\section{Storm Simulation}

The First Street Foundation Flood Model has recreated 4 flooding events that have occurred since the year 2000 in the state of 1 llinois. These events flooded around 3,770 properties across the state.**

\begin{tabular}{llr} 
Flood event & Date & $\begin{array}{r}\text { \# Properties } \\
\text { affected }\end{array}$ \\
River flood in Northern IL & Apr 2001 & 229 \\
\hline River flood across Western IL & Jun 2008 & 2,330 \\
\hline River flood near Peoria, IL & Apr 2013 & 1,133 \\
\hline River flood in Southwest IL & Dec 2015 & 81
\end{tabular}

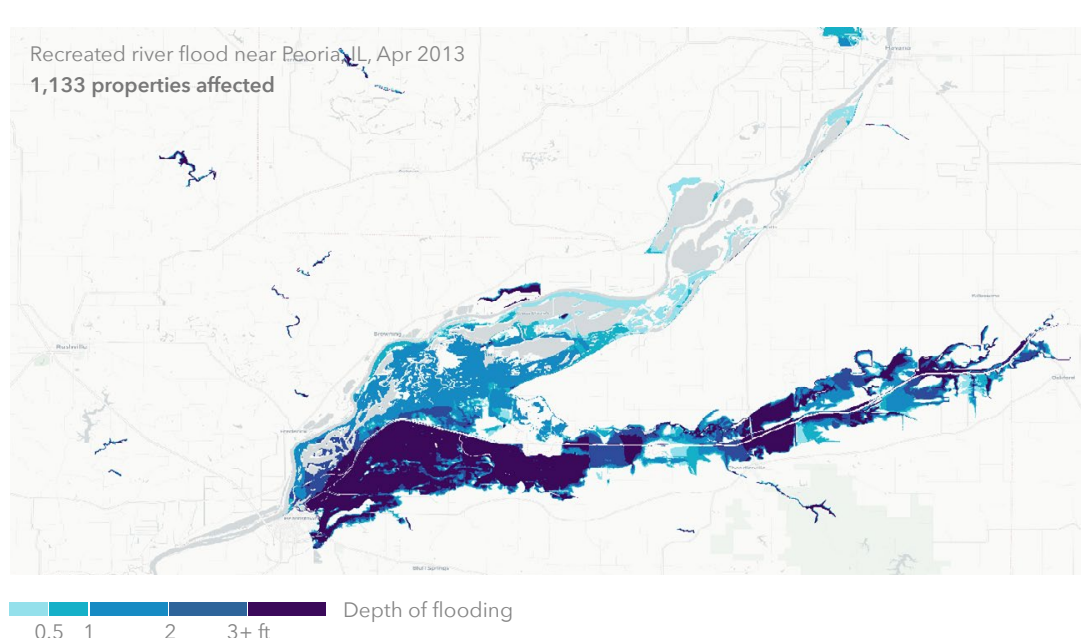

\section{$1.1 \mathrm{M}$}

Properties served by

protection measures

The First Street Foundation Flood

Model incorporates 538 flood control

measures throughout the state which

protect $1,110,600$ properties.

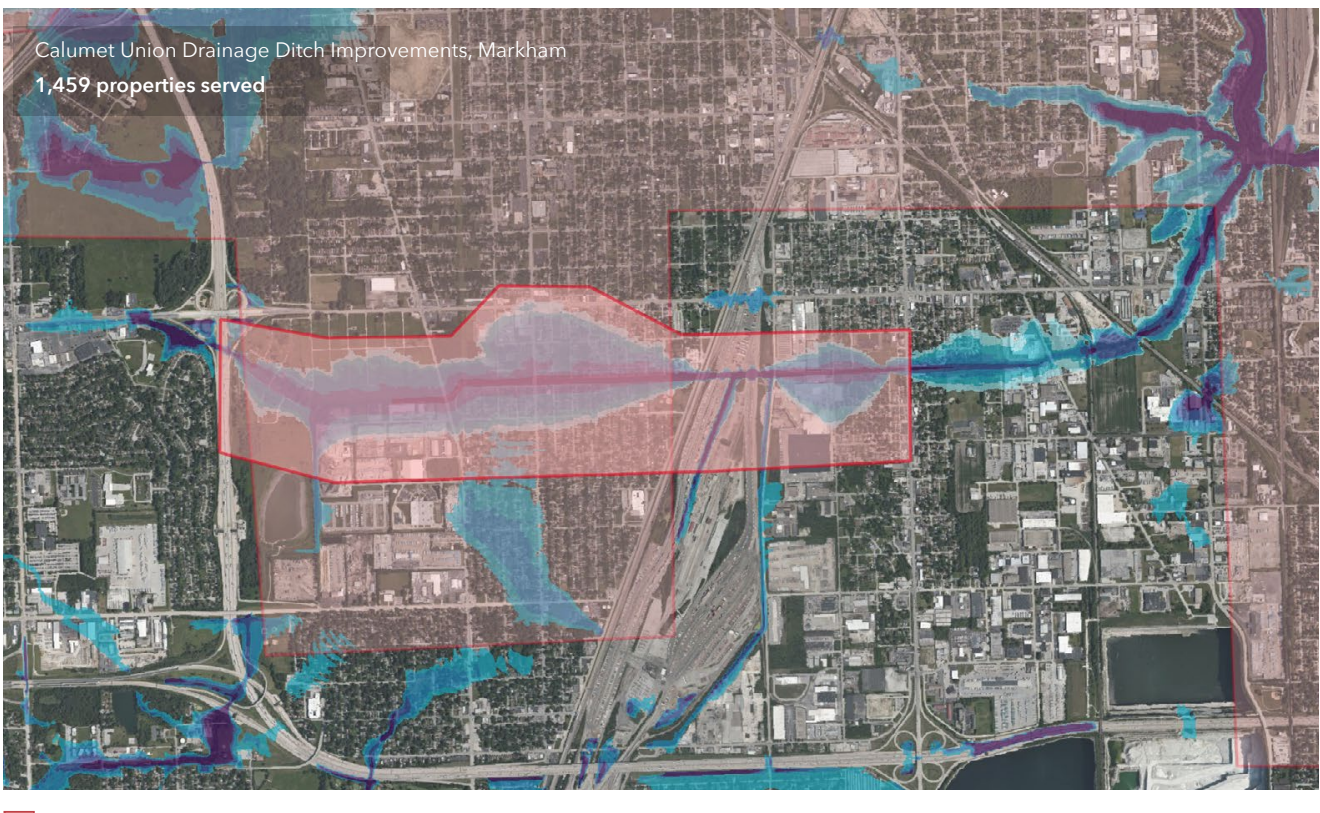

Type
Example

Stormwater vault

Tunnel and Reservoir Plan, Chicago

Levee

Reservoir, East St. Louis

Ditch

Metro East/Chain of Rocks, Markham

- Calumet Union Drainage Ditch Improvements, Markham
\# Properties served by type

966,204 45,711

$\begin{array}{lllll}0.5 & 1 & 2 & 3+\mathrm{ft} & \begin{array}{l}\text { Depth of flooding for a simulated } \\ 1 \text { in } 100 \text { flood event in } 2020\end{array}\end{array}$ 


\section{State Overview Indiana}

properties with substantial risk to 295,000 .

To understand personal flood risk, Americans leverage the Federal Emergency Management Agency (FEMA) Flood Insurance Rate Maps (FIRM). These maps identify 169,000 properties as having substantial risk in the state of Indiana. In comparison, the First Street Foundation Flood Model identifies 1.7 times the number of properties as facing this same level of risk. This discrepancy exists because the Foundation uses the current climate data, maps precipitation as a stand-alone risk, and includes areas that FEMA has not mapped. These new methods uncover an additional 113,600 properties currently not identified by FEMA as having substantial risk. When adjusting for future environmental changes, the FEMA gap further widens to 126,000 by the year 2050 .
Total properties at substantial risk *

\section{$\ln 2050$}

\section{$282,500 \quad 295,000$}

30-year change

$$
\Delta+12,500
$$

\section{Indianapolis, in the White River basin, sees flooding} from snowmelt, rainfall, flash floods, and intense storms. Wide, flat floodplains and heavy development within the basin exacerbate risk. Protection efforts include levees, floodwalls, and retention basins. Fort Wayne faces heavy rain and snowmelt that overrun the St. Joseph, St. Marys and Maumee rivers. Structural and non-structural flood protections seek to limit risks.

Difference in number of properties currently at substantial risk compared to FEMA**

\section{$\Delta+113,600$}

More properties at risk in FSF model $\longrightarrow$
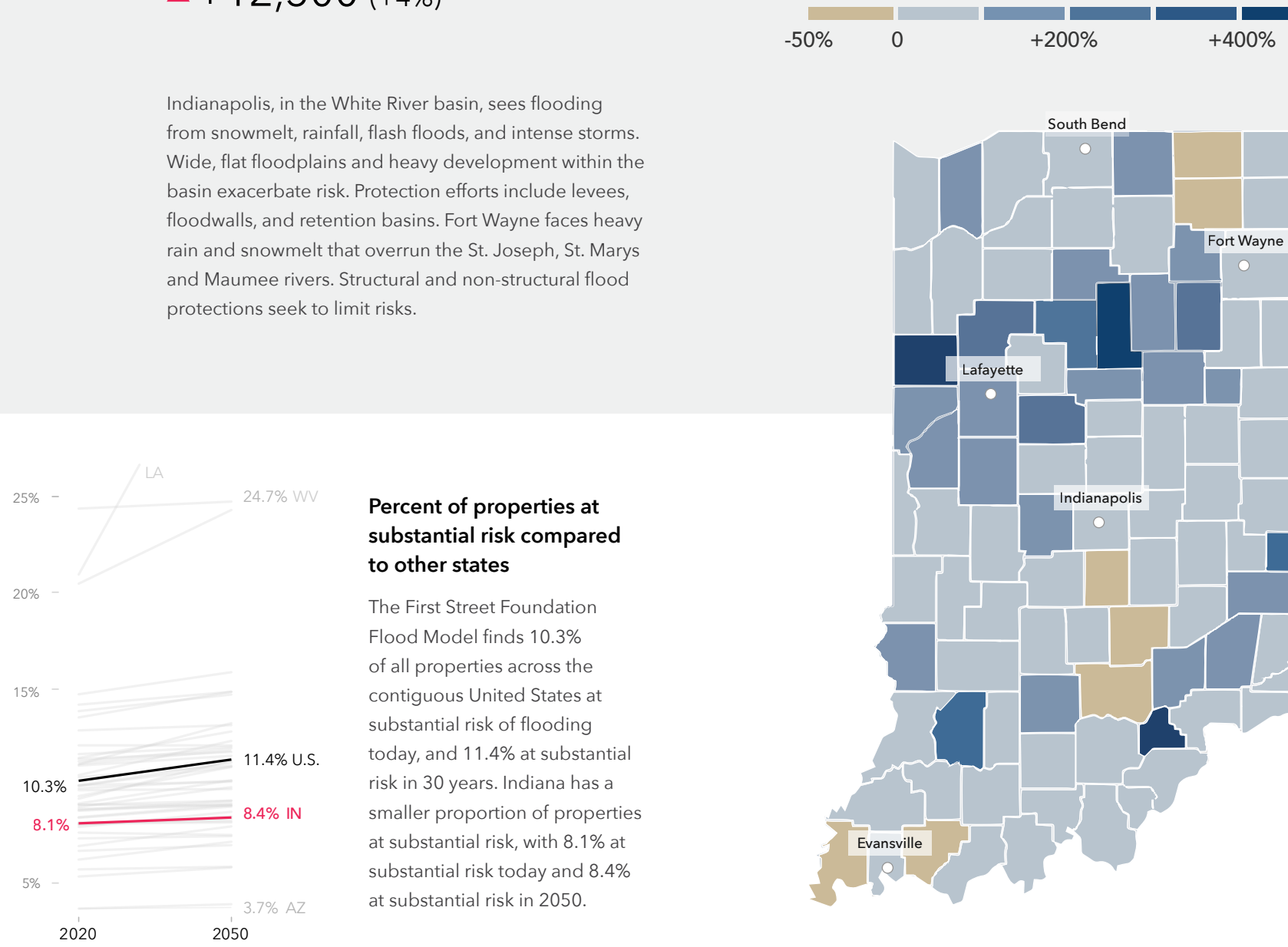

Pubstantial risk compared to other states

The First Street Foundation Flood Model finds $10.3 \%$ substantial risk of flooding substantial risk today and $8.4 \%$ 2050

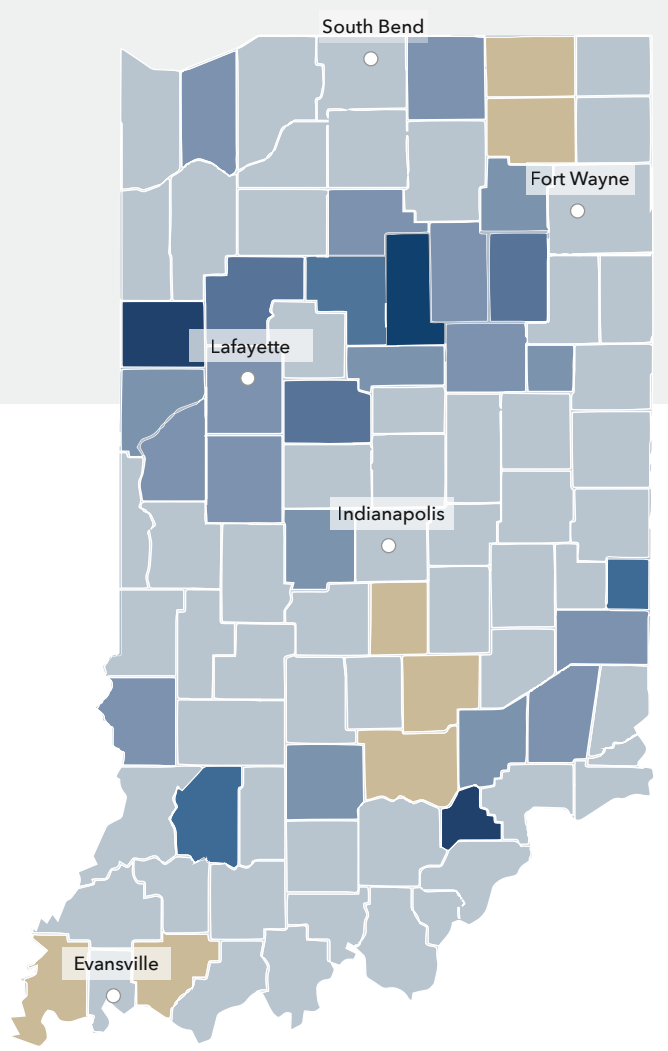




\section{Local details \\ Indiana}

The First Street Foundation Flood Model calculates the number of properties facing any risk* of flooding. When looking at this broader level of risk, the data identifies 440,800 properties in Indiana as at risk over the next 30 years. Of these properties, 73,100 were categorized as facing almost certain risk, with a $99 \%$ chance of flooding at least once over the next 30 years.

The city of Indianapolis has the greatest number of properties at risk of flooding in the state with 34,100 currently at risk, or $11 \%$ of its total number of properties. However, smaller cities or municipalities in the state, with fewer properties, may have a greater proportion of their total properties at risk. For example, $81 \%$ of properties in Peru are at risk of flooding. Other municipalities will see the greatest increase in risk over the next 30 years. Brownsburg, for example, will see a 15\% increase in the number of properties at risk.

Click here for a full breakdown of counties, cities, zip codes, and congressional districts in Indiana at risk.

\section{Greatest proportion of properties at risk*}

\begin{tabular}{lrr} 
Municipality & \multicolumn{2}{c}{2020} \\
\hline Peru & 4,859 & $81 \%$ \\
\hline Logansport & 4,505 & $51 \%$ \\
\hline East Chicago & 4,479 & $48 \%$ \\
\hline Aurora & 892 & $40 \%$ \\
\hline Dyer & 2,635 & $38 \%$ \\
\hline Munster & 3,581 & $37 \%$ \\
\hline Tipton & 1,140 & $36 \%$ \\
\hline Portland & 1,206 & $35 \%$ \\
\hline Hammond & 10,339 & $35 \%$ \\
\hline Highland & 3,240 & $32 \%$ \\
\hline
\end{tabular}

\section{Greatest number of properties at risk*}

\begin{tabular}{lcccccc} 
Municipality & \multicolumn{2}{c}{2020} & \multicolumn{2}{c}{2050} & \multicolumn{2}{c}{ Change } \\
Indianapolis & 34,124 & $11 \%$ & 34,808 & $11 \%$ & +684 & $+2.0 \%$ \\
\hline Fort Wayne & 11,210 & $11 \%$ & 11,413 & $12 \%$ & +203 & $+1.8 \%$ \\
\hline Hammond & 10,339 & $35 \%$ & 10,742 & $36 \%$ & +403 & $+3.9 \%$ \\
\hline Gary & 9,568 & $17 \%$ & 10,037 & $18 \%$ & +469 & $+4.9 \%$ \\
\hline South Bend & 7,654 & $16 \%$ & 7,847 & $17 \%$ & +193 & $+2.5 \%$ \\
\hline Terre Haute & 6,053 & $21 \%$ & 6,292 & $22 \%$ & +239 & $+3.9 \%$ \\
\hline Evansville & 5,868 & $12 \%$ & 6,389 & $13 \%$ & +521 & $+8.9 \%$ \\
\hline Peru & 4,859 & $81 \%$ & 4,864 & $81 \%$ & +5 & $+0.1 \%$ \\
\hline Mishawaka & 4,712 & $27 \%$ & 4,825 & $28 \%$ & +113 & $+2.4 \%$ \\
\hline Logansport & 4,505 & $51 \%$ & 4,526 & $52 \%$ & +21 & $+0.5 \%$
\end{tabular}

\section{Greatest relative growing risk $^{*}$}

\begin{tabular}{lcccccc} 
Municipality & \multicolumn{2}{c}{2020} & \multicolumn{2}{c}{2050} & \multicolumn{2}{c}{ Change } \\
Brownsburg & 432 & $4 \%$ & 496 & $5 \%$ & +64 & $+15 \%$ \\
\hline Nappanee & 195 & $7 \%$ & 223 & $8 \%$ & +28 & $+14 \%$ \\
\hline Lawrenceburg & 270 & $12 \%$ & 302 & $13 \%$ & +32 & $+12 \%$ \\
\hline Mount Vernon & 118 & $4 \%$ & 130 & $4 \%$ & +12 & $+10 \%$ \\
\hline Gas City & 134 & $5 \%$ & 147 & $5 \%$ & +13 & $+10 \%$ \\
\hline Hidden Valley & 129 & $4 \%$ & 141 & $4 \%$ & +12 & $+9 \%$ \\
\hline Vincennes & 1,996 & $23 \%$ & 2,181 & $25 \%$ & +185 & $+9 \%$ \\
\hline Evansville & 5,868 & $12 \%$ & 6,389 & $13 \%$ & +521 & $+9 \%$ \\
\hline Granger & 774 & $7 \%$ & 840 & $7 \%$ & +66 & $+9 \%$ \\
\hline Simonton Lake & 155 & $7 \%$ & 168 & $7 \%$ & +13 & $+8 \%$ \\
\hline
\end{tabular}

\section{Flood Factor distribution of properties at risk ${ }^{\star}(1000 s)$}

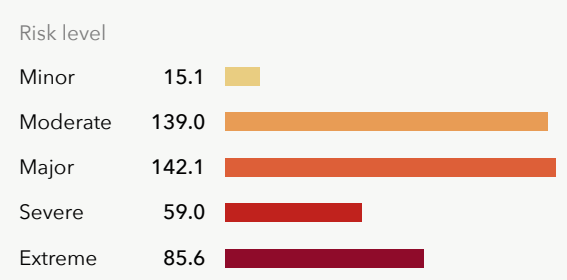

More than $12.6 \%$ of individual properties and properties in Indiana are at any risk of flooding over the next 30 years. Out of those at risk $65 \%$ are at major to extreme risk.

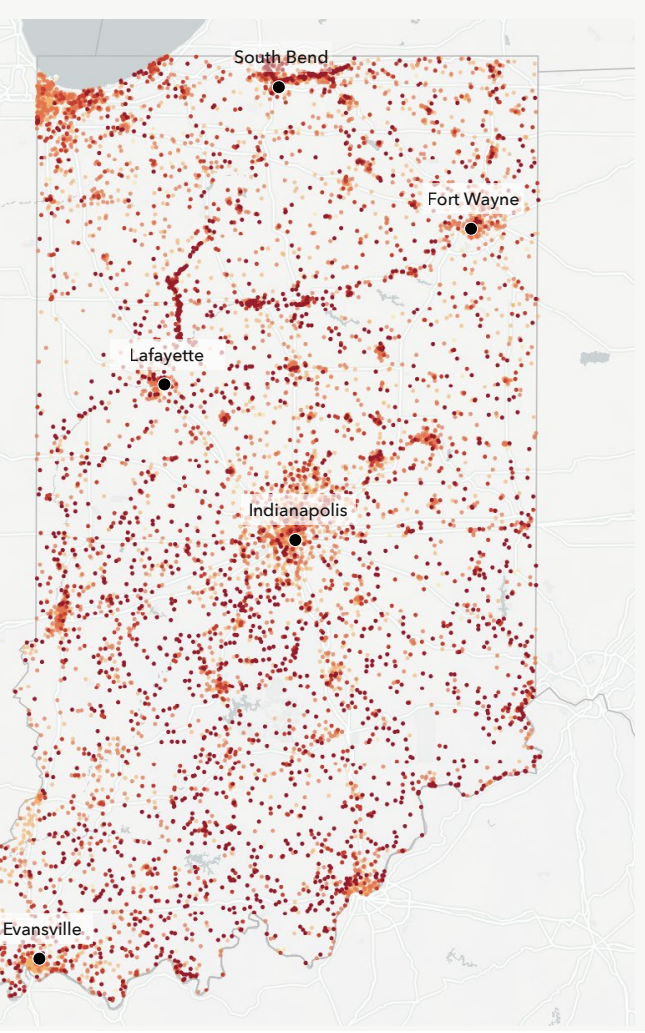




\section{Flood History \& Protection}

\section{Indiana}

\section{Claims History}

158,300 home and property owners in Indiana have made flood damage claims through FEMA since the year 2000.* These claims for reimbursement were made through either the National

Flood Insurance Program (NFIP) or Individual Assistance Program (IAP). The greatest number of

claims since the year 2000 have been concentrated in Lake, Delaware, Marion, Clark, and Porter

counties.

\section{Storm Simulation}

The First Street Foundation Flood Model has recreated 1 flooding event that occurred since the year 2000 in the state of Indiana. This event flooded around 1,700 properties across the state. $* \star$

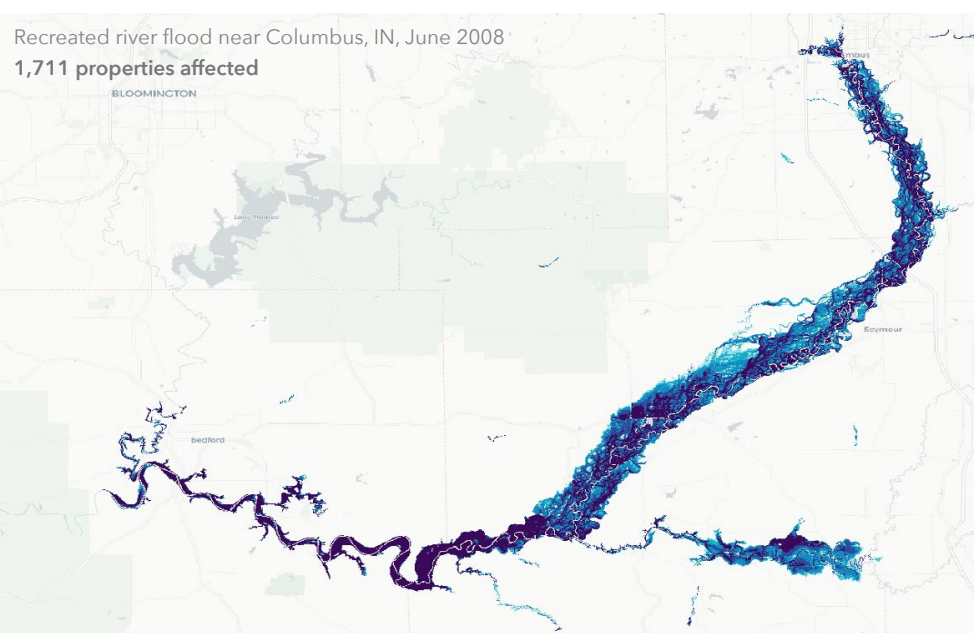

$0.5+1-2=3+f t=0$ Depth of flooding

\section{4,900}

Properties served by

protection measures

The First Street Foundation Flood

Model incorporates 128 flood control

measures throughout the state which

protect 104,900 properties

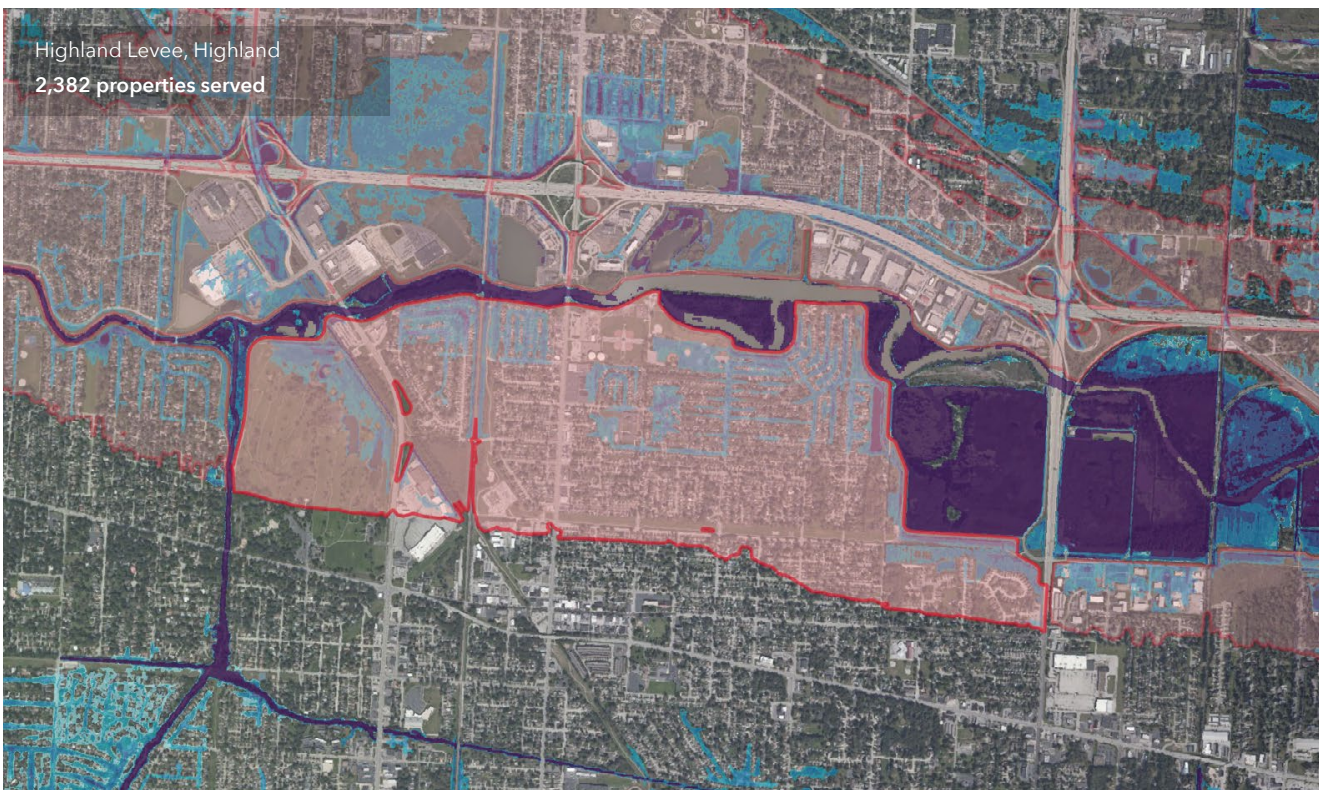

Area of protectio

Top protection measures in state by quantity

Type
Example

Levee

Highland Levee, Highland

Earthen berm

62

Acquition Fitigation - Acquisition, Fort Wayne

Dam

Eagle Creek Dam, Indianapolis

Detention basin 


\section{State Overview \\ lowa}

Flood risk is increasing in some areas in the state of lowa while decreasing in others. Over the next 30 years approximately 294,000 properties have a substantial risk* of flooding.

\section{To understand personal flood risk, Americans} leverage the Federal Emergency Management Agency (FEMA) Flood Insurance Rate Maps (FIRM) These maps identify 152,700 properties as having substantial risk in the state of lowa. In comparison, the First Street Foundation Flood Model identifies 1.9 times the number of properties as facing this same level of risk. This discrepancy exists because the Foundation uses the current climate data, maps precipitation as a stand-alone risk, and includes areas that FEMA has not mapped. These new methods uncover an additional 141,300 properties currently not identified by FEMA as having substantial risk.
Total properties at substantial risk *

\section{$\ln 2050$}

\section{$\mathbf{2 9 4 , 0 0 0 \quad 2 9 4 , 0 0 0}$}

lowa is among the most impacted states from inland flooding. Several large rivers, including the Racoon, Des Moines, and Mississippi rivers regularly overflow, causing heavy floods in cities across the state. Many cities in lowa have pioneered flood adaptation methods, which reduce the frequency and severity of flooding.

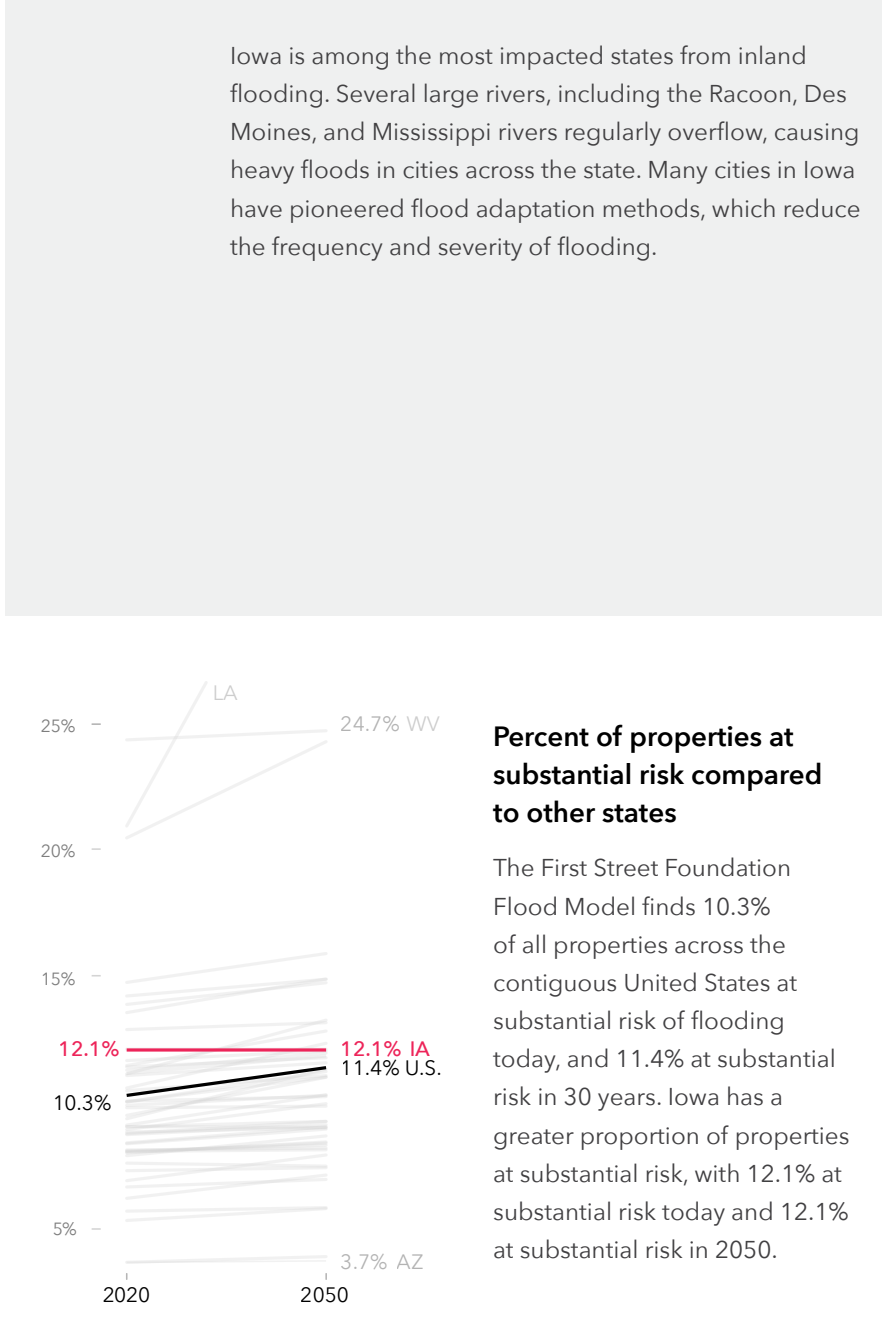

Difference in number of properties currently at substantial risk compared to FEMA**

\section{$\Delta+141,300$}

More properties at risk in FSF model $\longrightarrow$
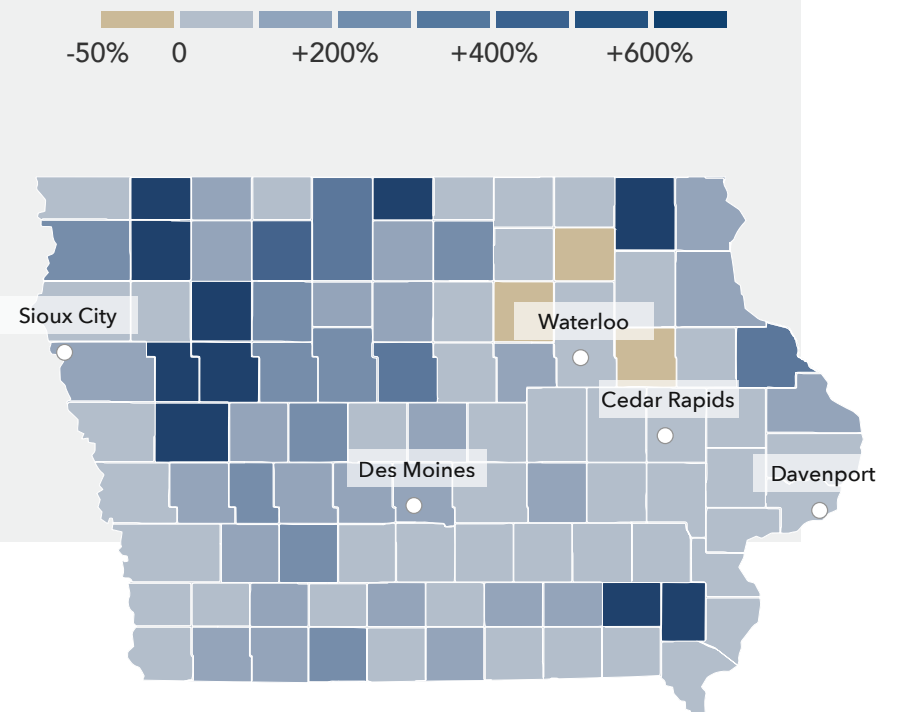


\section{Local details \\ lowa}

The First Street Foundation Flood Model calculates the number of properties facing any risk* of flooding. When looking at this broader level of risk, the data identifies 391,100 properties in lowa as at risk over the next 30 years. Of these properties, 101,000 were categorized as facing almost certain risk, with a $99 \%$ chance of flooding at least once over the next 30 years.

The city of Council Bluffs has the greatest number of properties at risk of flooding in the state with 11,000 currently at risk, or $37 \%$ of its total number of properties. However, smaller cities or municipalities in the state, with fewer properties, may have a greater proportion of their total properties at risk. For example, $62 \%$ of properties in Evansdale are at risk of flooding. Other municipalities will see the greatest increase in risk over the next 30 years. Shenandoah, for example, will see a $5 \%$ increase in the number of properties at risk.

Click here for a full breakdown of counties, cities, zip codes,

neighborhoods, and congressional districts in lowa at risk.

Click here for a full breakdown of counties, cities, zip codes, and congressional districts in lowa at risk.

\section{Greatest proportion of properties at risk*}

\begin{tabular}{lrr|} 
Municipality & \multicolumn{2}{c}{2020} \\
Evansdale & 1,550 & $62 \%$ \\
\hline Clinton & 4,918 & $39 \%$ \\
\hline Decorah & 1,267 & $37 \%$ \\
\hline Council Bluffs & 10,989 & $37 \%$ \\
\hline Red Oak & 1,006 & $31 \%$ \\
\hline Camanche & 675 & $31 \%$ \\
\hline Waterloo & 9,245 & $30 \%$ \\
\hline Waverly & 1,183 & $28 \%$ \\
\hline Humboldt & 808 & $24 \%$ \\
\hline Ottumwa & 3,876 & $24 \%$ \\
\hline
\end{tabular}

\section{Greatest number of properties at risk*}

\begin{tabular}{lc|ccccc} 
Municipality & \multicolumn{2}{c}{2020} & \multicolumn{2}{c}{2050} & \multicolumn{2}{c}{ Change } \\
Council Bluffs & 10,989 & $13 \%$ & 11,020 & $37 \%$ & +31 & $+0.3 \%$ \\
\hline Des Moines & 9,328 & $6 \%$ & 9,236 & $11 \%$ & -92 & $-1.0 \%$ \\
\hline Waterloo & 9,245 & $7 \%$ & 9,295 & $30 \%$ & +50 & $+0.5 \%$ \\
\hline Sioux City & 6,108 & $10 \%$ & 6,025 & $19 \%$ & -83 & $-1.4 \%$ \\
\hline Cedar Rapids & 5,899 & $12 \%$ & 5,969 & $13 \%$ & +70 & $+1.2 \%$ \\
\hline Dubuque & 5,012 & $52 \%$ & 5,047 & $22 \%$ & +35 & $+0.7 \%$ \\
\hline Clinton & 4,918 & $7 \%$ & 4,937 & $39 \%$ & +19 & $+0.4 \%$ \\
\hline Davenport & 4,327 & $13 \%$ & 4,322 & $11 \%$ & -5 & $-0.1 \%$ \\
\hline Ottumwa & 3,876 & $30 \%$ & 3,904 & $24 \%$ & +28 & $+0.7 \%$ \\
\hline Mason City & 2,343 & $51 \%$ & 2,343 & $17 \%$ & +0 & $+0.0 \%$
\end{tabular}

\section{Greatest relative growing risk*}

\begin{tabular}{lccccc|c|c|} 
Municipality & \multicolumn{2}{c}{2020} & \multicolumn{2}{c}{2050} & \multicolumn{2}{c}{ Change } \\
\hline Shenandoah & 403 & $15 \%$ & 422 & $15 \%$ & +19 & $+5 \%$ \\
\hline Washington & 163 & $5 \%$ & 170 & $5 \%$ & +7 & $+4 \%$ \\
\hline Manchester & 643 & $23 \%$ & 669 & $24 \%$ & +26 & $+4 \%$ \\
\hline Fort Madison & 768 & $14 \%$ & 794 & $15 \%$ & +26 & $+3 \%$ \\
\hline Dyersville & 469 & $20 \%$ & 482 & $20 \%$ & +13 & $+3 \%$ \\
\hline Oelwein & 301 & $9 \%$ & 308 & $9 \%$ & +7 & $+2 \%$ \\
\hline Camanche & 675 & $31 \%$ & 689 & $32 \%$ & +14 & $+2 \%$ \\
\hline Evansdale & 1,550 & $62 \%$ & 1,581 & $63 \%$ & +31 & $+2 \%$ \\
\hline Muscatine & 1,856 & $20 \%$ & 1,887 & $20 \%$ & +31 & $+2 \%$ \\
\hline North Liberty & 205 & $4 \%$ & 208 & $4 \%$ & +3 & $+2 \%$
\end{tabular}

\section{Flood Factor distribution of properties at risk ${ }^{\star}(1000 s)$}

\section{Risk leve}

Mino

Major

93.1

Severe

Extreme

More than $16.1 \%$ of individual properties and properties in lowa are at any risk of flooding over the next 30 years. Out of those at risk $75 \%$ are at major to extreme risk.

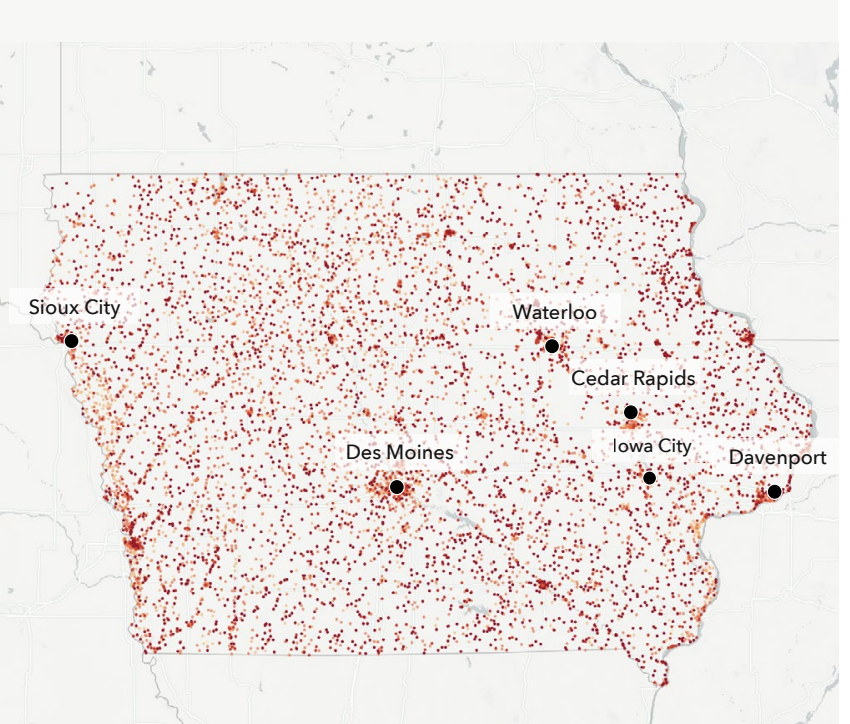




\section{Flood History \& Protection lowa}

\section{Claims History}

120,300 home and property owners in lowa have made flood damage claims through FEMA since the year 2000.* These claims for reimbursement were made through either the National Flood Insurance Program (NFIP) or Individual Assistance Program (IAP). The greatest number of claims since the year 2000 have been concentrated in Linn, Polk, Black Hawk, Johnson, and Benton counties.

\section{Storm Simulation}

The First Street Foundation Flood Model has recreated 5 flooding events that have occurred since the year 2000 in the state of lowa. These events flooded around 26,210 properties across the state.**

\begin{tabular}{llr} 
Flood event & Date & $\begin{array}{r}\text { \# Properties } \\
\text { affected }\end{array}$ \\
River flood near Camanche, IA & Apr 2001 & 1,024 \\
\hline River flood in Northeast IA & Apr 2001 Jun & 89 \\
\hline River flood across eastern lowa & 2008 & 13,483 \\
\hline River flood near Des Moines, IA & Jun 2008 & 6,577 \\
\hline River flood near Ames, IA & Jul 2008 & 5,036
\end{tabular}
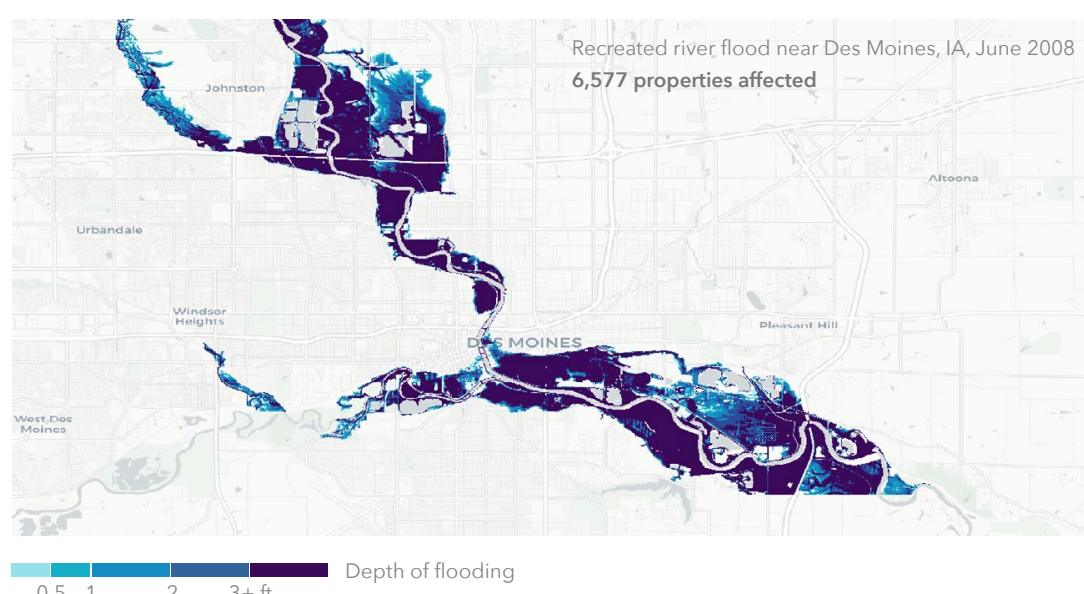

\section{3,200}

Properties served by

protection measures

The First Street Foundation Flood

Model incorporates 184 flood control

measures throughout the state which

protect 53,200 properties.

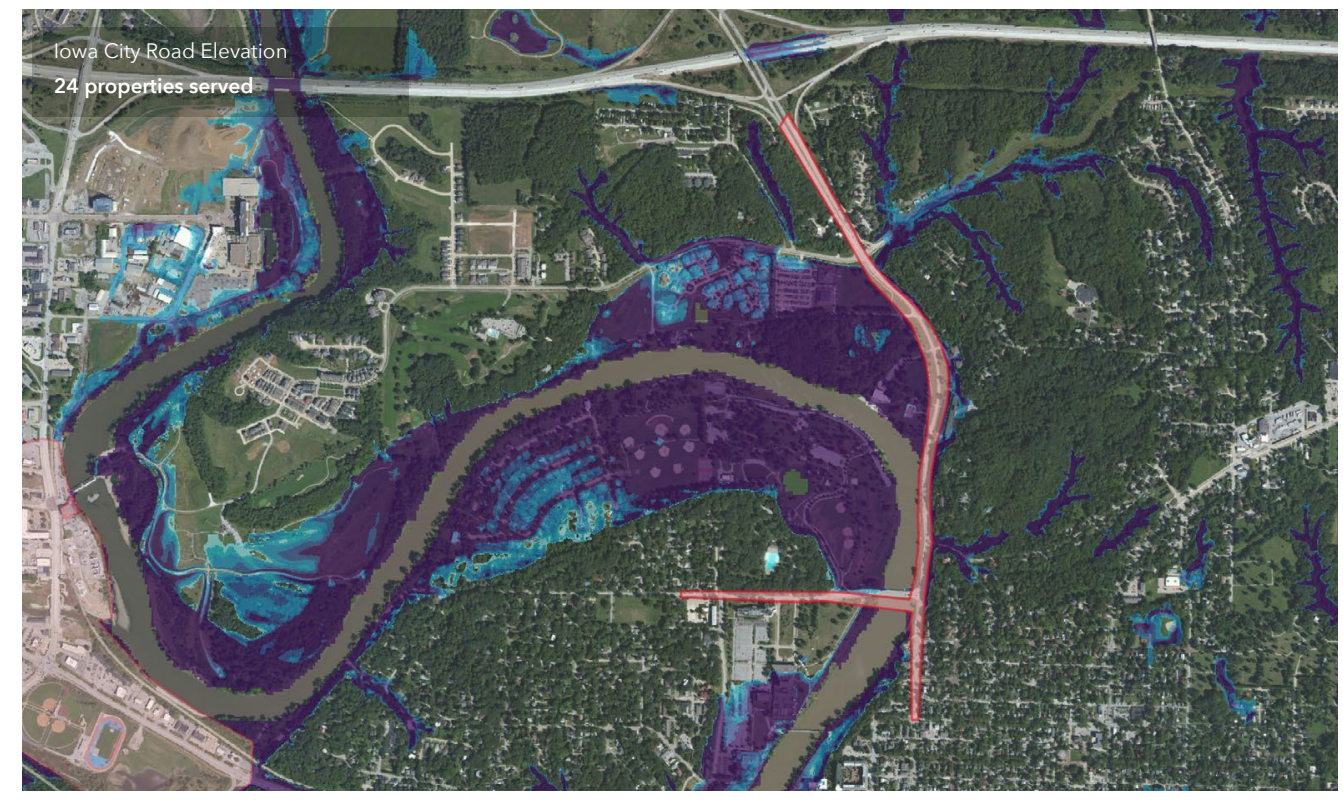

$\square$ Area of protectio
Top protection measures in state by quantity

\begin{tabular}{lr}
$\begin{array}{l}\text { Type } \\
\text { Example }\end{array}$ & \# Properties served by type \\
Levee & \\
L-627 MO River LB \& Indian Creek RB, Council Bluffs & \\
\hline $\begin{array}{l}\text { Culvert } \\
\text { Hamilton Drain Flood Control System, Des Moines }\end{array}$ & 4,968 \\
\hline $\begin{array}{l}\text { Detention basin } \\
\text { Bee Branch Creek Restoration, Dubuque }\end{array}$ & 279 \\
\hline $\begin{array}{l}\text { Elevated road } \\
\text { - lowa City Road Elevation, lowa City }\end{array}$ & 24 \\
$\begin{array}{l}\text { Pervious pavement } \\
\text { Dubuque washington st, Dubuque }\end{array}$ & 8
\end{tabular}

48,968 


\section{State Overview \\ Kansas}

Flood risk is increasing in the state of Kansas. 133,400 properties currently have a substantial risk* of flooding. Over the next 30 years, the number of properties with this risk will increase by another $0.9 \%$, bringing the total number of properties with substantial risk to 134,600

To understand personal flood risk, Americans leverage the Federal Emergency Management Agency (FEMA) Flood Insurance Rate Maps (FIRM). These maps identify 79,500 properties as having substantial risk in the state of Kansas. In comparison, the First Street Foundation Flood Model identifies 1.7 times the number of properties as facing this same level of risk. This discrepancy exists because the Foundation uses the current climate data, maps precipitation as a stand-alone risk, and includes areas that FEMA has not mapped. These new methods uncover an additional 54,000 properties currently not identified by FEMA as having substantial risk. When adjusting for future environmental changes, the FEMA gap further widens to 55,200 by the year 2050

\section{Total properties at substantial risk}

In 2020

\section{3,400}

30-year change

$$
\Delta+1,200(+1 \%)
$$

Difference in number of properties currently at substantial risk compared to FEMA**

\section{$\Delta+53,986$}

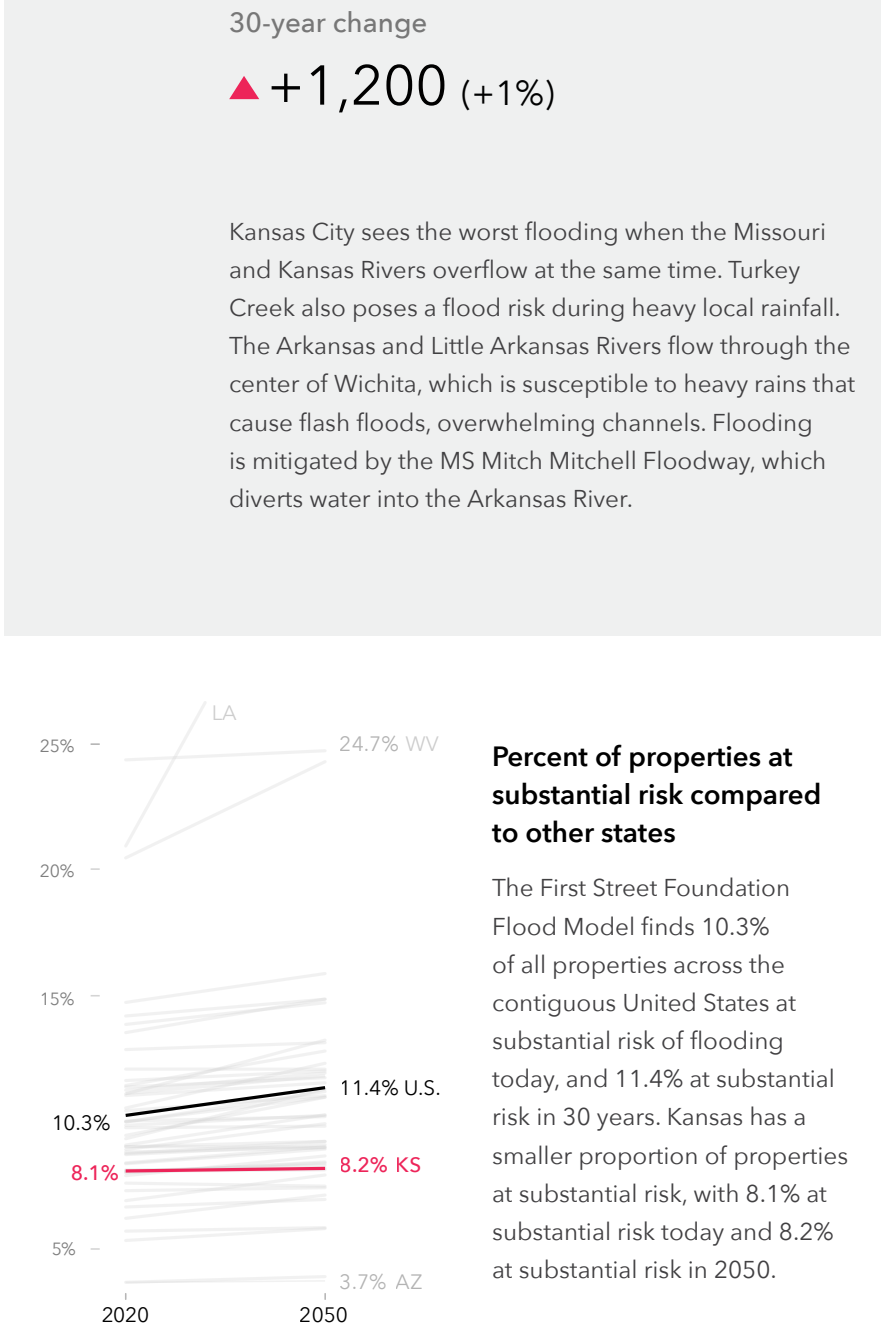

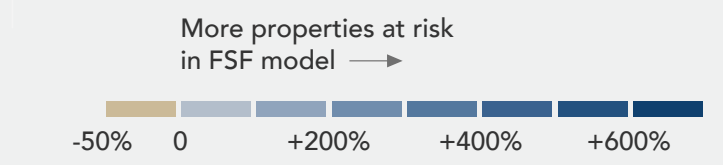

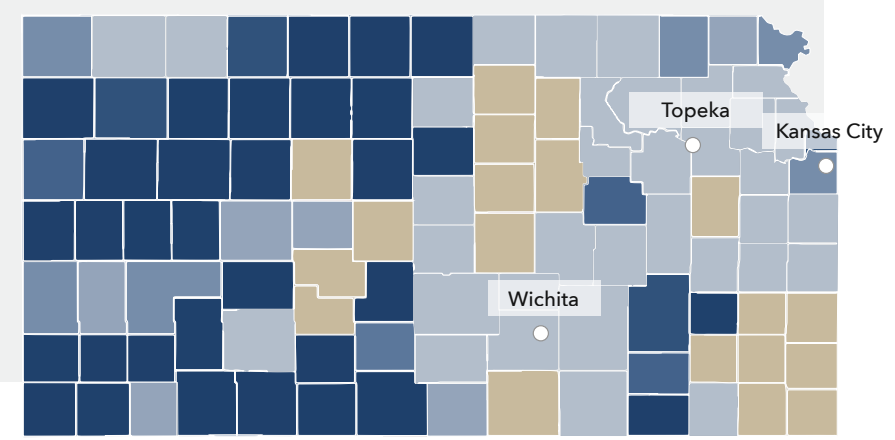




\section{Local details \\ Kansas}

The First Street Foundation Flood Model calculates the number of properties facing any risk* of flooding. When looking at this broader level of risk, the data identifies 198,000 properties in Kansas as at risk over the next 30 years. Of these properties, 29,900 were categorized as facing almost certain risk, with a $99 \%$ chance of flooding at least once over the next 30 years.

The city of Wichita has the greatest number of properties at risk of flooding in the state with 16,000 currently at risk, or $10 \%$ of its total number of properties. However, smaller cities or municipalities in the state, with fewer properties, may have a greater proportion of their total properties at risk. For example, $34 \%$ of properties in Haysville are at risk of flooding. Other municipalities will see the greatest increase in risk over the next 30 years. Valley Center, for example, will see a 9\% increase in the number of properties at risk.

Click here for a full breakdown of counties, cities, zip codes, and congressional districts in Kansas at risk.

\section{Greatest proportion of properties at risk*}

\begin{tabular}{lrr|} 
Municipality & \multicolumn{2}{c}{2020} \\
\hline Haysville & 1,494 & $34 \%$ \\
\hline Valley Center & 1,085 & $33 \%$ \\
\hline Hutchinson & 5,472 & $30 \%$ \\
\hline Liberal & 1,715 & $24 \%$ \\
\hline Abilene & 729 & $23 \%$ \\
\hline Maize & 506 & $20 \%$ \\
\hline lola & 623 & $18 \%$ \\
\hline Merriam & 878 & $18 \%$ \\
\hline Topeka & 7,628 & $15 \%$ \\
\hline Manhattan & 2,273 & $15 \%$ \\
\hline
\end{tabular}

\section{Greatest number of properties at risk*}

\begin{tabular}{l|c|ccccc} 
Municipality & \multicolumn{2}{c}{2020} & \multicolumn{2}{c}{2050} & \multicolumn{2}{c}{ Change } \\
Wichita & 16,034 & $10 \%$ & 16,528 & $10 \%$ & +494 & $+3.1 \%$ \\
\hline Topeka & 7,628 & $15 \%$ & 7,759 & $16 \%$ & +131 & $+1.7 \%$ \\
\hline Kansas City & 6,627 & $10 \%$ & 6,669 & $11 \%$ & +42 & $+0.6 \%$ \\
\hline Overland Park & 6,135 & $9 \%$ & 6,227 & $9 \%$ & +92 & $+1.5 \%$ \\
\hline Hutchinson & 5,472 & $30 \%$ & 5,594 & $31 \%$ & +122 & $+2.2 \%$ \\
\hline Olathe & 4,127 & $8 \%$ & 4,181 & $8 \%$ & +54 & $+1.3 \%$ \\
\hline Manhattan & 2,273 & $15 \%$ & 2,279 & $15 \%$ & +6 & $+0.3 \%$ \\
\hline Shawnee & 1,999 & $7 \%$ & 2,007 & $7 \%$ & +8 & $+0.4 \%$ \\
\hline Lawrence & 1,793 & $7 \%$ & 1,873 & $7 \%$ & +80 & $+4.5 \%$ \\
\hline Liberal & 1,715 & $24 \%$ & 1,720 & $24 \%$ & +5 & $+0.3 \%$
\end{tabular}

\section{Greatest relative growing risk*}

\begin{tabular}{lccccc|c|} 
Municipality & \multicolumn{2}{c}{2020} & \multicolumn{2}{c}{2050} & \multicolumn{2}{c}{ Change } \\
Valley Center & 1,085 & $33 \%$ & 1,185 & $36 \%$ & +100 & $+9 \%$ \\
\hline Roeland Park & 214 & $7 \%$ & 227 & $7 \%$ & +13 & $+6 \%$ \\
\hline El Dorado & 483 & $8 \%$ & 507 & $9 \%$ & +24 & $+5 \%$ \\
\hline Gardner & 483 & $6 \%$ & 505 & $7 \%$ & +22 & $+5 \%$ \\
\hline Lawrence & 1,793 & $7 \%$ & 1,873 & $7 \%$ & +80 & $+5 \%$ \\
\hline Emporia & 548 & $6 \%$ & 572 & $7 \%$ & +24 & $+4 \%$ \\
\hline Pratt & 277 & $8 \%$ & 288 & $9 \%$ & +11 & $+4 \%$ \\
\hline Bel Aire & 79 & $2 \%$ & 82 & $2 \%$ & +3 & $+4 \%$ \\
\hline Eudora & 108 & $4 \%$ & 112 & $5 \%$ & +4 & $+4 \%$ \\
\hline Winfield & 425 & $9 \%$ & 440 & $9 \%$ & +15 & $+4 \%$ \\
\hline
\end{tabular}

\section{Flood Factor distribution of properties at risk ${ }^{\star}(1000 s)$}

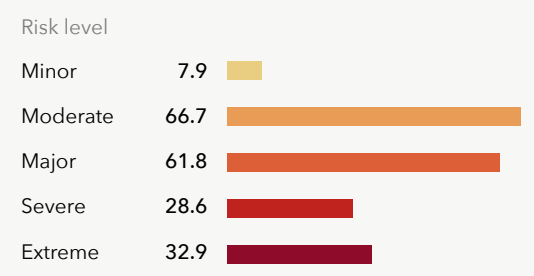

More than $12.1 \%$ of individual properties and properties in Kansas are at any risk of flooding over the next 30 years. Out of those at risk $62 \%$ are at major to extreme risk. 


\section{Flood History \& Protection}

\section{Kansas}

\section{Claims History}

21,900 home and property owners in Kansas have made flood damage claims through FEMA since the year 2000.* These claims for reimbursement were made through either the National Flood Insurance Program (NFIP) or Individual Assistance Program (IAP). The greatest number of claims since the year 2000 have been concentrated in Montgomery, Shawnee, Labette, Edwards, and Kiowa counties.

\section{Storm Simulation}

The First Street Foundation Flood Model has recreated 2 flooding events that have occurred since the year 2000 in the state of Kansas. These events flooded around 1,380 properties across the state **

\begin{tabular}{llr} 
Flood event & Date & $\begin{array}{r}\text { \# Properties } \\
\text { affected }\end{array}$ \\
- River flood accross Southern Kansas & Jul 2007 & 1,159 \\
\hline River flood across Northern Kansas & Mar 2019 & 221
\end{tabular}

emenecreated river flood accross.southern Kansas, July 2007

1,159 properties affected
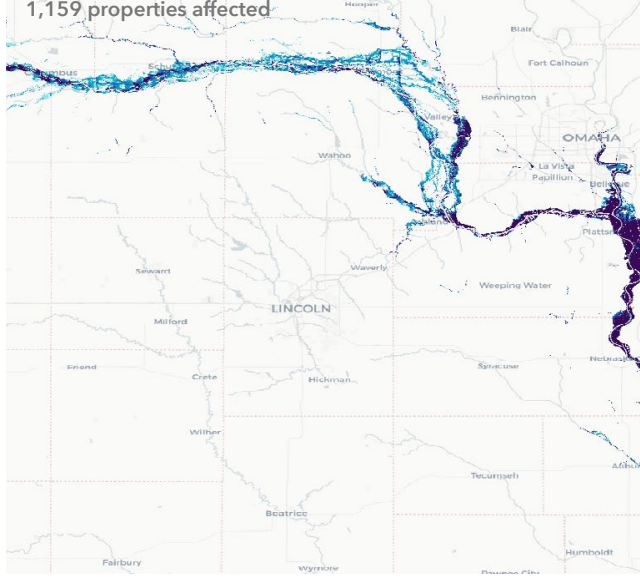

\section{8,600}

Properties served by

protection measures

The First Street Foundation Flood

Model incorporates 395 flood control

measures throughout the state which

protect 178,600 properties

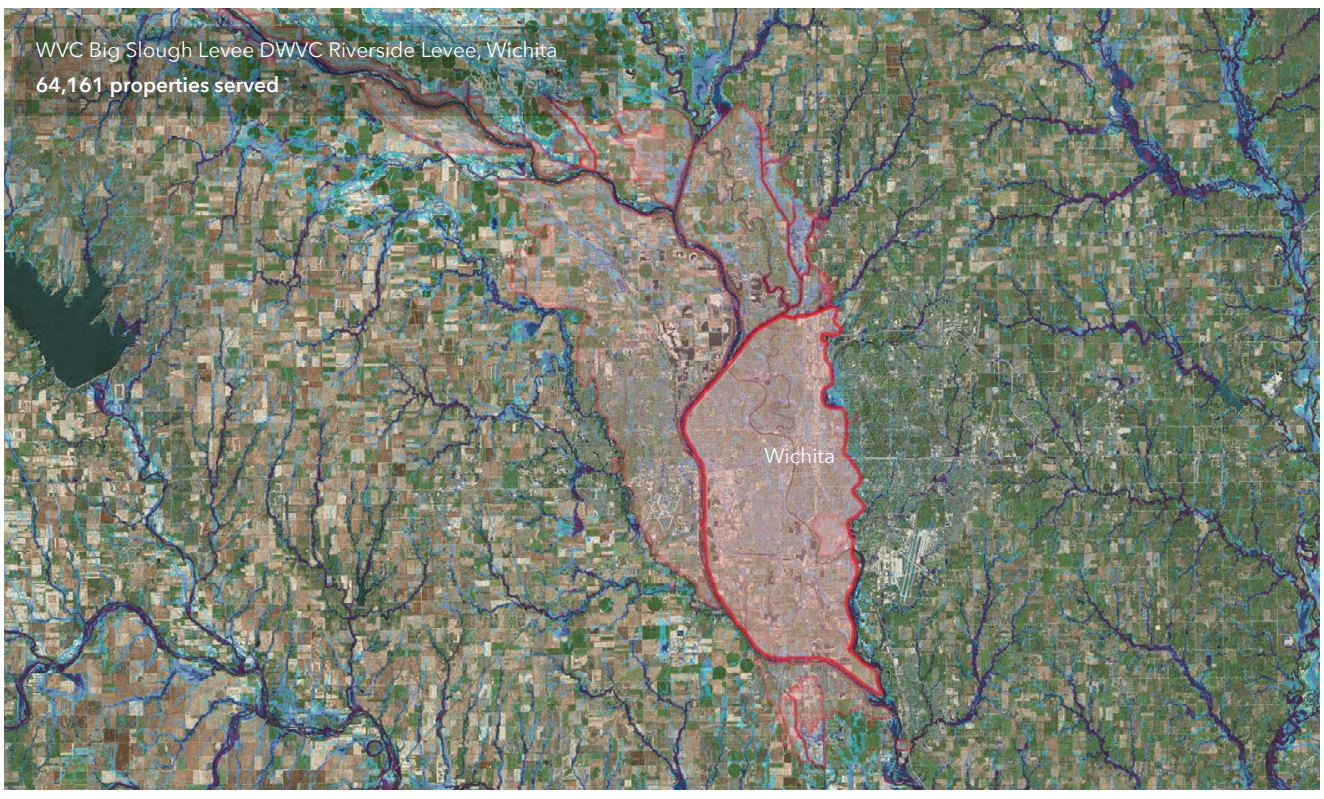

Area of protectio

2.5 1 Depth of flooding for a simulated
Top protection measures in state by quantity

Type
Example

\# Properties served by type

Levee 173,343

-WVC Big Slough Levee D/WVC Riverside Levee P, R, S. Wichita

$$
\text { Dam }
$$

Channe 


\section{State Overview \\ Kentucky}

Flood risk is increasing in the state of Kentucky. 227,000 properties currently have a substantial risk* of flooding. Over the next 30 years, the number of properties with this risk will increase by another $3.2 \%$, bringing the total number of properties with substantial risk to 234,300 .

To understand personal flood risk, Americans leverage the Federal Emergency Management Agency (FEMA) Flood Insurance Rate Maps (FIRM). These maps identify 96,800 properties as having substantial risk in the state of Kentucky. In comparison, the First Street Foundation Flood Model identifies 2.3 times the number of properties as facing this same level of risk. This discrepancy exists because the Foundation uses the current climate data, maps precipitation as a stand-alone risk, and includes areas that FEMA has not mapped. These new methods uncover an additional 130,200 properties currently not identified by FEMA as having substantial risk. When adjusting for future environmental changes, the FEMA gap further widens to 137,500 by the year 2050 .
Total properties at substantial risk *

$\ln 2020$

\section{7,000}

30-year change

$\Delta+7,300(+3 \%)$

Streams from Beargrass Creek flow through Jefferson County and eastern Louisville to the Ohio River causing overflows during rainstorms. Areas of Louisville at lower elevation and with poor drainage are especially at risk. Flood risk in Bowling Green and greater Warren County is highest in sinkhole depression areas when the Barren River and Drakes Creek flood. New development exacerbates floods as rain runoff flows easily over concrete.

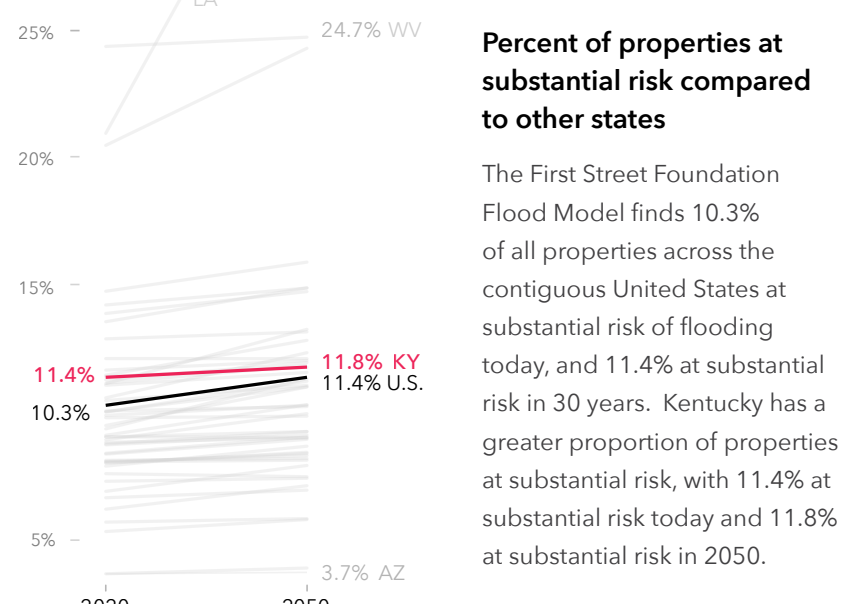

2050
Difference in number of properties currently at substantial risk compared to FEMA**

$$
\Delta+130,200
$$

More properties at risk in FSF model $\longrightarrow$

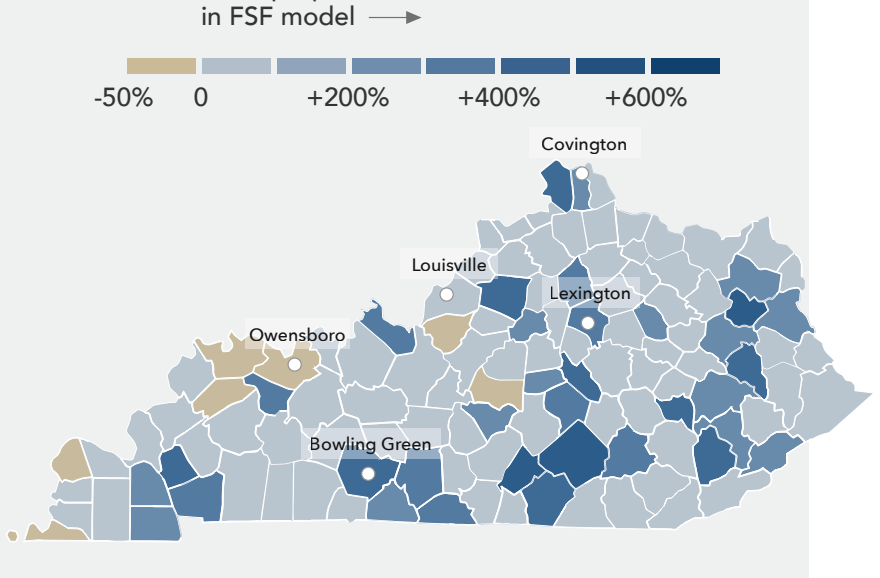




\section{Local details \\ Kentucky}

The First Street Foundation Flood Model calculates the number of properties facing any risk* of flooding. When looking at this broader level of risk, the data identifies 290,300 properties in Kentucky as at risk over the next 30 years. Of these properties, 94,700 were categorized as facing almost certain risk, with a $99 \%$ chance of flooding at least once over the next 30 years.

The Louisville/Jefferson County metro area has the greatest number of properties at risk of flooding in the state with 15,500 currently at risk, or $11 \%$ of its total number of properties. However, smaller cities or municipalities in the state, with fewer properties, may have a greater proportion of their total properties at risk. For example, 32\% of properties in Hazard are at risk of flooding. Other municipalities will see the greatest increase in risk over the next 30 years. Farley, for example, will see a $261 \%$ increase in the number of properties at risk.

Click here for a full breakdown of counties, cities, zip codes, and congressional districts in Kentucky at risk.

\section{Greatest proportion of properties at risk*}

\begin{tabular}{lrr} 
Municipality & \multicolumn{2}{c}{2020} \\
\hline Hazard & 746 & $32 \%$ \\
\hline Morehead & 625 & $30 \%$ \\
\hline Ashland & 2,718 & $25 \%$ \\
\hline Corbin & 801 & $25 \%$ \\
\hline Westwood & 562 & $24 \%$ \\
\hline Dayton & 526 & $23 \%$ \\
\hline Cynthiana & 562 & $22 \%$ \\
\hline Frankfort & 1,922 & $19 \%$ \\
\hline Shively & 1,070 & $18 \%$ \\
\hline Bellevue & 455 & $18 \%$ \\
\hline
\end{tabular}

\section{Greatest number of properties at risk*}

\begin{tabular}{lc|ccccc} 
Municipality & \multicolumn{2}{c}{2020} & \multicolumn{2}{c}{2050} & \multicolumn{2}{c}{ Change } \\
\cline { 2 - 5 } Louisville/Jefferson & 14,956 & $11 \%$ & 15,542 & $12 \%$ & +586 & $+3.9 \%$ \\
\cline { 2 - 5 } & 13,620 & $14 \%$ & 14,450 & $15 \%$ & +830 & $+6.1 \%$ \\
\hline Louisville & 8,317 & $7 \%$ & 8,721 & $8 \%$ & +404 & $+4.9 \%$ \\
\hline Lexington-Fayette & 2,718 & $25 \%$ & 2,761 & $25 \%$ & +43 & $+1.6 \%$ \\
\hline Ashland & 2,333 & $10 \%$ & 2,558 & $11 \%$ & +225 & $+9.6 \%$ \\
\hline Owensboro & 2,127 & $11 \%$ & 2,213 & $12 \%$ & +86 & $+4.0 \%$ \\
\hline Bowling Green & 1,922 & $19 \%$ & 1,953 & $19 \%$ & +31 & $+1.6 \%$ \\
\hline Frankfort & 1,736 & $13 \%$ & 1,778 & $13 \%$ & +42 & $+2.4 \%$ \\
\hline Hopkinsville & 1,478 & $9 \%$ & 1,533 & $10 \%$ & +55 & $+3.7 \%$ \\
\hline Covington & 1,166 & $9 \%$ & 1,178 & $9 \%$ & +12 & $+1.0 \%$ \\
\hline Georgetown & & & & & &
\end{tabular}

Greatest relative growing risk $^{*}$

\begin{tabular}{|c|c|c|c|c|c|c|}
\hline Municipality & & 20 & & 050 & & ange \\
\hline Farley & 135 & $6 \%$ & 487 & $22 \%$ & +352 & $+261 \%$ \\
\hline Fort Wright & 135 & $6 \%$ & 162 & $7 \%$ & +27 & $+20 \%$ \\
\hline Elsmere & 89 & $3 \%$ & 99 & $3 \%$ & +10 & $+11 \%$ \\
\hline Campbellsville & 265 & $6 \%$ & 292 & $6 \%$ & +27 & $+10 \%$ \\
\hline Walton & 149 & $7 \%$ & 164 & $8 \%$ & +15 & $+10 \%$ \\
\hline Owensboro & 2,333 & $10 \%$ & 2,558 & $11 \%$ & +225 & $+10 \%$ \\
\hline Taylor Mill & 240 & $10 \%$ & 262 & $10 \%$ & +22 & $+9 \%$ \\
\hline Newport & 616 & $10 \%$ & 670 & $11 \%$ & +54 & $+9 \%$ \\
\hline Hendron & 162 & $7 \%$ & 176 & $8 \%$ & +14 & $+9 \%$ \\
\hline Cold Spring & 96 & $5 \%$ & 104 & $5 \%$ & +8 & $+8 \%$ \\
\hline
\end{tabular}

\section{Flood Factor distribution of properties at risk ${ }^{\star}(1000 s)$}

\section{Risk level}

Minor $\quad 11.1$

Moderate

Major $\quad 70.7$

Severe

52.1

Extreme

39.9

16.6

More than $14.6 \%$ of individual properties and properties in Kentucky are at any risk of flooding over the next 30 years. Out of those at risk $78 \%$ are at major to extreme risk.

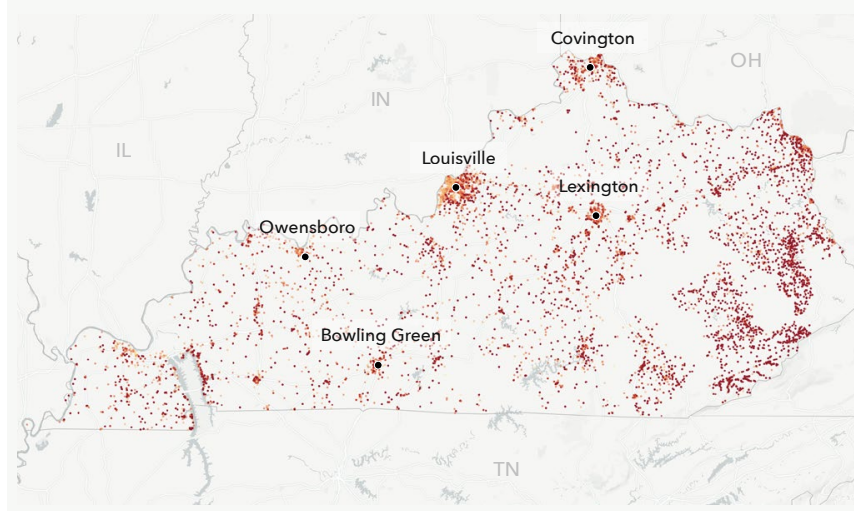




\section{Flood History \& Protection}

\section{Kentucky}

\section{Claims History}

121,600 home and property owners in Kentucky have made flood damage claims through FEMA since the year 2000.* These claims for reimbursement were made through either the National Flood Insurance Program (NFIP) or Individual Assistance Program (IAP). The greatest number of claims since the year 2000 have been concentrated in Jefferson, Pike, Johnson, Floyd, and Rowan counties.

\section{Storm Simulation}

The First Street Foundation Flood Model has recreated 1 flooding event that occurred since the year 2000 in the state of Kentucky. This event flooded around 470 properties across the state. **

Recreated river flood near Stanton, KY, May 2004

473 properties affected

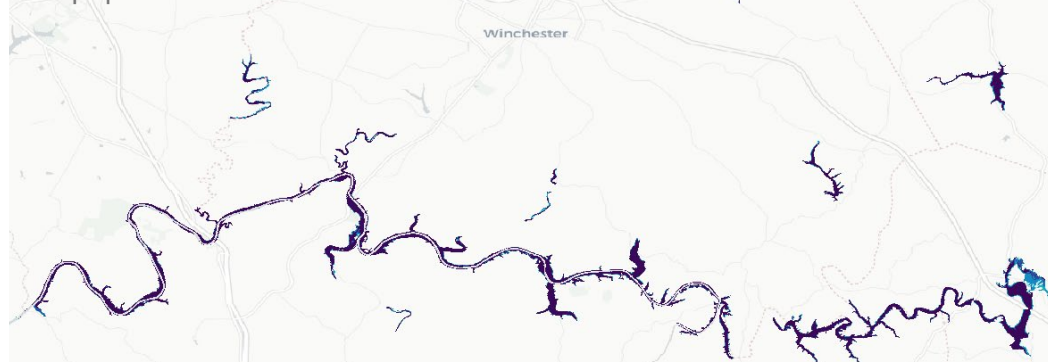

2

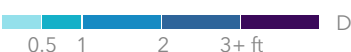

\section{9,000}

Properties served by

protection measures

The First Street Foundation Flood

Model incorporates 44 flood control

measures throughout the state which

protect 119,000 properties.

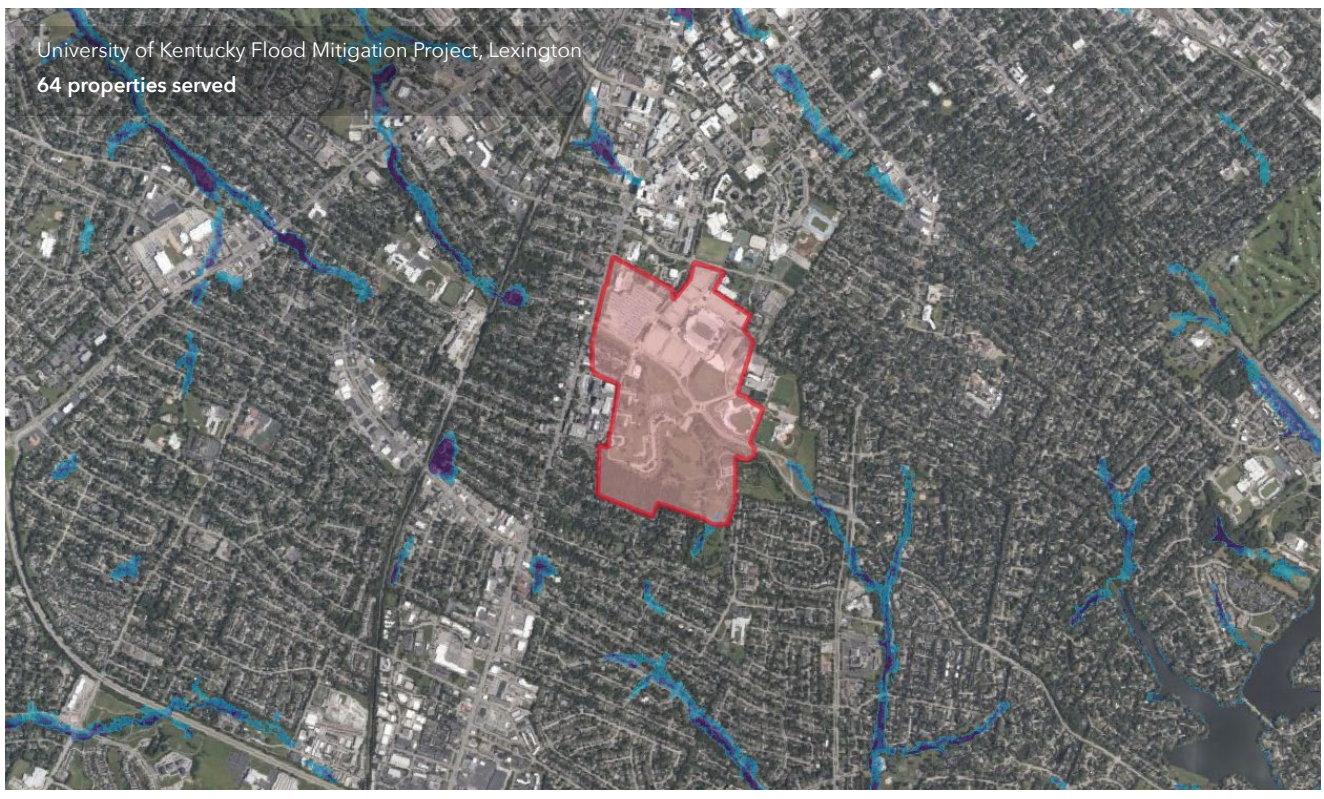

Top protection measures in state by quantity

Type
Example

\# Properties served by type

Levee

Dam

North Fork Little River floodwater retarding structures, Hopkinsville

Detention basin

roject, Lexington-Fayette

Acquisition

Marsh/wetland restoration Parkside Conservation Area, Alexandria 


\section{State Overview \\ Louisiana}

Total properties at substantial risk *

$\ln 2020$

477,100

30-year change

$\Delta+332,700$

In 2050

809,800

Difference in number of properties currently at substantial risk compared to FEMA**

$\nabla-83,900$

More properties at risk in FSF model $\longrightarrow$

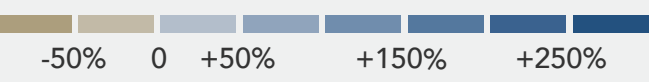

New Orleans sees annual floods from rain, hurricanes, and tropical storms. Despite levees, pump stations, and stormwater infrastructure, hurricanes Katrina and Rita caused catastrophic damage. The area remains vulnerable due to low elevation, land subsidence, and sea level rise. Baton Rouge sees backwater flood and heavy rainfall. New measures to dredge and widen key waterways to reduce backwater floods are underway.
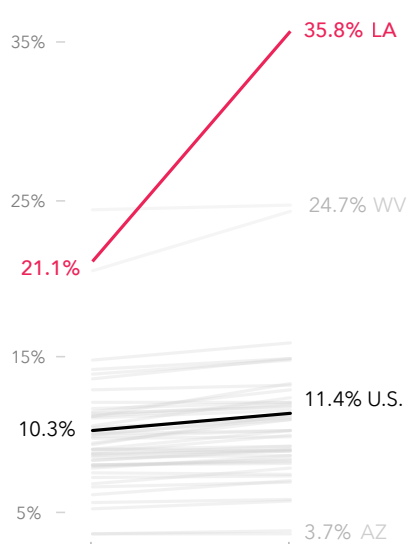

2020
Percent of properties at substantial risk compared to other states

The First Street Foundation Flood Model finds $10.3 \%$ of all properties across the contiguous United States at substantial risk of flooding today, and $11.4 \%$ at substantial risk in 30 years. Louisiana has a greater proportion of properties at substantial risk, with $21.1 \%$ at substantial risk today and $35.8 \%$ at substantial risk in 2050.

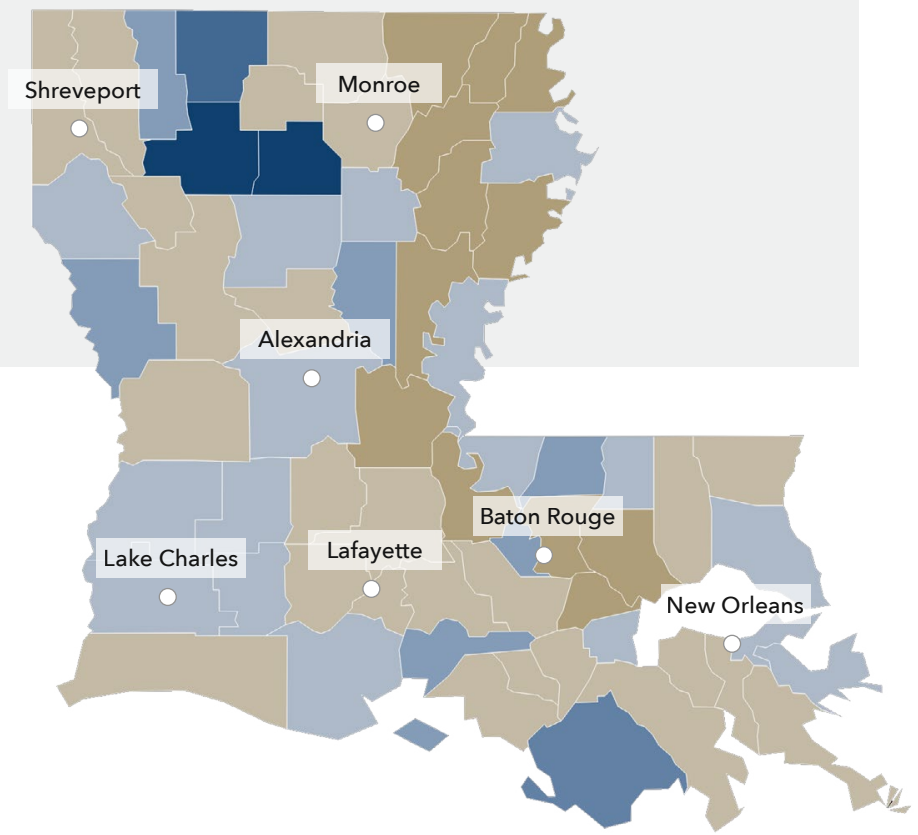
the First Street methods uncover an additional 332,700 properties with substantial risk by the year 2050, in turn showing 248,800 more properties with substantial risk than FEMA defines currently. 


\section{Local details}

\section{Louisiana}

The First Street Foundation Flood Model calculates the number of properties facing any risk* of flooding. When looking at this broader level of risk, the data identifies 973,000 properties in Louisiana as at risk over the next 30 years. Of these properties, 68,600 were categorized as facing almost certain risk, with a $99 \%$ chance of flooding at least once over the next 30 years.

The city of New Orleans has the greatest number of properties at risk of flooding in the state with 148,200 currently at risk, or $98 \%$ of its tota number of properties. However, smaller cities or municipalities in the state, with fewer properties, may have a greater proportion of their total properties at risk. For example, $100 \%$ of properties in Arabi are at risk of flooding. Other municipalities will see the greatest increase in risk over the next 30 years. Franklin, for example, will see a 1028\% increase in the number of properties at risk.

Click here for a full breakdown of counties, cities, zip codes, and congressional districts in Louisiana at risk.

\section{Greatest proportion of properties at risk*}

\begin{tabular}{lrl} 
Municipality & \multicolumn{2}{c}{2020} \\
Metairie & 64,424 & $100 \%$ \\
\hline Chalmette & 8,975 & $100 \%$ \\
\hline River Ridge & 7,216 & $100 \%$ \\
\hline Terrytown & 6,856 & $100 \%$ \\
\hline Jefferson & 6,269 & $100 \%$ \\
\hline Kenner & 3,912 & $100 \%$ \\
\hline Timberlane & 3,166 & $100 \%$ \\
\hline Meraux & 3,148 & $100 \%$ \\
\hline Arabi & 2,817 & $100 \%$ \\
\hline Violet & 2,748 & $99 \%$ \\
\hline
\end{tabular}

\section{Greatest number of properties at risk*}

\begin{tabular}{lcccccc} 
Municipality & \multicolumn{2}{c}{2020} & \multicolumn{2}{c}{2050} & \multicolumn{2}{c}{ Change } \\
New Orleans & 148,197 & $98 \%$ & 148,232 & $98 \%$ & +35 & $0.0 \%$ \\
\hline Metairie & 64,424 & $100 \%$ & 64,424 & $100 \%$ & 0 & $0.0 \%$ \\
\hline Lake Charles & 17,866 & $36 \%$ & 26,458 & $54 \%$ & $+8,592$ & $+48.1 \%$ \\
\hline Lafayette & 15,881 & $30 \%$ & 16,762 & $32 \%$ & +881 & $+5.5 \%$ \\
\hline Baton Rouge & 15,561 & $16 \%$ & 17,191 & $17 \%$ & $+1,630$ & $+10.5 \%$ \\
\hline Marrero & 14,591 & $99 \%$ & 14,591 & $99 \%$ & 0 & $0.0 \%$ \\
\hline Houma & 13,354 & $99 \%$ & 13,355 & $99 \%$ & +1 & $0.0 \%$ \\
\hline Shreveport & 13,046 & $14 \%$ & 14,230 & $15 \%$ & $+1,184$ & $+9.1 \%$ \\
\hline Harvey & 11,477 & $74 \%$ & 11,478 & $74 \%$ & +1 & $0.0 \%$ \\
\hline Laplace & 10,386 & $89 \%$ & 10,450 & $89 \%$ & +64 & $+0.6 \%$
\end{tabular}

\section{Greatest relative growing risk*}

\begin{tabular}{llll}
2050 & \multicolumn{2}{c}{ Change } \\
\hline 64,424 & $100 \%$ & +0 & $0.0 \%$ \\
\hline 8,976 & $100 \%$ & +1 & $0.0 \%$ \\
\hline 7,216 & $100 \%$ & +0 & $0.0 \%$ \\
\hline 6,856 & $100 \%$ & +0 & $0.0 \%$ \\
\hline 6,286 & $100 \%$ & +17 & $+0.3 \%$ \\
\hline 3,912 & $100 \%$ & +0 & $0.0 \%$ \\
\hline 3,166 & $100 \%$ & +0 & $0.0 \%$ \\
\hline 3,148 & $100 \%$ & +0 & $0.0 \%$ \\
\hline 2,817 & $100 \%$ & +0 & $0.0 \%$ \\
\hline 2,748 & $99 \%$ & +0 & $0.0 \%$ \\
\hline
\end{tabular}

\begin{tabular}{lrcrcr|r} 
Municipality & \multicolumn{2}{c}{2020} & \multicolumn{2}{c}{2050} & \multicolumn{2}{c}{ Change } \\
\hline Franklin & 478 & $9 \%$ & 5,390 & $98 \%$ & +4912 & $+1028 \%$ \\
\hline Thibodaux & 1,296 & $24 \%$ & 3,454 & $64 \%$ & +2158 & $+167 \%$ \\
\hline New lberia & 5,787 & $46 \%$ & 10,682 & $85 \%$ & +4895 & $+85 \%$ \\
\hline Schriever & 1,285 & $49 \%$ & 2,218 & $84 \%$ & +933 & $+73 \%$ \\
\hline Vinton & 1,954 & $67 \%$ & 2,919 & $100 \%$ & +965 & $+49 \%$ \\
\hline Lake Charles & 17,866 & $36 \%$ & 26,458 & $54 \%$ & $+8,592$ & $+48 \%$ \\
\hline Lacombe & 2,779 & $61 \%$ & 3,941 & $86 \%$ & $+1,162$ & $+42 \%$ \\
\hline Ponchatoula & 1,627 & $41 \%$ & 2,195 & $55 \%$ & +568 & $+35 \%$ \\
\hline Sulphur & 5,549 & $39 \%$ & 7,072 & $50 \%$ & $+1,523$ & $+27 \%$ \\
\hline Plaquemine & 682 & $20 \%$ & 843 & $24 \%$ & +161 & $+24 \%$ \\
\hline
\end{tabular}

\section{Flood Factor distribution of properties at risk ${ }^{\star}(1000 s)$}

\section{Risk leve}

Minor $\quad 64.3$

Moderate $\quad 499.0$

Major $\quad 200.4$

Severe $\quad 70.2$

Extreme

139.1

More than $42.8 \%$ of individual properties and properties in Louisiana are at any risk of flooding over the next 30 years. Out of those at risk $43 \%$ are at major to extreme risk.

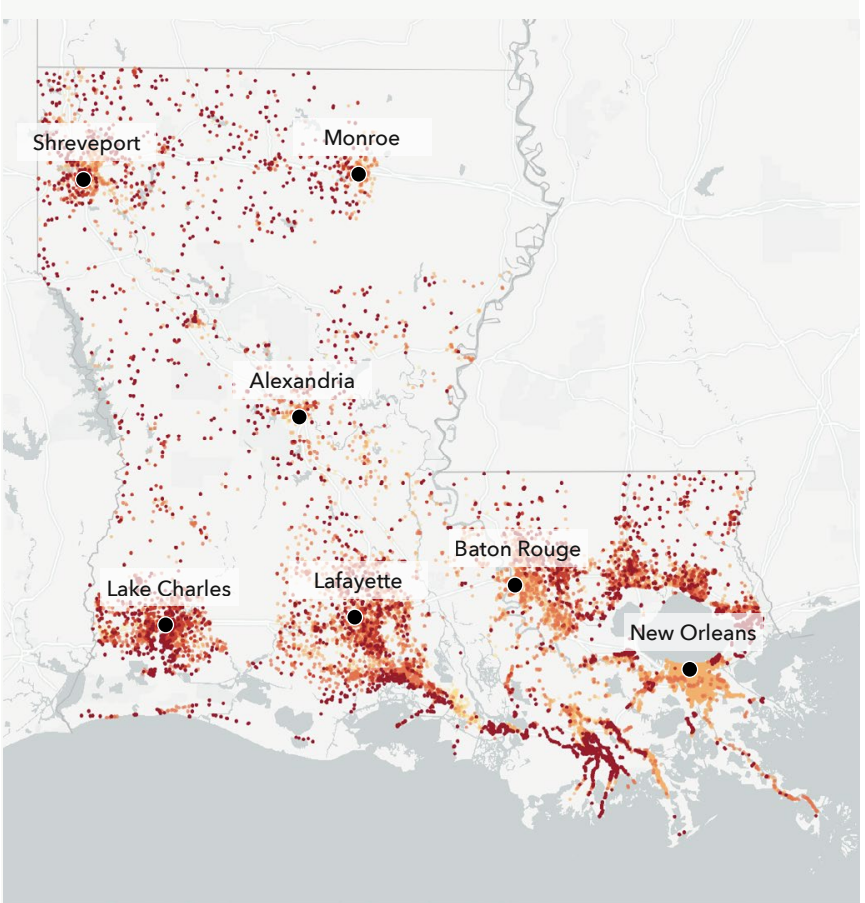




\section{Flood History \& Protection}

\section{Louisiana}

\section{Claims History}

$3,125,400$ home and property owners in Louisiana have made flood damage claims through FEMA since the year 2000.* These claims for reimbursement were made through either the National

Flood Insurance Program (NFIP) or Individual Assistance Program (IAP). The greatest number of

claims since the year 2000 have been concentrated in Orleans, Jefferson, East Baton Rouge, St.

Tammany, and Calcasieu counties.

\section{Storm Simulation}

The First Street Foundation Flood Model has recreated 6 flooding events that have occurred since the year 2000 in the state of Louisiana. These events flooded around 441,520 properties across the state.**
Flood event

\section{- Katrina}

Hurricane Gustav

Hurricane lke

Hurricane Isaac

River flood in Southwestern LA

\begin{tabular}{lr} 
Date & $\begin{array}{r}\text { \#Properties } \\
\text { affected }\end{array}$ \\
Jun 2001 & 6,892 \\
\hline Aug 2005 & 197,268 \\
\hline Aug 2008 & 17,606 \\
\hline Sep 2008 & 150,955 \\
\hline Aug 2012 & 64,696 \\
\hline
\end{tabular}

Mar $2016 \quad 4,106$
Tropical Storm Allison Hurrican
997,300

Properties served by

protection measures

The First Street Foundation Flood

Model incorporates 506 flood control

measures throughout the state which

protect 997,300 properties.

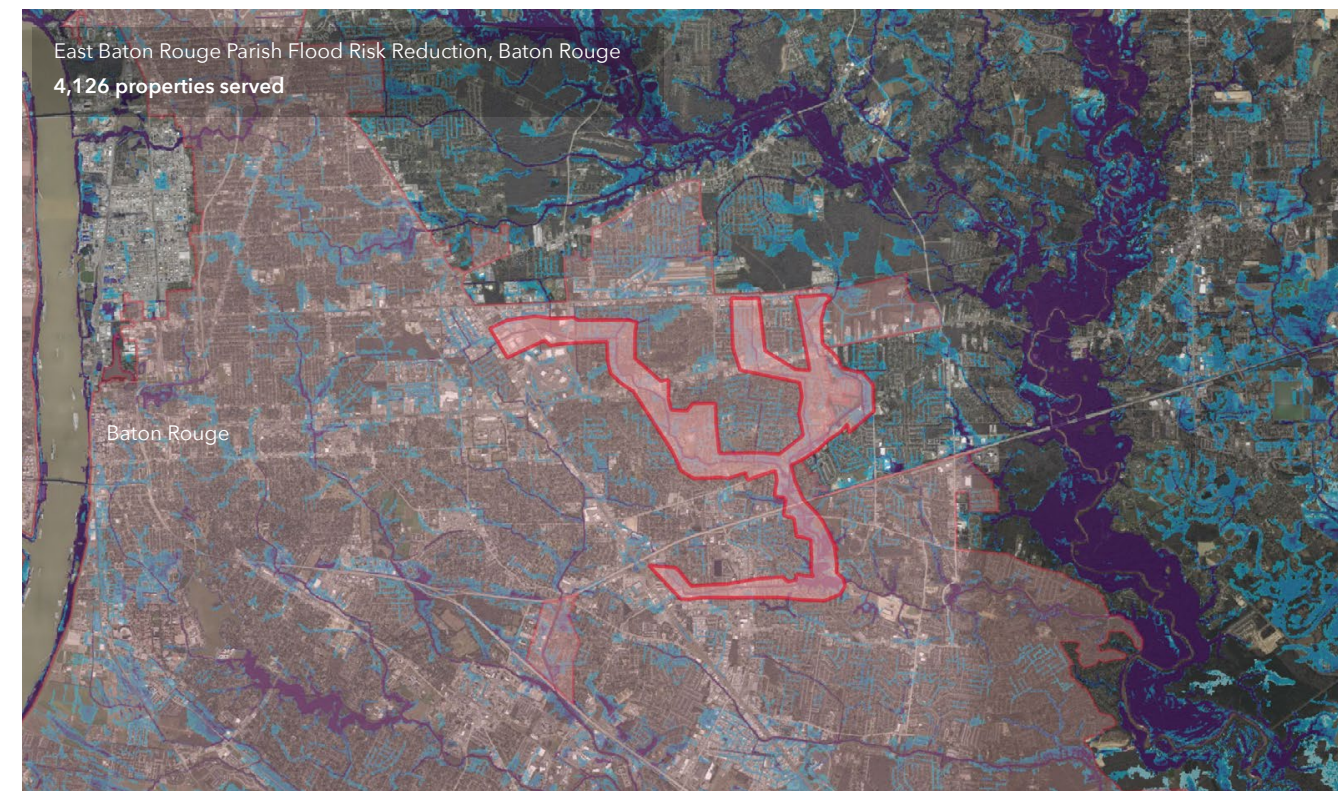

Area of protection

Top protection measures in state by quantity

Type
Example

\# Properties served by type

Levee

993,470

New Orleans East Bank, New Orlean

309,512

Pump statio

Chast Baton Rouge Parish Flood Risk Reduction Project, Baton Rouge

Living shoreline

Holly Beach

Marsh/wetland creation

1,915
Central Wetlands Marsh Creation - Component A, New Orleans

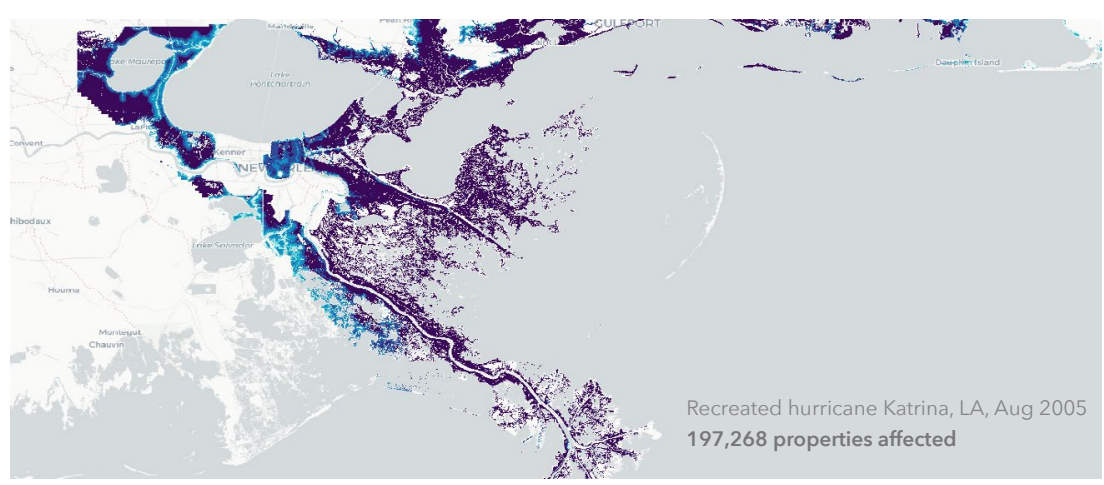

Depth of flooding 


\section{State Overview Maine}

Flood risk is increasing in the state of Maine. 55,700 properties currently have a substantial risk* of flooding. Over the next 30 years, the number of properties with this risk will increase by another $7.6 \%$, bringing the total number of properties with substantial risk to 59,900 .

To understand personal flood risk, Americans leverage the Federal Emergency Management Agency (FEMA) Flood Insurance Rate Maps (FIRM). These maps identify 29,500 properties as having substantial risk in the state of Maine. In comparison, the First Street Foundation Flood Model identifies 1.9 times the number of properties as facing this same level of risk. This discrepancy exists because the Foundation uses the current climate data, maps precipitation as a stand-alone risk, and includes areas that FEMA has not mapped. These new methods uncover an additional 26,200 properties currently not identified by FEMA as having substantial risk. When adjusting for future environmental changes, the FEMA gap further widens to 30,400 by the year 2050 .
Total properties at substantial risk *

$\ln 2020$

55,700

30-year change

$\Delta+4,200(+8 \%)$
Difference in number of properties currently at substantial risk compared to FEMA**

\section{$+26,200$}

More properties at risk in FSF model $\longrightarrow$

$\begin{array}{lll} & +50 \% & +150 \% \\ & +250 \%\end{array}$

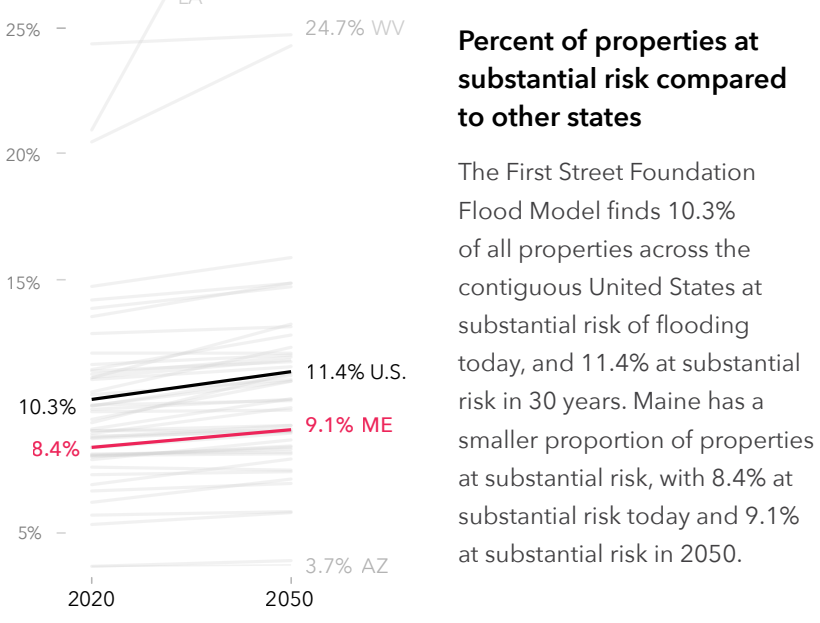

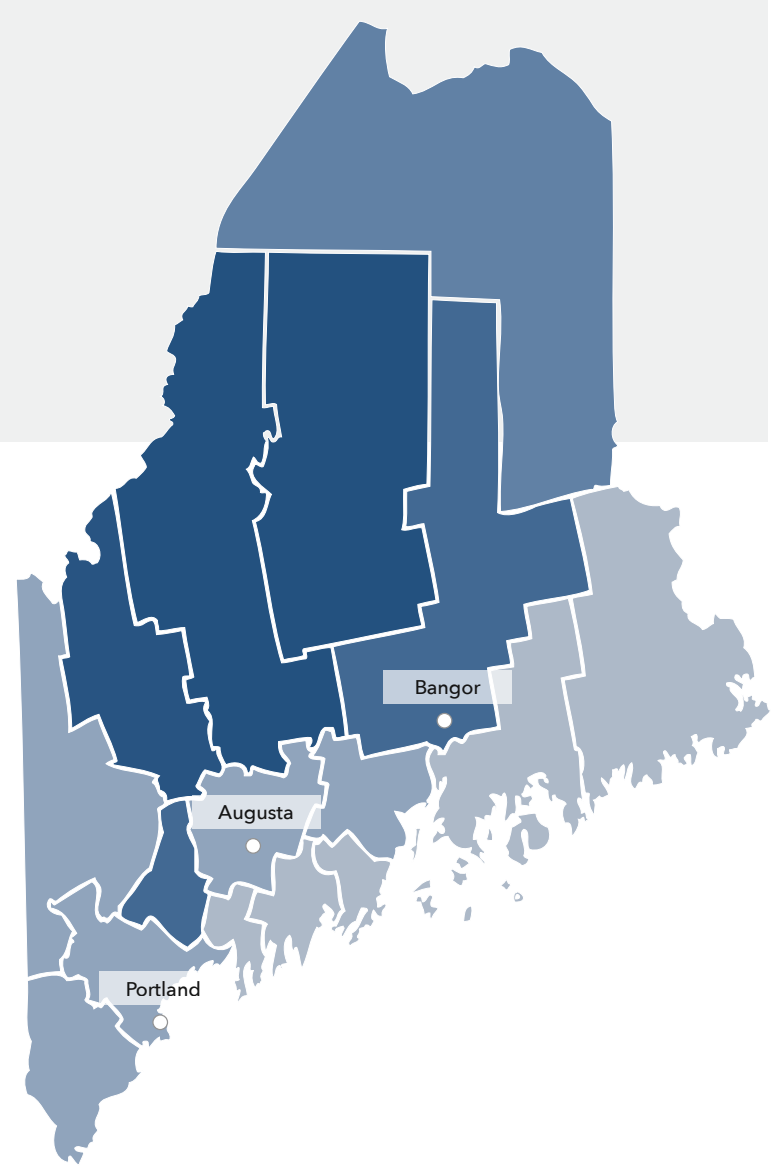




\section{Local details \\ Maine}

The First Street Foundation Flood Model calculates the number of properties facing any risk* of flooding. When looking at this broader level of risk, the data identifies 81,800 properties in Maine as at risk over the next 30 years. Of these properties, 23,900 were categorized as facing almost certain risk, with a $99 \%$ chance of flooding at least once over the next 30 years.

The city of Portland has the greatest number of properties at risk of flooding in the state with 2,400 currently at risk, or $8 \%$ of its total number of properties. However, smaller cities or municipalities in the state, with fewer properties, may have a greater proportion of their total properties at risk. For example, $22 \%$ of properties in Brewer are at risk of flooding. Other municipalities will see the greatest increase in risk over the next 30 years. Old Orchard Beach, for example, will see $79 \%$ increase in the number of properties at risk.

Click here for a full breakdown of counties, cities, zip codes, and congressional districts in Maine at risk.

\section{Greatest proportion of properties at risk*}

\begin{tabular}{lrr|} 
Municipality & \multicolumn{2}{c}{2020} \\
\hline Brewer & 836 & $22 \%$ \\
\hline Old Town & 603 & $19 \%$ \\
\hline Cape Neddick & 525 & $17 \%$ \\
\hline Biddeford & 1,225 & $16 \%$ \\
\hline Old Orchard Beach & 643 & $16 \%$ \\
\hline Skowhegan & 420 & $16 \%$ \\
\hline Bath & 532 & $14 \%$ \\
\hline Houlton & 280 & $14 \%$ \\
\hline Auburn & 1,150 & $13 \%$ \\
\hline Westbrook & 795 & $13 \%$ \\
\hline
\end{tabular}

\section{Greatest number of properties at risk}

\begin{tabular}{l|cccccc} 
Municipality & \multicolumn{2}{c}{2020} & \multicolumn{2}{c}{2050} & \multicolumn{2}{c}{ Change } \\
\cline { 2 - 4 } & 2,381 & $8 \%$ & 2,795 & $9 \%$ & +414 & $+17.4 \%$ \\
\hline Lewiston & 1,471 & $13 \%$ & 1,538 & $14 \%$ & +67 & $+4.6 \%$ \\
\hline Biddeford & 1,225 & $16 \%$ & 1,435 & $19 \%$ & +210 & $+17.1 \%$ \\
\hline Auburn & 1,150 & $13 \%$ & 1,186 & $14 \%$ & +36 & $+3.1 \%$ \\
\hline Augusta & 1,000 & $12 \%$ & 1,039 & $12 \%$ & +39 & $+3.9 \%$ \\
\hline South Portland & 947 & $11 \%$ & 1,176 & $14 \%$ & +229 & $+24.2 \%$ \\
\hline Sanford & 932 & $10 \%$ & 956 & $11 \%$ & +24 & $+2.6 \%$ \\
\hline Bangor & 876 & $9 \%$ & 914 & $9 \%$ & +38 & $+4.3 \%$ \\
\hline Brewer & 836 & $22 \%$ & 888 & $23 \%$ & +52 & $+6.2 \%$ \\
\hline Westbrook & 795 & $13 \%$ & 834 & $14 \%$ & +39 & $+4.9 \%$
\end{tabular}

\section{Greatest relative growing risk* $^{*}$}

\begin{tabular}{lrrrrrr} 
Municipality & \multicolumn{2}{c}{2020} & \multicolumn{2}{c}{2050} & \multicolumn{2}{c}{ Change } \\
Old Orchard Beach & 643 & $16 \%$ & 1,151 & $29 \%$ & +508 & $+79 \%$ \\
\hline Saco & 747 & $11 \%$ & 981 & $14 \%$ & +234 & $+31 \%$ \\
\hline South Portland & 947 & $11 \%$ & 1,176 & $14 \%$ & +229 & $+24 \%$ \\
\hline Gorham & 46 & $2 \%$ & 57 & $3 \%$ & +11 & $+24 \%$ \\
\hline Portland & 2,381 & $8 \%$ & 2,795 & $9 \%$ & +414 & $+17 \%$ \\
\hline Biddeford & 1,225 & $16 \%$ & 1,435 & $19 \%$ & +210 & $+17 \%$ \\
\hline Topsham & 211 & $9 \%$ & 243 & $10 \%$ & +32 & $+15 \%$ \\
\hline Bath & 532 & $14 \%$ & 579 & $16 \%$ & +47 & $+9 \%$ \\
\hline Skowhegan & 420 & $16 \%$ & 452 & $17 \%$ & +32 & $+8 \%$ \\
\hline Yarmouth & 151 & $7 \%$ & 162 & $8 \%$ & +11 & $+7 \%$ \\
\hline
\end{tabular}

\section{Flood Factor distribution of properties at risk* $(1000 s)$}

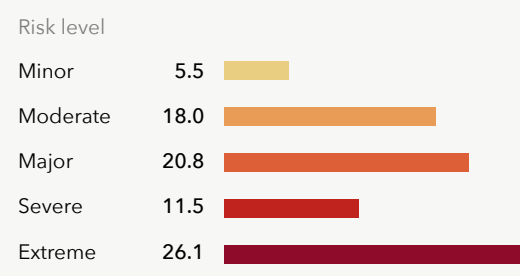

More than $12.1 \%$ of individual properties and properties in Maine are at any risk of flooding over the next 30 years. Out of those at risk $73 \%$ are at major to extreme risk.

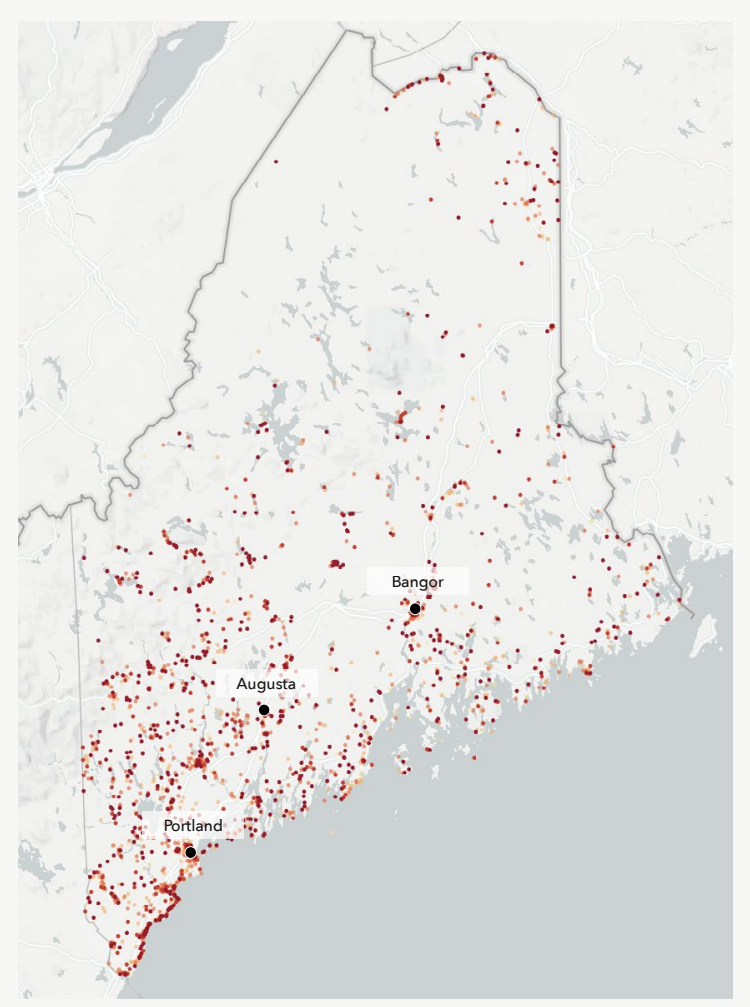




\section{Flood History \& Protection}

\section{Maine}

\section{Claims History}

6,300 home and property owners in Maine have made flood damage claims through FEMA since the year 2000.* These claims for reimbursement were made through either the National Flood Insurance Program (NFIP) or Individual Assistance Program (IAP). The greatest number of claims

since the year 2000 have been concentrated in York, Cumberland, Aroostook, Oxford, and Lincoln counties.

\section{3,265}

Properties served by

protection measures

The First Street Foundation Flood Model incorporates 148 flood control measures throughout the state which protect 3,300 properties
Top protection measures in state by quantity

Type
Example

Marsh/wetland restoration Webhannet River and Litte River Conserved Tidal Mars

River RB \& Fish Riv LB, Fort Kent

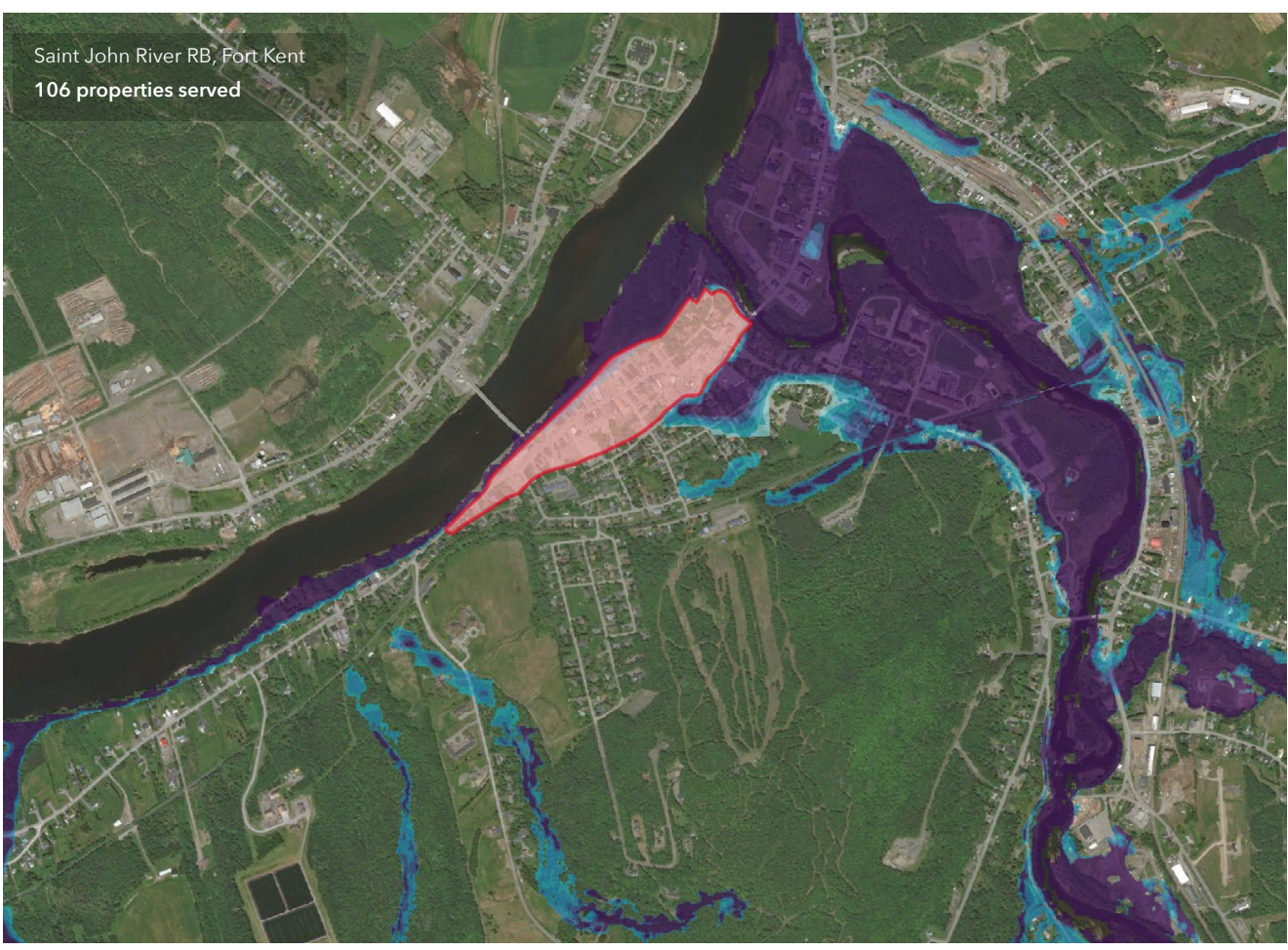

$\square$ Area of protection 


\section{State Overview Maryland}

Flood risk is increasing in the state of Maryland. 133,700 properties currently have a substantial risk* of flooding. Over the next 30 years, the number of properties with this risk will increase by another $14.8 \%$, bringing the total number of properties with substantial risk to 153,500 .

To understand personal flood risk, Americans leverage the Federal Emergency Management Agency (FEMA) Flood Insurance Rate Maps

(FIRM). These maps identify 58,700 properties as having substantial risk in the state of Maryland. In comparison, the First Street Foundation

Flood Model identifies 2.3 times the number of properties as facing this same level of risk. This discrepancy exists because the Foundation uses the current climate data, maps precipitation as a stand-alone risk, and includes areas that FEMA has not mapped. These new methods uncover an additional 75,000 properties currently not identified by FEMA as having substantial risk. When adjusting for future environmental changes, the FEMA gap further widens to 94,800 by the year 2050 .
Total properties at substantial risk*

In 2020

\section{3,700}

30-year change

$$
\Delta+19,800(+15 \%)
$$

Difference in number of properties currently at substantial risk compared to FEMA**

\section{$\Delta+75,000$}

Maryland is subject to localized flash flooding after short periods of heavy rainfall around small streams and creeks. Flooding along larger rivers such as the Potomac and Susquehanna comes from more prolonged and steady rains. Hurricanes and tropical storms can cause surges that create tidal flooding along bays and their tributaries. Hurricanes Fran (1996), Floyd (1999), and Isabel (2003) all caused significant floods.
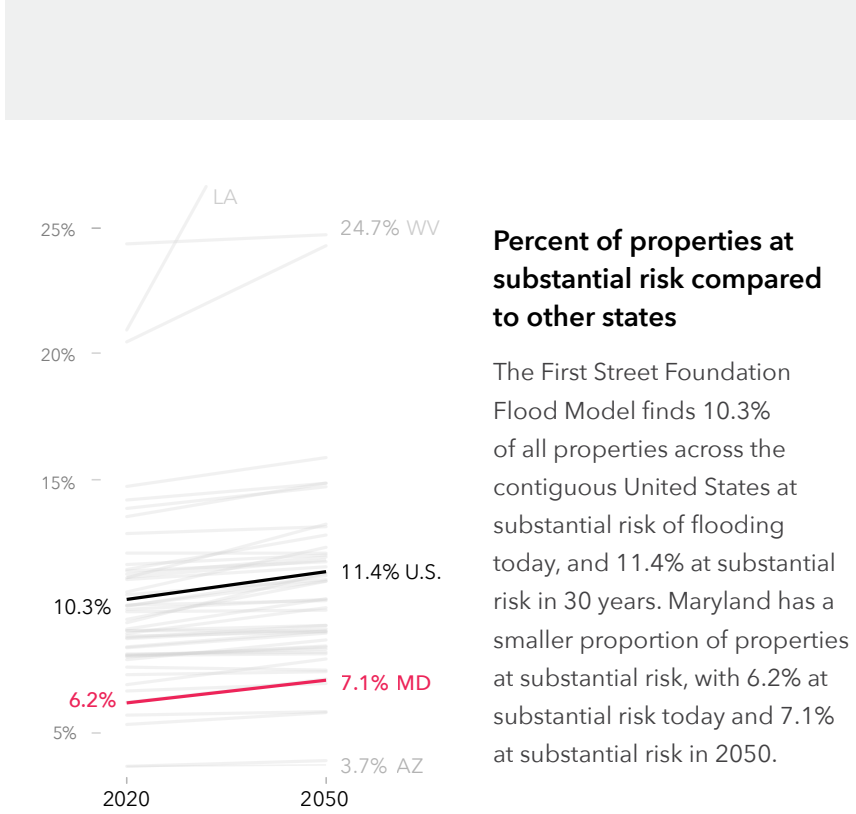

s

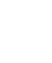

.
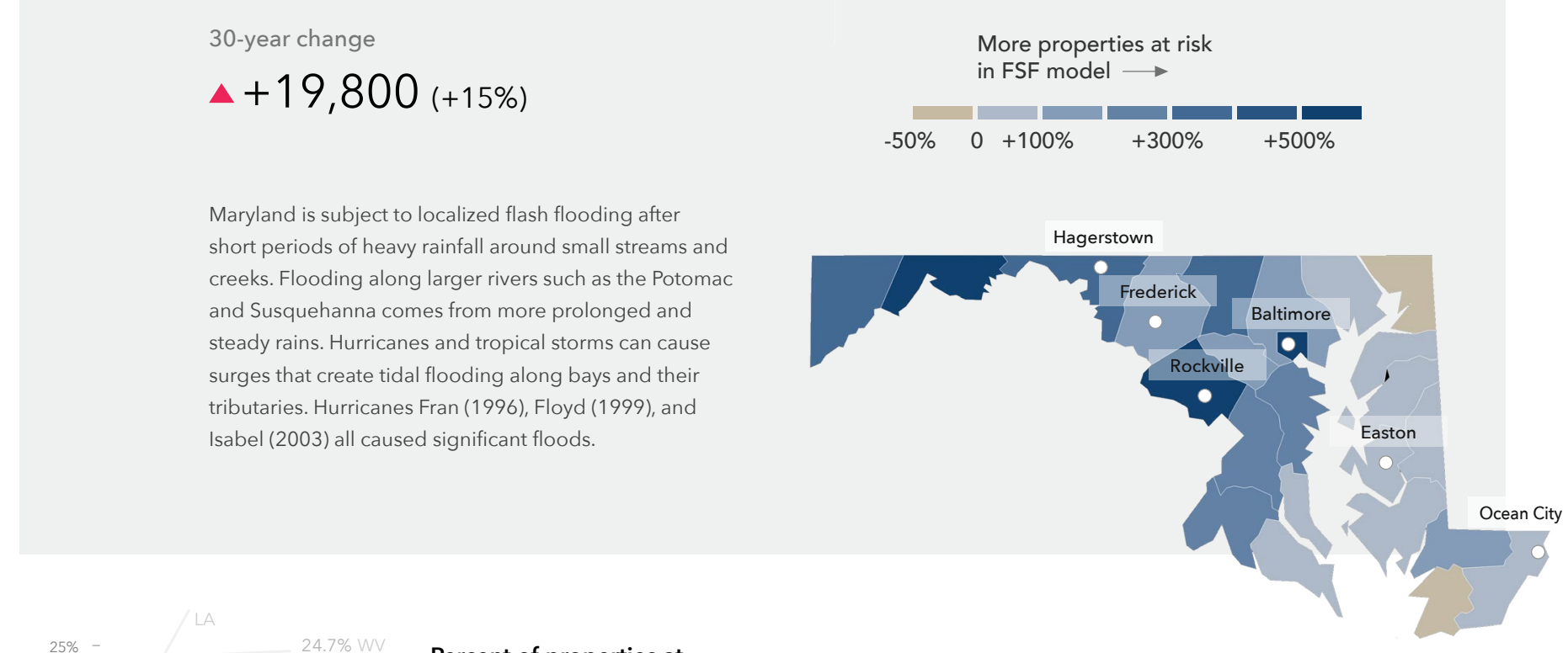

More properties at risk

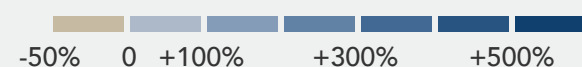
in FSF model 


\section{Local details \\ Maryland}

The First Street Foundation Flood Model calculates the number of properties facing any risk* of flooding. When looking at this broader level of risk, the data identifies 202,600 properties in Maryland as at risk over the next 30 years. Of these properties, 40,700 were categorized as facing almost certain risk, with a $99 \%$ chance of flooding at least once over the next 30 years.

The city of Baltimore has the greatest number of properties at risk of flooding in the state with 13,700 currently at risk, or $6 \%$ of its total number of properties. However, smaller cities or municipalities in the state, with fewer properties, may have a greater proportion of their total properties at risk. For example, $85 \%$ of properties in Ocean City are at risk of flooding. Other municipalities will see the greatest increase in risk over the next 30 years. Chester, for example, will see a $158 \%$ increase in the number of properties at risk.

Click here for a full breakdown of counties, cities, zip codes, and congressional districts in Maryland at risk.

\section{Greatest proportion of properties at risk*}

\begin{tabular}{lrll} 
Municipality & \multicolumn{2}{c}{2020} \\
Ocean City & 6,319 & $85 \%$ \\
\hline Crisfield & 1,749 & $83 \%$ \\
\hline West Ocean City & 2,020 & $57 \%$ \\
\hline Ocean Pines & 4,148 & $43 \%$ \\
\hline Shady Side & 1,312 & $40 \%$ \\
\hline Bowleys Quarters & 1,163 & $37 \%$ \\
\hline Deale & 739 & $28 \%$ \\
\hline Edgemere & 1,220 & $28 \%$ \\
\hline La Vale & 512 & $25 \%$ \\
\hline Pocomoke City & 434 & $20 \%$ \\
\hline
\end{tabular}

\section{Greatest number of properties at risk ${ }^{\star}$}

\begin{tabular}{l|cccccc} 
Municipality & \multicolumn{2}{c}{2020} & \multicolumn{2}{c}{2050} & \multicolumn{2}{c}{ Change } \\
\cline { 2 - 4 } & 13,705 & $6 \%$ & 15,378 & $7 \%$ & $+1,673$ & $+12.2 \%$ \\
\hline Ocean City & 6,319 & $85 \%$ & 7,190 & $97 \%$ & +871 & $+13.8 \%$ \\
\hline Ocean Pines & 4,148 & $43 \%$ & 6,273 & $65 \%$ & $+2,125$ & $+51.2 \%$ \\
\hline Dundalk & 2,123 & $8 \%$ & 3,731 & $14 \%$ & $+1,608$ & $+75.7 \%$ \\
\hline West Ocean City & 2,020 & $57 \%$ & 3,128 & $89 \%$ & $+1,108$ & $+54.9 \%$ \\
\hline Cumberland & 1,848 & $18 \%$ & 1,883 & $18 \%$ & +35 & $+1.9 \%$ \\
\hline Crisfield & 1,749 & $83 \%$ & 1,780 & $84 \%$ & +31 & $+1.8 \%$ \\
\hline Salisbury & 1,742 & $15 \%$ & 1,867 & $16 \%$ & +125 & $+7.2 \%$ \\
\hline Bethesda & 1,525 & $9 \%$ & 1,614 & $9 \%$ & +89 & $+5.8 \%$ \\
\hline Hagerstown & 1,400 & $10 \%$ & 1,499 & $11 \%$ & +99 & $+7.1 \%$
\end{tabular}

\section{Greatest relative growing risk $^{*}$}

\begin{tabular}{lrrrrrr} 
Municipality & \multicolumn{2}{c}{2020} & \multicolumn{2}{c}{2050} & \multicolumn{2}{c}{ Change } \\
Chester & 260 & $10 \%$ & 671 & $26 \%$ & +411 & $+158 \%$ \\
\hline Riviera Beach & 81 & $2 \%$ & 186 & $4 \%$ & +105 & $+130 \%$ \\
\hline Stevensville & 558 & $18 \%$ & 1,091 & $34 \%$ & +533 & $+96 \%$ \\
\hline Essex & 666 & $5 \%$ & 1,250 & $9 \%$ & +584 & $+88 \%$ \\
\hline Edgewater & 421 & $10 \%$ & 763 & $19 \%$ & +342 & $+81 \%$ \\
\hline Annapolis Neck & 788 & $16 \%$ & 1,417 & $28 \%$ & +629 & $+80 \%$ \\
\hline Dundalk & 2,123 & $8 \%$ & 3,731 & $14 \%$ & $+1,608$ & $+76 \%$ \\
\hline Mayo & 767 & $19 \%$ & 1,234 & $30 \%$ & +467 & $+61 \%$ \\
\hline Edgewood & 159 & $2 \%$ & 251 & $3 \%$ & +92 & $+58 \%$ \\
\hline West Ocean City & 2,020 & $57 \%$ & 3,128 & $89 \%$ & $+1,108$ & $+55 \%$ \\
\hline
\end{tabular}

\section{Flood Factor distribution of properties at risk ${ }^{\star}(1000 s)$}

\section{Risk leve}

Mino

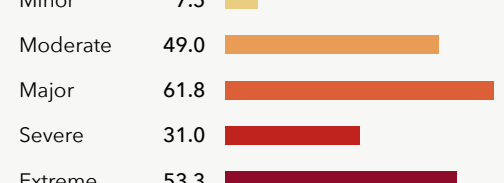

Extreme

More than $9.4 \%$ of individual properties and properties in Maryland are at any risk of flooding over the next 30 years. Out of those at risk $72 \%$ are at major to extreme risk.

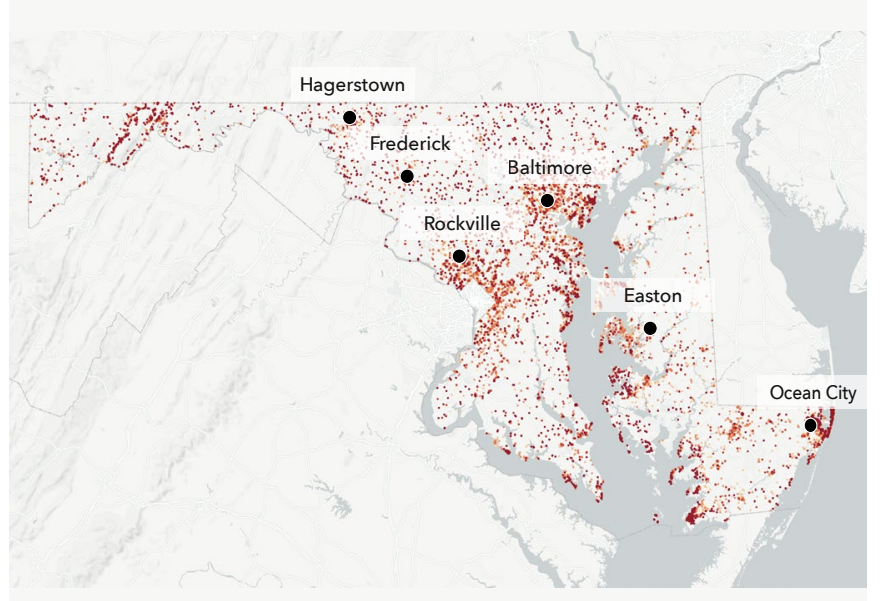




\section{Flood History \& Protection}

\section{Maryland}

\section{Claims History}

15,700 home and property owners in Maryland have made flood damage claims through FEMA since the year 2000.* These claims for reimbursement were made through either the National Flood Insurance Program (NFIP) or Individual Assistance Program (IAP). The greatest number of claims since the year 2000 have been concentrated in Baltimore, Somerset, Anne Arundel, Baltimore, and Worcester counties.

\section{Storm Simulation}

The First Street Foundation Flood Model has recreated 4 flooding events that have occurred since the year 2000 in the state of Maryland. These events flooded around 51,460 properties across the state **

\begin{tabular}{llr} 
Flood event & Date & $\begin{array}{r}\text { \# Properties } \\
\text { affected }\end{array}$ \\
Hurricane Isabel & Sep 2003 & 35,613 \\
\hline Nor'easter & Nov 2009 & 3,669 \\
\hline Hurricane Irene & Aug 2011 & 11,851 \\
\hline River flood in Western MD & Dec 2018 & 330
\end{tabular}

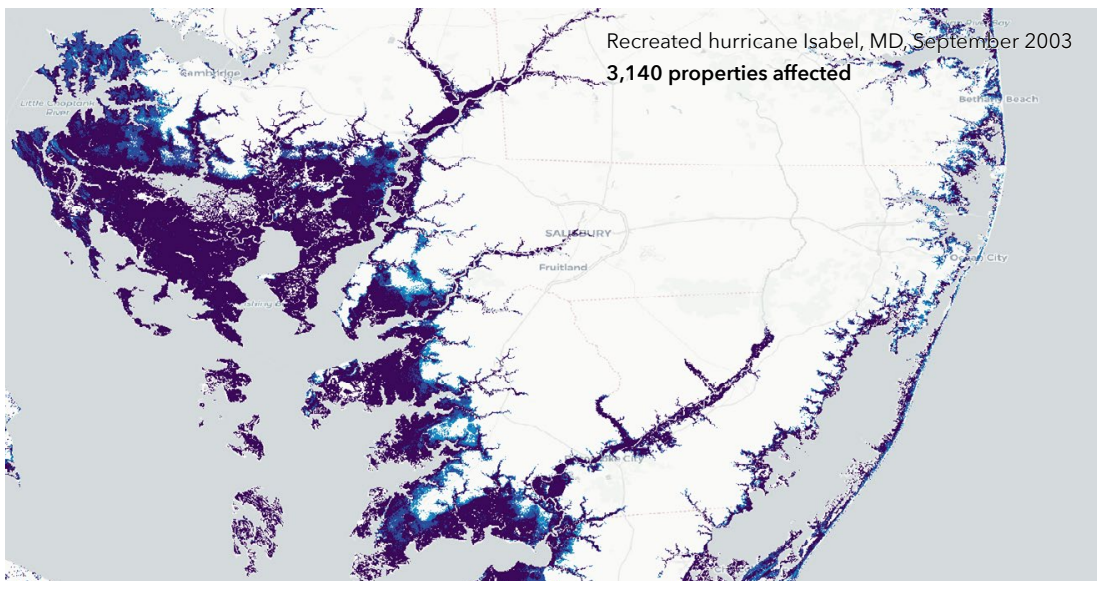

Depth of flooding

\section{4,900}

Properties served by

protection measures

The First Street Foundation Flood

Model incorporates 531 flood control

measures throughout the state which

protect 144,900 properties

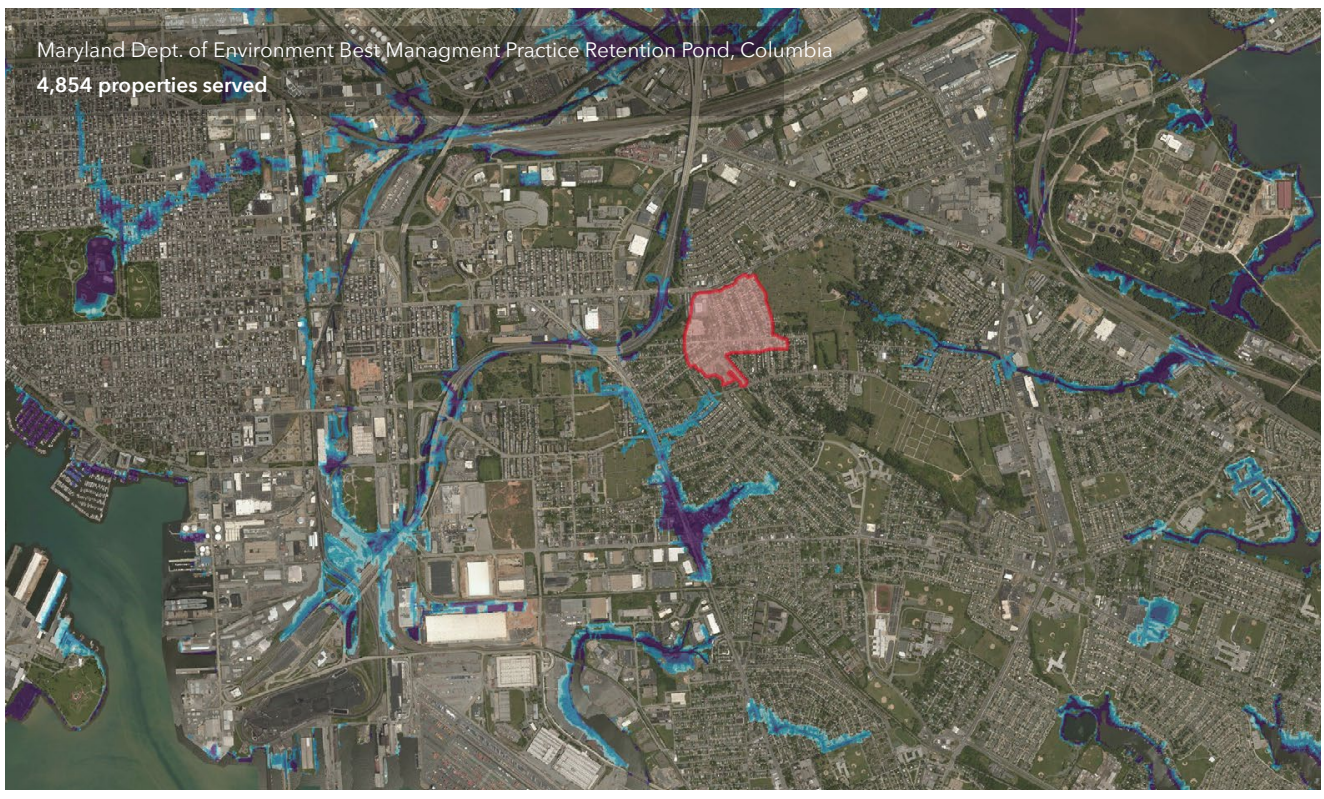

Area of protection
Top protection measures in state by quantity

Type

\# Properties served by type

Retention pond

137,50

Levee

Cumberland, Cumberland

Seawall

Marsh/wetland restoration 


\section{State Overview \\ Massachussets}

Flood risk is increasing in the state of Massachusetts. 193,300 properties currently have a substantial risk* of flooding. Over the next 30 years, the number of properties with this risk will increase by another $11.4 \%$, bringing the total number of properties with substantial risk to 215,400 .

To understand personal flood risk, Americans leverage the Federal Emergency Management Agency (FEMA) Flood Insurance Rate Maps (FIRM). These maps identify 117,100 properties as having substantial risk in the state of Massachusetts. In comparison, the First Street Foundation Flood Model identifies 1.6 times the number of properties as facing this same level of risk. This discrepancy exists because the Foundation uses the current climate data, maps precipitation as a stand-alone risk, and includes areas that FEMA has not mapped. These new methods uncover an additional 76,200 properties currently not identified by FEMA as having substantial risk. When adjusting for future environmental changes, the FEMA gap further widens to 98,300 by the year 2050 .
Total properties at substantial risk

In 2020

193,300

30-year change

$\Delta+22,100(+11.4 \%)$
Difference in number of properties currently at substantial risk compared to FEMA**

$\Delta+76,200$

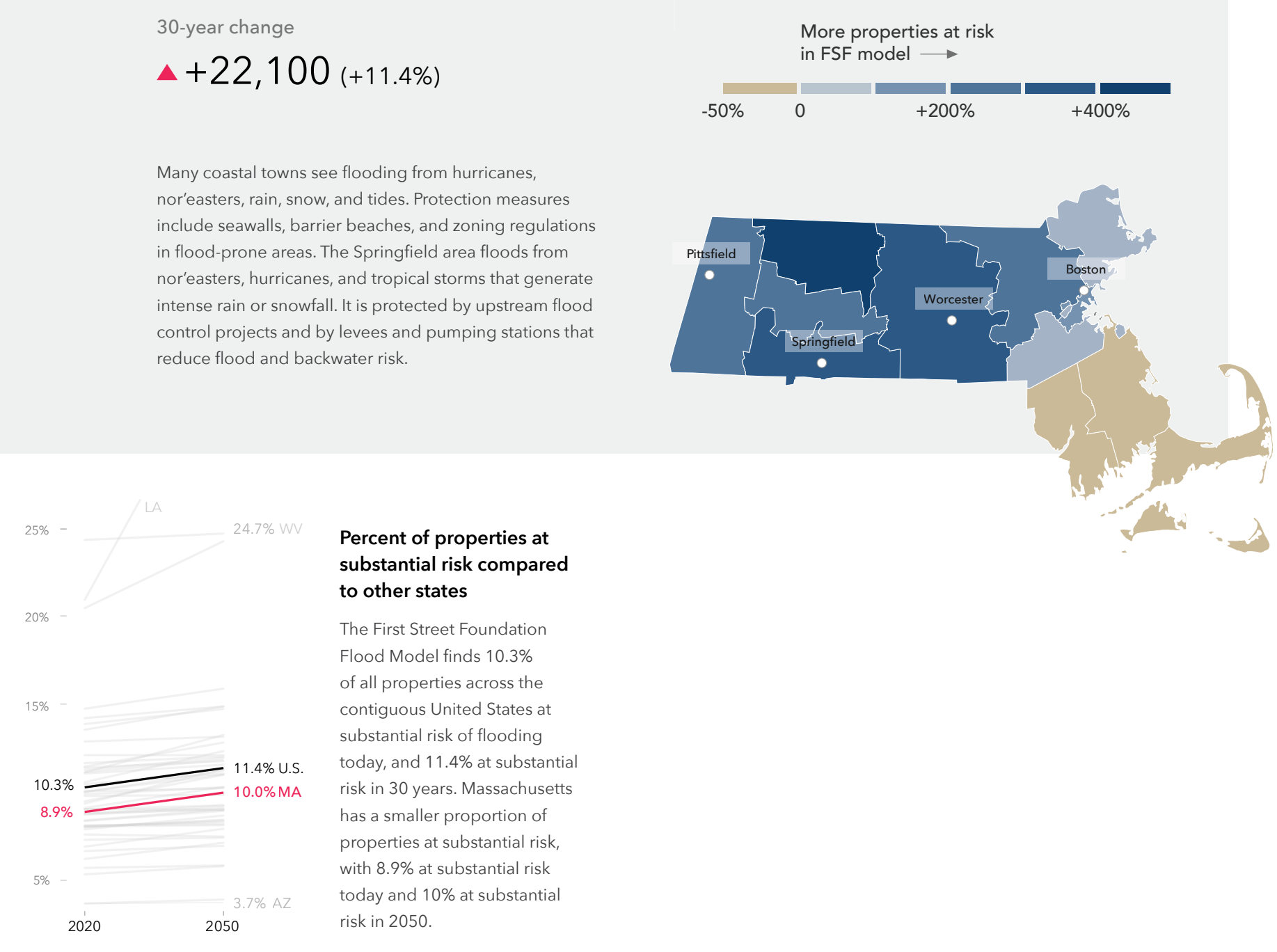




\section{Local details \\ Massachussets}

The First Street Foundation Flood Model calculates the number of properties facing any risk* of flooding. When looking at this broader level of risk, the data identifies 336,200 properties in Massachusetts as at risk over the next 30 years. Of these properties, 46,800 were categorized as facing almost certain risk, with a $99 \%$ chance of flooding at least once over the next 30 years.

The city of Boston has the greatest number of properties at risk of flooding in the state with 19,200 currently at risk, or 19\% of its total number of properties. However, smaller cities or municipalities in the state, with fewer properties, may have a greater proportion of their total properties at risk. For example, $64 \%$ of properties in Hull are at risk of flooding. Other municipalities will see the greatest increase in risk over the next 30 years. Dennis Port, for example, will see a 299\% increase in the number of properties at risk.

Click here for a full breakdown of counties, cities, zip codes, and congressional districts in Massachusetts at risk.

\section{Greatest proportion of properties at risk*}

\begin{tabular}{lrl|}
\hline Municipality & \multicolumn{2}{c}{2020} \\
\hline Hull & 3,056 & $65 \%$ \\
\hline Ocean Bluff-Brant Rock & 1,658 & $54 \%$ \\
\hline Adams & 1,070 & $48 \%$ \\
\hline Salisbury & 1,111 & $44 \%$ \\
\hline Provincetown & 906 & $40 \%$ \\
\hline Lawrence & 4,685 & $38 \%$ \\
\hline Winthrop Town & 1,575 & $35 \%$ \\
\hline North Adams & 1,676 & $32 \%$ \\
\hline Revere & 4,027 & $32 \%$ \\
\hline Wareham Center & 603 & $30 \%$ \\
\hline
\end{tabular}

\section{Greatest number of properties at risk*}

\begin{tabular}{lrlrlrl} 
Municipality & \multicolumn{2}{c}{2020} & \multicolumn{2}{c}{2050} & \multicolumn{2}{c}{ Change } \\
Boston & 19,177 & $19 \%$ & 27,819 & $28 \%$ & $+8,642$ & $+45.1 \%$ \\
\hline Worcester & 5,424 & $13 \%$ & 5,670 & $14 \%$ & +246 & $+4.5 \%$ \\
\hline Springfield & 4,766 & $11 \%$ & 4,989 & $12 \%$ & +223 & $+4.7 \%$ \\
\hline Lawrence & 4,685 & $38 \%$ & 4,963 & $41 \%$ & +278 & $+5.9 \%$ \\
\hline Quincy & 4,618 & $22 \%$ & 6,574 & $31 \%$ & $+1,956$ & $+42.4 \%$ \\
\hline Newton & 4,417 & $18 \%$ & 4,620 & $19 \%$ & +203 & $+4.6 \%$ \\
\hline Lowell & 4,291 & $20 \%$ & 4,648 & $21 \%$ & +357 & $+8.3 \%$ \\
\hline Revere & 4,027 & $32 \%$ & 5,034 & $39 \%$ & $+1,007$ & $+25.0 \%$ \\
\hline Lynn & 4,026 & $21 \%$ & 4,681 & $24 \%$ & +655 & $+16.3 \%$ \\
\hline Hull & 3,056 & $65 \%$ & 3,236 & $68 \%$ & +180 & $+5.9 \%$
\end{tabular}

\section{Greatest relative growing risk*}

\begin{tabular}{|c|c|c|c|c|c|c|}
\hline Municipality & & 20 & & 050 & & range \\
\hline Dennis Port & 364 & $10 \%$ & 1,452 & $38 \%$ & +1088 & $+299 \%$ \\
\hline Falmouth & 322 & $12 \%$ & 903 & $34 \%$ & +581 & $+180 \%$ \\
\hline Harwich Port & 184 & $9 \%$ & 445 & $21 \%$ & +261 & $+142 \%$ \\
\hline Chelsea & 691 & $14 \%$ & 1,425 & $29 \%$ & +734 & $+106 \%$ \\
\hline Cambridge & 3,048 & $23 \%$ & 5,595 & $43 \%$ & $+2,547$ & $+84 \%$ \\
\hline West Yarmouth & 705 & $16 \%$ & 1,293 & $30 \%$ & +588 & $+83 \%$ \\
\hline East Falmouth & 668 & $13 \%$ & 1,201 & $23 \%$ & +533 & $+80 \%$ \\
\hline Salem & 1,531 & $16 \%$ & 2,728 & $29 \%$ & $+1,197$ & $+78 \%$ \\
\hline Everett & 662 & $8 \%$ & 1,142 & $15 \%$ & +480 & $+73 \%$ \\
\hline Wareham Center & 603 & $30 \%$ & 1,023 & $50 \%$ & +420 & $+70 \%$ \\
\hline
\end{tabular}

\section{Flood Factor distribution of properties at risk ${ }^{\star}(1000 s)$}

\section{Risk level}

Minor

Moderate

91.8

Major

Extreme

More than $15.5 \%$ of individual properties and properties in Massachusetts are at any risk of flooding over the next 30 years. Out of those at risk $63 \%$ are at major to extreme risk.

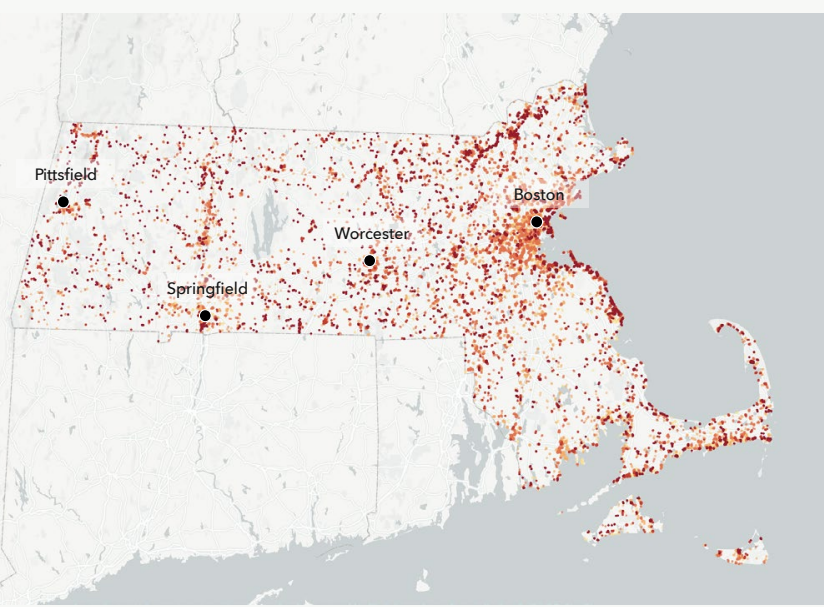




\section{Flood History \& Protection \\ Massachussets}

\section{Claims History}

88,000 home and property owners in Massachusetts have made flood damage claims through FEMA since the year 2000.* These claims for reimbursement were made through either the National Flood Insurance Program (NFIP) or Individual Assistance Program (IAP). The greatest number of claims since the year 2000 have been concentrated in Middlesex, Essex, Norfolk, Plymouth, and Bristol counties.

\section{Storm Simulation}

The First Street Foundation Flood Model has recreated 6 flooding events that have occurred since the year 2000 in the state of Massachusetts. These events flooded around 17,790 properties across the state **

\begin{tabular}{llr} 
Flood event & Date & $\begin{array}{r}\text { \# Properties } \\
\text { affected }\end{array}$ \\
Nor'easter & Feb 2003 & 2,616 \\
\hline Nor'easter & Nov 2009 & 3,565 \\
\hline - Nor'easter & Mar 2010 & 2,938 \\
\hline River flood near Springfield, MA & Aug 2011 & 658 \\
\hline Hurricane Irene & Aug 2011 & 103 \\
\hline Hurricane Sandy & Oct 2012 & 7,910
\end{tabular}

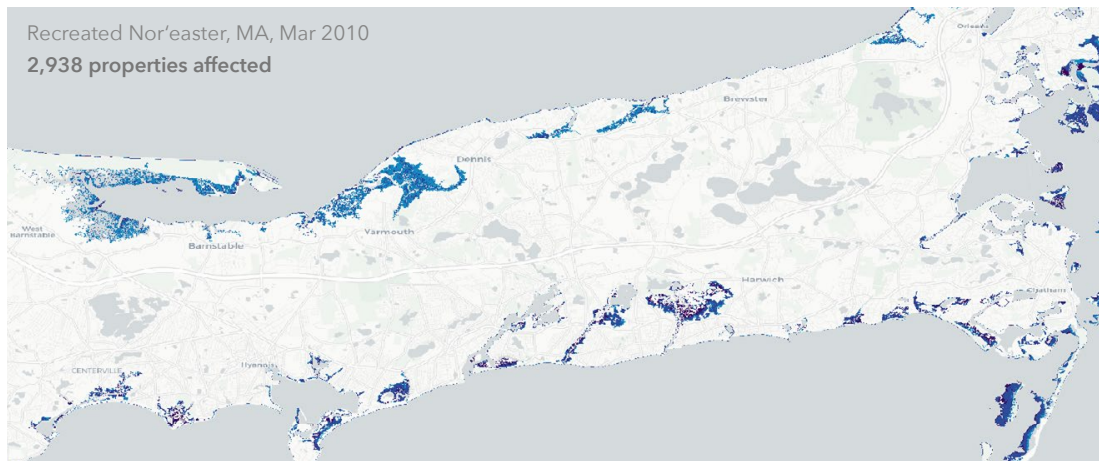

$\begin{array}{llll}0.5 & 1 & 2 & 3+\mathrm{ft}\end{array}$

* Source: Fema.gov

** Based on model simulation of historic events. Historic recreations do not include precipitation. See methodology for full model details.

\section{4,200}

Properties served by

protection measures

The First Street Foundation Flood

Model incorporates 935 flood control

measures throughout the state which

protect 34,200 properties.

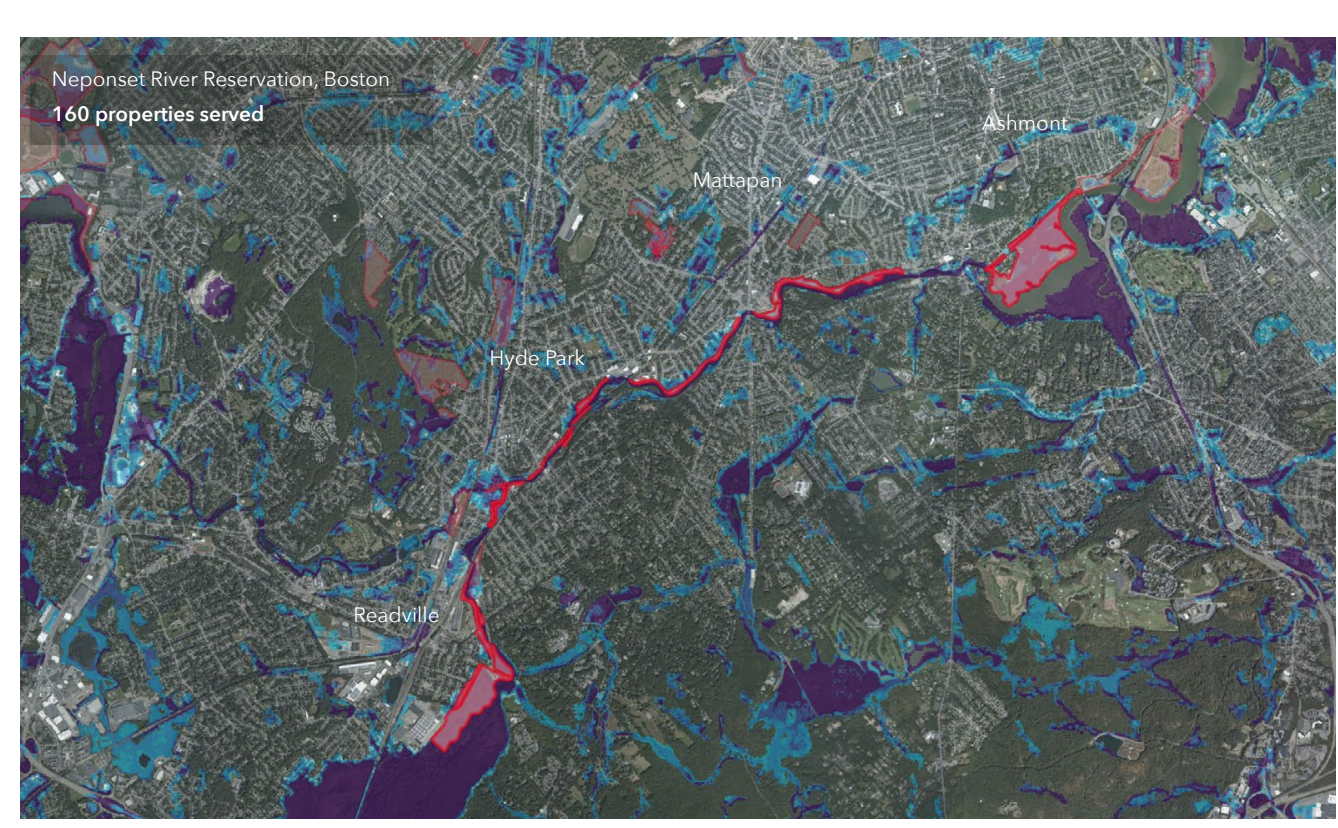

Area of protectio

0.5 1 Depth of flooding for a simulated

Top protection measures in state by quantity

Type
Example

Levee

( Chiv RB \& CT Riv LB - Chicopee, MA

Beach Barrie

Seawall

Marsh/wetland Restoration

tide gate

Hull-04, Bosto 


\section{State Overview \\ Michigan}

Flood risk is increasing in the state of Michigan. 315,600 properties currently have a substantial risk* of flooding. Over the next 30 years, the

number of properties with this risk will increase by another $4.5 \%$, bringing the total number of properties with substantial risk to 329,700 .

To understand personal flood risk, Americans leverage the Federal Emergency Management Agency (FEMA) Flood Insurance Rate Maps (FIRM). These maps identify 124,100 properties as having substantial risk in the state of Michigan. In comparison, the First Street Foundation

Flood Model identifies 2.5 times the number of properties as facing this same level of risk. This discrepancy exists because the Foundation uses the current climate data, maps precipitation as a stand-alone risk, and includes areas that FEMA has not mapped. These new methods uncover an additional 191,500 properties currently not identified by FEMA as having substantial risk. When adjusting for future environmental changes, the FEMA gap further widens to 205,600 by the year 2050 .
Difference in number of properties currently at substantial risk compared to FEMA ${ }^{\star \star}$

$315,600 \quad 329,700 \quad \Delta+191,500$ 30-year change

$\Delta+14,100$

$(+5 \%)$
More properties at risk in FSF model $\longrightarrow$

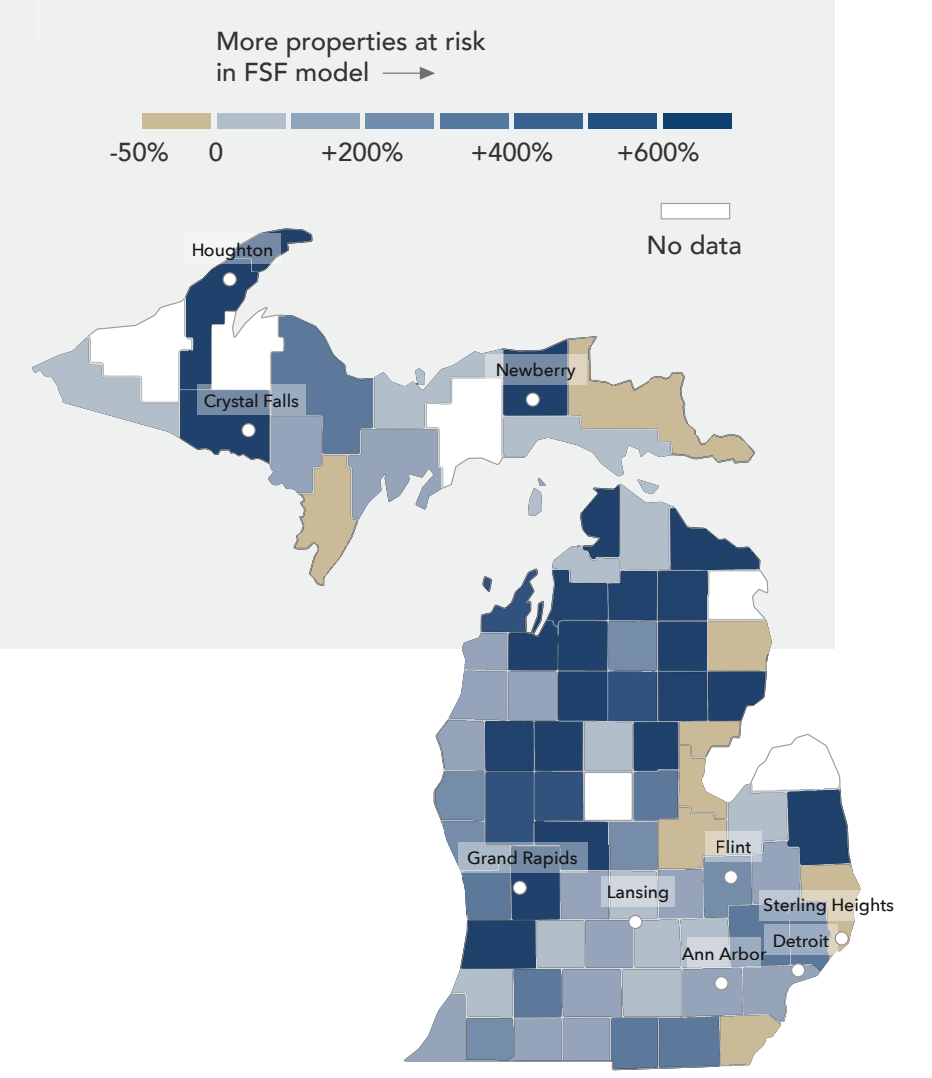

Percent of properties at substantial risk compared to other states
$20 \%$

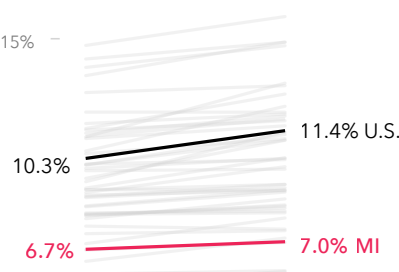

$5 \%$
The First Street Foundation Flood Model finds 10.3\% of all properties across the contiguous United States at substantial risk of flooding today, and $11.4 \%$ at substantial risk in 30 years. Michigan has a smaller proportion of properties at substantial risk, with $6.7 \%$ at substantial risk today and $7 \%$ at substantial risk in 2050 . 


\section{Local details \\ Michigan}

The First Street Foundation Flood Model calculates the number of properties facing any risk* of flooding. When looking at this broader level of risk, the data identifies 531,800 properties in Michigan as at risk over the next 30 years. Of these properties, 51,700 were categorized as facing almost certain risk, with a $99 \%$ chance of flooding at least once over the next 30 years.

The city of Detroit has the greatest number of properties at risk of flooding in the state with 39,700 currently at risk, or $10 \%$ of its total number of properties. However, smaller cities or municipalities in the state, with fewer properties, may have a greater proportion of their total properties at risk. For example, $81 \%$ of properties in River Rouge are at risk of flooding. Other municipalities will see the greatest increase in risk over the next 30 years. Milan, for example, will see a

$26 \%$ increase in the number of properties at risk.

Click here for a full breakdown of counties, cities, zip codes, and congressional districts in Michigan at risk.

\section{Greatest proportion of properties at risk*}

\begin{tabular}{lrr|} 
Municipality & \multicolumn{2}{c}{2020} \\
\hline River Rouge & 3,160 & $81 \%$ \\
\hline Grosse Pointe Woods & 4,102 & $60 \%$ \\
\hline Melvindale & 2,522 & $51 \%$ \\
\hline Manitou Beach-Devils Lake & 1,231 & $48 \%$ \\
\hline Ecorse & 2,109 & $42 \%$ \\
\hline Grosse Pointe Park & 1,789 & $42 \%$ \\
\hline Monroe & 2,687 & $36 \%$ \\
\hline Eaton Rapids & 656 & $31 \%$ \\
\hline Mount Clemens & 1,691 & $27 \%$ \\
\hline Port Huron & 3,293 & $26 \%$ \\
\hline
\end{tabular}

\section{Greatest number of properties at risk*}

\begin{tabular}{l|c|ccccc} 
Municipality & \multicolumn{2}{c}{2020} & \multicolumn{2}{c}{2050} & \multicolumn{2}{c}{ Change } \\
Detroit & 39,744 & $10 \%$ & 41,672 & $11 \%$ & $+1,928$ & $+4.9 \%$ \\
\hline Warren & 11,916 & $21 \%$ & 12,276 & $22 \%$ & +360 & $+3.0 \%$ \\
\hline Grand Rapids & 9,448 & $15 \%$ & 9,586 & $15 \%$ & +138 & $+1.5 \%$ \\
\hline Sterling Heights & 5,485 & $12 \%$ & 5,753 & $13 \%$ & +268 & $+4.9 \%$ \\
\hline Lansing & 5,164 & $12 \%$ & 5,263 & $12 \%$ & +99 & $+1.9 \%$ \\
\hline Flint & 5,161 & $9 \%$ & 5,212 & $9 \%$ & +51 & $+1.0 \%$ \\
\hline Dearborn & 5,051 & $15 \%$ & 5,266 & $15 \%$ & +215 & $+4.3 \%$ \\
\hline Dearborn Heights & 4,672 & $19 \%$ & 4,824 & $20 \%$ & +152 & $+3.3 \%$ \\
\hline St. Clair Shores & 4,115 & $15 \%$ & 4,289 & $16 \%$ & +174 & $+4.2 \%$ \\
\hline Grosse Pointe & 4,102 & $60 \%$ & 4,120 & $60 \%$ & +18 & $+0.4 \%$
\end{tabular}

Woods

\section{Greatest relative growing risk*}

\begin{tabular}{lrrrrrr} 
Municipality & \multicolumn{2}{c}{2020} & \multicolumn{2}{c}{2050} & \multicolumn{2}{c}{ Change } \\
Milan & 157 & $6 \%$ & 197 & $8 \%$ & +40 & $+26 \%$ \\
\hline Southfield & 1,294 & $5 \%$ & 1,622 & $7 \%$ & +328 & $+25 \%$ \\
\hline Center Line & 200 & $7 \%$ & 232 & $8 \%$ & +32 & $+16 \%$ \\
\hline Riverview & 169 & $4 \%$ & 196 & $5 \%$ & +27 & $+16 \%$ \\
\hline Grosse Pointe & 141 & $6 \%$ & 163 & $6 \%$ & +22 & $+16 \%$ \\
\hline Hamtramck & 749 & $11 \%$ & 863 & $13 \%$ & +114 & $+15 \%$ \\
\hline Garden City & 693 & $6 \%$ & 783 & $7 \%$ & +90 & $+13 \%$ \\
\hline Rogers City & 70 & $3 \%$ & 79 & $4 \%$ & +9 & $+13 \%$ \\
\hline Livonia & 1,692 & $4 \%$ & 1,901 & $5 \%$ & +209 & $+12 \%$ \\
\hline Southgate & 211 & $2 \%$ & 237 & $2 \%$ & +26 & $+12 \%$
\end{tabular}

\section{Flood Factor distribution of properties at risk ${ }^{\star}(1000 s)$}

\section{Risk level}

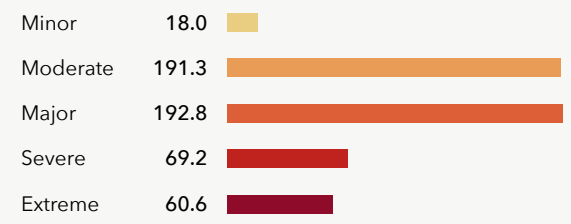

More than $11.2 \%$ of individual properties and properties in Michigan are at any risk of flooding over the next 30 years. Out of those at risk $61 \%$ are at major to extreme risk.

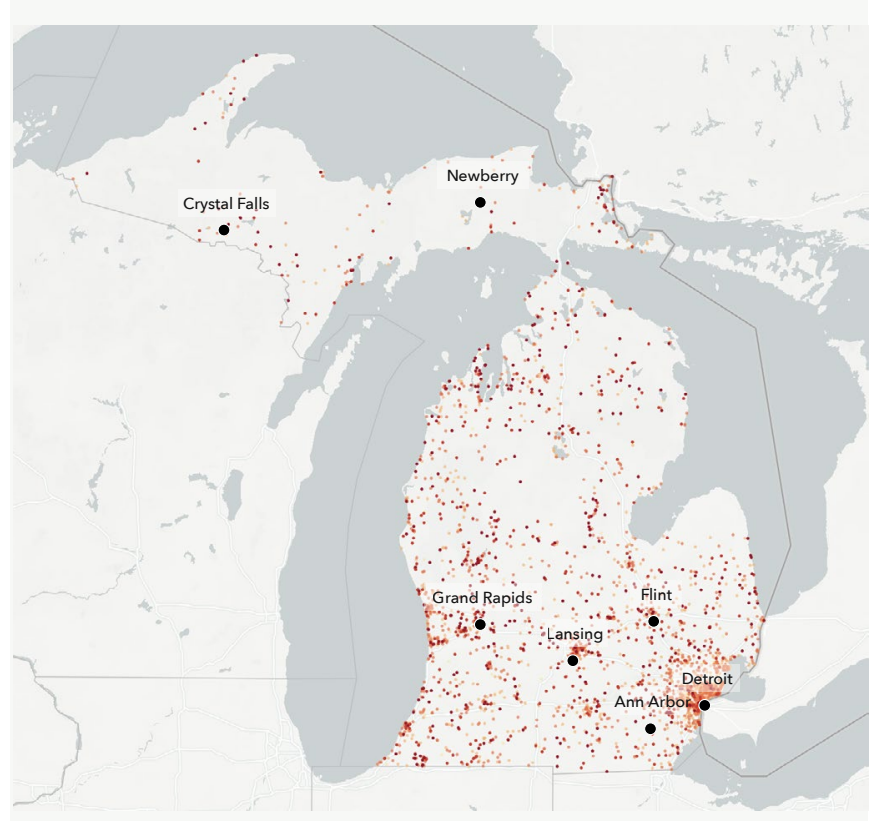




\section{Flood History \& Protection \\ Michigan}

\section{Claims History}

238,900 home and property owners in Michigan have made flood damage claims through FEMA since the year 2000.* These claims for reimbursement were made through either the National Flood Insurance Program (NFIP) or Individual Assistance Program (IAP). The greatest number of claims since the year 2000 have been concentrated in Wayne, Oakland, Macomb, Midland, and Genesee counties.

\section{Storm Simulation}

The First Street Foundation Flood Model has recreated 3 flooding events that have occurred since the year 2000 in the state of Michigan. These events flooded around 2,490 properties across the state $* \star$
Flood event
Date
\# Properties
affected

River flood near Lansing, Ml

May $2004 \quad 1,232$

- River flood near Grand Rapids, MI

Apr 2013

1,162

River flood in Southeast M

Jun 2015
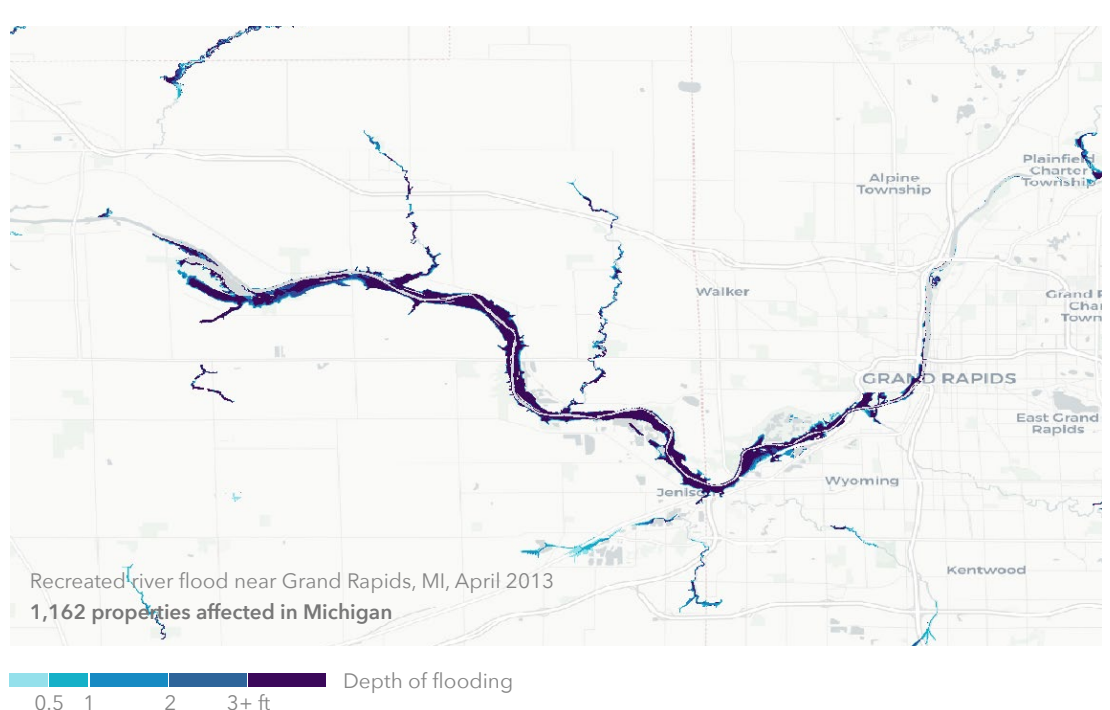

\section{9,600}

Properties served by

protection measures

The First Street Foundation Flood

Model incorporates 77 flood control

measures throughout the state which

protect 29,600 properties.

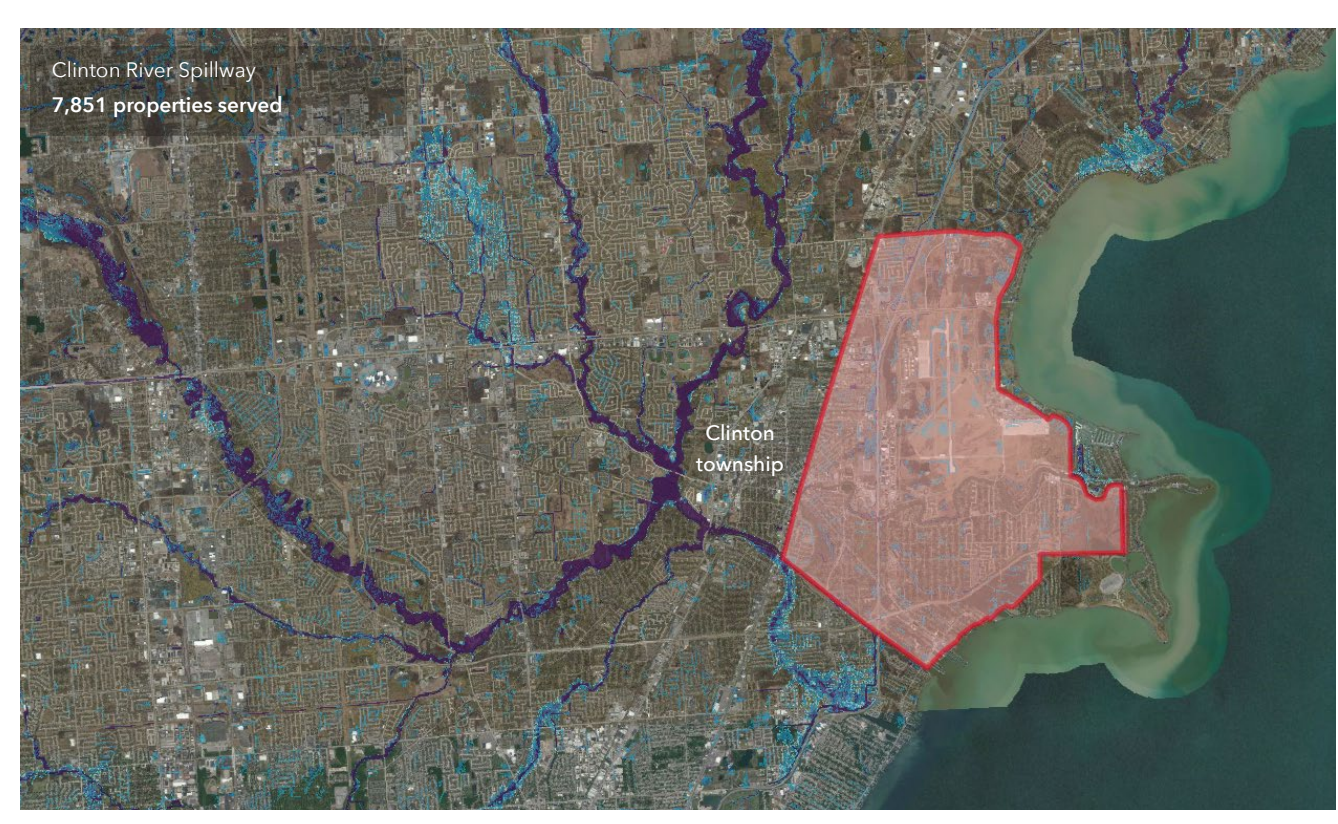

$\square$ Area of protection

Top protection measures in state by quantity

\begin{tabular}{lc}
$\begin{array}{l}\text { Type } \\
\text { Example }\end{array}$ & \# Properties served by type \\
Spillway & \\
- Clinton River Spillway & 9,555 \\
$\begin{array}{l}\text { Tide gate } \\
\text { Milk River Flood Control Structure, Grosse Pointe Woods }\end{array}$ & 8,302 \\
\hline $\begin{array}{l}\text { Levee } \\
\text { Grand Rapids Levee/Floodwall, Grand Rapids }\end{array}$ & 8,483 \\
\hline $\begin{array}{l}\text { Culvert } \\
\text { Mallets Creek improvement, Ann Arbor }\end{array}$ & 1,026 \\
\hline $\begin{array}{l}\text { Ditch } \\
\text { Battle Creek Cut-Off Channel and Flood Control Improvements }\end{array}$
\end{tabular}

Battle Creek Cut-Off Channel and Flood Control Improvements 


\section{State Overview \\ Minnesota}

Difference in number of properties currently at substantial risk compared to FEMA**

$$
\Delta+138,764
$$

Flood risk is increasing in the state of Minnesota. 215,600 properties currently have a substantial risk* of flooding. Over the next 30 years, the number of properties with this risk will increase by another $1.6 \%$, bringing the total number of properties with substantial risk to 219,100

To understand personal flood risk, Americans leverage the Federal Emergency Management Agency (FEMA) Flood Insurance Rate Maps (FIRM). These maps identify 76,800 properties as having substantial risk in the state of Minnesota. In comparison, the First Street Foundation Flood Model identifies 2.8 times the number of properties as facing this same level of risk. This discrepancy exists because the Foundation uses the current climate data, maps precipitation as a stand-alone risk, and includes areas that FEMA has not mapped. These new methods uncover an additional 138,800 properties currently not identified by FEMA as having substantial risk. When adjusting for future environmental changes, the FEMA gap further widens to 142,300 by the year 2050 .
Total properties at substantial risk *

In 2020

215,600

30-year change

$$
\triangle+3,500
$$

Flash floods occur throughout the state. Southeastern Minnesota, including the twin cities, encounters thunderstorms and heavy rainfall, leading to large scale flooding which overwhelms roads and highways making areas inaccessible. On the western side of the state, the Red River regularly overtops its banks from heavy autumn and winter precipitation as well as early spring snow melt.

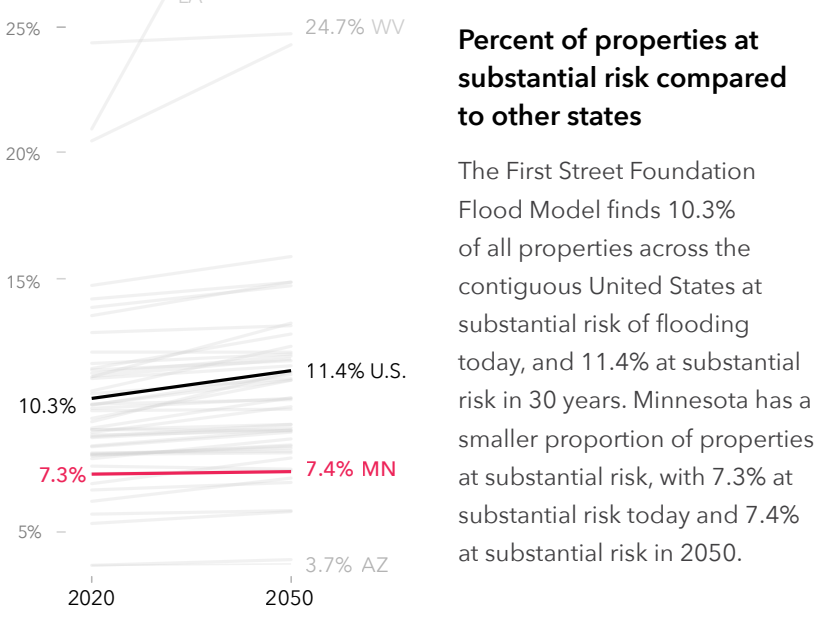

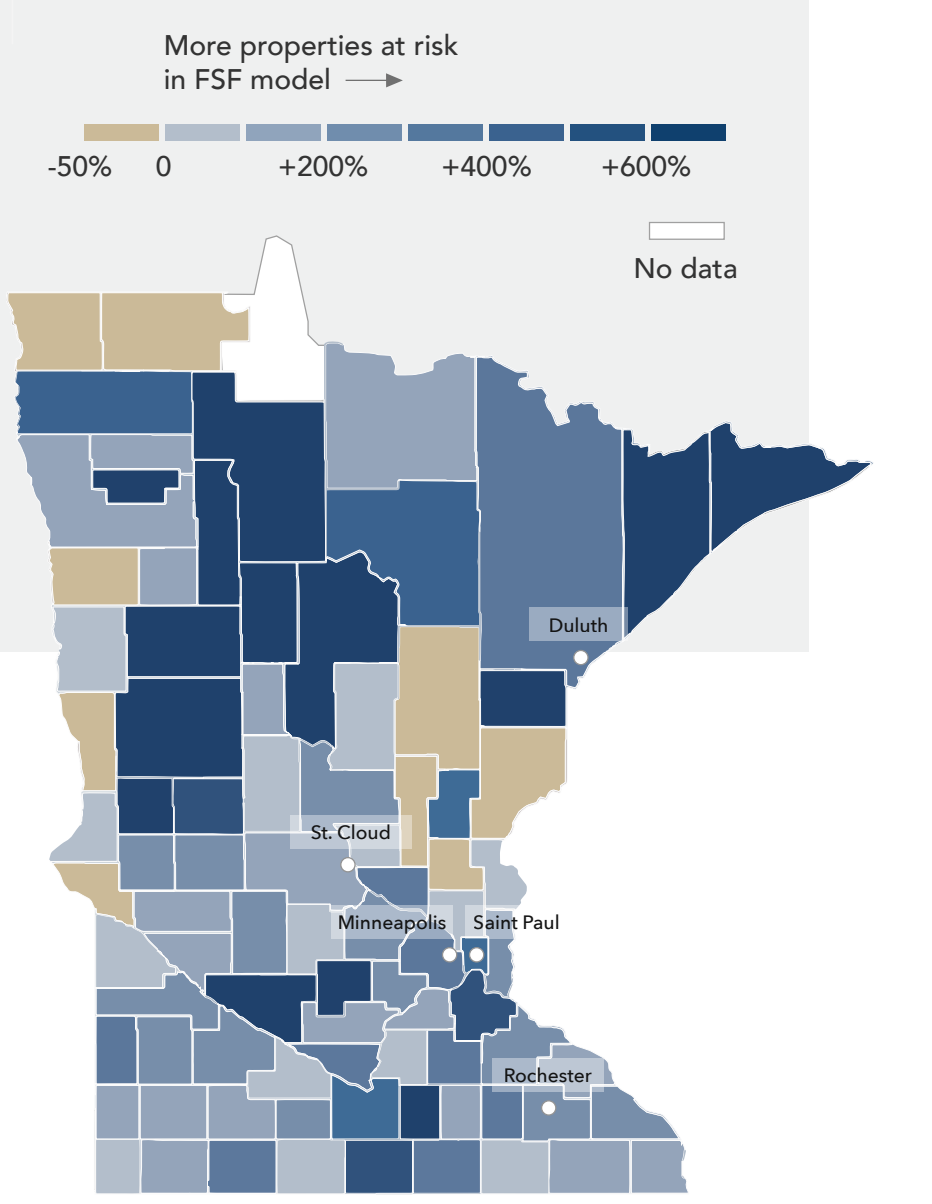

* Substantial risk is calculated as inundation $1 \mathrm{~cm}$ or more to the building in the 100 return period ( $1 \%$ annual risk) and rounded to the nearest 100 properties. See methodology for full model details. ${ }^{*}$ * Combstantial risk is calculated as inundation $1 \mathrm{~cm}$ or more to the bailding in the 100 return period $1 \%$ annual risk) and rounded to the nearest 100 properties. See methodology for full model de FEMA counts due to a variety of factors, including the generalization of SFHAs, assumptions around flood protection measures, and local context. FFMA zones are estimated by MassiveCert. Inc. 


\section{Local details \\ Minnesota}

The First Street Foundation Flood Model calculates the number of properties facing any risk* of flooding. When looking at this broader level of risk, the data identifies 322,300 properties in Minnesota as at risk over the next 30 years. Of these properties, 43,000 were categorized as facing almost certain risk, with a $99 \%$ chance of

flooding at least once over the next 30 years.

The city of Minneapolis has the greatest number of properties at risk of flooding in the state with 10,700 currently at risk, or $10 \%$ of its total number of properties. However, smaller cities or municipalities in the state, with fewer properties, may have a greater proportion of their total properties at risk. For example, 55\% of properties in East Grand Forks are at risk of flooding Other municipalities will see the greatest increase in risk over the next 30 years. Waite Park, for example, will see a $8 \%$ increase in the number of properties at risk.

Click here for a full breakdown of counties, cities, zip codes, and congressional districts in Minnesota at risk.

\section{Greatest proportion of properties at risk*}

\begin{tabular}{lrr|} 
Municipality & \multicolumn{2}{c}{2020} \\
East Grand Forks & 1,960 & $55 \%$ \\
\hline Winona & 4,567 & $49 \%$ \\
\hline Little Falls & 1,698 & $37 \%$ \\
\hline Champlin & 2,921 & $36 \%$ \\
\hline North Mankato & 1,826 & $36 \%$ \\
\hline Crookston & 1,016 & $31 \%$ \\
\hline Dayton & 922 & $29 \%$ \\
\hline Anoka & 1,624 & $28 \%$ \\
\hline Virginia & 1,178 & $25 \%$ \\
\hline Monticello & 1,120 & $22 \%$ \\
\hline
\end{tabular}

\section{Greatest number of properties at risk ${ }^{*}$}

\begin{tabular}{l|cccccc} 
Municipality & \multicolumn{2}{c}{2020} & \multicolumn{2}{c}{2050} & \multicolumn{2}{c}{ Change } \\
\cline { 2 - 3 } & 10,730 & $11 \%$ & 10,860 & $11 \%$ & +130 & $+1.2 \%$ \\
\hline St. Paul & 7,345 & $10 \%$ & 7,392 & $10 \%$ & +47 & $+0.6 \%$ \\
\hline Duluth & 5,445 & $11 \%$ & 5,525 & $11 \%$ & +80 & $+1.5 \%$ \\
\hline Rochester & 5,088 & $12 \%$ & 5,094 & $12 \%$ & +6 & $+0.1 \%$ \\
\hline Winona & 4,567 & $49 \%$ & 4,650 & $49 \%$ & +83 & $+1.8 \%$ \\
\hline Coon Rapids & 2,975 & $13 \%$ & 2,991 & $14 \%$ & +16 & $+0.5 \%$ \\
\hline Brooklyn Park & 2,928 & $13 \%$ & 2,949 & $13 \%$ & +21 & $+0.7 \%$ \\
\hline Champlin & 2,921 & $36 \%$ & 2,932 & $36 \%$ & +11 & $+0.4 \%$ \\
\hline Lakeville & 2,658 & $12 \%$ & 2,697 & $12 \%$ & +39 & $+1.5 \%$ \\
\hline St. Cloud & 2,541 & $12 \%$ & 2,630 & $13 \%$ & +89 & $+3.5 \%$
\end{tabular}

\section{Greatest relative growing risk*}

\begin{tabular}{lrrrrr} 
Municipality & 2020 & \multicolumn{2}{c}{2050} & \multicolumn{2}{c}{ Change } \\
Waite Park & $11 \%$ & 265 & $11 \%$ & +20 & $+8 \%$ \\
\hline International Falls & $8 \%$ & 310 & $9 \%$ & +22 & $+8 \%$ \\
\hline St. Joseph & $4 \%$ & 87 & $4 \%$ & +6 & $+7 \%$ \\
\hline Princeton & $10 \%$ & 232 & $10 \%$ & +13 & $+6 \%$ \\
\hline Hermantown & $4 \%$ & 185 & $4 \%$ & +9 & $+5 \%$ \\
\hline Park Rapids & $13 \%$ & 307 & $14 \%$ & +15 & $+5 \%$ \\
\hline Chanhassen & $5 \%$ & 509 & $5 \%$ & +23 & $+5 \%$ \\
\hline West St. Paul & $7 \%$ & 430 & $7 \%$ & +19 & $+5 \%$ \\
\hline Zimmerman & $5 \%$ & 114 & $5 \%$ & +5 & $+5 \%$ \\
\hline Sauk Rapids & $7 \%$ & 362 & $8 \%$ & +14 & $+4 \%$ \\
\hline
\end{tabular}

\section{Flood Factor distribution of properties at risk ${ }^{\star}(1000 s)$}

\section{Risk leve}

Mino

99.8

Major $\quad 112.5$

Severe

52.7

Extreme

52.2

More than $10.9 \%$ of individual properties and properties in

Minnesota are at any risk of flooding over the next 30 years. Out of those at risk $67 \%$ are at major to extreme risk.

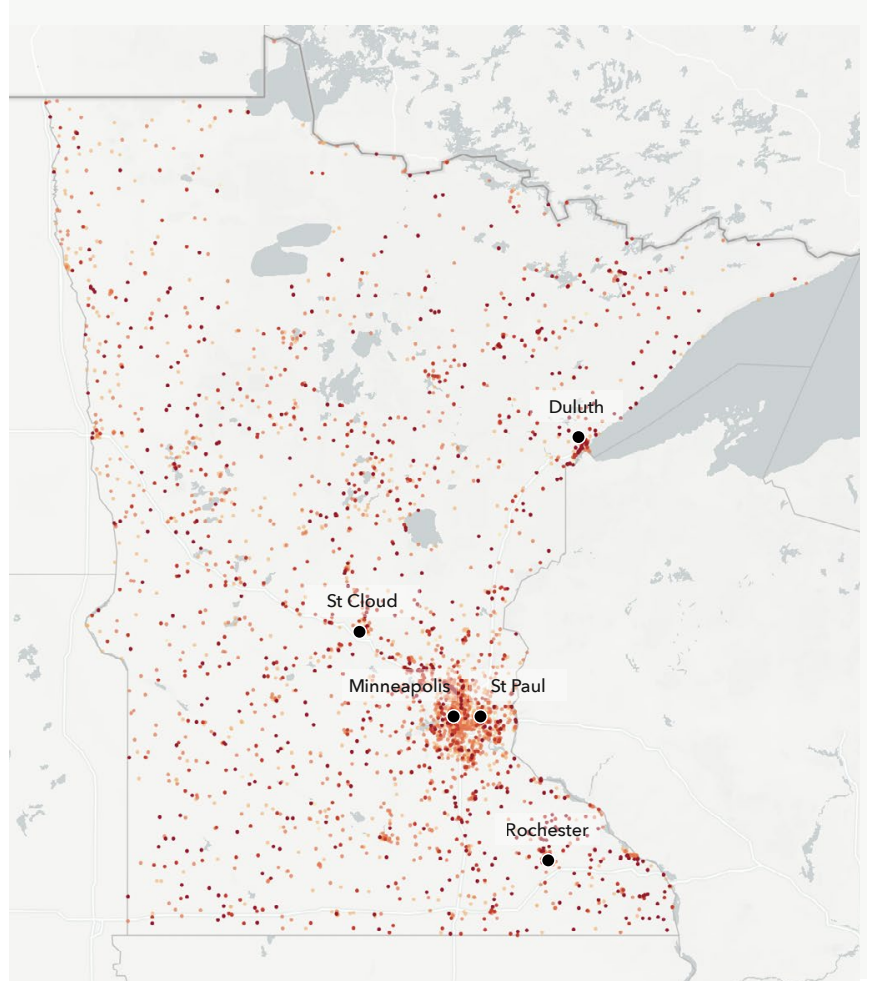




\section{Flood History \& Protection}

\section{Minnesota}

\section{Claims History}

22,600 home and property owners in Minnesota have made flood damage claims through FEMA since the year 2000.* These claims for reimbursement were made through either the National Flood Insurance Program (NFIP) or Individual Assistance Program (IAP). The greatest number of claims since the year 2000 have been concentrated in Winona, Olmsted, Freeborn, Houston, and Clay counties.

\section{Storm Simulation}

The First Street Foundation Flood Model has recreated 2 flooding events that have occurred since the year 2000 in the state of Minnesota. These events flooded around 2,310 properties across the state $* \star$
Flood event
\# Properties
affected
River flood near Minneapolis, MN
Apr 2001$$
\text { affected }
$$

- River flood near Winona, MN

Apr 2001 311
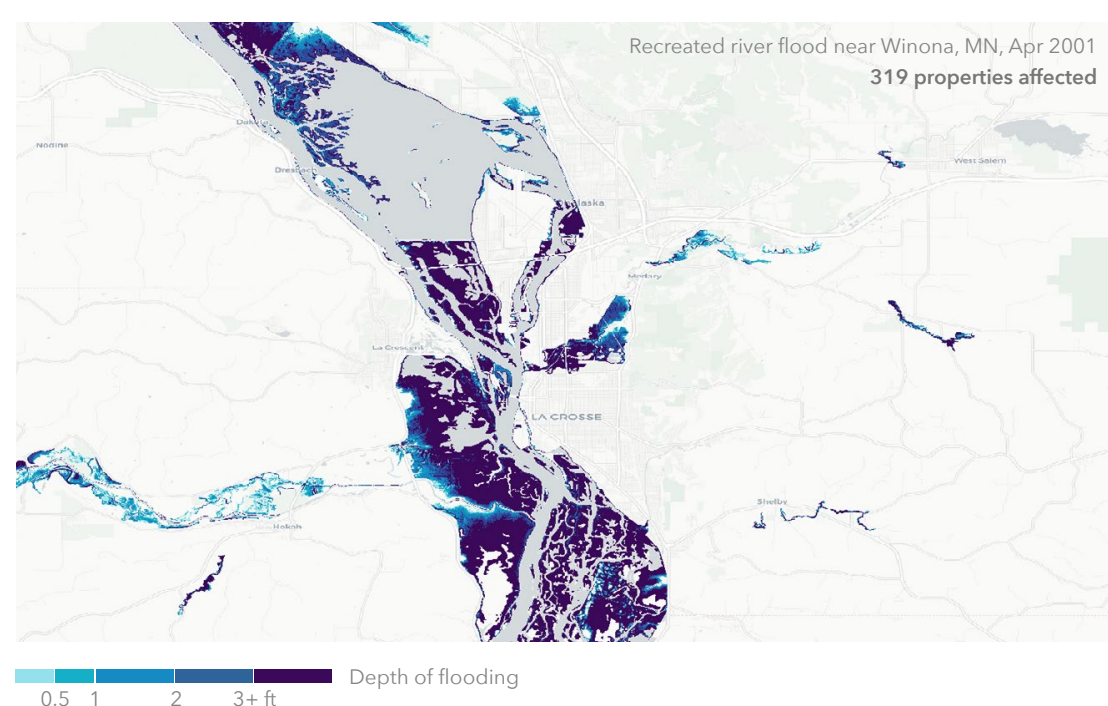

\section{6,200}

Properties served by

protection measures

The First Street Foundation Flood

Model incorporates 148 flood control

measures throughout the state which

protect 26,200 properties.

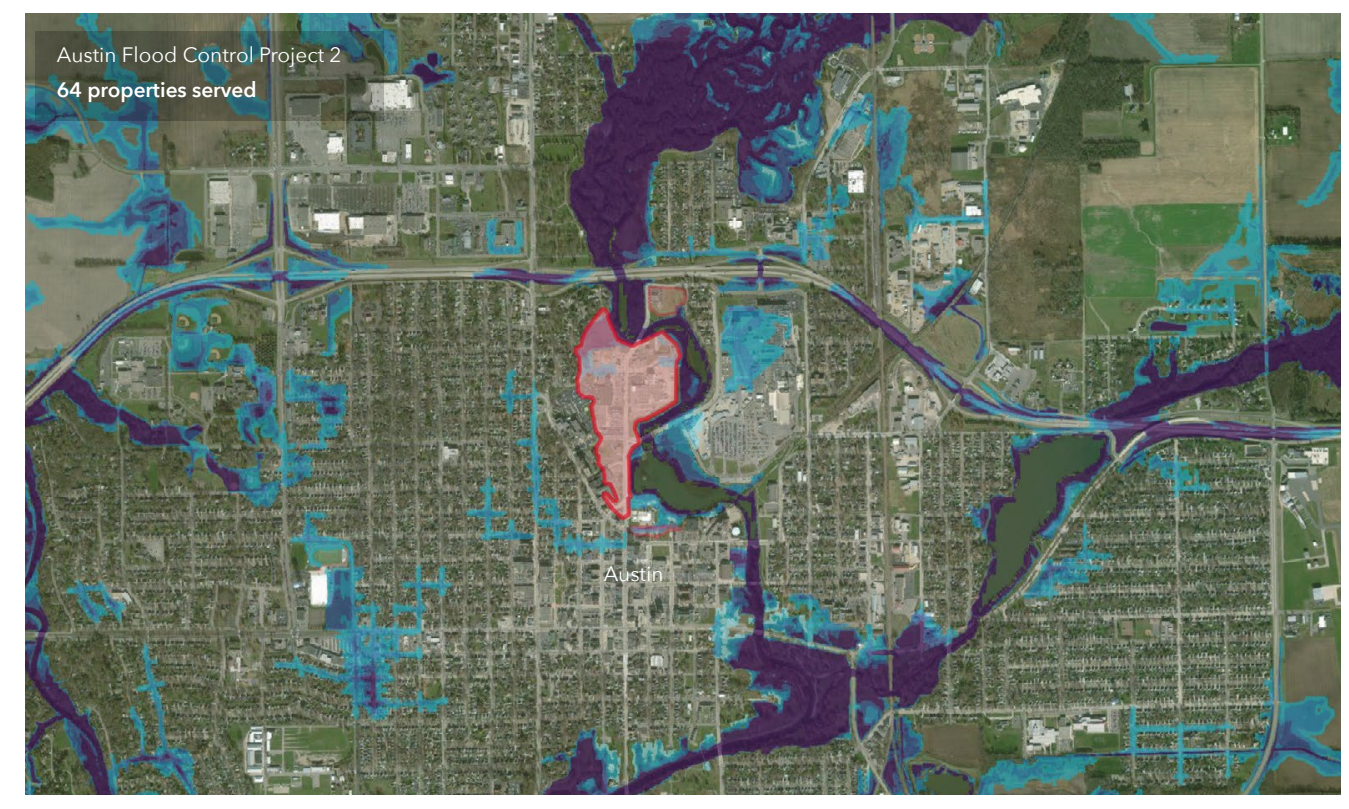

Area of protectio
Top protection measures in state by quantity

$$
\begin{aligned}
& \text { Type } \\
& \text { Example }
\end{aligned}
$$

Levee

Dike

Detention basin

Rain garden
The Rose Apartments Stormwater Plan, Minneapolis

* Source: Fema.gov

** Based on model simulation of historic events. Historic recreations do not include precipitation. See methodology for full model details. 


\section{State Overview Mississippi}

Flood risk is increasing in the state of Mississippi. 255,700 properties currently have a substantial risk* of flooding. Over the next 30 years, the number of properties with this risk will increase by another $9.8 \%$, bringing the total number of properties with substantial risk to 280,700

To understand personal flood risk, Americans leverage the Federal Emergency Management Agency (FEMA) Flood Insurance Rate Maps (FIRM). These maps identify 249,700 properties as having substantial risk in the state of Mississippi. In comparison, the First Street Foundation Flood Model identifies nearly 6,000 properties as facing this same level of risk. This discrepancy exists because the Foundation uses the current climate data, maps precipitation as a stand-alone risk, and includes areas that FEMA has not mapped. These new methods uncover an additional 5,900 properties currently not identified by FEMA as having substantial risk. When adjusting for future environmental changes, the FEMA gap further widens to 31,000 by the year 2050 .
Total properties at substantial risk *

$\ln 2020$

$255,700 \quad 280,700$

30-year change

$\Delta+25,000(+10 \%)$

Biloxi and the Mississippi Gulf Coast are especially exposed to storm surge and wave action during hurricane season, when heavy rains and tropical storms cause rivers, streams, and tributaries to overflow. The Mississippi, Yazoo, and Big Black Rivers flow through and alongside Warren County, which is subject to recurrent, large-scale flooding from frequent overflow.

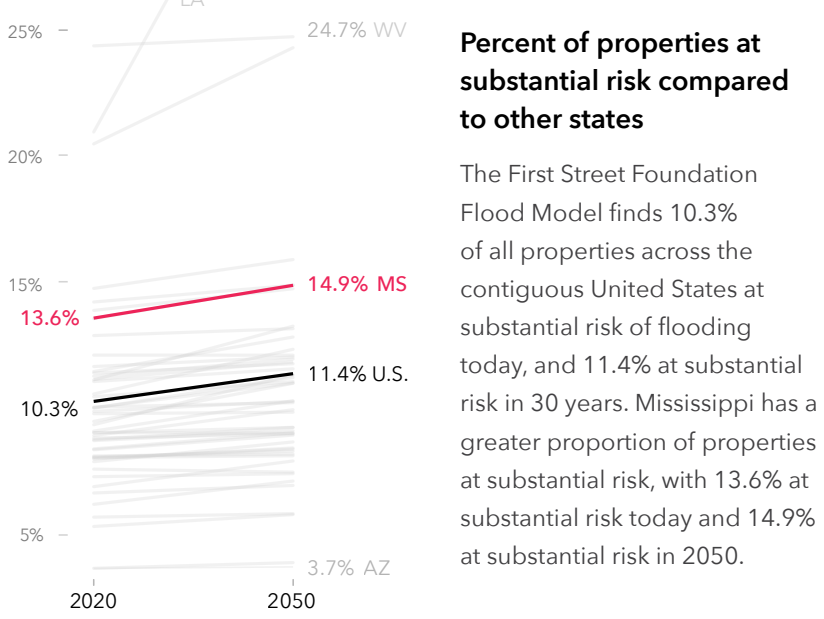

Difference in number of properties currently at substantial risk compared to FEMA**

$$
\Delta+5,900
$$

More properties at risk in FSF model $\longrightarrow$

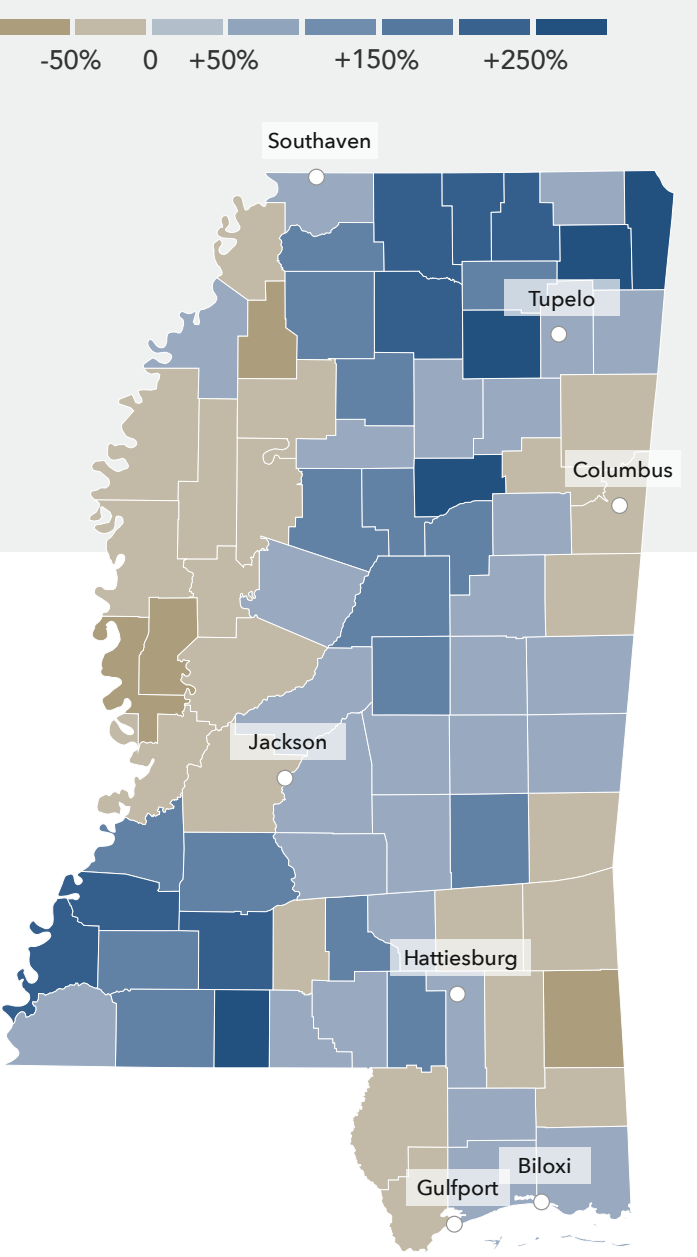




\section{Local details Mississippi}

The First Street Foundation Flood Model calculates the number of properties facing any risk* of flooding. When looking at this broader level of risk, the data identifies 352,100 properties in Mississippi as at risk over the next 30 years. Of these properties, 78,300 were categorized as facing almost certain risk, with a $99 \%$ chance of flooding at least once over the next 30 years.

The city of Jackson has the greatest number of properties at risk of flooding in the state with 10,300 currently at risk, or $14 \%$ of its total number of properties. However, smaller cities or municipalities in the state, with fewer properties, may have a greater proportion of their total properties at risk. For example, $98 \%$ of properties in Pascagoula are at risk of flooding. Other municipalities will see the greatest

increase in risk over the next 30 years. Ocean Springs, for example, will see a $166 \%$ increase in the number of properties at risk.

Click here for a full breakdown of counties, cities, zip codes, and congressional districts in Mississippi at risk.

\section{Greatest proportion of properties at risk*}

\begin{tabular}{lll} 
Municipality & \multicolumn{2}{c}{2020} \\
\hline Pascagoula & 9,706 & $98 \%$ \\
\hline Waveland & 7,482 & $91 \%$ \\
\hline Greenwood & 6,427 & $90 \%$ \\
\hline Bay St. Louis & 9,826 & $84 \%$ \\
\hline Pass Christian & 5,010 & $79 \%$ \\
\hline Moss Point & 6,310 & $73 \%$ \\
\hline Escatawpa & 1,384 & $63 \%$ \\
\hline Gautier & 6,298 & $61 \%$ \\
\hline D'lberville & 2,345 & $59 \%$ \\
\hline Gulf Park Estates & 2,154 & $56 \%$ \\
\hline
\end{tabular}

\section{Greatest number of properties at risk*}

\begin{tabular}{lcccccc} 
Municipality & \multicolumn{2}{c}{2020} & \multicolumn{2}{c}{2050} & \multicolumn{2}{c}{ Change } \\
Jackson & 10,287 & $14 \%$ & 10,918 & $15 \%$ & +631 & $+6.1 \%$ \\
\hline Gulfport & 10,079 & $30 \%$ & 14,825 & $44 \%$ & $+4,746$ & $+47.1 \%$ \\
\hline Bay St. Louis & 9,826 & $84 \%$ & 10,268 & $88 \%$ & +442 & $+4.5 \%$ \\
\hline Pascagoula & 9,706 & $98 \%$ & 9,718 & $98 \%$ & +12 & $+0.1 \%$ \\
\hline Biloxi & 9,461 & $52 \%$ & 13,359 & $73 \%$ & $+3,898$ & $+41.2 \%$ \\
\hline Waveland & 7,482 & $91 \%$ & 7,649 & $93 \%$ & +167 & $+2.2 \%$ \\
\hline Greenwood & 6,427 & $90 \%$ & 6,624 & $93 \%$ & +197 & $+3.1 \%$ \\
\hline Moss Point & 6,310 & $73 \%$ & 7,167 & $83 \%$ & +857 & $+13.6 \%$ \\
\hline Gautier & 6,298 & $61 \%$ & 7,194 & $70 \%$ & +896 & $+14.2 \%$ \\
\hline Hattiesburg & 5,685 & $27 \%$ & 6,019 & $29 \%$ & +334 & $+5.9 \%$
\end{tabular}

Greatest relative growing risk*

\begin{tabular}{|c|c|c|c|c|c|c|}
\hline Municipality & & 20 & & 050 & & ange \\
\hline Ocean Springs & 1,824 & $21 \%$ & 4,847 & $57 \%$ & +3023 & $+166 \%$ \\
\hline Gulf Hills & 709 & $18 \%$ & 1,337 & $34 \%$ & +628 & $+89 \%$ \\
\hline Gulf Park Estates & 2,154 & $56 \%$ & 3,548 & $93 \%$ & +1394 & $+65 \%$ \\
\hline Gulfport & 10,079 & $30 \%$ & 14,825 & $44 \%$ & $+4,746$ & $+47 \%$ \\
\hline Long Beach & 2,810 & $37 \%$ & 4,127 & $54 \%$ & +1317 & $+47 \%$ \\
\hline Biloxi & 9,461 & $52 \%$ & 13,359 & $73 \%$ & $+3,898$ & $+41 \%$ \\
\hline Latimer & 347 & $10 \%$ & 473 & $14 \%$ & +126 & $+36 \%$ \\
\hline Escatawpa & 1,384 & $63 \%$ & 1,865 & $84 \%$ & +481 & $+35 \%$ \\
\hline D'lberville & 2,345 & $59 \%$ & 3,034 & $76 \%$ & +689 & $+29 \%$ \\
\hline St. Martin & 1,852 & $55 \%$ & 2,326 & $69 \%$ & +474 & $+26 \%$ \\
\hline
\end{tabular}

\section{Flood Factor distribution of properties at risk ${ }^{\star}(1000 \mathrm{~s})$}

\section{Risk leve}

Mino

25.0

Major $\quad 110.5$

Severe

43.9

Extreme

12.0

More than $18.7 \%$ of individual properties and properties in Mississippi are at any risk of flooding over the next 30 years. Out of those at risk $76 \%$ are at major to extreme risk.

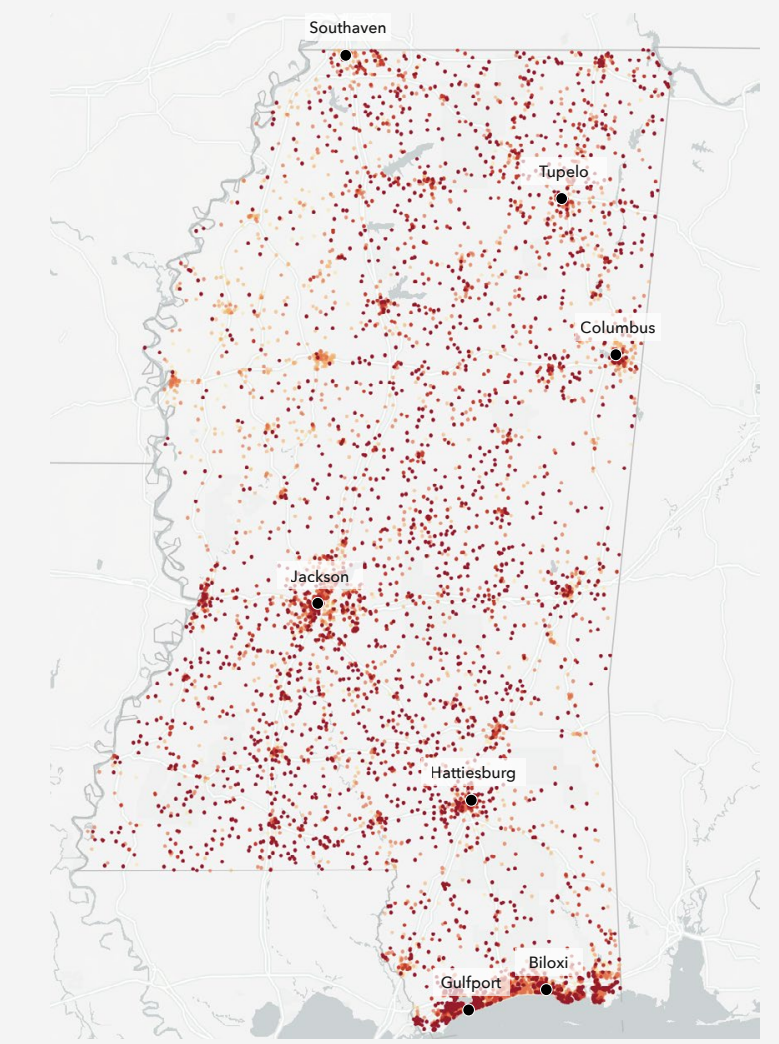




\section{Flood History \& Protection}

\section{Mississippi}

\section{Claims History}

1,087,200 home and property owners in Mississippi have made flood damage claims through FEMA since the year 2000.* These claims for reimbursement were made through either the National Flood Insurance Program (NFIP) or Individual Assistance Program (IAP). The greatest number of claims since the year 2000 have been concentrated in Harrison, Jackson, Hancock, Jones, and Forrest counties.

\section{Storm Simulation}

The First Street Foundation Flood Model has recreated 4 flooding events that have occurred since the year 2000 in the state of Mississippi. These events flooded around 119,760 properties across the state. ${ }^{\star \star}$

\begin{tabular}{llr} 
Flood event & Date & $\begin{array}{r}\text { \# Properties } \\
\text { affected }\end{array}$ \\
Hurricane Isidore & Sep 2002 & 14,260 \\
\hline Hurricane Katrina & Aug 2005 & 71,282 \\
\hline Hurricane Gustav & Aug 2008 & 17,519 \\
\hline Hurricane Isaac & Aug 2012 & 16,703
\end{tabular}

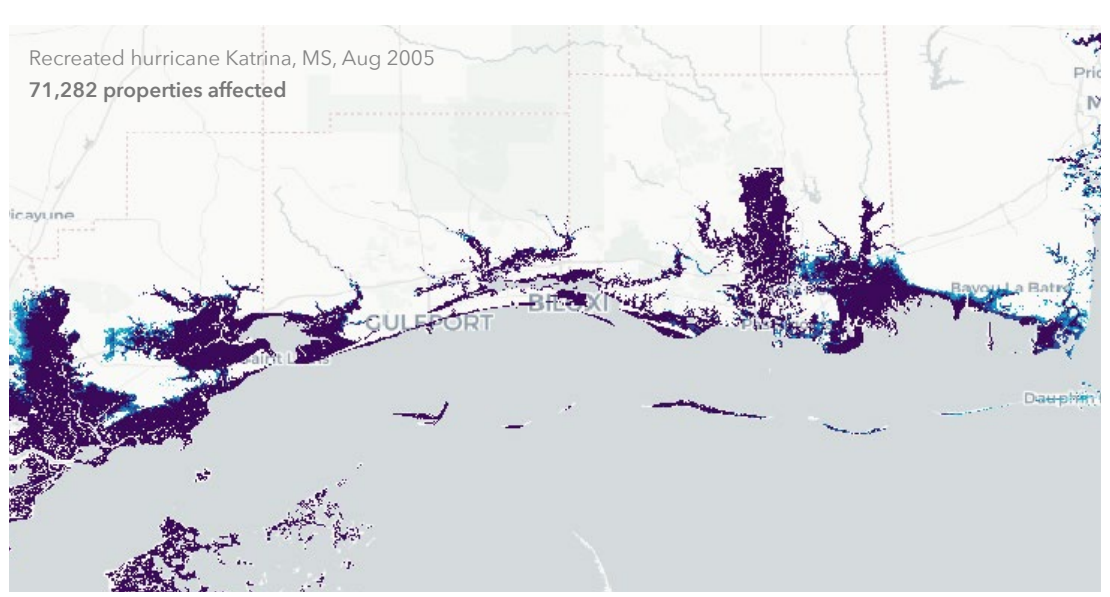

Depth of flooding

\section{4,100}

Properties served by

protection measures

The First Street Foundation Flood

Model incorporates 160 flood control

measures throughout the state which

protect 164,100 properties

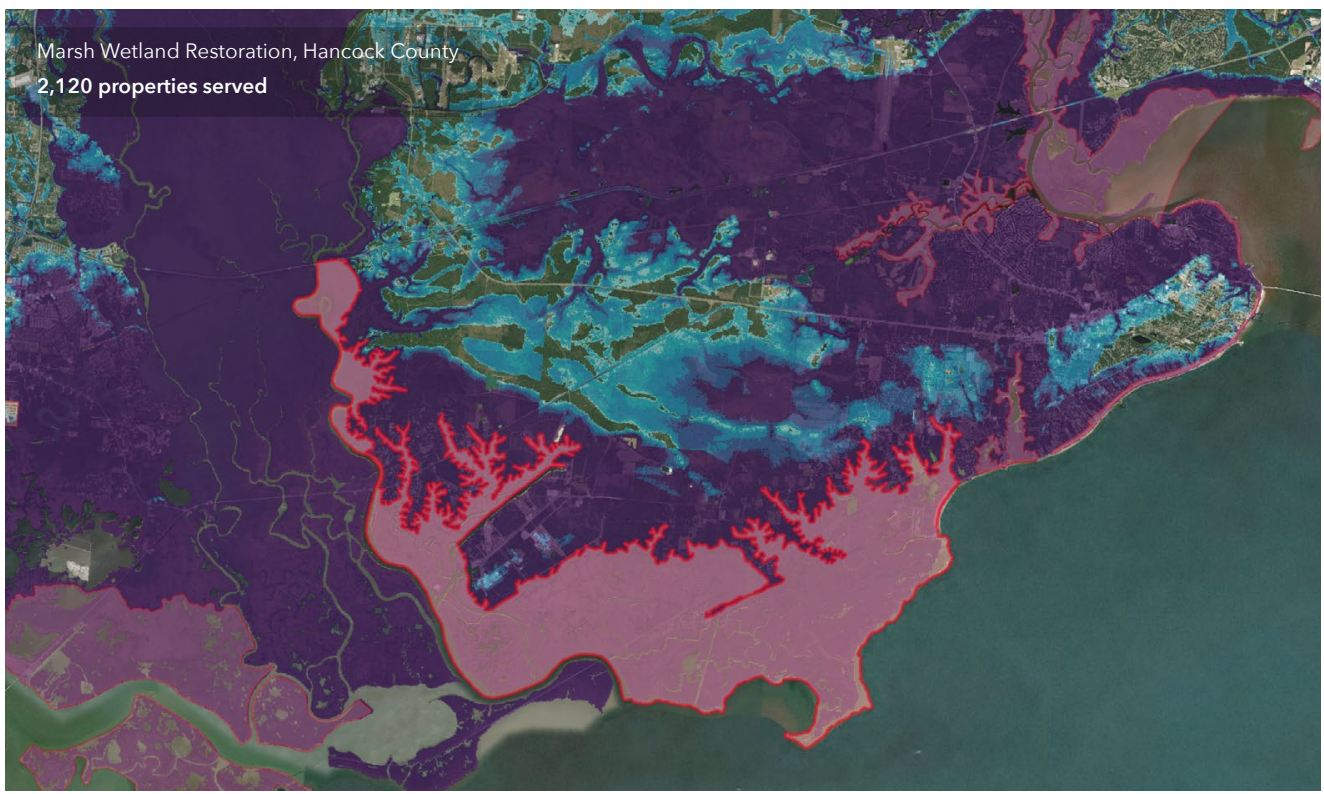

Area of protection

Top protection measures in state by quantity

Type
Example

Levee

49,951

Marsh/wetland Restoration

Biloxi Infrastructure Repair Program North Contract, Biloxi

Channel

Waveland Dune System, Bay St. Louls 


\section{State Overview \\ Missouri}

Total properties at substantial risk *

\section{$\ln 2050$}

$280,200 \quad 285,400$

30-year change

$\Delta+5,200(+2 \%)$

St. Louis faces floods where the Missouri, Illinois, and Meramec rivers meet the Mississippi. Levees mitigate riverine flooding, but are frequently overwhelmed. Springfield and Greene counties see flooding from urbanization, and the rolling topography of Springfield, which allows runoff to gain momentum, causing flash floods. Inadequate drainage and clogged ditches and channels also contribute to flooding during intense rainfall. by another $1.8 \%$, bringing the total number of properties with substantial risk to 285,400 .

To understand personal flood risk, Americans leverage the Federal Emergency Management Agency (FEMA) Flood Insurance Rate Maps (FIRM). These maps identify 157,900 properties as having substantial risk in the state of Missouri. In comparison, the First Street Foundation

Flood Model identifies 1.8 times the number of properties as facing this same level of risk. This discrepancy exists because the Foundation uses the current climate data, maps precipitation as a stand-alone risk, and includes areas that FEMA has not mapped. These new methods uncover an additional 122,300 properties currently not identified by FEMA as having substantial risk. When adjusting for future environmental changes, the FEMA gap further widens to 127,500 by the year 2050.

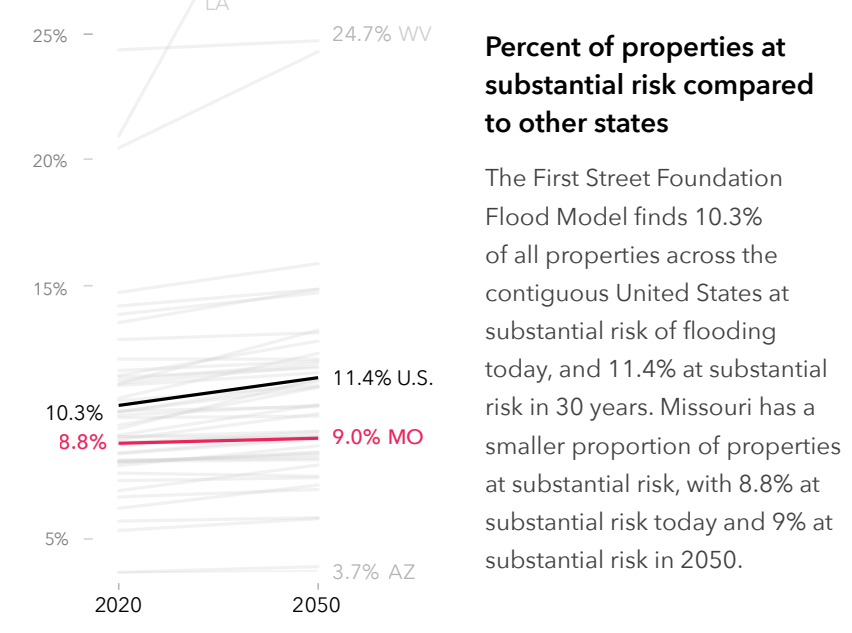

Percent of properties at substantial risk compared

The First Street Foundation Flood Model finds $10.3 \%$ substantial risk of flooding risk in 30 years. Missouri has a maller proportion of properties substantial risk today and $9 \%$ at 2050
Difference in number of properties currently at substantial risk compared to FEMA**

$$
\Delta+122,300
$$

More properties at risk in FSF model $\longrightarrow$

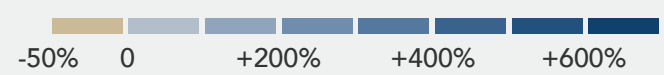




\section{Local details \\ Missouri}

The First Street Foundation Flood Model calculates the number of properties facing any risk* of flooding. When looking at this broader level of risk, the data identifies 355,200 properties in Missouri as at risk over the next 30 years. Of these properties, 96,700 were categorized as facing almost certain risk, with a $99 \%$ chance of flooding at least once over the next 30 years.

The city of Kansas City has the greatest number of properties at risk of flooding in the state with 14,900 currently at risk, or $8 \%$ of its total number of properties. However, smaller cities or municipalities in the state, with fewer properties, may have a greater proportion of their total properties at risk. For example, 33\% of properties in Valley Park are at risk of flooding. Other municipalities will see the greatest increase in risk over the next 30 years. Pacific, for example, will see a $14 \%$ increase in the number of properties at risk.

Click here for a full breakdown of counties, cities, zip codes, and congressional districts in Missouri at risk.

\section{Greatest proportion of properties at risk*}

\begin{tabular}{lrr|} 
Municipality & \multicolumn{2}{|c}{2020} \\
Valley Park & 918 & $33 \%$ \\
\hline Osage Beach & 1,104 & $28 \%$ \\
\hline Waynesville & 496 & $22 \%$ \\
\hline Poplar Bluff & 1,823 & $21 \%$ \\
\hline Charleston & 440 & $21 \%$ \\
\hline Lake Ozark & 578 & $21 \%$ \\
\hline Scott City & 442 & $20 \%$ \\
\hline De Soto & 557 & $18 \%$ \\
\hline Hannibal & 1,459 & $18 \%$ \\
\hline Branson & 1,534 & $16 \%$ \\
\hline
\end{tabular}

\section{Greatest number of properties at risk*}

\begin{tabular}{lcccccc} 
Municipality & \multicolumn{2}{c}{2020} & \multicolumn{2}{c}{2050} & \multicolumn{2}{c}{ Change } \\
Kansas City & 14,927 & $8 \%$ & 14,937 & $8 \%$ & +10 & $+0.1 \%$ \\
\hline St. Louis & 13,149 & $10 \%$ & 13,644 & $11 \%$ & +495 & $+3.8 \%$ \\
\hline Springfield & 3,623 & $6 \%$ & 3,775 & $6 \%$ & +152 & $+4.2 \%$ \\
\hline St. Joseph & 3,549 & $11 \%$ & 3,580 & $12 \%$ & +31 & $+0.9 \%$ \\
\hline O'Fallon & 3,451 & $11 \%$ & 3,513 & $11 \%$ & +62 & $+1.8 \%$ \\
\hline Independence & 3,389 & $7 \%$ & 3,383 & $7 \%$ & -6 & $-0.2 \%$ \\
\hline St. Charles & 3,150 & $12 \%$ & 3,227 & $12 \%$ & +77 & $+2.4 \%$ \\
\hline Jefferson City & 2,369 & $14 \%$ & 2,400 & $14 \%$ & +31 & $+1.3 \%$ \\
\hline Columbia & 2,338 & $6 \%$ & 2,344 & $6 \%$ & +6 & $+0.3 \%$ \\
\hline Lee's Summit & 2,280 & $6 \%$ & 2,270 & $6 \%$ & -10 & $-0.4 \%$
\end{tabular}

\section{Greatest relative growing risk*}

\begin{tabular}{lccccc|c|c|} 
Municipality & 2020 & \multicolumn{2}{c}{2050} & \multicolumn{2}{c}{ Change } \\
\hline Pacific & 413 & $14 \%$ & 470 & $16 \%$ & +57 & $+14 \%$ \\
\hline Caruthersville & 294 & $10 \%$ & 328 & $11 \%$ & +34 & $+12 \%$ \\
\hline Herculaneum & 175 & $9 \%$ & 193 & $9 \%$ & +18 & $+10 \%$ \\
\hline Ellisville & 202 & $6 \%$ & 220 & $6 \%$ & +18 & $+9 \%$ \\
\hline Marshfield & 149 & $5 \%$ & 162 & $5 \%$ & +13 & $+9 \%$ \\
\hline Butler & 61 & $3 \%$ & 66 & $3 \%$ & +5 & $+8 \%$ \\
\hline Malden & 288 & $11 \%$ & 311 & $12 \%$ & +23 & $+8 \%$ \\
\hline Kennett & 741 & $15 \%$ & 798 & $16 \%$ & +57 & $+8 \%$ \\
\hline Richmond Heights & 429 & $12 \%$ & 459 & $13 \%$ & +30 & $+7 \%$ \\
\hline Farmington & 310 & $6 \%$ & 331 & $6 \%$ & +21 & $+7 \%$
\end{tabular}

\section{Flood Factor distribution of properties at risk ${ }^{\star}(1000 s)$}

\section{Risk leve}

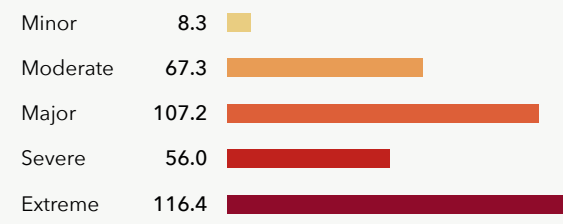

Extreme

More than $11.2 \%$ of individual properties and properties in Missouri are at any risk of flooding over the next 30 years. Out of those at risk $79 \%$ are at major to extreme risk.

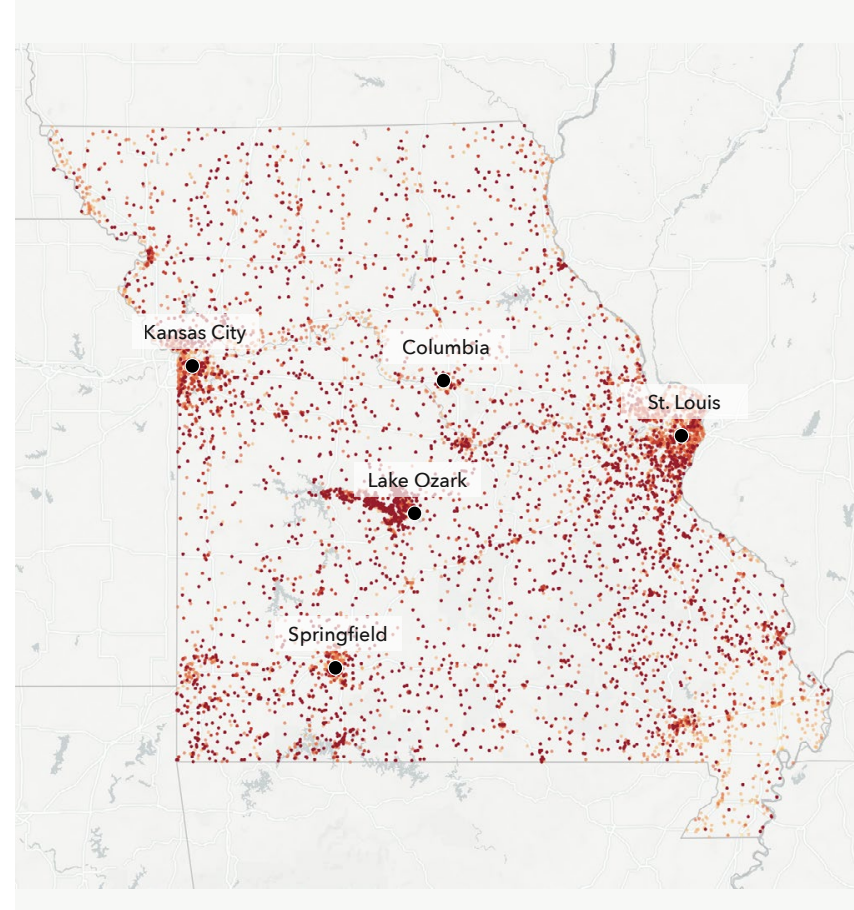




\section{Flood History \& Protection}

\section{Missouri}

\section{Claims History}

106,400 home and property owners in Missouri have made flood damage claims through FEMA since the year 2000.* These claims for reimbursement were made through either the National Flood Insurance Program (NFIP) or Individual Assistance Program (IAP). The greatest number of claims since the year 2000 have been concentrated in St. Louis, Jasper, Newton, Jefferson, and St. Louis counties.

\section{Storm Simulation}

The First Street Foundation Flood Model has recreated 2 flooding events that have occurred since the year 2000 in the state of Missouri. These events flooded around 3,300 properties across the state. ${ }^{\star \star}$
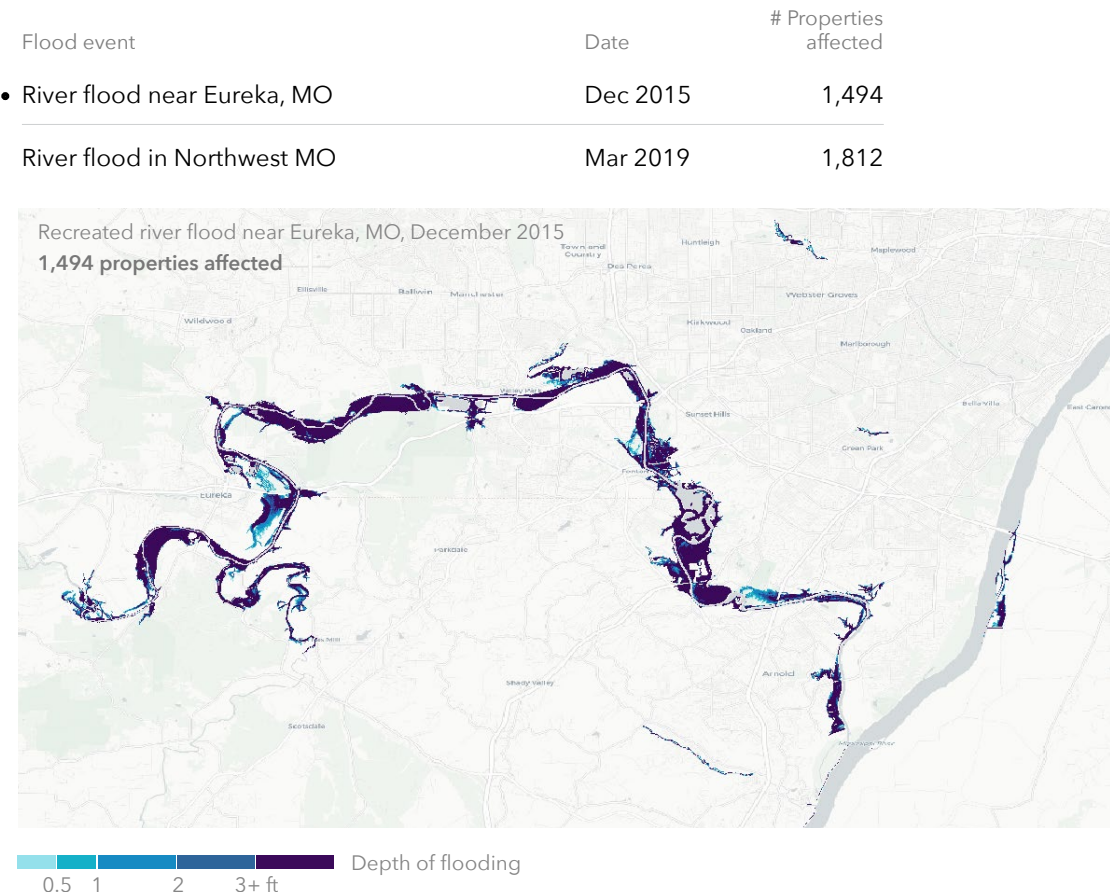

\section{6,600}

Properties served by

protection measures

The First Street Foundation Flood

Model incorporates 372 flood control

measures throughout the state which

protect 116,600 properties.

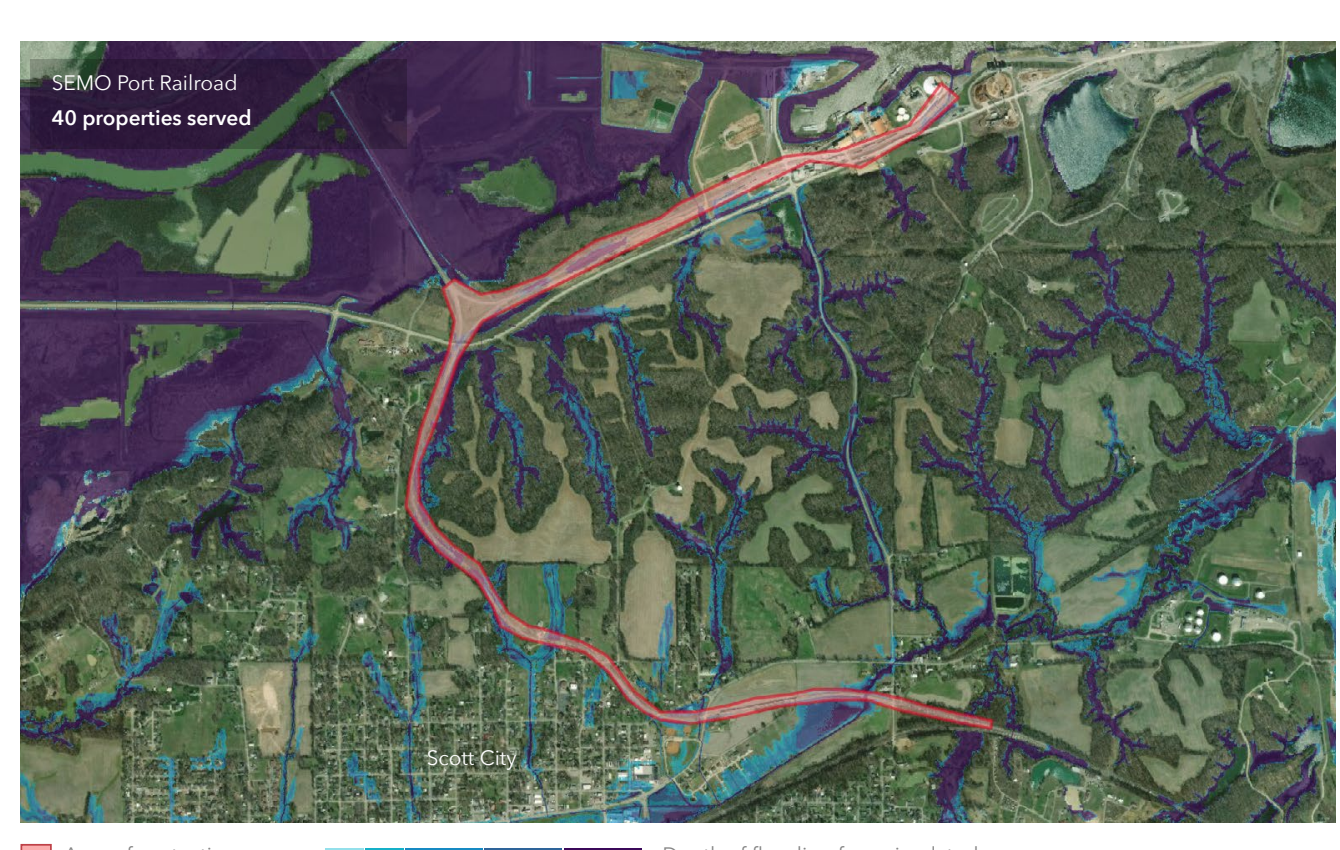

Area of protection

Top protection measures in state by quantity

Type
Example

Levee

Commerce-St Francis River System

Channel

Rain garden

Elevated road

- SEMO Port Railroad

Detention basin Drury Basin 


\section{State Overview \\ Montana}

Flood risk is increasing in the state of Montana. 122,600 properties currently have a substantial risk* of flooding. Over the next 30 years, the number of properties with this risk will increase by another $4.7 \%$, bringing the total number of properties with substantial risk to 128,300

To understand personal flood risk, Americans leverage the Federal Emergency Management Agency (FEMA) Flood Insurance Rate Maps (FIRM). These maps identify 29,800 properties as having substantial risk in the state of Montana. In comparison, the First Street Foundation Flood Model identifies 4.1 times the number of properties as facing this same level of risk. This discrepancy exists because the Foundation uses the current climate data, maps precipitation as a stand-alone risk, and includes areas that FEMA has not mapped. These new methods uncover an additional 92,700 properties currently not identified by FEMA as having substantial risk. When adjusting for future environmental changes, the FEMA gap further widens to 98,400 by the year 2050

\section{Total properties at substantial risk}

In 2020

\section{2,600}

30-year change

$$
\Delta+5,700(+5 \%)
$$

Difference in number of properties currently at substantial risk compared to FEMA ${ }^{\star \star}$

$$
\Delta+92,700
$$

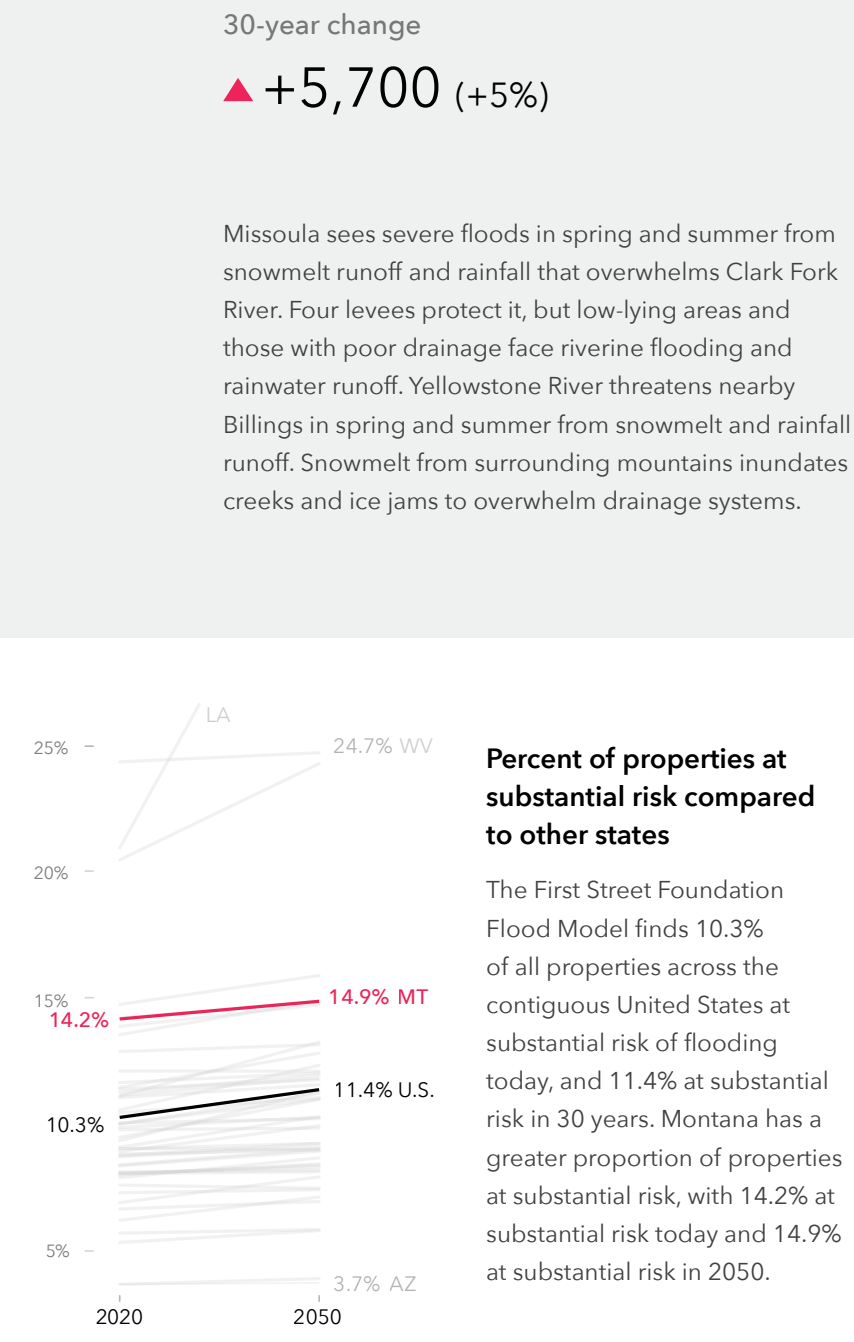

tial risk compared

The First Street Foundation

Flood Model finds $10.3 \%$

substantial risk of flooding

oday, and $11.4 \%$ at substantia

30 years. Montana has a

ion of properties

substantial risk today and $14.9 \%$

$$
2050
$$

More properties at risk in FSF model $\longrightarrow$

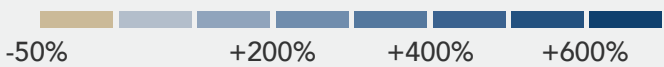

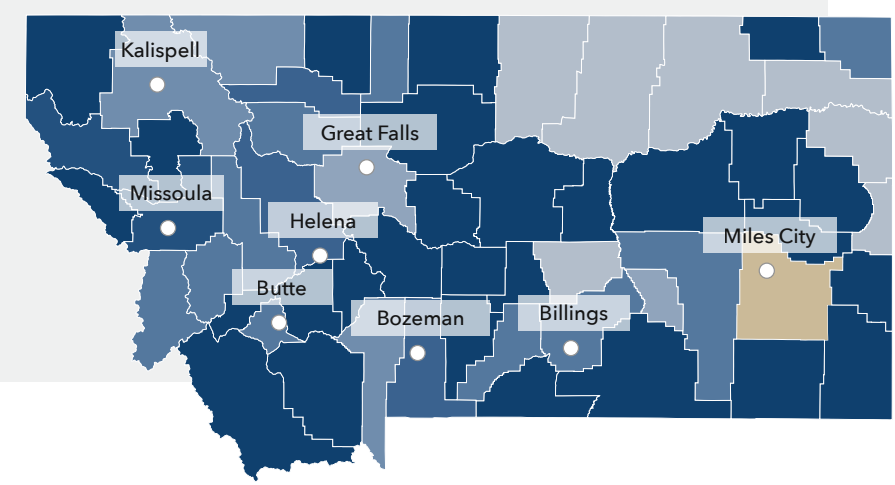




\section{Local details \\ Montana}

The First Street Foundation Flood Model calculates the number of properties facing any risk* of flooding. When looking at this broader level of risk, the data identifies 181,700 properties in Montana as at risk over the next 30 years. Of these properties, 26,000 were categorized as facing almost certain risk, with a $99 \%$ chance of flooding at least once over the next 30 years.

The city of Missoula has the greatest number of properties at risk of flooding in the state with 6,600 currently at risk, or $27 \%$ of its total number of properties. However, smaller cities or municipalities in the state, with fewer properties, may have a greater proportion of their total properties at risk. For example, $81 \%$ of properties in Evergreen are at risk of flooding. Other municipalities will see the greatest

increase in risk over the next 30 years. Belgrade, for example, will see $26 \%$ increase in the number of properties at risk.

Click here for a full breakdown of counties, cities, zip codes, and congressional districts in Montana at risk.

\section{Greatest proportion of properties at risk*}

\begin{tabular}{lrl} 
Municipality & \multicolumn{2}{c}{2020} \\
Evergreen & 2,338 & $81 \%$ \\
\hline Red Lodge & 1,071 & $51 \%$ \\
\hline Helena Valley West Central & 1,598 & $44 \%$ \\
\hline Miles City & 1,581 & $40 \%$ \\
\hline Lewistown & 1,015 & $33 \%$ \\
\hline Anaconda & 2,458 & $33 \%$ \\
\hline Four Corners & 777 & $32 \%$ \\
\hline Helena Valley Southeast & 836 & $30 \%$ \\
\hline Missoula & 6,607 & $27 \%$ \\
\hline Orchard Properties & 522 & $26 \%$ \\
\hline
\end{tabular}

\section{Greatest number of properties at risk*}

\begin{tabular}{l|cccccc}
\multirow{2}{*}{$\begin{array}{l}\text { Municipality } \\
\text { Missoula }\end{array}$} & \multicolumn{2}{c}{2020} & \multicolumn{2}{c}{2050} & \multicolumn{2}{c}{ Change } \\
\hline Billings & 6,607 & $27 \%$ & 7,063 & $29 \%$ & +456 & $+6.9 \%$ \\
\hline Great Falls & 6,506 & $14 \%$ & 6,881 & $15 \%$ & +375 & $+5.8 \%$ \\
\hline Butte-Silver Bow & 3,405 & $15 \%$ & 3,489 & $15 \%$ & +84 & $+2.5 \%$ \\
\hline Bozeman & 2,756 & $13 \%$ & 2,929 & $14 \%$ & +173 & $+6.3 \%$ \\
\hline Anaconda & 2,610 & $19 \%$ & 2,727 & $20 \%$ & +117 & $+4.5 \%$ \\
\hline Evergreen & 2,458 & $33 \%$ & 2,554 & $34 \%$ & +96 & $+3.9 \%$ \\
\hline Kalispell & 2,338 & $81 \%$ & 2,389 & $83 \%$ & +51 & $+2.2 \%$ \\
\hline Helena Valley West Central & 1,598 & $44 \%$ & 1,668 & $46 \%$ & +70 & $+4.4 \%$ \\
\hline Miles City & 1,924 & $19 \%$ & 2,023 & $20 \%$ & +99 & $+5.1 \%$ \\
\hline
\end{tabular}

\section{Greatest relative growing risk*}

\begin{tabular}{lrrrrrr} 
Municipality & \multicolumn{2}{c}{2020} & \multicolumn{2}{c}{2050} & \multicolumn{2}{c}{ Change } \\
Belgrade & 275 & $7 \%$ & 346 & $9 \%$ & +71 & $+26 \%$ \\
\hline Polson & 334 & $12 \%$ & 369 & $13 \%$ & +35 & $+11 \%$ \\
\hline Big Sky & 379 & $11 \%$ & 411 & $12 \%$ & +32 & $+8 \%$ \\
\hline Helena Valley Southeast & 836 & $30 \%$ & 906 & $33 \%$ & +70 & $+8 \%$ \\
\hline Orchard Homes & 522 & $26 \%$ & 561 & $28 \%$ & +39 & $+8 \%$ \\
\hline Miles City & 1,581 & $40 \%$ & 1,698 & $43 \%$ & +117 & $+7 \%$ \\
\hline Missoula & 6,607 & $27 \%$ & 7,063 & $29 \%$ & +456 & $+7 \%$ \\
\hline Hamilton & 356 & $17 \%$ & 380 & $18 \%$ & +24 & $+7 \%$ \\
\hline Butte-Silver Bow & 2,756 & $13 \%$ & 2,929 & $14 \%$ & +173 & $+6 \%$ \\
\hline Whitefish & 1,068 & $18 \%$ & 1,134 & $20 \%$ & +66 & $+6 \%$
\end{tabular}

\section{Flood Factor distribution of properties at risk ${ }^{\star}(1000 s)$}

\section{Risk leve}

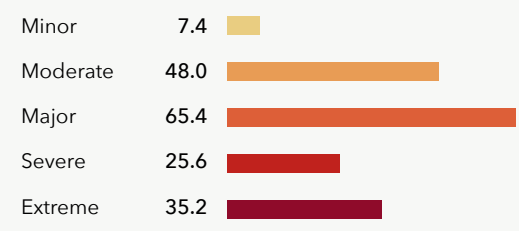

More than $21.1 \%$ of individual properties and properties in Montana are at any risk of flooding over the next 30 years. Out of those at risk $69 \%$ are at major to extreme risk.
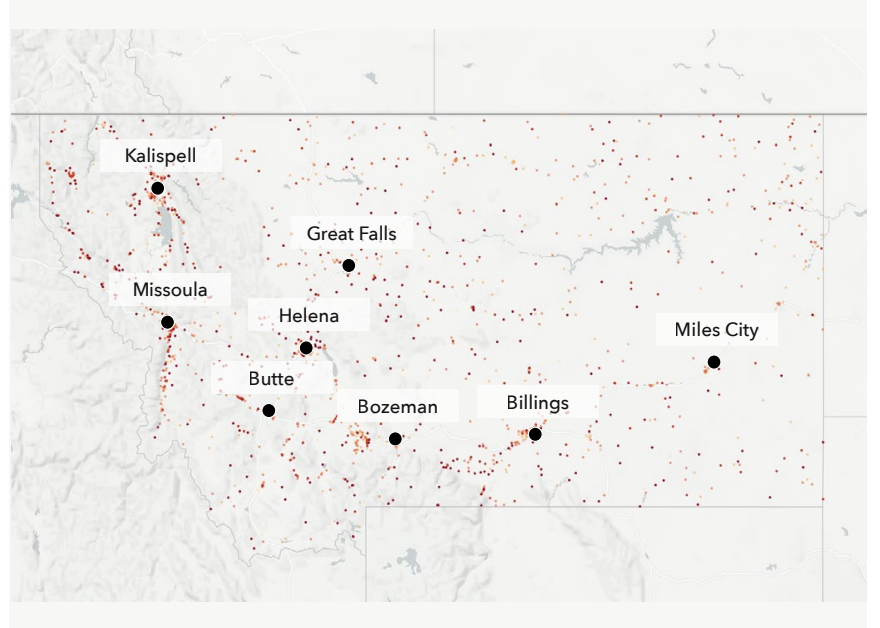


\section{Flood History \& Protection}

\section{Montana}

\section{Claims History}

6,300 home and property owners in Montana have made flood damage claims through FEMA since the year 2000. ${ }^{*}$ These claims for reimbursement were made through either the National Flood Insurance Program (NFIP) or Individual Assistance Program (IAP). The greatest number of claims since the year 2000 have been concentrated in Big Horn, Fergus, Valley, Blaine, and Yellowstone counties.

\section{0,600}

Properties served by

protection measures

The First Street Foundation Flood

Model incorporates 86 flood control

measures throughout the state which

protect 10,600 properties.
Top protection measures in state by quantity

Type
Example

\# Properties served by type

Levee

Tongue River Levee - Pacific Av to Yellowstone Riv, Miles City

Dike

Belt Creek Dike, Belt

Culvert

Ditch

Nutting Ditch, Laure

Channel

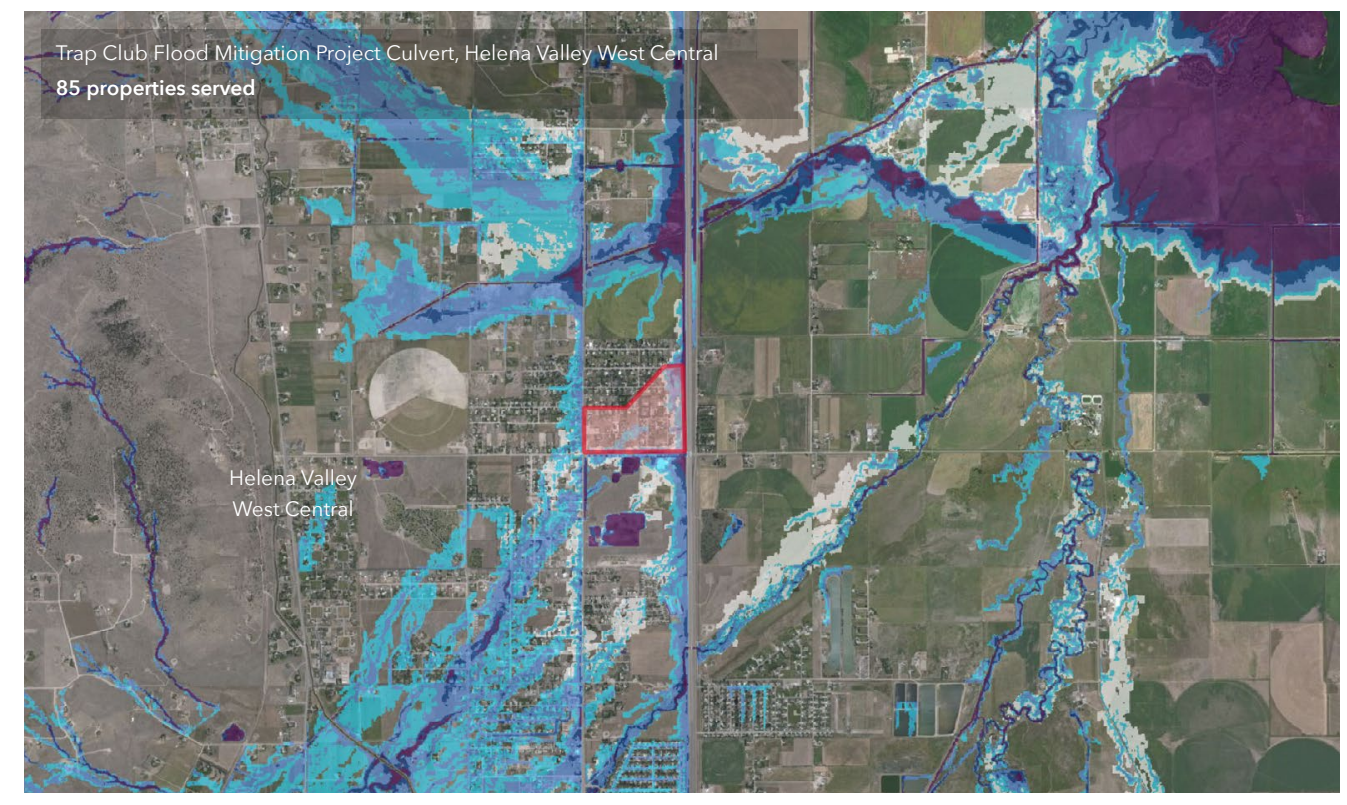

$\square$ Area of protection

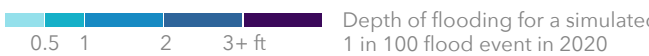




\section{State Overview Nebraska}

Flood risk is increasing in some areas in the state of Nebraska while decreasing in others. Over the next 30 years approximately 102,000 properties have a substantial risk* of flooding.

To understand personal flood risk, Americans leverage the Federal Emergency Management Agency (FEMA) Flood Insurance Rate Maps (FIRM). These maps identify 74,400 properties as having substantial risk in the state of Nebraska. In comparison, the First Street Foundation Flood Model identifies 1.4 times the number of properties as facing this same level of risk. This discrepancy exists because the Foundation uses the current climate data, maps precipitation as a stand-alone risk, and includes areas that FEMA has not mapped. These new methods uncover an additional 28,100 properties currently not identified by FEMA as having substantial risk.
Total properties at substantial risk ${ }^{*}$

In 2020

\section{2,000}

Nebraska's flat terrain results in wide floodplains. Most floods occur from April to June, when rapid snowmelt and rainfall runoff are aggravated by ice jams. The Missouri River was a major flood threat for eastern Omaha that a series of dams and reservoirs upstream have helped mitigate. The completion of the Omaha levee and floodwall along the river also protects the area.

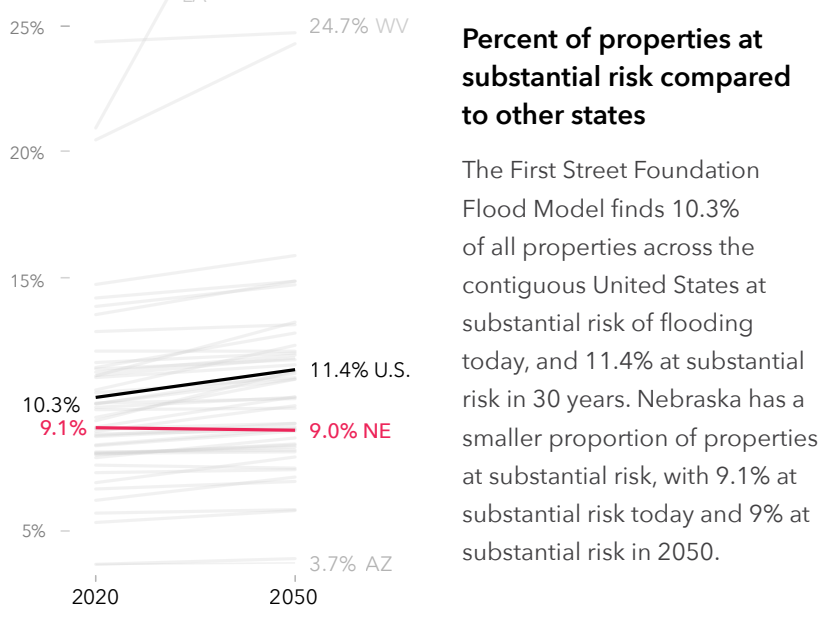

Difference in number of properties currently at substantial risk compared to FEMA**
$\Delta+28,100$
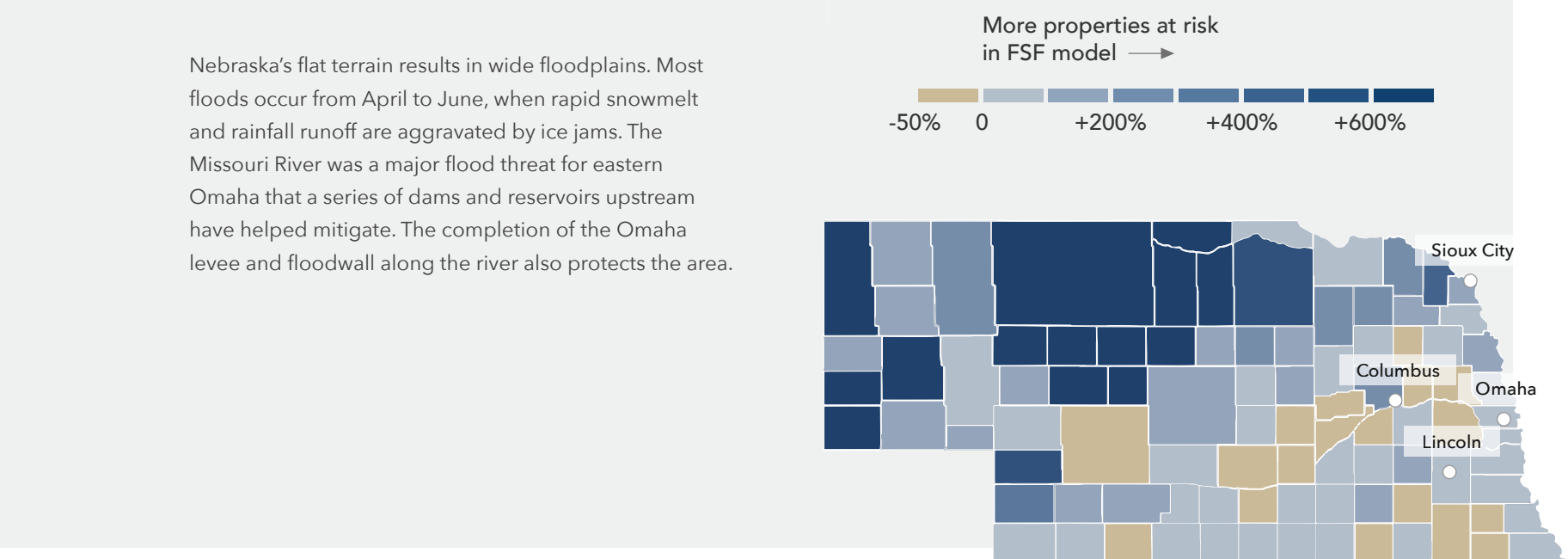


\section{Local details \\ Nebraska}

The First Street Foundation Flood Model calculates the number of properties facing any risk* of flooding. When looking at this broader level of risk, the data identifies 149,300 properties in Nebraska as at risk over the next 30 years. Of these properties, 23,600 were categorized as facing almost certain risk, with a $99 \%$ chance of flooding at least once over the next 30 years.

The city of Omaha has the greatest number of properties at risk of flooding in the state with 12,600 currently at risk, or $8 \%$ of its total number of properties. However, smaller cities or municipalities in the state, with fewer properties, may have a greater proportion of their total properties at risk. For example, $45 \%$ of properties in Columbus are at risk of flooding. Other municipalities will see the greatest

increase in risk over the next 30 years. Schuyler, for example, will see a $56 \%$ increase in the number of properties at risk.

Click here for a full breakdown of counties, cities, zip codes, and congressional districts in Nebraska at risk.

\section{Greatest proportion of properties at risk*}

\begin{tabular}{lrr} 
Municipality & \multicolumn{2}{c}{2020} \\
\hline Columbus & 4,171 & $45 \%$ \\
\hline Cozad & 921 & $45 \%$ \\
\hline Fremont & 4,092 & $40 \%$ \\
\hline South Sioux City & 1,288 & $30 \%$ \\
\hline Crete & 684 & $28 \%$ \\
\hline Norfolk & 2,305 & $23 \%$ \\
\hline Ogallala & 494 & $18 \%$ \\
\hline Sidney & 667 & $18 \%$ \\
\hline Plattsmouth & 508 & $17 \%$ \\
\hline Grand Island & 2,991 & $15 \%$ \\
\hline
\end{tabular}

\section{Greatest number of properties at risk*}

\begin{tabular}{l|c|ccccc} 
Municipality & \multicolumn{2}{c}{2020} & \multicolumn{2}{c}{2050} & \multicolumn{2}{c}{ Change } \\
Omaha & 12,616 & $8 \%$ & 12,630 & $8 \%$ & +14 & $+0.1 \%$ \\
\hline Lincoln & 7,923 & $9 \%$ & 7,970 & $9 \%$ & +47 & $+0.6 \%$ \\
\hline Columbus & 4,171 & $45 \%$ & 4,185 & $45 \%$ & +14 & $+0.3 \%$ \\
\hline Fremont & 4,092 & $40 \%$ & 4,188 & $41 \%$ & +96 & $+2.3 \%$ \\
\hline Grand Island & 2,991 & $15 \%$ & 3,098 & $16 \%$ & +107 & $+3.6 \%$ \\
\hline Norfolk & 2,305 & $23 \%$ & 2,329 & $23 \%$ & +24 & $+1.0 \%$ \\
\hline Bellevue & 1,840 & $10 \%$ & 1,843 & $10 \%$ & +3 & $+0.2 \%$ \\
\hline South Sioux City & 1,288 & $30 \%$ & 1,325 & $31 \%$ & +37 & $+2.9 \%$ \\
\hline Scottsbluff & 962 & $15 \%$ & 986 & $15 \%$ & +24 & $+2.5 \%$ \\
\hline Cozad & 921 & $45 \%$ & 927 & $45 \%$ & +6 & $+0.7 \%$
\end{tabular}

\section{Greatest relative growing risk*}

\begin{tabular}{lrrrrr|r|r|} 
Municipality & \multicolumn{2}{c}{2020} & \multicolumn{2}{c}{2050} & \multicolumn{2}{c}{ Change } \\
\hline Schuyler & 41 & $2 \%$ & 64 & $3 \%$ & +23 & $+56 \%$ \\
\hline Grand Island & 2,991 & $15 \%$ & 3,098 & $16 \%$ & +107 & $+4 \%$ \\
\hline Falls City & 68 & $3 \%$ & 70 & $3 \%$ & +2 & $+3 \%$ \\
\hline South Sioux City & 1,288 & $30 \%$ & 1,325 & $31 \%$ & +37 & $+3 \%$ \\
\hline Scottsbluff & 962 & $15 \%$ & 986 & $15 \%$ & +24 & $+3 \%$ \\
\hline Fremont & 4,092 & $40 \%$ & 4,188 & $41 \%$ & +96 & $+2 \%$ \\
\hline Blair & 370 & $10 \%$ & 375 & $10 \%$ & +5 & $+1 \%$ \\
\hline Lexington & 442 & $13 \%$ & 448 & $14 \%$ & +6 & $+1 \%$ \\
\hline Wayne & 187 & $9 \%$ & 189 & $9 \%$ & +2 & $+1 \%$ \\
\hline York & 445 & $12 \%$ & 450 & $12 \%$ & +5 & $+1 \%$
\end{tabular}

\section{Flood Factor distribution of properties at risk ${ }^{\star}(1000 s)$}

\section{Risk level}

Mino

Moderate

Major

Severe

Extreme

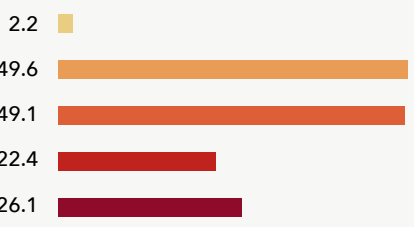

More than $13.2 \%$ of individual properties and properties in Nebraska are at any risk of flooding over the next 30 years. Out of those at risk $65 \%$ are at major to extreme risk. 


\section{Flood History \& Protection}

\section{Nebraska}

\section{Claims History}

25,300 home and property owners in Nebraska have made flood damage claims through FEMA since the year 2000.* These claims for reimbursement were made through either the National Flood Insurance Program (NFIP) or Individual Assistance Program (IAP). The greatest number of claims since the year 2000 have been concentrated in Douglas, Dodge, Washington, Saunders, and Sarpy counties.

\section{Storm Simulation}

The First Street Foundation Flood Model has recreated 3 flooding events that have occurred since the year 2000 in the state of Nebraska. These events flooded around 13,130 properties across the state.**
Flood event
\# Properties
affected
River flood in Northeast Nebraska
Jun 2014
96
River Flood across eastern Nebraska
Mar $2019 \quad 12,727$
- River flood in Northern Nebraska
Mar 2019
307

Recreated river flood in Northern Nebraska, March 2019

307 properties affected in Nebraska

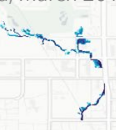
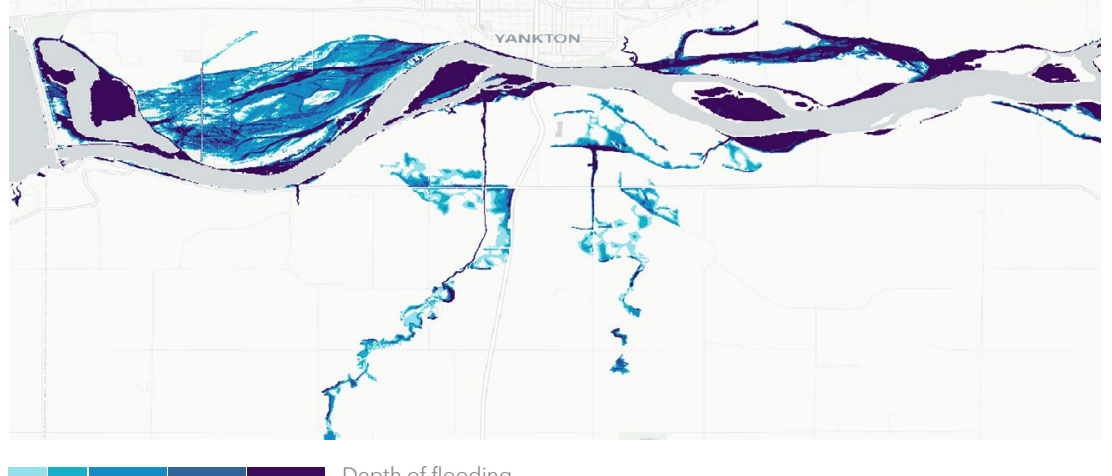

\section{8,600}

Properties served by

protection measures

The First Street Foundation Flood

Model incorporates 152 flood control

measures throughout the state which

protect 38,600 properties.

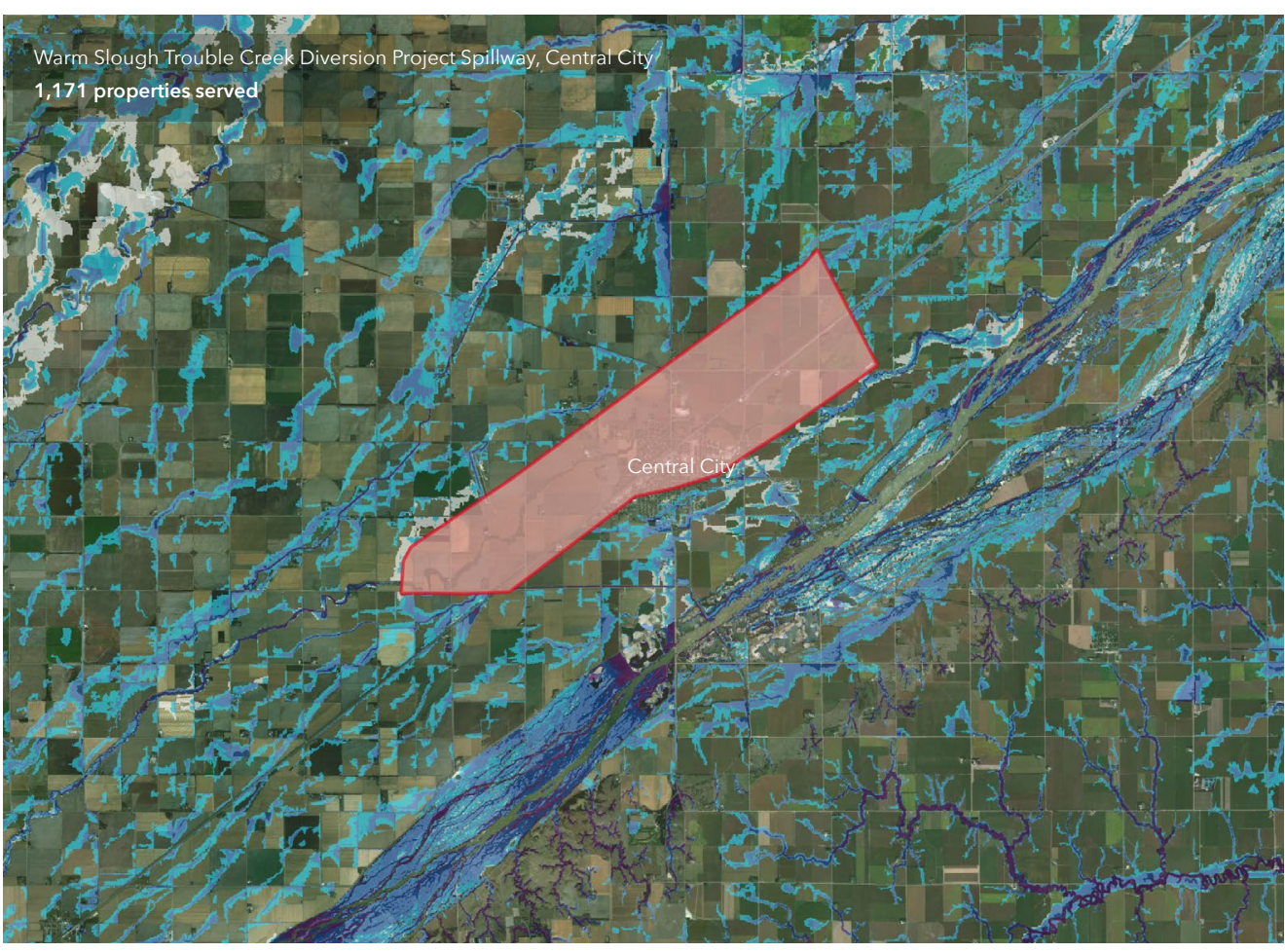

Top protection measures in state by quantity

Type
Example

Levee

Norfolk - Elkhorn RB, Norfolk

Spillway

1,346

Trouble Creek diversion project, Central City

Dam

Gavins Point Dam, Crofton 


\section{State Overview Nevada}

Flood risk is increasing in the state of Nevada. 44,600 properties currently have a substantial risk* of flooding. Over the next 30 years, the number of properties with this risk will increase by another $6.1 \%$, bringing the total number of properties with substantial risk to 47,300 .

To understand personal flood risk, Americans leverage the Federal Emergency Management Agency (FEMA) Flood Insurance Rate Maps (FIRM). These maps identify 41,300 properties as having substantial risk in the state of Nevada. In comparison, the First Street Foundation Flood Model identifies 1.1 times the number of properties as facing this same level of risk. This discrepancy exists because the Foundation uses the current climate data, maps precipitation as a stand-alone risk, and includes areas that FEMA has not mapped. These new methods uncover an additional 3,300 properties currently not identified by FEMA as having substantial risk. When adjusting for future environmental changes, the FEMA gap further widens to 6,000 by the year 2050.
Total properties at substantial risk *

In 2020

44,600

30-year change

$\triangle+2,700$

$+6 \%$

Flooding in Nevada typically arrives in the form of flash floods caused by sudden and intense rainfall events. The southern part of the state, including Las Vegas, experiences flooding all year round but the hot summer months bring lightning, thunder, and rain, which lead to dramatic runoff events that concentrate in the urbanized areas at lower elevations.

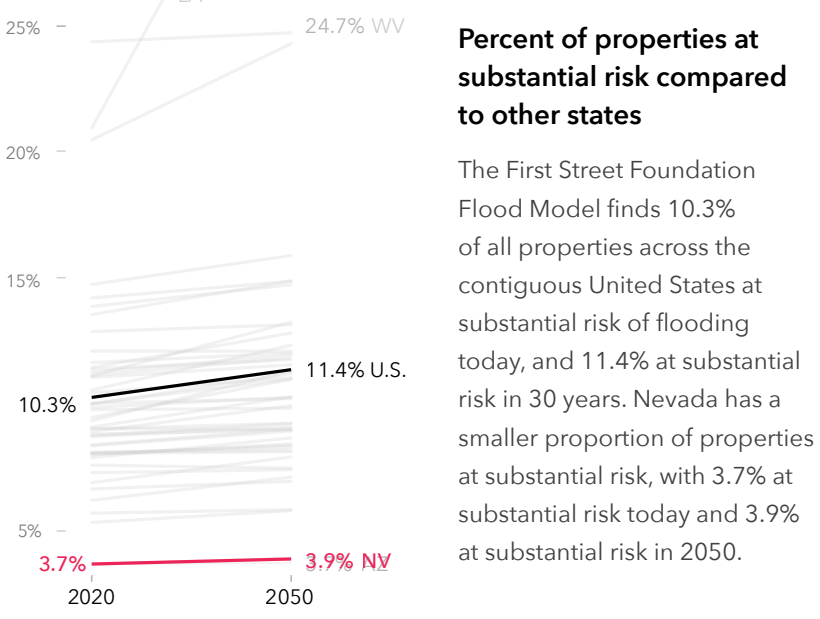

Difference in number of properties currently at substantial risk compared to FEMA ${ }^{\star \star}$

$$
\Delta+3,296
$$

More properties at risk in FSF model $\longrightarrow$
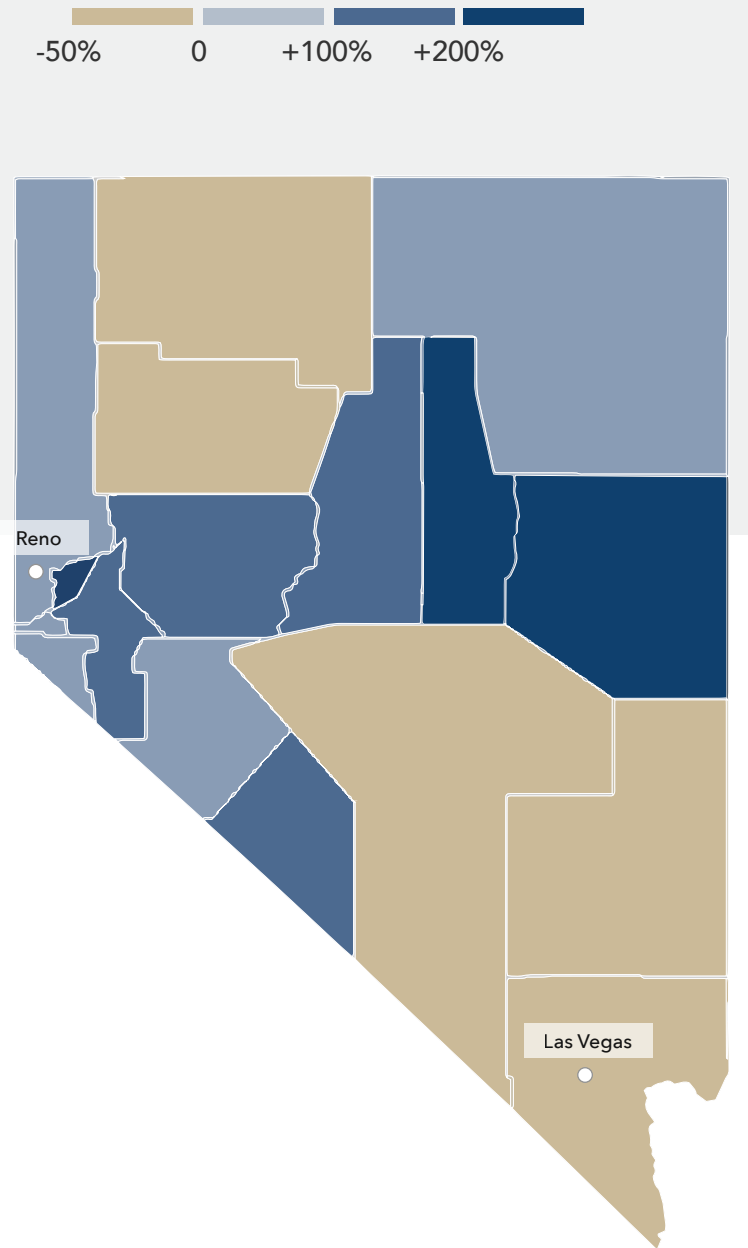


\section{Local details}

Nevada

The First Street Foundation Flood Model calculates the number of properties facing any risk* of flooding. When looking at this broader level of risk, the data identifies 132,000 properties in Nevada as at risk over the next 30 years. Of these properties, 1,000 were categorized as facing almost certain risk, with a $99 \%$ chance of flooding at least once over the next 30 years.

The city of Reno has the greatest number of properties at risk of flooding in the state with 14,200 currently at risk, or $17 \%$ of its total number of properties. However, smaller cities or municipalities in the state, with fewer properties, may have a greater proportion of their total properties at risk. For example, 30\% of properties in Gardnerville are at risk of flooding. Other municipalities will see the greatest increase in risk over the next 30 years. Humboldt River Ranch, for example, will see a $19 \%$ increase in the number of properties at risk.

Click here for a full breakdown of counties, cities, zip codes, and congressional districts in Nevada at risk.

\section{Greatest proportion of properties at risk*}

\begin{tabular}{lrr|} 
Municipality & \multicolumn{2}{c}{2020} \\
Gardnerville & 749 & $30 \%$ \\
\hline Lemmon Valley & 593 & $29 \%$ \\
\hline Sandy Valley & 661 & $26 \%$ \\
\hline Pahrump & 12,864 & $25 \%$ \\
\hline Ely & 580 & $23 \%$ \\
\hline Fernley & 1,952 & $21 \%$ \\
\hline Carson City & 3,718 & $19 \%$ \\
\hline Cold Springs & 696 & $18 \%$ \\
\hline Laughlin & 568 & $17 \%$ \\
\hline Reno & 14,214 & $17 \%$ \\
\hline
\end{tabular}

\section{Greatest number of properties at risk*}

\begin{tabular}{lcccccc} 
Municipality & \multicolumn{2}{c}{2020} & \multicolumn{2}{c}{2050} & \multicolumn{2}{c}{ Change } \\
\cline { 2 - 5 } Reno & 14,214 & $17 \%$ & 14,850 & $18 \%$ & +636 & $+4.5 \%$ \\
\hline Pahrump & 12,864 & $25 \%$ & 13,348 & $26 \%$ & +484 & $+3.8 \%$ \\
\hline Las Vegas & 11,947 & $6 \%$ & 12,235 & $6 \%$ & +288 & $+2.4 \%$ \\
\hline Henderson & 11,706 & $9 \%$ & 12,588 & $10 \%$ & +882 & $+7.5 \%$ \\
\hline North Las Vegas & 6,670 & $8 \%$ & 6,756 & $8 \%$ & +86 & $+1.3 \%$ \\
\hline Sparks & 5,065 & $14 \%$ & 5,670 & $16 \%$ & +605 & $+11.9 \%$ \\
\hline Enterprise & 4,875 & $7 \%$ & 5,168 & $7 \%$ & +293 & $+6.0 \%$ \\
\hline Sunrise Manor & 4,031 & $8 \%$ & 4,120 & $8 \%$ & +89 & $+2.2 \%$ \\
\hline Carson City & 3,718 & $19 \%$ & 3,832 & $19 \%$ & +114 & $+3.1 \%$ \\
\hline Spring Valley & 3,635 & $6 \%$ & 3,729 & $6 \%$ & +94 & $+2.6 \%$
\end{tabular}

\section{Greatest relative growing risk*}

\begin{tabular}{lrrrrrr} 
Municipality & \multicolumn{2}{c}{2020} & \multicolumn{2}{c}{2050} & \multicolumn{2}{c}{ Change } \\
Humboldt River Ranch & 117 & $6 \%$ & 139 & $7 \%$ & +22 & $+19 \%$ \\
\hline Winnemucca & 103 & $3 \%$ & 119 & $3 \%$ & +16 & $+16 \%$ \\
\hline Sparks & 5,065 & $14 \%$ & 5,670 & $16 \%$ & +605 & $+12 \%$ \\
\hline Fernley & 1,952 & $21 \%$ & 2,147 & $23 \%$ & +195 & $+10 \%$ \\
\hline Fallon & 89 & $2 \%$ & 97 & $3 \%$ & +8 & $+9 \%$ \\
\hline Spring Creek & 390 & $6 \%$ & 425 & $7 \%$ & +35 & $+9 \%$ \\
\hline Silver Springs & 920 & $16 \%$ & 995 & $17 \%$ & +75 & $+8 \%$ \\
\hline Whitney & 501 & $4 \%$ & 540 & $4 \%$ & +39 & $+8 \%$ \\
\hline Winchester & 128 & $2 \%$ & 138 & $3 \%$ & +10 & $+8 \%$ \\
\hline Henderson & 11,706 & $9 \%$ & 12,588 & $10 \%$ & +882 & $+8 \%$ \\
\hline
\end{tabular}

\section{Flood Factor distribution of properties at risk ${ }^{\star}(1000 s)$}

\section{Risk level}

Minor

80.5

Major $\quad 33.5$

Severe $\quad 8.2$

Extreme $\quad 3.3$

More than $10.9 \%$ of individual properties and properties in Nevada are at any risk of flooding over the next 30 years. Out of those at risk $34 \%$ are at major to extreme risk.

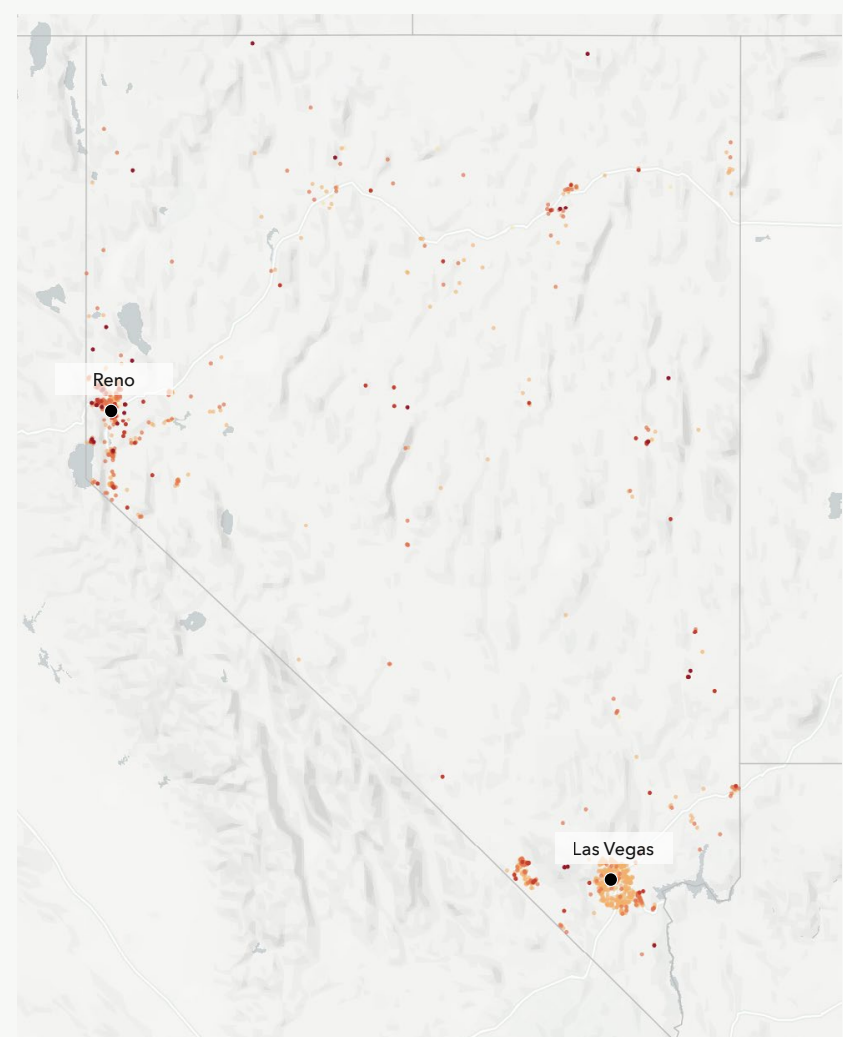




\section{Flood History \& Protection}

\section{Nevada}

\section{Claims History}

1,500 home and property owners in Nevada have made flood damage claims through FEMA since the year 2000.* These claims for reimbursement were made through either the National Flood Insurance Program (NFIP) or Individual Assistance Program (IAP). The greatest number of claims since the year 2000 have been concentrated in Lyon, Churchill, Washoe, Clark, and Douglas counties.

\section{Storm Simulation}

The First Street Foundation Flood Model has recreated 1 flooding event that occurred since the year 2000 in the state of Nevada. This event flooded around 140 properties across the state **

Recreated river flood near Mesquite, NV, Jan 2005

140 properties affected
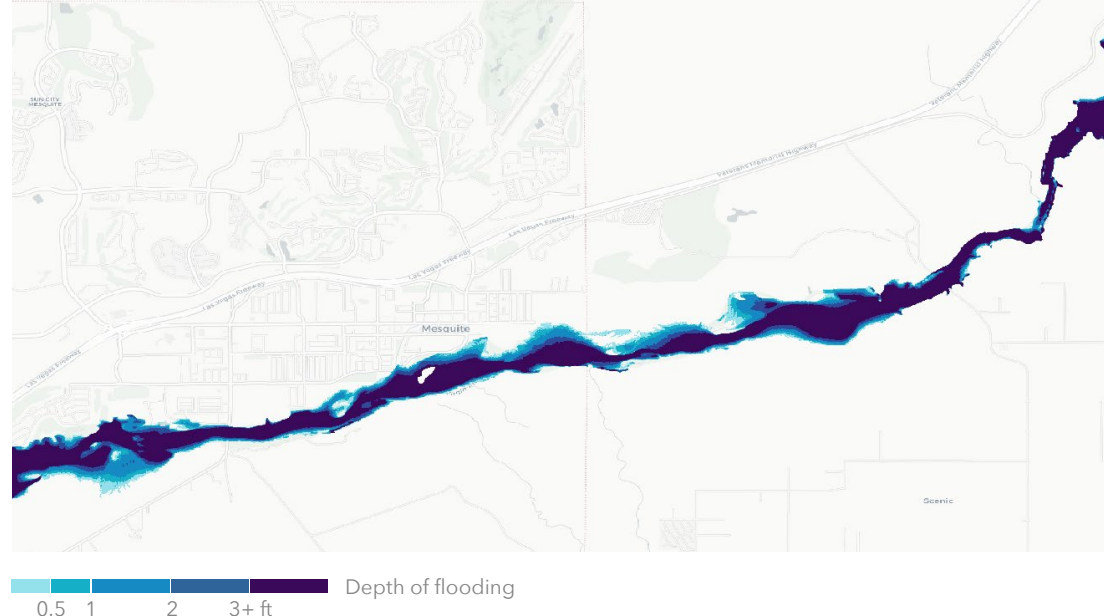

\section{2,800}

Properties served by

protection measures

The First Street Foundation Flood

Model incorporates 17 flood control

measures throughout the state which

protect 132,800 properties
Top protection measures in state by quantity

Type
Example

\# Properties served by type

Channel

27.428

North Las Vegas

9,105

- Upper Las Vegas Wash Interception Berm

Flood wall

canyon debris flow diversion structure project

Earthen berm

Swan Lake Berm/Barrier Protection Project, Lemmon Valley
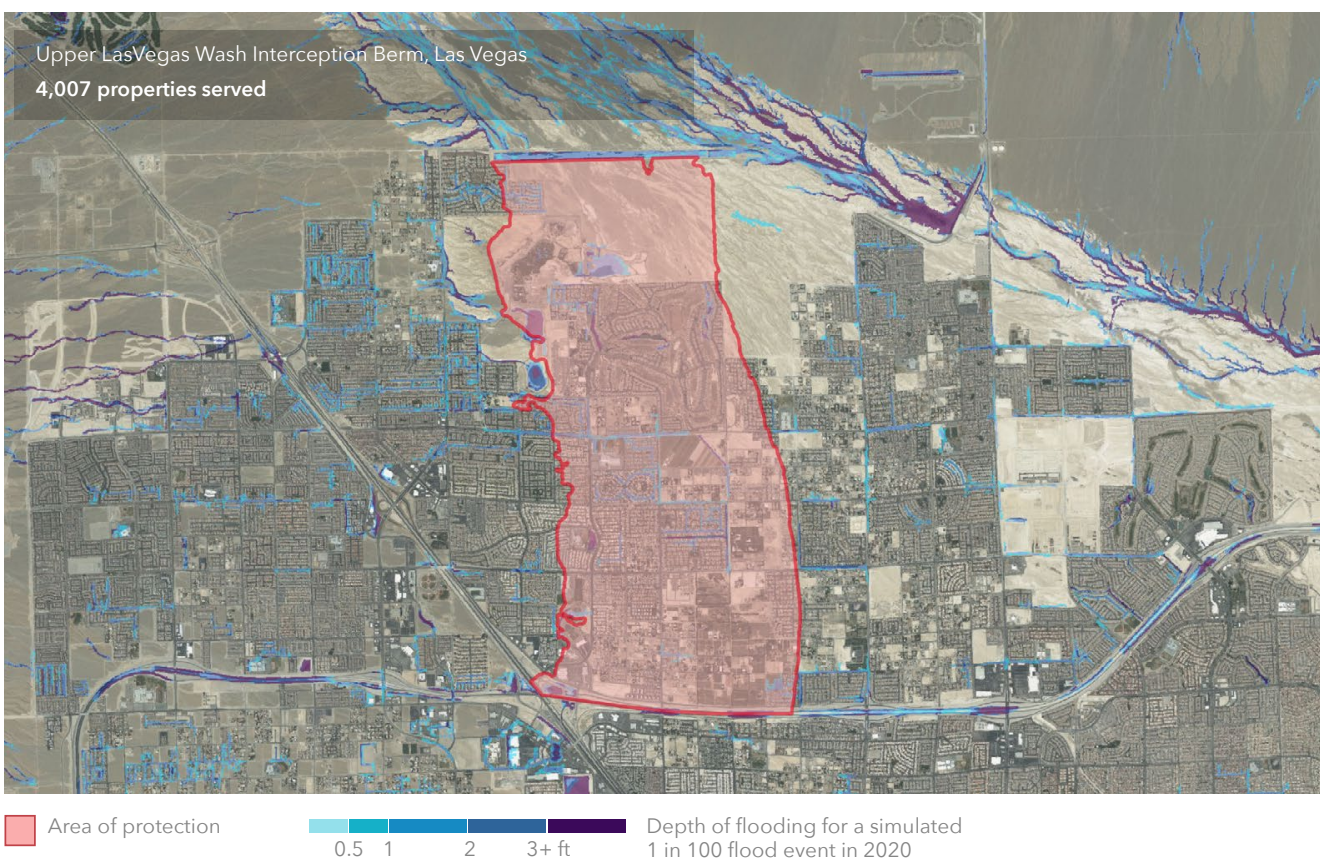


\section{State Overview \\ New Hampshire}

Flood risk is increasing in the state of New Hampshire. 64,900 properties currently have a substantial risk* of flooding. Over the next 30 years, the number of properties with this risk will increase by another $4.6 \%$, bringing the total number of properties with substantial risk to 67,900 .

To understand personal flood risk, Americans leverage the Federal Emergency Management Agency (FEMA) Flood Insurance Rate Maps (FIRM). These maps identify 29,000 properties as having substantial risk in the state of New Hampshire. In comparison, the First Street Foundation Flood Model identifies 2.2 times the number of properties as facing this same level of risk. This discrepancy exists because the Foundation uses the current climate data, maps precipitation as a stand-alone risk, and includes areas that FEMA has not mapped. These new methods uncover an additional 35,900 properties currently not identified by FEMA as having substantial risk. When adjusting for future environmental changes, the FEMA gap further widens to 38,900 by the year 2050
Total properties at substantial risk*

$\ln 2020$

\section{4,900}

30-year change

$\Delta+3,000(+5 \%)$
Difference in number of properties currently at substantial risk compared to FEMA**

$$
\Delta+35,900
$$

\section{More properties at risk} in FSF model $\longrightarrow$

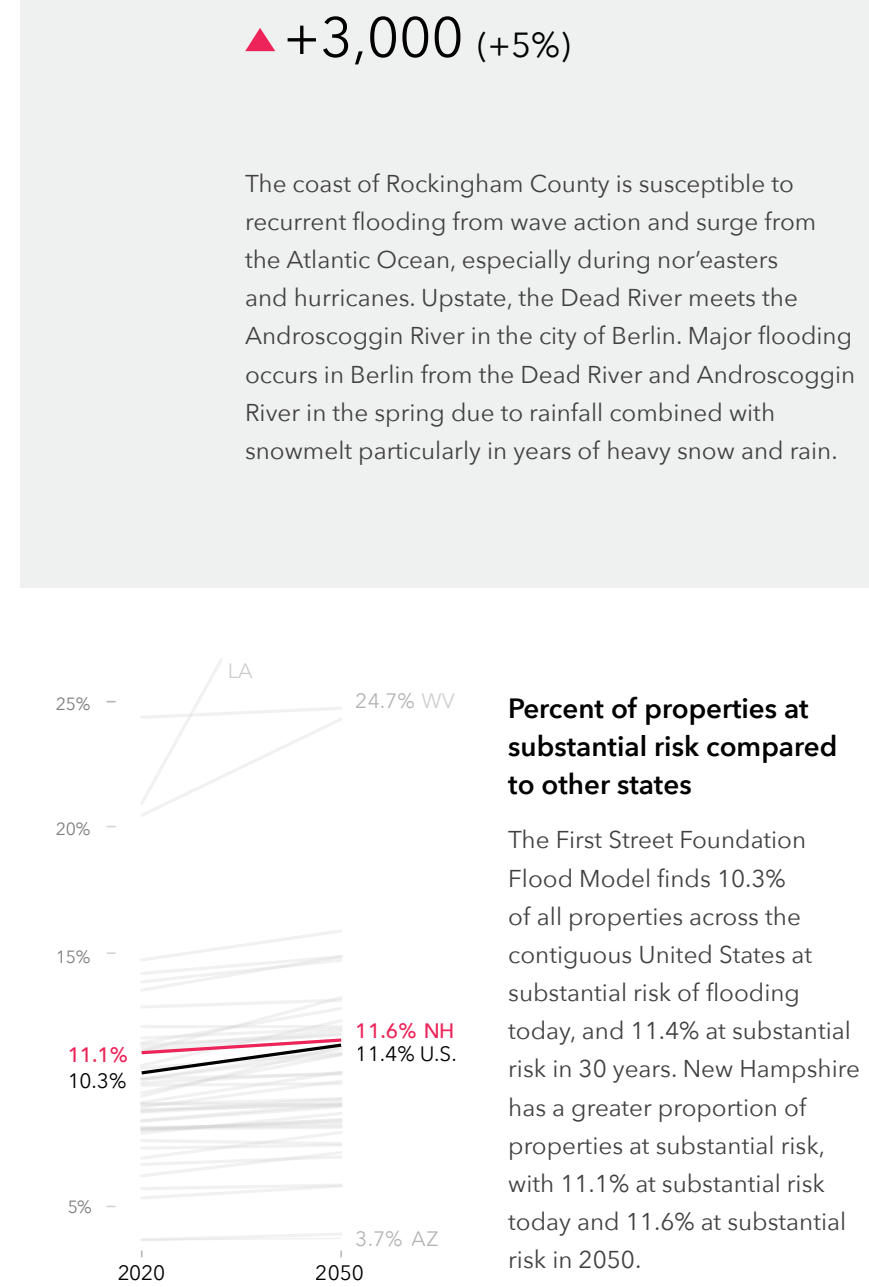

The coast of Rockingham County is susceptible to recurrent flooding from wave action and surge from Atlantic Ocean, especially during nor'easters Androscoggin River in the city of Berlin. Major flooding occurs in Berlin from the Dead River and Androscoggin River in the spring due to rainfall combined with

nowmelt particularly in years of heavy snow and rain. 


\section{Local details New Hampshire}

The First Street Foundation Flood Model calculates the number of properties facing any risk* of flooding. When looking at this broader level of risk, the data identifies 86,800 properties in New Hampshire as at risk over the next 30 years. Of these properties, 28,400 were categorized as facing almost certain risk, with a $99 \%$ chance of flooding at least once over the next 30 years.

The city of Manchester has the greatest number of properties at risk of flooding in the state with 4,200 currently at risk, or $14 \%$ of its total number of properties. However, smaller cities or municipalities in the state, with fewer properties, may have a greater proportion of their total properties at risk. For example, $27 \%$ of properties in Littleton are at risk of flooding. Other municipalities will see the greatest increase in risk over the next 30 years. Portsmouth, for example, will see a $36 \%$ increase in the number of properties at risk.

Click here for a full breakdown of counties, cities, zip codes, and congressional districts in New Hampshire at risk.

\section{Greatest proportion of properties at risk*}

\begin{tabular}{lrr} 
Municipality & \multicolumn{2}{c}{2020} \\
\hline Littleton & 555 & $27 \%$ \\
\hline Keene & 1,643 & $24 \%$ \\
\hline Laconia & 1,481 & $22 \%$ \\
\hline Hudson & 429 & $20 \%$ \\
\hline Lebanon & 809 & $19 \%$ \\
\hline Franklin & 496 & $15 \%$ \\
\hline Claremont & 695 & $14 \%$ \\
\hline Manchester & 4,184 & $14 \%$ \\
\hline Berlin & 601 & $13 \%$ \\
\hline Hampton & 411 & $13 \%$ \\
\hline
\end{tabular}

\section{Greatest number of properties at risk*}

\begin{tabular}{l|c|ccccc} 
Municipality & \multicolumn{2}{c}{2020} & \multicolumn{2}{c}{2050} & \multicolumn{2}{c}{ Change } \\
\cline { 2 - 3 } Manchter & 4,184 & $14 \%$ & 4,301 & $15 \%$ & +117 & $+2.8 \%$ \\
\hline Nashua & 2,648 & $13 \%$ & 2,770 & $14 \%$ & +122 & $+4.6 \%$ \\
\hline Keene & 1,643 & $24 \%$ & 1,684 & $25 \%$ & +41 & $+2.5 \%$ \\
\hline Concord & 1,483 & $12 \%$ & 1,526 & $12 \%$ & +43 & $+2.9 \%$ \\
\hline Laconia & 1,481 & $22 \%$ & 1,502 & $22 \%$ & +21 & $+1.4 \%$ \\
\hline Portsmouth & 815 & $13 \%$ & 1,104 & $17 \%$ & +289 & $+35.5 \%$ \\
\hline Lebanon & 809 & $19 \%$ & 820 & $19 \%$ & +11 & $+1.4 \%$ \\
\hline Claremont & 695 & $14 \%$ & 707 & $14 \%$ & +12 & $+1.7 \%$ \\
\hline Dover & 648 & $8 \%$ & 724 & $9 \%$ & +76 & $+11.7 \%$ \\
\hline Derry & 646 & $9 \%$ & 690 & $10 \%$ & +44 & $+6.8 \%$
\end{tabular}

Greatest relative growing risk $^{*}$

\begin{tabular}{lrrrrrr} 
Municipality & \multicolumn{2}{c}{2020} & \multicolumn{2}{c}{2050} & \multicolumn{2}{c}{ Change } \\
\hline Portsmouth & 815 & $13 \%$ & 1,104 & $17 \%$ & +289 & $+36 \%$ \\
\hline Hampton & 411 & $13 \%$ & 549 & $17 \%$ & +138 & $+34 \%$ \\
\hline Dover & 648 & $8 \%$ & 724 & $9 \%$ & +76 & $+12 \%$ \\
\hline Derry & 646 & $9 \%$ & 690 & $10 \%$ & +44 & $+7 \%$ \\
\hline Nashua & 2,648 & $13 \%$ & 2,770 & $14 \%$ & +122 & $+5 \%$ \\
\hline Exeter & 235 & $10 \%$ & 245 & $10 \%$ & +10 & $+4 \%$ \\
\hline Milford & 303 & $13 \%$ & 316 & $13 \%$ & +13 & $+4 \%$ \\
\hline Rochester & 609 & $6 \%$ & 632 & $6 \%$ & +23 & $+4 \%$ \\
\hline Londonderry & 255 & $6 \%$ & 263 & $6 \%$ & +8 & $+3 \%$ \\
\hline Concord & 1,483 & $12 \%$ & 1,526 & $12 \%$ & +43 & $+3 \%$ \\
\hline
\end{tabular}

\section{Flood Factor distribution of properties at risk ${ }^{\star}(1000 s)$}

\section{Risk level}

Minor

Moderate

Major

3.5

Extreme

23.7

12.9

Extreme

31.1

More than $14.8 \%$ of individual properties and properties in New Hampshire are at any risk of flooding over the next 30 years. Out of those at risk $78 \%$ are at major to extreme risk.

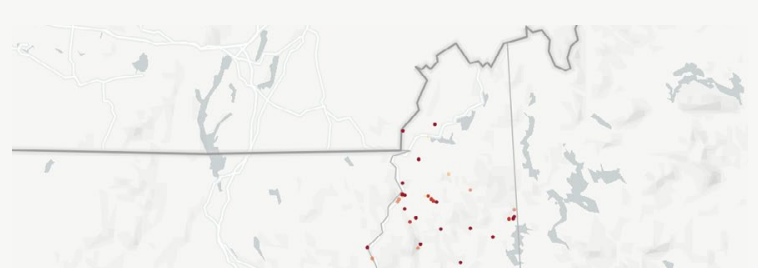




\section{Flood History \& Protection}

\section{New Hampshire}

\section{Claims History}

13,800 home and property owners in New Hampshire have made flood damage claims through FEMA since the year 2000.* These claims for reimbursement were made through either the National Flood Insurance Program (NFIP) or Individual Assistance Program (IAP). The greatest number of claims since the year 2000 have been concentrated in Rockingham, Hillsborough, Strafford, Merrimack, and Cheshire counties.

\section{Storm Simulation}

The First Street Foundation Flood Model has recreated 1 flooding event that has occurred since the year 2000 in the state of New Hampshire. This event flooded around 200 properties across the state **

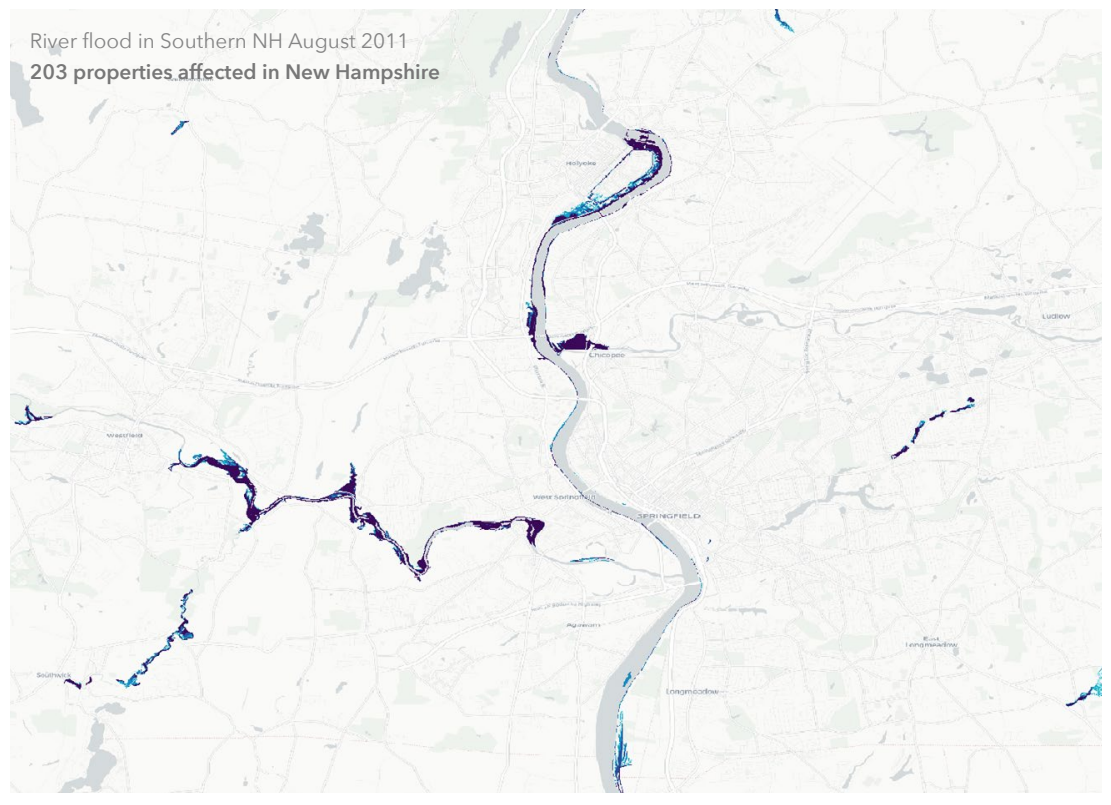

\section{2,000}

Properties served by

protection measures

The First Street Foundation Flood

Model incorporates 17 flood control

measures throughout the state which

protect 2,000 properties.

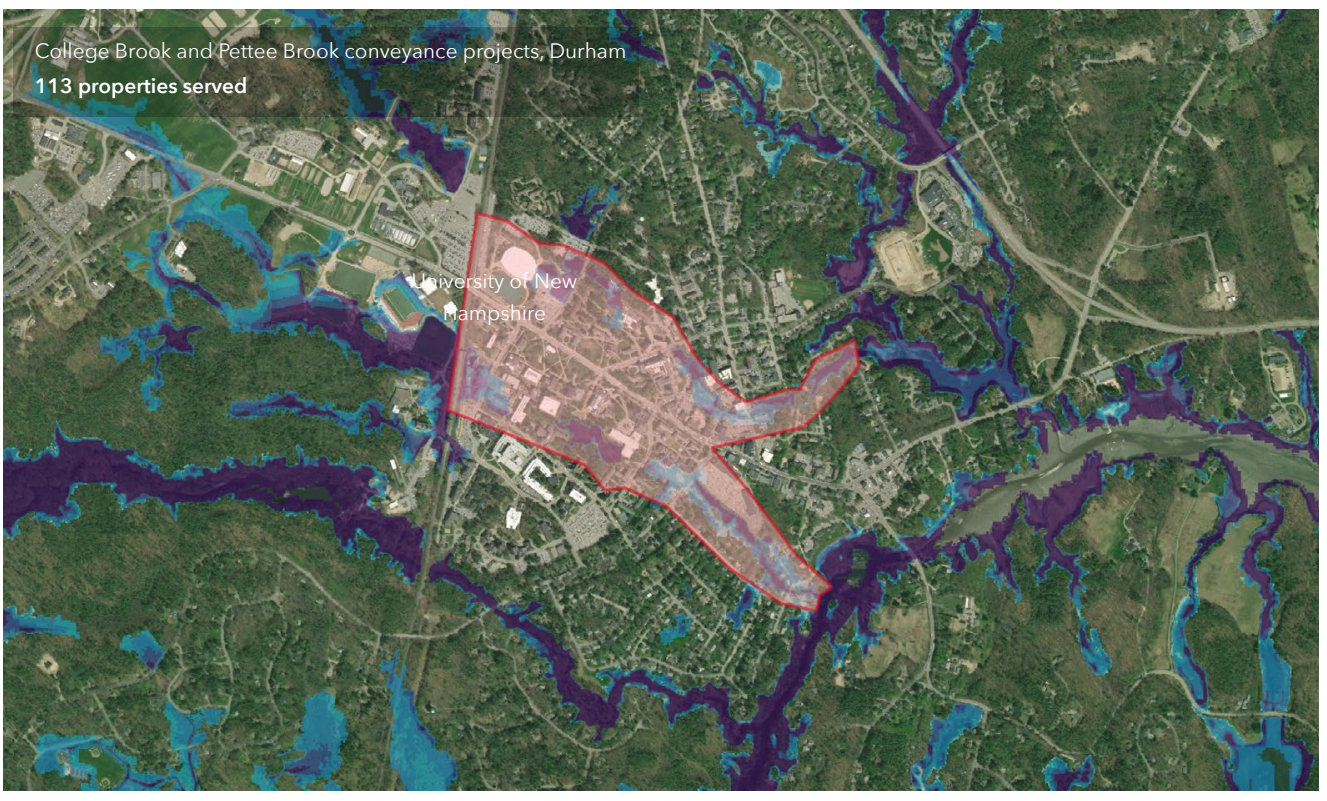

Area of protectio
Top protection measures in state by quantity

Type
Example

\# Properties served by type

Levee

Dike

Bartlett Dike

Culvert
Rye Berm along $1 \mathrm{~A}$ to protect highway

Depth of flooding for a simulated
in 100 flood event in 2020 


\section{State Overview New Jersey}

Flood risk is increasing in the state of New Jersey. 385,400 properties currently have a substantial risk* $^{*}$ of flooding. Over the next 30 years, the number of properties with this risk will increase by another $19.1 \%$, bringing the total number of properties with substantial risk to 459,000 .

To understand personal flood risk, Americans leverage the Federal Emergency Management Agency (FEMA) Flood Insurance Rate Maps (FIRM). These maps identify 393,600 properties as having substantial risk in the state of $\mathrm{New}$ Jersey. In comparison, the First Street Foundation Flood Model identifies 8,100 fewer of properties as facing this same level of risk. This discrepancy exists because of differences in the methods used to estimate risk. The Foundation's Flood Model uses the current climate data, maps precipitation as a stand-alone risk, and may include adaptation improvements not taken into account by FEMA. When adjusting for future environmental changes, the FEMA gap reverses, with the Foundation model identifying 65,500 properties at risk by the year 2050

\section{Total properties at substantial risk}

\section{$\ln 2050$} 385,400

30-year change

$$
\Delta+73,600(+19 \%)
$$

The Jersey Shore is threatened by major recurrent flooding including nuisance flooding with high tides as well as devastating regional flooding from strong storms, like Hurricane Sandy. The densely populated Raritan River region is threatened by rainfall and riverine flooding. The US Army Corps of Engineers is constructing a massive series of levees to reduce the threat, but a number of towns remain at risk.

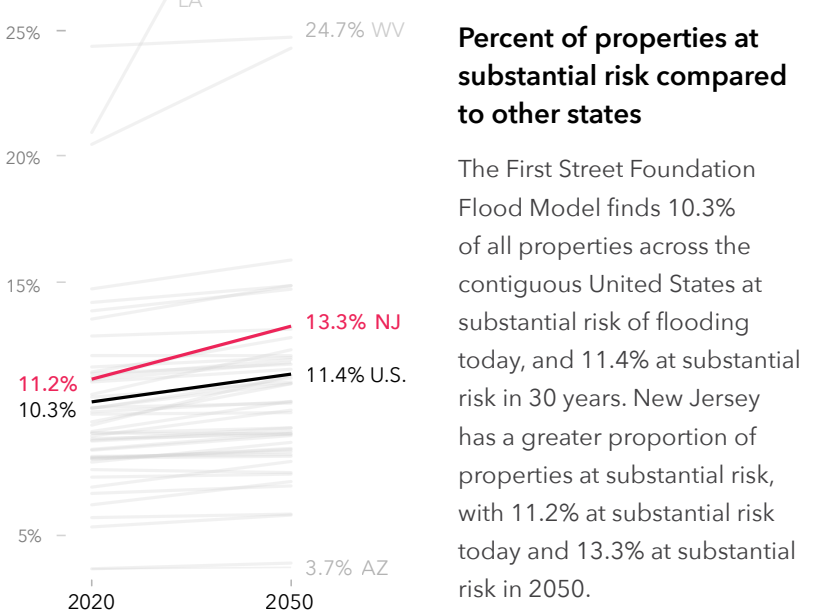
to other states

Street Foundation Model finds $10.3 \%$ substantial risk of flooding with $11.2 \%$ at substantial risk risk in 2050
Difference in number of properties currently at substantial risk compared to FEMA**

$\mathbf{v}-8,100$

More properties at risk in FSF model $\longrightarrow$

$-50 \% \quad 0 \quad+50 \% \quad+150 \%$

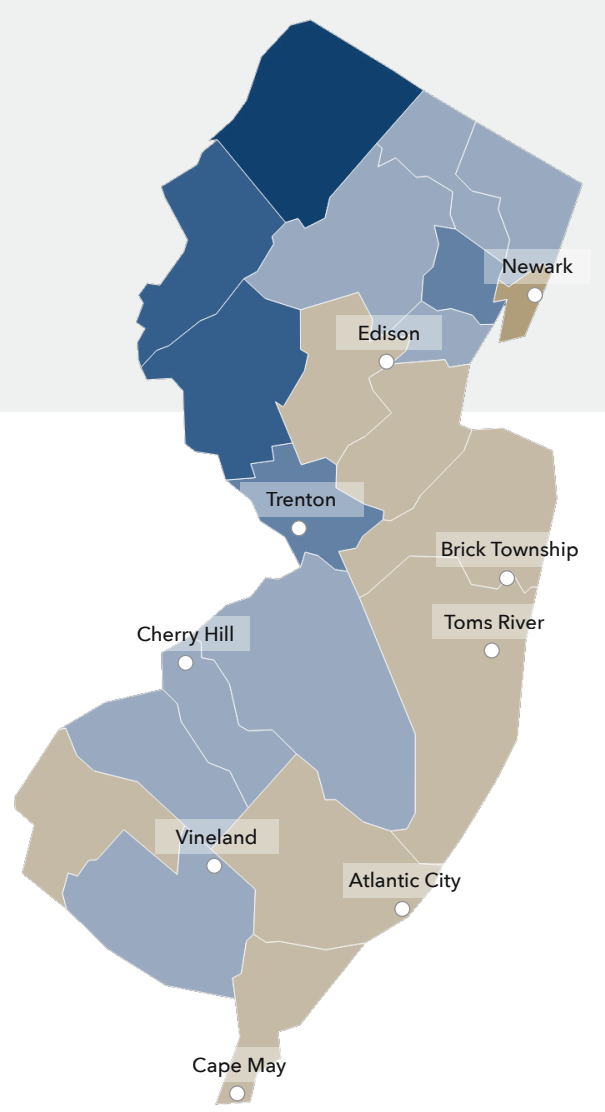




\section{Local details \\ New Jersey}

The First Street Foundation Flood Model calculates the number of properties facing any risk* of flooding. When looking at this broader level of risk, the data identifies 617,300 properties in New Jersey as at risk over the next 30 years. Of these properties, 150,700 were categorized as facing almost certain risk, with a $99 \%$ chance of flooding at least once over the next 30 years.

The city of Ocean City has the greatest number of properties at risk of flooding in the state with 17,300 currently at risk, or $81 \%$ of its total number of properties. However, smaller cities or municipalities in the state, with fewer properties, may have a greater proportion of their total properties at risk. For example, $98 \%$ of properties in Wildwood are at risk of flooding. Other municipalities will see the greatest

increase in risk over the next 30 years. Bradley Beach, for example, will see a $4140 \%$ increase in the number of properties at risk.

Click here for a full breakdown of counties, cities, zip codes, and congressional districts in New Jersey at risk.

\section{Greatest proportion of properties at risk*}

\begin{tabular}{lrl} 
Municipality & \multicolumn{2}{c}{2020} \\
\hline Wildwood & 4,371 & $98 \%$ \\
\hline Dover Beaches South & 3,456 & $95 \%$ \\
\hline Margate City & 6,188 & $93 \%$ \\
\hline Lavallette & 2,732 & $93 \%$ \\
\hline Surf City & 2,334 & $91 \%$ \\
\hline North Wildwood & 5,978 & $90 \%$ \\
\hline Seaside Heights & 2,045 & $89 \%$ \\
\hline Burlington & 5,133 & $87 \%$ \\
\hline Sea Isle City & 11,495 & $86 \%$ \\
\hline Ship Bottom & 1,924 & $85 \%$ \\
\hline
\end{tabular}

\section{Greatest number of properties at risk*}

\begin{tabular}{|c|c|c|c|c|c|c|}
\hline Municipality & 20 & & & 50 & & nange \\
\hline Ocean City & 17,255 & $81 \%$ & 19,876 & $94 \%$ & $+2,621$ & $+15.2 \%$ \\
\hline Toms River & 11,675 & $26 \%$ & 14,764 & $33 \%$ & $+3,089$ & $+26.5 \%$ \\
\hline Sea Isle City & 11,495 & $86 \%$ & 12,427 & $93 \%$ & +932 & $+8.1 \%$ \\
\hline Avalon & 10,055 & $80 \%$ & 11,880 & $95 \%$ & $+1,825$ & $+18.2 \%$ \\
\hline Atlantic City & 9,726 & $79 \%$ & 11,234 & $92 \%$ & $+1,508$ & $+15.5 \%$ \\
\hline Browns Mills & 7,195 & $25 \%$ & 7,338 & $25 \%$ & +143 & $+2.0 \%$ \\
\hline Camden & 7,000 & $25 \%$ & 8,005 & $28 \%$ & $+1,005$ & $+14.4 \%$ \\
\hline Newark & 6,790 & $15 \%$ & 7,818 & $17 \%$ & $+1,028$ & $+15.1 \%$ \\
\hline Trenton & 6,405 & $20 \%$ & 6,725 & $21 \%$ & +320 & $+5.0 \%$ \\
\hline Margate City & 6,188 & $93 \%$ & 6,449 & $97 \%$ & +261 & $+4.2 \%$ \\
\hline
\end{tabular}

\section{Greatest relative growing risk*}

\begin{tabular}{lrrrrrr} 
Municipality & \multicolumn{2}{c}{2020} & \multicolumn{2}{c}{2050} & \multicolumn{2}{c}{ Change } \\
\hline Bradley Beach & 20 & $1 \%$ & 848 & $38 \%$ & +828 & $+4140 \%$ \\
\hline Ocean Grove & 74 & $3 \%$ & 699 & $32 \%$ & +625 & $+845 \%$ \\
\hline Belmar & 243 & $9 \%$ & 1,878 & $68 \%$ & $+1,635$ & $+673 \%$ \\
\hline Edgewater & 250 & $6 \%$ & 1,581 & $40 \%$ & $+1,331$ & $+532 \%$ \\
\hline Paulsboro & 222 & $8 \%$ & 1,200 & $44 \%$ & +978 & $+441 \%$ \\
\hline Asbury Park & 343 & $7 \%$ & 1,465 & $32 \%$ & +1122 & $+327 \%$ \\
\hline South Amboy & 56 & $2 \%$ & 179 & $6 \%$ & +123 & $+220 \%$ \\
\hline Jersey City & 4,668 & $9 \%$ & 14,253 & $26 \%$ & $+9,585$ & $+205 \%$ \\
\hline Hoboken & 4,837 & $26 \%$ & 13,672 & $73 \%$ & $+8,835$ & $+183 \%$ \\
\hline Pine Beach & 161 & $5 \%$ & 385 & $13 \%$ & +224 & $+139 \%$ \\
\hline
\end{tabular}

\section{Flood Factor distribution of properties at risk ${ }^{\star}(1000 s)$}

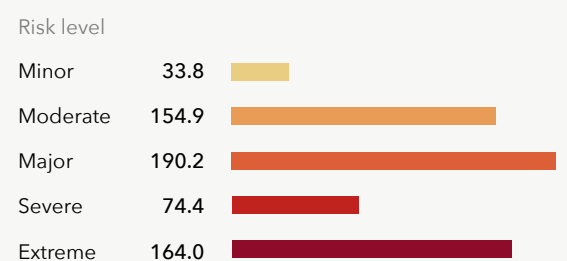

More than $17.9 \%$ of individual properties and properties in New Jersey are at any risk of flooding over the next 30 years. Out of those at risk $69 \%$ are at major to extreme risk.

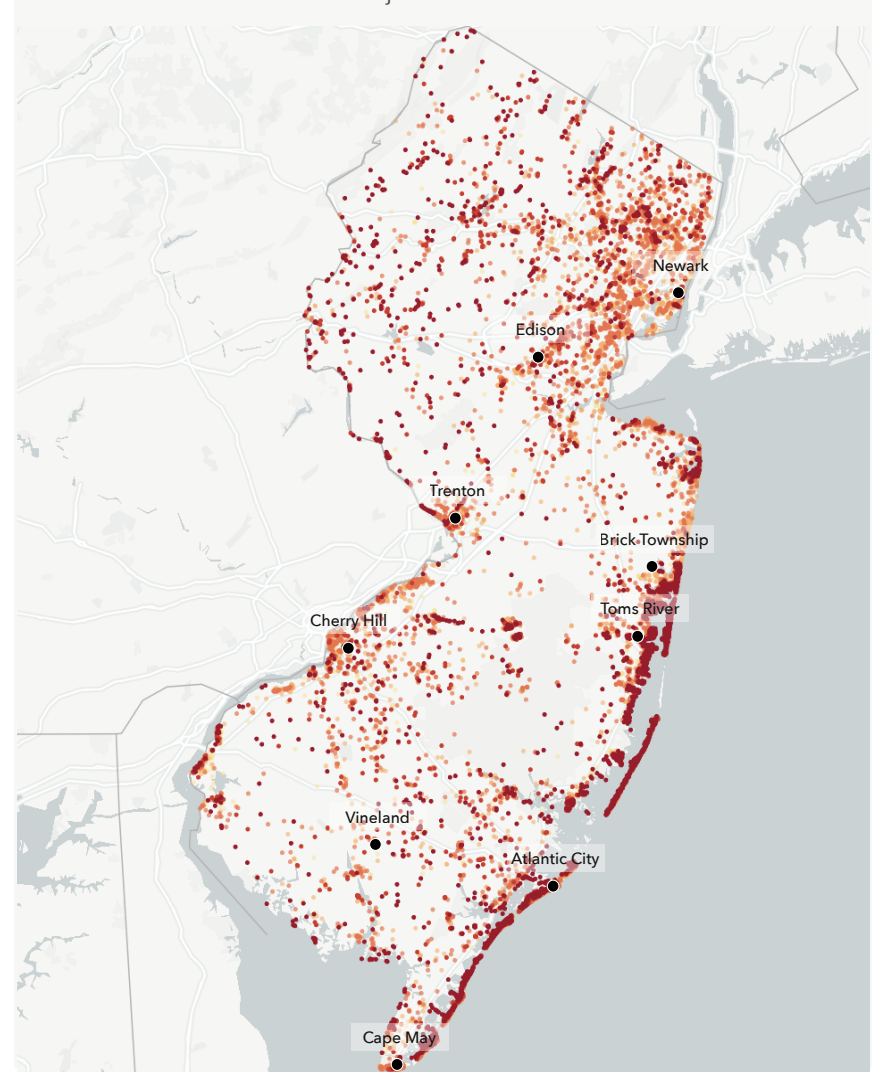


Flood History \& Protection

\section{New Jersey}

\section{Claims History}

588,700 home and property owners in New Jersey have made flood damage claims through FEMA since the year 2000.* These claims for reimbursement were made through either the National Flood Insurance Program (NFIP) or Individual Assistance Program (IAP). The greatest number of claims since the year 2000 have been concentrated in Ocean, Monmouth, Middlesex, Union, and Essex counties.

\section{Storm Simulation}

The First Street Foundation Flood Model has recreated 4 flooding events that have occurred since the year 2000 in the state of New Jersey. These events flooded around 406,870 properties across the state. ${ }^{\star \star}$

\section{Flood event}

- Hurricane Isabel

Date

\# Properties
affected

Nor'easter

Sep 2003

33,160

Hurricane Irene

Nov 2009

Aug 2011

Oct 2012

Hurricane Sandy

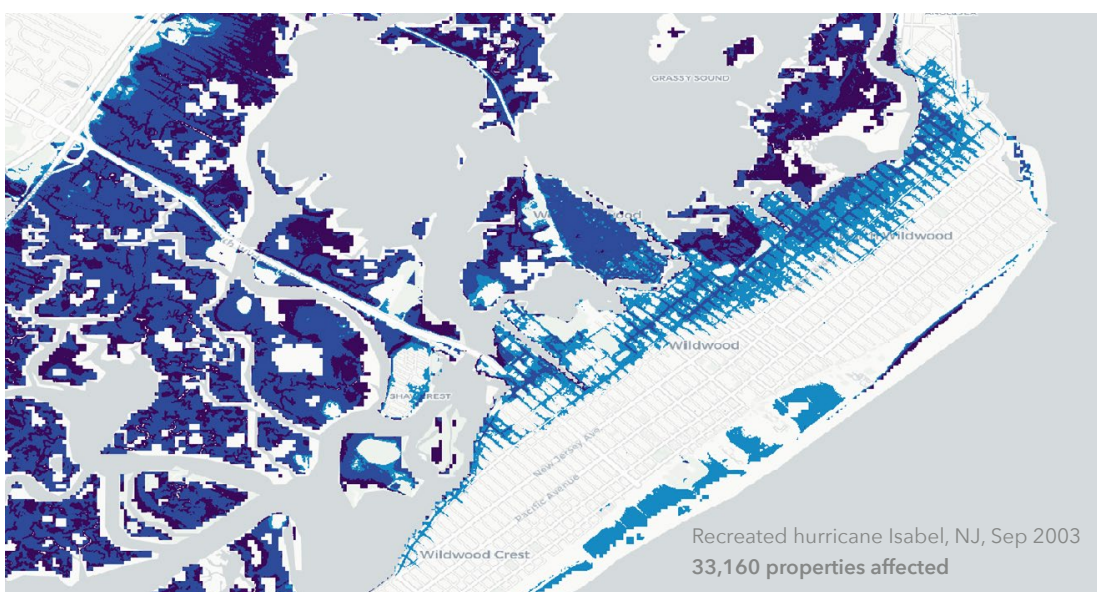

\section{0,200}

Properties served by

protection measures

The First Street Foundation Flood

Model incorporates 370 flood control

measures throughout the state which

protect 50,200 properties.
Top protection measures in state by quantity

Type
Example

Levee

Raritan Bay \& Sandy Hook Bay, Keansburg

Open space preserve

Dune

Pump station

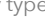

962

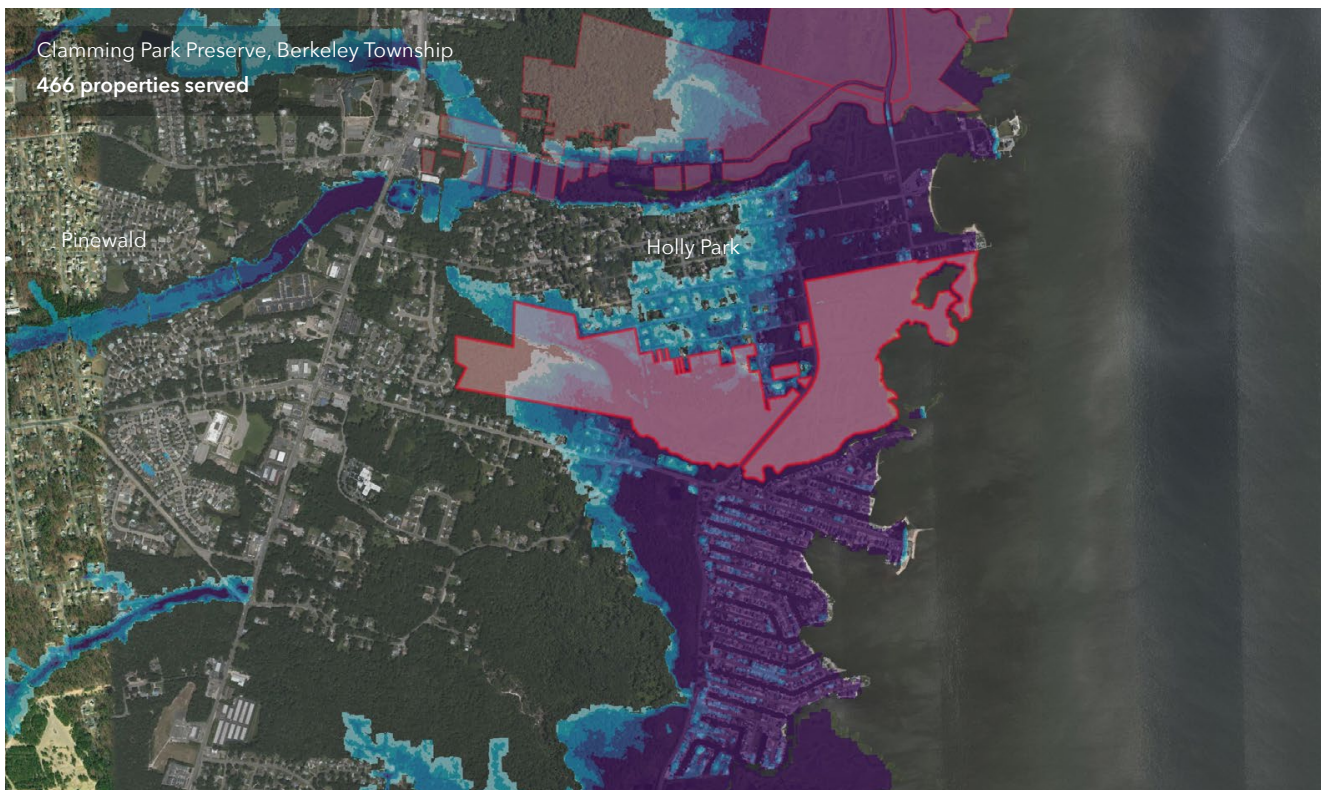

$\square$ Area of protection 


\section{State Overview New Mexico}

Flood risk is increasing in the state of New Mexico. 128,800 properties currently have a substantial risk* of flooding. Over the next 30 years, the number of properties with this risk will increase by another $0.7 \%$, bringing the total number of properties with substantial risk to 129,700

To understand personal flood risk, Americans leverage the Federal Emergency Management Agency (FEMA) Flood Insurance Rate Maps (FIRM). These maps identify 98,200 properties as having substantial risk in the state of New Mexico. In comparison, the First Street Foundation Flood Model identifies 1.3 times the number of properties as facing this same level of risk. This discrepancy exists because the Foundation uses the current climate data, maps precipitation as a stand-alone risk, and includes areas that FEMA has not mapped. These new methods uncover an additional 30,500 properties currently not identified by FEMA as having substantial risk. When adjusting for future environmental changes, the FEMA gap further widens to 31,500 by the year 2050 .
Total properties at substantial risk ${ }^{*}$

$\ln 2020$

\section{8,800}

30-year change

$\Delta+900(+0.7 \%)$
Difference in number of properties currently at substantial risk compared to FEMA**

$$
\Delta+30,500
$$

More properties at risk in FSF model $\longrightarrow$

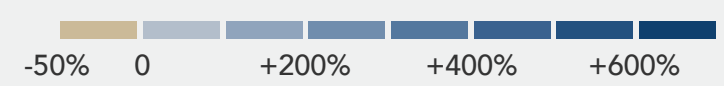

While Albuquerque slopes towards the Rio Grande, rain and thunderstorms can overwhelm a network of arroyos, diversion channels, and stormwater systems, thus leading to flash flooding. To the south, Las Cruces also slopes towards the Rio Grande, but faces monsoons and remnants of tropical storms causing flash floods down those slopes.
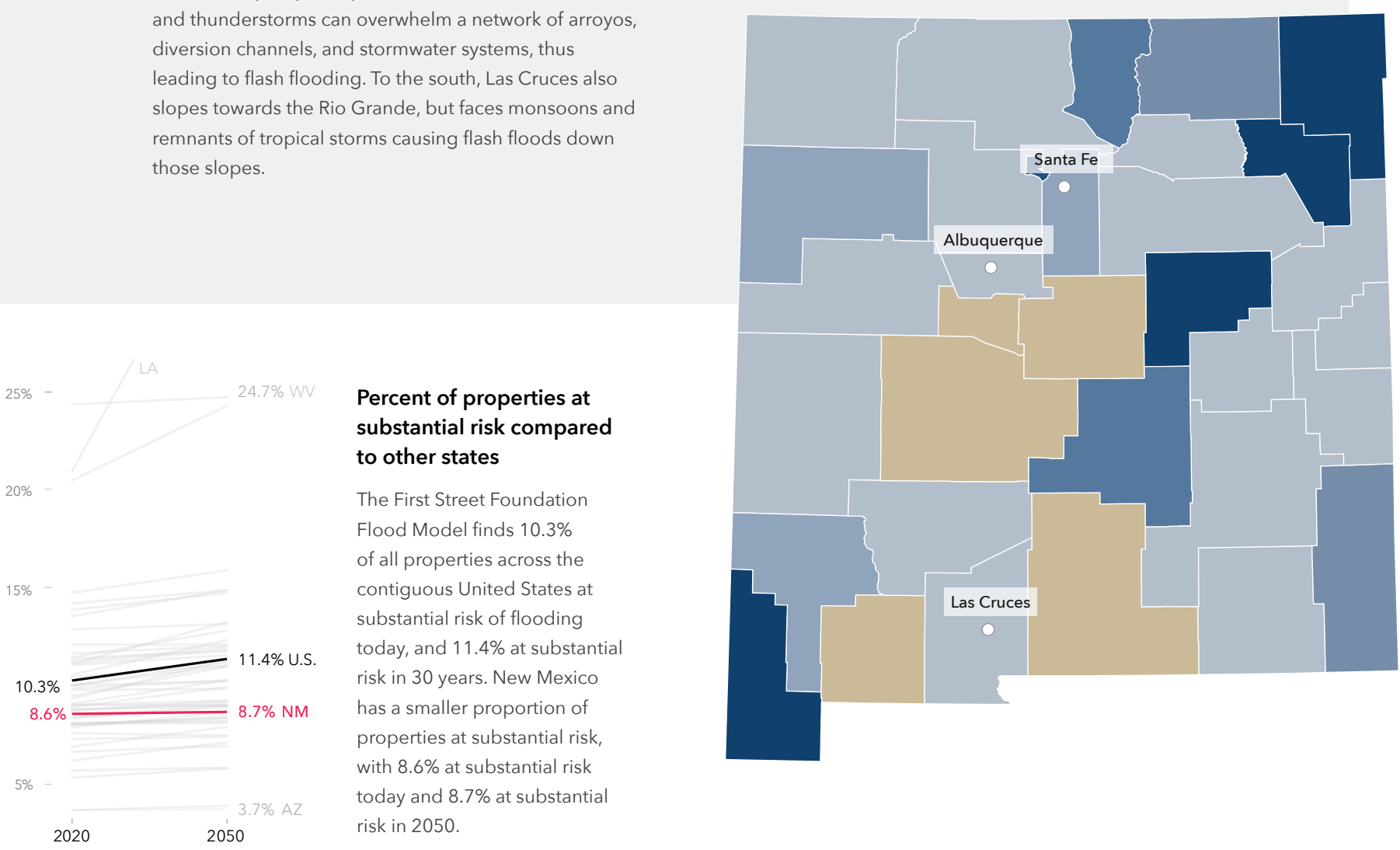


\section{Local details \\ New Mexico}

The First Street Foundation Flood Model calculates the number of properties facing any risk* of flooding. When looking at this broader level of risk, the data identifies 219,000 properties in New Mexico as at risk over the next 30 years. Of these properties, 22,000 were categorized as facing almost certain risk, with a $99 \%$ chance of flooding at least once over the next 30 years.

The city of Albuquerque has the greatest number of properties at risk of flooding in the state with 16,500 currently at risk, or $9 \%$ of its total number of properties. However, smaller cities or municipalities in the state, with fewer properties, may have a greater proportion of their total properties at risk. For example, $85 \%$ of properties in Lovington are at risk of flooding. Other municipalities will see the greatest increase in risk over the next 30 years. North Valley, for example, will see a $8 \%$ increase in the number of properties at risk.

Click here for a full breakdown of counties, cities, zip codes, and congressional districts in New Mexico at risk.

\section{Greatest proportion of properties at risk*}

\begin{tabular}{l|c|c|}
\hline $\begin{array}{l}\text { Municipality } \\
\text { Lovington }\end{array}$ & \multicolumn{2}{c}{2020} \\
\hline Los Ranchos de Albuquerque & 1,497 & $85 \%$ \\
\hline North Hobbs & 1,713 & $61 \%$ \\
\hline Artesia & 3,281 & $43 \%$ \\
\hline Socorro & 1,549 & $38 \%$ \\
\hline Hobbs & 5,152 & $36 \%$ \\
\hline Portales & 1,661 & $32 \%$ \\
\hline Los Chaves & 900 & $32 \%$ \\
\hline North Valley & 1,432 & $30 \%$ \\
\hline Corrales & 1,443 & $29 \%$ \\
\hline
\end{tabular}

\section{Greatest number of properties at risk*}

\begin{tabular}{l|cccccc} 
Municipality & \multicolumn{2}{c}{2020} & \multicolumn{2}{c}{2050} & \multicolumn{2}{c}{ Change } \\
\cline { 2 - 4 } & 16,540 & $9 \%$ & 17,502 & $9 \%$ & +962 & $+5.8 \%$ \\
\hline Las Cruces & 6,601 & $18 \%$ & 6,492 & $17 \%$ & -109 & $-1.7 \%$ \\
\hline Hobbs & 5,152 & $36 \%$ & 5,186 & $36 \%$ & +34 & $+0.7 \%$ \\
\hline Rio Rancho & 4,190 & $6 \%$ & 4,179 & $6 \%$ & -11 & $-0.3 \%$ \\
\hline Lovington & 4,053 & $85 \%$ & 4,131 & $87 \%$ & +78 & $+1.9 \%$ \\
\hline Carlsbad & 3,639 & $23 \%$ & 3,618 & $22 \%$ & -21 & $-0.6 \%$ \\
\hline Artesia & 3,281 & $43 \%$ & 3,311 & $43 \%$ & +30 & $+0.9 \%$ \\
\hline Roswell & 2,369 & $11 \%$ & 2,373 & $11 \%$ & +4 & $+0.2 \%$ \\
\hline Ruidoso & 2,310 & $20 \%$ & 2,301 & $20 \%$ & -9 & $-0.4 \%$ \\
\hline Santa Fe & 2,053 & $6 \%$ & 2,075 & $6 \%$ & +22 & $+1.1 \%$
\end{tabular}

\section{Greatest relative growing risk*}

\begin{tabular}{lrrrrrr} 
Municipality & \multicolumn{2}{c}{2020} & \multicolumn{2}{c}{2050} & \multicolumn{2}{c}{ Change } \\
North Valley & 1,432 & $30 \%$ & 1,553 & $32 \%$ & +121 & $+8 \%$ \\
\hline Ventura & 394 & $8 \%$ & 423 & $9 \%$ & +29 & $+7 \%$ \\
\hline Albuquerque & 16,540 & $9 \%$ & 17,502 & $9 \%$ & +962 & $+6 \%$ \\
\hline Aztec & 141 & $5 \%$ & 149 & $5 \%$ & +8 & $+6 \%$ \\
\hline Grants & 672 & $13 \%$ & 700 & $14 \%$ & +28 & $+4 \%$ \\
\hline Sunshine & 246 & $4 \%$ & 254 & $4 \%$ & +8 & $+3 \%$ \\
\hline Farmington & 1,225 & $7 \%$ & 1,263 & $7 \%$ & +38 & $+3 \%$ \\
\hline South Valley & 1,440 & $10 \%$ & 1,484 & $10 \%$ & +44 & $+3 \%$ \\
\hline Deming & 880 & $6 \%$ & 906 & $6 \%$ & +26 & $+3 \%$ \\
\hline Portales & 1,661 & $32 \%$ & 1,711 & $33 \%$ & +50 & $+3 \%$
\end{tabular}

\section{Flood Factor distribution of properties at risk ${ }^{\star}(1000 s)$}

\section{Risk level}

Moderate $\quad 94.9$

Major

Severe

62.3

Extreme

25.9

More than $14.8 \%$ of individual properties and properties in New Mexico are at any risk of flooding over the next 30 years. Out of those at risk $53 \%$ are at major to extreme risk.

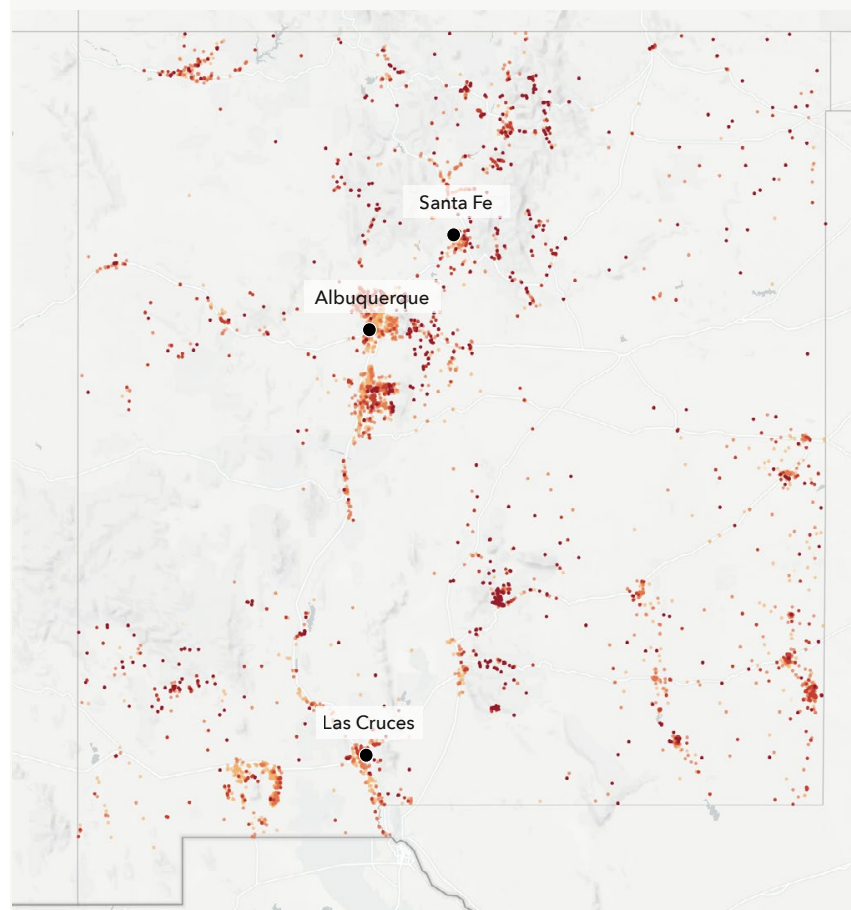




\section{Flood History \& Protection \\ New Mexico}

\section{Claims History}

3,900 home and property owners in New Mexico have made flood damage claims through FEMA since the year 2000.*These claims for reimbursement were made through either the National

Flood Insurance Program (NFIP) or Individual Assistance Program (IAP). The greatest number of

claims since the year 2000 have been concentrated in Curry, Roosevelt, Otero, and Quay counties.

\section{Storm Simulation}

The First Street Foundation Flood Model has recreated 1 flooding event that occurred since the year 2000 in the state of New Mexico. This event flooded around 600 properties across the state.*^

Recreated river flood near Ruidoso, NM, July 2008

603 properties affected

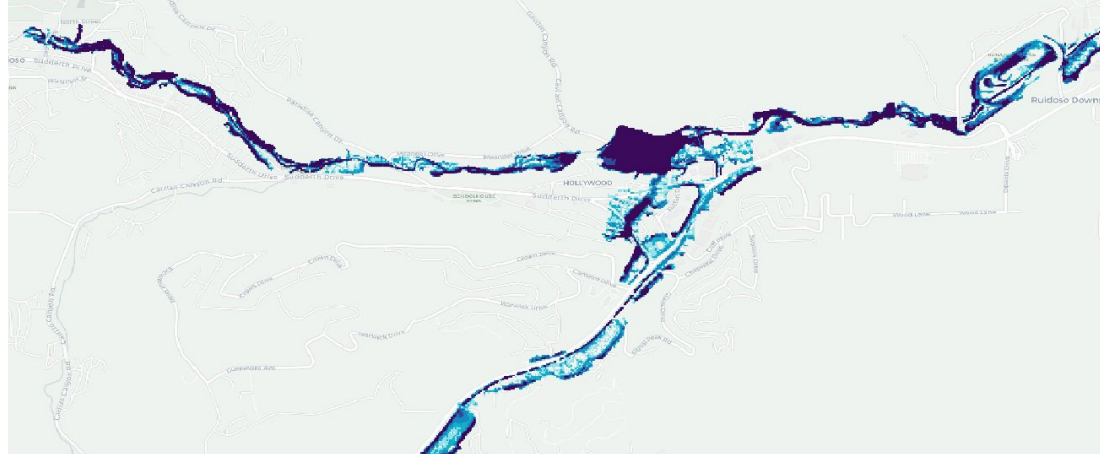

* Source: Fema.gov

** Based on model simulation of historic events. Historic recreations do not include precipitation. See methodology for full model details.

\section{5,300}

Properties served by

protection measures

The First Street Foundation Flood

Model incorporates 228 flood control

measures throughout the state which

protect 145,300 properties

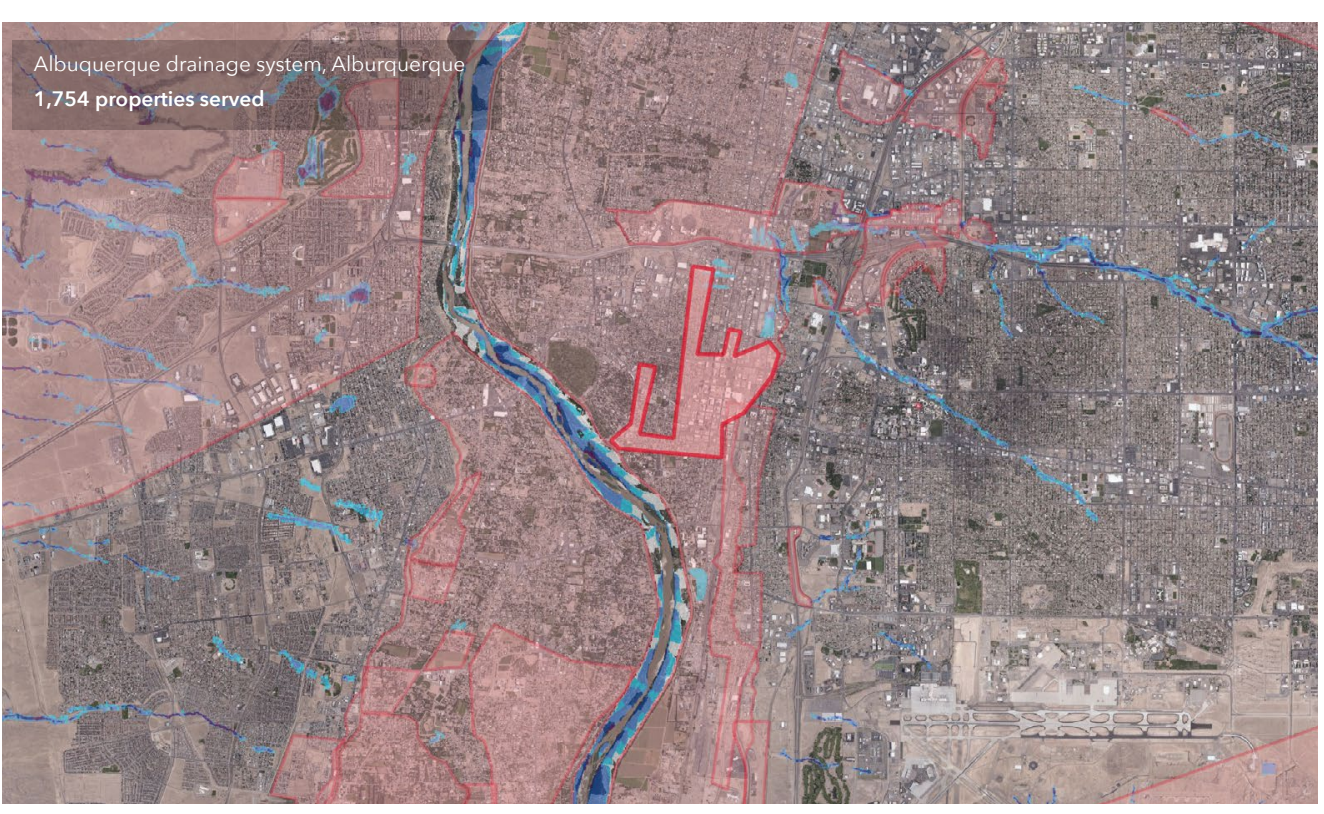

Area of protectio
Top protection measures in state by quantity

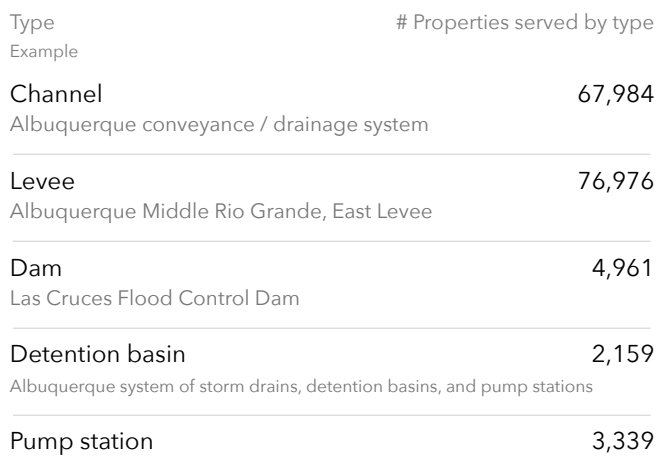

984 


\section{State Overview New York}

Flood risk is increasing in the state of New York. 615,500 properties currently have a substantial risk* of flooding. Over the next 30 years, the number of properties with this risk will increase by another $11.9 \%$, bringing the total number of properties with substantial risk to 688,800 .

To understand personal flood risk, Americans leverage the Federal Emergency Management Agency (FEMA) Flood Insurance Rate Maps (FIRM). These maps identify 239,000 properties as having substantial risk in the state of $\mathrm{New}$ York. In comparison, the First Street Foundation Flood Model identifies 2.6 times the number of properties as facing this same level of risk. This discrepancy exists because the Foundation uses the current climate data, maps precipitation as a stand-alone risk, and includes areas that FEMA has not mapped. These new methods uncover an additional 376,500 properties currently not identified by FEMA as having substantial risk.

When adjusting for future environmental changes, the FEMA gap further widens to 449,800 by the year 2050
Total properties at substantial risk *

In 2020

\section{5,500}

30-year change

$\Delta+73,300(+12 \%)$

NYC and Long Island are vulnerable to hurricanes and tidal floods. Poor drainage in urbanized areas leaves them susceptible to intense rains. The area is rebuilding infrastructure after Hurricane Sandy, and working on other protection efforts. Upstate, the Great Lakes face rising water levels impacting a number of communities. Flood protection efforts include levees, floodwalls,

managed open space, and pervious surfaces to increase infiltration

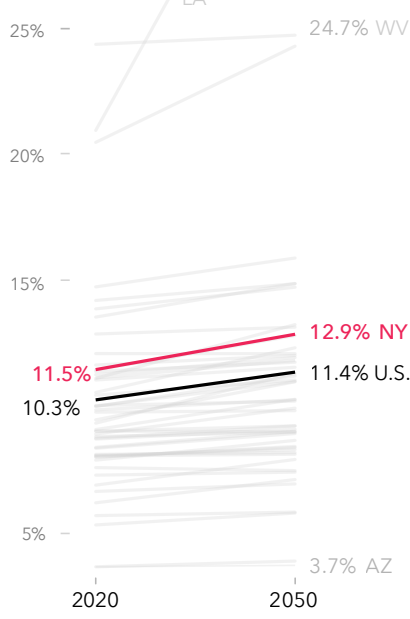

Percent of properties at substantial risk compared to other states

The First Street Foundation Flood Model finds $10.3 \%$ of all properties across the contiguous United States at substantial risk of flooding today, and $11.4 \%$ at substantial risk in 30 years. New York has a greater proportion of properties at substantial risk, with $11.5 \%$ at substantial risk today and $12.9 \%$ at substantial risk in 2050 .
Difference in number of properties currently at substantial risk compared to FEMA**

$$
\Delta+376,500
$$

More properties at risk in FSF model $\longrightarrow$
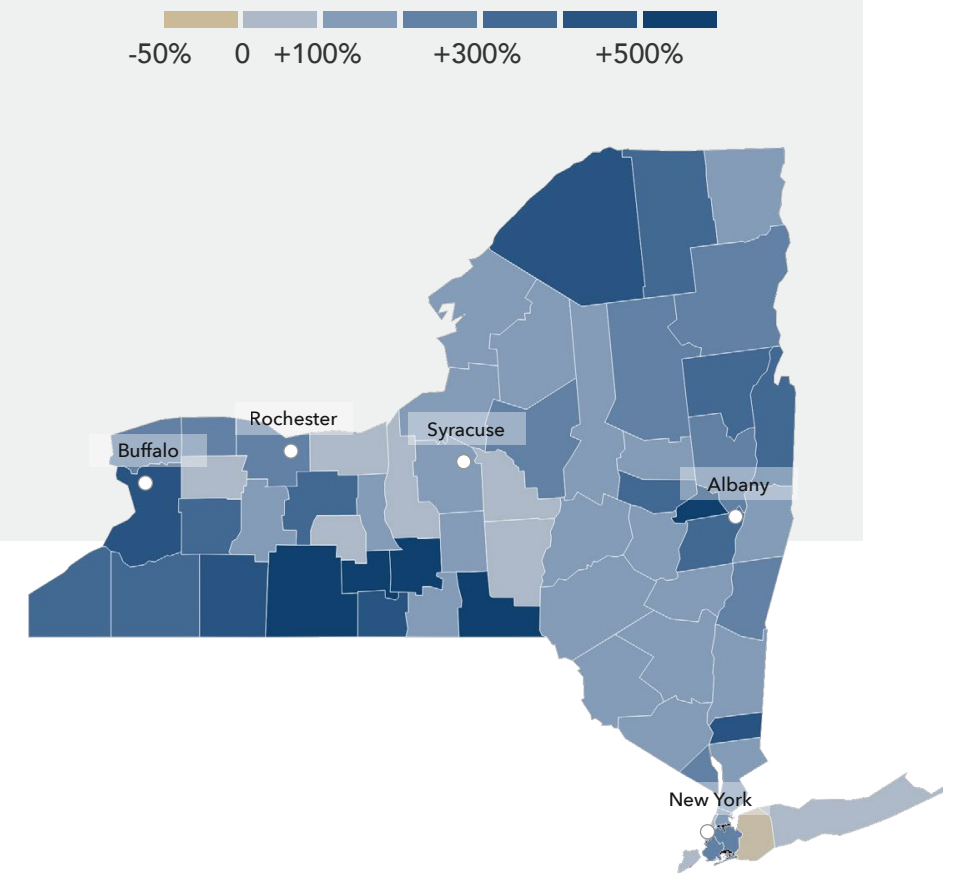


\section{Local details \\ New York}

The First Street Foundation Flood Model calculates the number of properties facing any risk* of flooding. When looking at this broader level of risk, the data identifies 998,600 properties in New York as at risk over the next 30 years. Of these properties, 172,800 were categorized as facing almost certain risk, with a $99 \%$ chance of flooding at least once over the next 30 years.

The city of New York has the greatest number of properties at risk of flooding in the state with 121,200 currently at risk, or $14 \%$ of its total number of properties. However, smaller cities or municipalities in the state, with fewer properties, may have a greater proportion of their total properties at risk. For example, $75 \%$ of properties in Hornell are at risk of flooding. Other municipalities will see the greatest increase in risk over the next 30 years. Merrick, for example, will see a 172\%

increase in the number of properties at risk.

Click here for a full breakdown of counties, cities, zip codes, and congressional districts in New York at risk.

\section{Greatest proportion of properties at risk*}

\begin{tabular}{lcccccc} 
Municipality & \multicolumn{2}{c}{2020} & \multicolumn{2}{c}{2050} & \multicolumn{2}{c}{ Change } \\
Hornell & 2,757 & $75 \%$ & 2,766 & $75 \%$ & +9 & $+0.3 \%$ \\
\hline Fire Island & 2,846 & $68 \%$ & 3,222 & $76 \%$ & +376 & $+13.2 \%$ \\
\hline Port Jervis & 2,022 & $66 \%$ & 2,051 & $67 \%$ & +29 & $+1.4 \%$ \\
\hline Conesus Lake & 1,237 & $60 \%$ & 1,251 & $61 \%$ & +14 & $+1.1 \%$ \\
\hline North Tonawanda & 7,590 & $59 \%$ & 7,822 & $61 \%$ & +232 & $+3.1 \%$ \\
\hline Southport & 2,208 & $59 \%$ & 2,261 & $60 \%$ & +53 & $+2.4 \%$ \\
\hline Elmira & 5,380 & $55 \%$ & 5,614 & $57 \%$ & +234 & $+4.3 \%$ \\
\hline Ithaca & 2,858 & $53 \%$ & 2,864 & $53 \%$ & +6 & $+0.2 \%$ \\
\hline Long Beach & 3,750 & $47 \%$ & 7,879 & $99 \%$ & $+4,129$ & \\
\hline Olean & 3,028 & $47 \%$ & 3,098 & $48 \%$ & +70 &
\end{tabular}

\section{Greatest number of properties at risk*}

\begin{tabular}{l|c|ccccc} 
Municipality & \multicolumn{2}{c}{2020} & \multicolumn{2}{c}{2050} & \multicolumn{2}{c}{ Change } \\
\cline { 2 - 6 } New York & 121,202 & $14 \%$ & 166,875 & $19 \%$ & $+45,673$ & $+37.7 \%$ \\
\hline Buffalo & 24,613 & $26 \%$ & 25,144 & $27 \%$ & +531 & $+2.2 \%$ \\
\hline Syracuse & 7,968 & $19 \%$ & 8,264 & $20 \%$ & +296 & $+3.7 \%$ \\
\hline North Tonawanda & 7,590 & $59 \%$ & 7,822 & $61 \%$ & +232 & $+3.1 \%$ \\
\hline Cheektowaga & 6,999 & $25 \%$ & 7,168 & $25 \%$ & +169 & $+2.4 \%$ \\
\hline Rochester & 6,953 & $11 \%$ & 7,150 & $11 \%$ & +197 & $+2.8 \%$ \\
\hline Binghamton & 6,499 & $41 \%$ & 6,802 & $43 \%$ & +303 & $+4.7 \%$ \\
\hline Tonawanda & 5,913 & $26 \%$ & 5,997 & $26 \%$ & +84 & $+1.4 \%$ \\
\hline Niagara Falls & 5,426 & $24 \%$ & 5,654 & $25 \%$ & +228 & $+4.2 \%$ \\
\hline Elmira & 5,380 & $55 \%$ & 5,614 & $57 \%$ & +234 & $+4.3 \%$
\end{tabular}

\section{Greatest relative growing risk*}

\begin{tabular}{lrrrrrr} 
Municipality & \multicolumn{2}{c}{2020} & \multicolumn{2}{c}{2050} & \multicolumn{2}{c}{ Change } \\
Merrick & 1,847 & $23 \%$ & 5,016 & $63 \%$ & $+3,169$ & $+172 \%$ \\
\hline Baldwin Harbor & 940 & $33 \%$ & 2,459 & $87 \%$ & $+1,519$ & $+162 \%$ \\
\hline Inwood & 550 & $24 \%$ & 1,222 & $53 \%$ & +672 & $+122 \%$ \\
\hline East Rockaway & 756 & $27 \%$ & 1,649 & $59 \%$ & +893 & $+118 \%$ \\
\hline Oceanside & 3,557 & $33 \%$ & 7,529 & $69 \%$ & $+3,972$ & $+112 \%$ \\
\hline Long Beach & 3,750 & $47 \%$ & 7,879 & $99 \%$ & $+4,129$ & $+110 \%$ \\
\hline Bellmore & 2,112 & $36 \%$ & 4,260 & $73 \%$ & $+2,148$ & $+102 \%$ \\
\hline Woodmere & 1,930 & $36 \%$ & 3,609 & $67 \%$ & $+1,679$ & $+87 \%$ \\
\hline Sag Harbor & 294 & $14 \%$ & 522 & $24 \%$ & +228 & $+78 \%$ \\
\hline Massapequa & 2,694 & $35 \%$ & 4,717 & $61 \%$ & $+2,023$ & $+75 \%$
\end{tabular}

\section{Flood Factor distribution of properties at risk* $(1000 s)$}

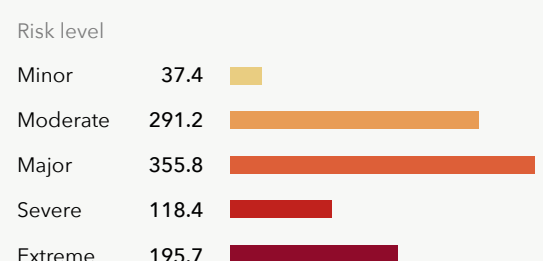

Extreme

More than $18.6 \%$ of individual properties and properties in New York are at any risk of flooding over the next 30 years. Out of those at risk $67 \%$ are at major to extreme risk.

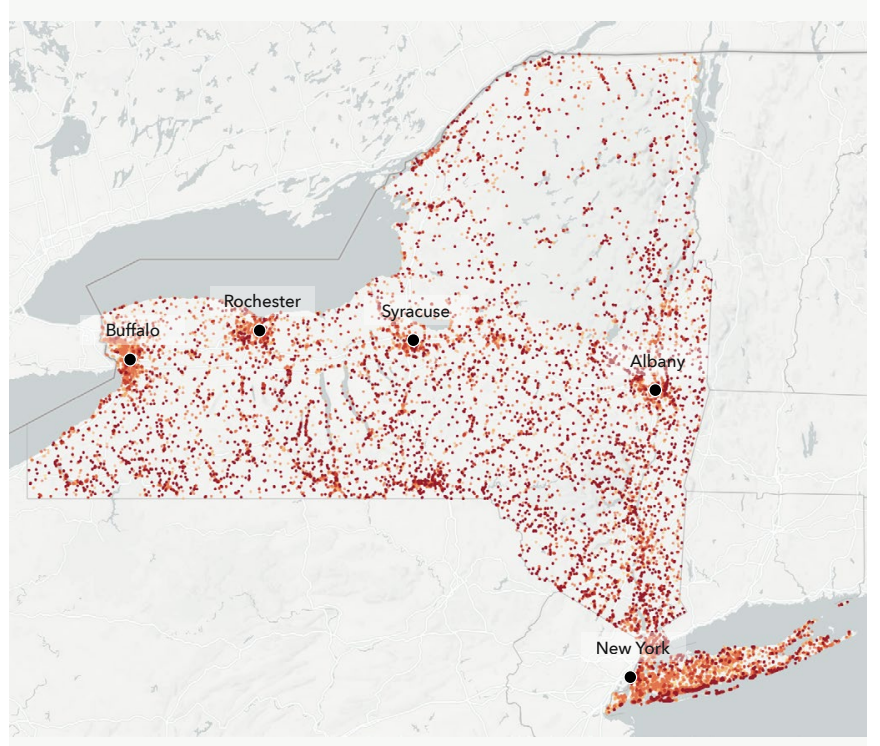




\section{Flood History \& Protection}

\section{New York}

\section{Claims History}

571,600 home and property owners in New York have made flood damage claims through FEMA since the year 2000. ${ }^{\star}$ These claims for reimbursement were made through either the National Flood Insurance Program (NFIP) or Individual Assistance Program (IAP). The greatest number of claims since the year 2000 have been concentrated in Nassau, Queens, Kings, Suffolk, and Richmond counties.

\section{Storm Simulation}

The First Street Foundation Flood Model has recreated 6 flooding events that have occurred since the year 2000 in the state of New York. These events flooded around 182,580 properties across the state. $^{* \star}$

\begin{tabular}{llr} 
Flood event & Date & $\begin{array}{r}\text { \# Properties } \\
\text { affected }\end{array}$ \\
Nor'easter & Feb 2003 & 1,647 \\
\hline Nor'easter & Nov 2009 & 20,641 \\
\hline Nor'easter & Mar 2010 & 1,870 \\
\hline River flood near Albany, NY & Apr 2011 & 2,194 \\
\hline Hurricane Irene & Aug 2011 & 35,716 \\
\hline Hurricane Sandy & Oct 2012 & 120,517
\end{tabular}
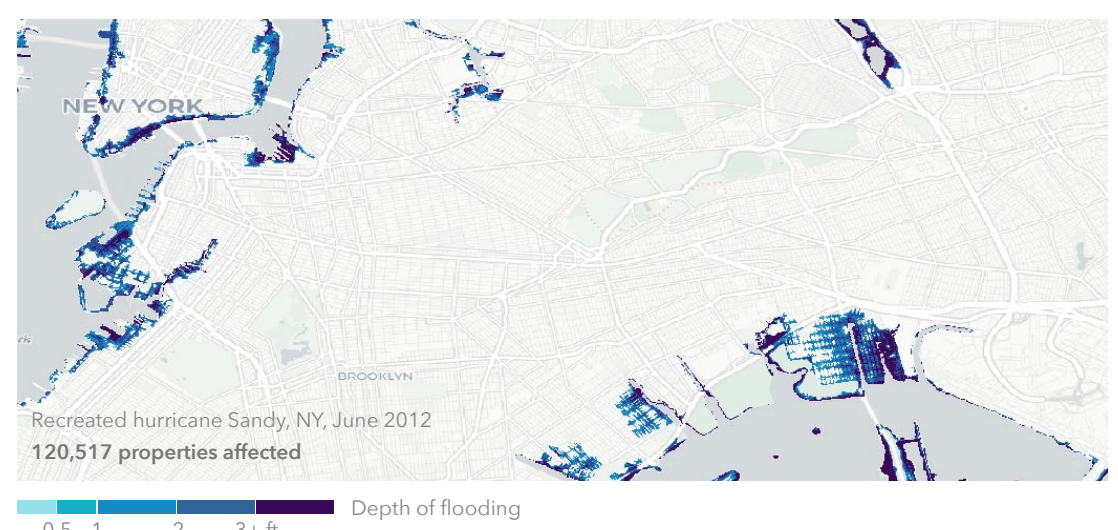

\section{0,000}

\section{Properties served by}

protection measures

The First Street Foundation Flood

Model incorporates 179 flood control

measures throughout the state which

protect 60,000 properties.

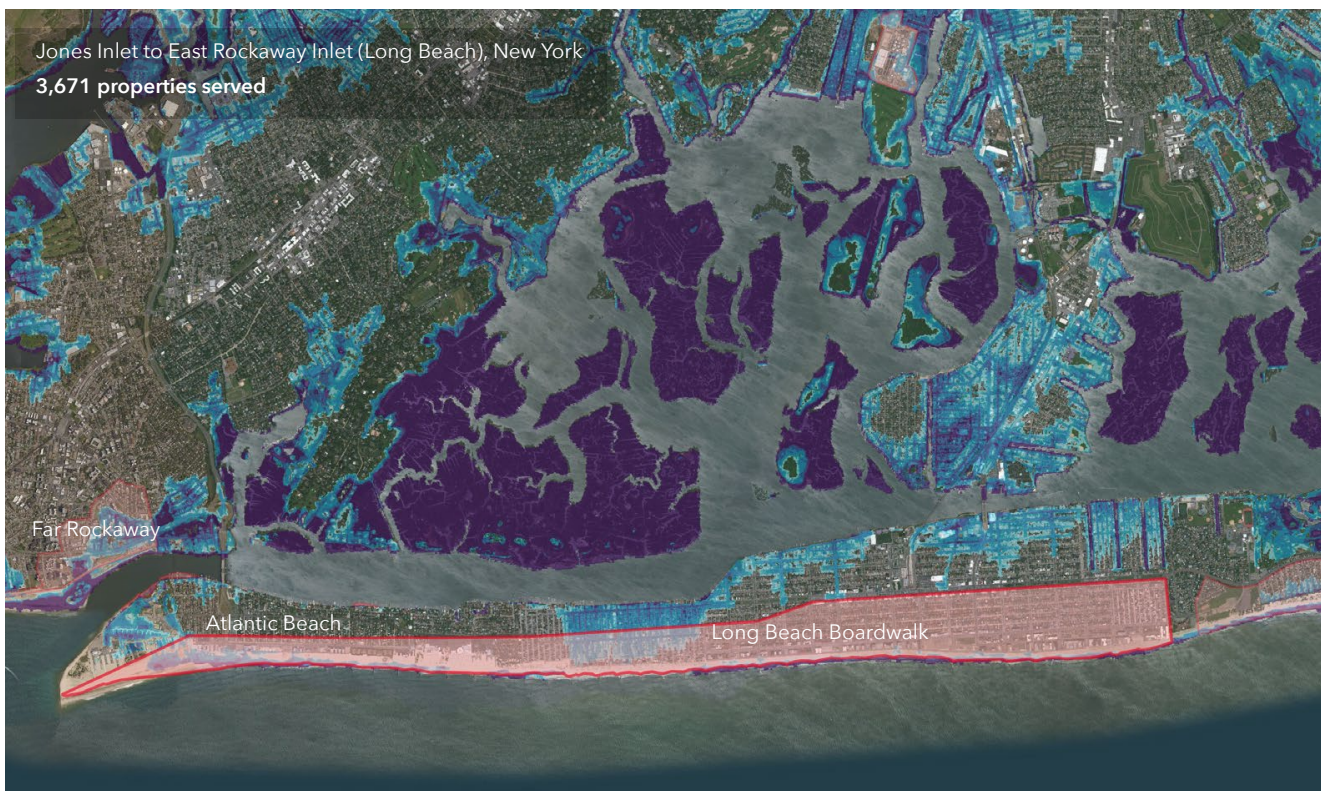

Area of protection $\begin{array}{lllll}0.5 & 1 & 2 & 3+\mathrm{ft} & \text { Depth of flooding for a simula } \\ 1 & \text { in } 100 \text { flood event in } 2020\end{array}$
Top protection measures in state by quantity

\begin{tabular}{lc}
$\begin{array}{l}\text { Type } \\
\text { Example }\end{array}$ & \# Properties served by type \\
Levee & 42,224 \\
North Elmira & \\
\hline $\begin{array}{l}\text { Channel } \\
\text { Lackawanna Flood Damage Reduction Project }\end{array}$ & 5,833 \\
\hline $\begin{array}{l}\text { Earthen berm } \\
\text { - Jones Inlet to East Rockaway Inlet (Long Beach), New York }\end{array}$ & 5,686 \\
\hline $\begin{array}{l}\text { Rain garden } \\
\text { Niagara Street Phase 3 \& 4, Buffalo }\end{array}$ & 2,378 \\
\hline Beach nourishment & 1,200
\end{tabular}

Sea Gate Area - Coney Island Coastal Storm Risk Reduction Project 


\section{State Overview North Carolina}

Flood risk is increasing in the state of North Carolina. 538,900 properties currently have a substantial risk* of flooding. Over the next 30 years, the number of properties with this risk will increase by another $12.1 \%$, bringing the total number of properties with substantial risk to 604,000 .

To understand personal flood risk, Americans leverage the Federal Emergency Management Agency (FEMA) Flood Insurance Rate Maps (FIRM) These maps identify 276,900 properties as having substantial risk in the state of North Carolina. In comparison, the First Street Foundation Flood Model identifies 1.9 times the number of properties as facing this same level of risk. This discrepancy exists because the Foundation uses the current climate data, maps precipitation as a stand-alone risk, and includes areas that FEMA has not mapped. These new methods uncover an additional 262,000 properties currently not identified by FEMA as having substantial risk. When adjusting for future environmental changes, the FEMA gap further widens to 327,100 by the year 2050 .
Total properties at substantial risk

$\ln 2020$ 538,900

30-year change

$$
\Delta+65,100(+12 \%)
$$

\section{Coastal areas face risk of storm surge from tropical} storms and hurricanes; wave action results in flood damage to coastal towns. Storm surge reaches inland through creeks and rivers. The state protects wetlands and coastal open space to limit flooding in urban areas. Charlotte faces risk from rain, thunderstorms, stationary frontal-storms, hurricanes, and flash floods that fill the Catawba River basin, threatening streets and properties.
Difference in number of properties currently at substantial risk compared to FEMA**

$\Delta+262,000$

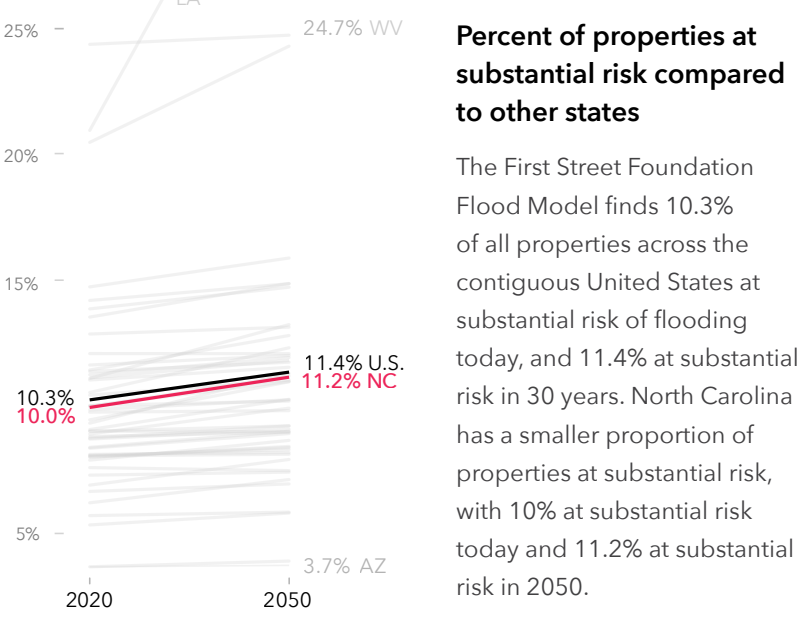

* Substantial risk is calculated as inundation $1 \mathrm{~cm}$ or more to the building in the 100 return period (1\% annual risk) and rounded to the nearest 100 properties See methodology for full model details. ** Cubstantialisk is calculated as ie FEMA con 


\section{Local details \\ North Carolina}

The First Street Foundation Flood Model calculates the number of properties facing any risk* of flooding. When looking at this broader level of risk, the data identifies 729,200 properties in North Carolina as at risk over the next 30 years. Of these properties, 182,300 were categorized as facing almost certain risk, with a $99 \%$ chance of flooding at least once over the next 30 years.

The city of Charlotte has the greatest number of properties at risk of flooding in the state with 17,500 currently at risk, or $7 \%$ of its total number of properties. However, smaller cities or municipalities in the state, with fewer properties, may have a greater proportion of their total properties at risk. For example, $94 \%$ of properties in Avon are at risk of flooding. Other municipalities will see the greatest increase in risk over the next 30 years. Plymouth, for example, will see a 103\% increase in the number of properties at risk.

Click here for a full breakdown of counties, cities, zip codes, and congressional districts in North Carolina at risk.

\section{Greatest proportion of properties at risk*}

\begin{tabular}{lll} 
Municipality & \multicolumn{2}{c}{2020} \\
\hline Avon & 2,052 & $94 \%$ \\
\hline Holden Beach & 2,908 & $86 \%$ \\
\hline Ocean Isle Beach & 3,015 & $80 \%$ \\
\hline Bald Head Island & 1,906 & $77 \%$ \\
\hline Washington & 3,992 & $77 \%$ \\
\hline Fairfield Harbour & 1,982 & $76 \%$ \\
\hline River Road & 1,996 & $75 \%$ \\
\hline Beaufort & 2,588 & $75 \%$ \\
\hline Surf City & 4,001 & $72 \%$ \\
\hline Moyock & 1,492 & $71 \%$ \\
\hline
\end{tabular}

\section{Greatest number of properties at risk*}

\begin{tabular}{lcccccc} 
Municipality & \multicolumn{2}{c}{2020} & \multicolumn{2}{c}{2050} & \multicolumn{2}{c}{ Change } \\
Charlotte & 17,545 & $7 \%$ & 18,562 & $7 \%$ & $+1,017$ & $+5.8 \%$ \\
\hline Wilmington & 11,184 & $27 \%$ & 13,153 & $32 \%$ & $+1,969$ & $+17.6 \%$ \\
\hline Raleigh & 8,469 & $7 \%$ & 8,835 & $7 \%$ & +366 & $+4.3 \%$ \\
\hline Fayetteville & 7,957 & $11 \%$ & 8,390 & $11 \%$ & +433 & $+5.4 \%$ \\
\hline New Bern & 7,940 & $48 \%$ & 8,313 & $51 \%$ & +373 & $+4.7 \%$ \\
\hline Durham & 5,958 & $7 \%$ & 6,168 & $7 \%$ & +210 & $+3.5 \%$ \\
\hline Elizabeth City & 5,510 & $64 \%$ & 6,375 & $74 \%$ & +865 & $+15.7 \%$ \\
\hline Winston-Salem & 5,494 & $6 \%$ & 5,843 & $6 \%$ & +349 & $+6.4 \%$ \\
\hline Oak Island & 5,141 & $42 \%$ & 6,202 & $51 \%$ & $+1,061$ & $+20.6 \%$ \\
\hline Greensboro & 5,121 & $5 \%$ & 5,431 & $6 \%$ & +310 & $+6.1 \%$
\end{tabular}

Greatest relative growing risk*

\begin{tabular}{|c|c|c|c|c|c|c|}
\hline Municipality & & 20 & & 050 & & inge \\
\hline Plymouth & 429 & $18 \%$ & 872 & $36 \%$ & +443 & $+103 \%$ \\
\hline Ogden & 771 & $21 \%$ & 1,188 & $33 \%$ & +417 & $+54 \%$ \\
\hline Emerald Isle & 2,681 & $36 \%$ & 4,057 & $55 \%$ & $+1,376$ & $+51 \%$ \\
\hline Kure Beach & 722 & $33 \%$ & 1,011 & $47 \%$ & +289 & $+40 \%$ \\
\hline Shallotte & 453 & $14 \%$ & 612 & $19 \%$ & +159 & $+35 \%$ \\
\hline Havelock & 1,334 & $27 \%$ & 1,793 & $37 \%$ & +459 & $+34 \%$ \\
\hline Duck & 932 & $35 \%$ & 1,249 & $47 \%$ & +317 & $+34 \%$ \\
\hline Edenton & 474 & $19 \%$ & 632 & $25 \%$ & +158 & $+33 \%$ \\
\hline Kitty Hawk & 1,394 & $40 \%$ & 1,776 & $51 \%$ & +382 & $+27 \%$ \\
\hline Nags Head & 2,843 & $52 \%$ & 3,511 & $65 \%$ & +668 & $+24 \%$ \\
\hline
\end{tabular}

\section{Flood Factor distribution of properties at risk ${ }^{\star}(1000 s)$}

\section{Risk level}

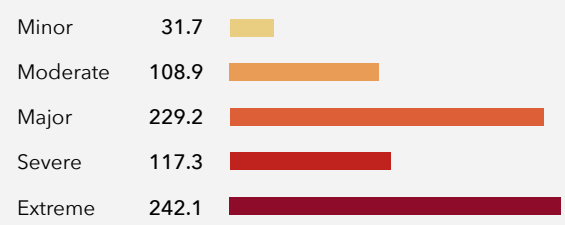

Extreme

More than $13.6 \%$ of individual properties and properties in North Carolina are at any risk of flooding over the next 30 years. Out of those at risk $81 \%$ are at major to extreme risk.

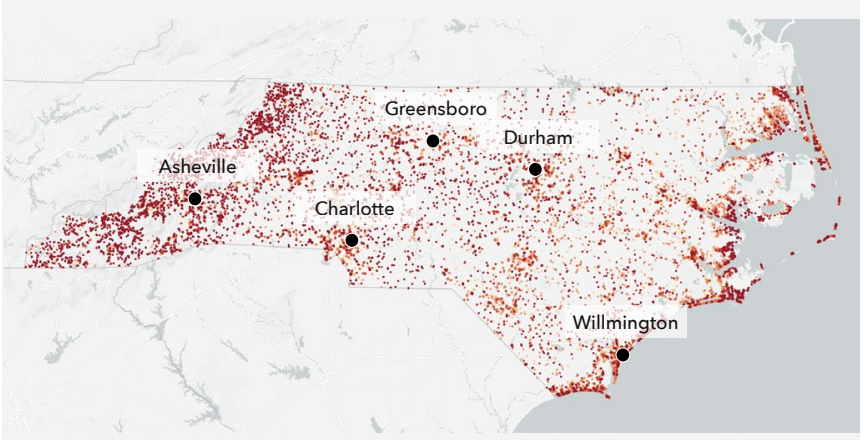


Flood History \& Protection North Carolina

\section{Claims History}

545,800 home and property owners in North Carolina have made flood damage claims through FEMA since the year 2000.* These claims for reimbursement were made through either the National Flood Insurance Program (NFIP) or Individual Assistance Program (IAP). The greatest number of claims since the year 2000 have been concentrated in Robeson, Cumberland, Onslow, Craven, and Bladen counties.

\section{Storm Simulation}

The First Street Foundation Flood Model has recreated 4 flooding events that have occurred since the year 2000 in the state of North Carolina. These events flooded around 140,190 properties across the state.*

\begin{tabular}{llr} 
Flood event & Date & $\begin{array}{r}\text { \# Properties } \\
\text { affected }\end{array}$ \\
Hurricane Isabel & Sep 2003 & 84,224 \\
\hline Nor'easter & Nov 2009 & 107 \\
\hline Hurricane Irene & Aug 2011 & 55,457 \\
\hline River flood near Rocky Mount, NC & Oct 2016 & 404
\end{tabular}

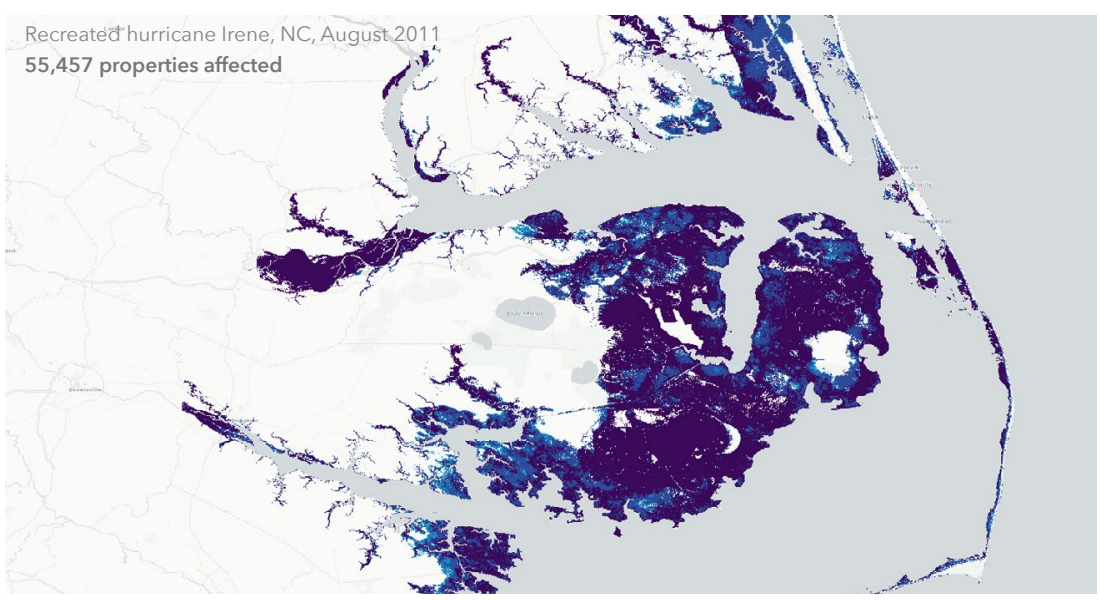

\section{7,800}

Properties served by

protection measures

The First Street Foundation Flood

Model incorporates 296 flood control

measures throughout the state which

protect 47,800 properties.

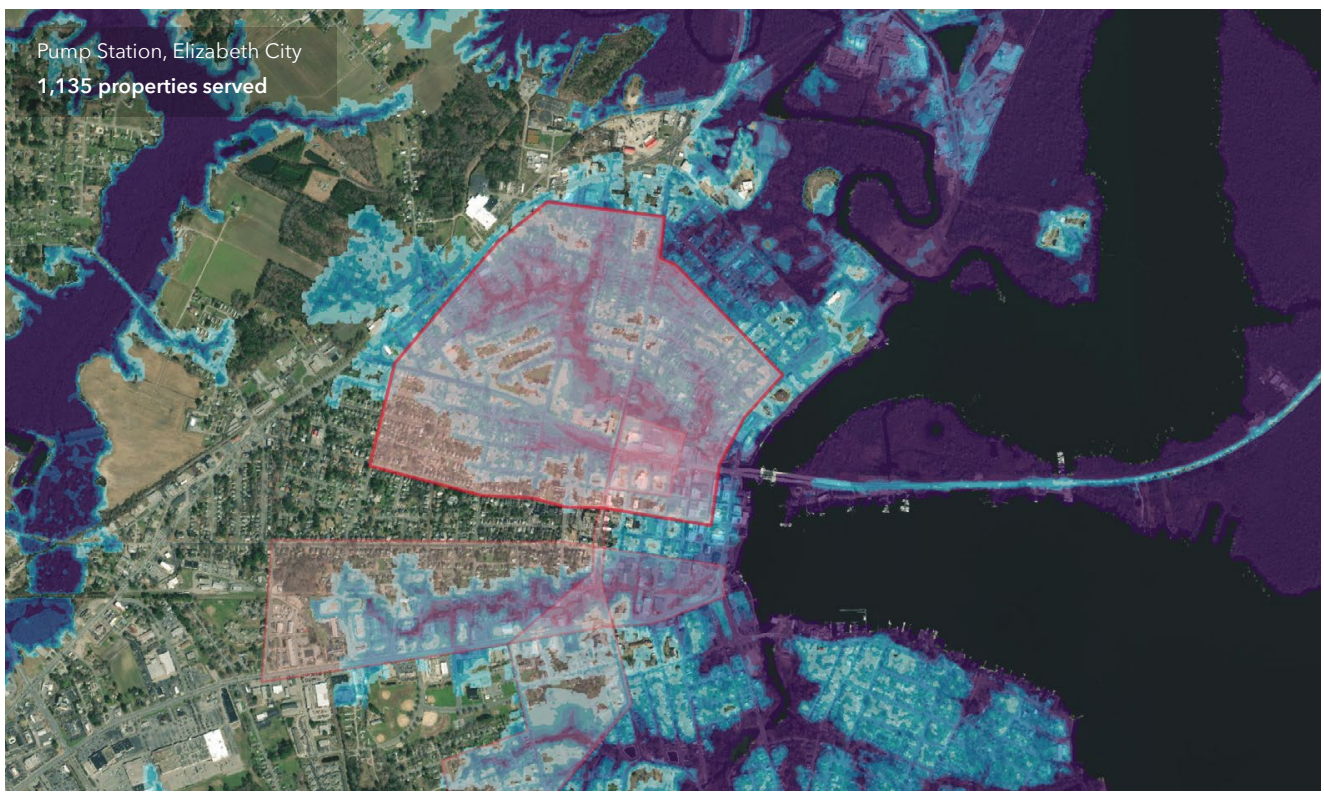

Area of protectio
Top protection measures in state by quantity

Type

Marsh/wetland restoration

\# Properties served by type

24,689

Beach nourishment

14,673

Oak Island

Levee

Pump station

- Elizabeth City NC Pump Station 2

Marsh/wetland creation

CM Buckridge Coastal Reserve, Gum Neck 


\section{State Overview North Dakota}

Flood risk is increasing in the state of North Dakota. 56,400 properties currently have a substantial risk* of flooding. Over the next 30 years, the number of properties with this risk will increase by another $2.4 \%$, bringing the total number of properties with substantial risk to 57,700 .

To understand personal flood risk, Americans leverage the Federal Emergency Management Agency (FEMA) Flood Insurance Rate Maps (FIRM). These maps identify 30,300 properties as having substantial risk in the state of North Dakota. In comparison, the First Street Foundation Flood Model identifies 1.9 times the number of properties as facing this same level of risk. This discrepancy exists because the Foundation uses the current climate data, maps precipitation as a stand-alone risk, and includes areas that FEMA has not mapped. These new methods uncover an additional 26,100 properties currently not identified by FEMA as having substantial risk. When adjusting for future environmental changes, the FEMA gap further widens to 27,400 by the year 2050 .
Total properties at substantial risk *

$\ln 2020$

\section{6,400}

30-year change

$$
\Delta+1,300(+2.4 \%)
$$

The Red River Valley experiences springtime flooding when snow around the river's tributaries melts into flat and low-lying farmland. Heavy snows in the fall and winter lead the banks of the Red River to overflow in spring. This predictable cycle of precipitation and flooding has enabled protection efforts, but ice jams and the region's unique topography leave many vulnerable.

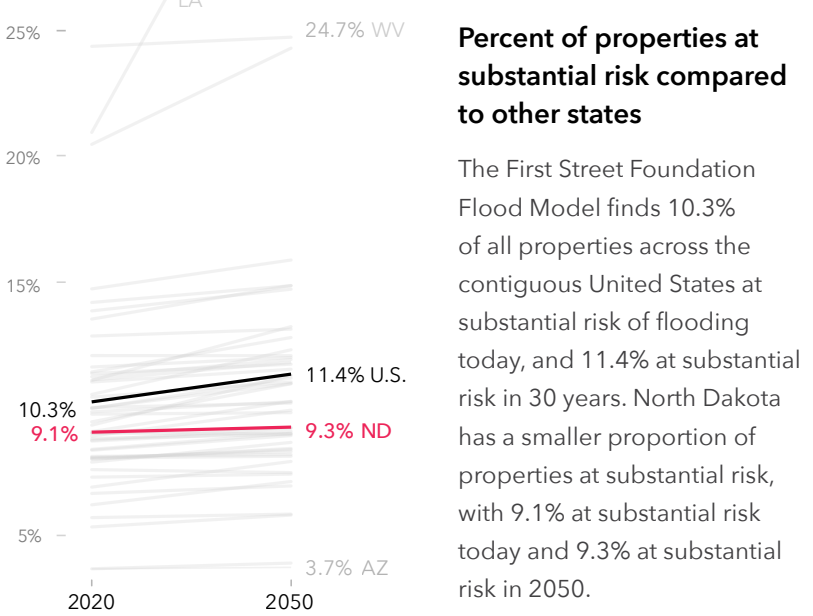

Difference in number of properties currently at substantial risk compared to FEMA**

$$
\Delta+26,100
$$

More properties at risk in FSF model $\longrightarrow$
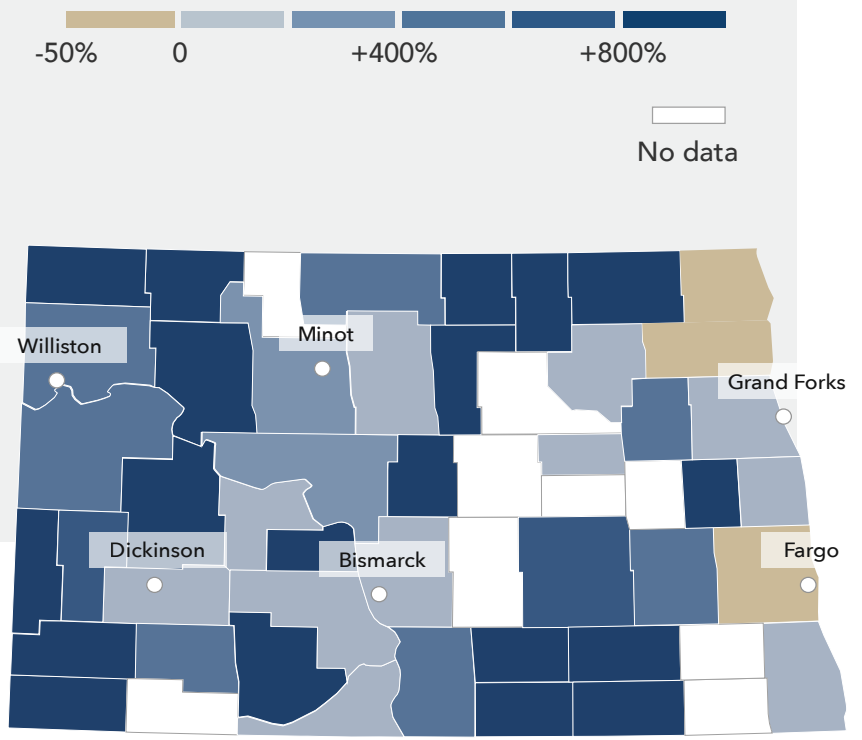


\section{Local details \\ North Dakota}

The First Street Foundation Flood Model calculates the number of properties facing any risk* of flooding. When looking at this broader level of risk, the data identifies 87,100 properties in North Dakota as at risk over the next 30 years. Of these properties, 12,400 were categorized as facing almost certain risk, with a $99 \%$ chance of flooding at least once over the next 30 years.

The city of West Fargo has the greatest number of properties at risk of flooding in the state with 5,200 currently at risk, or $41 \%$ of its total number of properties. However, smaller cities or municipalities in the state, with fewer properties, may have a greater proportion of their total properties at risk. For example, $41 \%$ of properties in West Fargo are at risk of flooding. Other municipalities will see the greatest increase in risk over the next 30 years. Mandan, for example, will see a $9 \%$ increase in the number of properties at risk.

Click here for a full breakdown of counties, cities, zip codes, and congressional districts in North Dakota at risk.

\section{Greatest proportion of properties at risk*}

\begin{tabular}{lrr|}
\hline Municipality & \multicolumn{2}{|c}{2020} \\
\hline West Fargo & 5,248 & $41 \%$ \\
\hline Grand Forks & 2,567 & $17 \%$ \\
\hline Mandan & 1,146 & $14 \%$ \\
\hline Fargo & 3,891 & $12 \%$ \\
\hline Dickinson & 1,154 & $11 \%$ \\
\hline Cannon Ball & 212 & $11 \%$ \\
\hline Bismarck & 2,297 & $9 \%$ \\
\hline Williston & 778 & $8 \%$ \\
\hline Wahpeton & 219 & $8 \%$ \\
\hline Watford City & 157 & $8 \%$ \\
\hline
\end{tabular}

\section{Greatest number of properties at risk*}

\begin{tabular}{l|c|ccccc} 
Municipality & \multicolumn{2}{c}{2020} & \multicolumn{2}{c}{2050} & \multicolumn{2}{c}{ Change } \\
West Fargo & 5,248 & $41 \%$ & 5,256 & $41 \%$ & +8 & $+0.2 \%$ \\
\hline Fargo & 3,891 & $12 \%$ & 3,959 & $12 \%$ & +68 & $+1.7 \%$ \\
\hline Grand Forks & 2,567 & $17 \%$ & 2,598 & $17 \%$ & +31 & $+1.2 \%$ \\
\hline Bismarck & 2,297 & $9 \%$ & 2,384 & $10 \%$ & +87 & $+3.8 \%$ \\
\hline Minot & 1,252 & $6 \%$ & 1,292 & $6 \%$ & +40 & $+3.2 \%$ \\
\hline Dickinson & 1,154 & $11 \%$ & 1,187 & $11 \%$ & +33 & $+2.9 \%$ \\
\hline Mandan & 1,146 & $14 \%$ & 1,253 & $15 \%$ & +107 & $+9.3 \%$ \\
\hline Williston & 778 & $8 \%$ & 806 & $8 \%$ & +28 & $+3.6 \%$ \\
\hline Devils Lake & 227 & $7 \%$ & 234 & $8 \%$ & +7 & $+3.1 \%$ \\
\hline Wahpeton & 219 & $8 \%$ & 230 & $8 \%$ & +11 & $+5.0 \%$
\end{tabular}

\section{Greatest relative growing risk*}

\begin{tabular}{|c|c|c|c|c|c|c|}
\hline \multirow{2}{*}{$\begin{array}{l}\text { Municipality } \\
\text { Mandan }\end{array}$} & \multicolumn{2}{|c|}{2020} & \multicolumn{2}{|c|}{2050} & \multicolumn{2}{|c|}{ Change } \\
\hline & 1,146 & $14 \%$ & 1,253 & $15 \%$ & +107 & $+9 \%$ \\
\hline Watford City & 157 & $8 \%$ & 168 & $8 \%$ & +11 & $+7 \%$ \\
\hline Wahpeton & 219 & $8 \%$ & 230 & $8 \%$ & +11 & $+5 \%$ \\
\hline Bismarck & 2,297 & $9 \%$ & 2,384 & $10 \%$ & +87 & $+4 \%$ \\
\hline Williston & 778 & $8 \%$ & 806 & $8 \%$ & +28 & $+4 \%$ \\
\hline Minot & 1,252 & $6 \%$ & 1,292 & $6 \%$ & +40 & $+3 \%$ \\
\hline Devils Lake & 227 & $7 \%$ & 234 & $8 \%$ & +7 & $+3 \%$ \\
\hline Dickinson & 1,154 & $11 \%$ & 1,187 & $11 \%$ & +33 & $+3 \%$ \\
\hline Fargo & 3,891 & $12 \%$ & 3,959 & $12 \%$ & +68 & $+2 \%$ \\
\hline Grand Forks & 2,567 & $17 \%$ & 2,598 & $17 \%$ & +31 & $+1 \%$ \\
\hline
\end{tabular}

\section{Flood Factor distribution of properties at risk ${ }^{\star}(1000 s)$}

\section{Risk level}

Minor

Major

Severe

Extreme

21

29.7

26.4

14.2

4.6

More than $14 \%$ of individual properties and properties in North Dakota are at any risk of flooding over the next 30 years. Out of those at risk $63 \%$ are at major to extreme risk.

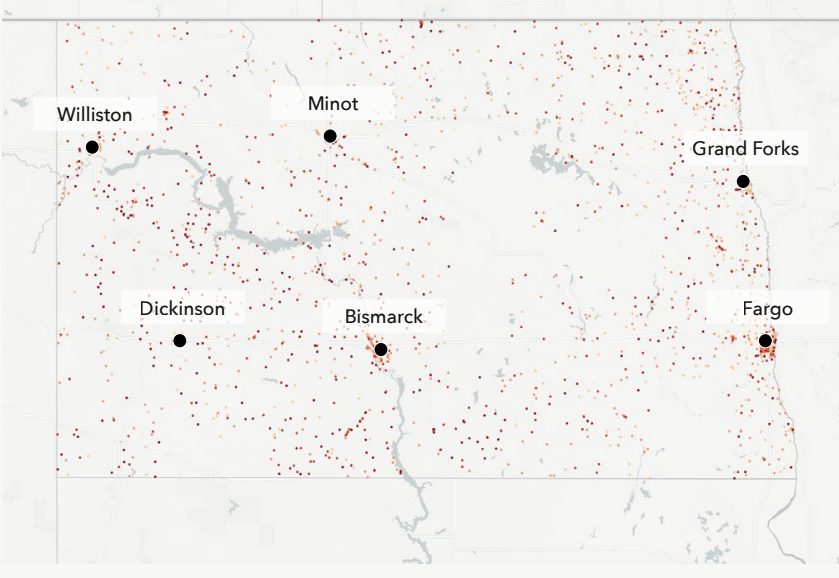


Flood History \& Protection

North Dakota

\section{Claims History}

30,400 home and property owners in North Dakota have made flood damage claims through FEMA since the year 2000. ${ }^{*}$ These claims for reimbursement were made through either the National Flood Insurance Program (NFIP) or Individual Assistance Program (IAP). The greatest number of claims since the year 2000 have been concentrated in Ward, Cass, Burleigh, Emmons, and Benson counties.

\section{Storm Simulation}

The First Street Foundation Flood Model has recreated 2 flooding events that have occurred since the year 2000 in the state of North Dakota. These events flooded around 1,160 properties across the state**

\section{Flood event}

- River flood near Bismark, ND

\# Properties
affected

River flood near Towner, ND

Jun 2011

809

Jun 2011

356

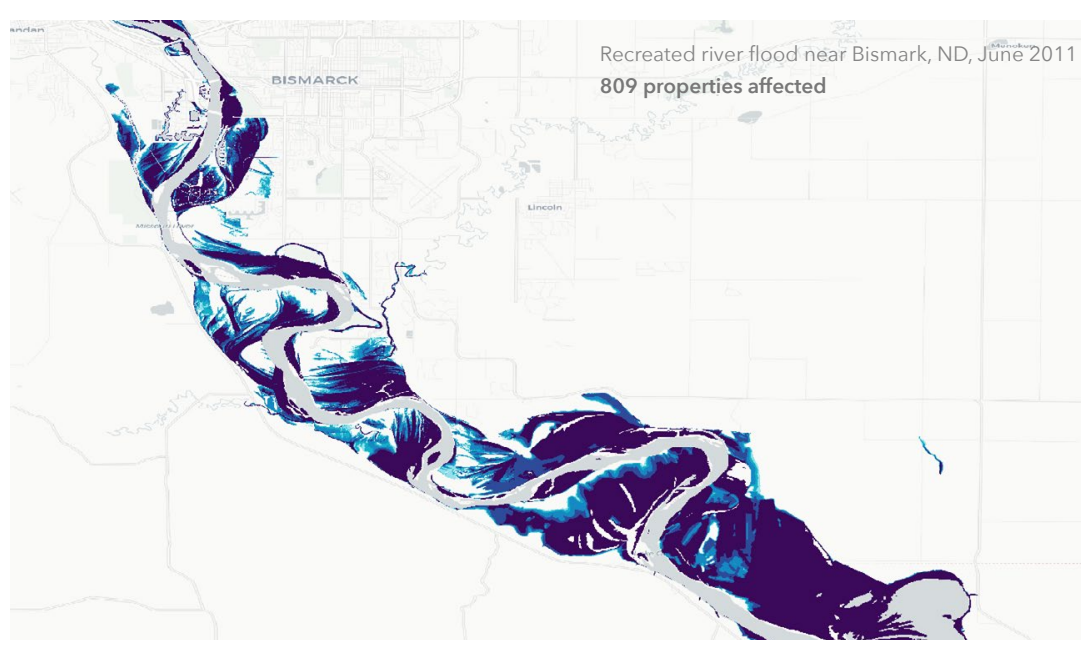

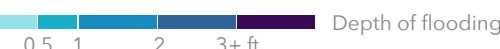

\section{7,700}

Properties served by

protection measures

The First Street Foundation Flood

Model incorporates 222 flood control

measures throughout the state which

protect 47,700 properties.

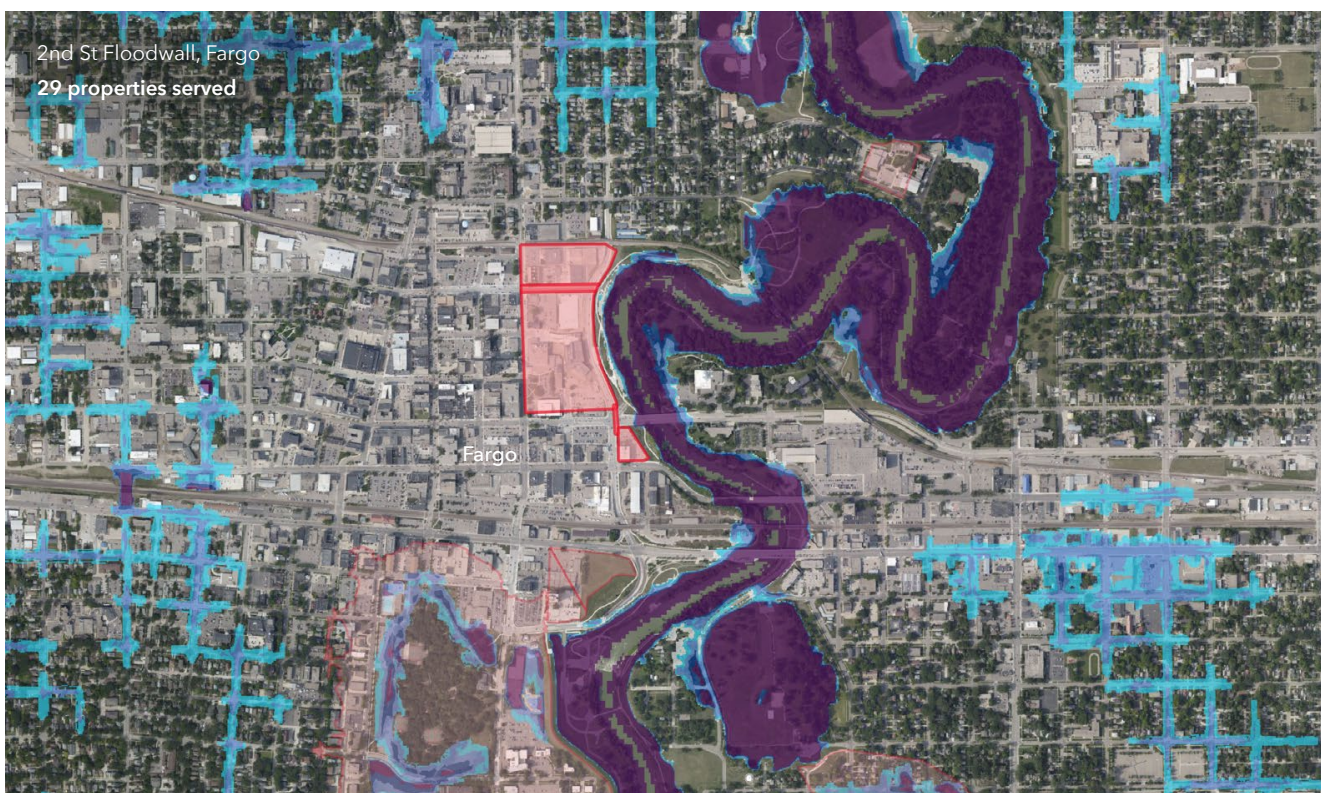

$\square$ Area of protection

$0.51320 p t h$ of flooding for a simulated
1 in 100 flood event
Top protection measures in state by quantity

Type
Example

Levee

\# Properties served by type

47,363

Earthen berm

295

Acquisition

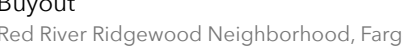

Flood wall

2nd Street North Floodwall, Fargo
Drain 27/Prairie Rose Flood Risk Reduction, Fargo 


\section{State Overview Ohio}

Total properties at substantial risk *

\section{$\ln 2050$}

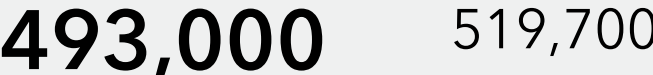

30-year change

$\Delta+26,700$

$(+5 \%)$

High rainfall and heavy storms over Lake Erie drive wave actions that are the major flood risk for Ohio communities. Rising lake water levels cause inland streams to overtop, resulting in the flooding of surrounding areas. Cincinnati and other river communities are most at risk from heavy rainfall, as the river backwater inundates streams and creeks causing waterways to overtop and flood surrounding communities and low-lying areas.

To understand personal flood risk, Americans leverage the Federal Emergency Management Agency (FEMA) Flood Insurance Rate Maps (FIRM) These maps identify 219,900 properties as having substantial risk in the state of Ohio. In comparison, the First Street Foundation Flood Model identifies 2.2 times the number of properties as facing this same level of risk. This discrepancy exists because the Foundation uses the current climate data, maps precipitation as a stand-alone risk, and includes areas that FEMA has not mapped. These new methods uncover an additional 273,100 properties currently not identified by FEMA as having substantial risk. When adjusting for future environmental changes, the FEMA gap further widens to 299,800 by the year 2050 .

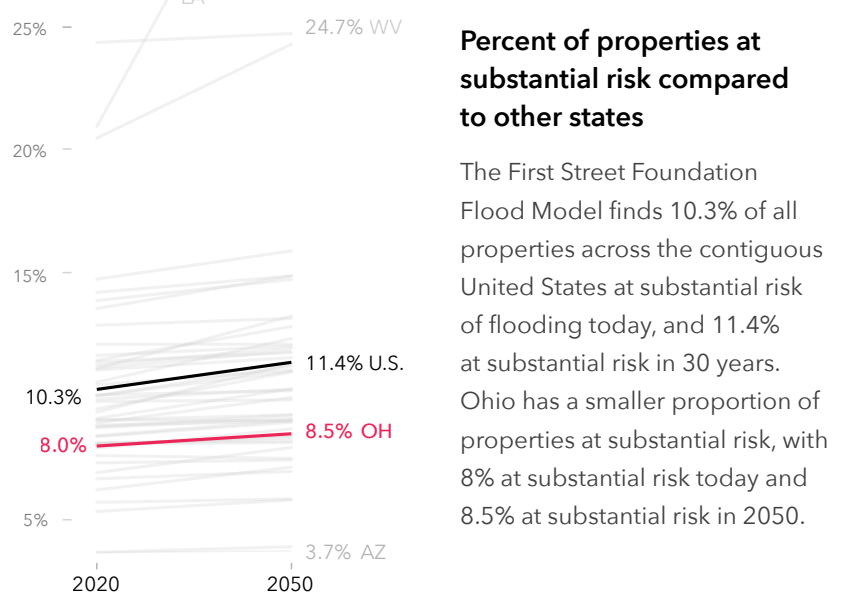

Difference in number of properties currently at substantial risk compared to FEMA**

$\Delta+273,100$
More properties at risk in FSF model $\longrightarrow$
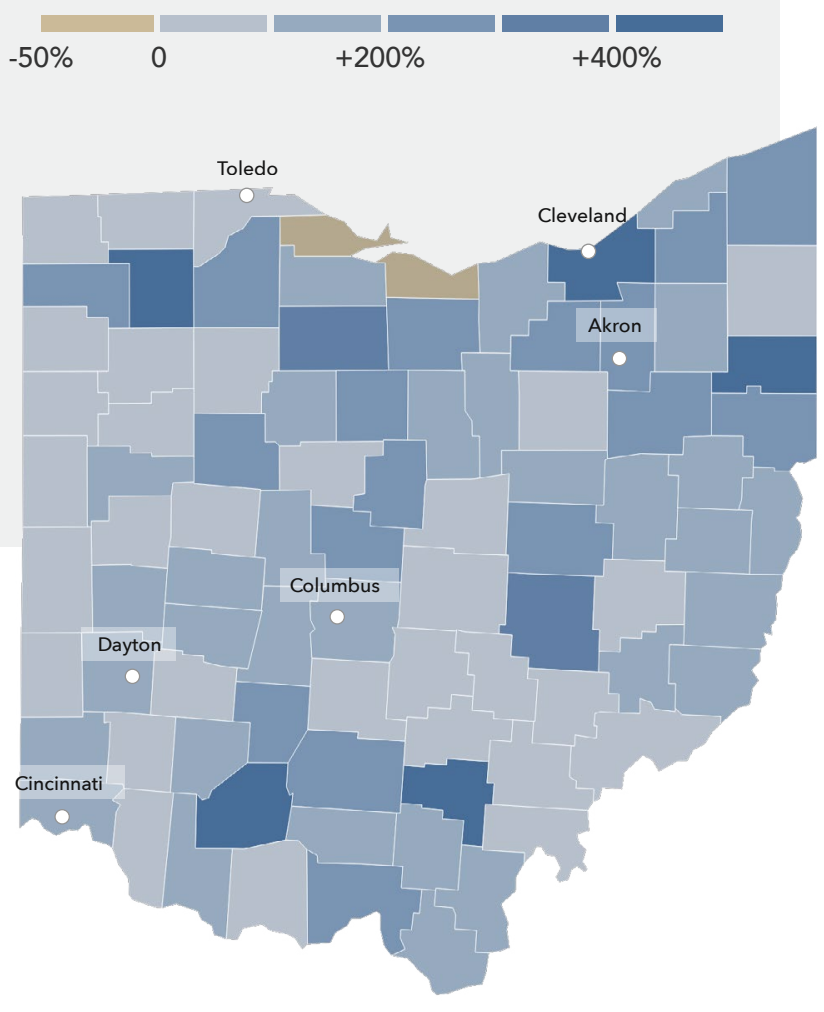


\section{Local details}

Ohio

The First Street Foundation Flood Model calculates the number of properties facing any risk* of flooding. When looking at this broader level of risk, the data identifies 708,400 properties in Ohio as at risk over the next 30 years. Of these properties, 142,400 were categorized as facing almost certain risk, with a $99 \%$ chance of flooding at least once over the next 30 years.

The city of Cincinnati has the greatest number of properties at risk of flooding in the state with 21,200 currently at risk, or $13 \%$ of its total number of properties. However, smaller cities or municipalities in the state, with fewer properties, may have a greater proportion of their total properties at risk. For example, $87 \%$ of properties in Gallipolis are at risk of flooding. Other municipalities will see the greatest increase in risk over the next 30 years. Delhi Hills, for example, will see a 23\% increase in the number of properties at risk.

Click here for a full breakdown of counties, cities, zip codes, and congressional districts in Ohio at risk.

\section{Greatest proportion of properties at risk*}

\begin{tabular}{lll} 
Municipality & \multicolumn{2}{c}{2020} \\
\hline Gallipolis & 2,585 & $87 \%$ \\
\hline Middleport & 2,131 & $83 \%$ \\
\hline New Richmond & 1,681 & $72 \%$ \\
\hline Wellsville & 1,702 & $66 \%$ \\
\hline Shadyside & 1,431 & $65 \%$ \\
\hline Bellaire & 2,192 & $60 \%$ \\
\hline Pomeroy & 2,064 & $58 \%$ \\
\hline Marietta & 6,757 & $52 \%$ \\
\hline Athens & 3,786 & $51 \%$ \\
\hline Belpre & 2,243 & $50 \%$ \\
\hline
\end{tabular}

\section{Greatest number of properties at risk*}

\begin{tabular}{l|c|ccccc} 
Municipality & \multicolumn{2}{c}{2020} & \multicolumn{2}{c}{2050} & \multicolumn{2}{c}{ Change } \\
\cline { 2 - 4 } Cincinnati & 21,236 & $13 \%$ & 22,321 & $14 \%$ & $+1,085$ & $+5.1 \%$ \\
\hline Columbus & 17,728 & $6 \%$ & 19,117 & $7 \%$ & $+1,389$ & $+7.8 \%$ \\
\hline Cleveland & 12,261 & $7 \%$ & 13,354 & $8 \%$ & $+1,093$ & $+8.9 \%$ \\
\hline Toledo & 12,166 & $10 \%$ & 12,830 & $11 \%$ & +664 & $+5.5 \%$ \\
\hline Dayton & 10,770 & $12 \%$ & 11,911 & $13 \%$ & $+1,141$ & $+10.6 \%$ \\
\hline Marietta & 6,757 & $52 \%$ & 6,778 & $52 \%$ & +21 & $+0.3 \%$ \\
\hline Akron & 6,563 & $7 \%$ & 6,870 & $7 \%$ & +307 & $+4.7 \%$ \\
\hline Canton & 5,098 & $13 \%$ & 5,355 & $13 \%$ & +257 & $+5.0 \%$ \\
\hline Findlay & 4,937 & $30 \%$ & 5,067 & $31 \%$ & +130 & $+2.6 \%$ \\
\hline Athens & 3,786 & $51 \%$ & 3,812 & $51 \%$ & +26 & $+0.7 \%$
\end{tabular}

\section{Greatest relative growing risk*}

\begin{tabular}{lrrrrrr} 
Municipality & \multicolumn{2}{c}{2020} & \multicolumn{2}{c}{2050} & \multicolumn{2}{c}{ Change } \\
\hline Delhi Hills & 120 & $5 \%$ & 148 & $7 \%$ & $+1,085$ & $+23 \%$ \\
\hline Drexel & 74 & $3 \%$ & 89 & $4 \%$ & $+1,389$ & $+20 \%$ \\
\hline Highland Heights & 120 & $3 \%$ & 143 & $4 \%$ & $+1,093$ & $+19 \%$ \\
\hline Lima & 782 & $5 \%$ & 930 & $6 \%$ & +664 & $+19 \%$ \\
\hline Bowling Green & 579 & $6 \%$ & 677 & $7 \%$ & $+1,141$ & $+17 \%$ \\
\hline Harrison & 526 & $10 \%$ & 612 & $12 \%$ & +21 & $+16 \%$ \\
\hline Springboro & 256 & $3 \%$ & 296 & $4 \%$ & +307 & $+16 \%$ \\
\hline Willowick & 386 & $6 \%$ & 445 & $7 \%$ & +257 & $+15 \%$ \\
\hline Mack & 200 & $4 \%$ & 230 & $4 \%$ & +130 & $+15 \%$ \\
\hline Canfield & 116 & $3 \%$ & 133 & $4 \%$ & +26 & $+15 \%$
\end{tabular}

\section{Flood Factor distribution of properties at risk ${ }^{\star}(1000 s)$}

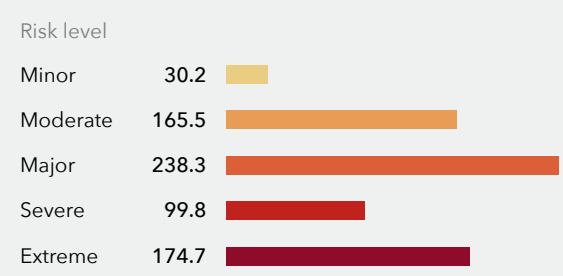

More than $11.5 \%$ of individual properties and properties in Ohio are at any risk of flooding over the next 30 years. Out of those at risk $72 \%$ are at major to extreme risk.

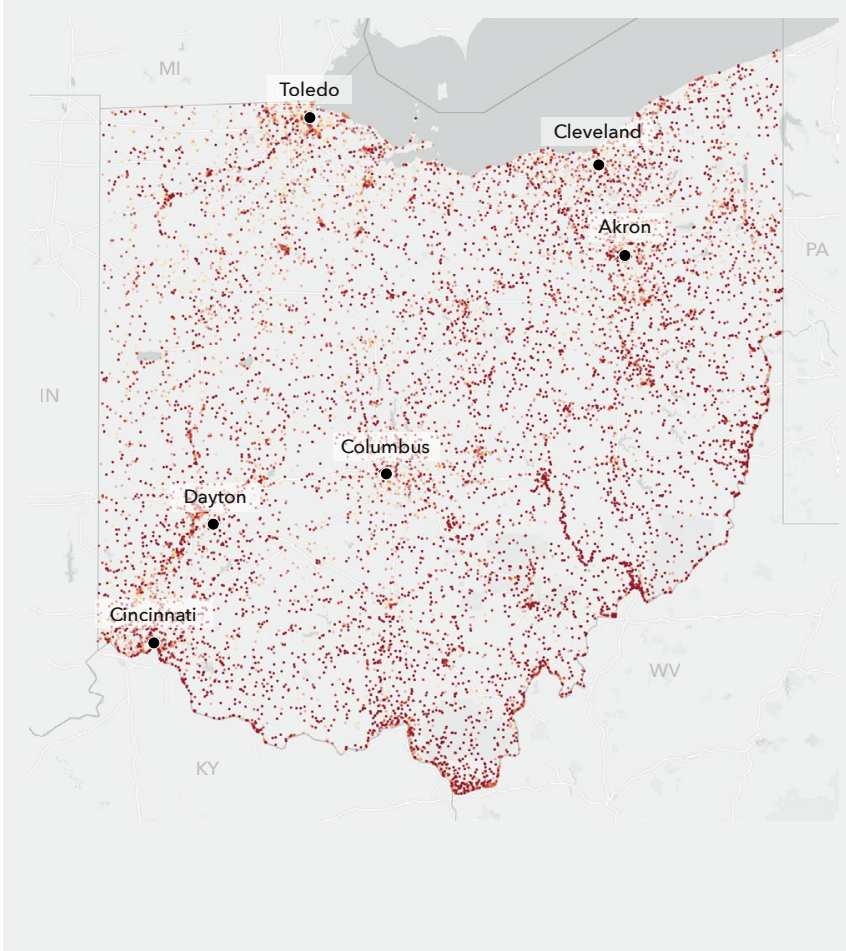




\section{Flood History \& Protection}

Ohio

\section{Claims History}

143,000 home and property owners in Ohio have made flood damage claims through FEMA since the year 2000. ${ }^{\star}$ These claims for reimbursement were made through either the National Flood Insurance Program (NFIP) or Individual Assistance Program (IAP). The greatest number of claims since the year 2000 have been concentrated in Cuyahoga, Richland, Lake, Mahoning, and Lucas counties.

\section{Storm Simulation}

The First Street Foundation Flood Model has recreated 3 flooding events that have occurred since the year 2000 in the state of Ohio. These events flooded around 9,000 properties across the state.**

\begin{tabular}{llr} 
Flood event & Date & $\begin{array}{r}\text { \# Properties } \\
\text { affected }\end{array}$ \\
River flood in Eastern OH & Sept 2004 & 6,240 \\
\hline River flood near Piketon, OH & Jan 2005 & 870 \\
\hline River flood near Zanesville, OH & Jan 2005 & 274 \\
\hline River flood near Toledo, OH & Jun 2015 & 1,621
\end{tabular}

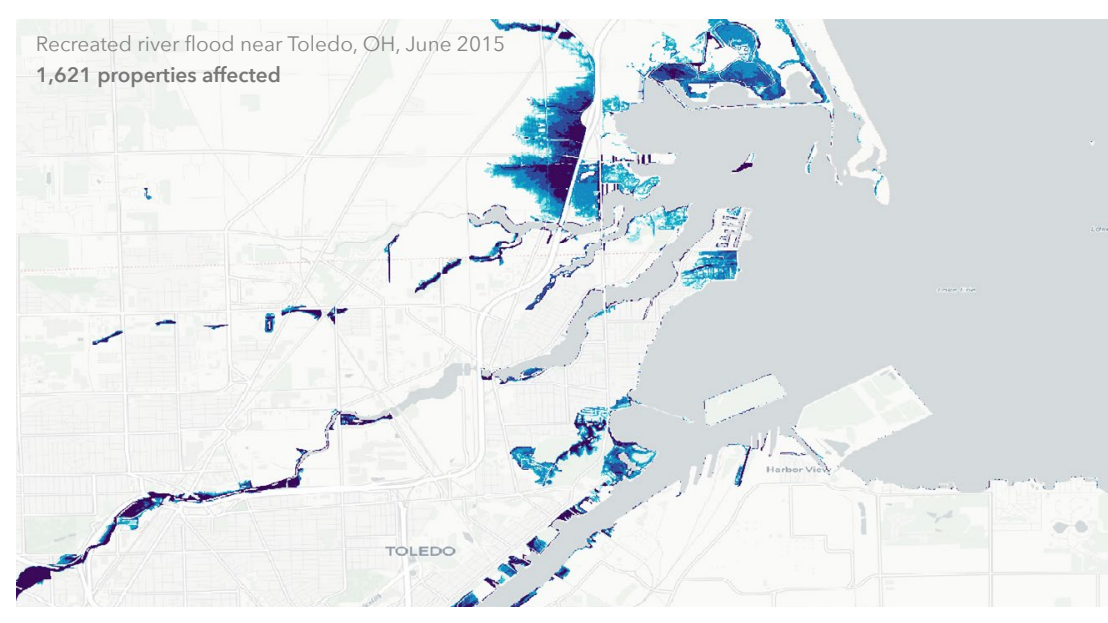

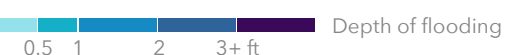

\section{8,400}

Properties served by

protection measures

The First Street Foundation Flood

Model incorporates 299 flood control

measures throughout the state which

protect 78,400 properties.

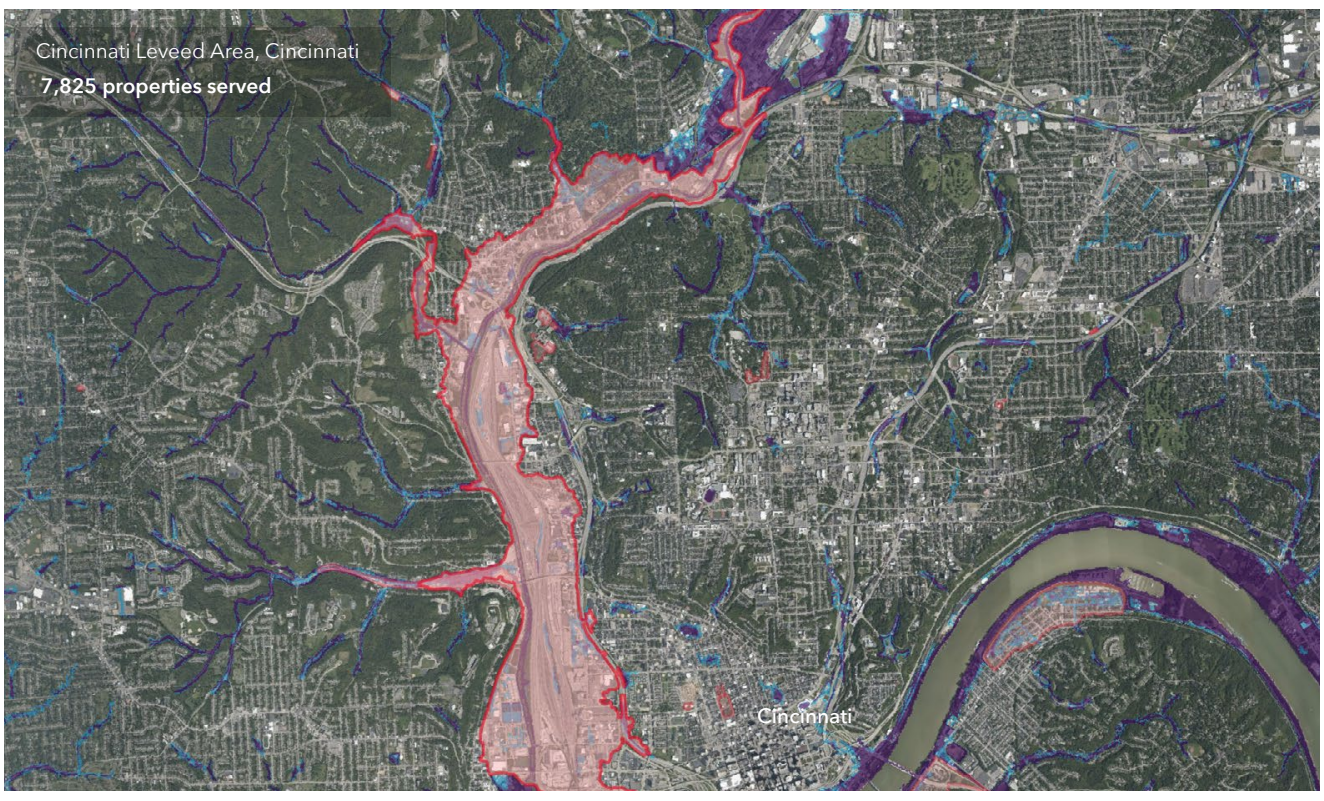

Area of protection

Top protection measures in state by quantity

Type
Example

Levee

- Cincinnati Leveed Area, Cincinnat

Dam

Earthen berm

Newport Earthen

New Lexington Diversion, New Lexington

Retention pond

Lick Run Greenway Cincinnat
Source: Fema.go

** Based on model simulation of historic events. Historic recreations do not include precipitation. See methodology for full model details. 


\section{State Overview Oklahoma}

Flood risk is decreasing in the state of Oklahoma. 168,900 properties currently have a substantial risk* $^{*}$ of flooding. Over the next 30 years, the number of properties with this risk will decrease by $1.6 \%$, shifting the total number of properties with substantial risk to 166,200 .

To understand personal flood risk, Americans leverage the Federal Emergency Management Agency (FEMA) Flood Insurance Rate Maps (FIRM). These maps identify 107,400 properties as having substantial risk in the state of Oklahoma. In comparison, the First Street Foundation Flood Model identifies 1.6 times fewer properties as facing this same level of risk. This discrepancy exists because the Foundation uses the current climate data, maps precipitation as a standalone risk, and includes areas that FEMA has not mapped. These new methods uncover an additional 61,500 properties currently not identified by FEMA as having substantial risk. When adjusting for future environmental changes, the FEMA gap narrows to 58,800 by the year 2050 .

\section{Total properties at substantial risk}

$\ln 2020$

168,900

30-year change

$\nabla-2,700(-1.6 \%)$ $\ln 2050$

166,200
Tulsa floods when rains overtop the Arkansas River, Cherry Creek, Mingo Creek, and Joe Creek. Channel modifications, levee systems, detention basins, and non-structural regulations have been implemented. Lawton floods with spring and summer rainfall, impactin property in the wide, flat, East Cache Creek floodplain. Flood protection efforts include removing structures in the floodplain, channeling streams, and detention basins.
Difference in number of properties currently at substantial risk compared to FEMA** in FSF model $\longrightarrow$
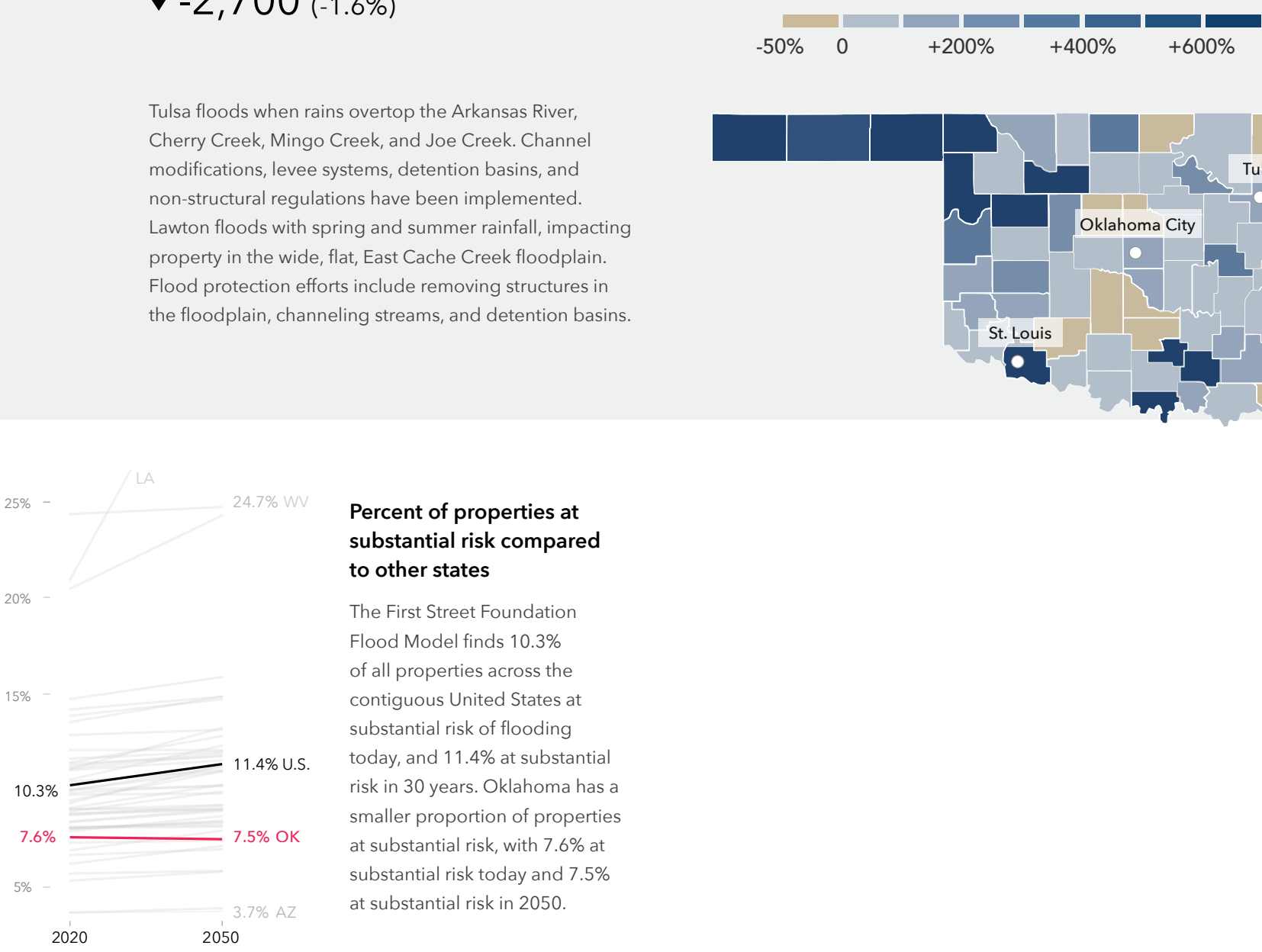

to other states

Model finds $10.3 \%$

substantial risk of flooding

roportion of properties

substantial risk today and $7.5 \%$

Substantial risk is calculated as inundation $1 \mathrm{~cm}$ or more to the building in the 100 return period ( $1 \%$ annual risk) and rounded to the nearest 100 properties. See methodology for full model detail ** Comparison of calculated as orties within a Special Flood Hazard A Area (1 in 100 layer) versus those with $1 \%$ risk from the First Street Foundation Flood Model. Some counties may show higher FEMA counts due to a variety of factors, including the generalization of SFHAs, assumptions around flood protection measures, and local context FEMA zones are estimated by MassiveCert. Inc 


\section{Local details \\ Oklahoma}

The First Street Foundation Flood Model calculates the number of properties facing any risk* of flooding. When looking at this broader level of risk, the data identifies 222,800 properties in Oklahoma as at risk over the next 30 years. Of these properties, 49,800 were categorized as facing almost certain risk, with a $99 \%$ chance of flooding at least once over the next 30 years.

The city of Tulsa has the greatest number of properties at risk of flooding in the state with 21,700 currently at risk, or $14 \%$ of its total number of properties. However, smaller cities or municipalities in the state, with fewer properties, may have a greater proportion of their total properties at risk. For example, $40 \%$ of properties in Copeland are at risk of flooding. Other municipalities will see the greatest

increase in risk over the next 30 years. Pawhuska, for example, will see

a $4 \%$ increase in the number of properties at risk.

Click here for a full breakdown of counties, cities, zip codes, and congressional districts in Oklahoma at risk.

\section{Greatest proportion of properties at risk*}

\begin{tabular}{lrr} 
Municipality & \multicolumn{2}{|c}{2020} \\
\hline Copeland & 818 & $40 \%$ \\
\hline Bixby & 3,587 & $31 \%$ \\
\hline Jenks & 2,296 & $23 \%$ \\
\hline Pawhuska & 612 & $22 \%$ \\
\hline Grove & 1,042 & $21 \%$ \\
\hline Chickasha & 1,526 & $19 \%$ \\
\hline Pauls Valley & 571 & $17 \%$ \\
\hline Cleora & 516 & $16 \%$ \\
\hline Tulsa & 21,727 & $14 \%$ \\
\hline Mangum & 301 & $13 \%$ \\
\hline
\end{tabular}

\section{Greatest number of properties at risk*}

\begin{tabular}{lcccccc} 
Municipality & \multicolumn{2}{c}{2020} & \multicolumn{2}{c}{2050} & \multicolumn{2}{c}{ Change } \\
\cline { 2 - 4 } & 21,727 & $14 \%$ & 21,931 & $14 \%$ & +204 & $+0.9 \%$ \\
\hline Oklahoma City & 19,852 & $8 \%$ & 19,867 & $8 \%$ & +15 & $+0.1 \%$ \\
\hline Bixby & 3,587 & $31 \%$ & 3,610 & $31 \%$ & +23 & $+0.6 \%$ \\
\hline Norman & 3,272 & $8 \%$ & 3,286 & $8 \%$ & +14 & $+0.4 \%$ \\
\hline Broken Arrow & 3,118 & $7 \%$ & 3,132 & $7 \%$ & +14 & $+0.4 \%$ \\
\hline Lawton & 2,694 & $8 \%$ & 2,696 & $8 \%$ & +2 & $+0.1 \%$ \\
\hline Jenks & 2,296 & $23 \%$ & 2,320 & $23 \%$ & +24 & $+1.0 \%$ \\
\hline Moore & 2,284 & $10 \%$ & 2,284 & $10 \%$ & +0 & $+0.0 \%$ \\
\hline Enid & 2,060 & $9 \%$ & 2,065 & $9 \%$ & +5 & $+0.2 \%$ \\
\hline Edmond & 1,894 & $5 \%$ & 1,894 & $5 \%$ & +0 & $+0.0 \%$
\end{tabular}

\section{Greatest relative growing risk*}

\begin{tabular}{lrrrrr|r} 
Municipality & \multicolumn{2}{c}{2020} & \multicolumn{2}{c}{2050} & \multicolumn{2}{c}{ Change } \\
Pawhuska & 612 & $22 \%$ & 637 & $23 \%$ & +25 & $+4 \%$ \\
\hline Bartlesville & 1,232 & $7 \%$ & 1,265 & $7 \%$ & +33 & $+3 \%$ \\
\hline Claremore & 779 & $10 \%$ & 798 & $10 \%$ & +19 & $+2 \%$ \\
\hline Pocola & 166 & $7 \%$ & 170 & $7 \%$ & +4 & $+2 \%$ \\
\hline Skiatook & 402 & $10 \%$ & 410 & $10 \%$ & +8 & $+2 \%$ \\
\hline Pryor Creek & 180 & $4 \%$ & 183 & $4 \%$ & +3 & $+2 \%$ \\
\hline Nowata & 263 & $10 \%$ & 267 & $10 \%$ & +4 & $+2 \%$ \\
\hline Sand Springs & 1,061 & $12 \%$ & 1,076 & $13 \%$ & +15 & $+1 \%$ \\
\hline Blackwell & 313 & $7 \%$ & 317 & $8 \%$ & +4 & $+1 \%$ \\
\hline Oakhurst & 170 & $8 \%$ & 172 & $8 \%$ & +2 & $+1 \%$
\end{tabular}

\section{Flood Factor distribution of properties at risk ${ }^{\star}(1000 s)$}

\section{Risk level}

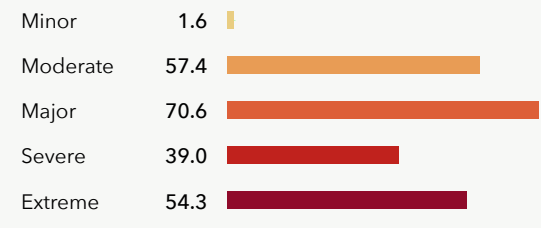

Extreme

More than $10.1 \%$ of individual properties and properties in Oklahoma are at any risk of flooding over the next 30 years. Out of those at risk $74 \%$ are at major to extreme risk. 
Flood History \& Protection

\section{Oklahoma}

\section{Claims History}

74,200 home and property owners in Oklahoma have made flood damage claims through FEMA since the year 2000. * These claims for reimbursement were made through either the National Flood Insurance Program (NFIP) or Individual Assistance Program (IAP). The greatest number of claims since the year 2000 have been concentrated in Oklahoma, Cleveland, Pottawatomie, Canadian, and Grady counties.

\section{Storm Simulation}

The First Street Foundation Flood Model has recreated 1 flooding event that occurred since the year 2000 in the state of Oklahoma. This event flooded around 1,630 properties across the state. ${ }^{\star *}$
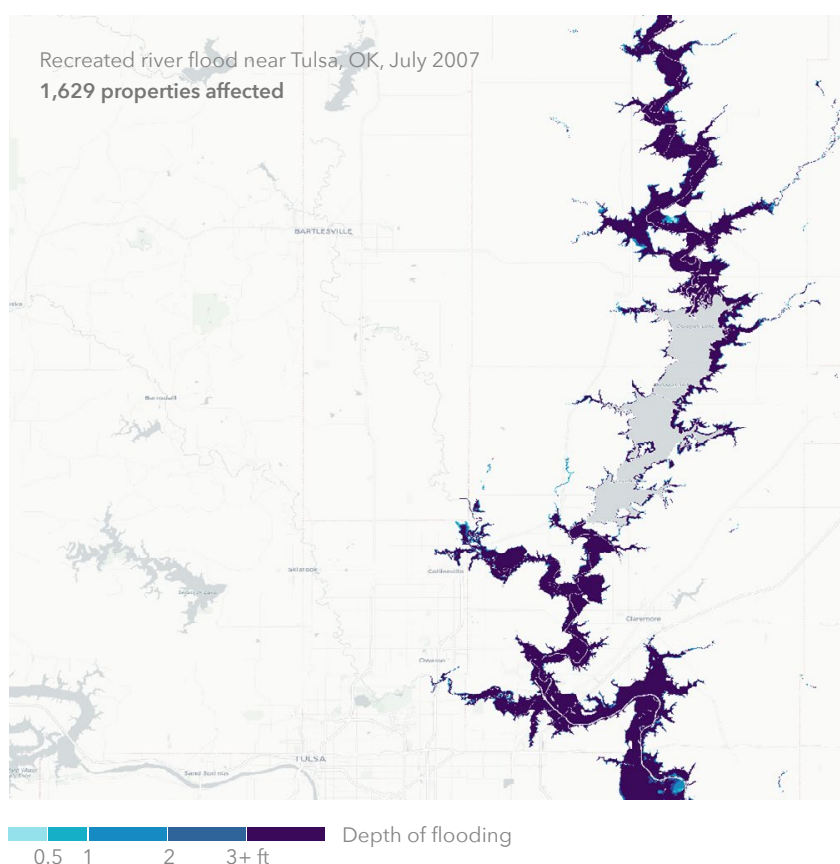

\section{8,400}

Properties served by

protection measures

The First Street Foundation Flood

Model incorporates 263 flood control

measures throughout the state which

protect 78,400 properties.
Top protection measures in state by quantity

Type
Example

\# Properties served by type

Channel

10,007

- Tulsa-West Tulsa Levee - Levee A and B

Detention basin

City of Tulsa Detention Basin / Bishop Tract Detention Facility MS-2

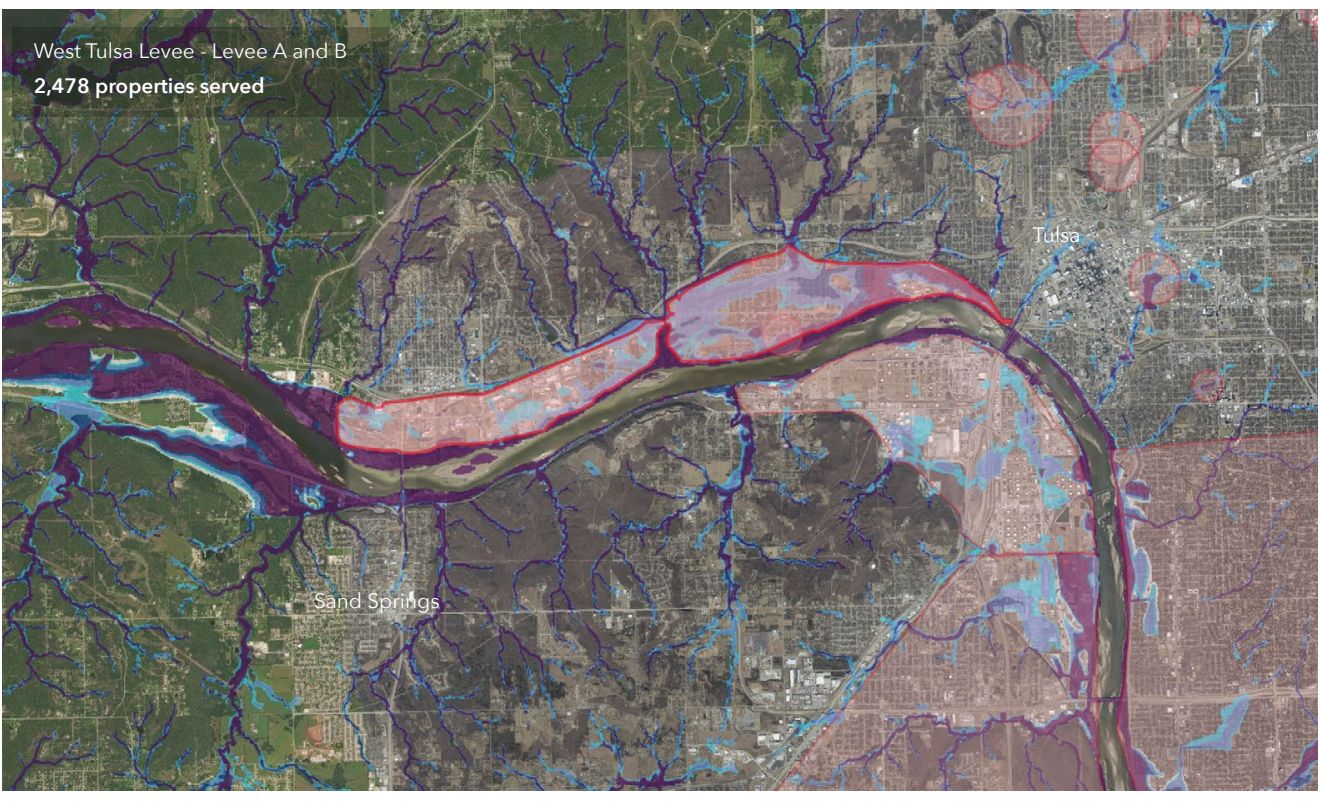

Area of protectio 


\section{State Overview Oregon}

Flood risk is increasing in the state of Oregon. 268,000 properties currently have a substantial risk* of flooding. Over the next 30 years, the number of properties with this risk will increase by another $6.2 \%$, bringing the total number of properties with substantial risk to 284,600 .

To understand personal flood risk, Americans leverage the Federal Emergency Management Agency (FEMA) Flood Insurance Rate Maps (FIRM). These maps identify 97,900 properties as having substantial risk in the state of Oregon. In comparison, the First Street Foundation

Flood Model identifies 2.7 times the number of properties as facing this same level of risk. This discrepancy exists because the Foundation uses the current climate data, maps precipitation as a stand-alone risk, and includes areas that FEMA has not mapped. These new methods uncover an additional 170,100 properties currently not identified by FEMA as having substantial risk.

When adjusting for future environmental changes, the FEMA gap further widens to 186,700 by the year 2050 .
Total properties at substantial risk*

\section{$\ln 2050$}

$268,000 \quad 284,600$

30-year change

$\Delta+16,600$

$(+6 \%)$
Difference in number of properties currently at substantial risk compared to FEMA ${ }^{\star *}$

$\Delta+170,100$
Willamette Valley, which includes the major cities of Portland, Salem, and Eugene, is home to $70 \%$ of Oregon's population. It is surrounded by mountains on three sides, and prone to flooding from springtime melting of snowpack. To reduce flood risk, the Army Corps of Engineers began the Willamette Valley Project to build a series of flood control dams in the surrounding mountains.

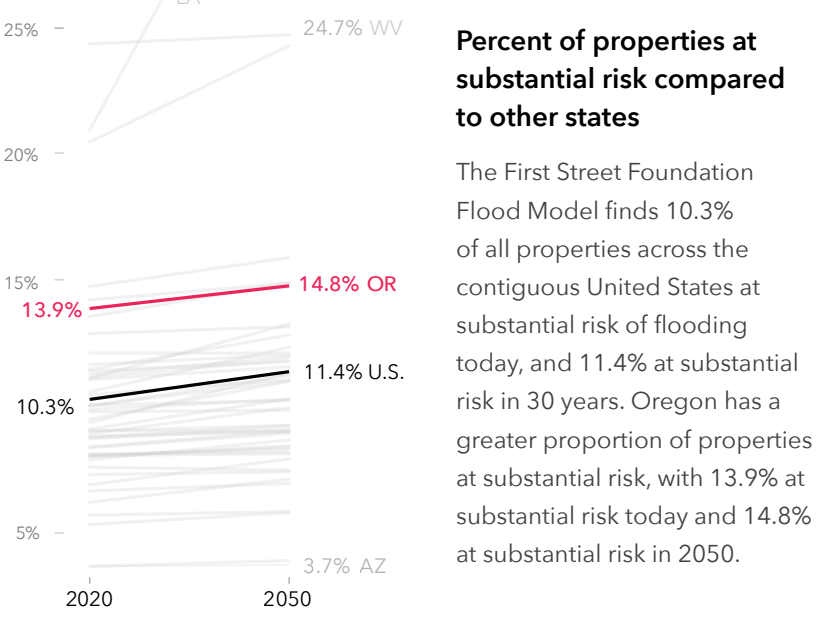

More properties at risk in FSF model $\longrightarrow$

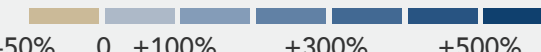

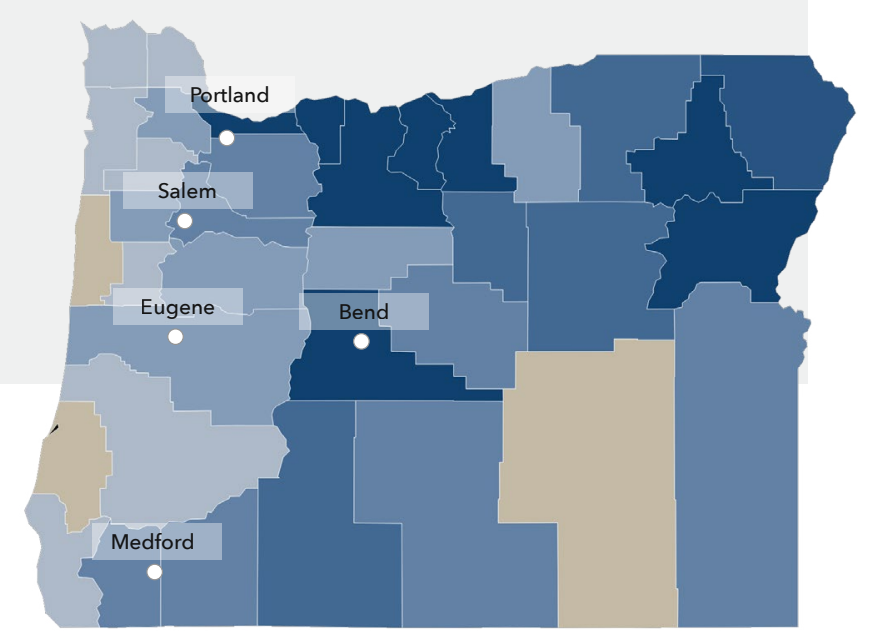




\section{Local details \\ Oregon}

The First Street Foundation Flood Model calculates the number of properties facing any risk* of flooding. When looking at this broader level of risk, the data identifies 398,500 properties in Oregon as at risk over the next 30 years. Of these properties, 69,100 were categorized as facing almost certain risk, with a $99 \%$ chance of flooding at least once over the next 30 years.

The city of Portland has the greatest number of properties at risk of flooding in the state with 46,000 currently at risk, or $20 \%$ of its total number of properties. However, smaller cities or municipalities in the state, with fewer properties, may have a greater proportion of their total properties at risk. For example, $90 \%$ of properties in MiltonFreewater are at risk of flooding. Other municipalities will see the greatest increase in risk over the next 30 years. Astoria, for example, will see a $95 \%$ increase in the number of properties at risk.

Click here for a full breakdown of counties, cities, zip codes, and congressional districts in Oregon at risk.

\section{Greatest proportion of properties at risk*}

\begin{tabular}{llll} 
Municipality & \multicolumn{2}{c}{2020} \\
\hline Milton-Freewater & 2,176 & $90 \%$ \\
\hline Baker City & 4,506 & $86 \%$ \\
\hline La Grande & 3,802 & $75 \%$ \\
\hline Keizer & 6,471 & $57 \%$ \\
\hline Junction City & 1,292 & $55 \%$ \\
\hline Sisters & 1,205 & $54 \%$ \\
\hline Seaside & 2,639 & $51 \%$ \\
\hline Prineville & 2,382 & $51 \%$ \\
\hline Eugene & 26,264 & $48 \%$ \\
\hline Mount Hood Village & 2,455 & $48 \%$ \\
\hline
\end{tabular}

\begin{tabular}{llll}
\multicolumn{2}{c}{2050} & \multicolumn{2}{c}{ Change } \\
2,196 & $91 \%$ & +20 & $+0.9 \%$ \\
\hline 4,556 & $87 \%$ & +50 & $+1.1 \%$ \\
\hline 3,837 & $76 \%$ & +35 & $+0.9 \%$ \\
\hline 6,601 & $59 \%$ & +130 & $+2.0 \%$ \\
\hline 1,348 & $58 \%$ & +56 & $+4.3 \%$ \\
\hline 1,237 & $55 \%$ & +32 & $+2.7 \%$ \\
\hline 2,772 & $53 \%$ & +133 & $+5.0 \%$ \\
\hline 2,407 & $51 \%$ & +25 & $+1.0 \%$ \\
\hline 27,426 & $50 \%$ & $+1,162$ & $+4.4 \%$ \\
\hline 2,516 & $49 \%$ & +61 & $+2.5 \%$
\end{tabular}

\section{Greatest number of properties at risk*}

\begin{tabular}{lcllllll} 
Municipality & \multicolumn{2}{c}{2020} & \multicolumn{2}{c}{2050} & \multicolumn{2}{c}{ Change } \\
Portland & 45,951 & $20 \%$ & 47,554 & $21 \%$ & $+1,603$ & $+3.5 \%$ \\
\hline Eugene & 26,264 & $48 \%$ & 27,426 & $50 \%$ & $+1,162$ & $+4.4 \%$ \\
\hline Salem & 10,648 & $21 \%$ & 11,011 & $22 \%$ & +363 & $+3.4 \%$ \\
\hline Springfield & 8,469 & $43 \%$ & 9,023 & $46 \%$ & +554 & $+6.5 \%$ \\
\hline Bend & 6,885 & $17 \%$ & 7,066 & $17 \%$ & +181 & $+2.6 \%$ \\
\hline Medford & 6,661 & $23 \%$ & 6,860 & $23 \%$ & +199 & $+3.0 \%$ \\
\hline Keizer & 6,471 & $57 \%$ & 6,601 & $59 \%$ & +130 & $+2.0 \%$ \\
\hline Grants Pass & 5,795 & $40 \%$ & 5,890 & $40 \%$ & +95 & $+1.6 \%$ \\
\hline Baker City & 4,506 & $86 \%$ & 4,556 & $87 \%$ & +50 & $+1.1 \%$ \\
\hline Albany & 4,037 & $22 \%$ & 4,223 & $23 \%$ & +186 & $+4.6 \%$
\end{tabular}

Greatest relative growing risk*

\begin{tabular}{lrrrrrr} 
Municipality & \multicolumn{2}{c}{2020} & \multicolumn{2}{c}{2050} & \multicolumn{2}{c}{ Change } \\
Astoria & 247 & $4 \%$ & 482 & $8 \%$ & +235 & $+95 \%$ \\
\hline Newport & 324 & $5 \%$ & 545 & $9 \%$ & +221 & $+68 \%$ \\
\hline Warrenton & 1,353 & $33 \%$ & 1,867 & $45 \%$ & +514 & $+38 \%$ \\
\hline Cannon Beach & 122 & $5 \%$ & 168 & $7 \%$ & +46 & $+38 \%$ \\
\hline Pacific City & 442 & $21 \%$ & 598 & $28 \%$ & +156 & $+35 \%$ \\
\hline Lincoln Beach & 80 & $3 \%$ & 101 & $4 \%$ & +21 & $+26 \%$ \\
\hline Rockaway Beach & 596 & $20 \%$ & 746 & $25 \%$ & +150 & $+25 \%$ \\
\hline Brookings & 92 & $3 \%$ & 113 & $3 \%$ & +21 & $+23 \%$ \\
\hline Lincoln City & 706 & $9 \%$ & 841 & $10 \%$ & +135 & $+19 \%$ \\
\hline Ontario & 1,309 & $32 \%$ & 1,530 & $37 \%$ & +221 & $+17 \%$ \\
\hline
\end{tabular}

\section{Flood Factor distribution of properties at risk ${ }^{\star}(1000 s)$}

\section{Risk level}

Minor $\quad 14.9$

Moderate $\quad 112.3$

Major $\quad 153.2$

Severe $\quad 42.5$

Extreme $\quad 75.5$

More than $21.5 \%$ of individual properties and properties in Oregon are at any risk of flooding over the next 30 years. Out of those at risk $66 \%$ are at major to extreme risk. 
Flood History \& Protection

\section{Oregon}

\section{Claims History}

7,400 home and property owners in Oregon have made flood damage claims through FEMA since the year 2000.* These claims for reimbursement were made through either the National Flood Insurance Program (NFIP) or Individual Assistance Program (IAP). The greatest number of claims since the year 2000 have been concentrated in Clatsop, Columbia, Washington, Tillamook, and Polk counties.

\section{0,900}

Properties served by

protection measures

The First Street Foundation Flood

Model incorporates 251 flood control

measures throughout the state which

protect 30,900 properties.
Top protection measures in state by quantity

Type
Example

Levee

Springfield Levee

30,597

Marsh/wetland restoration

- Southern Flow Corridor, Tillamook

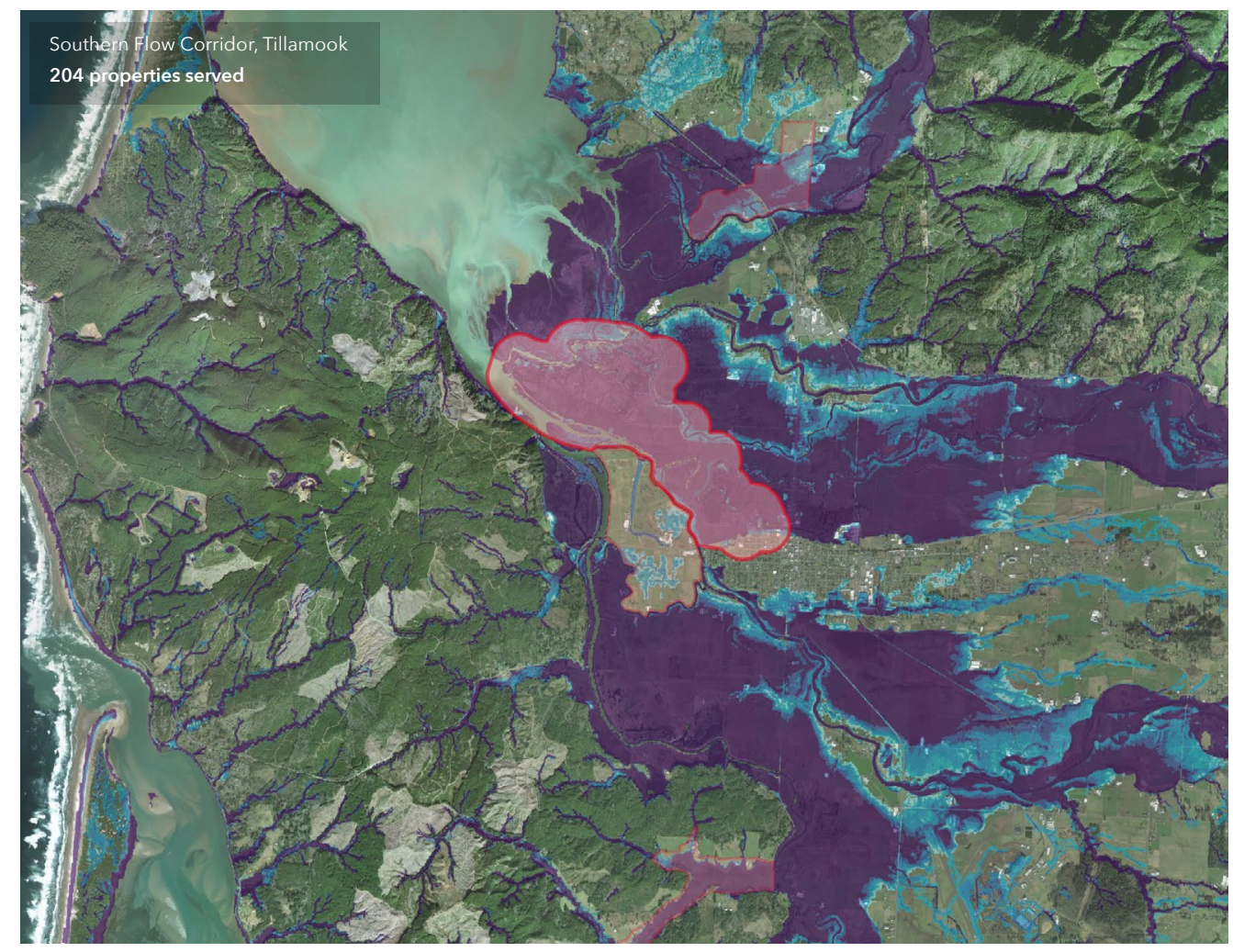

$\square$ Area of protectio in 100 flood event in 2020 


\section{State Overview \\ Pennsylvania}

\section{Flood risk is increasing in the state of}

Pennsylvania. 564,600 properties currently have a substantial risk* of flooding. Over the next 30 years, the number of properties with this risk will increase by another $4 \%$, bringing the total number of properties with substantial risk to 587,400 .

To understand personal flood risk, Americans leverage the Federal Emergency Management Agency (FEMA) Flood Insurance Rate Maps (FIRM). These maps identify 194,400 properties as having substantial risk in the state of Pennsylvania. In comparison, the First Street Foundation

Flood Model identifies 2.9 times the number of properties as facing this same level of risk. This discrepancy exists because the Foundation uses the current climate data, maps precipitation as a stand-alone risk, and includes areas that FEMA has not mapped. These new methods uncover an additional 370,200 properties currently not identified by FEMA as having substantial risk.

When adjusting for future environmental changes, the FEMA gap further widens to 393,000 by the year 2050 .
Total properties at substantial risk*

$\ln 2020$

564,600

$$
\begin{aligned}
& \text { 30-year change } \\
& \Delta+22,800(+4 \%)
\end{aligned}
$$

Pittsburgh faces flooding from snowmelt and rainfall. Winter ice jams both cause and intensify backwater flooding along upstream tributaries of the Allegheny and Monongahela rivers. Upstream dams attempt to manage their flows. Philadelphia sees riverine, storm surge, and high tide flood events from hurricanes and tropical storms. It has focused on stabilizing streams and improving infrastructure to reduce flood risk.

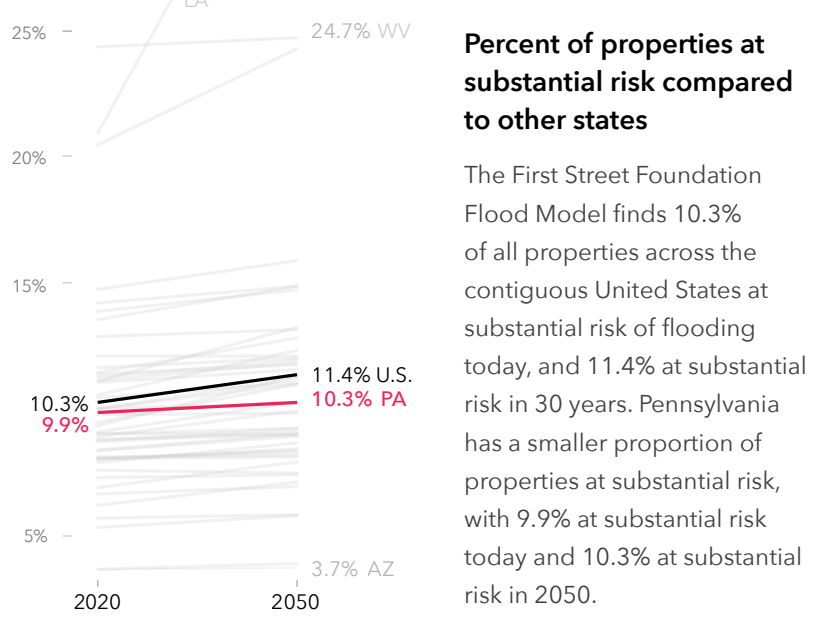

Difference in number of properties currently at substantial risk compared to FEMA ${ }^{\star \star}$

$$
\Delta+370,200
$$

More properties at risk in FSF model $\longrightarrow$

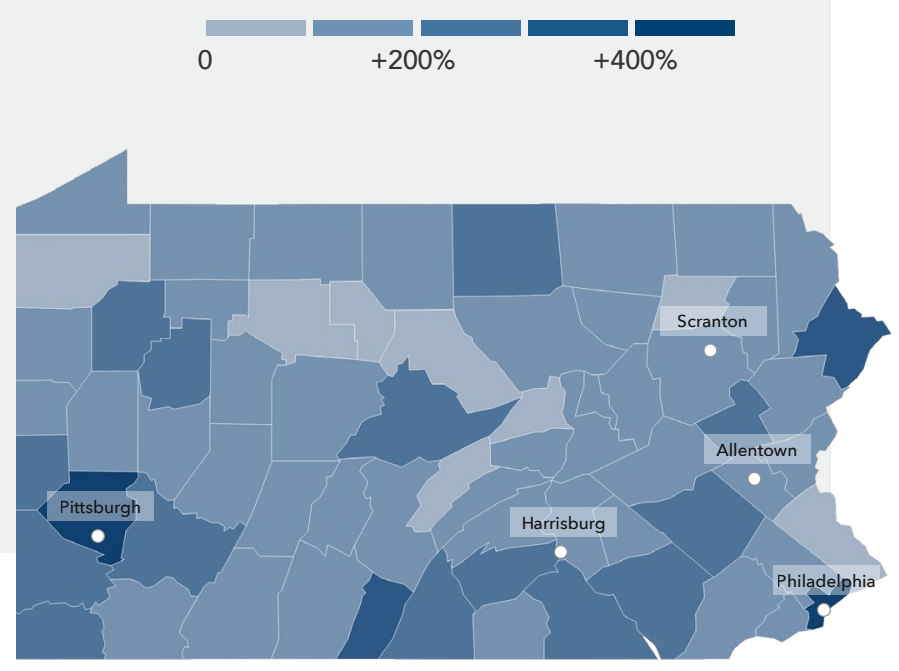




\section{Local details \\ Pennsylvania}

The First Street Foundation Flood Model calculates the number of properties facing any risk* of flooding. When looking at this broader level of risk, the data identifies 743,600 properties in Pennsylvania as at risk over the next 30 years. Of these properties, 202,700 were categorized as facing almost certain risk, with a $99 \%$ chance of

flooding at least once over the next 30 years.

The city of Philadelphia has the greatest number of properties at risk of flooding in the state with 53,400 currently at risk, or $10 \%$ of its total number of properties. However, smaller cities or municipalities in the state, with fewer properties, may have a greater proportion of their total properties at risk. For example, $98 \%$ of properties in Kingston are at risk of flooding. Other municipalities will see the greatest increase in risk over the next 30 years. Folcroft, for example, will see a $56 \%$

increase in the number of properties at risk.

Click here for a full breakdown of counties, cities, zip codes, and congressional districts in Pennsylvania at risk.

\section{Greatest proportion of properties at risk*}

\begin{tabular}{lrl} 
Municipality & \multicolumn{2}{c}{2020} \\
\hline Kingston & 4,869 & $98 \%$ \\
\hline Swoyersville & 2,002 & $78 \%$ \\
\hline Exeter & 1,652 & $70 \%$ \\
\hline Danville & 1,278 & $62 \%$ \\
\hline McKees Rocks & 1,775 & $60 \%$ \\
\hline West Pittston & 1,250 & $60 \%$ \\
\hline Honesdale & 1,247 & $55 \%$ \\
\hline Bristol & 2,040 & $54 \%$ \\
\hline Williamsport & 5,039 & $53 \%$ \\
\hline Lock Haven & 2,147 & $53 \%$ \\
\hline
\end{tabular}

\section{Greatest number of properties at risk*}

\begin{tabular}{l|c|ccccc} 
Municipality & \multicolumn{2}{c}{2020} & \multicolumn{2}{c}{2050} & \multicolumn{2}{c}{ Change } \\
Philadelphia & 53,378 & $10 \%$ & 60,561 & $11 \%$ & $+7,183$ & $+13.5 \%$ \\
\hline Pittsburgh & 21,803 & $15 \%$ & 22,373 & $16 \%$ & +570 & $+2.6 \%$ \\
\hline Harrisburg & 7,395 & $37 \%$ & 7,686 & $39 \%$ & +291 & $+3.9 \%$ \\
\hline Wilkes-Barre & 6,919 & $44 \%$ & 6,984 & $44 \%$ & +65 & $+0.9 \%$ \\
\hline Williamsport & 5,039 & $53 \%$ & 5,152 & $55 \%$ & +113 & $+2.2 \%$ \\
\hline Kingston & 4,869 & $98 \%$ & 4,906 & $99 \%$ & +37 & $+0.8 \%$ \\
\hline Johnstown & 4,532 & $41 \%$ & 4,586 & $41 \%$ & +54 & $+1.2 \%$ \\
\hline Scranton & 3,558 & $13 \%$ & 3,652 & $14 \%$ & +94 & $+2.6 \%$ \\
\hline Erie & 3,287 & $9 \%$ & 3,405 & $9 \%$ & +118 & $+3.6 \%$ \\
\hline Altoona & 3,276 & $15 \%$ & 3,386 & $15 \%$ & +110 & $+3.4 \%$
\end{tabular}

Greatest relative growing risk*

\begin{tabular}{lrrrrrr} 
Municipality & \multicolumn{2}{c}{2020} & \multicolumn{2}{c}{2050} & \multicolumn{2}{c}{ Change } \\
Folcroft & 99 & $4 \%$ & 154 & $6 \%$ & +55 & $+56 \%$ \\
\hline Arnold & 367 & $16 \%$ & 563 & $24 \%$ & +196 & $+53 \%$ \\
\hline Wilson & 28 & $1 \%$ & 40 & $1 \%$ & +12 & $+43 \%$ \\
\hline Carnot-Moon & 211 & $5 \%$ & 279 & $7 \%$ & +68 & $+32 \%$ \\
\hline Richboro & 48 & $2 \%$ & 58 & $3 \%$ & +10 & $+21 \%$ \\
\hline Ancient Oaks & 130 & $6 \%$ & 155 & $7 \%$ & +25 & $+19 \%$ \\
\hline Hemlock Farms & 85 & $2 \%$ & 98 & $3 \%$ & +13 & $+15 \%$ \\
\hline Fairless Hills & 40 & $2 \%$ & 46 & $2 \%$ & +6 & $+15 \%$ \\
\hline Levittown & 1,461 & $8 \%$ & 1,670 & $10 \%$ & +209 & $+14 \%$ \\
\hline Philadelphia & 53,378 & $10 \%$ & 60,561 & $11 \%$ & $+7,183$ & $+14 \%$
\end{tabular}

\section{Flood Factor distribution of properties at risk ${ }^{\star}(1000 s)$}

\section{Risk level}

Minor $\quad 26.1$

Moderate

(25.1

Extreme

257.6

More than $13 \%$ of individual properties and properties in

Pennsylvania are at any risk of flooding over the next 30 years. Out of those at risk $78 \%$ are at major to extreme risk.

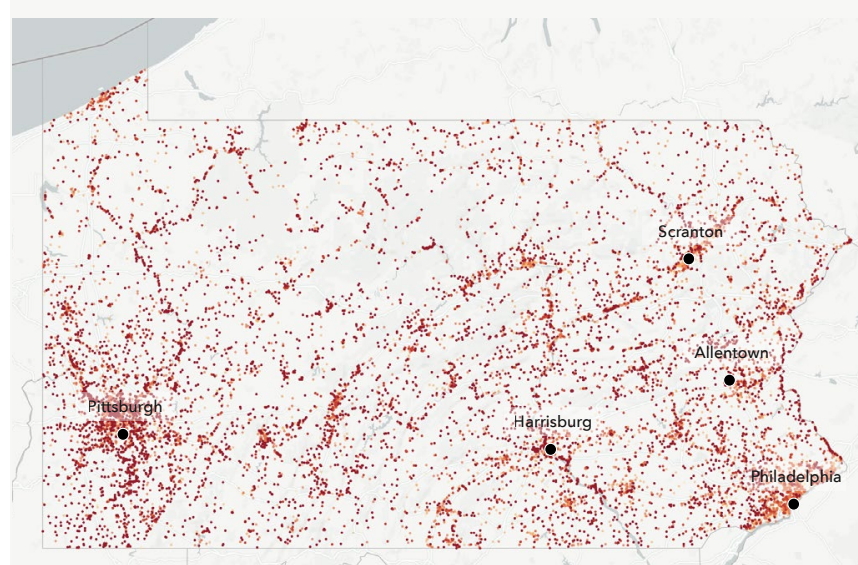




\section{Flood History \& Protection \\ Pennsylvania}

\section{Claims History}

257,100 home and property owners in Pennsylvania have made flood damage claims through FEMA since the year 2000.* These claims for reimbursement were made through either the National Flood Insurance Program (NFIP) or Individual Assistance Program (IAP). The greatest number of claims since the year 2000 have been concentrated in Philadelphia, Luzerne, Dauphin, Allegheny, and Montgomery counties.

\section{Storm Simulation}

The First Street Foundation Flood Model has recreated 6 flooding events that have occurred since the year 2000 in the state of Pennsylvania. These events flooded around 27,100 properties across the state.**

\begin{tabular}{llr} 
Flood event & Date & $\begin{array}{r}\text { \# Properties } \\
\text { affected }\end{array}$ \\
Hurricane Isabel & Sep 2003 & 160 \\
\hline River flood near Harrisburg, PA & Sep 2004 & 8,565 \\
\hline River flood near Pittsburgh, PA & Sep 2004 & 5,020 \\
\hline Nor'easter & Nov 2009 & 69 \\
\hline Hurricane Irene & Aug 2011 & 10 \\
\hline River flood across central Pennsylvania & Sep 2011 & 13,277
\end{tabular}

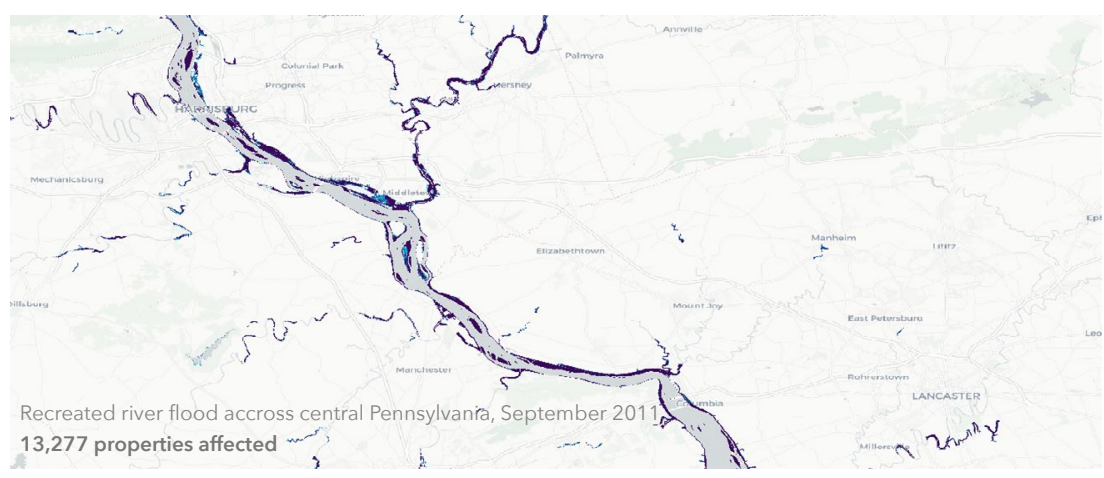
13,277 properties affected

epth of flooding

\section{5,100}

Properties served by

protection measures

The First Street Foundation Flood

Model incorporates 231 flood control

measures throughout the state which

protect 55,100 properties.
Top protection measures in state by quantity

Type
Example

Levee

-Wilkes-Barre-Hanover Township Levee

Retention pond

Stormwater Project

Bioswale

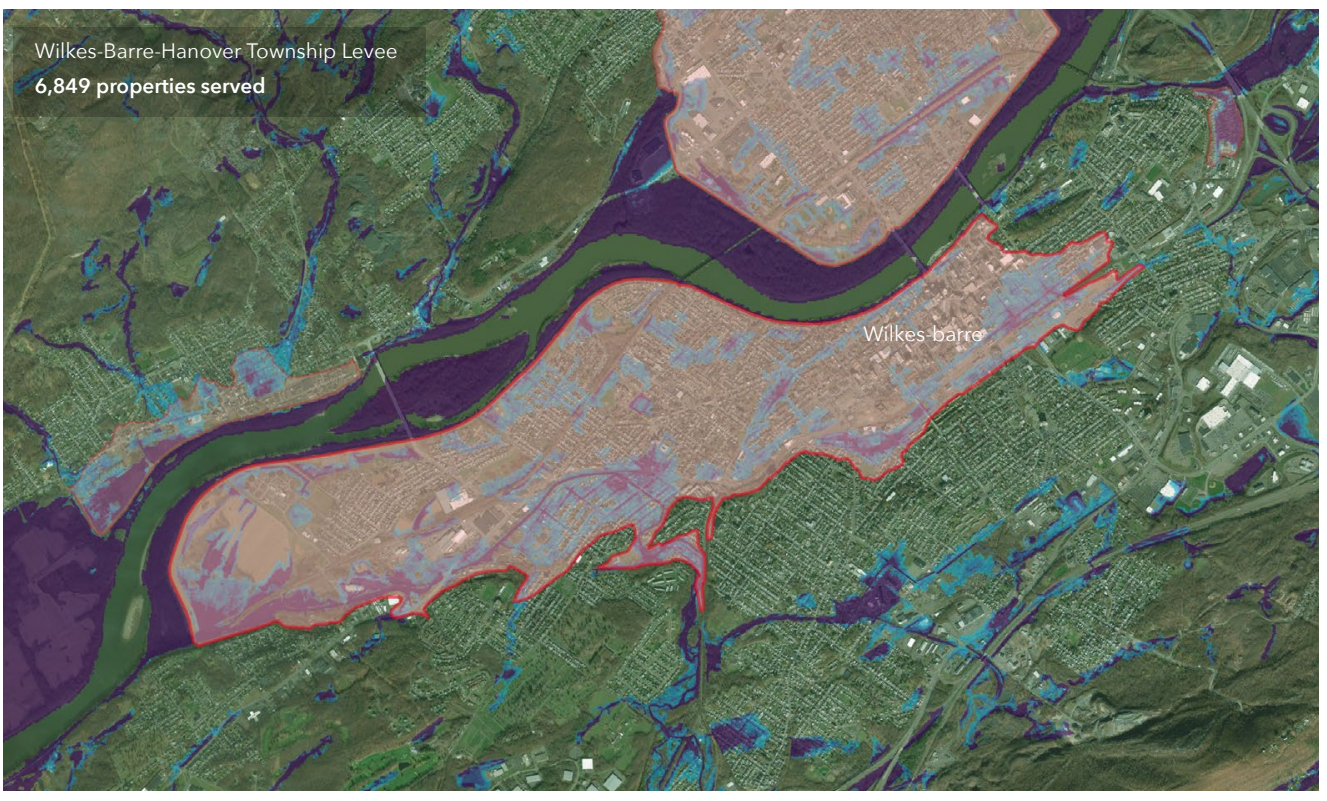

Area of protection 


\section{State Overview Rhode Island}

Flood risk is increasing in the state of Rhode Island. 26,500 properties currently have a substantial risk* of flooding. Over the next 30 years, the number of properties with this risk will increase by another $14.7 \%$, bringing the total number of properties with substantial risk to 30,400 .

To understand personal flood risk, Americans leverage the Federal Emergency Management Agency (FEMA) Flood Insurance Rate Maps (FIRM). These maps identify 23,900 properties as having substantial risk in the state of Rhode Island. In comparison, the First Street Foundation Flood Model identifies 1.1 times the number of properties as facing this same level of risk. This discrepancy exists because the Foundation uses the current climate data, maps precipitation as a stand-alone risk, and includes areas that FEMA has not mapped. These new methods uncover an additional 2,600 properties currently not identified by FEMA as having substantial risk. When adjusting for future environmental changes, the FEMA gap further widens to 6,400 by the year 2050 .
Total properties at substantial risk ${ }^{*}$

$\ln 2020$

26,500

30-year change

$\Delta+3,900(+15 \%)$
Difference in number of properties currently at substantial risk compared to FEMA**

$\Delta+2,600$

More properties at risk in FSF model

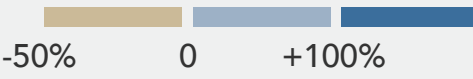

Rhode Island faces year-round floods, with high impact tropical storms and hurricanes in late summer and early fall. Winter and spring flooding is caused by storms in combination with snowmelt or ice jams. Mid-spring and fall thunderstorms produce localized flooding. Most rivers in Providence County rose above flood stage in 2010 when moderate to heavy rainfall events resulted in about 20 inches of rainfall.
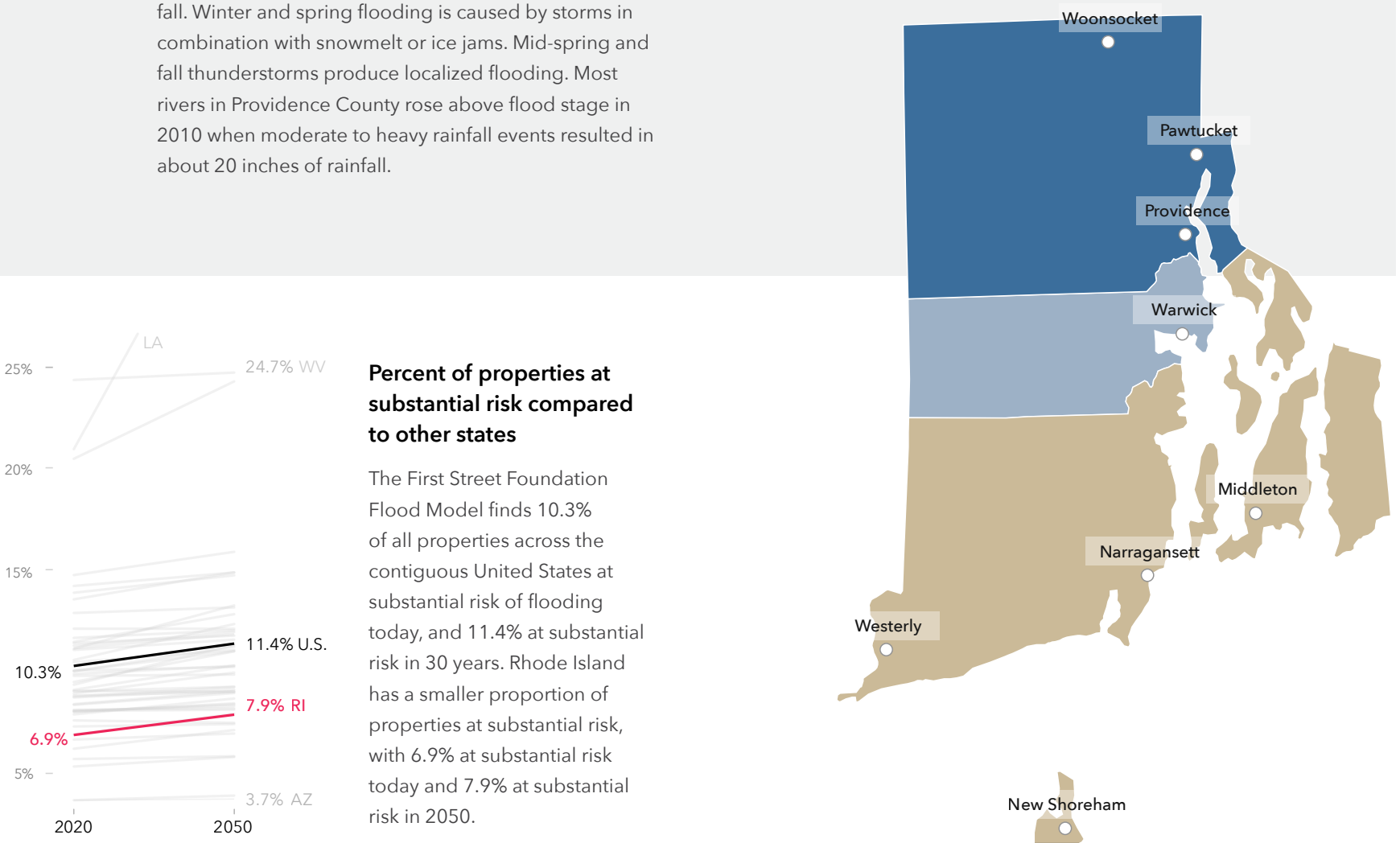


\section{Local details \\ Rhode Island}

The First Street Foundation Flood Model calculates the number of properties facing any risk* of flooding. When looking at this broader level of risk, the data identifies 49,000 properties in Rhode Island as at risk over the next 30 years. Of these properties, 6,600 were categorized as facing almost certain risk, with a $99 \%$ chance of flooding at least once over the next 30 years.

The city of Providence has the greatest number of properties at risk of flooding in the state with 5,200 currently at risk, or $13 \%$ of its total number of properties. However, smaller cities or municipalities in the state, with fewer properties, may have a greater proportion of their total properties at risk. For example, $27 \%$ of properties in Charlestown are at risk of flooding. Other municipalities will see the greatest

increase in risk over the next 30 years. Tiverton, for example, will see a $64 \%$ increase in the number of properties at risk.

Click here for a full breakdown of counties, cities, zip codes, and congressional districts in Rhode Island at risk.

\section{Greatest proportion of properties at risk*}

\begin{tabular}{lrr|l} 
Municipality & \multicolumn{2}{c}{2020} \\
Charlestown & 570 & $27 \%$ \\
\hline Central Falls & 464 & $16 \%$ \\
\hline Newport & 985 & $13 \%$ \\
\hline Providence & 5,176 & $13 \%$ \\
\hline Woonsocket & 1,253 & $12 \%$ \\
\hline Pawtucket & 2,117 & $11 \%$ \\
\hline Warwick & 4,095 & $11 \%$ \\
\hline Wakefield-Peacedale & 321 & $10 \%$ \\
\hline Westerly & 720 & $10 \%$ \\
\hline East Providence & 1,454 & $10 \%$ \\
\hline
\end{tabular}

\section{Greatest number of properties at risk*}

\begin{tabular}{l|c|ccccc} 
Municipality & \multicolumn{2}{c}{2020} & \multicolumn{2}{c}{2050} & \multicolumn{2}{c}{ Change } \\
Providence & 5,176 & $13 \%$ & 5,519 & $14 \%$ & +343 & $+6.6 \%$ \\
\hline Warwick & 4,095 & $11 \%$ & 5,580 & $15 \%$ & $+1,485$ & $+36.3 \%$ \\
\hline Cranston & 2,875 & $9 \%$ & 3,047 & $10 \%$ & +172 & $+6.0 \%$ \\
\hline Pawtucket & 2,117 & $11 \%$ & 2,319 & $12 \%$ & +202 & $+9.5 \%$ \\
\hline East Providence & 1,454 & $10 \%$ & 1,606 & $11 \%$ & +152 & $+10.5 \%$ \\
\hline Woonsocket & 1,253 & $12 \%$ & 1,287 & $12 \%$ & +34 & $+2.7 \%$ \\
\hline Newport & 985 & $13 \%$ & 1,403 & $19 \%$ & +418 & $+42.4 \%$ \\
\hline Westerly & 720 & $10 \%$ & 827 & $11 \%$ & +107 & $+14.9 \%$ \\
\hline Charlestown & 570 & $27 \%$ & 733 & $34 \%$ & +163 & $+28.6 \%$ \\
\hline Central Falls & 464 & $16 \%$ & 487 & $17 \%$ & +23 & $+5.0 \%$
\end{tabular}

Greatest relative growing risk*

\begin{tabular}{|c|c|c|c|c|c|c|}
\hline \multirow{2}{*}{$\begin{array}{l}\text { Municipality } \\
\text { Tiverton }\end{array}$} & \multicolumn{2}{|c|}{2020} & \multicolumn{2}{|c|}{2050} & \multicolumn{2}{|c|}{ Change } \\
\hline & 105 & $3 \%$ & 172 & $5 \%$ & +67 & $+64 \%$ \\
\hline Narragansett Pier & 174 & $7 \%$ & 255 & $10 \%$ & +81 & $+47 \%$ \\
\hline Newport & 985 & $13 \%$ & 1,403 & $19 \%$ & +418 & $+42 \%$ \\
\hline Warwick & 4,095 & $11 \%$ & 5,580 & $15 \%$ & $+1,485$ & $+36 \%$ \\
\hline Charlestown & 570 & $27 \%$ & 733 & $34 \%$ & +163 & $+29 \%$ \\
\hline Newport East & 140 & $3 \%$ & 175 & $4 \%$ & +35 & $+25 \%$ \\
\hline Westerly & 720 & $10 \%$ & 827 & $11 \%$ & +107 & $+15 \%$ \\
\hline East Providence & 1,454 & $10 \%$ & 1,606 & $11 \%$ & +152 & $+11 \%$ \\
\hline Pawtucket & 2,117 & $11 \%$ & 2,319 & $12 \%$ & +202 & $+10 \%$ \\
\hline Providence & 5,176 & $13 \%$ & 5,519 & $14 \%$ & +343 & $+7 \%$ \\
\hline
\end{tabular}

\section{Flood Factor distribution of properties at risk ${ }^{\star}(1000 s)$}

Risk level

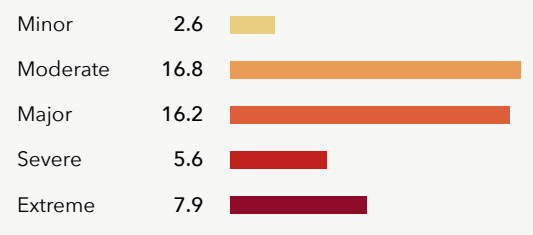

More than $12.8 \%$ of individual properties and properties in Rhode Island are at any risk of flooding over the next 30 years. Out of those at risk $61 \%$ are at major to extreme risk.

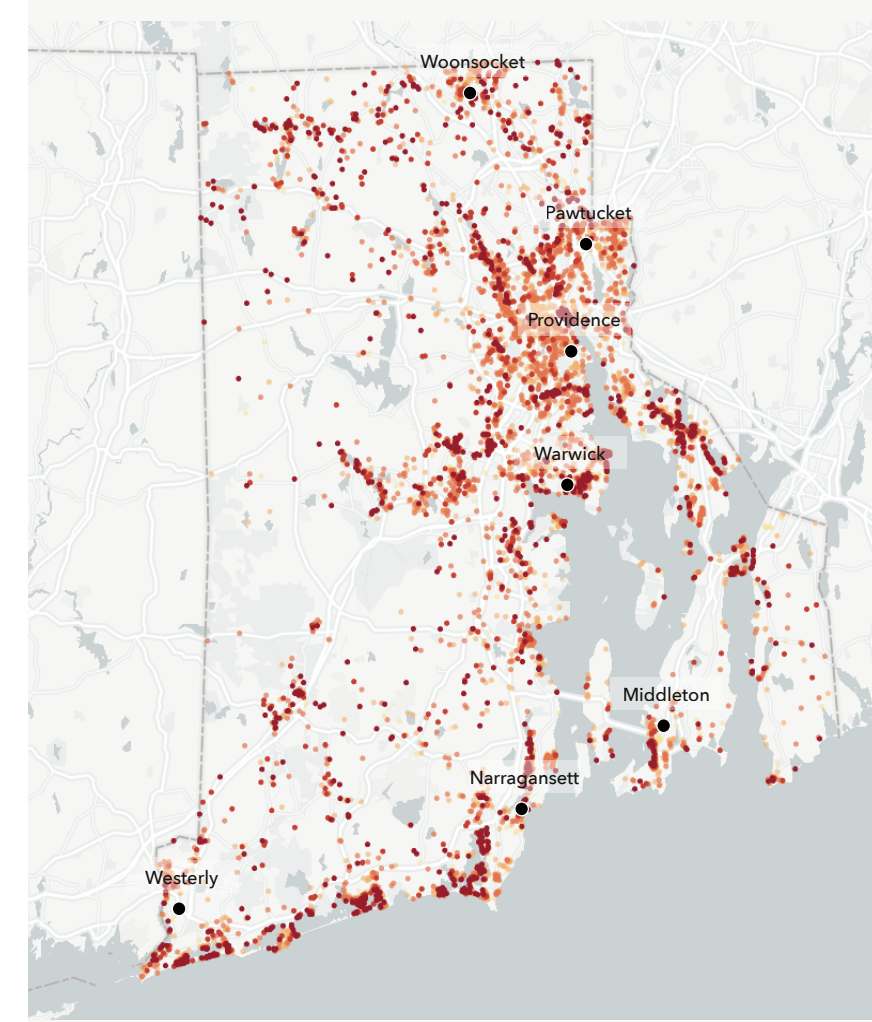




\section{Flood History \& Protection}

\section{Rhode Island}

\section{Claims History}

35,700 home and property owners in Rhode Island have made flood damage claims through FEMA since the year 2000.* These claims for reimbursement were made through either the National Flood Insurance Program (NFIP) or Individual Assistance Program (IAP). The greatest number of claims since the year 2000 have been concentrated in Kent, Providence, Washington, Bristol, and Newport counties.

\section{Storm Simulation}

The First Street Foundation Flood Model has recreated 5 flooding events that have occurred since the year 2000 in the state of Rhode Island. These events flooded around 12,790 properties across the state.*

\begin{tabular}{llr} 
Flood event & Date & $\begin{array}{r}\text { \# Properties } \\
\text { affected }\end{array}$ \\
Nor'easter & Feb 2003 & 825 \\
\hline Nor'easter & Nov 2009 & 1,929 \\
\hline Nor'easter & Mar 2010 & 1,566 \\
\hline Hurricane Irene & Aug 2011 & 4,284 \\
\hline Hurricane Sandy & Oct 2012 & 4,187
\end{tabular}

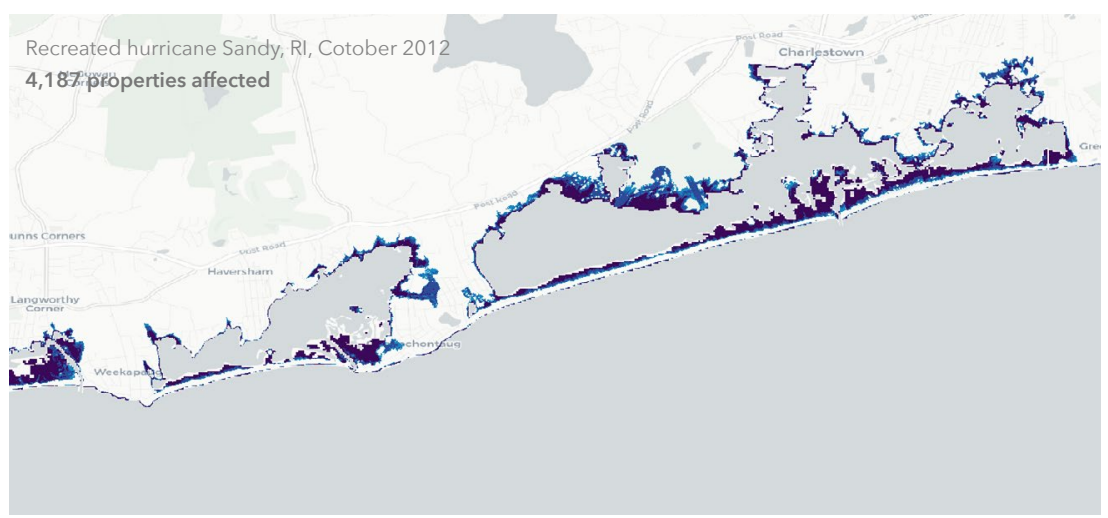

$\begin{array}{llll}0 & 1 & 2 & 3+\mathrm{ft}\end{array}$

\section{2,600}

Properties served by

protection measures

The First Street Foundation Flood

Model incorporates 17 flood control

measures throughout the state which

protect 2,600 properties.

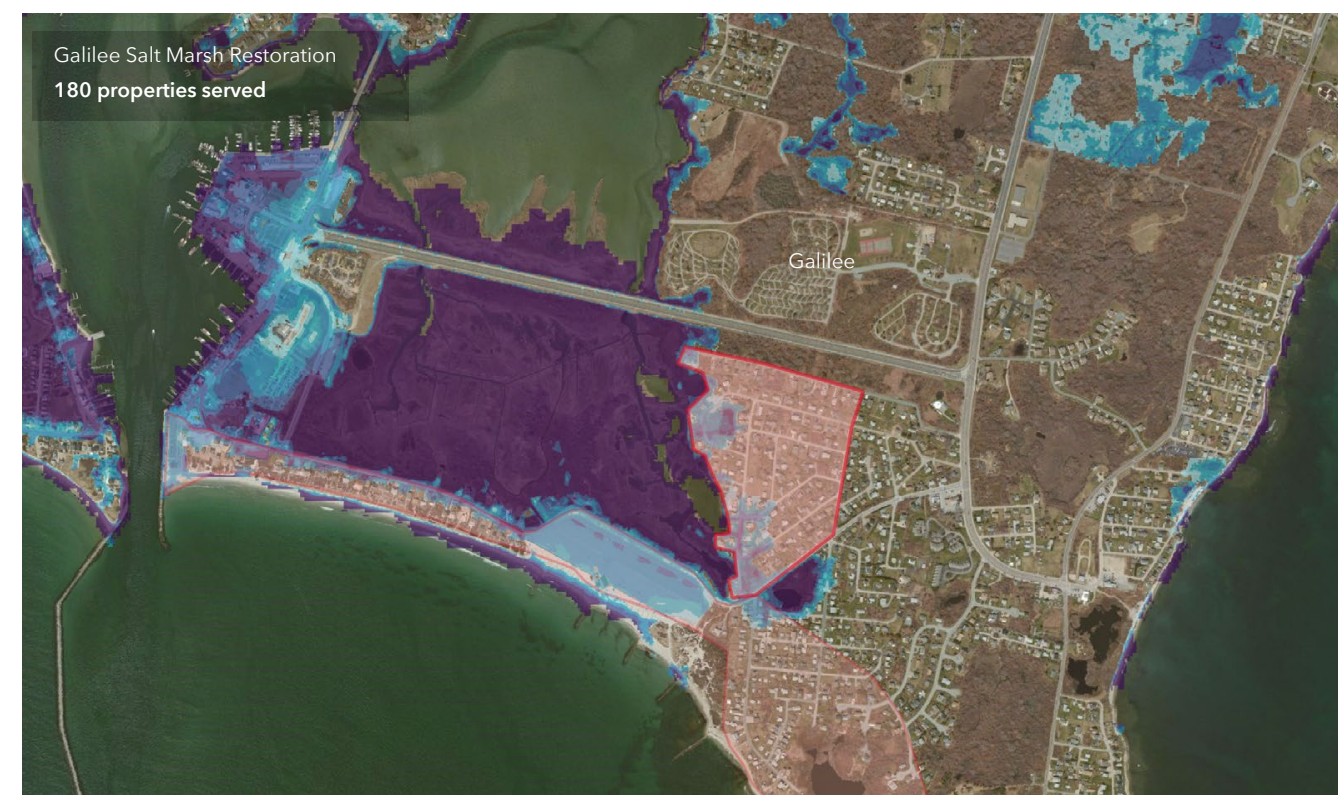

Area of protection
Top protection measures in state by quantity

Type
Example

Levee

Breakwater

Point Judith Harbor of Refuge

Marsh/wetland restoration

- Galilee Salt Marsh Restoration

Baker Street Brook channel improvements, West Warwick

Dam 


\section{State Overview \\ South Carolina}

Flood risk is increasing in the state of South Carolina. 271,500 properties currently have a substantial risk* of flooding. Over the next 30 years, the number of properties with this risk will increase by another $16.7 \%$, bringing the total number of properties with substantial risk to 316,900 .

To understand personal flood risk, Americans leverage the Federal Emergency Management Agency (FEMA) Flood Insurance Rate Maps (FIRM) These maps identify 196,900 properties as having substantial risk in the state of South Carolina.

In comparison, the First Street Foundation

Flood Model identifies 1.4 times the number of properties as facing this same level of risk. This discrepancy exists because the Foundation uses the current climate data, maps precipitation as a stand-alone risk, and includes areas that FEMA has not mapped. These new methods uncover an additional 74,600 properties currently not identified by FEMA as having substantial risk. When adjusting for future environmental changes, the FEMA gap further widens to 120,000 by the year 2050 .
Total properties at substantial risk

In 2020

271,500

30-year change

$\Delta+45,400$

$(+17 \%)$

Charleston floods from tides, storm surge, and heavy rains, given its low elevation, proximity to the ocean, and increases in extreme rain events. To the west, areas around the Blue Ridge Mountains flood from river overflow due to heavy rain and the steep slope of the land. Columbia and surrounding areas see flooding from intense rains, which can cause dam failures and flash floods, making the flooding extremely dangerous.

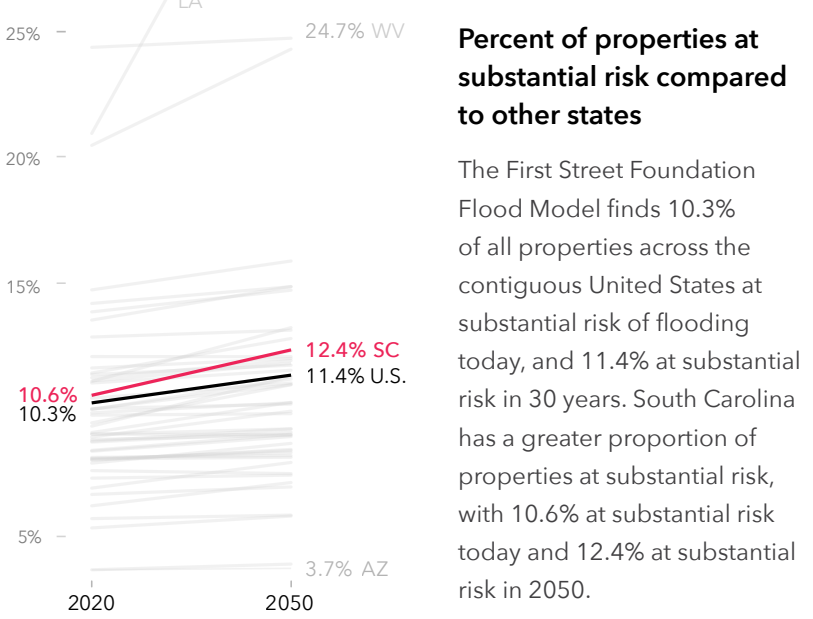

* Substantial risk is calculated as inundation $1 \mathrm{~cm}$ or more to the building in the 100 return period ( $1 \%$ annual risk) and rounded to the nearest 100 properties. See methodology for full model details. ** Comparison of count of properties within a Special Elood Hazard Area (1 in 100 layer) versus those with $1 \%$ risk from the First Street Foundation Flood Model. Some counties may show higher FEMA counts due to a variety of factors, including the generalization of SFHAs, assumptions around flood protection measures, and local context FEMA zones are estimated by MassiveCert. Inc
Difference in number of properties currently at substantial risk compared to FEMA**

$$
\Delta+74,600
$$

More properties at risk in FSF model $\longrightarrow$
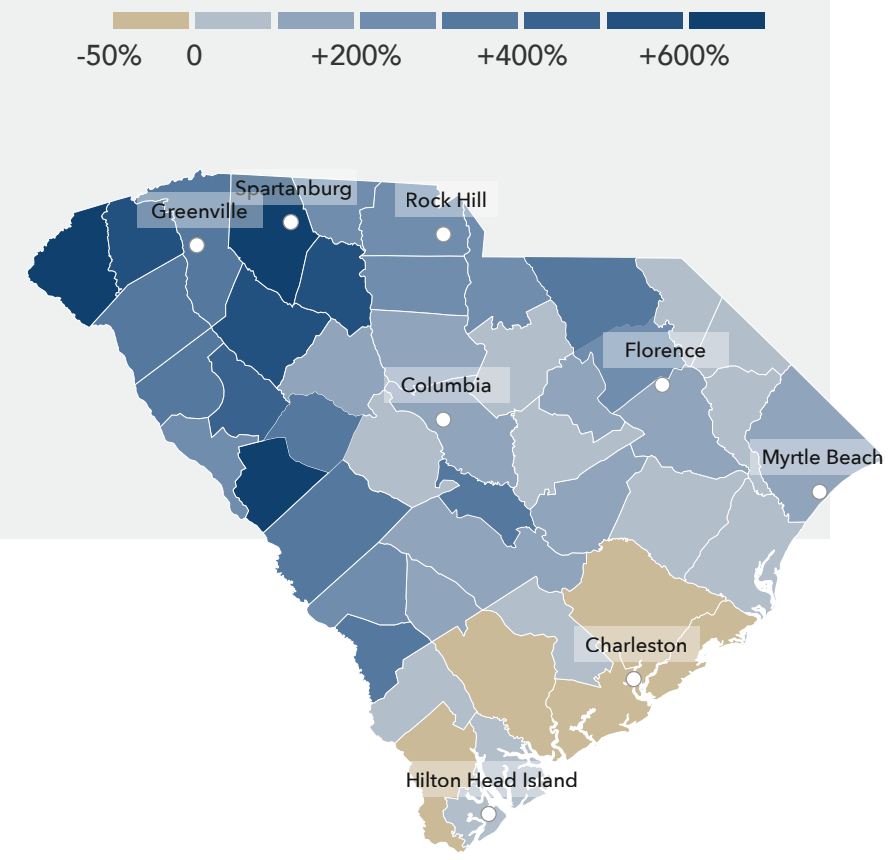


\section{Local details}

\section{South Carolina}

The First Street Foundation Flood Model calculates the number of properties facing any risk* of flooding. When looking at this broader level of risk, the data identifies 430,800 properties in South Carolina as at risk over the next 30 years. Of these properties, 55,900 were categorized as facing almost certain risk, with a $99 \%$ chance of flooding at least once over the next 30 years.

The city of Charleston has the greatest number of properties at risk of flooding in the state with 29,500 currently at risk, or $59 \%$ of its total number of properties. However, smaller cities or municipalities in the state, with fewer properties, may have a greater proportion of their total properties at risk. For example, $97 \%$ of properties in Seabrook Island are at risk of flooding. Other municipalities will see the greatest increase in risk over the next 30 years. Bluffton, for example, will see a $181 \%$ increase in the number of properties at risk.

Click here for a full breakdown of counties, cities, zip codes, and congressional districts in South Carolina at risk.

\section{Greatest proportion of properties at risk*}

\begin{tabular}{lrr} 
Municipality & \multicolumn{2}{c}{2020} \\
Seabrook Island & 2,296 & $97 \%$ \\
\hline Isle of Palms & 3,783 & $96 \%$ \\
\hline Kiawah Island & 3,428 & $95 \%$ \\
\hline Edisto Beach & 2,246 & $93 \%$ \\
\hline Hilton Head Island & 18,699 & $91 \%$ \\
\hline Folly Beach & 1,829 & $90 \%$ \\
\hline James Island & 4,279 & $82 \%$ \\
\hline Andrews & 1,466 & $73 \%$ \\
\hline Charleston & 29,469 & $59 \%$ \\
\hline Port Royal & 1,927 & $54 \%$ \\
\hline
\end{tabular}

\section{Greatest number of properties at risk*}

\begin{tabular}{lcccccc} 
Municipality & \multicolumn{2}{c}{2020} & \multicolumn{2}{c}{2050} & \multicolumn{2}{c}{ Change } \\
\cline { 2 - 5 } Charleston & 29,469 & $59 \%$ & 33,074 & $67 \%$ & $+3,605$ & $+12.2 \%$ \\
\hline Hilton Head Island & 18,699 & $91 \%$ & 20,131 & $98 \%$ & $+1,432$ & $+7.7 \%$ \\
\hline Mount Pleasant & 12,306 & $39 \%$ & 21,534 & $68 \%$ & $+9,228$ & $+75.0 \%$ \\
\hline North Charleston & 5,855 & $16 \%$ & 7,988 & $22 \%$ & $+2,133$ & $+36.4 \%$ \\
\hline North Myrtle Beach & 5,548 & $36 \%$ & 5,808 & $38 \%$ & +260 & $+4.7 \%$ \\
\hline James Island & 4,279 & $82 \%$ & 5,072 & $97 \%$ & +793 & $+18.5 \%$ \\
\hline Columbia & 3,927 & $10 \%$ & 4,123 & $10 \%$ & +196 & $+5.0 \%$ \\
\hline Isle of Palms & 3,783 & $96 \%$ & 3,835 & $97 \%$ & +52 & $+1.4 \%$ \\
\hline Myrtle Beach & 3,764 & $25 \%$ & 4,240 & $28 \%$ & +476 & $+12.6 \%$ \\
\hline Kiawah Island & 3,428 & $95 \%$ & 3,437 & $96 \%$ & +9 & $+0.3 \%$
\end{tabular}

\section{Greatest relative growing risk*}

\begin{tabular}{lrrrrrr} 
Municipality & \multicolumn{2}{c}{2020} & \multicolumn{2}{c}{2050} & \multicolumn{2}{c}{ Change } \\
Bluftton & 2,703 & $20 \%$ & 7,600 & $57 \%$ & $+4,897$ & $+181 \%$ \\
\hline Beaufort & 2,064 & $34 \%$ & 4,970 & $81 \%$ & $+2,906$ & $+141 \%$ \\
\hline Burton & 1,035 & $35 \%$ & 2,074 & $71 \%$ & $+1,039$ & $+100 \%$ \\
\hline Mount Pleasant & 12,306 & $39 \%$ & 21,534 & $68 \%$ & $+9,228$ & $+75 \%$ \\
\hline Georgetown & 2,222 & $39 \%$ & 3,732 & $65 \%$ & $+1,510$ & $+68 \%$ \\
\hline Port Royal & 1,927 & $54 \%$ & 2,770 & $77 \%$ & +843 & $+44 \%$ \\
\hline Hollywood & 858 & $24 \%$ & 1,214 & $34 \%$ & +356 & $+42 \%$ \\
\hline Hanahan & 444 & $7 \%$ & 608 & $10 \%$ & +164 & $+37 \%$ \\
\hline North Charleston & 5,855 & $16 \%$ & 7,988 & $22 \%$ & +2133 & $+36 \%$ \\
\hline Murrells Inlet & 376 & $8 \%$ & 478 & $10 \%$ & +102 & $+27 \%$
\end{tabular}

\section{Flood Factor distribution of properties at risk ${ }^{\star}(1000 s)$}

\section{Risk level}

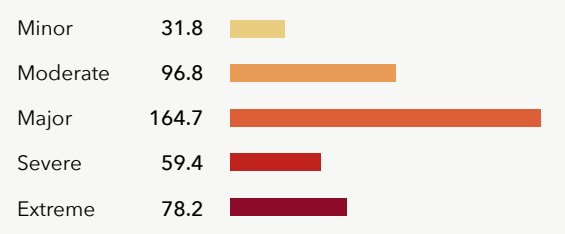

Extreme

More than $16.8 \%$ of individual properties and properties in South Carolina are at any risk of flooding over the next 30 years. Out of those at risk $70 \%$ are at major to extreme risk.

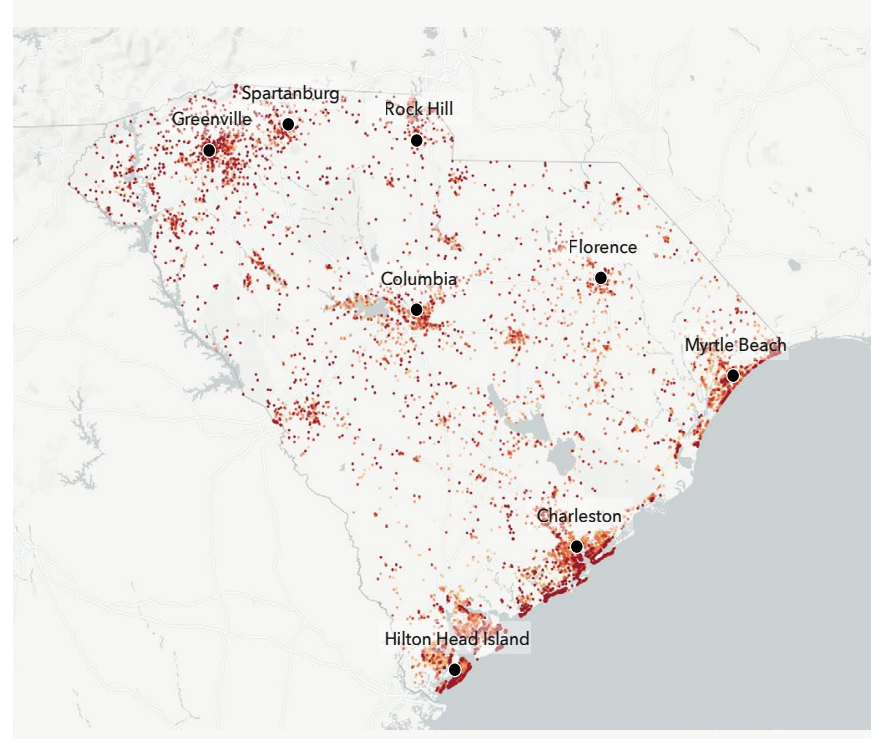


Flood History \& Protection

\section{South Carolina}

\section{Claims History}

294,100 home and property owners in South Carolina have made flood damage claims through FEMA since the year 2000. * These claims for reimbursement were made through either the National Flood Insurance Program (NFIP) or Individual Assistance Program (IAP). The greatest number of claims since the year 2000 have been concentrated in Charleston, Horry, Richland, Williamsburg, and Florence counties.

\section{4,700}

Properties served by

protection measures

The First Street Foundation Flood

Model incorporates 47 flood control

measures throughout the state which

protect 14,700 properties.
Top protection measures in state by quantity

Type
Example

\# Properties served by type

Channel

6,639

- Church Creek Basin Drainage Network and Easements, Charleston

Beach nourishment

2,916

Hilton Head Island Beach Renourishment Pt 4, Hilton Head Island

Sewer upgrade

1,841

Retention pond

1,330

Hillside Drive Retention Basins, North Myrtle Beach

Culvert

Byrnes Down Drainage Improvement Project, Charleston

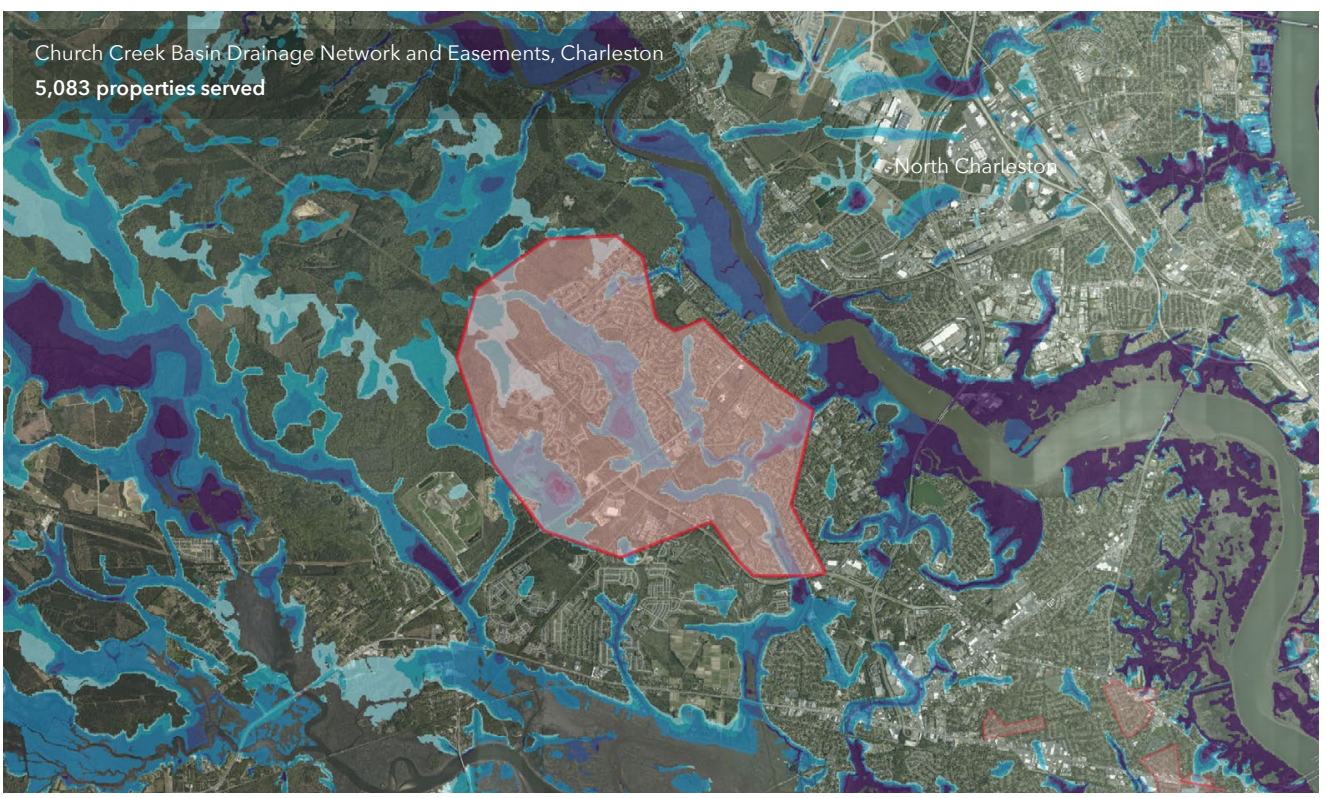

$\square$ Area of protection 


\section{State Overview \\ South Dakota}

Flood risk is increasing in some areas in the state of South Dakota while decreasing in others. Over the next 30 years approximately 63,000 properties have a substantial risk* of flooding.

To understand personal flood risk, Americans leverage the Federal Emergency Management Agency (FEMA) Flood Insurance Rate Maps (FIRM). These maps identify 24,900 properties as having substantial risk in the state of South Dakota. In comparison, the First Street Foundation Flood Model identifies 2.5 times the number of properties as facing this same level of risk. This discrepancy exists because the Foundation uses the current climate data, maps precipitation as a stand-alone risk, and includes areas that FEMA has not mapped. These new methods uncover an additional 37,600 properties currently not identified by FEMA as having substantial risk.
Total properties at substantial risk*

In 2020

\section{2,600}

30-year change

$\Delta+400(+0.6 \%)$

Many areas throughout South Dakota are vulnerable to flooding due to its many big waterways, including the Big Sioux, Missouri, and Rapid Creek rivers. Many bigger cities along these river systems, including Sioux Falls,

Pierre and Rapid City, are regularly impacted by flooding.

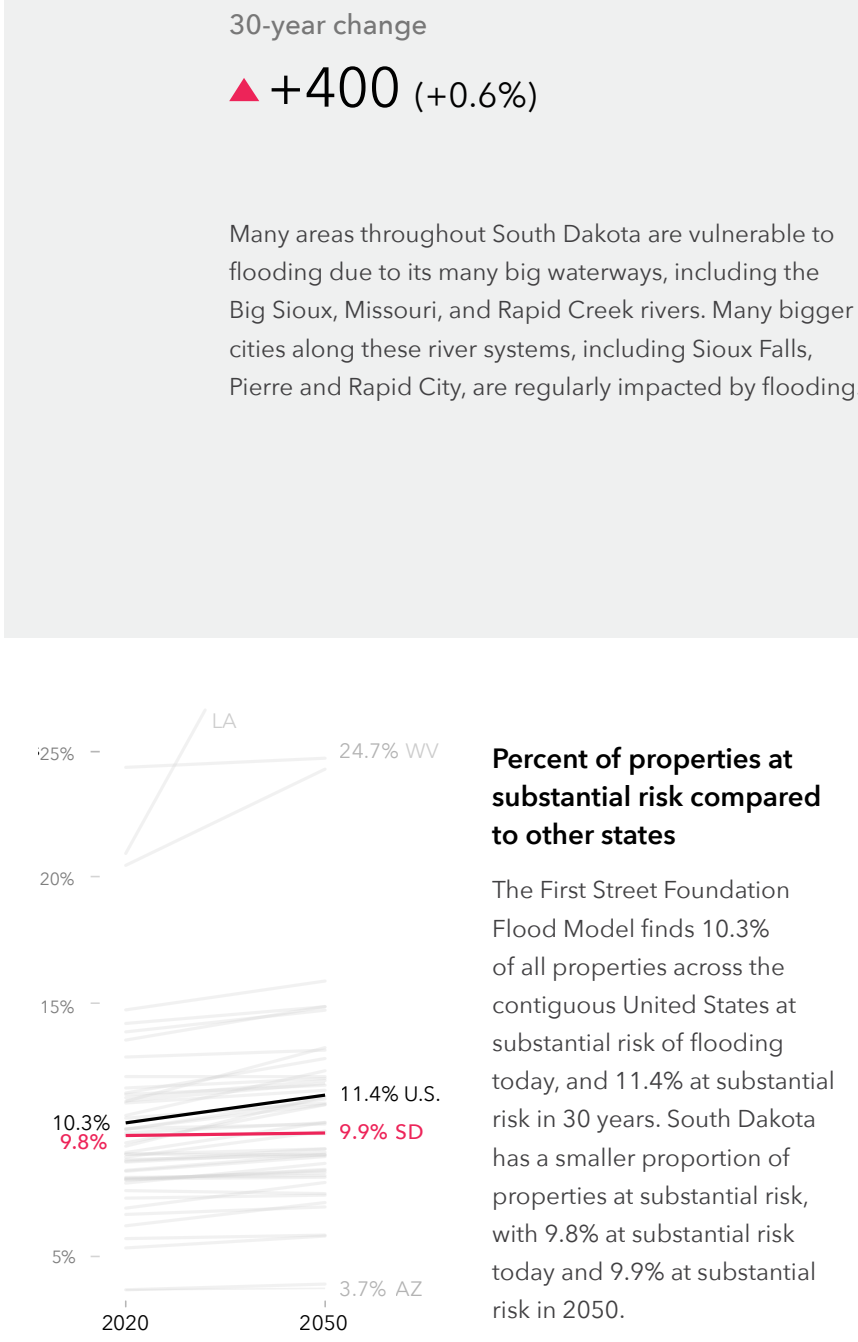

Difference in number of properties currently at substantial risk compared to FEMA**

$$
\Delta+37,600
$$
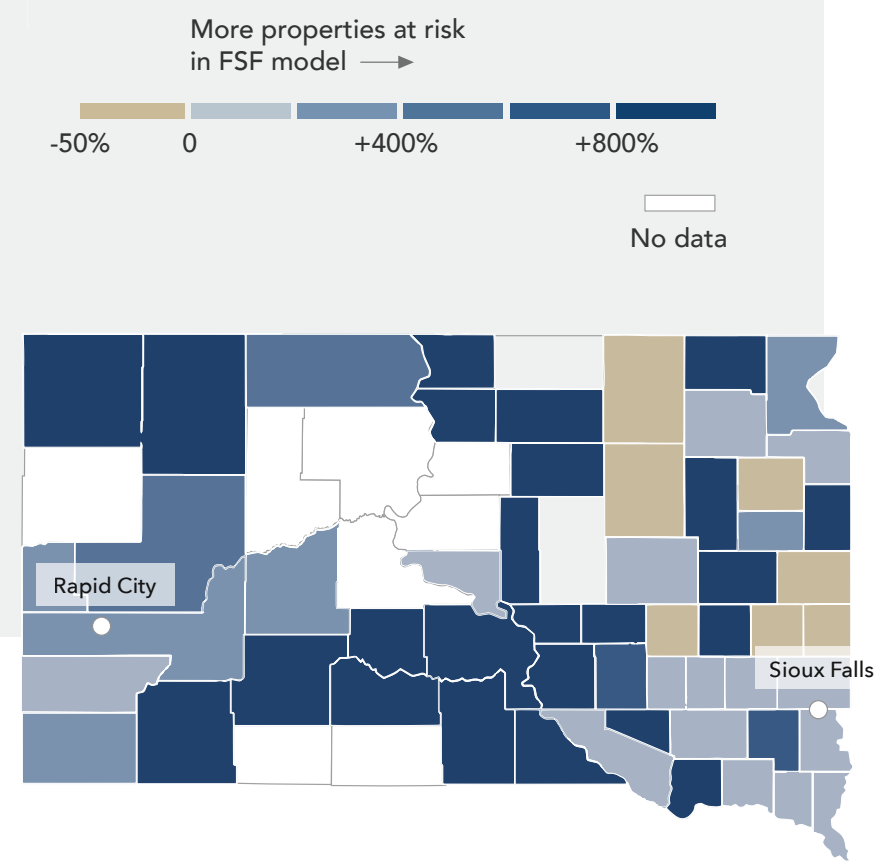


\section{Local details}

\section{South Dakota}

The First Street Foundation Flood Model calculates the number of properties facing any risk* of flooding. When looking at this broader level of risk, the data identifies 83,400 properties in South Dakota as at risk over the next 30 years. Of these properties, 17,700 were categorized as facing almost certain risk, with a $99 \%$ chance of flooding at least once over the next 30 years.

The city of Rapid City has the greatest number of properties at risk of flooding in the state with 4,600 currently at risk, or $18 \%$ of its total number of properties. However, smaller cities or municipalities in the state, with fewer properties, may have a greater proportion of their total properties at risk. For example, $40 \%$ of properties in Sturgis are at risk of flooding. Other municipalities will see the greatest increase in risk over the next 30 years. Aberdeen, for example, will see a $4 \%$

increase in the number of properties at risk.

Click here for a full breakdown of counties, cities, zip codes, and congressional districts in South Dakota at risk.

\section{Greatest proportion of properties at risk*}

\begin{tabular}{lrr|} 
Municipality & \multicolumn{2}{c}{2020} \\
\hline Sturgis & 1,267 & $40 \%$ \\
\hline Hot Springs & 517 & $22 \%$ \\
\hline Spearfish & 1,093 & $22 \%$ \\
\hline Box Elder & 479 & $20 \%$ \\
\hline Rapid City & 4,594 & $18 \%$ \\
\hline Rapid Valley & 560 & $17 \%$ \\
\hline Madison & 453 & $16 \%$ \\
\hline Pierre & 823 & $15 \%$ \\
\hline Watertown & 1,221 & $13 \%$ \\
\hline Aberdeen & 1,048 & $10 \%$ \\
\hline
\end{tabular}

\begin{tabular}{rrrrr}
\multicolumn{2}{c}{2050} & \multicolumn{2}{c}{ Change } \\
\hline 1,273 & $40 \%$ & +6 & $+0.5 \%$ \\
\hline 522 & $22 \%$ & +5 & $+1.0 \%$ \\
\hline 1,124 & $22 \%$ & +31 & $+2.8 \%$ \\
\hline 487 & $20 \%$ & & +8 & $+1.7 \%$ \\
\hline 4,642 & $18 \%$ & +48 & $+1.0 \%$ \\
\hline 569 & $18 \%$ & & +9 & $+1.6 \%$ \\
\hline 456 & $16 \%$ & & +3 & $+0.7 \%$ \\
\hline 843 & $16 \%$ & +20 & $+2.4 \%$ \\
\hline 1,231 & $13 \%$ & +10 & $+0.8 \%$ \\
\hline 1,092 & $11 \%$ & +44 & $+4.2 \%$
\end{tabular}

\section{Greatest number of properties at risk*}

\begin{tabular}{l|c|ccccc} 
Municipality & \multicolumn{2}{c}{2020} & \multicolumn{2}{c}{2050} & \multicolumn{2}{c}{ Change } \\
\cline { 2 - 4 } Rapid City & 4,594 & $18 \%$ & 4,642 & $18 \%$ & +48 & $+1.0 \%$ \\
\hline Sioux Falls & 3,150 & $5 \%$ & 3,164 & $5 \%$ & +14 & $+0.4 \%$ \\
\hline Sturgis & 1,267 & $40 \%$ & 1,273 & $40 \%$ & +6 & $+0.5 \%$ \\
\hline Watertown & 1,221 & $13 \%$ & 1,231 & $13 \%$ & +10 & $+0.8 \%$ \\
\hline Spearfish & 1,093 & $22 \%$ & 1,124 & $22 \%$ & +31 & $+2.8 \%$ \\
\hline Aberdeen & 1,048 & $10 \%$ & 1,092 & $11 \%$ & +44 & $+4.2 \%$ \\
\hline Pierre & 823 & $15 \%$ & 843 & $16 \%$ & +20 & $+2.4 \%$ \\
\hline Mitchell & 562 & $8 \%$ & 562 & $8 \%$ & +0 & $+0.0 \%$ \\
\hline Rapid Valley & 560 & $17 \%$ & 569 & $18 \%$ & +9 & $+1.6 \%$ \\
\hline Huron & 528 & $8 \%$ & 528 & $8 \%$ & +0 & $+0.0 \%$
\end{tabular}

Greatest relative growing risk $^{*}$

\begin{tabular}{lrlrlll} 
Municipality & \multicolumn{2}{c}{2020} & \multicolumn{2}{c}{2050} & \multicolumn{2}{c}{ Change } \\
Aberdeen & 1,048 & $10 \%$ & 1,092 & $11 \%$ & +44 & $+4 \%$ \\
\hline Spearfish & 1,093 & $22 \%$ & 1,124 & $22 \%$ & +31 & $+3 \%$ \\
\hline Pierre & 823 & $15 \%$ & 843 & $16 \%$ & +20 & $+2 \%$ \\
\hline Brookings & 294 & $4 \%$ & 300 & $5 \%$ & +6 & $+2 \%$ \\
\hline Box Elder & 479 & $20 \%$ & 487 & $20 \%$ & +8 & $+2 \%$ \\
\hline Rapid Valley & 560 & $17 \%$ & 569 & $18 \%$ & +9 & $+2 \%$ \\
\hline Hot Springs & 517 & $22 \%$ & 522 & $22 \%$ & +5 & $+1 \%$ \\
\hline Rapid City & 4,594 & $18 \%$ & 4,642 & $18 \%$ & +48 & $+1 \%$ \\
\hline Yankton & 428 & $7 \%$ & 432 & $7 \%$ & +4 & $+1 \%$ \\
\hline Watertown & 1,221 & $13 \%$ & 1,231 & $13 \%$ & +10 & $+1 \%$
\end{tabular}

\section{Flood Factor distribution of properties at risk ${ }^{\star}(1000 s)$}

\section{Risk level}

Minor

Moderate

Major

Severe

Extreme

0.8

20.8

15.9

15.9
21.1

More than $13.1 \%$ of individual properties and properties in South Dakota are at any risk of flooding over the next 30 years. Out of

those at risk $74 \%$ are at major to extreme risk.

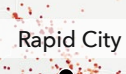




\section{Flood History \& Protection}

\section{South Dakota}

\section{Claims History}

13,100 home and property owners in South Dakota have made flood damage claims through FEMA since the year 2000.* These claims for reimbursement were made through either the National Flood Insurance Program (NFIP) or Individual Assistance Program (IAP). The greatest number of claims since the year 2000 have been concentrated in Brown, Union, Spink, Day, and Lyman counties.

\section{Storm Simulation}

Storm Simulation: The First Street Foundation Flood Model has recreated 3 flooding events that have occurred since the year 2000 in the state of South Dakota. These events flooded around 1,080 properties across the state.**

$$
\begin{array}{rr}
\text { Flood event Daterarties } \\
\text { affected }
\end{array}
$$

River flood in Northern SD

Jun 2011

River flood near Sioux City, SD Jun 2014 449

- River flood near Yankton, SD Mar 2019 627

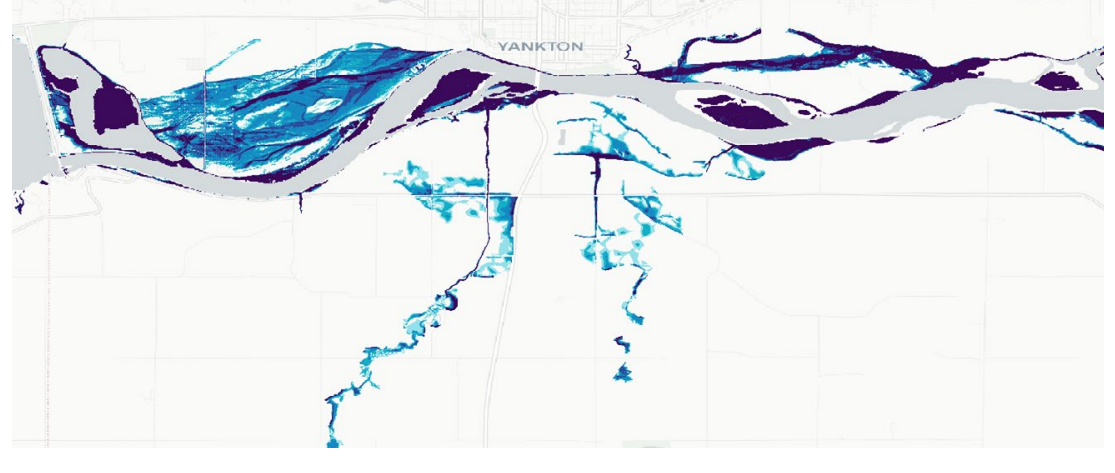

\section{7,400}

Properties served by

protection measures

The First Street Foundation Flood

Model incorporates 111 flood control

measures throughout the state which

protect 17,400 properties.
Top protection measures in state by quantity

Type
Example

Dam

Gavins Point Dam, Yankton

Levee

Moccasin Creek RB, Aberdee

Culvert

- Mt Vernon Ditch, Mount Verno

Detention basin

Browns Valley MN floodway channel, Becker Township

Elevated road

Browns Valley Elevated Bridge, Becker Township

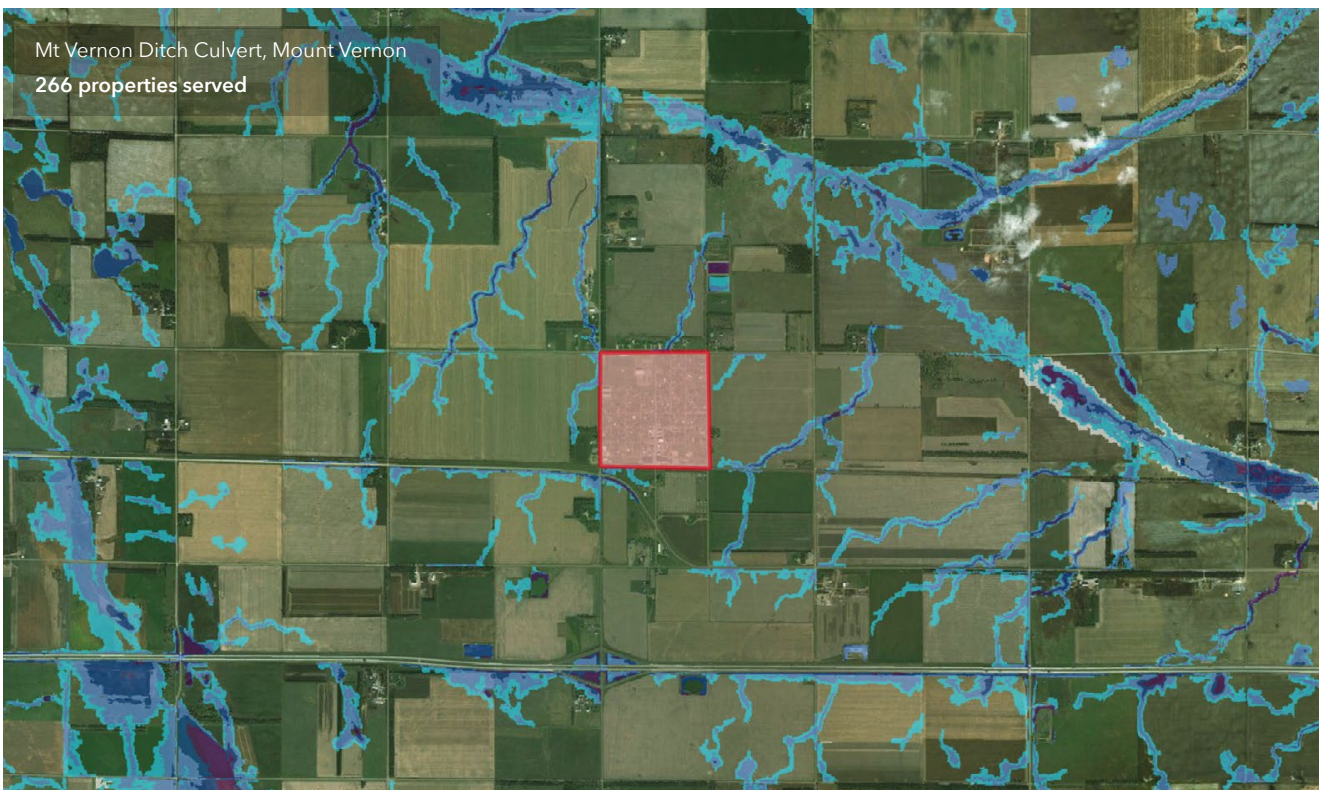

$\square$ Area of protectio 


\section{State Overview Tennessee}

Flood risk is increasing in the state of Tennessee. 383,200 properties currently have a substantial risk* $^{*}$ of flooding. Over the next 30 years, the number of properties with this risk will increase by another $3.2 \%$, bringing the total number of properties with substantial risk to 395,600

To understand personal flood risk, Americans leverage the Federal Emergency Management Agency (FEMA) Flood Insurance Rate Maps (FIRM). These maps identify 101,400 properties as having substantial risk in the state of Tennessee. In comparison, the First Street Foundation Flood Model identifies 3.8 times the number of properties as facing this same level of risk. This discrepancy exists because the Foundation uses the current climate data, maps precipitation as a stand-alone risk, and includes areas that FEMA has not mapped. These new methods uncover an additional 281,800 properties currently not identified by FEMA as having substantial risk.

When adjusting for future environmental changes, the FEMA gap further widens to 294,300 by the year 2050.
Total properties at substantial risk *

\section{In 2020}

383,200

30-year change

$\Delta+12,400$

$(+3 \%)$

Riverine flooding has been the major flood threat facing Tennessee for well over a century, so much so that the famous Tennessee Valley Authority was created in 1933 to manage the flow of water along the Tennessee Valley watershed. An intricate system of dams protects valuable farmland and large population centers like Chattanooga from the 100 year flood events, but an increase in

dramatic rain events still poses risk for the state.
Difference in number of properties currently at substantial risk compared to FEMA ${ }^{\star \star}$

$\Delta+281,800$

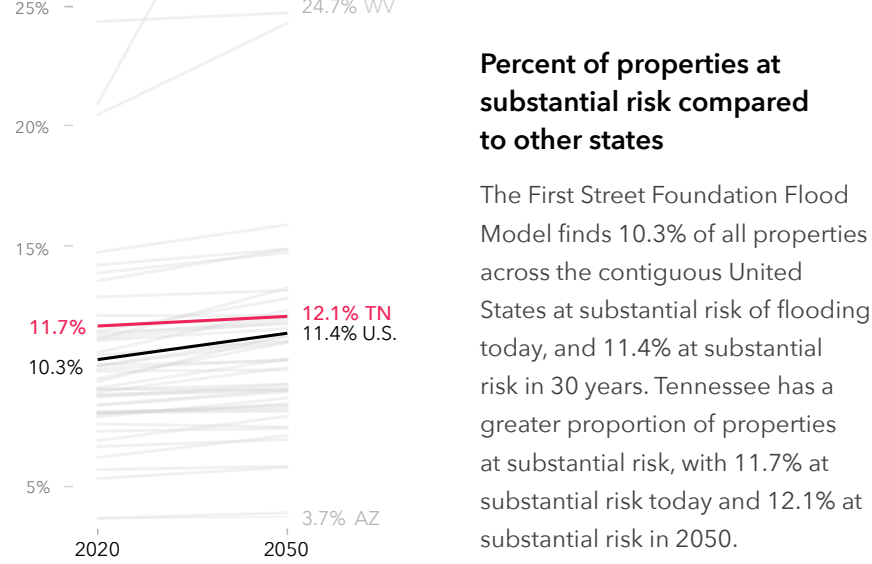

More properties at risk in FSF model $\longrightarrow$
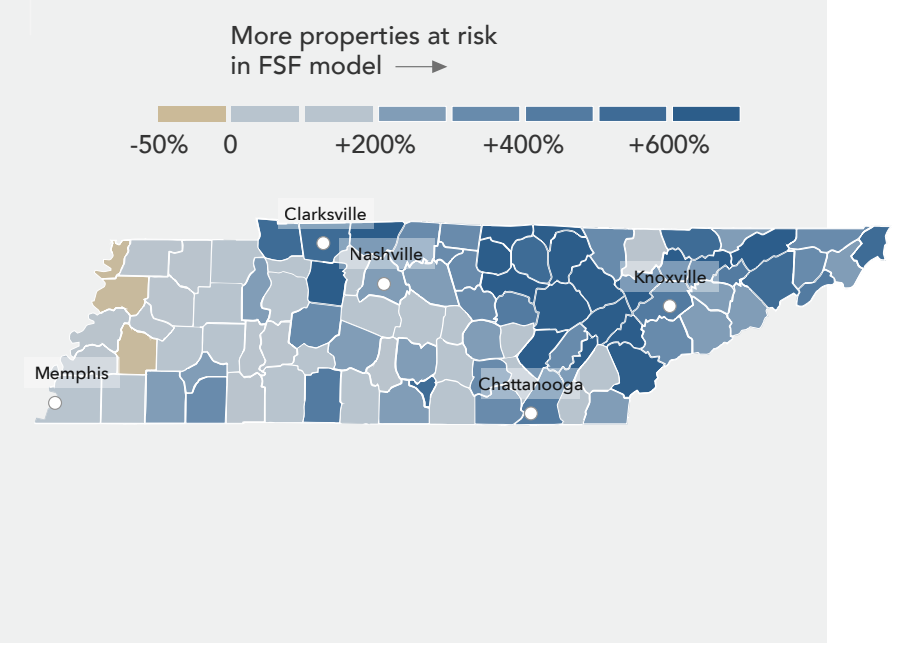


\section{Local details}

Tennessee

The First Street Foundation Flood Model calculates the number of properties facing any risk* of flooding. When looking at this broader level of risk, the data identifies 495,300 properties in Tennessee as at risk over the next 30 years. Of these properties, 135,500 were categorized as facing almost certain risk, with a $99 \%$ chance of flooding at least once over the next 30 years.

The Nashville-Davidson metropolitan area has the greatest number of properties at risk of flooding in the state with 33,200 currently at risk, or $13 \%$ of its total number of properties. However, smaller cities or municipalities in the state, with fewer properties, may have a greater proportion of their total properties at risk. For example, $42 \%$ of properties in Chattanooga are at risk of flooding. Other municipalities will see the greatest increase in risk over the next 30 years. Lakewood Park, for example, will see a $17 \%$ increase in the number of properties at risk.

Click here for a full breakdown of counties, cities, zip codes, and congressional districts in Tennessee at risk.

\section{Greatest proportion of properties at risk*}

\begin{tabular}{lrr} 
Municipality & \multicolumn{2}{c}{2020} \\
\hline Chattanooga & 31,575 & $42 \%$ \\
\hline Kingston & 1,252 & $41 \%$ \\
\hline Louisville & 1,032 & $40 \%$ \\
\hline Dayton & 1,257 & $39 \%$ \\
\hline Erwin & 1,073 & $39 \%$ \\
\hline Middle Valley & 1,905 & $38 \%$ \\
\hline East Ridge & 2,928 & $35 \%$ \\
\hline Lenoir City & 1,662 & $34 \%$ \\
\hline Pigeon Forge & 1,114 & $32 \%$ \\
\hline Soddy-Daisy & 1,890 & $31 \%$ \\
\hline
\end{tabular}

\section{Greatest number of properties at risk*}

\begin{tabular}{lcccccc} 
Municipality & \multicolumn{2}{c}{2020} & \multicolumn{2}{c}{2050} & \multicolumn{2}{c}{ Change } \\
\cline { 2 - 5 } Nashville-Davidson & 33,153 & $13 \%$ & 33,813 & $14 \%$ & +660 & $+2.0 \%$ \\
\hline Memphis & 32,455 & $14 \%$ & 35,837 & $15 \%$ & $+3,382$ & $+10.4 \%$ \\
\hline Chattanooga & 31,575 & $42 \%$ & 31,868 & $42 \%$ & +293 & $+0.9 \%$ \\
\hline Knoxville & 10,565 & $14 \%$ & 10,763 & $14 \%$ & +198 & $+1.9 \%$ \\
\hline Clarksville & 5,548 & $10 \%$ & 5,827 & $11 \%$ & +279 & $+5.0 \%$ \\
\hline Murfreesboro & 3,833 & $10 \%$ & 4,057 & $11 \%$ & +224 & $+5.8 \%$ \\
\hline Kingsport & 3,483 & $14 \%$ & 3,576 & $15 \%$ & +93 & $+2.7 \%$ \\
\hline Hendersonville & 3,313 & $16 \%$ & 3,351 & $17 \%$ & +38 & $+1.1 \%$ \\
\hline East Ridge & 2,928 & $35 \%$ & 2,982 & $35 \%$ & +54 & $+1.8 \%$ \\
\hline Johnson City & 2,731 & $11 \%$ & 2,876 & $12 \%$ & +145 & $+5.3 \%$
\end{tabular}

\section{Greatest relative growing risk*}

\begin{tabular}{lrrrrrr} 
Municipality & \multicolumn{2}{c}{2020} & \multicolumn{2}{c}{2050} & \multicolumn{2}{c}{ Change } \\
\hline Lakewood Park & 201 & $6 \%$ & 235 & $7 \%$ & $+1,085$ & $+17 \%$ \\
\hline Memphis & 32,455 & $14 \%$ & 35,837 & $15 \%$ & $+1,389$ & $+10 \%$ \\
\hline Jefferson City & 350 & $11 \%$ & 384 & $12 \%$ & $+1,093$ & $+10 \%$ \\
\hline Millington & 400 & $10 \%$ & 436 & $11 \%$ & +664 & $+9 \%$ \\
\hline Lakeland & 266 & $5 \%$ & 287 & $6 \%$ & $+1,141$ & $+8 \%$ \\
\hline Collierville & 642 & $4 \%$ & 691 & $4 \%$ & +21 & $+8 \%$ \\
\hline Bartlett & 1,078 & $5 \%$ & 1,149 & $5 \%$ & +307 & $+7 \%$ \\
\hline Oak Ridge & 1,528 & $11 \%$ & 1,621 & $12 \%$ & +257 & $+6 \%$ \\
\hline Germantown & 1,200 & $8 \%$ & 1,272 & $8 \%$ & +130 & $+6 \%$ \\
\hline Manchester & 468 & $9 \%$ & 496 & $10 \%$ & +26 & $+6 \%$
\end{tabular}

\section{Flood Factor distribution of properties at risk* $(1000 \mathrm{~s})$}

\section{Risk level}

Minor $\quad 14.3$

Moderate 83.8

Major $\quad 141.1$

Severe $\quad 81.5$

Extreme $\quad 174.6$

More than $15.1 \%$ of individual properties and properties in

Tennessee are at any risk of flooding over the next 30 years. Out of those at risk $80 \%$ are at major to extreme risk.

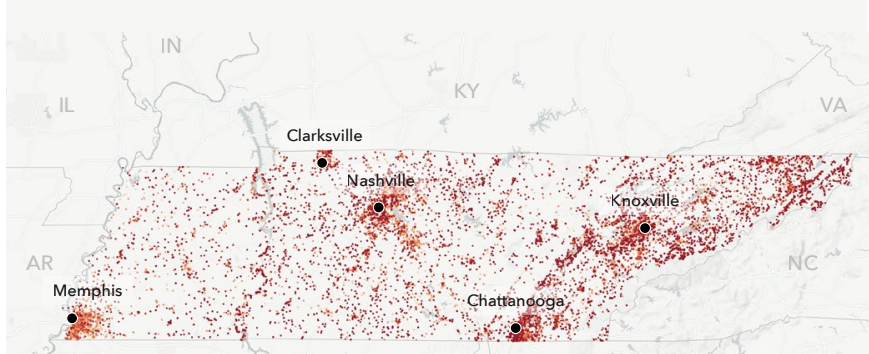


Flood History \& Protection

Tennessee

\section{Claims History}

157,100 home and property owners in Tennessee have made flood damage claims through FEMA since the year 2000. ${ }^{\star}$ These claims for reimbursement were made through either the National Flood Insurance Program (NFIP) or Individual Assistance Program (IAP). The greatest number of claims since the year 2000 have been concentrated in Davidson, Shelby, Williamson, Hamilton, and Sumner counties.

\section{0,000}

\section{Properties served by}

protection measures

The First Street Foundation Flood

Model incorporates 41 flood control

measures throughout the state which

protect 20,000 properties.
Top protection measures in state by quantity

Type
Example

Levee

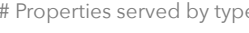

- Mem

Dam

TVA D

Detention basin

Founders and Kings Parks, Johnson City

Culvert

Jonesborough Culvert Project, Jonesborough

Pervious pavement

Johnson Street pervious pavement project, Chattanooga

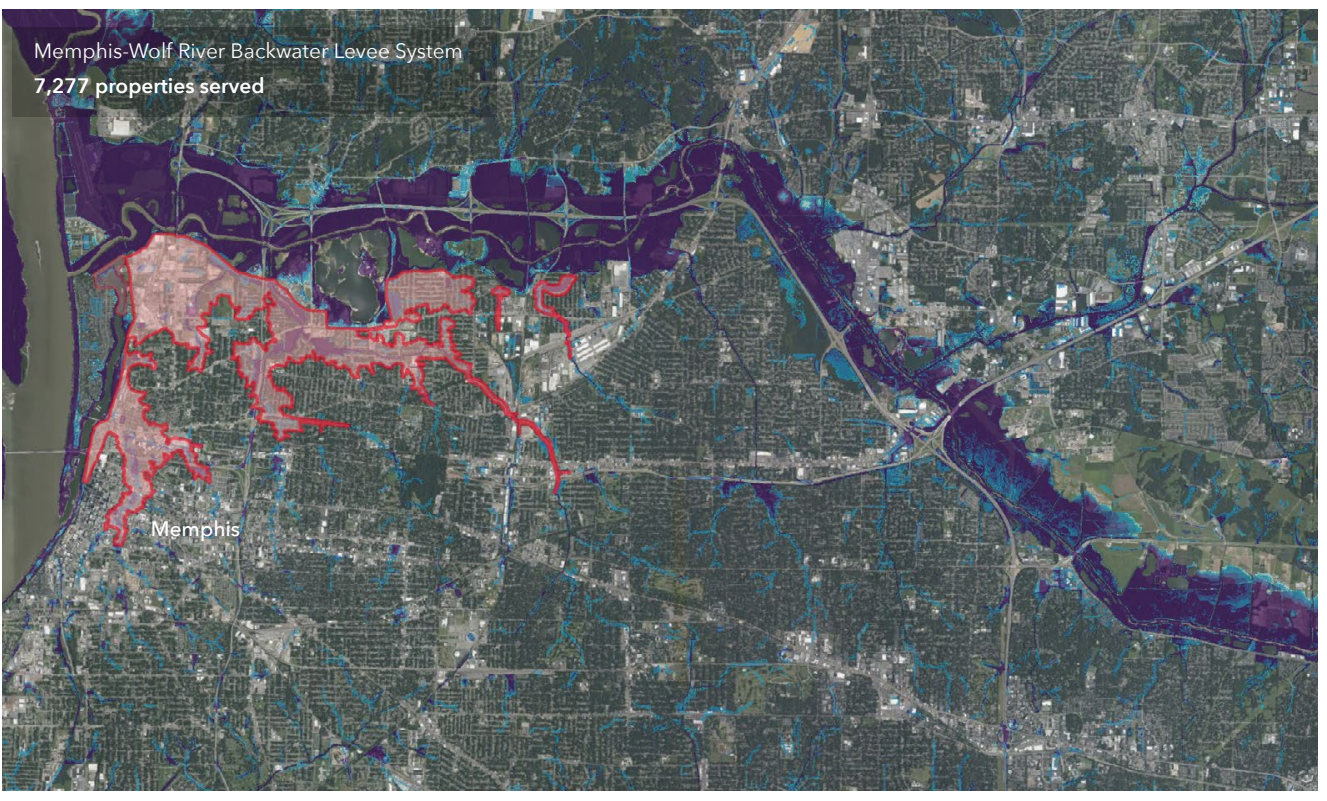

$\square$ Area of protection 


\section{State Overview Texas}

Flood risk is increasing in the state of Texas. $1,150,900$ properties currently have a substantial risk* of flooding. Over the next 30 years, the number of properties with this risk will increase by another $15.9 \%$, bringing the total number of properties with substantial risk to $1,333,700$

To understand personal flood risk, Americans leverage the Federal Emergency Management Agency (FEMA) Flood Insurance Rate Maps (FIRM) These maps identify 860,000 properties as having substantial risk in the state of Texas. In comparison, the First Street Foundation Flood Model identifies 1.3 times the number of properties as facing this same level of risk. This discrepancy exists because the Foundation uses the current climate data, maps precipitation as a stand-alone risk, and includes areas that FEMA has not mapped. These new methods uncover an additional 290,900 properties currently not identified by FEMA as having substantial risk. When adjusting for future environmental changes, the FEMA gap further widens to 473,700 by the year 2050 .
Total properties at substantial risk*

In 2020

\section{$1.15 \mathrm{M}$}

30-year change

$\Delta+182,800$ $\ln 2050$

$1.33 \mathrm{M}$

$+860,000$

More properties at risk in FSF model $\longrightarrow$
Difference in number of properties currently at substantial risk compared to FEMA**

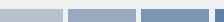

The Gulf of Mexico makes Southeast Texas vulnerable to tropical storms, and urbanization exacerbates the risk of runoff. To mitigate, networks of drainage channels move and store flood water. In western Texas, El Paso faces a monsoon season with heavy rains that flood waterways and the Rio Grande. Urban infrastructure increases runoff and limits natural infiltration. Flood storage projects can reduce flash flood risks from heavy rainfall.

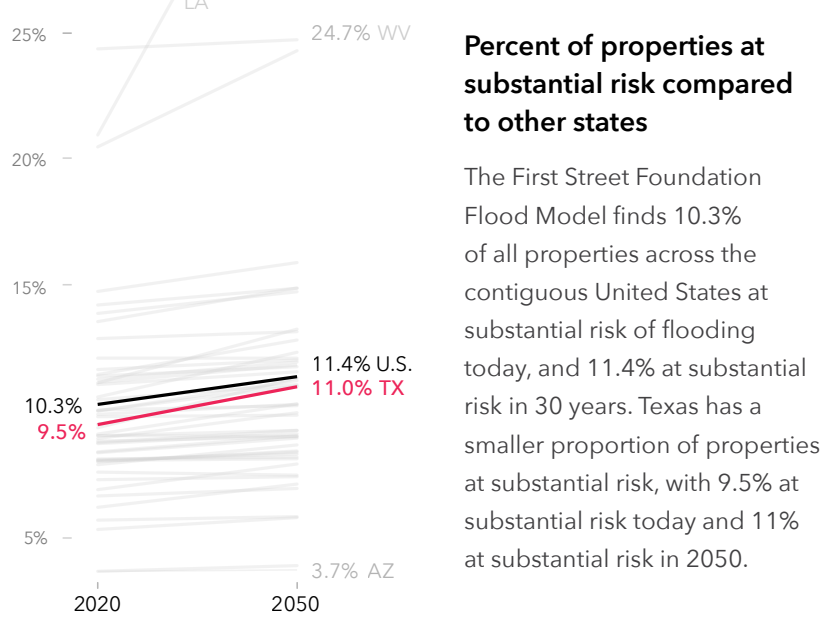

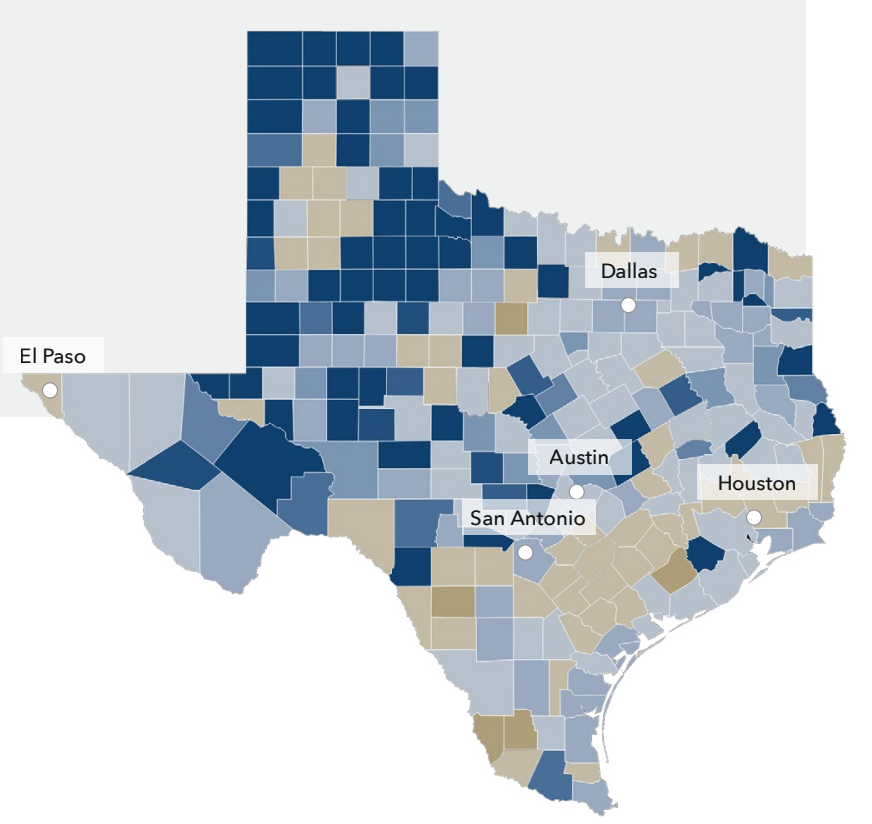




\section{Local details}

Texas

The First Street Foundation Flood Model calculates the number of properties facing any risk* of flooding. When looking at this broader level of risk, the data identifies 2,116,800 properties in Texas as at risk over the next 30 years. Of these properties, 218,700 were categorized as facing almost certain risk, with a $99 \%$ chance of flooding at least once over the next 30 years.

The city of Houston has the greatest number of properties at risk of flooding in the state with 186,500 currently at risk, or $32 \%$ of its total number of properties. However, smaller cities or municipalities in the state, with fewer properties, may have a greater proportion of their total properties at risk. For example, $100 \%$ of properties in Groves are at risk of flooding. Other municipalities will see the greatest increase in risk over the next 30 years. Ingleside, for example, will see a 194\% increase in the number of properties at risk.

Click here for a full breakdown of counties, cities, zip codes, and congressional districts in Texas at risk.

\section{Greatest proportion of properties at risk*}

\begin{tabular}{lrl} 
Municipality & \multicolumn{2}{c}{2020} \\
\hline Groves & 7,074 & $100 \%$ \\
\hline Dickinson & 7,553 & $99 \%$ \\
\hline Bacliff & 4,019 & $99 \%$ \\
\hline Palacios & 2,092 & $99 \%$ \\
\hline Bridge City & 4,017 & $99 \%$ \\
\hline Holiday Beach & 2,683 & $98 \%$ \\
\hline San Leon & 4,667 & $98 \%$ \\
\hline Port O'Connor & 2,682 & $97 \%$ \\
\hline Galveston & 26,651 & $97 \%$ \\
\hline Clute & 3,832 & $96 \%$ \\
\hline
\end{tabular}

\section{Greatest number of properties at risk*}

\begin{tabular}{lcccccc} 
Municipality & \multicolumn{2}{c}{2020} & \multicolumn{2}{c}{2050} & \multicolumn{2}{c}{ Change } \\
\cline { 2 - 4 } & 186,481 & $32 \%$ & 202,317 & $34 \%$ & $+15,836$ & $+8.5 \%$ \\
\hline Corpus Christi & 36,952 & $34 \%$ & 47,248 & $43 \%$ & $+10,296$ & $+27.9 \%$ \\
\hline San Antonio & 30,587 & $7 \%$ & 31,777 & $8 \%$ & $+1,190$ & $+3.9 \%$ \\
\hline Port Arthur & 27,723 & $96 \%$ & 27,731 & $96 \%$ & +8 & $+0.0 \%$ \\
\hline League City & 27,419 & $70 \%$ & 31,858 & $82 \%$ & $+4,439$ & $+16.2 \%$ \\
\hline Galveston & 26,651 & $97 \%$ & 26,662 & $97 \%$ & +11 & $+0.0 \%$ \\
\hline El Paso & 24,306 & $12 \%$ & 24,105 & $12 \%$ & -201 & $-0.8 \%$ \\
\hline Sugar Land & 22,044 & $66 \%$ & 22,309 & $66 \%$ & +265 & $+1.2 \%$ \\
\hline Dallas & 21,687 & $7 \%$ & 22,045 & $7 \%$ & +358 & $+1.7 \%$ \\
\hline Fort Worth & 20,648 & $8 \%$ & 21,132 & $8 \%$ & +484 & $+2.3 \%$
\end{tabular}

\section{Greatest relative growing risk*}

\begin{tabular}{lrrrrrr} 
Municipality & \multicolumn{2}{c}{2020} & \multicolumn{2}{c}{2050} & \multicolumn{2}{c}{ Change } \\
\hline Ingleside & 629 & $17 \%$ & 1,852 & $49 \%$ & $+1,223$ & $+194 \%$ \\
\hline Channelview & 2,583 & $20 \%$ & 4,847 & $38 \%$ & $+2,264$ & $+88 \%$ \\
\hline Baytown & 11,220 & $44 \%$ & 18,724 & $74 \%$ & $+7,504$ & $+67 \%$ \\
\hline La Porte & 8,793 & $63 \%$ & 13,261 & $95 \%$ & $+4,468$ & $+51 \%$ \\
\hline Vidor & 1,172 & $22 \%$ & 1,767 & $33 \%$ & +595 & $+51 \%$ \\
\hline Deer Park & 2,016 & $18 \%$ & 2,907 & $26 \%$ & +891 & $+44 \%$ \\
\hline Port Lavaca & 3,430 & $70 \%$ & 4,819 & $99 \%$ & $+1,389$ & $+41 \%$ \\
\hline Friendswood & 6,805 & $46 \%$ & 9,328 & $64 \%$ & $+2,523$ & $+37 \%$ \\
\hline Nederland & 5,639 & $74 \%$ & 7,445 & $98 \%$ & $+1,806$ & $+32 \%$ \\
\hline Corpus Christi & 36,952 & $34 \%$ & 47,248 & $43 \%$ & $+10,296$ & $+28 \%$ \\
\hline
\end{tabular}

\section{Flood Factor distribution of properties at risk ${ }^{\star}(1000 s)$}

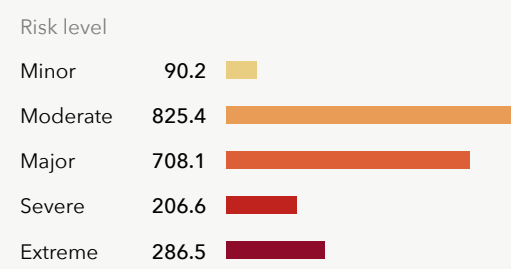

More than $17.5 \%$ of individual properties and properties in Texas are at any risk of flooding over the next 30 years. Out of those at risk $57 \%$ are at major to extreme risk.

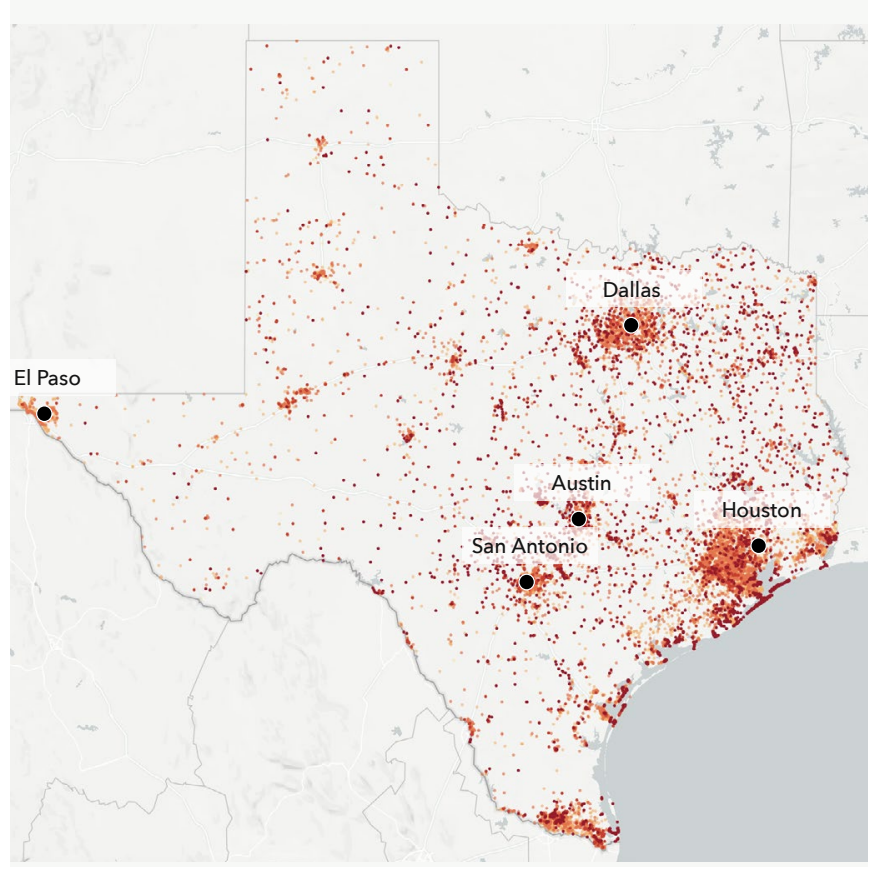




\section{Flood History \& Protection}

\section{Texas}

\section{Claims History}

2,900,700 home and property owners in Texas have made flood damage claims through FEMA Flood Insurance Program (NFIP) or Individual Assistance Program (IAP). The greatest number of

claims since the year 2000 have been concentrated in Harris, Jefferson, Galveston, Fort Bend, and Brazoria counties

\section{Storm Simulation}

The First Street Foundation Flood Model has recreated 4 flooding events that have occurred since the year 2000 in the state of Texas. These events flooded around 107,920 properties across the state. ${ }^{\star \star}$
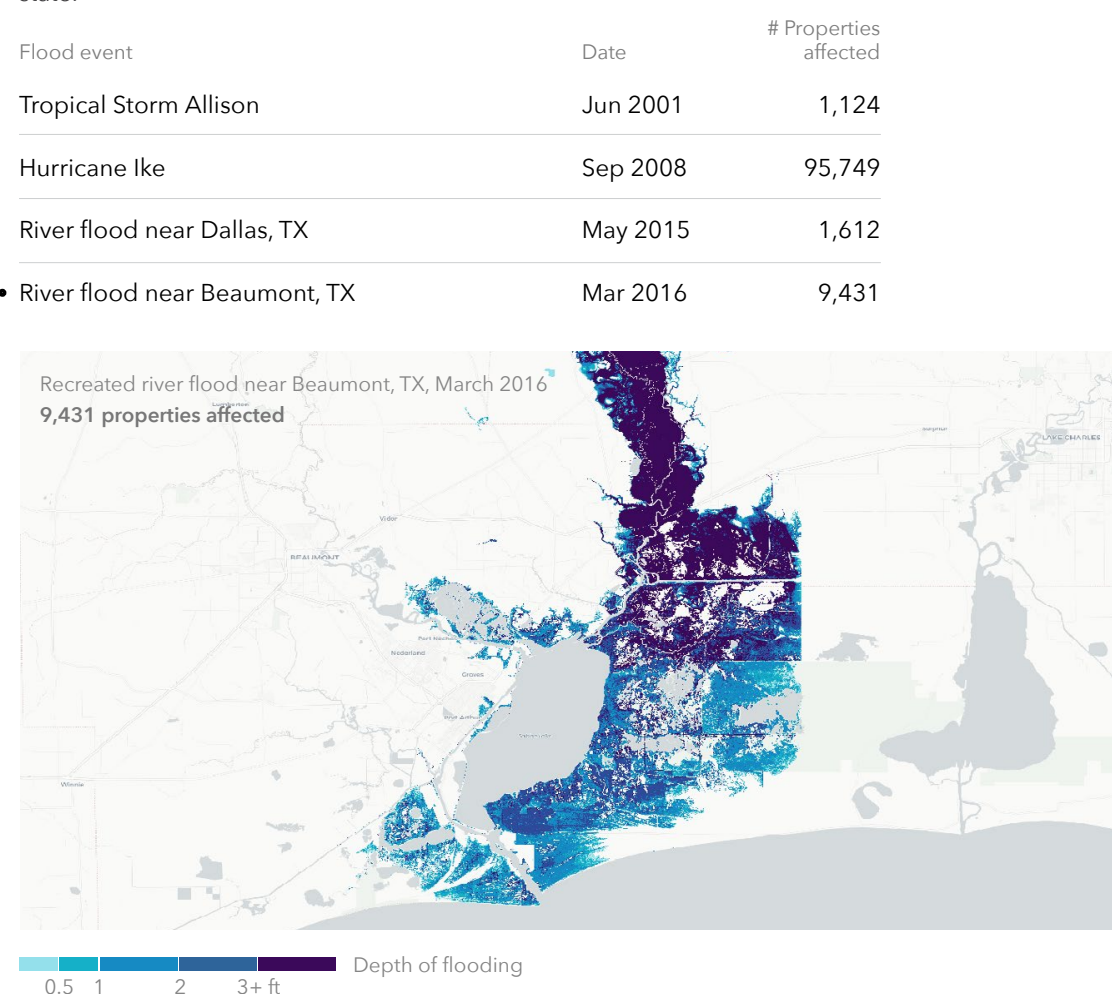
since the year 2000.* These claims for reimbursement were made through either the National

\section{5,000}

Properties served by

protection measures

The First Street Foundation Flood

Model incorporates 492 flood control

measures throughout the state which

protect 555,000 properties

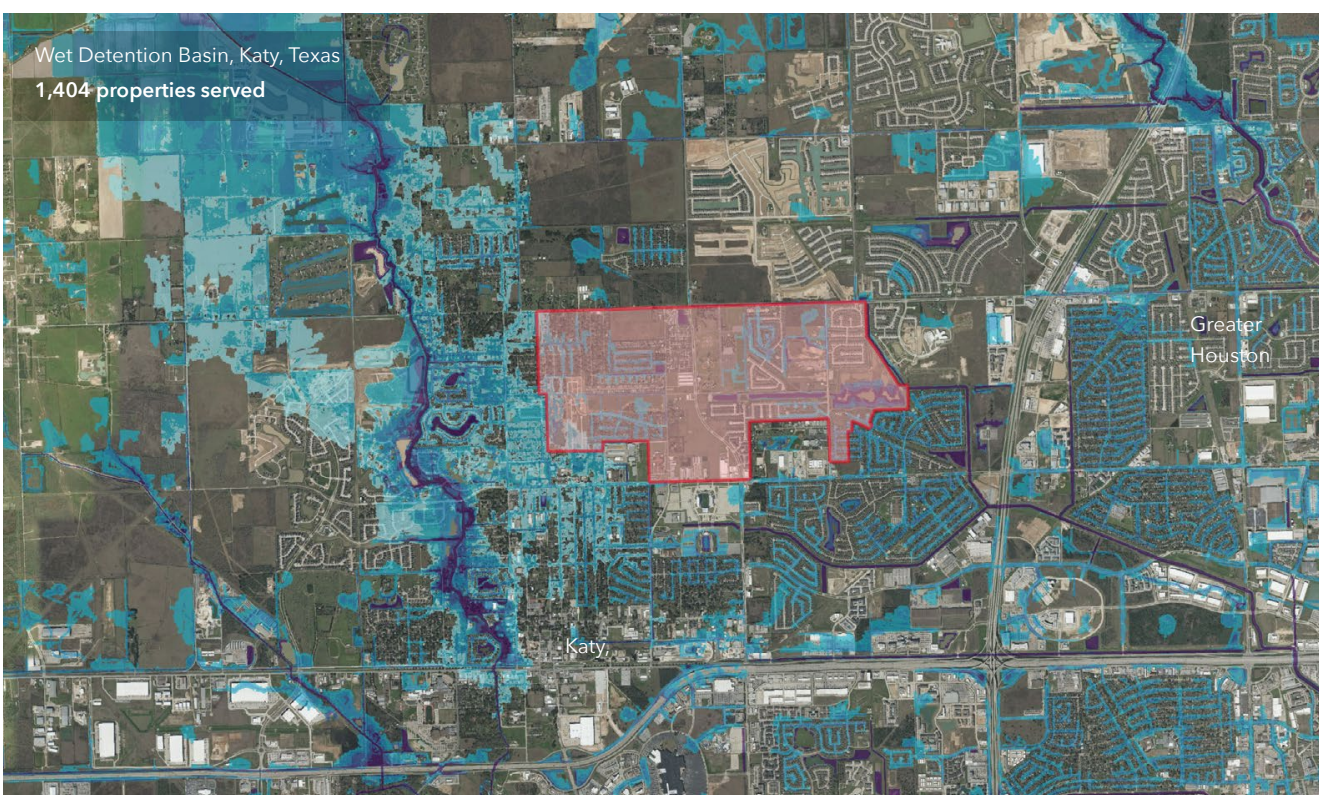

$\square$ Area of protection

Top protection measures in state by quantity

Type
Example

Levee

\# Properties served by type

Valley Authority Canal Levee, Bearnont

Seawall

Galveston Seawall 2, Galvesto

Buyout 


\section{State Overview Utah}

Flood risk is increasing in the state of Utah. 113,100 properties currently have a substantial risk $^{\star}$ of flooding. Over the next 30 years, the number of properties with this risk will increase by another $6.9 \%$, bringing the total number of properties with substantial risk to 120,900

To understand personal flood risk, Americans leverage the Federal Emergency Management Agency (FEMA) Flood Insurance Rate Maps (FIRM). These maps identify 21,800 properties as having substantial risk in the state of Utah. In comparison, the First Street Foundation Flood Model identifies 5.2 times the number of properties as facing this same level of risk. This discrepancy exists because the Foundation uses the current climate data, maps precipitation as a stand-alone risk, and includes areas that FEMA has not mapped. These new methods uncover an additional 91,300 properties currently not identified by FEMA as having substantial risk. When adjusting for future environmental changes, the FEMA gap further widens to 99,100 by the year 2050 .
In 2020

\section{3,100}

30-year change

$\Delta+7,800(+7 \%)$
Total properties at substantial risk ${ }^{*}$

Difference in number of properties currently at substantial risk compared to FEMA**

\section{$\Delta+91,300$}

More properties at risk in FSF model $\longrightarrow$

0 $+200 \%$ $+400 \%$ $+600 \%$

Salt Lake Valley floods when snowmelt and storms raise Utah Lake, flooding the Jordan River. USACE and Salt Lake County regulate development in the floodplain, while projects like the Surplus Canal divert runof upstream. The City of St. George in Washington County manages the floodplain through land-use regulations and dredging to mitigate flash floods from summer storms that overflow the Virgin and Santa Clara rivers.
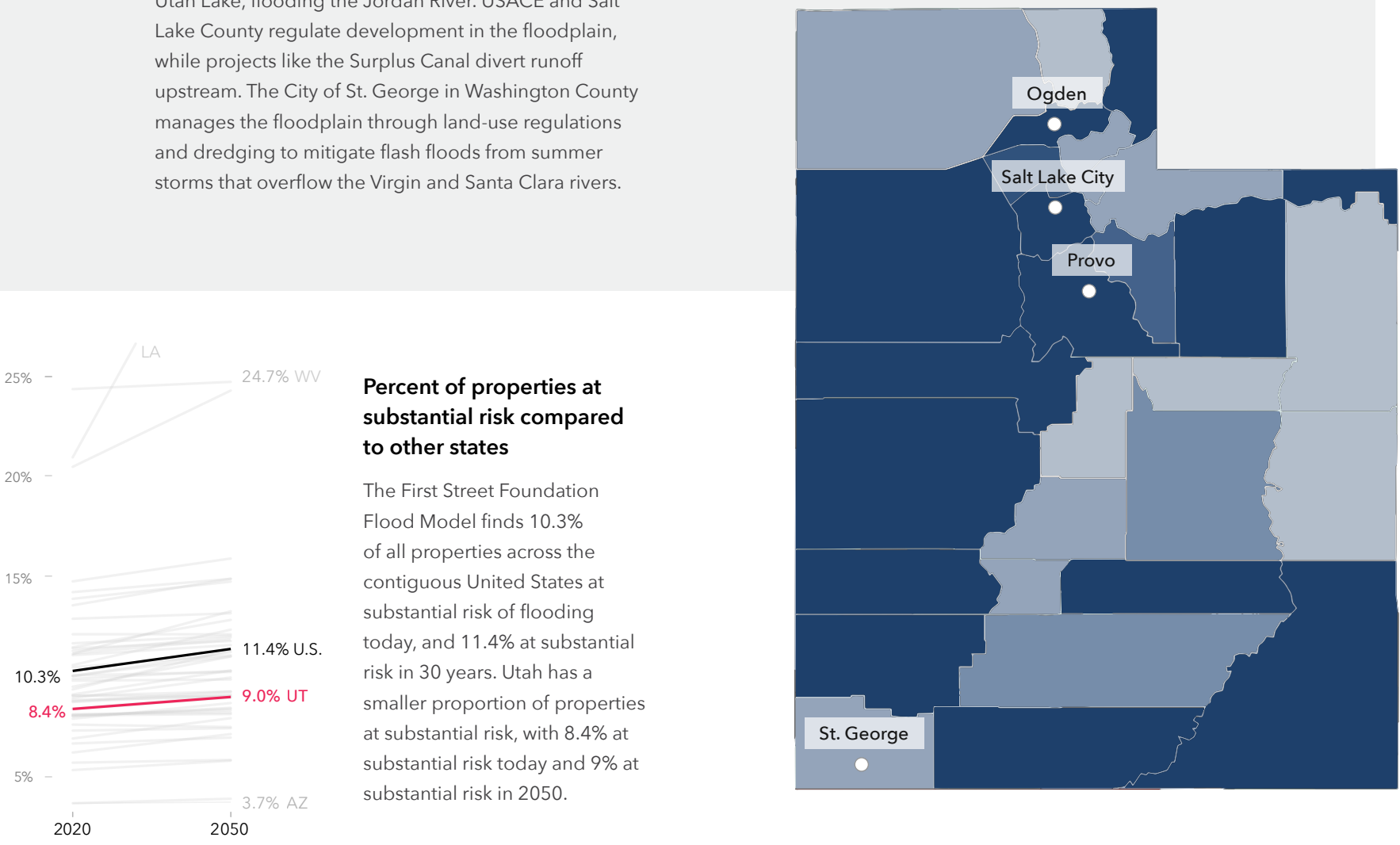


\section{Local details \\ Utah}

The First Street Foundation Flood Model calculates the number of properties facing any risk* of flooding. When looking at this broader level of risk, the data identifies 210,800 properties in Utah as at risk over the next 30 years. Of these properties, 6,600 were categorized as facing almost certain risk, with a $99 \%$ chance of flooding at least once over the next 30 years.

The city of Salt Lake City has the greatest number of properties at risk of flooding in the state with 15,600 currently at risk, or $23 \%$ of its total number of properties. However, smaller cities or municipalities in the state, with fewer properties, may have a greater proportion of their total properties at risk. For example, $51 \%$ of properties in Parowan are at risk of flooding. Other municipalities will see the greatest increase in risk over the next 30 years. Clearfield, for example, will see a $318 \%$ increase in the number of properties at risk.

Click here for a full breakdown of counties, cities, zip codes, and congressional districts in Utah at risk.

\section{Greatest proportion of properties at risk*}

\begin{tabular}{lrr|} 
Municipality & \multicolumn{2}{c}{2020} \\
\hline Parowan & 1,139 & $51 \%$ \\
\hline Harrisville & 1,164 & $44 \%$ \\
\hline Stansbury Park & 1,215 & $39 \%$ \\
\hline West Bountiful & 794 & $36 \%$ \\
\hline Springville & 4,150 & $36 \%$ \\
\hline North Ogden & 2,704 & $35 \%$ \\
\hline Lindon & 1,536 & $35 \%$ \\
\hline Heber & 2,127 & $35 \%$ \\
\hline South Salt Lake & 2,931 & $35 \%$ \\
\hline Centerville & 1,988 & $34 \%$ \\
\hline
\end{tabular}

\section{Greatest number of properties at risk*}

\begin{tabular}{l|c|ccccc} 
Municipality & \multicolumn{2}{c}{2020} & \multicolumn{2}{c}{2050} & \multicolumn{2}{c}{ Change } \\
\cline { 2 - 4 } Salt Lake City & 15,584 & $23 \%$ & 16,167 & $24 \%$ & +583 & $+3.7 \%$ \\
\hline Ogden & 8,243 & $27 \%$ & 8,568 & $28 \%$ & +325 & $+3.9 \%$ \\
\hline Millcreek & 4,583 & $22 \%$ & 5,002 & $24 \%$ & +419 & $+9.1 \%$ \\
\hline West Jordan & 4,496 & $14 \%$ & 4,758 & $15 \%$ & +262 & $+5.8 \%$ \\
\hline Springville & 4,150 & $36 \%$ & 4,251 & $37 \%$ & +101 & $+2.4 \%$ \\
\hline Provo & 4,032 & $15 \%$ & 4,217 & $16 \%$ & +185 & $+4.6 \%$ \\
\hline West Valley City & 3,496 & $10 \%$ & 3,913 & $11 \%$ & +417 & $+11.9 \%$ \\
\hline Riverton & 3,342 & $25 \%$ & 3,420 & $25 \%$ & +78 & $+2.3 \%$ \\
\hline Murray & 3,267 & $18 \%$ & 3,440 & $19 \%$ & +173 & $+5.3 \%$ \\
\hline Bountiful & 3,204 & $22 \%$ & 3,461 & $24 \%$ & +257 & $+8.0 \%$
\end{tabular}

\section{Greatest relative growing risk*}

\begin{tabular}{lrlrlrl} 
Municipality & \multicolumn{2}{c}{2020} & \multicolumn{2}{c}{2050} & \multicolumn{2}{c}{ Change } \\
\hline Clearfield & 11 & $0 \%$ & 46 & $1 \%$ & +35 & $+318 \%$ \\
\hline Clinton & 150 & $2 \%$ & 195 & $3 \%$ & +45 & $+30 \%$ \\
\hline Midvale & 414 & $4 \%$ & 527 & $6 \%$ & +113 & $+27 \%$ \\
\hline Washington Terrace & 31 & $1 \%$ & 38 & $1 \%$ & +7 & $+23 \%$ \\
\hline Vineyard & 56 & $2 \%$ & 67 & $2 \%$ & +11 & $+20 \%$ \\
\hline Woods Cross & 729 & $18 \%$ & 846 & $21 \%$ & +117 & $+16 \%$ \\
\hline Plain City & 139 & $4 \%$ & 161 & $5 \%$ & +22 & $+16 \%$ \\
\hline Layton & 2,001 & $8 \%$ & 2,316 & $10 \%$ & +315 & $+16 \%$ \\
\hline Nibley & 79 & $3 \%$ & 91 & $4 \%$ & +12 & $+15 \%$ \\
\hline Roosevelt & 100 & $3 \%$ & 115 & $4 \%$ & +15 & $+15 \%$
\end{tabular}

\section{Flood Factor distribution of properties at risk ${ }^{\star}(1000 s)$}

\section{Risk level}

Minor

Moderate

Major

7.3
80.5

Severe

33.5

Extreme

More than $15.3 \%$ of individual properties and properties in Utah are at any risk of flooding over the next 30 years. Out of those at risk $56 \%$ are at major to extreme risk.

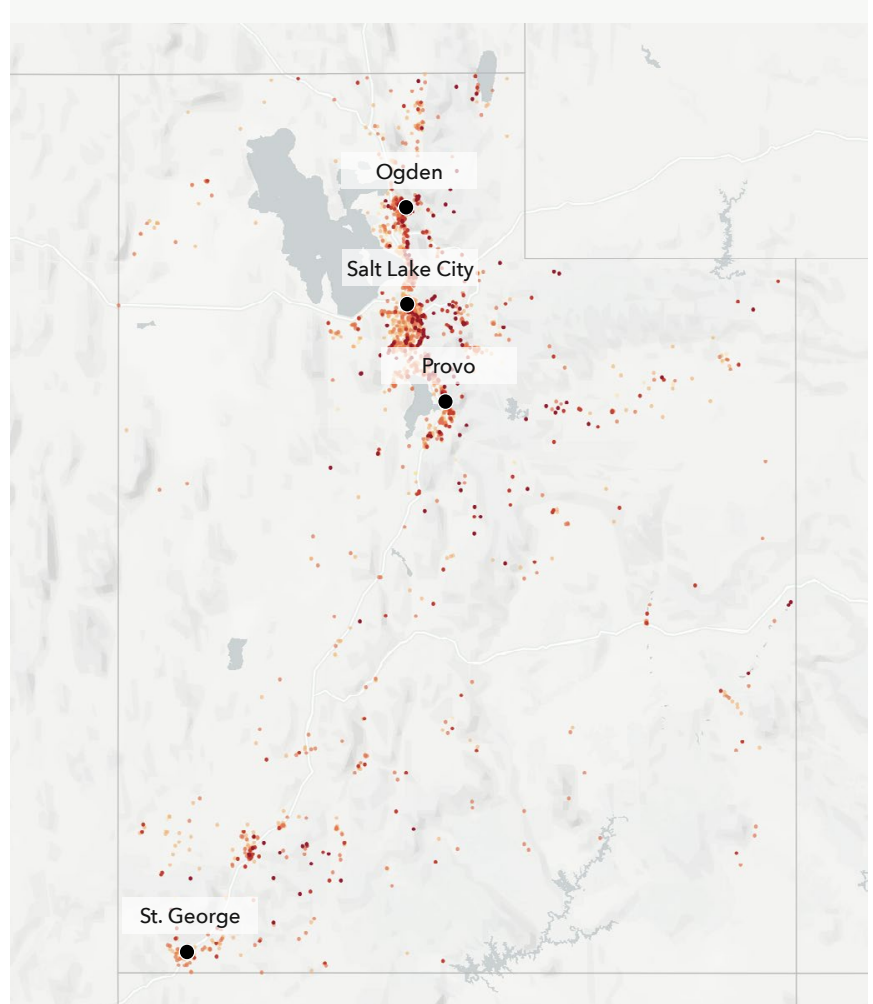




\section{Flood History \& Protection}

\section{Utah}

\section{Claims History}

300 home and property owners in Utah have made flood damage claims through FEMA since the year 2000.* These claims for reimbursement were made through either the National Flood Insurance Program (NFIP) or Individual Assistance Program (IAP). The greatest number of claims since the year 2000 have been concentrated in Salt Lake, Davis, Washington, Utah, and Weber counties.

\section{Storm Simulation}

The First Street Foundation Flood Model has recreated 1 flooding event that has occurred since the year 2000 in the state of Utah. This event flooded around 40 properties across the state. ${ }^{*}$

\section{Recreated river flood in Southern UT, Jan 2005}

39 properties affected in Utah
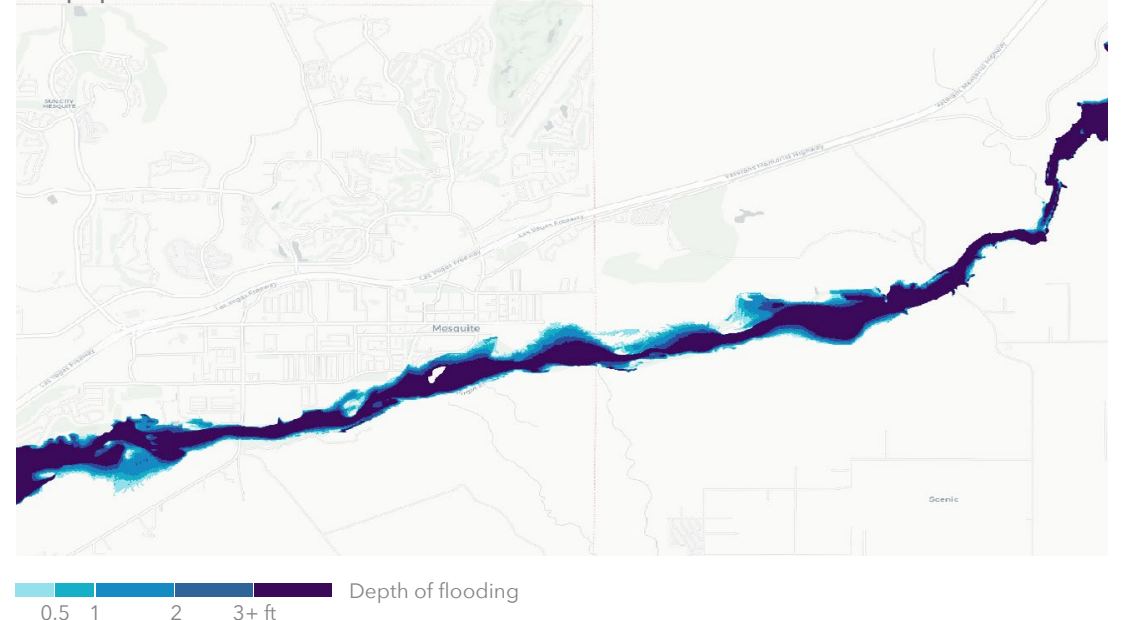

\section{4,600}

Properties served by

protection measures

The First Street Foundation Flood

Model incorporates 38 flood contro

measures throughout the state which

protect 14,600 properties.
Top protection measures in state by quantity

Type
Example

\# Properties served by type

Levee

Surplus Canal East Bank, Salt Lake City

- Dry Creek Restoration Project, Sand

Dam

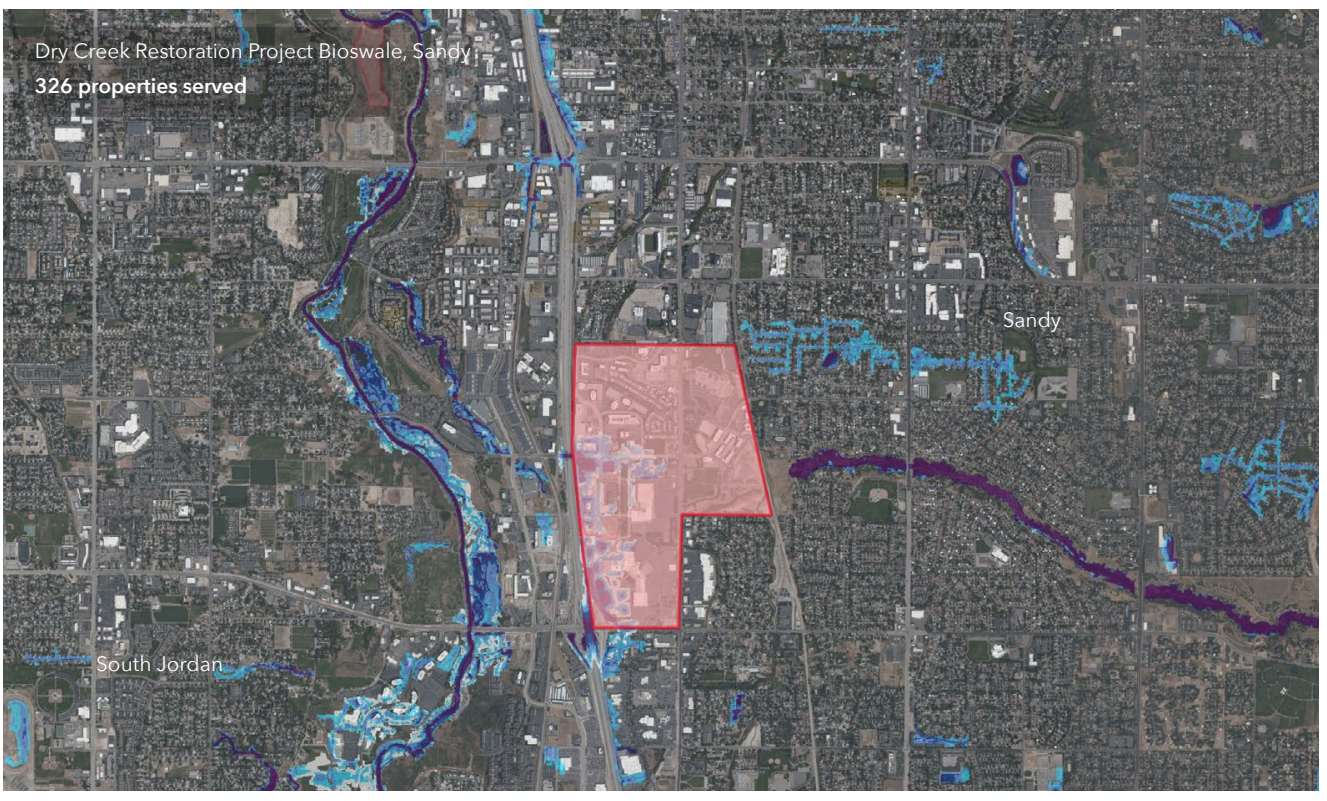

$\square$ Area of protection 


\section{State Overview Vermont}

Total properties at substantial risk *

\section{9,700}

30-year change

$\Delta+900(+2 \%)$
Difference in number of properties currently at substantial risk compared to FEMA**

$$
\Delta+26,700
$$

More properties at ris

in FSF model $\longrightarrow$
Flood risk is increasing in the state of Vermont. 39,700 properties currently have a substantial risk* of flooding. Over the next 30 years, the number of properties with this risk will increase by another $2.1 \%$, bringing the total number of properties with substantial risk to 40,600 .

To understand personal flood risk, Americans leverage the Federal Emergency Management Agency (FEMA) Flood Insurance Rate Maps (FIRM). These maps identify 13,000 properties as having substantial risk in the state of Vermont. In comparison, the First Street Foundation Flood Model identifies 3.1 times the number of properties as facing this same level of risk. This discrepancy exists because the Foundation uses the current climate data, maps precipitation as a stand-alone risk, and includes areas that FEMA has not mapped. These new methods uncover an additional 26,700 properties currently not identified by FEMA as having substantial risk. When adjusting for future environmental changes, the FEMA gap further widens to 27,600 by the year 2050
Percent of properties at substantial risk compared to other states

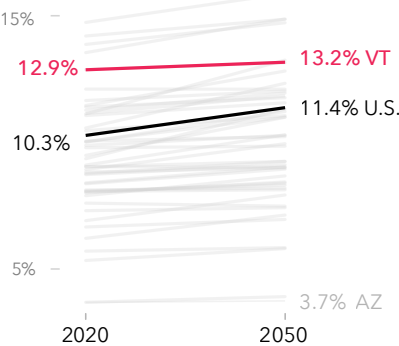
2050
The First Street Foundation Flood Model finds $10.3 \%$ of all properties across the contiguous United States at substantial risk of flooding today, and $11.4 \%$ at substantial risk in 30 years. Vermont has a greater proportion of properties at substantial risk, with $12.9 \%$ at substantial risk today and $13.2 \%$ at substantial risk in 2050.

\section{While landlocked, Vermont faces flood risk from} Champlain towns face flood risk from rain and snowmelt Stormwater ponds and storage tanks reduce the risk of rainfall flooding. Common sources of flooding in the southern region include spring ice jams and snowmelt.

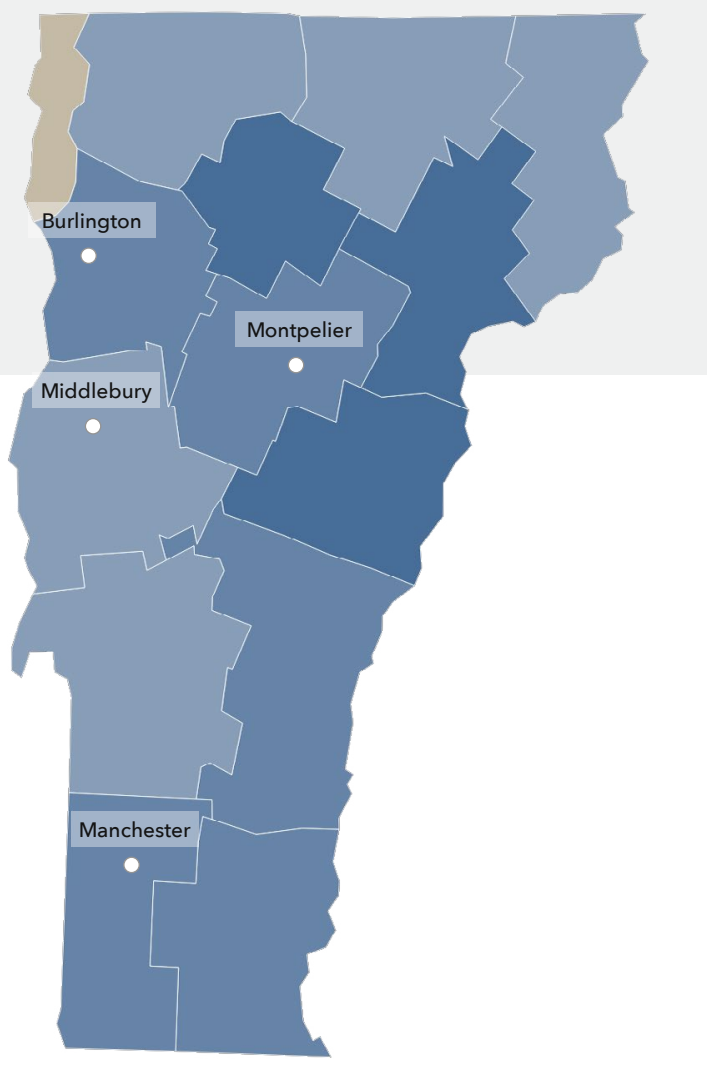




\section{Local details \\ Vermont}

The First Street Foundation Flood Model calculates the number of properties facing any risk* of flooding. When looking at this broader level of risk, the data identifies 52,300 properties in Vermont as at risk over the next 30 years. Of these properties, 20,200 were categorized as facing almost certain risk, with a $99 \%$ chance of flooding at least once over the next 30 years.

The city of Bennington has the greatest number of properties at risk of flooding in the state with 1,300 currently at risk, or $43 \%$ of its total number of properties. However, smaller cities or municipalities in the state, with fewer properties, may have a greater proportion of their total properties at risk. For example, $43 \%$ of properties in Bennington are at risk of flooding. Other municipalities will see the greatest

increase in risk over the next 30 years. Rutland, for example, will see a

$6 \%$ increase in the number of properties at risk.

Click here for a full breakdown of counties, cities, zip codes, and congressional districts in Vermont at risk.

\section{Greatest proportion of properties at risk*}

\begin{tabular}{lr|r|} 
Municipality & \multicolumn{2}{c}{2020} \\
\hline Bennington & 1,292 & $43 \%$ \\
\hline Montpelier & 1,045 & $35 \%$ \\
\hline Barre & 1,052 & $33 \%$ \\
\hline St. Johnsbury & 442 & $20 \%$ \\
\hline Brattleboro & 362 & $15 \%$ \\
\hline Rutland & 768 & $13 \%$ \\
\hline St. Albans & 251 & $11 \%$ \\
\hline Burlington & 460 & $5 \%$ \\
\hline Essex Junction & 130 & $5 \%$ \\
\hline South Burlington & 285 & $4 \%$ \\
\hline
\end{tabular}

\section{Greatest number of properties at risk*}

\begin{tabular}{l|c|ccccc} 
Municipality & \multicolumn{2}{c}{2020} & \multicolumn{2}{c}{2050} & \multicolumn{2}{c}{ Change } \\
\cline { 2 - 4 } Bennington & 1,292 & $43 \%$ & 1,306 & $44 \%$ & +14 & $+1.1 \%$ \\
\hline Barre & 1,052 & $33 \%$ & 1,060 & $33 \%$ & +8 & $+0.8 \%$ \\
\hline Montpelier & 1,045 & $35 \%$ & 1,058 & $35 \%$ & +13 & $+1.2 \%$ \\
\hline Rutland & 768 & $13 \%$ & 813 & $14 \%$ & +45 & $+5.9 \%$ \\
\hline Burlington & 460 & $5 \%$ & 464 & $6 \%$ & +4 & $+0.9 \%$ \\
\hline St. Johnsbury & 442 & $20 \%$ & 454 & $20 \%$ & +12 & $+2.7 \%$ \\
\hline Brattleboro & 362 & $15 \%$ & 363 & $15 \%$ & +1 & $+0.3 \%$ \\
\hline South Burlington & 285 & $4 \%$ & 292 & $4 \%$ & +7 & $+2.5 \%$ \\
\hline St. Albans & 251 & $11 \%$ & 253 & $11 \%$ & +2 & $+0.8 \%$ \\
\hline Essex Junction & 130 & $5 \%$ & 131 & $5 \%$ & +1 & $+0.8 \%$
\end{tabular}

\section{Greatest relative growing risk*}

\begin{tabular}{lcccccc} 
Municipality & \multicolumn{2}{c}{2020} & \multicolumn{2}{c}{2050} & \multicolumn{2}{c}{ Change } \\
Rutland & 768 & $13 \%$ & 813 & $14 \%$ & +45 & $+6 \%$ \\
\hline St. Johnsbury & 442 & $20 \%$ & 454 & $20 \%$ & +12 & $+3 \%$ \\
\hline South Burlington & 285 & $4 \%$ & 292 & $4 \%$ & +7 & $+3 \%$ \\
\hline Montpelier & 1,045 & $35 \%$ & 1,058 & $35 \%$ & +13 & $+1 \%$ \\
\hline Bennington & 1,292 & $43 \%$ & 1,306 & $44 \%$ & +14 & $+1 \%$ \\
\hline Burlington & 460 & $5 \%$ & 464 & $6 \%$ & +4 & $+1 \%$ \\
\hline Barre & 1,052 & $33 \%$ & 1,060 & $33 \%$ & +8 & $+1 \%$ \\
\hline Essex Junction & 130 & $5 \%$ & 131 & $5 \%$ & +1 & $+1 \%$ \\
\hline St. Albans & 251 & $11 \%$ & 253 & $11 \%$ & +2 & $+1 \%$ \\
\hline Brattleboro & 362 & $15 \%$ & 363 & $15 \%$ & +1 & $+0 \%$
\end{tabular}

\section{Flood Factor distribution of properties at risk ${ }^{\star}(1000 s)$}

\section{Risk leve}

Minor

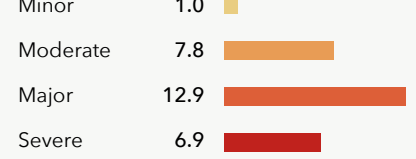

Extreme

23.7

More than $16.1 \%$ of individual properties and properties in Vermont are at any risk of flooding over the next 30 years. Out of those at risk $88 \%$ are at major to extreme risk.

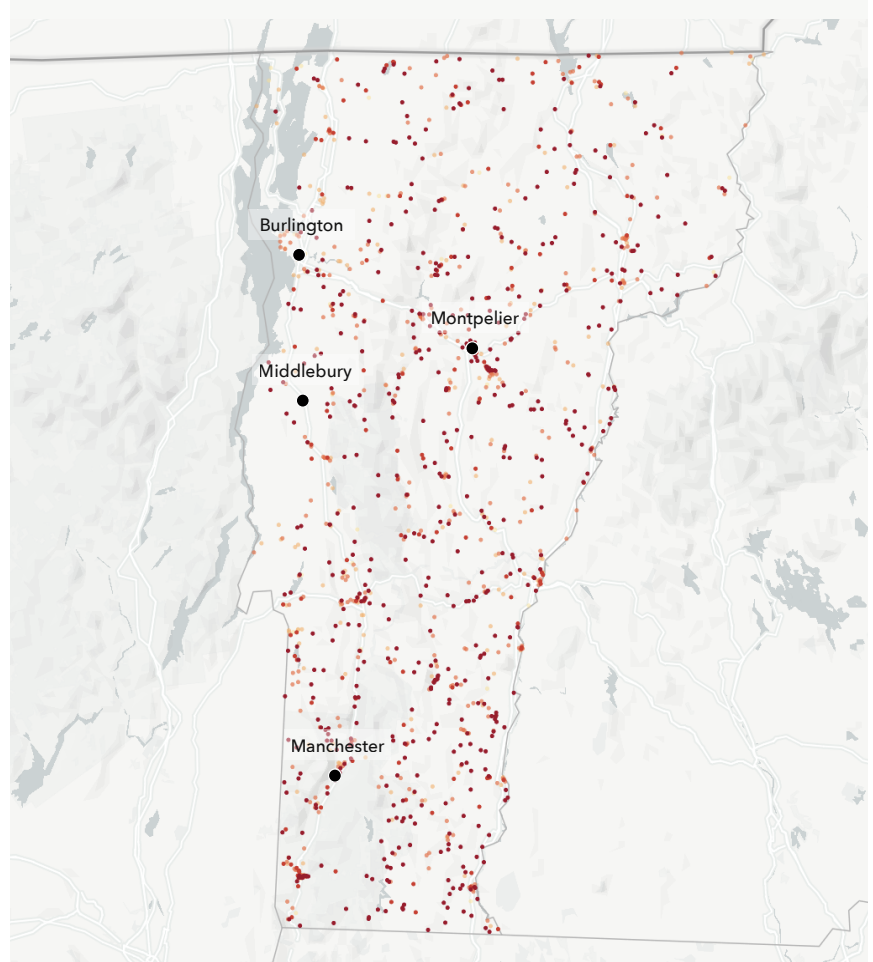




\section{Flood History \& Protection}

\section{Vermont}

\section{Claims History}

16,100 home and property owners in Vermont have made flood damage claims through FEMA since the year 2000 * These claims for reimbursement were made through either the National Flood Insurance Program (NFIP) or Individual Assistance Program (IAP). The greatest number of claims since the year 2000 have been concentrated in Windsor, Washington, Windham, Rutland, and Orange counties.

\section{3,400}

Properties served by

protection measures

The First Street Foundation Flood Model incorporates 984 flood control measures throughout the state which protect 3,400 properties.
Top protection measures in state by quantity

Type
Example \# Properties served by type 2,628

- Detention pond with forebay, Middlebury

Roaring Branch Left Bank, Bennington

\section{Storm Simulation}

The First Street Foundation Flood Model has recreated 1 flooding event that has occurred since the year 2000 in the state of Vermont. This event flooded around 410 properties across the state. .*
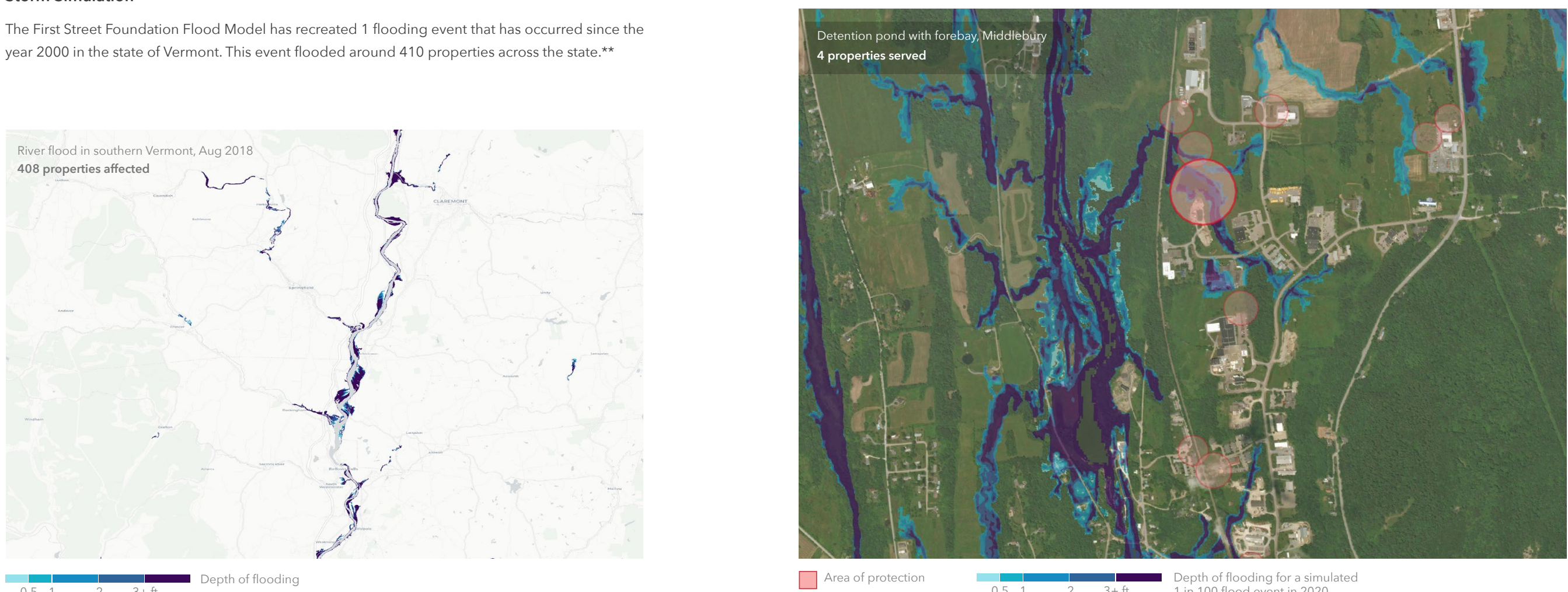

$\square$ Area of protectio 


\section{State Overview Virginia}

Flood risk is increasing in the state of Virginia. 344,400 properties currently have a substantial risk* of flooding. Over the next 30 years, the number of properties with this risk will increase by another $13.1 \%$, bringing the total number of properties with substantial risk to 389,700 .

To understand personal flood risk, Americans leverage the Federal Emergency Management Agency (FEMA) Flood Insurance Rate Maps (FIRM). These maps identify 162,500 properties as having substantial risk in the state of Virginia. In comparison, the First Street Foundation

Flood Model identifies 2.1 times the number of properties as facing this same level of risk. This discrepancy exists because the Foundation uses the current climate data, maps precipitation as a stand-alone risk, and includes areas that FEMA has not mapped. These new methods uncover an additional 181,900 properties currently not identified by FEMA as having substantial risk.

When adjusting for future environmental changes, the FEMA gap further widens to 227,200 by the year 2050
Total properties at substantial risk

\section{$\ln 2050$}

344,400

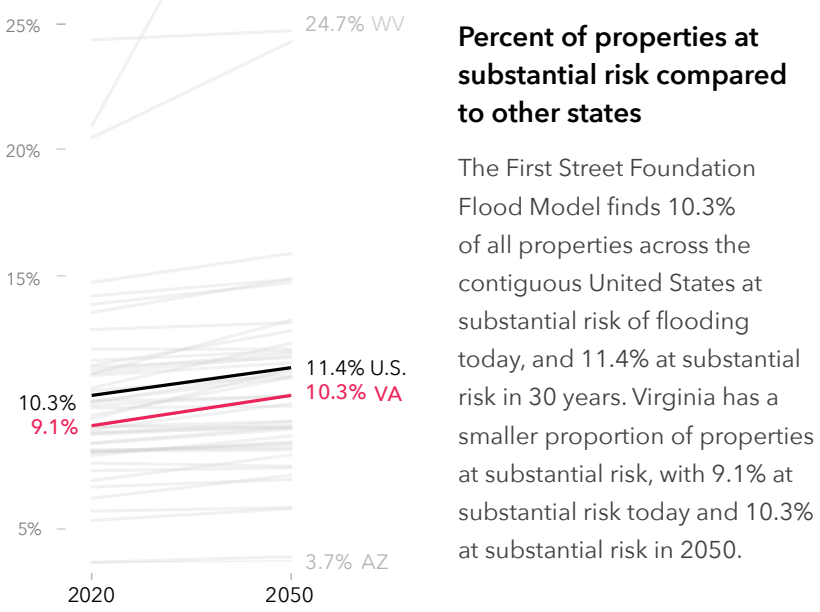

Difference in number of properties currently at substantial risk compared to FEMA**

$$
\Delta+181,934
$$

30-year change

$$
\Delta+45,300(+13 \%)
$$

Coastal cities face risk from rising sea levels and more frequent tidal flooding. Hurricanes and other storms cause erosion and destruction from storm surge. Hampton Roads has worked to enhance existing infrastructure built to protect coastal communities. Inland areas are most often flooded from heavy rainfall. Richmond is particularly flood prone on the James

River. It is protected by levees to limit the destruction of infrastructure.
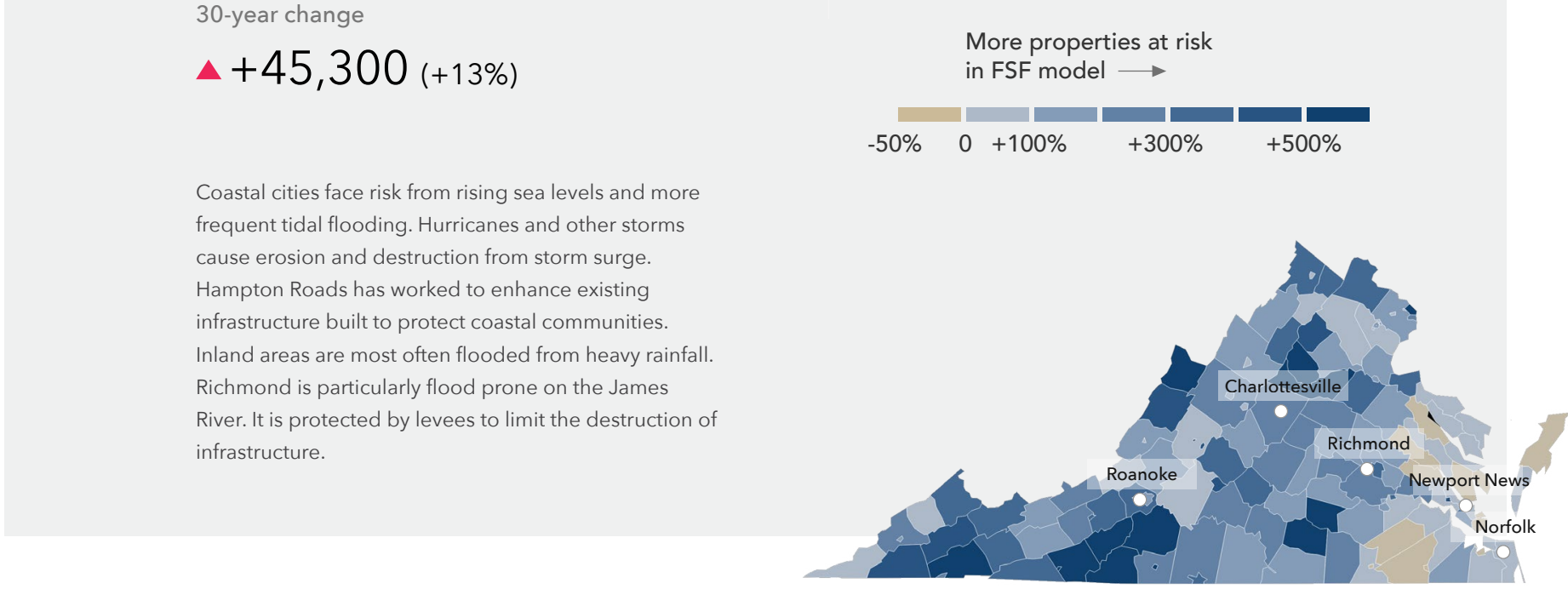
Mroperties at risk 


\section{Local details}

\section{Virginia}

The First Street Foundation Flood Model calculates the number of properties facing any risk* of flooding. When looking at this broader level of risk, the data identifies 570,800 properties in Virginia as at risk over the next 30 years. Of these properties, 133,700 were categorized as facing almost certain risk, with a $99 \%$ chance of flooding at least once over the next 30 years.

The city of Virginia Beach has the greatest number of properties at risk of flooding in the state with 28,900 currently at risk, or $20 \%$ of its total number of properties. However, smaller cities or municipalities in the state, with fewer properties, may have a greater proportion of their total properties at risk. For example, $80 \%$ of properties in Chincoteague are at risk of flooding. Other municipalities will see the greatest increase in risk over the next 30 years. Norfolk, for example, will see a $200 \%$ increase in the number of properties at risk.

Click here for a full breakdown of counties, cities, zip codes, and congressional districts in Virginia at risk.

\section{Greatest proportion of properties at risk*}

\begin{tabular}{lrr} 
Municipality & \multicolumn{2}{c}{2020} \\
Chincoteague & 4,514 & $80 \%$ \\
\hline Poquoson & 3,907 & $73 \%$ \\
\hline Glasgow & 1,908 & $50 \%$ \\
\hline Big Stone Gap & 1,165 & $43 \%$ \\
\hline Bridgewater & 894 & $43 \%$ \\
\hline Buena Vista & 2,533 & $39 \%$ \\
\hline Tazewell & 1,017 & $36 \%$ \\
\hline Deltaville & 872 & $35 \%$ \\
\hline Richlands & 1,056 & $33 \%$ \\
\hline Hampton & 16,820 & $33 \%$ \\
\hline
\end{tabular}

\section{Greatest number of properties at risk*}

\begin{tabular}{lllllll} 
Municipality & \multicolumn{2}{c}{2020} & \multicolumn{2}{c}{2050} & \multicolumn{2}{c}{ Change } \\
\cline { 2 - 6 } Virginia Beach & 28,943 & $20 \%$ & 52,125 & $37 \%$ & $+23,182$ & $+80.1 \%$ \\
\hline Norfolk & 18,042 & $27 \%$ & 54,054 & $80 \%$ & $+36,012$ & $+199.6 \%$ \\
\hline Hampton & 16,820 & $33 \%$ & 34,085 & $67 \%$ & $+17,265$ & $+102.6 \%$ \\
\hline Chesapeake & 16,543 & $19 \%$ & 25,418 & $29 \%$ & $+8,875$ & $+53.6 \%$ \\
\hline Portsmouth & 8,543 & $24 \%$ & 21,736 & $60 \%$ & $+13,193$ & $+154.4 \%$ \\
\hline Newport News & 7,285 & $14 \%$ & 8,999 & $17 \%$ & $+1,714$ & $+23.5 \%$ \\
\hline Roanoke & 6,444 & $15 \%$ & 6,530 & $15 \%$ & +86 & $+1.3 \%$ \\
\hline Richmond & 5,067 & $7 \%$ & 5,245 & $8 \%$ & +178 & $+3.5 \%$ \\
\hline Chincoteague & 4,514 & $80 \%$ & 4,517 & $80 \%$ & +3 & $+0.1 \%$ \\
\hline Poquoson & 3,907 & $73 \%$ & 4,946 & $92 \%$ & $+1,039$ & $+26.6 \%$
\end{tabular}

\section{Greatest relative growing risk*}

\begin{tabular}{lrrrrrr} 
Municipality & \multicolumn{2}{c}{2020} & \multicolumn{2}{c}{2050} & \multicolumn{2}{c}{ Change } \\
Norfolk & 18,042 & $27 \%$ & 54,054 & $80 \%$ & $+36,012$ & $+200 \%$ \\
\hline Portsmouth & 8,543 & $24 \%$ & 21,736 & $60 \%$ & $+13,193$ & $+154 \%$ \\
\hline West Point & 660 & $16 \%$ & 1,449 & $35 \%$ & +789 & $+120 \%$ \\
\hline Hampton & 16,820 & $33 \%$ & 34,085 & $67 \%$ & $+17,265$ & $+103 \%$ \\
\hline Gloucester Point & 998 & $18 \%$ & 1,910 & $34 \%$ & +912 & $+91 \%$ \\
\hline Stone Ridge & 53 & $1 \%$ & 97 & $3 \%$ & +44 & $+83 \%$ \\
\hline Virginia Beach & 28,943 & $20 \%$ & 52,125 & $37 \%$ & $+23,182$ & $+80 \%$ \\
\hline Horntown & 433 & $14 \%$ & 709 & $23 \%$ & +276 & $+64 \%$ \\
\hline Chesapeake & 16,543 & $19 \%$ & 25,418 & $29 \%$ & $+8,875$ & $+54 \%$ \\
\hline Belle Haven & 374 & $18 \%$ & 535 & $26 \%$ & +161 & $+43 \%$
\end{tabular}

\section{Flood Factor distribution of properties at risk ${ }^{\star}(1000 s)$}

\section{Risk level}

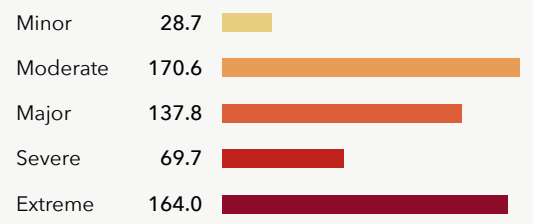

More than $15.1 \%$ of individual properties and properties in Virginia are at any risk of flooding over the next 30 years. Out of those at risk $65 \%$ are at major to extreme risk.

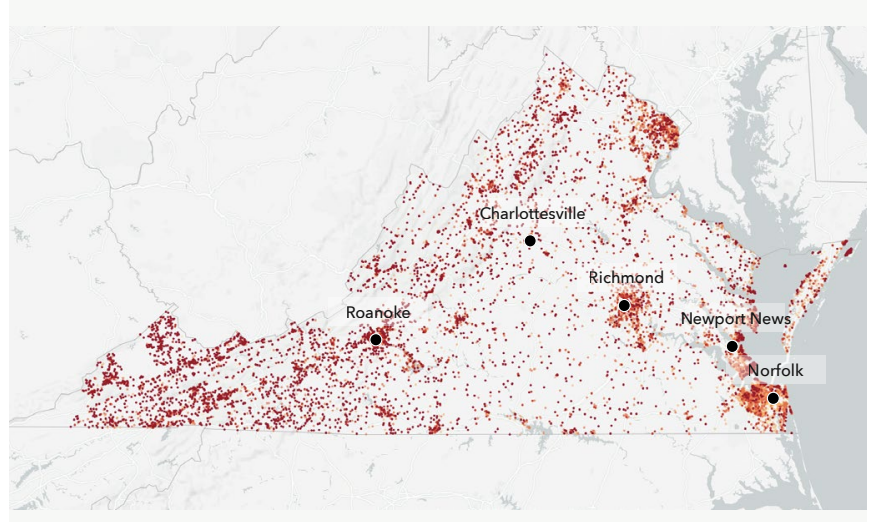




\section{Flood History \& Protection}

\section{Virginia}

\section{Claims History}

95,900 home and property owners in Virginia have made flood damage claims through FEMA since the year 2000.* These claims for reimbursement were made through either the National Flood Insurance Program (NFIP) or Individual Assistance Program (IAP). The greatest number of

claims since the year 2000 have been concentrated in Virginia Beach, Hampton, Norfolk, York, and Louisa counties.

\section{Storm Simulation}

The First Street Foundation Flood Model has recreated 4 flooding events that have occurred since the year 2000 in the state of Virginia. These events flooded around 169,930 properties across the state **

\begin{tabular}{llr} 
Flood event & Date & $\begin{array}{r}\text { \# Properties } \\
\text { affected }\end{array}$ \\
Hurricane Isabel & Sep 2003 & 105,638 \\
\hline Nor'easter & Nov 2009 & 14,055 \\
\hline Hurricane Irene & Aug 2011 & 50,120 \\
\hline River flood near Northern VA & Dec 2018 & 115
\end{tabular}

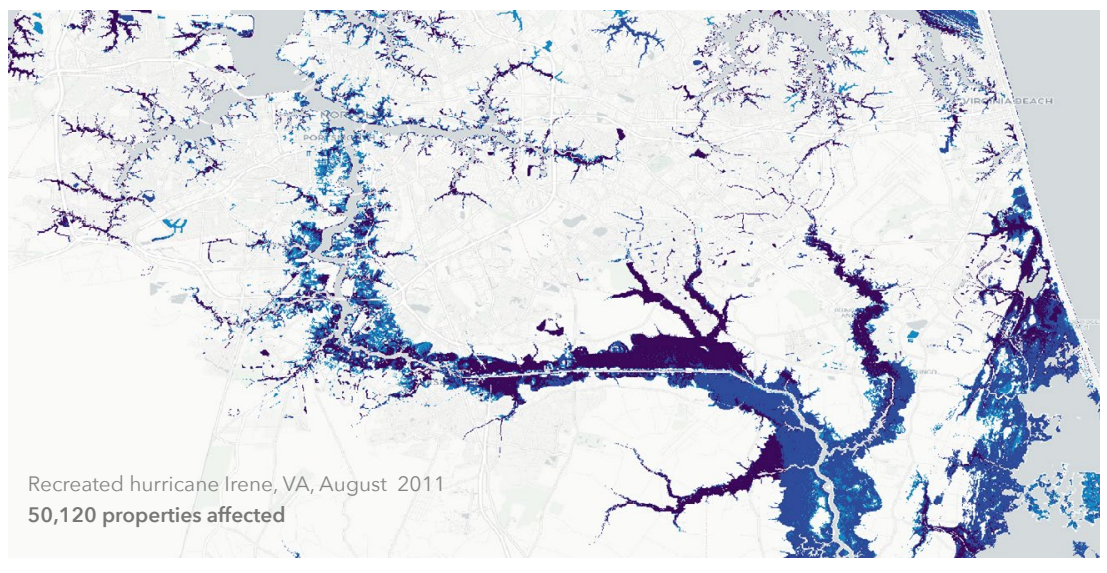

\section{7,600}

Properties served by

protection measures

The First Street Foundation Flood

Model incorporates 107 flood control

measures throughout the state which

protect 17,600 properties.

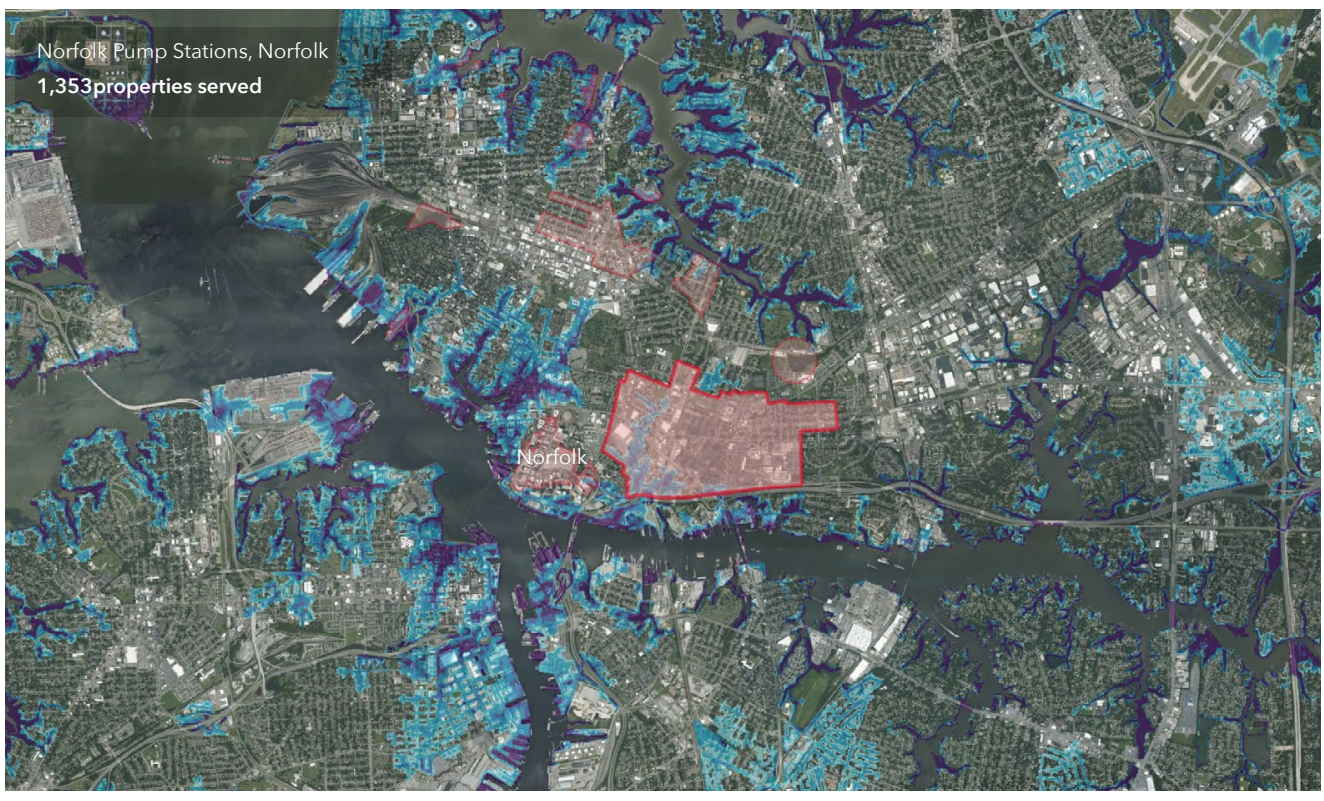

Top protection measures in state by quantity

Type

Pump station

\# Properties served by type

5,682

Levee

Buena Vista

Channel

Dam

$\square$ Area of protection 


\section{State Overview Washington}

Flood risk is increasing in the state of Washington. 362,600 properties currently have a substantial risk* of flooding. Over the next 30 years, the number of properties with this risk will increase by another $6 \%$, bringing the total number of properties with substantial risk to 384,400 .

To understand personal flood risk, Americans leverage the Federal Emergency Management Agency (FEMA) Flood Insurance Rate Maps (FIRM). These maps identify 121,500 properties as having substantial risk in the state of Washington. In comparison, the First Street Foundation Flood Model identifies 3 times the number of properties as facing this same level of risk. This discrepancy exists because the Foundation uses the current climate data, maps precipitation as a stand-alone risk, and includes areas that FEMA has not mapped. These new methods uncover an additional 241,100 properties currently not identified by FEMA as having substantial risk.

When adjusting for future environmental changes, the FEMA gap further widens to 262,900 by the year 2050
In 2020

362,600

30-year change

$\Delta+21,800(+6 \%)$
Total properties at substantial risk*
Difference in number of properties currently at substantial risk compared to FEMA**

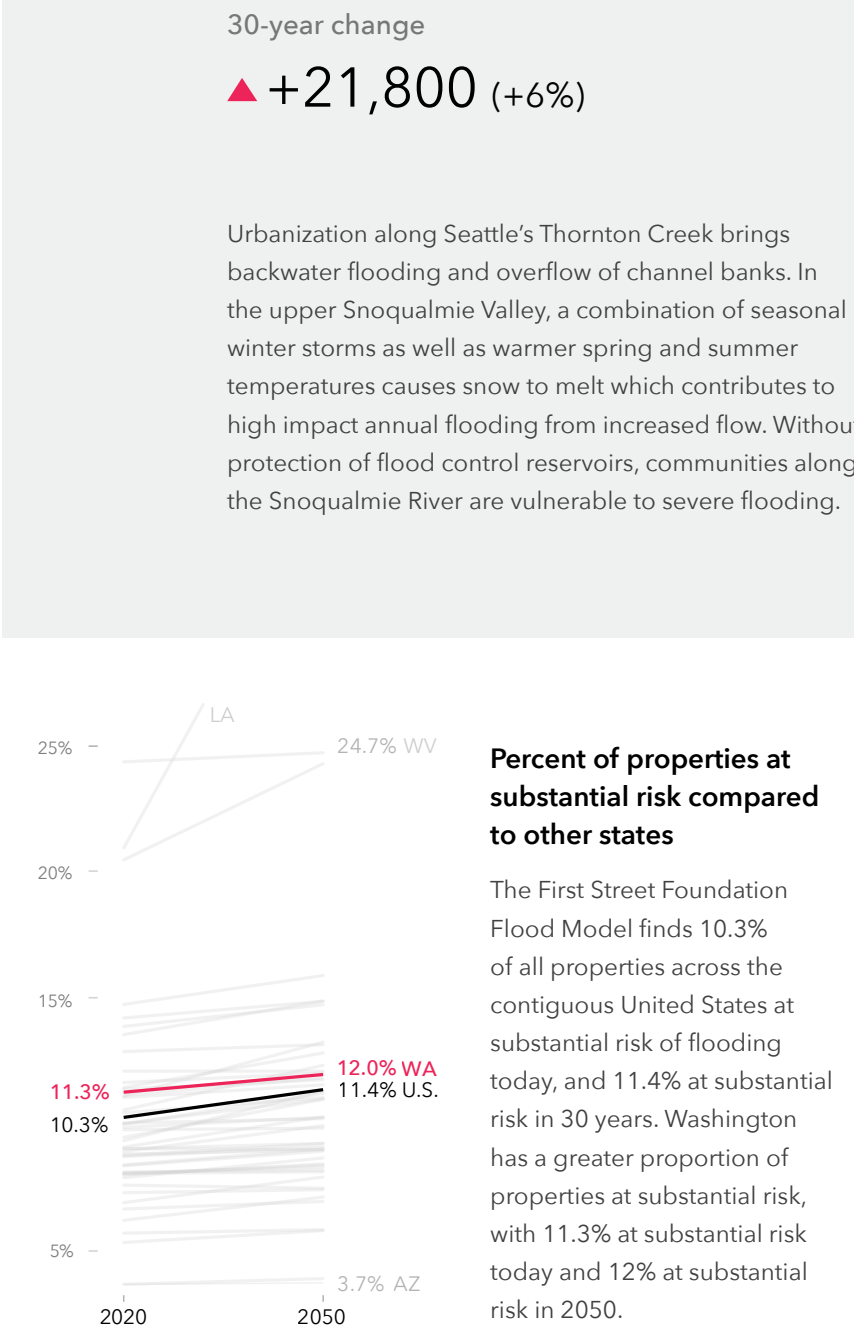

More properties at risk in FSF model

$0+100 \%+300 \%+500 \%$

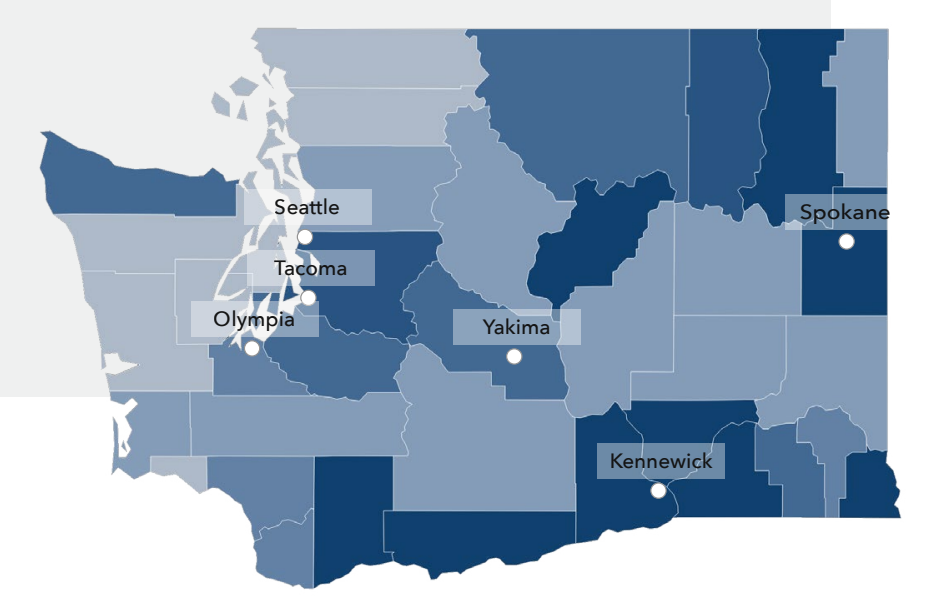




\section{Local details \\ Washington}

The First Street Foundation Flood Model calculates the number of properties facing any risk* of flooding. When looking at this broader level of risk, the data identifies 543,400 properties in Washington as at risk over the next 30 years. Of these properties, 100,700 were categorized as facing almost certain risk, with a $99 \%$ chance of flooding at least once over the next 30 years.

The city of Seattle has the greatest number of properties at risk of flooding in the state with 14,000 currently at risk, or $8 \%$ of its total number of properties. However, smaller cities or municipalities in the state, with fewer properties, may have a greater proportion of their total properties at risk. For example, $100 \%$ of properties in Toppenish are at risk of flooding. Other municipalities will see the greatest

increase in risk over the next 30 years. Indianola, for example, will see

a $63 \%$ increase in the number of properties at risk.

Click here for a full breakdown of counties, cities, zip codes, and congressional districts in Washington at risk.

\section{Greatest proportion of properties at risk*}

\begin{tabular}{lll} 
Municipality & \multicolumn{2}{|c}{2020} \\
\hline Toppenish & 2,438 & $100 \%$ \\
\hline Fife & 2,954 & $96 \%$ \\
\hline Finley & 2,011 & $88 \%$ \\
\hline Pacific & 1,937 & $88 \%$ \\
\hline Longview & 12,524 & $87 \%$ \\
\hline Hoquiam & 3,458 & $82 \%$ \\
\hline North Bend & 2,258 & $81 \%$ \\
\hline Orting & 2,442 & $79 \%$ \\
\hline Centralia & 4,867 & $75 \%$ \\
\hline Sedro-Woolley & 3,049 & $74 \%$ \\
\hline
\end{tabular}

\section{Greatest number of properties at risk*}

\begin{tabular}{l|c|ccccc} 
Municipality & \multicolumn{2}{c}{2020} & \multicolumn{2}{c}{2050} & \multicolumn{2}{c}{ Change } \\
Seattle & 13,977 & $8 \%$ & 15,647 & $9 \%$ & $+1,670$ & $+11.9 \%$ \\
\hline Longview & 12,524 & $87 \%$ & 12,532 & $87 \%$ & +8 & $+0.1 \%$ \\
\hline Spokane & 9,493 & $12 \%$ & 10,389 & $13 \%$ & +896 & $+9.4 \%$ \\
\hline Walla Walla & 7,107 & $60 \%$ & 7,268 & $61 \%$ & +161 & $+2.3 \%$ \\
\hline Spokane Valley & 6,880 & $21 \%$ & 7,386 & $22 \%$ & +506 & $+7.4 \%$ \\
\hline Tacoma & 6,652 & $9 \%$ & 7,198 & $10 \%$ & +546 & $+8.2 \%$ \\
\hline Puyallup & 6,324 & $48 \%$ & 6,381 & $48 \%$ & +57 & $+0.9 \%$ \\
\hline Vancouver & 6,038 & $12 \%$ & 6,411 & $13 \%$ & +373 & $+6.2 \%$ \\
\hline Centralia & 4,867 & $75 \%$ & 4,945 & $76 \%$ & +78 & $+1.6 \%$ \\
\hline Aberdeen & 4,710 & $58 \%$ & 4,789 & $59 \%$ & +79 & $+1.7 \%$
\end{tabular}

Greatest relative growing risk*

\begin{tabular}{lrrrrrr} 
Municipality & \multicolumn{2}{c}{2020} & \multicolumn{2}{c}{2050} & \multicolumn{2}{c}{ Change } \\
Indianola & 110 & $5 \%$ & 179 & $8 \%$ & +69 & $+63 \%$ \\
\hline Ocean Shores & 1,434 & $13 \%$ & 2,133 & $19 \%$ & +699 & $+49 \%$ \\
\hline Point Roberts & 137 & $4 \%$ & 201 & $6 \%$ & +64 & $+47 \%$ \\
\hline Birch Bay & 652 & $12 \%$ & 851 & $15 \%$ & +199 & $+31 \%$ \\
\hline Oak Harbor & 266 & $5 \%$ & 342 & $6 \%$ & +76 & $+29 \%$ \\
\hline Port Townsend & 487 & $7 \%$ & 621 & $9 \%$ & +134 & $+28 \%$ \\
\hline Port Ludlow & 99 & $5 \%$ & 126 & $6 \%$ & +27 & $+27 \%$ \\
\hline Anacortes & 609 & $7 \%$ & 773 & $9 \%$ & +164 & $+27 \%$ \\
\hline Bainbridge Island & 821 & $7 \%$ & 1,040 & $9 \%$ & +219 & $+27 \%$ \\
\hline Clarkston & 249 & $9 \%$ & 309 & $11 \%$ & +60 & $+24 \%$
\end{tabular}

\section{Flood Factor distribution of properties at risk ${ }^{\star}(1000 s)$}

\section{Risk level}

Minor $\quad 23.6$

Moderate $\quad 156.8$

Major $\quad 174.9$

Severe $\quad 61.2$

Extreme $\quad 127.0$

More than $17.1 \%$ of individual properties and properties in Washington are at any risk of flooding over the next 30 years. Out of those at risk $66 \%$ are at major to extreme risk.

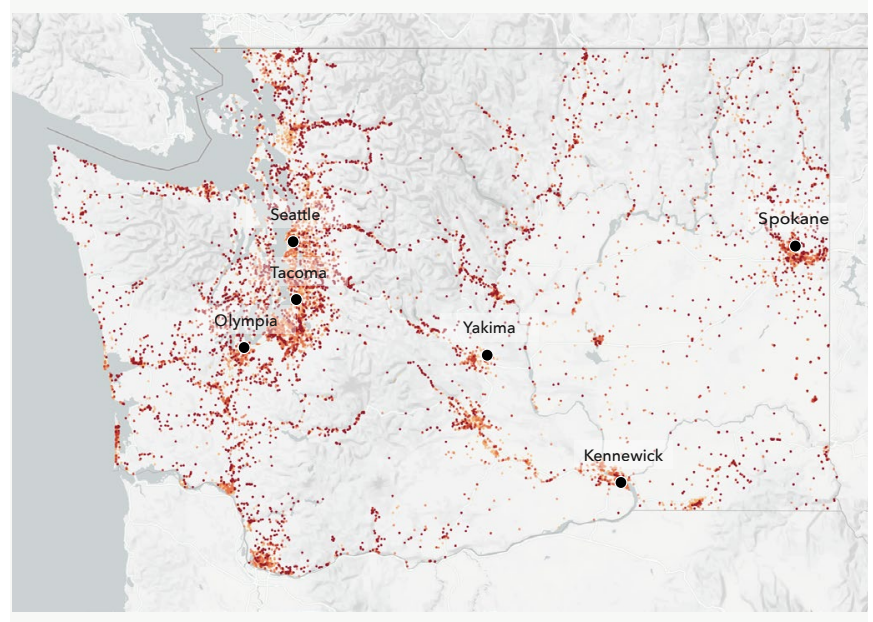


Flood History \& Protection

\section{Washington}

\section{Claims History}

32,000 home and property owners in Washington have made flood damage claims through FEMA since the year 2000.* These claims for reimbursement were made through either the National Flood Insurance Program (NFIP) or Individual Assistance Program (IAP). The greatest number of

claims since the year 2000 have been concentrated in Grays Harbor, Lewis, King, Snohomish, and Thurston counties.

\section{1,600}

Properties served by

protection measures

The First Street Foundation Flood

Model incorporates 2,169 flood control

measures throughout the state which

protect 101,600 properties.
Top protection measures in state by quantity

\begin{tabular}{lc}
$\begin{array}{l}\text { Type } \\
\text { Example }\end{array}$ & \# Properties served by type \\
Levee & \\
Cowlitz CDID 1 Protected Area, Longview & 89,772 \\
\hline $\begin{array}{l}\text { Detention basin } \\
\text { Glen Acres, Glendale }\end{array}$ & 4,175 \\
\hline $\begin{array}{l}\text { Channel } \\
\text { Sammamish River Channelization Project }\end{array}$ & 2,929 \\
\hline $\begin{array}{l}\text { Stormwater vault } \\
\text { Griffis Seattle South at Brookside-Vault 1 }\end{array}$ & 2,212 \\
\hline $\begin{array}{l}\text { Infiltration basin } \\
\text { Park Place Estates, Auburn }\end{array}$ & 1,216
\end{tabular}

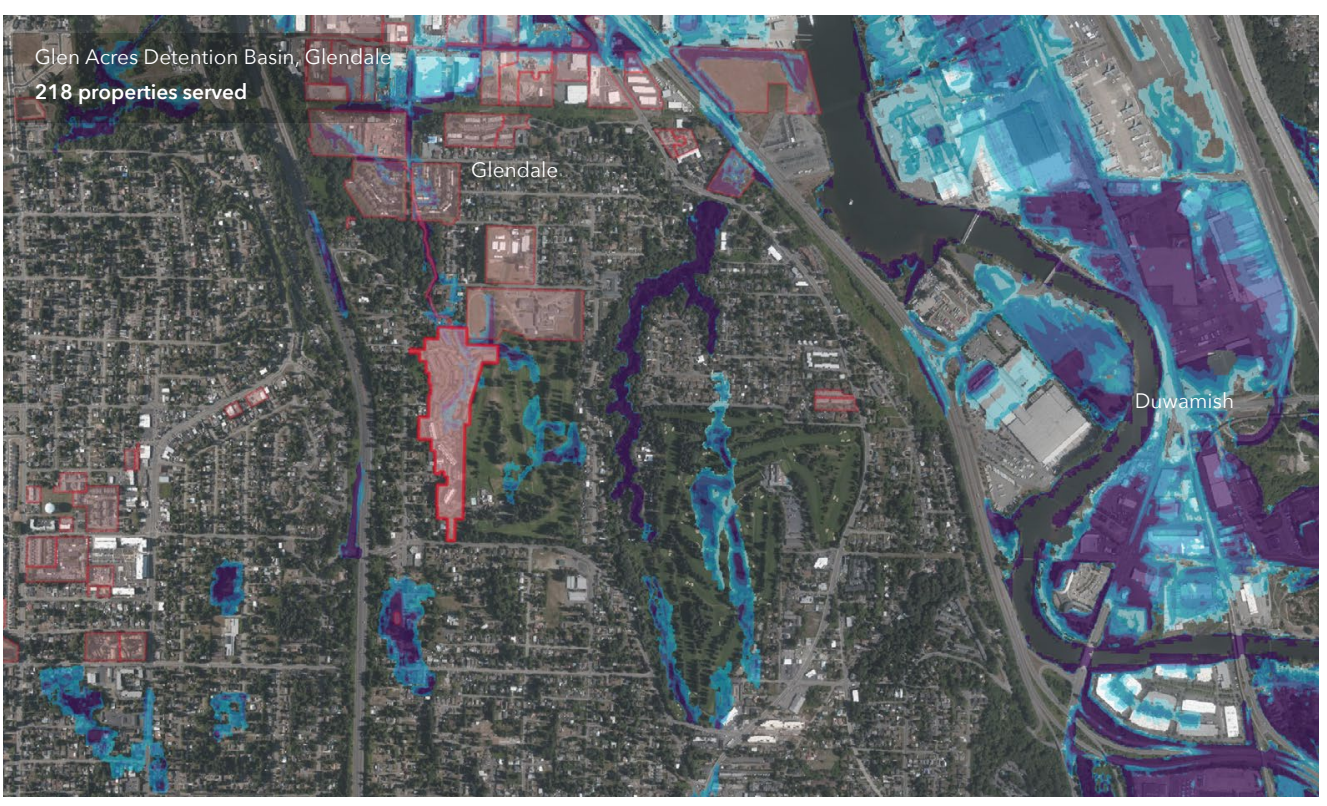

$\square$ Area of protection 


\section{Overview Washington, D.C.}

Flood risk is increasing in the federal district Washington D.C. 7,300 properties currently have a substantial risk* of flooding. Over the next 30 years, the number of properties with this risk will increase by another $8.8 \%$, bringing the total number of properties with substantial risk to 8,000 .

To understand personal flood risk, Americans leverage the Federal Emergency Management Agency (FEMA) Flood Insurance Rate Maps (FIRM). These maps identify 1,400 properties as having substantial risk in the state of Washington D.C.. In comparison, the First Street Foundation Flood Model identifies 5.4 times the number of properties as facing this same level of risk**. This discrepancy exists because the Foundation uses the current climate data, maps precipitation as a stand-alone risk, and includes areas that FEMA has not mapped. These new methods uncover an additional 6,000 properties currently not identified by FEMA as having substantial risk. When adjusting for future environmental changes, the FEMA gap further widens to 6,600 by the year 2050.

\section{7,300}

30-year change

$\Delta+700(+9 \%)$

Low-lying Foggy Bottom and Buzzard Point face risk from river flooding and rainfall runoff coming from other areas of the city. Widespread flooding persists despite D.C's substantial stormwater management systems. The National Mall and surrounding government buildings are protected by a large levee that holds riverine flood waters at bay. Plans for joint parking structures and

floodwater basins beneath the Mall are currently in the concept phase.

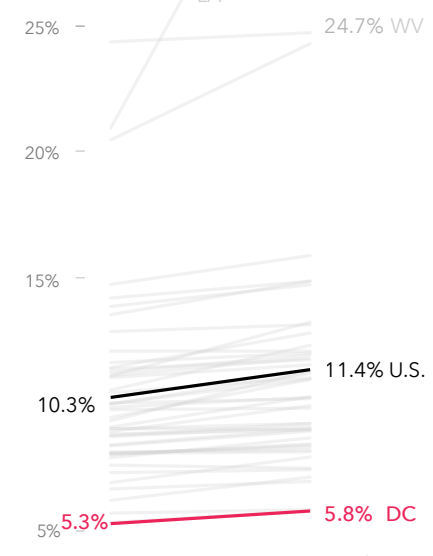

2020
Percent of properties at substantial risk compared to other states

The First Street Foundation Flood Model finds $10.3 \%$ of all properties across the contiguous United States at substantial risk of flooding today, and $11.4 \%$ at substantial risk in 30 years. Washington D.C. has a smaller proportion of properties at substantial risk, with $5.3 \%$ at substantial risk today and $5.8 \%$ at substantial risk in 2050.
Flood Factor distribution of properties at risk ${ }^{\star \star \star}$ (1000s)

Risk level

Minor

Moderate

Major

Severe

4.0

6.0

Extreme

\section{7}

The First Street Foundation Flood Model calculates the number of properties facing any risk ${ }^{\star \star \star}$ of flooding. When looking at this broader level of risk, the data identifies 12,500 propertie in Washington D.C. as at risk over the next 30 years. Of these properties, 100 were categorized as facing almost certain risk, with a $99 \%$ chance of flooding at least once over the next 30 years.

More than $9.2 \%$ of individual properties and properties in

Washington D.C. are at any risk of flooding over the next 30 years. Out of those at risk $62 \%$ are at major to extreme risk.

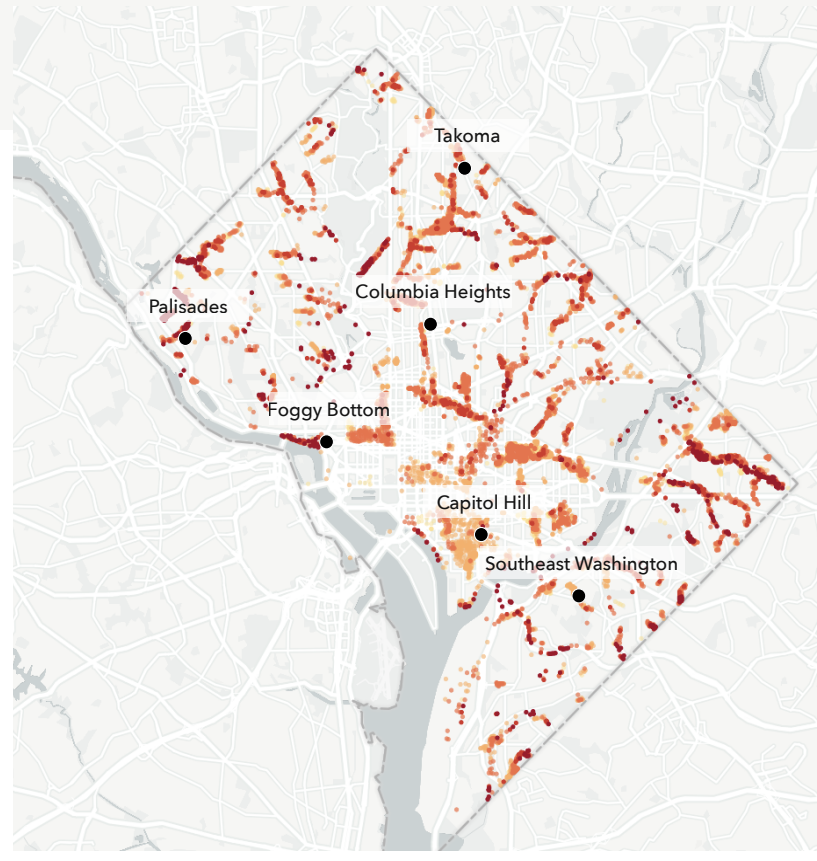




\section{State Overview West Virginia}

Flood risk is increasing in the state of West Virginia. 326,600 properties currently have a substantial risk $^{*}$ of flooding. Over the next 30 years, the number of properties with this risk will increase by another $1.5 \%$, bringing the total number of properties with substantial risk to 331,500 .

To understand personal flood risk, Americans leverage the Federal Emergency Management Agency (FEMA) Flood Insurance Rate Maps (FIRM). These maps identify 134,200 properties as having substantial risk in the state of West Virginia. In comparison, the First Street Foundation Flood Model identifies 2.4 times the number of properties as facing this same level of risk. This discrepancy exists because the Foundation uses the current climate data, maps precipitation as a stand-alone risk, and includes areas that FEMA has not mapped. These new methods uncover an additional 192,400 properties currently not identified by FEMA as having substantial risk. When adjusting for future environmental changes, the FEMA gap further widens to 197,300 by the year 2050 .
Total properties at substantial risk *

In 2020

\section{6,600}

30-year change

$\Delta+4,900$

$(+1 \%)$

Frequent large rainfall events cause the banks of the Kanawha and Ohio rivers to overflow, posing the largest flood risk to population centers like Huntington and Charleston. The state's flood protection efforts stem primarily from its extensive system of dams, including the Stonewall Jackson Dam, Tygart River Dam, and Burnsville Dam

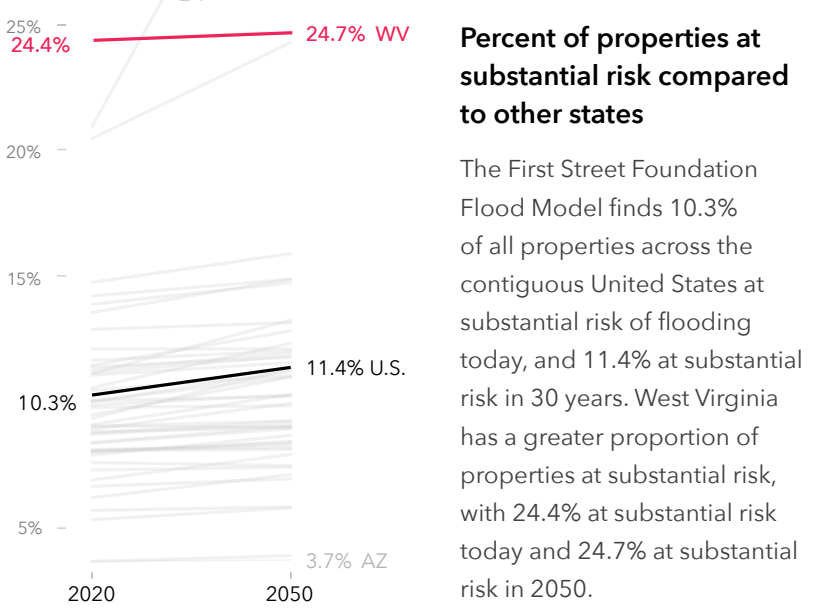

Difference in number of properties currently at substantial risk compared to FEMA**

$\Delta+273,100$
More properties at risk in FSF model $\longrightarrow$
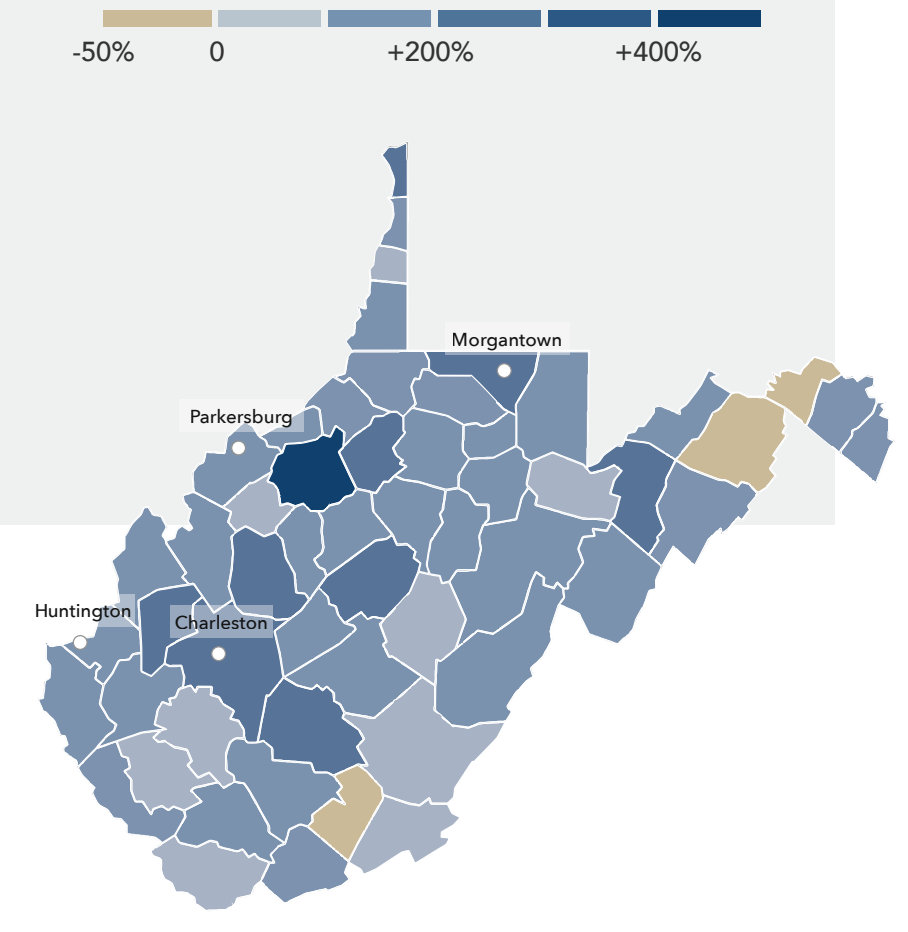


\section{Local details \\ West Virginia}

The First Street Foundation Flood Model calculates the number of properties facing any risk* of flooding. When looking at this broader level of risk, the data identifies 381,500 properties in West Virginia as at risk over the next 30 years. Of these properties, 174,300 were categorized as facing almost certain risk, with a $99 \%$ chance of

flooding at least once over the next 30 years.

The city of Charleston has the greatest number of properties at risk of flooding in the state with 12,800 currently at risk, or $44 \%$ of its total number of properties. However, smaller cities or municipalities in the state, with fewer properties, may have a greater proportion of their total properties at risk. For example, $76 \%$ of properties in Dunbar are at risk of flooding. Other municipalities will see the greatest increase in risk over the next 30 years. Huntington, for example, will see a $18 \%$ increase in the number of properties at risk.

Click here for a full breakdown of counties, cities, zip codes, and congressional districts in West Virginia at risk.

\section{Greatest proportion of properties at risk*}

\begin{tabular}{lrr} 
Municipality & \multicolumn{2}{c}{2020} \\
\hline Dunbar & 3,090 & $76 \%$ \\
\hline New Martinsville & 2,376 & $76 \%$ \\
\hline Nitro & 2,752 & $72 \%$ \\
\hline St. Albans & 3,954 & $66 \%$ \\
\hline Weston & 1,802 & $59 \%$ \\
\hline Mount Gay-Shamrock & 1,184 & $58 \%$ \\
\hline Wheeling & 9,018 & $56 \%$ \\
\hline Moundsville & 2,641 & $52 \%$ \\
\hline Buckhannon & 1,511 & $49 \%$ \\
\hline Vienna & 2,758 & $46 \%$ \\
\hline
\end{tabular}

\section{Greatest number of properties at risk*}

\begin{tabular}{l|c|ccccc} 
Municipality & \multicolumn{2}{c}{2020} & \multicolumn{2}{c}{2050} & \multicolumn{2}{c}{ Change } \\
Charleston & 12,767 & $44 \%$ & 12,834 & $44 \%$ & +67 & $+0.5 \%$ \\
\hline Wheeling & 9,018 & $56 \%$ & 9,056 & $56 \%$ & +38 & $+0.4 \%$ \\
\hline Parkersburg & 7,927 & $39 \%$ & 8,053 & $40 \%$ & +126 & $+1.6 \%$ \\
\hline St. Albans & 3,954 & $66 \%$ & 3,979 & $66 \%$ & +25 & $+0.6 \%$ \\
\hline Huntington & 3,724 & $15 \%$ & 4,402 & $18 \%$ & +678 & $+18.2 \%$ \\
\hline South Charleston & 3,105 & $44 \%$ & 3,123 & $44 \%$ & +18 & $+0.6 \%$ \\
\hline Dunbar & 3,090 & $76 \%$ & 3,097 & $76 \%$ & +7 & $+0.2 \%$ \\
\hline Vienna & 2,758 & $46 \%$ & 2,795 & $46 \%$ & +37 & $+1.3 \%$ \\
\hline Nitro & 2,752 & $72 \%$ & 2,761 & $73 \%$ & +9 & $+0.3 \%$ \\
\hline Moundsville & 2,641 & $52 \%$ & 2,705 & $53 \%$ & +64 & $+2.4 \%$
\end{tabular}

\section{Greatest relative growing risk*}

\begin{tabular}{|c|c|c|c|c|c|c|}
\hline Municipality & & 20 & & 050 & & nge \\
\hline Huntington & 3,724 & $15 \%$ & 4,402 & $18 \%$ & +678 & $+18 \%$ \\
\hline Elkins & 672 & $17 \%$ & 728 & $18 \%$ & +56 & $+8 \%$ \\
\hline Shady Spring & 166 & $7 \%$ & 178 & $8 \%$ & +12 & $+7 \%$ \\
\hline Hurricane & 328 & $9 \%$ & 351 & $10 \%$ & +23 & $+7 \%$ \\
\hline Lewisburg & 147 & $6 \%$ & 155 & $7 \%$ & +8 & $+5 \%$ \\
\hline Grafton & 190 & $5 \%$ & 200 & $5 \%$ & +10 & $+5 \%$ \\
\hline Teays Valley & 660 & $10 \%$ & 690 & $11 \%$ & +30 & $+5 \%$ \\
\hline Princeton & 993 & $23 \%$ & 1,037 & $24 \%$ & +44 & $+4 \%$ \\
\hline Cross Lanes & 717 & $16 \%$ & 744 & $16 \%$ & +27 & $+4 \%$ \\
\hline Martinsburg & 934 & $12 \%$ & 968 & $13 \%$ & +34 & $+4 \%$ \\
\hline
\end{tabular}

\section{Flood Factor distribution of properties at risk ${ }^{\star}(1000 s)$}

\section{Risk leve}

Minor

Moderate $\quad 42.3$

Major $\quad 79.3$

Severe $\quad 44.5$

Extreme $\quad 209.6$

More than $28.5 \%$ of individual properties and properties in West Virginia are at any risk of flooding over the next 30 years. Out of those at risk $87 \%$ are at major to extreme risk.

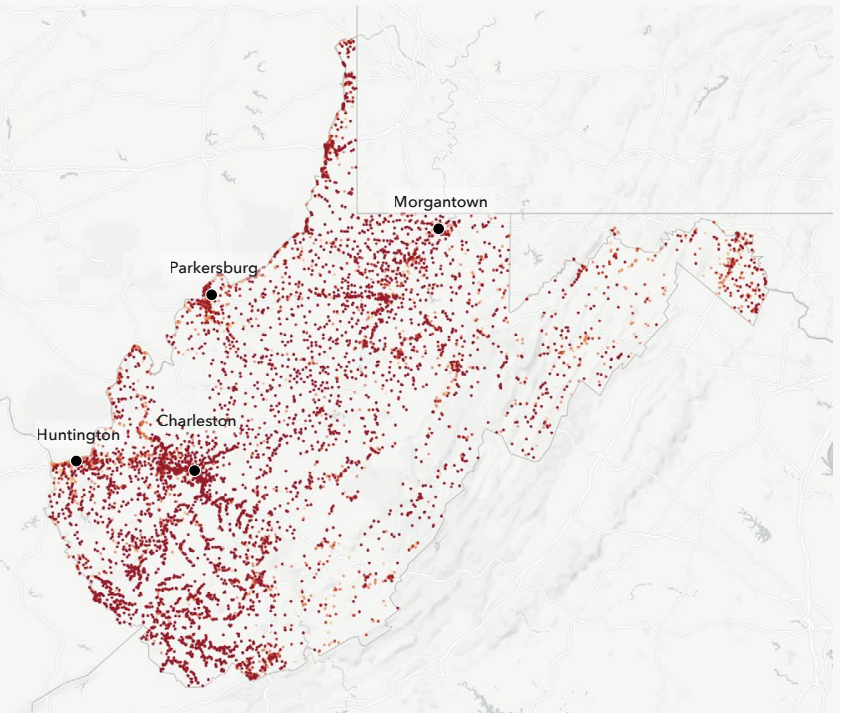




\section{Flood History \& Protection}

\section{West Virginia}

\section{Claims History}

91,700 home and property owners in West Virginia have made flood damage claims through

FEMA since the year 2000.* These claims for reimbursement were made through either the

National Flood Insurance Program (NFIP) or Individual Assistance Program (IAP). The greatest

number of claims since the year 2000 have been concentrated in Mingo, Kanawha, Ohio, Brooke,

and Marshall counties.

\section{Storm Simulation}

The First Street Foundation Flood Model has recreated 2 flooding events that have occurred since the year 2000 in the state of West Virginia. These events flooded around 8,020 properties across the state **

Flood event

\# Properties
affected

River flood in Northern, WV

Sept $2004 \quad 7,802$

- River flood near Shepherdstown, WV

$$
\text { Dec } 2018
$$
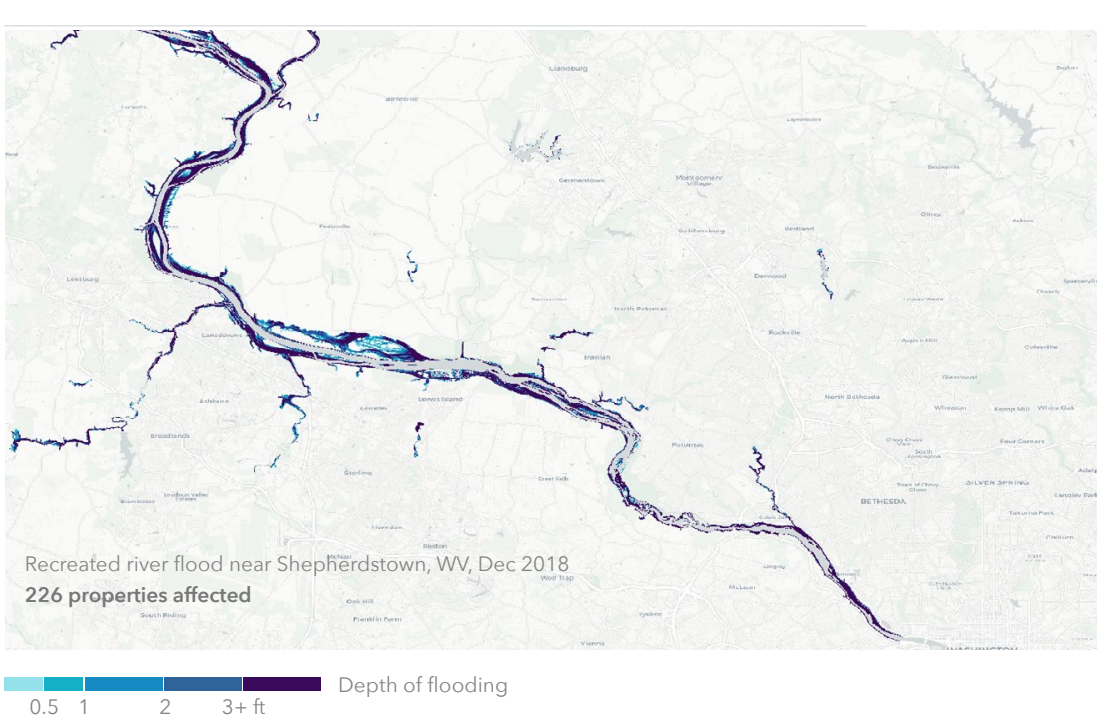

\section{3,700}

Properties served by

protection measures

The First Street Foundation Flood Model incorporates 29 flood control measures throughout the state which protect 33,700 properties.

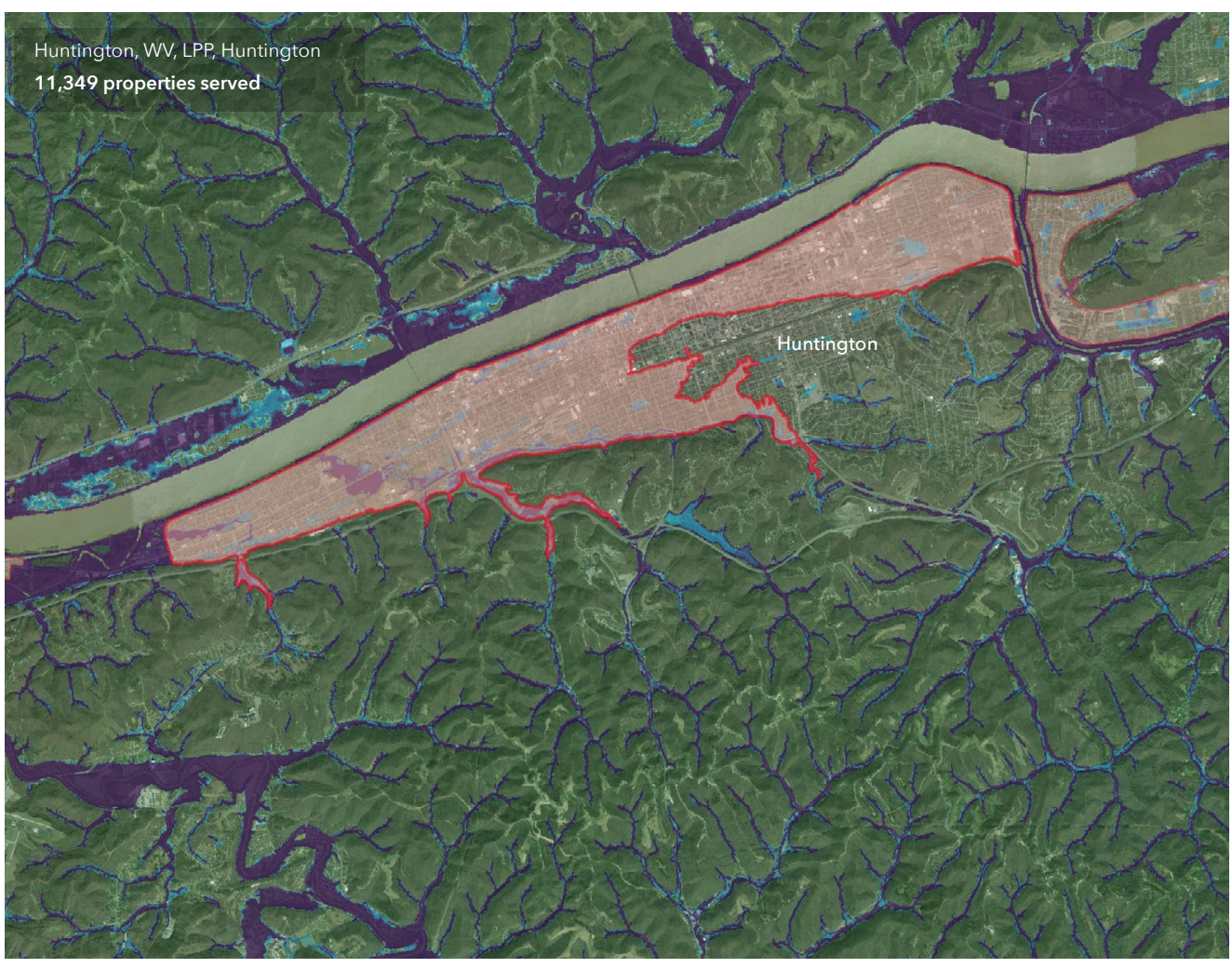

$\square$ Area of protection
Top protection measures in state by quantity

Type

Levee

Huntington, WV, LPP
\# Properties served by type 


\section{State Overview Wisconsin}

Difference in number of properties currently at substantial risk compared to FEMA**

$\Delta+129,400$
Flood risk is increasing in the state of Wisconsin. 273,400 properties currently have a substantial risk* of flooding. Over the next 30 years, the number of properties with this risk will increase by another $2.8 \%$, bringing the total number of properties with substantial risk to 281,100 .

To understand personal flood risk, Americans leverage the Federal Emergency Management Agency (FEMA) Flood Insurance Rate Maps (FIRM). These maps identify 144,000 properties as having substantial risk in the state of

Wisconsin. In comparison, the First Street Foundation Flood Model identifies 1.9 times the number of properties as facing this same level of risk. This discrepancy exists because the Foundation uses the current climate data, maps precipitation as a stand-alone risk, and includes areas that FEMA has not mapped. These new methods uncover an additional 129,400 properties currently not identified by FEMA as having substantial risk. When adjusting for future environmental changes, the FEMA gap further widens to 137,100 by the year 2050 .
Total properties at substantial risk *

In 2020

273,400

30-year change

$\Delta+7,700$

$+3 \%$ $\ln 2050$

281,100

More properties at risk in FSF model $\longrightarrow$

$-50 \%$

$+200 \%$ $+400 \%$ $+600 \%$

Milwaukee sees floods from rainfall and snowmelt flowing into the watersheds of surrounding rivers. Development has reduced absorption which overwhelms stormwater systems. Protection efforts include channel improvements, natural storage, and regulation. Madison sees flash floods and overflow from surrounding lakes, threatening low-lying areas. The city has improved stormwater systems and reinforced shorelines.
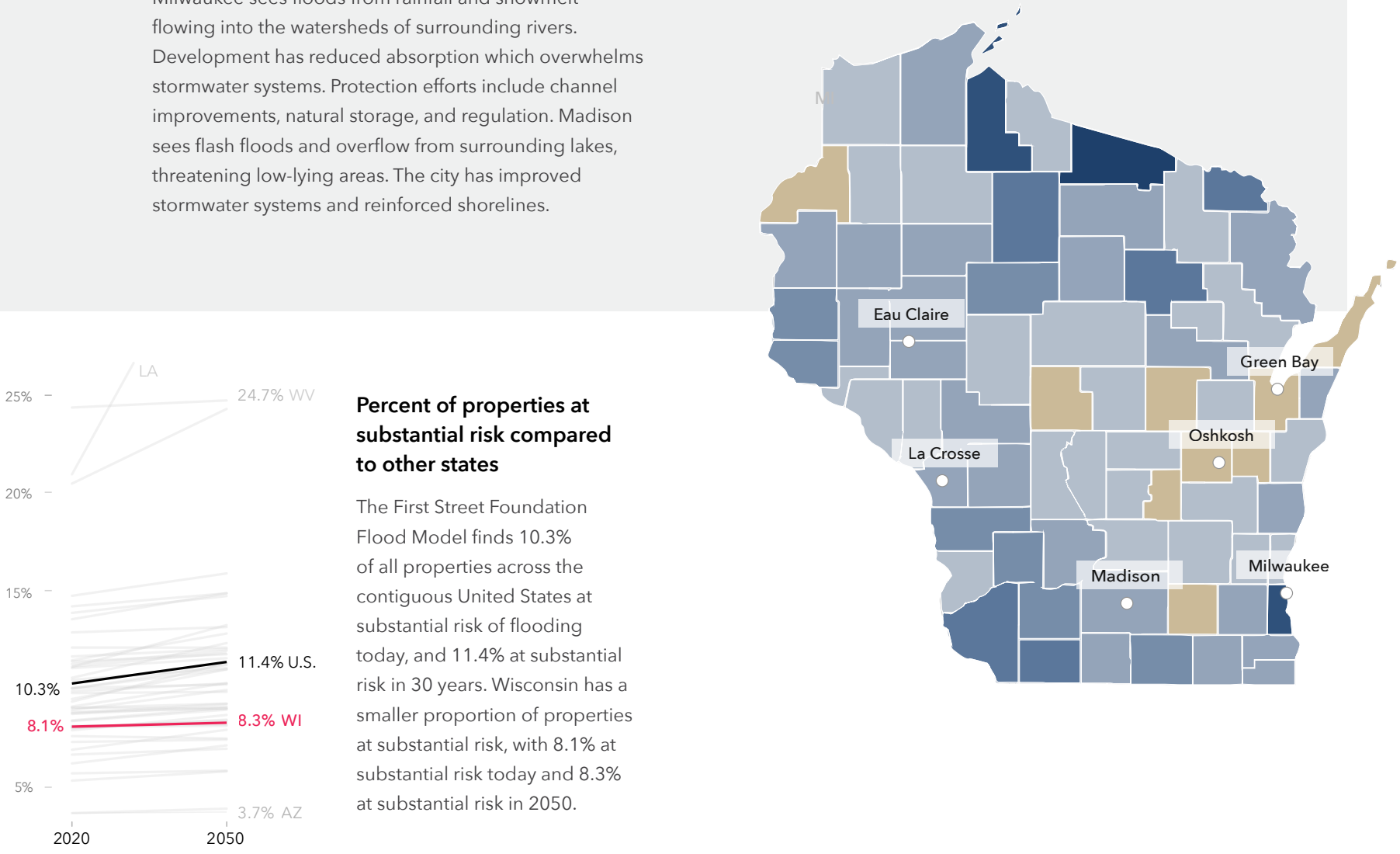


\section{Local details \\ Wisconsin}

The First Street Foundation Flood Model calculates the number of properties facing any risk* of flooding. When looking at this broader level of risk, the data identifies 389,700 properties in Wisconsin as at risk over the next 30 years. Of these properties, 71,100 were categorized as facing almost certain risk, with a $99 \%$ chance of flooding at least once over the next 30 years.

The city of Milwaukee has the greatest number of properties at risk of flooding in the state with 12,200 currently at risk, or $8 \%$ of its total number of properties. However, smaller cities or municipalities in the state, with fewer properties, may have a greater proportion of their total properties at risk. For example, $58 \%$ of properties in Oconto are at risk of flooding. Other municipalities will see the greatest increase in risk over the next 30 years. Milton, for example, will see a 23\% increase in the number of properties at risk.

Click here for a full breakdown of counties, cities, zip codes, and congressional districts in Wisconsin at risk.

\section{Greatest proportion of properties at risk*}

\begin{tabular}{lrr} 
Municipality & \multicolumn{2}{c}{2020} \\
\hline Oconto & 1,351 & $58 \%$ \\
\hline Lake Wisconsin & 1,311 & $37 \%$ \\
\hline Ladysmith & 728 & $35 \%$ \\
\hline La Crosse & 5,699 & $35 \%$ \\
\hline Fond du Lac & 4,963 & $33 \%$ \\
\hline Richland Center & 778 & $33 \%$ \\
\hline Prairie du Chien & 1,006 & $32 \%$ \\
\hline Rhinelander & 1,214 & $32 \%$ \\
\hline Tichigan & 846 & $30 \%$ \\
\hline Merrill & 1,271 & $26 \%$ \\
\hline
\end{tabular}

\section{Greatest number of properties at risk*}

\begin{tabular}{l|c|ccccc} 
Municipality & \multicolumn{2}{c}{2020} & \multicolumn{2}{c}{2050} & \multicolumn{2}{c}{ Change } \\
Milwaukee & 12,203 & $8 \%$ & 12,499 & $8 \%$ & +296 & $+2.4 \%$ \\
\hline Madison & 5,755 & $9 \%$ & 5,932 & $10 \%$ & +177 & $+3.1 \%$ \\
\hline La Crosse & 5,699 & $35 \%$ & 5,746 & $35 \%$ & +47 & $+0.8 \%$ \\
\hline Fond du Lac & 4,963 & $33 \%$ & 5,112 & $34 \%$ & +149 & $+3.0 \%$ \\
\hline Eau Claire & 4,270 & $19 \%$ & 4,312 & $19 \%$ & +42 & $+1.0 \%$ \\
\hline Kenosha & 3,748 & $13 \%$ & 3,943 & $13 \%$ & +195 & $+5.2 \%$ \\
\hline Racine & 3,677 & $14 \%$ & 3,817 & $15 \%$ & +140 & $+3.8 \%$ \\
\hline Green Bay & 3,120 & $9 \%$ & 3,231 & $9 \%$ & +111 & $+3.6 \%$ \\
\hline Wausau & 2,807 & $18 \%$ & 2,843 & $19 \%$ & +36 & $+1.3 \%$ \\
\hline Janesville & 2,718 & $11 \%$ & 2,818 & $12 \%$ & +100 & $+3.7 \%$
\end{tabular}

\section{Greatest relative growing risk*}

\begin{tabular}{lcccccc} 
Municipality & \multicolumn{2}{c}{2020} & \multicolumn{2}{c}{2050} & \multicolumn{2}{c}{$\begin{array}{c}\text { Change } \\
\text { Milton }\end{array}$} \\
\hline Cottage Grove & 205 & $9 \%$ & 252 & $11 \%$ & +47 & $+23 \%$ \\
\hline Camp Lake & 200 & $8 \%$ & 225 & $10 \%$ & +25 & $+13 \%$ \\
\hline Sturgeon Bay & 263 & $12 \%$ & 293 & $14 \%$ & +30 & $+11 \%$ \\
\hline Verona & 188 & $4 \%$ & 208 & $4 \%$ & +20 & $+11 \%$ \\
\hline Oshkosh & 332 & $8 \%$ & 364 & $9 \%$ & +32 & $+10 \%$ \\
\hline DeForest & 1,670 & $8 \%$ & 1,829 & $8 \%$ & +159 & $+10 \%$ \\
\hline Evansville & 271 & $7 \%$ & 296 & $8 \%$ & +25 & $+9 \%$ \\
\hline Menasha & 235 & $10 \%$ & 256 & $11 \%$ & +21 & $+9 \%$ \\
\hline Ripon & 475 & $7 \%$ & 514 & $8 \%$ & +39 & $+8 \%$ \\
\hline & 272 & $9 \%$ & 291 & $10 \%$ & +19 & $+7 \%$
\end{tabular}

\section{Flood Factor distribution of properties at risk ${ }^{\star}(1000 s)$}

\section{Risk leve}

Minor

Moderate 103.6

Major $\quad 130.1$

Severe $\quad 63.0$

Extreme $\quad 83.6$

More than $11.6 \%$ of individual properties and properties in Wisconsin are at any risk of flooding over the next 30 years. Out of those at risk $71 \%$ are at major to extreme risk.

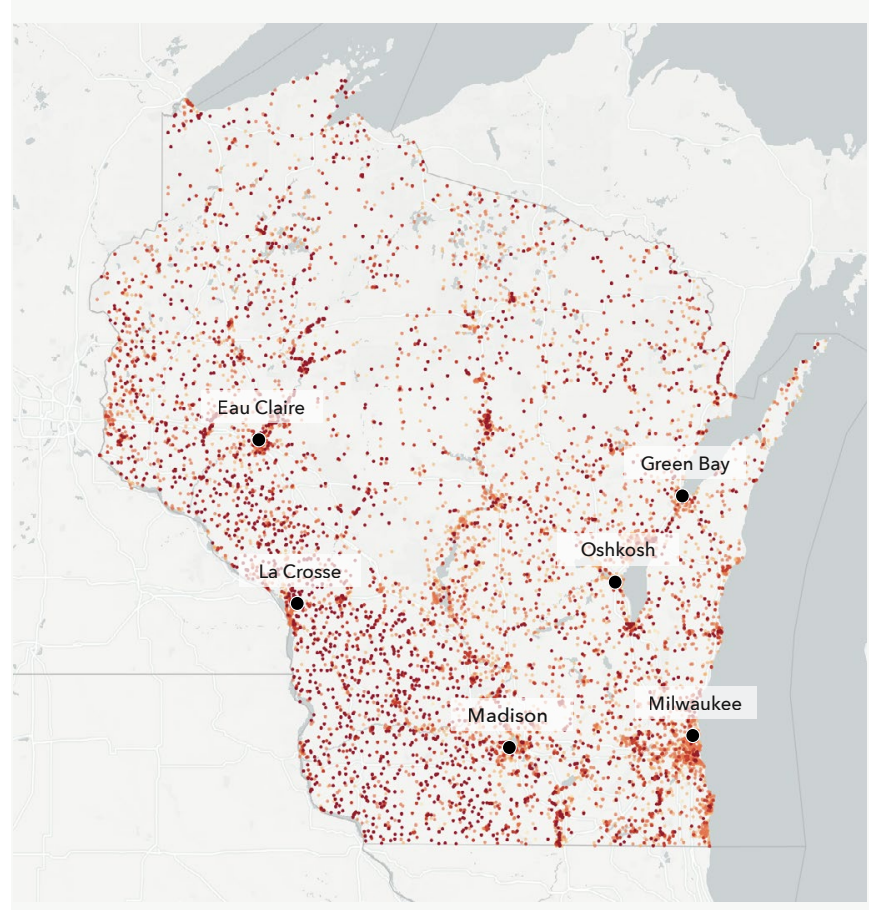




\section{Flood History \& Protection}

\section{Wisconsin}

\section{Claims History}

124,500 home and property owners in Wisconsin have made flood damage claims through FEMA since the year 2000. ${ }^{\star}$ These claims for reimbursement were made through either the National Flood Insurance Program (NFIP) or Individual Assistance Program (IAP). The greatest number of claims since the year 2000 have been concentrated in Milwaukee, Waukesha, Dane, Fond du Lac, and Vernon counties.

\section{Storm Simulation}

The First Street Foundation Flood Model has recreated 3 flooding events that have occurred since the year 2000 in the state of Wisconsin. These events flooded around 2,860 properties across the state.**

\begin{tabular}{llr} 
Flood event & Date & $\begin{array}{r}\text { \# Properties } \\
\text { affected }\end{array}$ \\
River flood in Western WI & Apr 2001 & 101 \\
\hline River flood in Northwest WI & Apr 2001 & 1,526 \\
\hline River flood near Wisconsin Dells, WI & Jun 2008 & 1,238
\end{tabular}
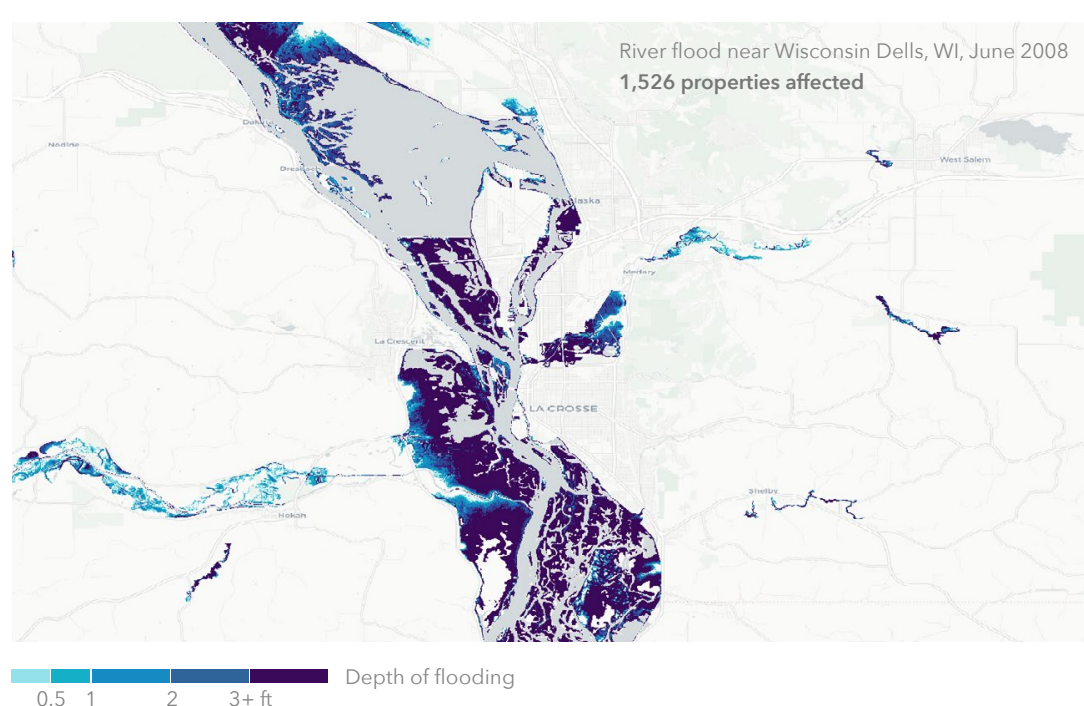

\section{3,600}

Properties served by

protection measures

The First Street Foundation Flood

Model incorporates 42 flood control

measures throughout the state which

protect 3,600 properties

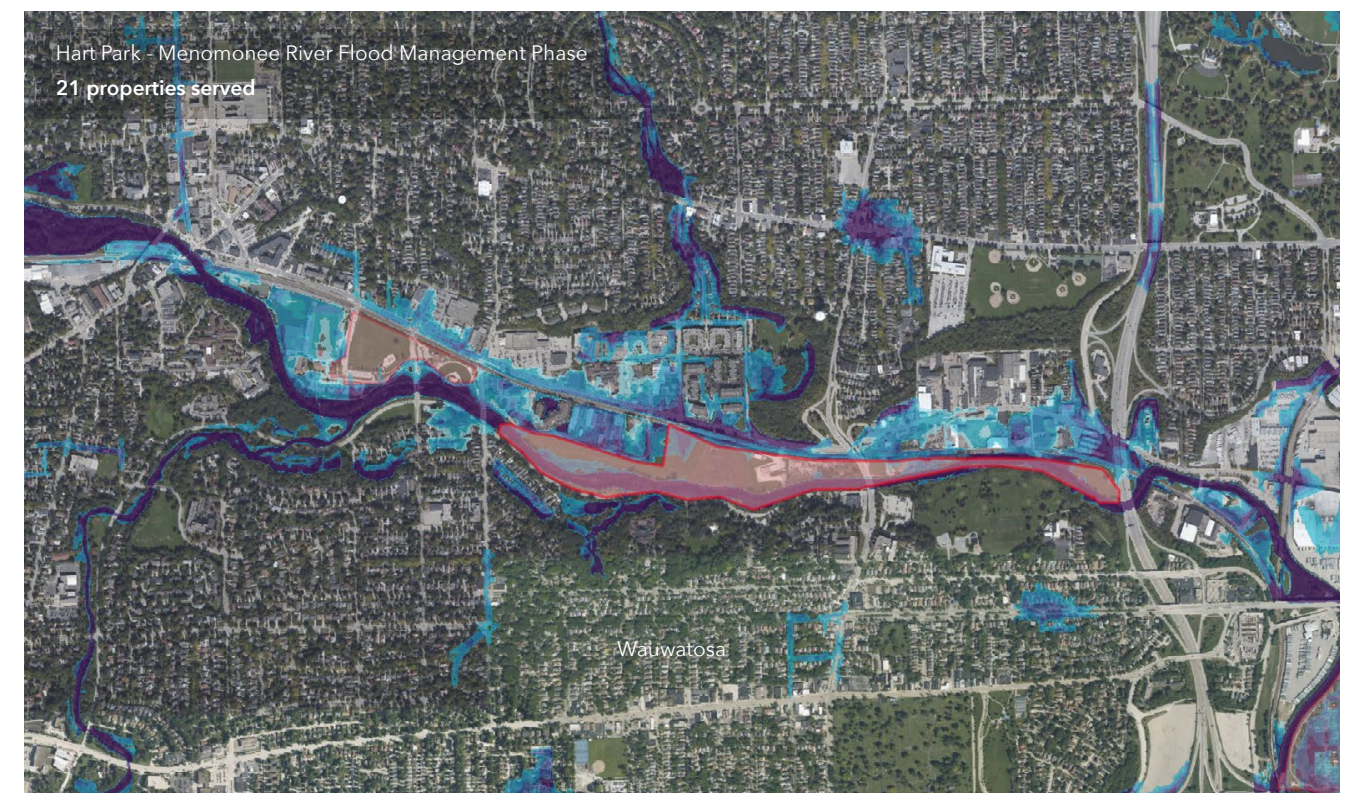

Top protection measures in state by quantity

Type
Example

Levee

Portage levee

Acquisition

- Acquark-Menomonee River Flood Management Phase 2

Detention basin

Incoln Creek Flood

Retention pond

Freshwater Plaza near School of Freshwater Sciences 


\section{State Overview Wyoming}

Total properties at substantial risk*

In 2020

\section{5,200}

30-year change

$\Delta+2,000(+6 \%)$
Difference in number of properties currently at substantial risk compared to FEMA**

$$
\Delta+26,900
$$

More properties at risk in FSF model $\longrightarrow$
0

Flood risk is increasing in the state of Wyoming. 35,200 properties currently have a substantial risk* of flooding. Over the next 30 years, the number of properties with this risk will increase by another $5.7 \%$, bringing the total number of properties with substantial risk to 37,200 .

To understand personal flood risk, Americans leverage the Federal Emergency Management Agency (FEMA) Flood Insurance Rate Maps (FIRM). These maps identify 8,300 properties as having substantial risk in the state of Wyoming. In comparison, the First Street Foundation Flood Model identifies 4.3 times the number of properties as facing this same level of risk. This discrepancy exists because the Foundation uses the current climate data, maps precipitation as a stand-alone risk, and includes areas that FEMA has not mapped. These new methods uncover an additional 26,900 properties currently not identified by FEMA as having substantial risk. When adjusting for future environmental changes, the FEMA gap further widens to 29,000 by the year 2050
Much of Wyoming is susceptible to flash flooding due to storms and heavy rainfall. Cheyenne is vulnerable to heavy thunderstorms as well as riverine and flash flooding between late spring and fall. Since the Cheyenne Flood in 1985, the City has rerouted the Dry Creek channel and enacted non-structural policies to regulate floodplain development in order to reduce flood risk.

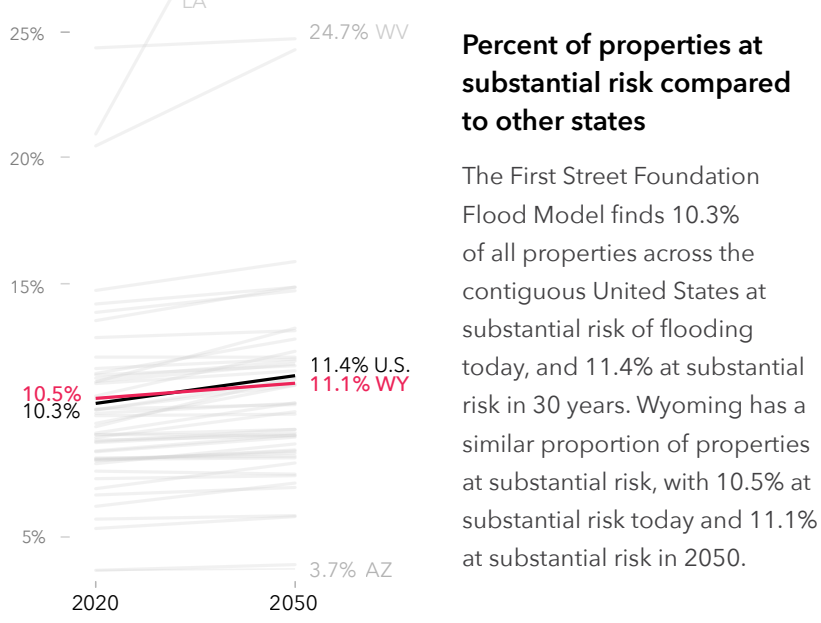

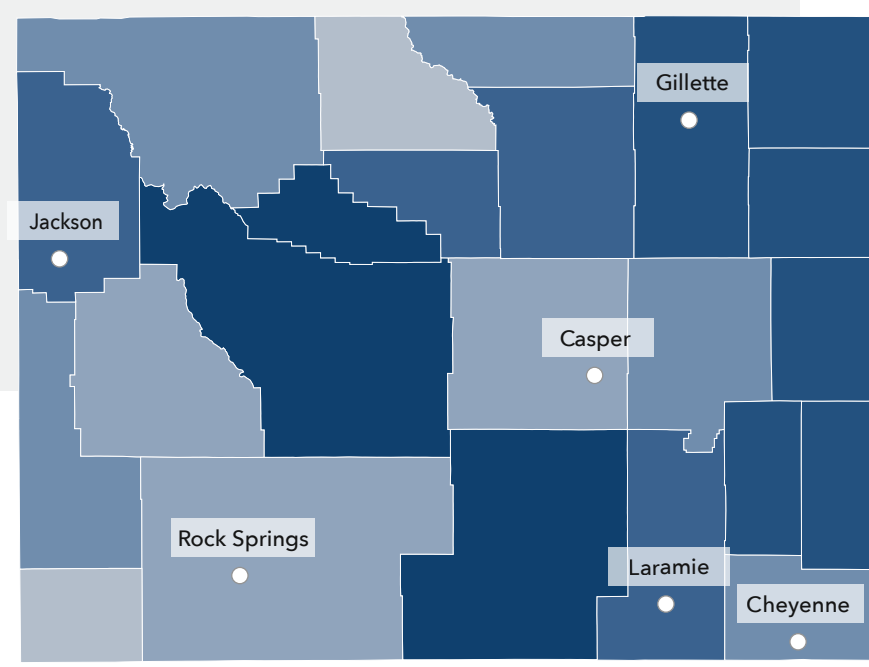




\section{Local details \\ Wyoming}

The First Street Foundation Flood Model calculates the number of properties facing any risk* of flooding. When looking at this broader level of risk, the data identifies 61,200 properties in Wyoming as at risk over the next 30 years. Of these properties, 4,000 were categorized as facing almost certain risk, with a $99 \%$ chance of flooding at least once over the next 30 years.

The city of Casper has the greatest number of properties at risk of flooding in the state with 4,700 currently at risk, or $19 \%$ of its total number of properties. However, smaller cities or municipalities in the state, with fewer properties, may have a greater proportion of their total properties at risk. For example, 34\% of properties in Jackson are at risk of flooding. Other municipalities will see the greatest increase in risk over the next 30 years. Worland, for example, will see a $22 \%$

increase in the number of properties at risk.

Click here for a full breakdown of counties, cities, zip codes, and congressional districts in Wyoming at risk.

\section{Greatest proportion of properties at risk*}

\begin{tabular}{lrr} 
Municipality & \multicolumn{2}{c}{2020} \\
Jackson & 1,812 & $34 \%$ \\
\hline Lander & 906 & $27 \%$ \\
\hline Mills & 598 & $27 \%$ \\
\hline Sheridan & 2,089 & $25 \%$ \\
\hline Laramie & 2,470 & $25 \%$ \\
\hline Torrington & 622 & $24 \%$ \\
\hline Rawlins & 818 & $22 \%$ \\
\hline Rock Springs & 1,831 & $22 \%$ \\
\hline Worland & 526 & $19 \%$ \\
\hline Casper & 4,718 & $19 \%$ \\
\hline
\end{tabular}

\section{Greatest number of properties at risk*}

\begin{tabular}{l|cccccc} 
Municipality & \multicolumn{2}{c}{2020} & \multicolumn{2}{c}{2050} & \multicolumn{2}{c}{ Change } \\
\cline { 2 - 4 } & 4,718 & $19 \%$ & 4,963 & $20 \%$ & +245 & $+5.2 \%$ \\
\hline Laramie & 2,470 & $25 \%$ & 2,535 & $25 \%$ & +65 & $+2.6 \%$ \\
\hline Cheyenne & 2,400 & $9 \%$ & 2,563 & $10 \%$ & +163 & $+6.8 \%$ \\
\hline Sheridan & 2,089 & $25 \%$ & 2,159 & $26 \%$ & +70 & $+3.4 \%$ \\
\hline Rock Springs & 1,831 & $22 \%$ & 1,864 & $22 \%$ & +33 & $+1.8 \%$ \\
\hline Jackson & 1,812 & $34 \%$ & 2,036 & $38 \%$ & +224 & $+12.4 \%$ \\
\hline Gillette & 1,535 & $13 \%$ & 1,569 & $14 \%$ & +34 & $+2.2 \%$ \\
\hline Lander & 906 & $27 \%$ & 939 & $28 \%$ & +33 & $+3.6 \%$ \\
\hline Rawlins & 818 & $22 \%$ & 860 & $23 \%$ & +42 & $+5.1 \%$ \\
\hline Evanston & 748 & $14 \%$ & 763 & $15 \%$ & +15 & $+2.0 \%$
\end{tabular}

\section{Greatest relative growing risk*}

\begin{tabular}{|c|c|c|c|c|c|c|}
\hline Municipality & & & & 050 & & inge \\
\hline Worland & 526 & $19 \%$ & 639 & $23 \%$ & +113 & $+22 \%$ \\
\hline Cody & 276 & $6 \%$ & 316 & $6 \%$ & +40 & $+15 \%$ \\
\hline Jackson & 1,812 & $34 \%$ & 2,036 & $38 \%$ & +224 & $+12 \%$ \\
\hline Powell & 69 & $3 \%$ & 76 & $3 \%$ & +7 & $+10 \%$ \\
\hline Riverton & 93 & $2 \%$ & 101 & $2 \%$ & +8 & $+9 \%$ \\
\hline Cheyenne & 2,400 & $9 \%$ & 2,563 & $10 \%$ & +163 & $+7 \%$ \\
\hline Casper & 4,718 & $19 \%$ & 4,963 & $20 \%$ & +245 & $+5 \%$ \\
\hline Rawlins & 818 & $22 \%$ & 860 & $23 \%$ & +42 & $+5 \%$ \\
\hline Ranchettes & 222 & $8 \%$ & 231 & $8 \%$ & +9 & $+4 \%$ \\
\hline Lander & 906 & $27 \%$ & 939 & $28 \%$ & +33 & $+4 \%$ \\
\hline
\end{tabular}

\section{Flood Factor distribution of properties at risk* $(1000 s)$}

\section{Risk leve}

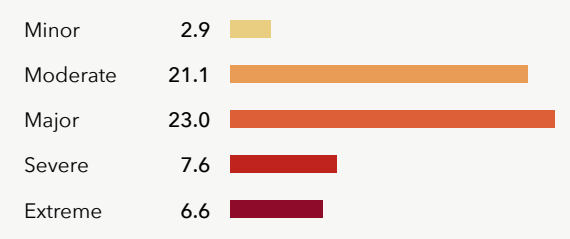

More than $18.2 \%$ of individual properties and properties in

Wyoming are at any risk of flooding over the next 30 years. Out of those at risk $61 \%$ are at major to extreme risk.

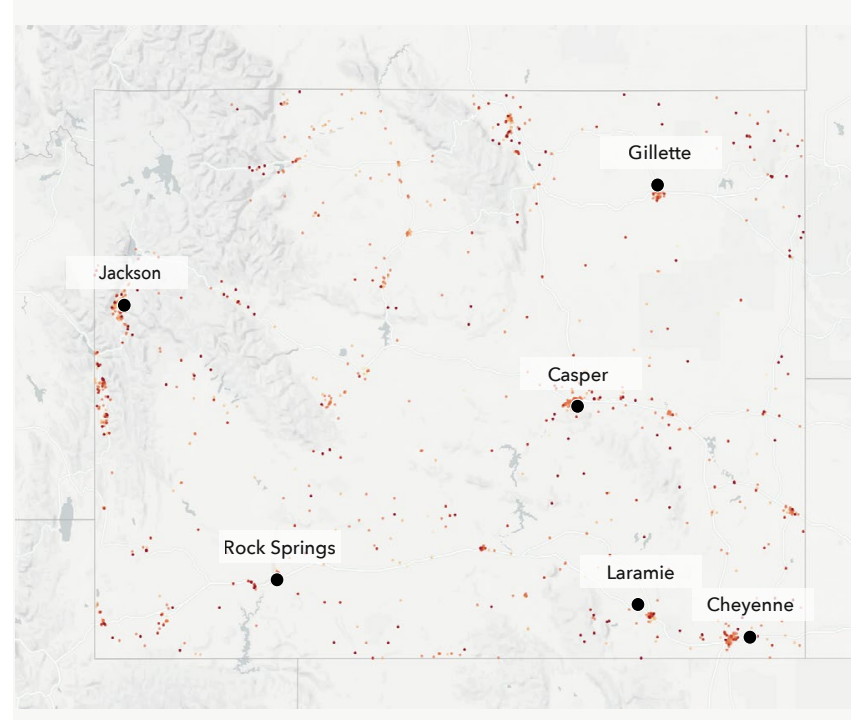




\section{Flood History \& Protection}

\section{Wyoming}

\section{Claims History}

900 home and property owners in Wyoming have made flood damage claims through FEMA since the year 2000. ${ }^{*}$ These claims for reimbursement were made through either the National Flood Insurance Program (NFIP) or Individual Assistance Program (IAP). The greatest number of claims

since the year 2000 have been concentrated in Campbell, Niobrara, Goshen, Johnson, and Laramie counties.

\section{5,000}

Properties served by

protection measures

The First Street Foundation Flood

Model incorporates 34 flood control

measures throughout the state which protect 15,000 properties.
Top protection measures in state by quantity

Type
Example

\# Properties served by type

Channel

10,226

- Sheridan City Flood Control, Sheridan

Jackson Hole Upper Right Bank, Moose Wilson Road

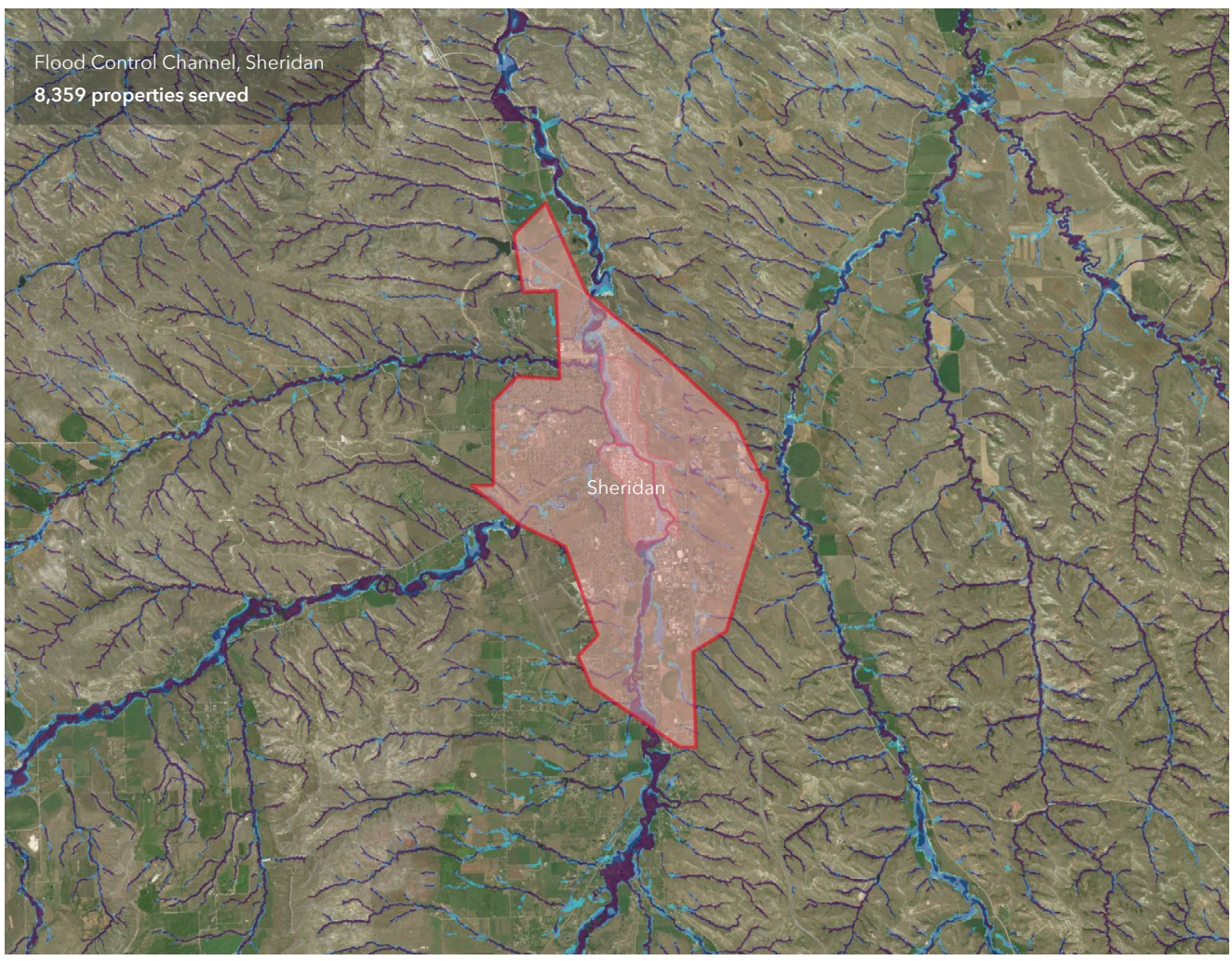

Area of protection 
Contributors to the First Street Foundation Flood Model and "First National Flood Risk Assessment"

The following First Street Foundation current and past personnel contributed to the preparation of this report, data or First Street products supporting this report. Our First Street Foundation Flood Model partners, First Street Foundation Flood Lab members, Advisory Board members and many others also deserve credit for their valuable contributions.

$\begin{array}{lll}\text { Mike Amodeo } & \text { Angela Jin } & \text { Daniel Sieberg } \\ \text { Dr. Saman Armal } & \text { Mike Kaminski } & \text { Katrina Skovan } \\ \text { Max Arnell } & \text { Shannon Keane } & \text { Miguel Vacas } \\ \text { Elizabeth Bertan } & \text { Dr. Ed Kearns } & \text { Sam Vincent } \\ \text { Jonathan Brannock } & \text { Kelvin Lai } & \text { Ray Yong } \\ \text { Lindsay Brown } & \text { Marguerite Lally } & \text { Gabriel Zarate } \\ \text { llan Bubb } & \text { Sharai Lewis-Gruss } & \\ \text { Glen Cantrell } & \text { Haoyu Li } & \\ \text { Mikala Chadwick } & \text { Brett Lingle } & \\ \text { Sara Chadwick } & \text { Mike Lopes } & \\ \text { Collyn Chan } & \text { Steven McAlpine } & \\ \text { Ziyan Chu } & \text { Dr. Michael Marston } & \\ \text { Carolyn Costello } & \text { David Miller } & \\ \text { Matthew Eby } & \text { Kristina Nicholas } & \\ \text { Colleen Ensor } & \text { Natalie Pardy } & \\ \text { Neil Freeman } & \text { Dr. Jeremy Porter } & \\ \text { Alan Friedman } & \text { Dr. Roozbeh Raoufi } & \\ \text { Raphael Halloran } & \text { Leilani Rose } & \\ \text { Ebony Hopkins } & \text { Nathan Rosler } \\ \text { Ho Hsieh } & \text { Daniel Seripap } & \end{array}$

\section{Map and Data}

Contributions

\section{Basemap imagery (C) Mapbox on pages}

$16,19,22,25,28,31,34,37,40,43,46,49,52,55,58,61,64,67,70,73,76,79,82,85,88,91,94,97$, $100,103,106,109,112,115,118,121,124,127,130 ., 133,136,139,142,145,148,151,153,155,158,161$

Basemap imagery $\odot$ CARTO on pages

$1,2,3,19,20,22,23,25,26,28,31,32,34,35,37,38,40,41,43,46,49,50,52,53,55,56,58,59,61,62$ $64,65,67,70,71,73,74,76,77,79,80,82,83,85,86,88,91,92,94,95,97,98,100,101,103,104,106$, $107,109,110,112,113,115,116,118,119,121,124,125,127,128,130,133,134,136,139,140,142$, $143,145,146,148,149,151,153,155,156,158,159,161$

Satellite basemap imagery (c) Bing on pages

$4,5,6,7,17,20,23,26,29,32,35,38,41,42,47,450,53,56,59,62,65,68,71,74,77,80,83,86,89$, $92,95,98,101,104,107,110,113,116,119,122,125,128,131,134,137,140,143,146,149,152,156,159,162$ Source data $\odot$ OpenStreetMap contributors, used under the Open Database License on pages $1,2,3,16,19,20,22,23,25,26,28,31,32,34,35,37,38,40,41,43,46,49,50,52,53,55,56,58,59$, $61,62,64,65,67,70,71,73,74,76,77,79,80,82,83,85,86,88,91,92,94,95,97,98,100,101,103$, $104,106,107,109,110,112,113,115,116,118,119,121,124,125,127,128,130,133,134,136,139$, $140,142,143,145,146,148,149,151,153,155,156,158,159,161$

State and county boundaries from the US Census TIGER dataset on pages $9,10,11,18-161$

This report is not endorsed or certified by the Census Bureau.

National boundaries from Natural Earth on page 16

This report is neither affiliated with, nor authorized, sponsored, approved, endorsed or certified by any of the foregoing providers.

\section{Disclaimers}

First Street's flood and climate change risk estimates are based on one or more models designed to approximate risk and are not intended as precise estimates, or to be a comprehensive analysis of all possible flood-related and climate change risks. 